UNIVERSIDADE DE SÃO PAULO

FACULDADE DE AROUITETURA E URBANISMO

JULIANA BECHARA SAFT

Qualidade ambiental na gestão de áreas de guarda de acervos em papel em edifícios históricos na cidade de São Paulo

São Paulo 


\title{
Qualidade ambiental na gestão de áreas de guarda de acervos em papel em edifícios históricos na cidade de São Paulo
}

\section{Versão Corrigida}

Tese de Doutorado apresentada ao Programa de Pós-Graduação da Faculdade de Arquitetura e Urbanismo da Universidade de São Paulo (FAU USP).

Área de Concentração: Tecnologia da Arquitetura

Orientadora: Profa. Dra. Sheila Walbe Ornstein

\author{
São Paulo
}


EXEMPLAR REVISADO E ALTERADO EM RELAÇÃO À VERSÃO ORIGINAL, SOB RESPONSABILIDADE DA AUTORA E ANUÊNCIA DA ORIENTADORA. A versão original, em formato digital, ficará arquivada na Biblioteca da Faculdade.

São Paulo, 21 de junho de 2021.

Autorizo a reprodução e divulgação total ou parcial deste trabalho, por qualquer meio convencional ou eletrônico, para fins de estudo e pesquisa, desde que citada a fonte.

Catalogação na publicação

Serviço de Biblioteca e Documentação

Faculdade de Arquitetura e Urbanismo da Universidade de São Paulo

Saft, Juliana Bechara

Qualidade ambiental na gestão de áreas de guarda de acervos em papel em edifícios históricos na cidade de São Paulo / Juliana Bechara Saft; orientadora Sheila Walbe Ornstein. - São Paulo, 2021.

$416 \mathrm{f}$.

Tese (Doutorado) - Faculdade de Arquitetura e Urbanismo da Universidade de São Paulo. Área de concentração: Tecnologia da Arquitetura.

1. Avaliação Pós-ocupação. 2. Reserva Técnica (museologia) 3. Acervo. 4. Patrimônio Cultural. I. Ornstein, Sheila Walbe, orient. II. Título. 
DEDICATÓRIA

Estes trabalho é dedicado a todos aqueles que amam a ciência e as artes... 


\section{AGRADECIMENTOS}

Este trabalho não poderia ter sido concluído não fosse pela colaboração, contribuição e apoio de muitas pessoas cujo ponto em comum é o interesse e a preocupação com o patrimônio cultural. Assim, meu muito obrigada a todos, professores, profissionais de museus, bibliotecas e arquivos, colegas de estudo e companheiros de jornada pelo carinho, atenção e cuidado com que pacientemente se dispuseram a conversar e contribuir. Ainda que não seja possível nomear a todos, gostaria de destacar:

Profa. Dra. Sheila Walbe Ornstein;

Profa. Dra. Rosaria Ono, Profa. Dra. Claudia Terezinha de Andrade Oliveira, Profa. Dra. Fabiana Lopes de Oliveira, bem como demais professores e funcionários do Departamento de Tecnologia da Arquitetura da FAU USP;

Prof. Dr. Alberto Hernandes Neto (Poli USP);

Profa. Dra. Marcia de Almeida Rizzutto (IF USP);

Profa. Dra. Dalva Lúcia Araújo de Faria (IQ USP);

Conservadoras Ina Hergert e Flavia Urzua (MP USP);

Profa. Dra. Solange Ferraz de Lima, professores e funcionários do Museu Paulista (Museu do Ipiranga e Museu Republicano Convenção de Itu da USP);

Prof. Dr. Carlos Alberto Zeron e equipe da Biblioteca Brasiliana Guita e José Mindlin (BBM USP);

Equipe da Biblioteca Mário de Andrade (BMA);

Equipe do Arquivo Histórico Municipal (AHM);

Equipe da Biblioteca da FAU USP;

Equipe do Centro de Conservação Cultural (CPC USP);

Equipe do Instituto de Estudos Brasileiros (IEB USP); 
Pesquisadores, colegas do programa de pós-graduação em museologia (PPGMus USP);

Conservadores, bibliotecários e demais colegas da Rede de Conservação Preventiva da USP;

Prof. Dr. Francisco Ferreira Cardoso e equipe da Superintendência do Espaço Físico (SEF USP);

Engenheiro Dr. Fúlvio Vittorino, biólogo Dr. Gonzalo Lopez e biólogo Dr. Ricardo Gomes Pereira (IPT);

Prof. Dr. Carlos Roberto Ferreira Brandão, Profa. Dra. Ana Gonçalves Magalhães, professores e funcionários do Museu de Arte Contemporânea (MAC USP);

Professores e equipe do Museu de Arqueologia e Etnologia (MAE USP);

Equipe do Museu Afro Brasil;

Equipe do Museu da Imigração;

Equipe do Instituto Butantan;

Profa. Dra. Claudia Suely Rodrigues Carvalho e equipe da Fundação Casa de Rui Barbosa, no Rio de Janeiro; Equipe do Museu de Astronomia e Ciências Afins (MAST), no Rio de Janeiro;

Equipe do Centro de Documentação e Informação (Cedi) e da Biblioteca Pedro Aleixo da Câmara dos Deputados, em Brasília;

Profa. Cristina Sanches Morais e demais professores e técnicos do Núcleo de Conservação e Restauro de Papel e Celulose do SENAl Theobaldo de Nigris, bem como todos os colegas do curso de conservação de papéis;

Profa. Dra. Gabriela Krist, professores e alunos do Instituto de Conservação da Universidade de Artes Aplicadas de Viena e funcionários de museus, bibliotecas e arquivos em Viena que pacientemente explicaram suas atividades e as características de suas instituições;

Prof. Dr. Stefan Simon, funcionários do Laboratório Rathgen, funcionários da Fundação para o Patrimônio Cultural Prussiano e funcionários de museus, bibliotecas e arquivos em Berlim e Brandemburgo que pacientemente explicaram suas atividades e as características de suas instituições. 
"Eu acredito que a humanidade deve aceitar como axioma para sua conduta o princípio pelo qual orientei minha vida: o direito de investigar. É o credo dos homens livres esta oportunidade de tentar, este privilégio de errar, esta coragem de experimentar de novo. Nós, cientistas do espírito humano, devemos experimentar, experimentar, sempre experimentar." (Roger Bacon, Opus Majus, 1268; tradução livre da pesquisadora.) 


\title{
RESUMO
}

\author{
SAFT, J. B.. Qualidade ambiental na gestão de áreas de guarda de acervos em papel em edifícios \\ históricos na cidade de São Paulo. 2021. 416 f. Tese (Doutorado em Tecnologia da Arquitetura) - \\ Faculdade de Arquitetura e Urbanismo da Universidade de São Paulo, São Paulo, 2021.
}

A preservação sustentável do patrimônio propõe que as instituições culturais dediquem mais recursos à prevenção do que à recuperação, fazendo uso, para isso, de estratégias de gestão, pesquisa e trabalho interdisciplinar adaptadas à realidade institucional. No intuito de contribuir com o tema, pela perspectiva da arquitetura, propôs-se o desenvolvimento de um modelo teórico-metodológico para diagnóstico do desempenho de ambientes para a guarda (reservas técnicas) de acervos com suporte em papel localizados em edifícios históricos na cidade de São Paulo. A escolha se deu pela relevância e complexidade desta tipologia construtiva e por serem os edifícios tombados com acervos em papel uma situação prevalente nas instituições culturais paulistanas. A utilização do sistema multimétodos de Avaliação Pós-Ocupação (APO) do ambiente construído adaptado às áreas de guarda pode ser um grande aliado neste processo porque inclui arquitetos e engenheiros como parceiros em todas as etapas da gestão preventiva de acervos; considera a perspectiva dos especialistas e dos usuários; coloca as ameaças externas no centro da avaliação; e é flexível o suficiente para ser adaptada a variadas características. 0 desenvolvimento do modelo foi embasado na coleta de dados qualitativos e quantitativos por meio de revisão sistemática da literatura, visitas e consultas a instituições culturais e científicas em São Paulo, Rio de Janeiro, Brasília, Viena e Berlim e na aplicação de instrumentos de APO a quatro casos de estudo: Setor de Papel do Museu do Ipiranga, Biblioteca Brasiliana Guita e José Mindlin, Biblioteca Mário de Andrade e Arquivo Histórico Municipal. 0 Modelo Integrado para Diagnóstico de Áreas de Guarda de Acervos proposto combina as metodologias de Avaliação Pós-Ocupação e de gestão de riscos ao patrimônio cultural (desenvolvida pelo ICCROM / CCI) à estratégia SOBANE e também utiliza uma classificação dos sistemas construtivos e dos agentes de deterioração de acervos adaptada às condições observadas nas instituições visitadas. Para a apresentação da síntese dos resultados, são utilizados Quadros e Mapas de Diagnósticos e Recomendações adaptados a cada grau de avaliação. 0 Modelo proposto precisará ser futuramente validado mediante aplicação em estudos de caso. Se devidamente adaptado e validado, ele poderá ser aplicado a outras tipologias construtivas, acervos e cidades brasileiras.

Palavras-chave: Avaliação Pós-Ocupação (APO). Reserva Técnica (museologia). Acervo. Patrimônio Cultural. 


\title{
ABSTRACT
}

\author{
SAFT, J. B.. Environmental quality for storage facilities management for paper collections in \\ historic buildings in the city of São Paulo. 2021. 416 p. Thesis (Doctorate in Architecture Technology) - \\ School of Architecture and Urbanism of the University of Sao Paulo, Sao Paulo, 2021.
}

The sustainable preservation of cultural heritage proposes that institutions devote more resources to prevention than to recovery, making use of management, research, and interdisciplinary work strategies adapted to institutional reality. To contribute to the theme, from the perspective of architecture, it was proposed the development of a theoretical-methodological model for diagnosing the environmental performance of storage facilities of paper-based collections located in historic buildings in the city of São Paulo. The choice was made due to the relevance and complexity of this constructive typology and because the listed buildings with paper collections are a prevalent situation in São Paulo's cultural sector. The use of the multi-method Post-Occupancy Evaluation (POE) system of the built environment adapted to the storage facilities can be a great ally in this process because it includes architects and engineers as partners in all stages of the collection preventive management; it contemplates the perspective of experts and users; it considers external threats at the center of the assessment, and it is flexible enough to be adapted to various characteristics. The development of the model was based on the gathering of qualitative and quantitative data through systematic literature review, visits, and consultations to cultural and scientific institutions in São Paulo, Rio de Janeiro, Brasília, Vienna, and Berlin, and also on the application of POE instruments to four study cases: Paper Sector of the Ipiranga Museum, Guita and Jose Mindlin Brasiliana Library, Mario de Andrade Library and Municipal Historic Archive. The Integrated Model for the Diagnosis of Storage Facilities proposed combines the methodologies of Post-Occupancy Evaluation and risk management for cultural heritage (developed by ICCROM / CCI) with the SOBANE strategy and also uses a classification of construction systems and agents of deterioration adapted to the conditions observed in the institutions visited. For the presentation of the synthesis of the results, Tables and Maps of Diagnostics and Recommendations adapted to each degree of evaluation are used. The proposed model will need to be validated in the future through application in case studies. If properly adapted and validated, it can also be applied to other construction typologies, collections, and Brazilian cities.

Keywords: Post-Occupancy Evaluation (POE). Storage Facilities (museology). Collections. Cultural Heritage. 


\section{LISTA DE FIGURAS}

pág.

Figura 01. Fluxograma dos procedimentos de pesquisa

031

Figura 02. Número de desastres por causas naturais, no mundo, entre 1980 e 2014

Figura 03. Impacto de desastres: 1980 a 1999 versus 2000 a 2019

037

Figura 04. Comparação entre parâmetros para conforto humano e conservação de objetos

Figura 05. As zonas de sobreposição entre conforto humano [...]

060

Figura 06. Espectro eletromagnético da radiação solar

061

Figura 07. Propagação da radiação a partir de uma fonte pontual S

064

Figura 08. Espectros (gráfico) e imagens espectrais de uma lâmpada LED [...]

065

Figura 09. Efeito da temperatura de cor da lâmpada sobre flores

066

Figura 10. Qualidade visual associada a diferentes IRCS

066

Figura 11. Medidas básicas de luminotécnica

067

Figura 12. Curva de distribuição da luz do conjunto lâmpada e luminária

067

Figura 13. Simulação com cálculo da iluminância [lux] para um ambiente modelo

068

Figura 14. Carta psicrométrica mostrando a temperatura de ponto de orvalho [...]

073

Figura 15. Comparação entre as diretrizes de T e UR [...]

085

Figura 16. Diagramas com as isopletas de Te UR para formação de mofo [...]

Figura 17. Linhas de igual taxa de degradação ou 'Isoburns' [...]

Figura 18. A rota do papel do Oriente ao Ocidente

Figura 19. Etapas da fabricação artesanal do papel 100

Figura 20. Tipos de pasta de celulose (\%) produzidos no Brasil - 2015

Figura 21. Modificações químicas da celulose 
Figura 23. Modelo esquemático das alterações propostas em fibras de pasta kraft [...] $\quad$....... 106

Figura 24. Indústria 4.0 ou Industrial Internet of Things (IIoT) $\quad$............................. 121

Figura 25. As três fases da gestão organizacional estratégica .................................. 122

Figura 26. Análise SWOT .............................................................. 124

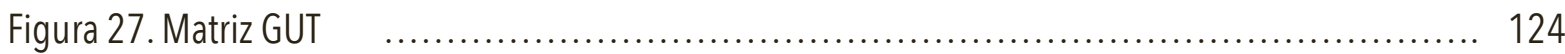

Figura 28. Matriz Custo x Benefício $\quad$.................................................... 125

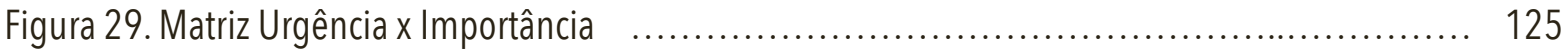

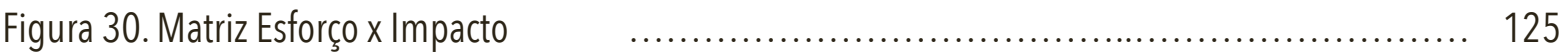

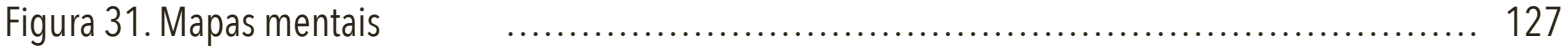

Figura 32. 0 processo para encontrar respostas a um problema $\quad$.............................. 127

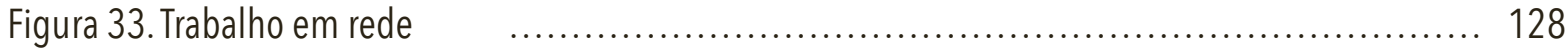

Figura 34. Metodologia para análise simplificada de riscos proposta $[\ldots] \quad$........................ 132

Figura 35. As etapas do processo de gestão de riscos $\quad$.................................... 133

Figura 36. As etapas da gestão de riscos, adaptadas da norma ISO $31000[\ldots] \quad$................ 134

Figura 37. Exemplo de matriz de hierarquização dos riscos por agente de deterioração [...] $\quad$........ 135

Figura 38. Exemplo de avaliação das escalas ABC para cada risco identificado [...] $\quad$................ 139

Figura 39. Exemplo de registro do antes e depois da aplicação do método RE-ORG [...] $\quad$....... 144

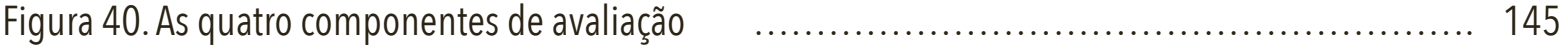

Figura 41. Exemplo de gráfico para avaliação do clima interno $\quad$............................ 146

Figura 42. Exemplo de matriz de risco, a partir de modelo sugerido por Martens (2012) _ _..... 147

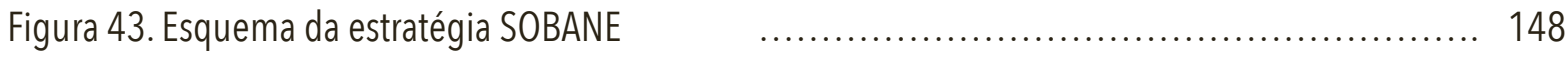


Figura 44. Prática corrente [... ] e Prática sugerida [...]

Figura 46. Abordagem multimétodo na aplicação da APO 160

Figura 47. Visão convencional e linear do processo 162

Figura 48. Visão contemporânea do processo 163

Figura 49. As atividades de APO ao longo do ciclo de vida do edifício 164

Figura 50. Metodologia da APO 165

Figura 51. Fluxograma das etapas de APO adaptado para esta pesquisa 166

Figura 52. Exemplo de um Quadro-síntese de Diagnósticos e Recomendações (QDR) 182

Figura 53. Exemplo de Mapa de Diagnósticos e Recomendações (MDR) aplicado a um museu 183

Figura 54. Mapa de Riscos com escala de degradação para a fachada principal [...] 187

Figura 55. Modelo 3D do antigo Templo de Bel, em Palmira, Síria 189

Figura 56. Análise estrutural a partir de modelo 3D 189

Figura 57. Aplicativo para gestão documental do patrimônio 190

Figura 58. Escaneamento 3D e reconstrução digital de um edifício histórico 190

Figura 59. Gestão de dados em um sistema SIG associado ao modelamento [... ] 191

Figura 60. 0 sistema BIM adaptado ao patrimônio cultural 193

Figura 61. Criação e visualização do modelo 3D construído a partir de uma nuvem de pontos 194

Figura 62. Fotogrametria da Basílica de Notre Dame em Montreal 195

Figura 63. 0 comissionamento ao longo do ciclo de vida do edifício 196

Figura 64. Gestão das fases do edifício e as atividades de retrocomissionamento [...] 196

Figura 65. Metodologia de abordagem dos processos para FM 
Figura 66. Organograma do Louvre, em 2012

Figura 67. 0 edifício-monumento e seu jardim

Figura 68. 0 museu-casa e seu jardim frontal

Figura 70. Comunicação visual na entrada da Reserva Técnica indicando a temperatura [...]

Figura 71. Vista da fachada principal do Instituto e de um dos andares com laboratórios [...] 225

Figura 72. Atividades de conservação propostas para o Neukloster em trabalho de doutorado 227

Figura 73. Edifício onde se localiza o Laboratório Rathgen e sala de pesquisa [...] 230

Figura 74. Temperatura média diária para 0 ano de 2020 (estação INMET Interlagos) 235

Figura 75. Umidade Relativa média diária para 0 ano de 2020 (estação INMET Interlagos) 236

Figura 76. Probabilidade diária de precipitação (1980 -2016) 236

Figura 77. Horas de luz solar 237

Figura 78. Radiação solar de ondas curtas, média diária (1980 -2016) 238

Figura 79. Sumário das projeções de mudanças climáticas para a RMSP 239

Figura 80. Conjunto de edifícios do AHM, antes e depois das obras de reforma 246

Figura 81. Subsolo do edifício sede 246

Figura 82. Biblioteca da Torre da Memória 246

Figura 83. Edifício sede da BMA: embasamento [...] e torre [...] 250

Figura 84. Imagem à esquerda, torre [...]. Imagem à direita, edifício anexo [...] 250

Figura 85. Um dos andares de guarda de acervo no edifício anexo (hemeroteca) 250

Figura 86.0 edifício-monumento logo após sua inauguração e em dezembro de 2019

Figura 87. Saguão [...]; piso do pavimento superior [...]; estrutura em abóboda [...] 
Figura 88. Edifício temporário para reserva técnica do acervo em papel (frente e fundos)

Figura 89. Laboratório de conservação de papel no subsolo [...] e no novo endereço [...] 256

Figura 90. Concepção final do projeto dos arquitetos Hereñú e Ferroni 257

Figura 91. Obras de escavação e contenção para ampliação no subsolo 257

Figura 92. Projeto da BBM / IEB por Eduardo de Almeida + Mindlin Loeb + Dotto Arquitetos 259

Figura 93. Vista do conjunto BBM / IEB USP 260

Figura 94. Vista interna dos anéis com o acervo Mindlin 260

Figura 95. Fluxograma do modelo teórico-metodológico proposto: Etapa 1 - Planejamento 297

Figura 96. As oito camadas de avaliação propostas pela pesquisa 299

Figura 97. Fluxograma do modelo teórico-metodológico proposto: Etapa 2 - Execução 303

Figura 98. Fluxograma do modelo teórico-metodológico proposto: Etapa 3 - Análise 315

Figura 99. Carta psicrométrica com as estratégias bioclimáticas adaptadas por Givoni (1992) 317

Figura 100. Dispersão de T e UR internas, com indicação das zonas de dano provável ao acervo 318

Figura 101. Carta bioclimática com anotação das zonas de maior risco para acervos [...] 318

Figura 102. Fluxograma do modelo teórico-metodológico proposto: Etapa 4 - Resultados 320

Figura 103. Legenda de símbolos propostos para os MDR (parte 1) 323

Figura 103. Legenda de símbolos propostos para os MDR (parte 2) 324

Figura 104. Mapa de Diagnósticos e Recomendações (MDR) sugerido para o grau S 325

Figura 105. Mapa de Diagnósticos e Recomendações (MDR) sugerido para o grau OB 328

Figura 106. Mapa de Diagnósticos e Recomendações (MDR) sugerido para o grau AN 331

Figura 107. Exemplos de diagramas de radar com indicação da quantidade de ocorrências [...] 332 


\section{LISTA DE QUADROS}

pág.

Quadro 01: Principais entidades internacionais consultadas

042

Quadro 02: Principais entidades nacionais consultadas

045

Quadro 03: Principais normas internacionais e nacionais consultadas

046

Quadro 04. Recomendações ASHRAE (2007) para museus, galerias, bibliotecas e arquivos

078

Quadro 05. Seleção de normas e recomendações internacionais para Te UR [...]

080

Quadro 06. Características da fibra de Pinus e de Eucalipto

102

Quadro 07. Danos à capa e ao miolo

109

Quadro 08. Danos químicos

110

Quadro 09. Danos mecânicos

Quadro 10. Danos por pragas

Quadro 11. Danos porágua

Quadro 12. Danos por mofo

Quadro 13. Matriz de classificação dos dados climáticos [...]

Quadro 14. Especificidades de cada nível do protocolo SOBANE

Quadro 15. Formas de incertezas no contexto da conservação preventiva [...]

Quadro 16. Plano estratégico para aplicação da APO, adaptado para esta pesquisa 166

Quadro 17. Avaliação operacional: de 3 a 6 meses após a ocupação do edifício

Quadro 18. Avaliação projetual: de 12 a 18 meses após a ocupação do edifício

Quadro 19. Avaliação estratégica: a cada n anos, conforme planejamento institucional [...]

Quadro 20. Os aspectos considerados em uma avaliação com foco no processo

Quadro 21. Os aspectos considerados em uma avaliação com foco no desempenho funcional 
Quadro 22. Os aspectos considerados em uma avaliação com foco no desempenho técnico

Quadro 23. Quem deve participar de uma APO (adaptado para instituições culturais) 173

Quadro 24. Vantagens e desvantagens de se utilizar uma abordagem metodológica [...]

Quadro 25. Características, [...] da aplicação do instrumento visitas técnicas 176

Quadro 26. Características, [...] da aplicação do instrumento medições e análises

Quadro 27. Características, [...] da aplicação do instrumento observações dos usuários

Quadro 28. Características, [...] da aplicação do instrumento dinâmicas de grupo

Quadro 29. Características, vantagens e desvantagens da aplicação do instrumento entrevistas 178

Quadro 30. Características, [... ] da aplicação do instrumento questionários 179

Quadro 31. Características, [...] da aplicação do instrumento grupos focais 180

Quadro 32. Quadro-resumo dos aspectos identificados durante as visitas técnicas [...] 262

Quadro 33. Entrevista com profissional-chave da conservação preventiva 275

Quadro 34. Entrevista com profissional-chave de acervos em papel 278

Quadro 35. Entrevista com profissional-chave da manutenção do edifício 278

Quadro 36. Análise SWOT para instituições com acervos em papel em São Paulo 289

Quadro 37. Quais camadas precisam ser avaliadas? 299

Quadro 38. Agentes de deterioração, comparação entre diferentes propostas 307

Quadro 39. Os agentes de deterioração (ameaças ao acervo) adaptados para esta pesquisa 310

Quadro 40. Os sistemas construtivos, adaptados para esta pesquisa 313

Quadro 41. Quadro de Diagnósticos e Recomendações (QDR) sugerido para o grau S 322

Quadro 42. Quadros de Diagnósticos e Recomendações (QDR) sugerido para o grau OB 327

Quadro 43. Quadro de Diagnósticos e Recomendações (QDR) sugerido para o grau AN 330 


\section{LISTA DE TABELAS}

pág.

Tabela 01: Exemplo de ponto de orvalho e quantidade de vapor constantes [...]

073

Tabela 02. Resumo dos valores de Te UR, segundo a ASHRAE (2015) [...]

077

Tabela 03. TWPI e o feito do ambiente nas reações químicas espontâneas [...]

092

Tabela 04. Perda de valor conforme a magnitude do risco (MR) 137

Tabela 05. Nível de prioridade conforme a magnitude do risco (MR) 


\section{LISTA DE ABREVIATURAS E SIGLAS}

2D: duas dimensões, desenho técnico

3D: três dimensões, maquetes virtuais

4D: quatro dimensões, vídeo

AAM: American Alliance of Museums

ABNT: Associação Brasileira de Normas Técnicas

ACCR: Associação Catarinense de Conservadores e Restauradores de Bens Culturais

a.E.C.: antes da Era Comum

AEC: Architectural, Engineering and Construction

AEC: Arquitetura, Engenharia e Construção

AECO: Arquitetura, Engenharia, Construção e Operação

AHM: Arquivo Histórico Municipal

AIC: American Institute for Conservation

AICCM: Australian Institute for the Conservation of Cultural Material

ANVISA: Agência Nacional de Vigilância Sanitária

APCR: Associação Paulista de Conservadores Restauradores de Bens Culturais

APO: Avaliação Pós-Ocupação

APU: Avaliação Pós-Uso

AS/NZS: Australia Standards / New Zealand Standards

ASHRAE: American Society of Heating, Refrigerating, and Air-Conditioning Engineers

AVAC: Aquecimento, Ventilação e Ar-Condicionado

BBM USP: Biblioteca Brasiliana Guita e José Mindlin da Universidade de São Paulo

BID: Banco Interamericano de Desenvolvimento 
BIM: Building Information Modeling

BMA: Biblioteca Mário de Andrade

BN: Fundação Biblioteca Nacional

BPE: Building Performance Evaluation

CAAE: Certificado de Apresentação para Apreciação Ética

CAD: Computer Aided Design

CADOPO: Casa do Politécnico

CCl: Canadian Conservation Institute

CCPM: Critical Chain Project Management

CEB: Council of Europe Development Bank

CEP: Comitê de Ética em Pesquisa

CHI: Cultural Heritage Imaging

CIE: Commission Internationale de l'Eclairage

CIPA: Comissão Interna de Prevenção de Acidentes

CIVVIH: International Committee on Historic Towns and Villages

CMSP: Câmara Municipal de São Paulo

CONAMA: Conselho Nacional do Meio Ambiente

CONDEPHAAT: Conselho de Defesa do Patrimônio Histórico, Arqueológico, Artístico e Turístico

CONPRESP: Conselho Municipal de Presenvação do Patrimônio Histórico, Cultural e Ambiental da Cidade de São Paulo

CPC USP: Centro de Presenvação Cultural da Universidade de São Paulo

CRED: Centre for Research on the Epidemiology of Disasters

DAMT: Direction Architecture, Muséographie, Technique

DCPCR: Délégation de Conservation Préventive et Coordenation de Régie 
DIAPReM: Development of Integrated Automatic Procedures for Restoration of Monuments DMO: Direction de la Maîtrise d'Ouvrage

DRM: Disaster Risk Management

DRR: Disaster Risk Reduction

EACH USP: Escola de Artes, Ciências e Humanidades da Universidade de São Paulo

E.C.: Era Comum

ECF: Elemental Chlorine Free

EM-DAT: International Disaster Database

EN: European Committee for Standardization

ENCAC: Encontro Nacional de Conforto no Ambiente Construído

ENTAC: Encontro Nacional de Tecnologia no Ambiente Construído

EPI: Equipamento de Proteção Individual

FAU USP: Faculdade de Arquitetura e Urbanismo da Universidade de São Paulo

FCC: Fundação Catarinense de Cultura

FCRB: Fundação Casa de Rui Barbosa

FEMA: Federal Emergency Management Agency

FFC: Federal Facilities Council

FM: Facility Management (Gestão de Facilidades)

FUSP: Fundação de Apoio à Universidade de São Paulo

GCl: Getty Conservation Institute

GIS: Geographic Information System

Grupo Bizot / Groupe Bizot: The International Group of Organizers of Major Exhibitions

HBIM: Heritage Building Information Modelling 
HEFCEA: Higher Education Funding Council for England

HEPA (filtro): Hight Efficiency Particulate Air

HFA: Hyogo Framework for Action

IAG: Insurance Australia Group

IBRAM: Instituto Brasileiro de Museus

ICA: International Council on Archives

ICBS: International Committee for the Blue Shield

ICMS: International Committee for Museum Security

ICCROM: International Centre for the Study of the Preservation and Restoration of Cultural Property

ICN: Netherlands Institute for Cultural Heritage

ICOM: International Council of Museums

ICOM-CC: International Council of Museums - Committee for Conservation

ICOMOS: International Council of Monuments and Sites

ICTOP: International Committee for the Training of Personnel

IEB USP: Instituto de Estudos Brasileiros da Universidade de São Paulo

IEDI: Instituto de Estudos para o Desenvolvimento Industrial

IFC: Industry Foundation Classes

IFLA: International Federation of Libraries Association

IFMA: International Facility Management Association

IIC: International Institute for Conservation of Historic and Artistic Works

IIOT: Industrial Internet of Things

INTACH: Indian National Trust for Art and Cultural Heritage

IPCC: Intergovernmental Panel on Climate Change 
IPESP: Instituto de Pagamentos Especiais de São Paulo

IPHAN: Instituto de Patrimônio Histórico e Artístico Nacional

IPI: Image Permanence Institute

IPM: Integrated Pest Management (Manejo Integrado de Pragas)

IPT: Instituto de Pesquisas Tecnológicas do Estado de São Paulo

IR: Infrared

IRM: Institute of Risk Management

ISO: International Organization for Standardization

IT: Instruções Técnicas do Corpo de Bombeiros

laser: Light Amplification by Stimulated Emission of Radiation

LED: Light-Emitting Diode (diodo emissor de luz)

LEED (selo): Leadership in Energy and Environmental Design

LIM: Lowest Isopleth for Mould (Menor Isopleta para Mofo)

LoC: Library of Congress

LWC (papel): Light Weight Coated

MAC USP: Museu de Arte Contemporânea da Universidade de São Paulo

MAE USP: Museu de Arqueologia e Etnologia da Universidade de São Paulo

MAS: Museu de Arte Sacra de São Paulo

MAST: Museu de Astronomia e Ciências Afins

Matriz BASICO: Benefícios, Abrangência, Satisfação, Investimento, Cliente externo, Operacionalidade

Matriz FOFA: Forças, Oportunidades, Fraquezas e Ameaças

Matriz GUT: Gravidade, Urgência e Tendência

Matriz RICE: Reach/Alcance, Impact/Impacto, Confidence/Confiança e Effort/Esforço 
Matriz SWOT :Strenghts, Weaknesses, Opportunities and Threats

MDPP: Standing Committee for Museum Definition, Prospects and Potentials

MDR: Mapa de Diagnósticos e Recomendações

Metamorfoze: National Programme for the Preservation of the Netherlands' Paper Heritage

MHAV: Multi-Hazard Assessment of Vulnerability

MINON: Movement for a New Museology

MP USP: Museu Paulista (Museu do Ipiranga) da Universidade de São Paulo

MR: Magnitude do Risco

MS: Ministério da Saúde

MVS: Multi-Viewpoint Stereo

NBR: Norma Brasileira

NPS: National Park Service

NR: Norma Regulamentadora da Secretaria Especial de Previdência e Trabalho

OLED: Organic Light-Emitting Diode (diodo orgânico emissor de luz)

ONU: Organização das Nações Unidas

PIAF: Portail International Archivistique Francophone

PCF: Prince Claus Fund of Netherlands

PCS: Preventive Conservation Services (Serviços de Conservação Preventiva)

PDF (formato): Portable Document Format

PI: Preservation Index (Índice de Preservação)

PIXE: Particle-Induced X-ray Emission

PMSP: Prefeitura Municipal de São Paulo

POE: Post-Occupancy Evaluation 
PPRA: Programa de Prevenção de Riscos Ambientais

QDR: Quadro de Diagnósticos e Recomendações

SDGs: Sustainable Development Goals

SEF USP: Superintendência de Espaço Físico da Universidade de São Paulo

SEM: Strategic Enterprise Management (Gestão Organizacional Estratégica)

SENAI: Serviço Nacional de Aprendizagem Industrial

SIG: Sistemas de Informações Geográficas

SiLK: SicherheitsLeitfaden Kulturgut

SISEM-SP: Sistema Estadual de Museus de São Paulo

SNEL: Sindicato Nacional dos Editores de Livros

SOBANE: Screening, Observation, Analysis, Expertise

SVIDHCO: Serviço de Documentação Histórica e Iconografia do Museu Paulista

T: temperatura

TALE: Termo de Assentimento Livre e Esclarecido

TCF: Totally Chlorine Free

TCLE: Termo de Consentimento Livre e Esclarecido

TGA: Teoria Geral da Administração

TGS: Teoria Geral de Sistemas

TWPI: Time Weighted Preservation Index (Índice de Preservação Ponderado no Tempo)

UFJR: Universidade Federal de Juiz de Fora

UFSC: Universidade Federal de Santa Catarina

UnB: Universidade de Brasília

UNDRR: United Nations Office for Disaster Risk Reduction 
UNESP: Universidade do Estado de São Paulo

UNESCO: United Nations Educational, Scientific and Cultural Organization

UNI (norma): L'Ente Nazionale Italiano di Unificazione

Unicamp: Universidade Estadual de Campinas

UNISDR: United Nations International Strategy for Disaster Reduction

UNOSD: United Nations Office for Sustainable Development

UR: umidade relativa

USP: Universidade de São Paulo

UV: Ultraviolet

VOCs: Volatile Organic Compounds (Compostos Orgânicos Voláteis)

VUP: Vida Útil de Projeto

WHC: World Heritage Centre 


\section{SUMÁRIO}

pág.

1 INTRODUÇÃO

029

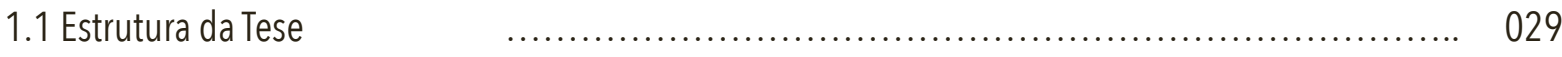

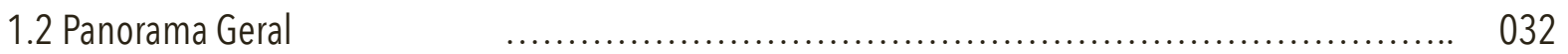

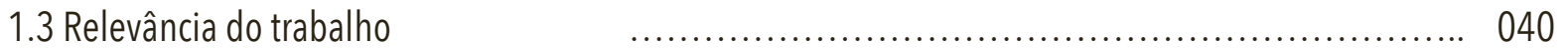

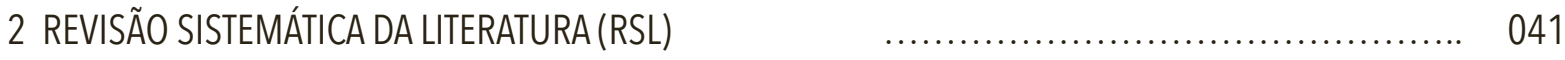

2.1 Referências utilizadas $\quad$.................................................. 041

2.1.1 Entidades internacionais e nacionais de referência $\quad$........................... 042

2.1.2 Normas internacionais e nacionais de referência $\quad$............................. 046

2.2 Fundamentação teórica $\quad$................................................. 049

2.2.1 Conservação preventiva e preservação sustentável $\quad$............................. 050

2.2.2 Qualidade ambiental em áreas de guarda de acervos $\quad$............................. 055

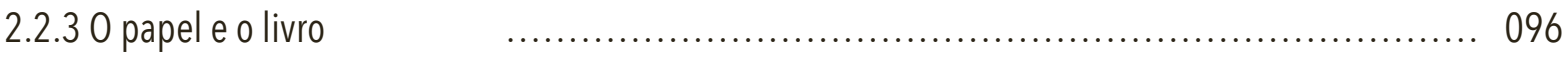

2.2.4 Gestão do patrimônio e gestão de riscos $\quad$................................... 118

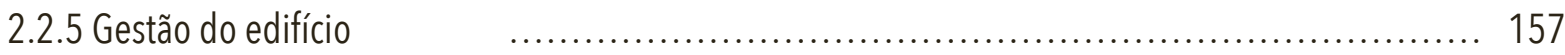

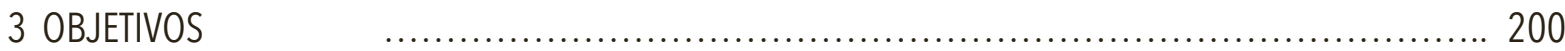

4 HIPÓTESE $\quad$.

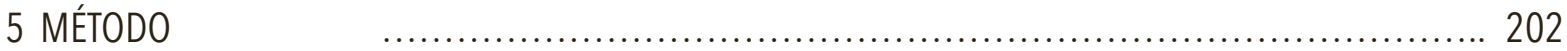

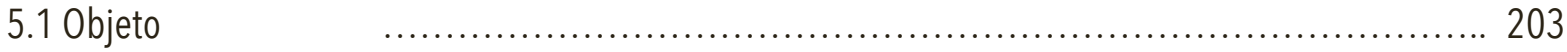

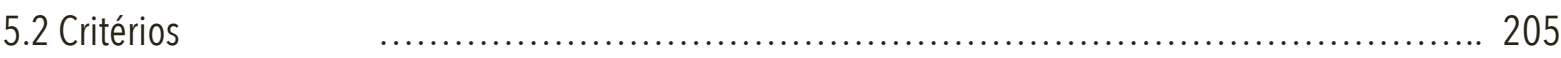

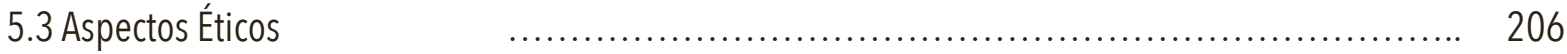

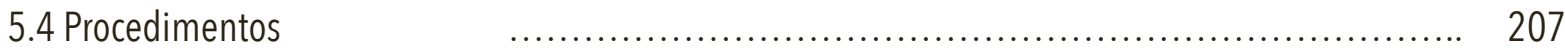


5.5 Estudos de Referência (Benchmarks) $\quad$...................................... 211

5.5.1 São Paulo: Museu Paulista - Museu do Ipiranga $\quad$............................ 212

5.5.2 Rio de Janeiro: Fundação Casa de Rui Barbosa $\quad$............................. 215

5.5.3 Brasília: CeDI - Centro de Documentação e Informação [...] $\quad$........................ 219

5.5.4 Viena $\quad$.................................................................. 224

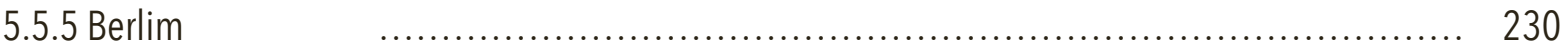

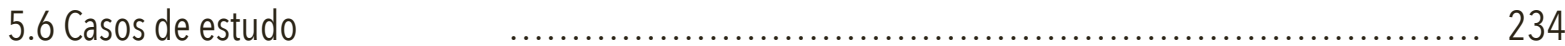

5.6.1 Caracterização climática da cidade de São Paulo $\quad$............................... 234

5.6.2 As interrelações entre edifícios históricos e áreas de guarda de acervos $\quad \ldots \ldots \ldots \ldots \ldots \ldots . . \ldots 240$

5.6.3 Arquivo Histórico Municipal (AHM) $\quad$..................................... 243

5.6.4 Biblioteca Mário de Andrade (BMA) $\quad$..................................... 247

5.6.5 Museu Paulista - Setor de Papel do Museu do Ipiranga (MP USP) $\quad$............... 252

5.6.6 Biblioteca Brasiliana Guita e José Mindlin (BBM USP) $\quad$...................... 258

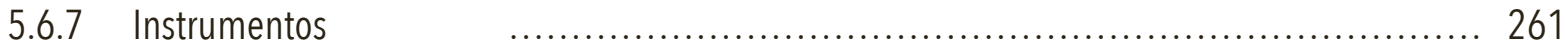

5.6.8 Análise do desempenho ambiental das áreas de guarda $\quad$...................... 281

5.6.9 Considerações finais sobre os casos de estudo $\quad$............................. 285

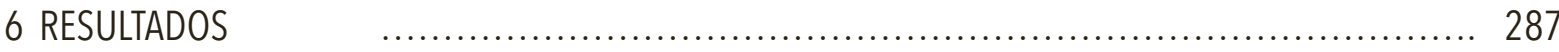

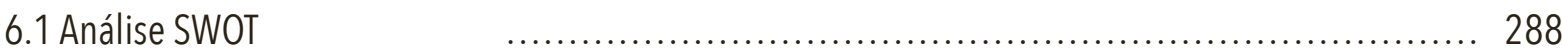

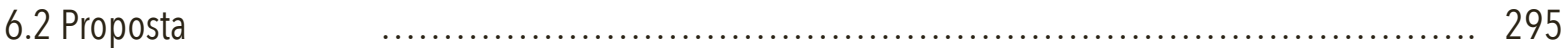

6.2.1 Etapa 1: Planejamento $\quad$............................................. 297

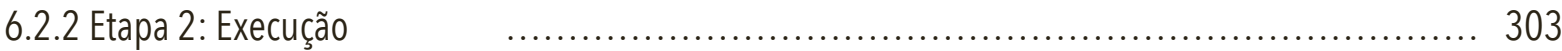

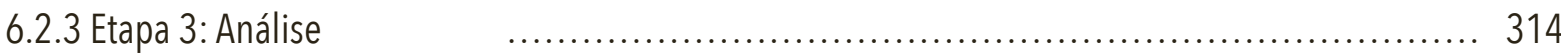


6.2.4 Etapa 4: Resultados $\quad$............................................ 320

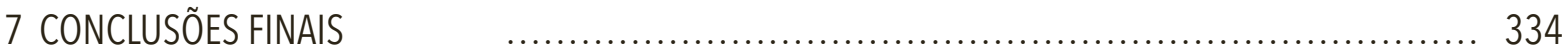

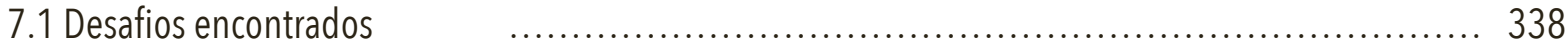

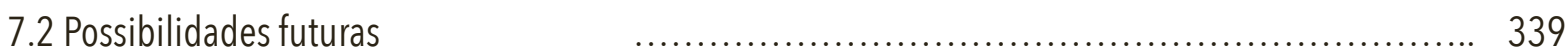

REFERÊNCIAS

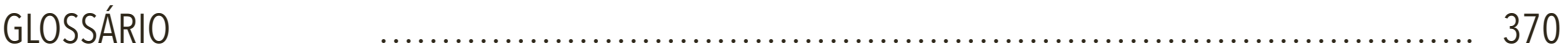

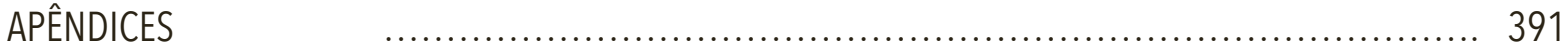

A - Aprovação da pesquisa junto ao CEP $\quad$........................................... 391

B - Solicitação de Autorização (AHM, BMA, MP, BBM) $\quad$............................. 393

C- Modelo de TCLE $\quad$.......................................................... 400

D - Roteiro de entrevista 01

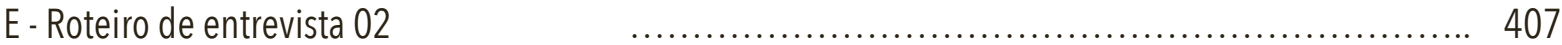

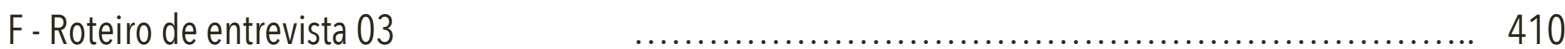





\section{INTRODUÇÃO}

\section{$1.1 \quad$ ESTRUTURA DATESE}

Os recursos culturais são, certamente, um dos elementos mais representativos da experiência humana, dado seu elevado valor simbólico. Em se tratando do patrimônio cultural, todas as ações têm um significado profundo: preservá-lo ou destruí-lo, exaltá-lo ou desprezá-lo, integrá-lo ou apartá-lo, repercutem na maneira como os seres humanos se relacionam com o mundo que os cerca. Por isso, ao longo das eras, amantes do conhecimento e da cultura sempre se esforçaram por encontrar modos de assegurar que, mesmo frente às mais variadas ameaças, o máximo de elementos culturais possível pudesse ser transmitido às novas gerações.

Paralelamente, no que tange os saberes humanos, o contínuo aprimoramento de técnicas e tecnologias, bem como o desenvolvimento de estratégias conceituais mais eficientes, exigem que, nas múltiplas áreas das ciências aplicadas, seus sistemas metodológicos também passem por aprimoramentos à luz das novas descobertas. Além desta revisão temporal, é preciso adaptar os métodos à realidade própria de cada caso em particular.

Porém, dificuldades no desenvolvimento de uma visão estratégica global, que perceba a instituição cultural em sua totalidade, ou seja, seus pontos fortes e fracos, e as oportunidades (de curto, médio e longo prazo), mesmo quando se está diante de grandes limitações, interferem na capacidade institucional de adaptação às necessidades do momento presente.

0 sistema multi-métodos de Avaliação Pós-Ocupação (APO) do ambiente construído está intrinsecamente fundamentado em conceitos de planejamento institucional estratégico e, se corretamente adaptado ao setor cultural, pode ser um excelente aliado na escolha de procedimentos e instrumentos para avaliação do desempenho do edifício e seus ambientes frente às demandas de pessoas e coleções, e, consequentemente, na identificação das vulnerabilidades e dos riscos, na proposição de ações adequadas aos objetivos e recursos institucionais, no monitoramento dos resultados e no aperfeiçoamento das decisões, em um processo de melhoria continuada ao longo de toda a vida útil da instituição.

Não existe, até o presente momento, no Brasil, um modelo metodológico para avaliação do desempenho em uso de áreas de guarda de acervos, que esteja adaptado a países em desenvolvimento em regiões de clima tropical, e que considere, em igual proporção, a perspectiva dos especialistas, tanto em edifícios como em coleções, bem como dos usuários. Assim, esta tese de 
doutorado propõe um modelo teórico-metodológico para o planejamento de soluções orientadas às boas práticas visando uma gestão integral do desempenho ambiental de áreas de guarda de acervos com suporte em papel localizadas em edifícios históricos na cidade de São Paulo. A escolha do tema se dá em virtude da importância, para a cultura e a ciência do país, de se avançar na compreensão e na utilização da metodologia de conservação preventiva orientada à preservação sustentável do patrimônio cultural brasileiro e na necessidade de se ampliar a quantidade de trabalhos nesta área, principalmente pela perspectiva da arquitetura, da engenharia e da construção (AEC).

A conservação preventiva do patrimônio cultural, por se tratar de um conjunto de métodos para a identificação dos riscos aos acervos e proposição de soluções, apesar de sua complexidade multi e interdisciplinar, tem-se mostrado como o caminho mais eficiente, seja em instituições grandes ou pequenas, ricas ou pobres, para se assegurar a salvaguarda dos bens ao longo do tempo. Para que ela seja efetiva, é fundamental um conhecimento aprofundado do comportamento do edifício e de suas facilidades 1 , e, portanto, o monitoramento da qualidade ambiental interna, a documentação sistemática dos processos e o desenvolvimento de pesquisas aplicadas, de modo que o uso e a ocupação, a manutenção, a reforma e a construção de novas áreas estejam o máximo possível orientadas à preservação, em sua totalidade, do patrimônio cultural móvel e imóvel.

Decidiu-se, nesta pesquisa, pelo recorte dos edifícios históricos com acervos em papel por ser esta a situação mais frequente no país e, talvez, a mais desafiadora, dada a complexidade de se adaptar tipologias construtivas, elas mesmas protegidas pelos órgãos de proteção do patrimônio, a uma função tão específica quanto assegurar a permanência, a segurança e a estabilidade, pelo maior tempo possível, de objetos bastante frágeis, que, a princípio, não foram produzidos para durar mais do que algumas décadas.

0 primeiro capítulo deste trabalho apresenta um panorama geral da preservação do patrimônio cultural, no Brasil e no mundo. No capítulo seguinte, tem-se a revisão sistemática da literatura sobre conservação preventiva do patrimônio cultural, características e fragilidades do papel, parâmetros que atribuem qualidade aos ambientes para a guarda de acervos, e métodos para avaliação do desempenho das áreas de guarda e gestão dos riscos, com o intuito de apresentar uma visão holística do estado da arte dos temas relacionados aos objetos de estudo desta pesquisa.

1 Facilidade(s) ou Facility(ies) é o termo utilizado para designar os sistemas, principalmente ativos mas também passivos, que 'apoiam' 0 edifício e seus usuários ou 'facilitam' o seu funcionamento. 
Na segunda parte desta tese, são apresentados os objetivos, a hipótese e o método utilizado. Tem-se, a seguir, a descrição das atividades realizadas com o intuito de se compreender o problema. São descritos os principais aspectos observados, mediante visitas exploratórias a instituições de referência (benchmarks) no Brasil e no exterior, e por meio de visitas técnicas e entrevistas com pessoas-chave, a quatro instituições culturais paulistanas selecionadas como casos de estudo (Arquivo Histórico Municipal, Biblioteca Mário de Andrade, Museu Paulista - Museu do Ipiranga e Biblioteca Brasiliana Guita e José Mindlin). Para os casos de estudo desta pesquisa, são descritos os instrumentos utilizados na avaliação exploratória fundamentada em APO, as características e condições observadas nas áreas de guarda de acervos em papel, bem como as conclusões obtidas. Também são discutidas as características macroclimáticas da cidade de São Paulo e os impactos das mudanças climáticas, bem como as principais características construtivas e de adaptação bioclimática dos edifícios históricos paulistanos, além dos impactos de todos estes fatores para a conservação de coleções em papel.

Nos capítulos finais, de conclusão da pesquisa, é apresentado o Modelo Metodológico Integrado proposto para a gestão do desempenho ambiental das áreas de guarda, e são discutidos os avanços obtidos, as dificuldades encontradas e as possibilidades para pesquisas futuras (Figura 01).

Figura 01. Fluxograma dos procedimentos de pesquisa

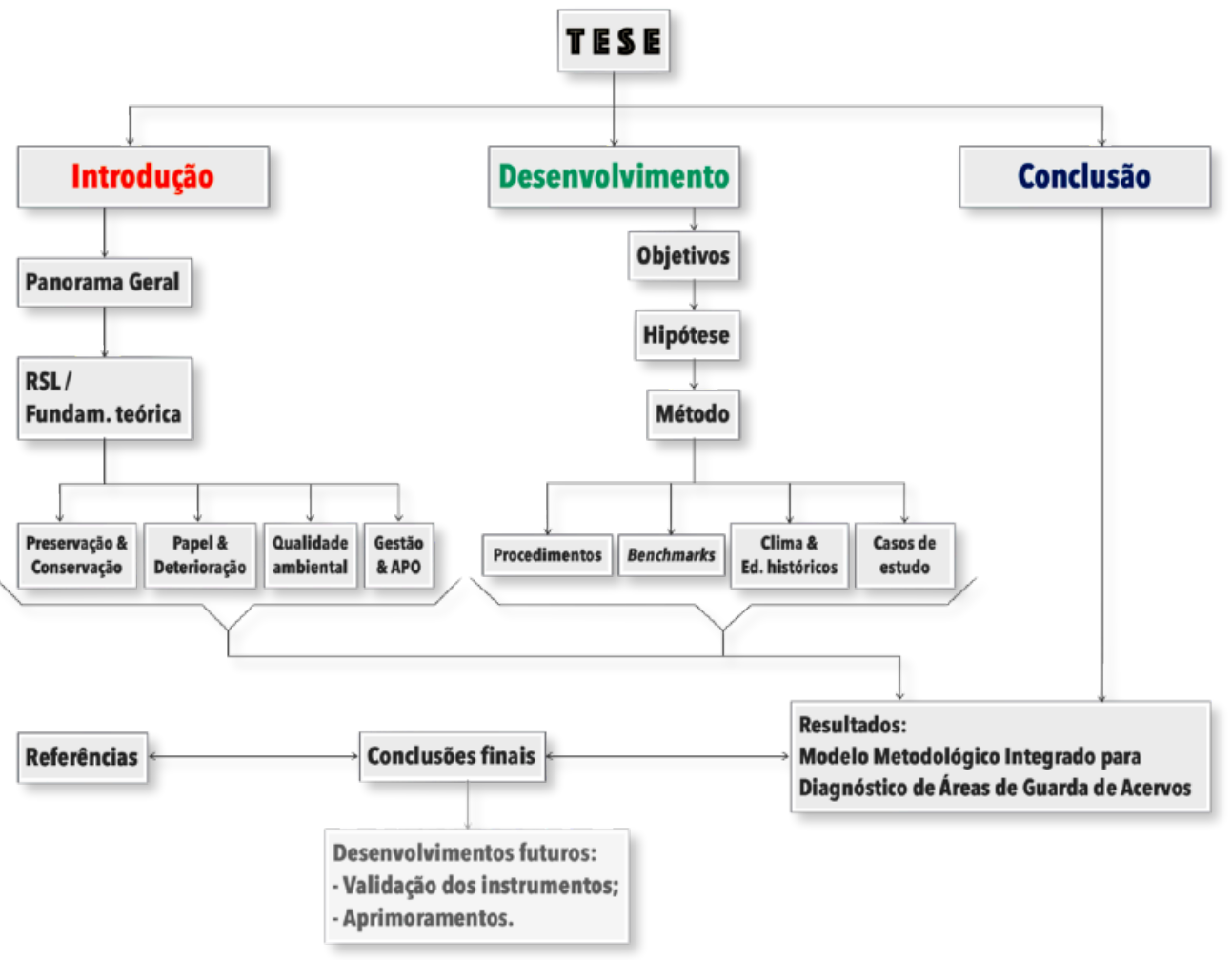

Fonte: a pesquisadora. 


\subsection{PANORAMA GERAL}

0 patrimônio cultural é tradicionalmente entendido como o conjunto de elementos comuns a uma comunidade que representam sua história e identidade. Este patrimônio é composto por itens tangíveis (objetos) como artefatos, edifícios e sítios arqueológicos e itens intangíveis (conhecimentos e tradições) como a dança, a música e demais formas de expressão da criatividade humana.

Gradualmente o conceito de patrimônio tangível vem sendo ampliado para incluir a própria comunidade, suas cidades e 0 ambiente natural a sua volta. Tem-se, assim, o conceito de patrimônio ambiental (UNESCO, 1972; ICCROM, 2005), definido pelo Historical England como:

um edifício, monumento, sítio, local, área ou paisagem identificado como possuidor de um grau de significado que merece consideração no planejamento de decisões por causa do seu interesse como patrimônio (HISTORIC ENGLAND, 2012; tradução da pesquisadora).

Desde a década de 1970, as questões ambientais vêm, aos poucos, ganhando destaque, diante da crescente preocupação mundial com a sobrevivência da espécie humana e de suas expressões culturais (UNESCO, 1994; UNESCO, 2005; CEB, 2015).

A Convenção de Ramsar (Irã) da UNESCO (Organização das Nações Unidas para a Educação, a Ciência e a Cultura), em 1971, reconheceu pela primeira vez a interdependência entre o ser humano e seu meio ambiente (UNESCO, 1994). Em 1972, durante a Convenção de Paris para o Patrimônio Mundial, a entidade salientou que tanto o patrimônio cultural como o natural "são de excepcional interesse e, portanto, precisam ser preservados como parte do patrimônio mundial que pertence à humanidade como um todo" (UNESCO, 2005; tradução da pesquisadora).

Quatro anos mais tarde, em 1976, a UNESCO escreveu a Carta de Nairobi, em que definiu ambiência de conjuntos históricos ou tradicionais como "o quadro natural ou construído que influi na percepção estática ou dinâmica desses conjuntos, ou a eles se vincula de maneira imediata no espaço, ou por laços sociais, econômicos ou culturais". E salvaguarda como "a identificação, a proteção, a conservação, a restauração, a reabilitação, a manutenção e a revitalização dos conjuntos históricos ou tradicionais e de seu entorno" (IPHAN, 2015). 
Provavelmente, a primeira associação entre patrimônio cultural e natural tenha ocorrido ainda no século XIX com a criação dos Museus de História Natural e dos Jardins Botânicos, locais destinados a estudar e preservar espécies animais, vegetais e minerais, porém, não com o objetivo de conservação ambiental, mas sim para satisfazer à curiosidade pública (MENDES, 2011).

Somente várias décadas depois, em 1971, Georges Henry Rivière e Hugues de Varine criaram o conceito de Ecomuseu (Écomusée). 0 prefixo eco remete à ideia de diversidade, em uma referência à ecologia natural e humana (BRULON, 2015). Nesta proposta, a ideia de coleção foi ampliada para incluir a integração entre território, patrimônio e público.

O ICOM (International Council of Museums), organização fundada em 1946 para representar os museus e seus profissionais, realizou, em 1984, em Québec, um encontro que deu início ao movimento MINON (International Movement for a New Museology), instituído pela Declaração de Québec (Cadernos de Sociomuseologia, 2010). 0 movimento da Nova Museologia consistiu na "busca pelas origens de uma cultura submersa, seja ela rural ou industrial, das periferias ou de favelas" (MAIRESSE, 2002).

No ano seguinte, durante a Conferência Mundial sobre as Políticas Culturais, o ICOMOS (International Council of Monuments and Sites) redigiu a Declaração do México que, em acordo com as novas teorias da Ecomuseologia e da Nova Museologia, afirmou que é preciso haver uma visão integrada entre ser humano, território, patrimônio e comunidade (IPHAN, 2015).

Em 1994, a Declaração de Lisboa (ICTOP - International Committee for the Training of Personnel) afirmou que os museus são "instituições ao serviço da sociedade e do seu desenvolvimento" e assumem "um papel de liderança na comunidade internacional" (Cadernos de Sociomuseologia, 1999), instituindo assim a Sociomuseologia, definida por Mário Moutinho, um dos seus principais teóricos, como o "recurso para o desenvolvimento sustentável da humanidade, assente na igualdade de oportunidades e na inclusão social e económica", caracterizada pela "interdisciplinaridade com que apela a áreas do conhecimento perfeitamente consolidadas e as relaciona com a Museologia propriamente dita" (Cadernos de Sociomuseologia, 2007).

Assim, tem-se que as novas linhas museológicas - Ecomuseologia, Nova Museologia e Sociomuseologia compartilham a influência das demandas por preservação e sustentabilidade e a valorização da integração entre o ser humano e o seu meio (material e imaterial), utilizando-se, para isso, de todos os conhecimentos tecnológicos e científicos que permitam a manutenção da qualidade ambiental do conjunto. 
Em 2007, o ICOM fez pequenos ajustes na definição de museu, que passou a ser:

uma instituição permanente, sem fins lucrativos, ao serviço da sociedade e de seu desenvolvimento, aberta ao público, que adquire, conserva, pesquisa, comunica e exibe 0 patrimônio tangível e intangível da humanidade e de seus ambientes visando à educação, ao estudo e ao lazer. (ICOM, 2007)

No entanto, dadas as crescentes transformações sociais, econômicas e ambientais pelas quais o mundo vem passando, a entidade submeteu ao Comitê Permanente para Definição, Perspectivas e Potenciais de Museus (MDPP - Standing Committee for Museum Definition, Prospects and Potentials) um pedido para que uma nova definição, mais adaptada ao século XXI, fosse anunciada no ICOM's 25th General Conference, em Kyoto, em setembro de 2019. Pessoas e instituições ligadas a museus foram convidadas a enviar sugestões.

Porém, durante a Assembléia Geral, a França liderou um grupo de países (Itália, Espanha, Alemanha, Canadá, Irã, Israel, Brasil, Peru e Argentina) contra a proposta apresentada, que foi classificada por eles como "uma confusa coleção de frases politicamente corretas e posturas da moda com pouco ou nenhum valor legal" (The Art Newspaper, 2019)² e venceram uma moção de adiamento na escolha de uma nova definição. A UNESCO, nas 'Recomendações Relativas à Proteção e Promoção dos Museus e das Coleções, sua Diversidade e sua Função na Sociedade', de 2015, adota a definição do ICOM de 2007 e salienta que as principais funções de um museu são a preservação, a pesquisa, a comunicação e a educação. 0 texto também destaca que os principais temas que permeiam as funções dos museus para com as sociedades do século XXI são a globalização; a economia e a qualidade de vida; o seu papel social; e o uso de tecnologias de comunicação e informação.

As transformações pelas quais os museus vêm passando nesta transição para o século XXI são profundas e complexas e refletem as mudanças percebidas no planeta e nas sociedades humanas. Até o século XX, as coleções eram formadas a partir de um modo de pensar binário, oriundo do racionalismo ocidental, que dividia o conhecimento em díades como cultura e natureza, arte e cultura, arte e etnografia, história e tecnologia, estando, assim, alinhadas ao pensamento corrente de que algumas coisas eram melhores do que outras. As transformações neste modo de pensar resultaram em mudanças também nas coleções.

2 Informação disponível em: https://www.theartnewspaper.com/news/icom-kyoto. Acesso em jun. 2020. 
Surge, assim, a necessidade de se estabelecer visões inclusivas, que sejam holísticas, inter, multi e transdisciplinares, multiétnicas, em que não se pode mais separar o ser humano da natureza ou um grupo humano de outro (ICOM, 2019).

Além disso, nos séculos passados, as exposições, em sintonia com o método científico, faziam uso de formatos tradicionais que retratavam de modo compartimentado saberes e características de grupos específicos, bem como informaç̧ões sobre animais, vegetais e minerais do passado da Terra. Atualmente, o desenvolvimento tecnológico e a mudança de foco nas pesquisas acadêmicas, que se voltam para as questões prementes do presente e do futuro próximo (mais do que para uma busca pela compreensão do passado), transparece em exposições com formatos muito variados, que abordam temas como a mudança climática e a destruição da biodiversidade; desigualdade e ausência de oportunidades; migrações; discriminações; conflitos e guerras; responsabilidade e transparência governamentais (ICOM, 2019).

A correlação entre o patrimônio tangível e intangível e o desenvolvimento sustentável vem sendo abordada pelo ICOMOS pelo menos desde 1978, quando, na conferência de Moscou e Suzdal, discutiu-se "a proteção de cidades e bairros históricos no contexto do desenvolvimento urbano", e o subtema "monumentos históricos como um meio para o desenvolvimento econômico e social" (ICOMOS, 2011).

A Declaração de Florença, de 2014, reforçou a urgência da questão e afirmou "a importância de se medir o impacto da cultura e da criatividade para o desenvolvimento sustentável de modo a mantê-lo em destaque na agenda política" (UNESCO, 2014, tradução da pesquisadora).

A comunidade internacional (os 193 países membros da ONU), em 2015, em reunião na UNESCO, adotou uma nova agenda para o desenvolvimento mundial, chamada Agenda 2030: For People, Planet and Prosperity (Agenda 2030: Para Pessoas, Planeta e Prosperidade), que estabeleceu as 169 metas para os próximos 15 anos, organizados em 17 SDGs (Sustainable Development Goals / Metas para 0 Desenvolvimento Sustentável). Nesta agenda, o patrimônio aparece na "meta 11:4 - ampliar esforços para proteger e salvaguardar o patrimônio cultural e natural mundial" (target 11:4 - strengthen efforts to protect and safeguard the world's cultural and natural heritage). Particularmente, o CIVVIH (International Committee on Historic Towns and Villages / Comitê Internacional para Cidades e Vilas Históricas), se comprometeu a "reconhecer e estimular a interseção entre patrimônio cultural e cidades resilientes e sustentáveis". 
Um pouco antes, em 2011, o ICOMOS, em um simpósio realizado em Paris, também destacou que a cultura (da qual o patrimônio é uma parte) é o quarto pilar para o desenvolvimento sustentável, sendo "um componente essencial ao desenvolvimento humano (...) permitindo o crescimento econômico e 0 pertencimento nos processos de desenvolvimento" (ICOMOS, 2016). 0 papel da arquitetura, dos arquitetos e dos edifícios pode ser encontrado nas seguintes seções da Declaração de Paris:

Inspirando a arquitetura inovadora:

Edifícios históricos tradicionais são um tesouro da experiência arquitetural. Eles são uma fonte universal inexaurivel de inspiração para a arquitetura moderna e inovadora, em termos de materiais, métodos construtivos, planejamento e projeto, contribuindo para uma maior qualidade de vida.

(...)

Treinamento profissional:

Os principais agentes no desenvolvimento da conservação do patrimônio - arquitetos, conservadores, gestores, planejadores, investidores e operadores turísticos - precisam de treinamento e capacitação.

(...)

Pesquisa:

Institutos de pesquisa, universidades, organizações consultivas especializadas, como 0 ICOMOS, e organizações intergovernamentais, como a UNESCO, precisam fortalecer seus estudos e programas de pesquisa. Estas iniciativas devem envolver a verificação in-loco das ferramentas analíticas utilizadas para aferir o desempenho físico do patrimônio edificado, a medição do valor econômico do patrimônio, a avaliação do impacto do turismo cultural no emprego e na riqueza regional, e a investigação das condições, riscos e oportunidades de se investir na proteção do patrimônio, atraindo parceiros para o desenvolvimento econômico e financeiro (ICOMOS, 2011; tradução da pesquisadora).

As recentes mudanças econômicas globais, que geram crises financeiras recorrentes, dificultam a capacidade das instituições de incorporarem políticas de longo prazo para a gestão do patrimônio cultural e a prevenção de riscos (TANDON, 2013). Soma-se a isso o fato de que a ocorrência de eventos climáticos extremos vêm aumentando nas últimas décadas, tanto em frequência quanto em intensidade e, consequentemente, 0 risco de perdas significativas, inclusive do patrimônio (LYNN, 2016; HARMELING e ECKSTEIN, 2012).

0 Fórum Econômico Mundial constatou, em pesquisa realizada em 2014, que a quantidade de desastres naturais cresceu de cerca de 150 por ano em 1980 para mais de 350 a partir dos anos 2000 (Figura 02), com uma distribuição desproporcional ao redor do planeta e impacto maior nos países em desenvolvimento, principalmente naqueles economicamente dependentes da agricultura (World Economic Forum, 2014). 
Figura 02. Número de desastres por causas naturais, no mundo, entre 1980 e 2014

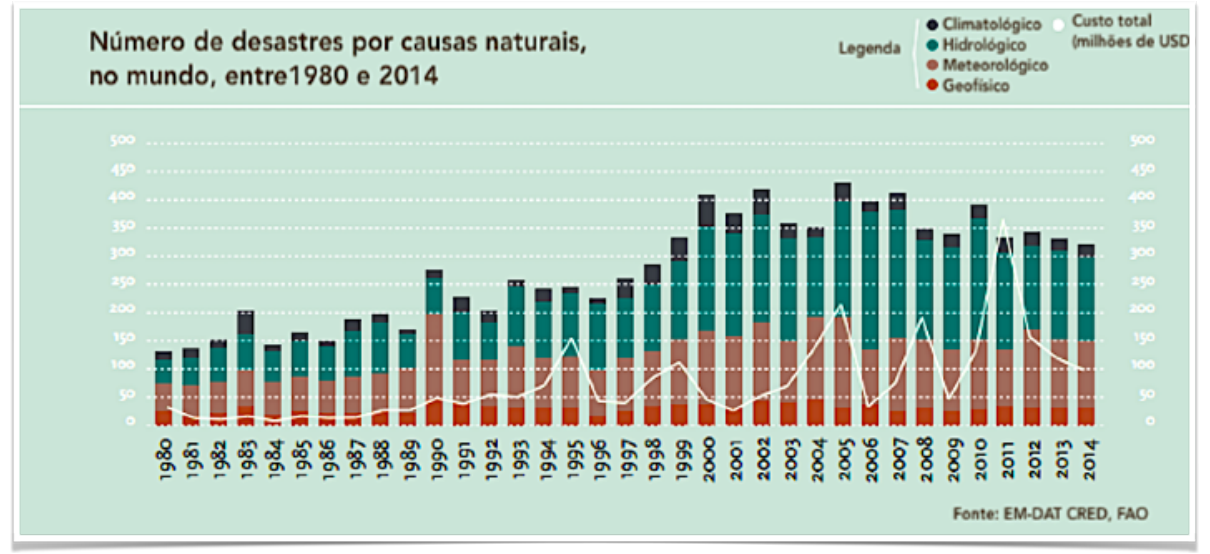

Fonte: traduzido de WEF, 2015.

0 EM-DAT3 (The International Disaster Database / Banco de dados internacional de desastres) do CRED (Centre for Research on the Epidemiology of Disasters / Centro de Pesquisa em Epidemiologia de Desastres) é um banco de dados dos principais eventos adversos desde 1900, criado para auxiliar a OMS em suas políticas de prevenção e preparação a desastres. 0 CRED publica, em conjunto com a ONU (Organização das Nações Unidas), relatórios anuais de acompanhamento da evolução dos desastres no mundo. Em 2019 foi feito um balanço dos primeiros vinte anos do século XXI, no qual se constatou um incremento preocupante nos principais indicadores, em relação às duas décadas anteriores: número de desastres, total de pessoas afetadas, total de mortos e total de perdas econômicas (Figura 03).

Figura 03. Impacto de desastres: 1980 a 1999 versus 2000 a 2019

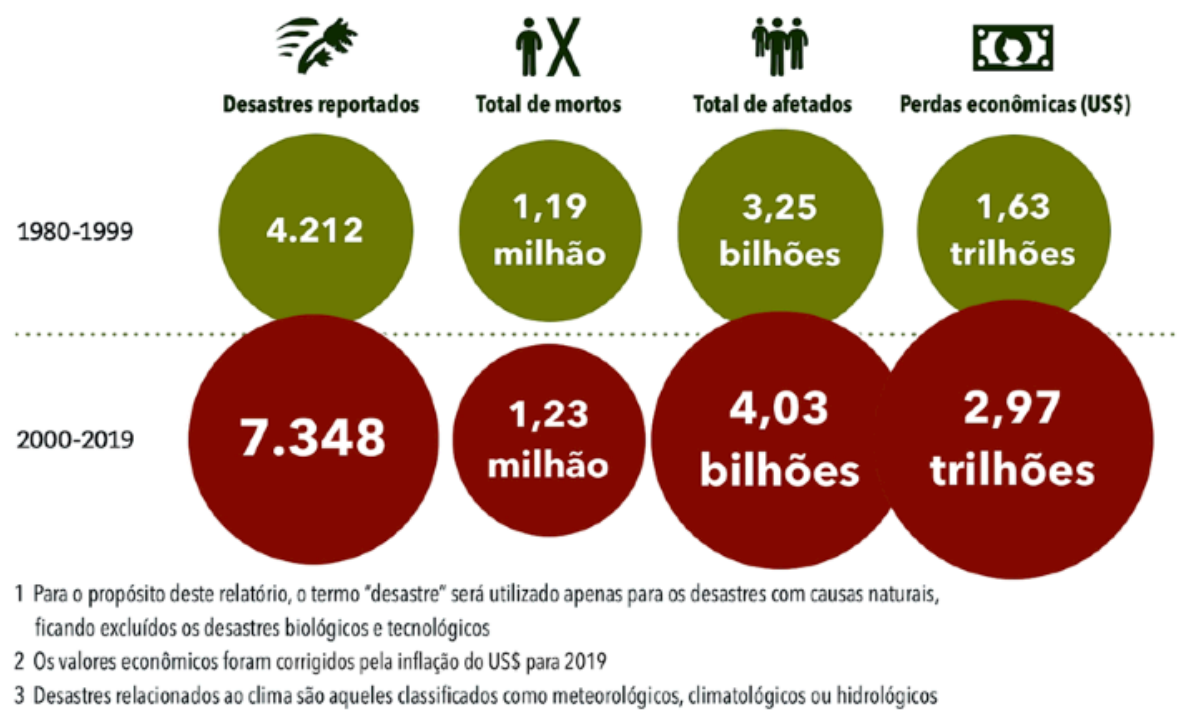

Fonte: traduzido de CRED / UNDRR, 2019.

${ }^{3}$ Maiores informações em: https://www.emdat.be. Acesso em dez. 2020. 
A atenção internacional se voltou para a preservação do patrimônio em três momentos cruciais: 1. no período de reconstrução da Europa pós Segunda Guerra Mundial, com a Convenção de Haia em 1954 (UNESCO, 1954 e 1999); 2. após a inundação de Florença em 1966 (VAROLI-PIAZZA, 2007); 3. a partir de 1990, com a maior recorrência de eventos climáticos e humanos (incêndios na Austrália; conflitos armados na lugoslávia, no Golfo Pérsico, no Afeganistão, na Síria; tsunamis no Oriente; inundação em Nova Orleans e Paris; terremoto em Kioto, no Haiti, no Nepal; incêndio no Museu Nacional do Rio de Janeiro, na NotreDame de Paris, dentre muitos outros).

Na década de 1990, diversas agências internacionais para proteção do patrimônio cultural da humanidade foram criadas: Comitê Internacional para o Escudo Azul (ICBS - International Committee for the Blue Shield), em homenagem à Convenção de Haia, associada ao Conselho Internacional para Monumentos e Sítios (ICOMOS - International Council on Monuments and Sites); Conselho Internacional de Museus (ICOM International Council of Museums); Conselho Internacional para Arquivos (ICA - International Council on Archives); e Federação Internacional da Associação das Bibliotecas (IFLA - International Federation of Libraries Association) (STOVEL, 1998).

Em 1998 foi publicado o Risk Preparedness: A Management Manual for World Cultural Heritage (STOVEL, 1998), documento elaborado em conjunto pela UNESCO, ICOMOS e ICCROM (International Centre for the Study of the Preservation and Restoration of Cultural Property). Este documento enfatiza "a importância de se adotar um novo paradigma de conservação focado na prevenção (...) que ofereça uma visão mais holística do que as abordagens convencionais" (STOVEL, 1998).

Segundo TANDON (2013), os principais atributos que instituições culturais devem ter para lidar com 0 cenário atual são boa governança, solidez institucional, disponibilidade de recursos, especialistas e sistemas organizados de previsão e resposta, tudo isso sustentado por processos sistematizados de gestão do patrimônio e de riscos. Atualmente, segundo a entidade, a ênfase deve ser colocada na resiliência do edifício, que se traduz como prevenção adequada, novos mecanismos de gestão e adaptação às mudanças climáticas (UNISDR, 2009; FIELD et al., 2011).

A ONU organizou, em 2005, no Japão, a Conferência Global para Redução de Desastres. Nesta conferência, foi assinado o Quadro de Ação de Hyogo 2005-2015 (HFA - Hyogo Framework for Action), que associou, pela primeira vez, desenvolvimento sustentável à redução de risco de desastres, correlacionando sociedade, economia e cultura (UNISDR, 2005). 
Em 2006, na conferência internacional organizada pelo Fundo Holandês do Príncipe Carlos (Prince Claus Fund of Netherlands), e publicada sob o título Cultura é uma Necessidade Básica (Culture is a Basic Need), descreve-se a importância da preservação cultural como uma ajuda humanitária a comunidades em risco por promover um senso de esperança e continuidade para esta população (PCF, 2006).

Em 2012, o Escritório do Alto Comissariado das Nações Unidas para Direitos Humanos (Office of the United Nations High Commissioner for Human Rights) propôs que o acesso ao patrimônio cultural fosse incluído entre os direitos humanos (SHAHEED, 2011).

No mesmo período (2010-2011), a Federação Internacional da Associação das Bibliotecas (IFLA) definiu os Princípios de Compromisso (Principles of Engagement) com o objetivo de guiar as bibliotecas quando em situações de recuperação de danos (IFLA, 2012).

Em Veneza, a 'Conferência sobre Resiliência de Edifícios Urbanos a Desastres: protegendo o patrimônio cultural e adaptando-se às mudanças climáticas' (2012), relacionou, pela primeira vez, a resiliência de uma cidade a planejamento urbano, proteção do patrimônio cultural e adaptação às mudanças climáticas, estabelecendo a necessidade de cooperação entre governantes, planejadores e gestores do patrimônio (UNISDR, 2012).

0 patrimônio histórico urbano é definido pela UNESCO (2011) como "a dimensão histórica de valores e atributos culturais e naturais", e engloba também a dimensão do tangível e do intangível. A UNESCO destaca a necessidade de proteger, salvaguardar, conservar e valorizar o patrimônio em um mundo marcado pela urbanização acelerada e descontrolada, utilizando, para isso, estratégias e projetos para o desenvolvimento sustentável (NOCCA, 2017).

0 patrimônio pode ter função positiva no desenvolvimento sustentável mas, para isso, precisa ser percebido pela comunidade como um agente que contribui para o desenvolvimento econômico, social e ambiental de uma região, ou seja, como um setor econômico que gera investimentos e não custos (NOCCA, 2017). Esta percepção exige também uma mudança no modo de se enxergar a economia. Braungart e McDonough (2008; tradução da pesquisadora) explicam que muitas estratégias chamadas de sustentáveis ainda "se apoiam num sistema de produção linear, em que apenas se estica a linha", ou seja, elas se preocupam mais com a redução dos impactos (custos) do que com as potencialidades (ganhos). Por outro lado, em uma visão circular da economia, o foco está na percepção e na valorização dos benefícios, pela expectativa de que promover ações sustentáveis irão, como consequência, fazer decrescer os impactos negativos (Ellen MacArthur Foundation, 2015). 


\subsection{RELEVÂNCIA DO TRABALHO}

Por melhores que sejam as técnicas e as tecnologias para o restauro do patrimônio cultural e por mais capacitados os profissionais envolvidos, é consenso que este é um processo trabalhoso, demorado, oneroso e que interfere no estado original do objeto. Assim, em uma abordagem holística, aconselha-se a presenvação sustentável do patrimônio, metodologia que propõe que as instituições dediquem mais recursos 4 à prevenção do que à recuperação, por meio de gestão, pesquisa e trabalho interdisciplinar, por ser esta uma estratégia para a salvaguarda do maior número possível de itens, pelo maior tempo possível, dentro da realidade própria de cada instituição em particular. Para que este objetivo possa ser atingido, os trabalhos de preservação precisam começar pela etapa de diagnóstico do estado de conservação dos acervos e de avaliação dos riscos ao patrimônio. Todas as metodologias disponíveis correlacionam, de alguma forma, ameaças aos objetos e vulnerabilidades construtivas. No entanto, estas atividades são, frequentemente, realizadas pelos profissionais que trabalham diretamente com os acervos, porém, com pouca ou nenhuma participação dos profissionais da construção responsáveis pela gestão das facilidades e manutenção do edifício. Arquitetos e engenheiros costumam ser consultados a posteriori, com o intuito de transformar o diagnóstico em ações para a mitigação ou eliminação dos riscos.

Esta tese procura demonstrar que esta abordagem pode não ser a mais efetiva ${ }^{5}$ pois exclui profissionais-chave das etapas iniciais de trabalho, o que pode resultar em retrabalhos, falhas e conflitos dentro das instituições. 0 sistema multimétodos de Avaliação Pós-Ocupação (APO), desenvolvido para avaliar o desempenho de edificações complexas já ocupadas e em uso, é uma metodologia do tipo "guarda-chuva", que, se devidamente adaptada às demandas do patrimônio cultural, pode se combinar às análises diagnósticas do estado de conservação de acervos e dos riscos ao patrimônio, em uma avaliação global das interrelações entre construção, qualidade ambiental, coleções e usuários. Destaca-se também que a APO permite a colaboração entre especialistas de diversas áreas do conhecimento, e inclui instrumentos que captam o ponto de vista de todos sujeitos envolvidos (funcionários, visitantes, projetistas, pesquisadores, comunidade e/ou outros). A AP0 adaptada a áreas de guarda localizadas em regiões tropicais pode auxiliar em um diagnóstico mais preciso das vulnerabilidades, na proposição de ações orientadas às pessoas, e no desenvolvimento de pesquisas que respondam às demandas locais.

\footnotetext{
4 Recurso é um termo amplo que expressa os meios disponíveis. Em uma instituição cultural, eles podem ser: administrativos, financeiros, temporais, energéticos, tecnológicos, dentre outros. 0 próprio patrimônio é entendido como um recurso cultural de que dispõe uma sociedade.

5 Para que uma tarefa seja efetiva (tenha excelência), ela precisa ser eficiente (usar adequadamente os recursos) e eficaz (ser executada conforme o planejado). Esta abordagem é conhecida como os 3Es da gestão = Eficiente (como fazer), Eficaz (o que fazer) e Efetiva (o que e como fazer).
} 


\section{REVISÃO SISTEMÁTICA DA LITERATURA (RSL)}

\subsection{REFERÊNCIAS UTILIZADAS}

Para que esta pesquisa de doutorado pudesse ser adequadamente desenvolvida foi preciso fazer uso de saberes provenientes de múltiplas áreas do conhecimento, principalmente arquitetura, engenharia, conservação preventiva de acervos, administração, física, química e biologia, do modo a compor um arcabouço técnico e científico que descrevesse o desempenho ambiental esperado para a correta preservação de acervos em papel em edifícios históricos na cidade de São Paulo.

Para o desenvolvimento desta pesquisa de doutorado, foram utilizadas:

- as principais plataformas de busca acadêmica - Web of Science e Scopus (CAPES / CAFE) e Google Scholar - com o intuito de se buscar os artigos científicos com menos de vinte anos mais relevantes para cada um dos descritores (palavras-chave) da pesquisa;

- os documentos arquivados nas bases de dados das principais entidades internacionais e nacionais que atuam na preservação do patrimônio;

- livros, manuais e revistas reconhecidos como referências tradicionais nas áreas de estudo da pesquisa;

- normas e recomendações, nacionais e internacionais, relativas ao edifício, suas facilidades e 0 desempenho esperado para a preservação de acervos.

Foram pesquisados os seguintes assuntos:

a. a história do papel e do livro;

b. os processos químicos envolvidos na fabricação e na degradação do papel;

c. a preservação sustentável e a conservação preventiva do patrimônio cultural;

d. técnicas para a análise físico-química de artefatos culturais;

e. características ambientais recomendadas para a salvaguarda de coleções;

g. a gestão de riscos aplicada ao patrimônio cultural;

h. materiais, sistemas e técnicas tradicionais brasileiras de construção e adaptação bioclimática;

i. Avaliação do Desempenho do Edifício e Avaliação Pós-Ocupação (APO);

j. manutenção preventiva, comissionamento e gestão de facilidades;

k. plataforma BIM aplicada ao patrimônio cultural (HBIM);

I. sustentabilidade aplicada ao patrimônio cultural;

m. características climáticas e mudanças climáticas para a cidade de São Paulo; 
n. histórico dos edifícios casos de estudo (Arquivo Histórico Municipal, Biblioteca Mário de Andrade, Museu Paulista - Museu do Ipiranga e Biblioteca Brasiliana Guita e José Mindlin).

\subsubsection{Entidades internacionais e nacionais de referência}

Tem-se, a seguir, os quadros-resumo das principais entidades de referência internacionais (Quadro 01) e nacionais (Quadro 02) consultadas.

Quadro 01: Principais entidades internacionais consultadas ${ }^{1}$

\begin{tabular}{|c|c|c|}
\hline 需 Entidade (sigla) & Propósito / missão & Endereço eletrônico \\
\hline American Alliance of Museums (AAM) & $\begin{array}{l}\text { "rede de oportunidades, produtos e } \\
\text { serviços que auxiliam no aprimoramento } \\
\text { das carreiras de profissionais e } \\
\text { voluntários e no enriquecimento das } \\
\text { instituiç̧ões" }\end{array}$ & https://www.aam-us.org \\
\hline American Institute for Conservation (AIC) & $\begin{array}{c}\text { "apoia e empodera profissionais, } \\
\text { instituições, e o público para a } \\
\text { preservação do insubstituível patrimônio } \\
\text { cultural" }\end{array}$ & $\frac{\text { https://www.culturalheritage.org/ }}{\text { publications }}$ \\
\hline APOYOnline & $\begin{array}{l}\text { "organização sem fins lucrativos para a } \\
\text { promoção de comunicação, troca e } \\
\text { desenvolvimento profissional no campo } \\
\text { da preservação do patrimônio nas } \\
\text { Américas e nos países de língua } \\
\text { portuguesa e espanhola" }\end{array}$ & $\frac{\text { http://apoyonline.org/en_US/resources/ }}{\text { publications/ }}$ \\
\hline $\begin{array}{l}\text { Australian Institute for the Conservation } \\
\text { of Cultural Material (AICCM) }\end{array}$ & $\begin{array}{l}\text { "organização profissional para os } \\
\text { conservadores na Austrália" }\end{array}$ & https://aiccm.org.au/conservation/ \\
\hline Blue Shields Intenational & $\begin{array}{l}\text { "entidade comprometida com a proteção } \\
\text { da propriedade cultural mundial, e } \\
\text { preocupada com a proteção do } \\
\text { patrimônio cultural e natural, tangível e } \\
\text { intangível, na eventualidade de conflitos } \\
\text { armados e desastres naturais ou } \\
\text { provocados pelo ser humano" }\end{array}$ & https://theblueshield.org \\
\hline Canadian Conservation Institute (CCI) & $\begin{array}{l}\text { "desenvolve e promove a conservação } \\
\text { dos acervos do patrimônio do Canadá } \\
\text { por meio de sua experiência em ciência } \\
\text { da conservação, conservação preventiva } \\
\text { e curativa" }\end{array}$ & $\frac{\text { https://www.canada.ca/en/conservation- }}{\underline{\text { institute.html }}}$ \\
\hline
\end{tabular}

(continua)

1 Traduções da pesquisadora. 
Quadro 01: Principais entidades internacionais consultadas (continuação)

\begin{tabular}{|c|c|c|}
\hline 鮦 Entidade (sigla) & Propósito / missão & Endereço eletrônico \\
\hline Collectioncare & $\begin{array}{l}\text { "serviços inovadores e acessíveis para o } \\
\text { monitoramento visando à conservação } \\
\text { preventiva de artefatos culturais } \\
\text { individuais durante sua exibição, } \\
\text { guarda, manuseio e transporte" }\end{array}$ & $\frac{\text { https://www.collectioncare.eu/ }}{\text { publications/ }}$ \\
\hline English Heritage & $\begin{array}{c}\text { "protege uma coleção } \\
\text { internacionalmente importante } \\
\text { composta por sítios históricos e artefatos } \\
\text { compreendidos em seis milênios de } \\
\text { existência }(\ldots)^{\prime \prime}\end{array}$ & $\begin{array}{l}\frac{\text { https://www.english-heritage.org.uk/learn/ }}{\text { conservation/collections-advice-and- }} \\
\text { quidance? } \\
\frac{\text { fbclid=IwAR3RE2MKTrPAdPh3uykmp- }}{\underline{\text { udgS8tclNAEdBwDk5UeVCiBWtiUf1NuCRr8P }}}\end{array}$ \\
\hline Getty Conservation Institute (GCI) & $\begin{array}{c}\text { "trabalha internacionalmente pelo } \\
\text { avanço das estratégias de conservação } \\
\text { nas artes visuais" }\end{array}$ & $\frac{\text { https://www.getty.edu/conservation/ }}{\text { publications_resources/ }}$ \\
\hline Image Permanence Institute (IPI) & $\begin{array}{c}\text { "apoia a preservação dos acervos do } \\
\text { patrimônio cultural" }\end{array}$ & https://ipisustainability.org \\
\hline $\begin{array}{l}\text { Indian National Trust for Art and Cultural } \\
\text { Heritage (INTACH) }\end{array}$ & $\begin{array}{l}\text { "a conservação do patrimônio está } \\
\text { fundamentada na consciência de que } \\
\text { viver em harmonia com o patrimônio } \\
\text { aumenta a qualidade de vida, e é um } \\
\text { dever de todo cidadão da Índia, como } \\
\text { determinado pela Constituição" }\end{array}$ & http://www.intach.org/index.php \\
\hline $\begin{array}{l}\text { International Centre for the Study of the } \\
\text { Preservation and Restoration of Cultural } \\
\text { Property (ICCROM) }\end{array}$ & $\begin{array}{l}\text { "organização intergovernamental que } \\
\text { trabalha a serviço dos seus Estados } \\
\text { Membros promovendo a conservação de } \\
\text { todas as formas de patrimônio cultural, } \\
\text { em todas as regiões do mundo" }\end{array}$ & $\frac{\text { https://www.iccrom.org/resources/ }}{\text { publications }}$ \\
\hline $\begin{array}{l}\text { International Council of Museums } \\
\text { (ICOM) } \\
\& \\
\text { International Committee for Museum } \\
\text { Security (ICMS) }\end{array}$ & $\begin{array}{l}\text { "associação de membros e organização } \\
\text { não governamental com o objetivo de } \\
\text { estabelecer requisitos profissionais e } \\
\text { éticos para as atividades museais" }\end{array}$ & $\begin{array}{l}\text { https://icom.museum/en/resources/ } \\
\text { http://network.icom.museum/icms/ }\end{array}$ \\
\hline $\begin{array}{l}\text { International Council on Monuments } \\
\text { and Sites (ICOMOS) }\end{array}$ & $\begin{array}{l}\text { "organização internacional não } \\
\text { governamental dedicada à conservação } \\
\text { de monumentos e sítios do mundo" }\end{array}$ & https://www.icomos.org/en \\
\hline $\begin{array}{l}\text { International Federation of Library } \\
\text { Associations and Institutions (IFLA) }\end{array}$ & $\begin{array}{c}\text { "representa os interesses de bibliotecas } \\
\text { e serviços de informação e seus } \\
\text { usuários" }\end{array}$ & https://www.ifla.org/ifla-publications \\
\hline
\end{tabular}


Quadro 01: Principais entidades internacionais consultadas (continuação)

\begin{tabular}{|c|c|c|}
\hline 齿 Entidade (sigla) & Propósito / missão & Endereço eletrônico \\
\hline $\begin{array}{l}\text { International Institute for Conservation } \\
\text { of Historic and Artistic Works (IIC) }\end{array}$ & $\begin{array}{l}\text { "reúne profissionais da conservação de } \\
\text { todo o mundo para educar, incentivar e } \\
\text { reconhecer excelência" }\end{array}$ & $\frac{\text { https://www.iiconservation.org/ }}{\text { publications }}$ \\
\hline $\begin{array}{l}\text { Intergovernmental Panel on Climate } \\
\text { Change (IPCC) }\end{array}$ & $\begin{array}{l}\text { "seu objetivo é fornecer aos governos } \\
\text { em todos os níveis informações para que } \\
\text { possam desenvolver políticas climáticas" }\end{array}$ & https://www.ipcc.ch/documentation/ \\
\hline Library of Congress (LoC) & "a maior biblioteca do mundo" & https://www.loc.gov \\
\hline PADFIELD, T. Conservation Physics & "livro digital" & $\frac{\text { https://www.conservationphysics.org/ }}{\underline{\text { index.html }}}$ \\
\hline $\begin{array}{l}\text { Portail International Archivistique } \\
\text { Francophone (PIAF) }\end{array}$ & $\begin{array}{c}\text { "um local para a formação na profissão } \\
\text { de arquivista" }\end{array}$ & $\frac{\text { https://www.piaf-archives.org/se- }}{\underline{\text { documenter/presentation }}}$ \\
\hline reCollections & $\begin{array}{l}\text { "guia com conselhos práticos, projetado } \\
\text { para auxiliar o leitor no cuidado com o } \\
\text { patrimônio (...) explica como utilizar } \\
\text { técnicas de conservação preventiva em } \\
\text { coleções e objetos culturais" }\end{array}$ & $\frac{\text { http://culturalmaterials.net/wp/28-2/ }}{\text { cultural-material/ }}$ \\
\hline RE-ORG & $\begin{array}{l}\text { "método passo-a-passo para planejar e } \\
\text { implementar um projeto de } \\
\text { reorganização de reservas técnicas" }\end{array}$ & $\begin{array}{l}\text { https://www.iccrom.org/section/ } \\
\text { preventive-conservation/re-org }\end{array}$ \\
\hline SicherheitsLeitfaden Kulturgut (SiLK) & $\begin{array}{l}\text { "diretrizes para a proteção da } \\
\text { propriedade cultural" }\end{array}$ & $\frac{\text { http://www.konferenz-kultur.de/SLF/EN/ }}{\underline{\text { index1.php?lang }=e n}}$ \\
\hline $\begin{array}{l}\text { United Nations Educational, Scientific } \\
\text { and Cultural Organization (UNESCO) } \\
\text { World Heritage Centre (WHC) }\end{array}$ & $\begin{array}{l}\text { "auxilia na formulação e na } \\
\text { operacionalização de políticas públicas } \\
\text { que estejam em sintonia com as } \\
\text { estratégias acordadas entre os Estados- } \\
\text { membros" }\end{array}$ & $\begin{array}{c}\text { https://unesdoc.unesco.org/archives } \\
\text { https://whc.unesco.org }\end{array}$ \\
\hline $\begin{array}{l}\text { United Nations Office for Disaster Risk } \\
\text { Reduction (UNDRR) }\end{array}$ & $\begin{array}{l}\text { "auxilia na implementação do Sendai } \\
\text { Framework for Disaster Risk Reduction } \\
\text { 2015-2030, apoiando países na sua } \\
\text { implementação, monitorando e } \\
\text { compartilhando o que funciona na } \\
\text { redução e na prevenção de riscos" }\end{array}$ & $\frac{\text { https://www.undrr.org/building-risk- }}{\underline{\text { knowledge }}}$ \\
\hline $\begin{array}{l}\text { United Nations Office for Sustainable } \\
\text { Development ( UNOSD) }\end{array}$ & $\begin{array}{l}\text { "auxilia os Estados-membros no } \\
\text { planejamento e na implementação da } \\
2030 \text { Agenda for Sustainable } \\
\text { Development, por meio do } \\
\text { compartilhamento de informações, } \\
\text { pesquisas, treinamentos e parcerias" }\end{array}$ & https://unosd.un.org/node/855 \\
\hline
\end{tabular}

Fonte: a pesquisadora 
Quadro 02: Principais entidades nacionais consultadas

\begin{tabular}{|c|c|c|}
\hline 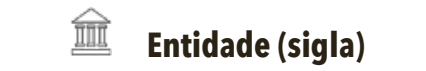 & Propósito / missão & Endereço eletrônico \\
\hline Arquivo Nacional & $\begin{array}{l}\text { "tem por finalidade implementar e acompanhar a } \\
\text { política nacional de arquivos, definida pelo Conselho } \\
\text { Nacional de Arquivos - Conarq, por meio da gestão, do } \\
\text { recolhimento, do tratamento técnico, da preservação e } \\
\text { da divulgação do patrimônio documental do País" }\end{array}$ & $\frac{\text { http://arquivonacional.gov.br/br/ }}{\text { publicacoes }}$ \\
\hline $\begin{array}{l}\text { Associação Catarinense de } \\
\text { Conservadores e Restauradores } \\
\text { de Bens Culturais (ACCR) }\end{array}$ & $\begin{array}{l}\text { "órgão de classe, com o compromisso de reunir os } \\
\text { profissionais da área da conservação e restauração de } \\
\text { bens culturais móveis, imóveis e integrados e da área } \\
\text { da ciência da conservação, do Estado de Santa } \\
\text { Catarina, interessados em defender e preservar o } \\
\text { patrimônio cultural" }\end{array}$ & http://accr.org.br/noticias/ \\
\hline $\begin{array}{l}\text { Associação Paulista de } \\
\text { Conservadores Restauradores de } \\
\text { Bens Culturais (APCR) }\end{array}$ & $\begin{array}{l}\text { "reúne profissionais da área da conservação e } \\
\text { restauração de bens culturais móveis e imóveis, tanto do } \\
\text { Estado de São Paulo como de outros Estados brasileiros, } \\
\text { interessados em participar da defesa e preservação de } \\
\text { nosso patrimônio histórico cultural estadual e federal" }\end{array}$ & $\frac{\text { https://apcr.sampa.br/leituras-e- }}{\underline{\text { artigos/ }}}$ \\
\hline $\begin{array}{l}\text { Biblioteca Brasiliana Guita e José } \\
\text { Mindlin (BBM USP) }\end{array}$ & $\begin{array}{l}\text { "reune especialistas, sedia projetos e apoia iniciativas de } \\
\text { estudos, desenvolvendo atividades em torno de quatro } \\
\text { campos do saber: 1) Estudos Brasileiros; 2) História do } \\
\text { Livro e da Leitura; 3) Tecnologia do Conhecimento e } \\
\text { Humanidades Digitais; e 4) Preservação, conservação e } \\
\text { restauração do livro e do papel" }\end{array}$ & $\frac{\text { https://www.bbm.usp.br/pt-br/ }}{\text { publicações-bbm/ }}$ \\
\hline $\begin{array}{l}\text { Centro de Preservação Cultural } \\
\text { (CPC USP) }\end{array}$ & $\begin{array}{c}\text { "promove ações e reflexões de caráter acadêmico e de } \\
\text { extensão universitária em torno da temática do } \\
\text { patrimônio cultural" }\end{array}$ & $\frac{\text { https://cpc.webhostusp.sti.usp.br/ }}{\underline{\text { index.php/publicacoes/ }}}$ \\
\hline $\begin{array}{l}\text { Fundação Biblioteca Nacional } \\
\text { (BN) }\end{array}$ & $\begin{array}{l}\text { "tem a missão de coletar, registrar, salvaguardar e dar } \\
\text { acesso à produção intelectual brasileira, assegurando } \\
\text { o intercâmbio com instituições nacionais e } \\
\text { internacionais e a preservação da memória } \\
\text { bibliográfica e documental do país" }\end{array}$ & https://www.bn.gov.br/producao \\
\hline $\begin{array}{l}\text { Fundação Casa de Rui Barbosa } \\
\text { (FCRB) }\end{array}$ & $\begin{array}{l}\text { "visa proporcionar um espaço de acesso à cultura, } \\
\text { pesquisa, ensino e lazer, contribuindo para a } \\
\text { preservação de acervos, a difusão da memória } \\
\text { nacional e o exercício da cidadania" }\end{array}$ & $\frac{\underline{\text { http:// }}}{\text { www.casaruibarbosa.gov.br/ }}$ \\
\hline $\begin{array}{l}\text { Fundação Catarinense de Cultura } \\
\text { (FCC) }\end{array}$ & $\begin{array}{l}\text { "seu compromisso é ser uma instituição reconhecida } \\
\text { pela excelência na valorização da memória e estímulo } \\
\text { à produção e difusão cultural, com autonomia para } \\
\text { realizar suas ações de modo a democratizar o acesso à } \\
\text { cultura no Estado de Santa Catarina" }\end{array}$ & $\begin{array}{l}\frac{\text { https://www.cultura.sc.gov.br/ }}{\text { downloads/patrimonio-cultural/ }} \\
\underline{\text { colecao-estudos-museologicos }}\end{array}$ \\
\hline
\end{tabular}


Quadro 02: Principais entidades nacionais consultadas (continuação)

\begin{tabular}{|c|c|c|}
\hline 嵒 Entidade (sigla) & Propósito / missão & Endereço eletrônico 洸 \\
\hline $\begin{array}{l}\text { Instituto Brasileiro de Museus } \\
\text { (IBRAM) }\end{array}$ & $\begin{array}{l}\text { "o órgão é responsável pela Política Nacional de } \\
\text { Museus (PNM) e pela melhoria dos serviços do setor } \\
\text { (...). Também é responsável pela administração direta } \\
\text { de } 30 \text { museus." }\end{array}$ & https://www.museus.gov.br \\
\hline $\begin{array}{l}\text { Instituto do Patrimônio Histórico } \\
\text { e Artístico Nacional (IPHAN) }\end{array}$ & $\begin{array}{c}\text { "autarquia federal (...) para proteger e promover } \\
\text { os bens culturais do País, assegurando sua } \\
\text { permanência e usufruto para as gerações presentes e } \\
\text { futuras" }\end{array}$ & $\frac{\text { http://portal.iphan.gov.br/pagina/ }}{\underline{\text { detalhes/617 }}}$ \\
\hline $\begin{array}{l}\text { International Council of Museums } \\
\text { - Brasil (ICOM Brasil) }\end{array}$ & $\begin{array}{l}\text { "promover a cooperação, a assistência mútua e o } \\
\text { intercâmbio de informação entre seus membros, } \\
\text { profissionais de museus e instituições culturais (...)" }\end{array}$ & $\frac{\text { http://www.icom.org. br/? }}{\text { page_id }=34}$ \\
\hline $\begin{array}{l}\text { Museu de Astronomia e Ciências } \\
\text { Afins (MAST) }\end{array}$ & $\begin{array}{l}\text { "tem como missão ampliar o acesso da sociedade ao } \\
\text { conhecimento científico e tecnológico por meio da } \\
\text { pesquisa, da preservação de acervos, divulgação e } \\
\text { história da ciência e da tecnologia no Brasil" }\end{array}$ & $\frac{\text { http://www.mast.br/pt-br/ }}{\text { publicacoes.html }}$ \\
\hline $\begin{array}{l}\text { Sistema Estadual de Museus de } \\
\text { São Paulo (SISEM-SP) }\end{array}$ & $\begin{array}{l}\text { "congrega e articula os museus paulistas, com o } \\
\text { objetivo de promover a qualificação e o fortalecimento } \\
\text { institucional em favor da preservação, pesquisa e } \\
\text { difusão do acervo museológico do Estado" }\end{array}$ & $\underline{\text { https://www.sisemsp.org.br }}$ \\
\hline
\end{tabular}

Fonte: a pesquisadora

\subsubsection{Normas internacionais e nacionais de referência}

Tem-se, a seguir, o quadro-resumo das principais normas de referência internacionais e nacionais consultadas (Quadro 03).

Quadro 03: Principais normas internacionais e nacionais consultadas

\begin{tabular}{l|c}
\hline \multicolumn{1}{c|}{ 国 Norma } & Título \\
\hline AS/NZS 4360:2004 & Risk management \\
\hline ASHRAE HandBook of Applications Chapter 23:2015 & Museums, Galleries, Archives, and Libraries \\
ASHRAE HandBook of Applications Chapter 24:2019 & Specification for managing environmental conditions for cultural \\
British Standards PAS198:2012 & \begin{tabular}{c} 
collections \\
\hline
\end{tabular}
\end{tabular}


Quadro 03: Principais normas internacionais e nacionais consultadas (continuação)

\begin{tabular}{|c|c|}
\hline 蒏 Norma & Título \\
\hline $\begin{array}{l}\text { Commission Internationale de l'Eclairage Technical Report } \\
\text { CIE 157:2004 }\end{array}$ & Control of damage to museum objects by optical radiation \\
\hline European Committee for Standardization EN 15757:2010 & $\begin{array}{c}\text { Conservation of Cultural Property - Specifications for Temperature } \\
\text { and Relative Humidity to Limit Climate-Induced Mechanical } \\
\text { Damage in Organic Hygroscopic Materials }\end{array}$ \\
\hline European Committee for Standardization EN 16242:2012 & $\begin{array}{c}\text { Conservation of Cultural Heritage - Procedures and Instruments } \\
\text { for Measuring Humidity in the Air and Moisture Exchanges } \\
\text { Between Air and Cultural Property }\end{array}$ \\
\hline ISO 6241:1984 & $\begin{array}{c}\text { Performance standards in building - Principles for their } \\
\text { preparation and factors to be considered }\end{array}$ \\
\hline ISO 15686-7:2017 & $\begin{array}{l}\text { Buildings and constructed assets - Service life planning - Part 7: } \\
\text { Performance evaluation for feedback of service life data from } \\
\text { practice }\end{array}$ \\
\hline ISO 19208:2016 & Framework for specifying performance in buildings \\
\hline ISO 29481-1:2010 & $\begin{array}{l}\text { Building Information Modelling - Information Delivery Manual - } \\
\text { Part 1, Methodology and Format }\end{array}$ \\
\hline ISO 31000:2009 & Risk management - Principles and guidelines \\
\hline 目 Norma & Título \\
\hline ABNT/NBR 5671:1991 & $\begin{array}{l}\text { Participação dos intervenientes em serviços e obras de engenharia } \\
\text { e arquitetura }\end{array}$ \\
\hline ABNT/NBR 5674:2012 & $\begin{array}{l}\text { Manutenção de Edificações - Requisitos para o sistema de gestão } \\
\text { de manutenção }\end{array}$ \\
\hline ABNT/NBR/ISO/CIE 8995-1:2013 & Iluminação de ambientes de trabalho \\
\hline ABNT/NBR /ISO 9000:2005 & Sistemas de gestão da qualidade - Fundamentos e vocabulário \\
\hline ABNT/NBR /ISO 9001:2015 & Sistemas de gestão da qualidade - Requisitos \\
\hline ABNT/NBR 9050:2020 & $\begin{array}{l}\text { Acessibilidade a edificações, mobiliário, espaços e equipamentos } \\
\text { urbanos }\end{array}$ \\
\hline ABNT/NBR 9077:2001 & Saídas de emergência em edifícios \\
\hline ABNT/NBR 13971:2014 & $\begin{array}{l}\text { Sistemas de refrigeração, condicionamento de ar, ventilação e } \\
\text { aquecimento - Manutenção programada }\end{array}$ \\
\hline
\end{tabular}


Quadro 03: Principais normas internacionais e nacionais consultadas (continuação)

\begin{tabular}{|c|c|}
\hline 国 Norma & Título \\
\hline ABNT/NBR 14037:2014 & $\begin{array}{l}\text { Diretrizes para elaboração de manuais de uso, operação e } \\
\text { manutenção das edificações }\end{array}$ \\
\hline ABNT/NBR 14432:2001 & $\begin{array}{l}\text { Exigências de resistência ao fogo de elementos construtivos de } \\
\text { edificações - Procedimento }\end{array}$ \\
\hline ABNT/NBR 15575:2013 & Edificações habitacionais - Desempenho \\
\hline ABNT/NBR 16280:2015 & Reforma em edificações - Sistema de gestão de reformas \\
\hline ABNT/NBR/ISO 41001:2020 & $\begin{array}{c}\text { Facility management - Sistemas de gestão - Requisitos com } \\
\text { orientações para uso }\end{array}$ \\
\hline ABNT/NBR/ISO 41011:2019 & Facility management - Vocabulário \\
\hline ABNT/NBR/ISO 41013:2019 & Facility management - Escopo, conceitos-chave e benefícios \\
\hline $\begin{array}{l}\text { Instruções Técnicas do Corpo de Bombeiros } \\
\text { IT 01:2019 a IT 26:2019 }\end{array}$ & Vários assuntos \\
\hline $\begin{array}{l}\text { Instrução Técnica do Corpo de Bombeiros } \\
\text { IT 40:2019 }\end{array}$ & $\begin{array}{l}\text { Edificações históricas, museus e instituições culturais com acervos } \\
\text { museológicos }\end{array}$ \\
\hline Lei $n^{0} 13.589: 2018$ & $\begin{array}{l}\text { Dispõe sobre a manutenção de instalações e equipamentos de } \\
\text { sistemas de climatização de ambientes }\end{array}$ \\
\hline $\begin{array}{l}\text { Normas Regulamentadoras da Secretaria Especial de } \\
\text { Previdência e Trabalho } \\
\text { NR 01:2020; NR 05:2019; NR 06:2018; NR 08:2011; NR } \\
\text { 09:2019; NR 10:2019; NR 11:2016; NR 15:2019; NR } \\
\text { 17:2018; NR 23:2011 e NR 24:2019 }\end{array}$ & Vários assuntos \\
\hline Portaria nº 3.523:1998 MS/GM & $\begin{array}{l}\text { Dispõe sobre procedimentos de verificação visual (...) de todos os } \\
\text { componentes dos sistemas de climatização }\end{array}$ \\
\hline Resolução CONAMA n 491:2018 & Dispõe sobre padrões de qualidade do ar \\
\hline Resolução-RE nº 09:2003 MS/ANVISA & $\begin{array}{l}\text { Padrões Referenciais de Qualidade do Ar Interior, em ambientes } \\
\text { climatizados artificialmente de uso público e coletivo }\end{array}$ \\
\hline
\end{tabular}

Fonte: a pesquisadora 


\subsection{FUNDAMENTAÇÃO TEÓRICA}

Uma vez que o objetivo desta pesquisa é o desenvolvimento de um modelo teórico-metodológico para avaliação e diagnóstico do desempenho do ambiente construído de áreas de guarda com acervos em papel em edifícios históricos na cidade de São Paulo, faz-se necessário compreender os conceitos envolvidos. E eles são múltiplos e variados. Como ponto de partida, é importante conhecer os princípios da preservação sustentável e da conservação preventiva do patrimônio cultural, os quais estão intimamente interrelacionados a um conjunto de saberes, de diversas áreas do conhecimento, que se combinam com o objetivo de gerir os recursos institucionais (humanos, materiais, financeiros, energéticos, etc.) disponíveis, na busca por um ambiente que seja seguro e adaptado à conservação dos bens. 0 desempenho deste ambiente depende de fatores internos e externos e, portanto, é importante compreender as variáveis climáticas e as condicionantes do entorno, bem como as características construtivas que interferem nos parâmetros ambientais recomendados para minimizar ou desacelerar os processos de deterioração dos itens. 0 entendimento dos mecanismos de degradação próprios dos objetos com suporte em papel dependem da compreensão das suas características físico-químicas. Conhecendo-se as condicionantes ambientais, construtivas e das coleções é preciso, então, correlacioná-las com as possíveis ameaças, fazendo-se uso, para isso, de métodos diagnósticos, de avaliação dos riscos aos acervos, bem como de avaliação do desempenho físico do edifício. Como o que se pretende é que a instituição seja sustentável, ou seja, que funcione da maneira mais harmoniosa possível, com baixo impacto para as gerações presente e futuras, é importante uma gestão institucional consciente, capaz de assimilar os conhecimentos técnico-científicos disponíveis e adaptá-los às características da instituição, compatibilizando as condicionantes técnicas e as vulnerabilidades identificadas com as necessidades, tanto dos usuários como dos itens dos acervos, e propondo ações que eliminem ou mitiguem quaisquer perigos.

Assim, ao longo deste capítulo, estão descritos os principais conceitos, métodos e instrumentos sobre os quais se apoia o desenvolvimento desta pesquisa. No primeiro item são descritos os conceitos de conservação preventiva e preservação sustentável. A seguir, são apresentados os parâmetros, as diretrizes e as recomendações para qualidade ambiental para acervos em papel. 0 terceiro item discorre sobre as características do papel e os processos de degradação associados a ele. Na sequência, são explicados os instrumentos para a gestão e o planejamento estratégico, bem como as metodologias disponíveis adaptadas ao patrimônio cultural. Por fim, tem-se os sistemas multimétodos para a avaliação e gestão do edifício, bem como as técnicas e equipamentos auxiliares a esta análise. 


\subsubsection{Conservação preventiva e preservação sustentável}

A conservação $0^{2}$ é "qualquer método que se prove eficiente em manter um determinado patrimônio em uma condição o mais próximo possível do original pelo maior período de tempo possível" (VIDUKA, 2012). A conservação é uma atividade trabalhosa e custosa, pela qual poucas instituições podem pagar, pois só pode ser realizada por profissionais especialmente treinados e com acesso aos equipamentos e materiais apropriados.

Salvador Muñoz-Viñas, um dos teóricos contemporâneos no campo da preservação do patrimônio cultural, discute, em sua obra, as inconsistências e os conflitos inerentes às práticas conservativas. No texto 'The Transactional Nature of Heritage Conservation' (2017), ele afirma que:

Um dos belos paradoxos do universo da conservação do patrimônio é que sua atuação frequentemente altera o objeto que precisa ser conservado. Em outras palavras, conservar modifica. (...)

0 que é mais interessante aqui, contudo, é o fato de que muitos conservadores, assim como 0 público em geral, ainda querem ver a conservação como uma atividade completamente neutra, uma atividade que se coloca à parte da história do objeto. (...)

Esta cegueira seletiva, e não o fato da conservação com frequência criar novas composições, é a isso que se dá o nome de "Síndrome de Frankenstein". (MUÑOZ-VIÑAS, 2017; tradução da pesquisadora).

Para 0 autor, processos de conservação, por mais sutil que sejam, resultam em mudanças nas condições iniciais do objeto (ainda que em escala microscópica). Os responsáveis pelo planejamento de ações de conservação precisam ter consciência de que não é tarefa fácil pesar os prós e contras de cada decisão. Frequentemente, o conservador-restaurador se sente em uma encruzilhada diante de prioridades conflitantes, cujas decisões dificilmente agradarão da mesma forma a todos os interessados. Além disso, materiais, técnicas, procedimentos e valores se modificam com o passar do tempo e é comum, no campo da conservação e do restauro, que uma visão tida como a mais correta seja superada e passe a ser vista como equivocada. É um desafio precisar todos os ganhos e perdas resultantes de um tratamento de conservação, dadas as incertezas tanto técnicas como axiológicas 3

\footnotetext{
${ }^{2}$ A conservação, em sua acepção tradicional, pode ser entendida atualmente como conservação curativa, definida pelo ICOM-CC (2008) Como "todas as ações que incidem diretamente sobre um bem ou grupo de bens culturais, com o objetivo de deter processos de degradação ativos ou reforçar a sua estrutura". O ICOM-CC define conservação-restauro como o conjunto de ações que visam a salvaguarda, às gerações presente e futuras, do patrimônio cultural material e congrega medidas de restauro, conservação curativa e conservação preventiva.

${ }^{3}$ Axiologia é o estudo da atribuição de valores segundo princípios morais.
} 
envolvidas. Por outro lado, a tomada de decisão exige que alguma valoração seja feita, e ela deve ser a mais criteriosa possível (MUÑOZ-VIÑAS, 2017).

Ao contrário da conservação, a preservação tem a função de diminuir a taxa de deterioração de um determinado acervo e é frequentemente entendida como o conjunto de ações gerenciais, administrativas, financeiras e de pessoal necessárias à salvaguarda do bem-estar das coleções (BOYLAN, 2004). Ela está associada à garantia de um determinado nível de segurança, controle ambiental, armazenamento, cuidado e transporte, que pode retardar a deterioração, seja por agentes químicos ou físicos (ADCOCK, 1998). A preservação pode ser implementada por uma equipe menos especializada que a conservação.

0 uso de medidas preventivas pode aumentar consideravelmente a vida útil de um acervo e possui melhor custo-benefício do que medidas curativas com o propósito de remediar um dano ocorrido (WALKER, 2013).

0 conjunto destas atividades gerenciais e técnicas em prol da preservação dos acervos recebe o nome de conservação preventiva. 0 termo "conservação preventiva4" foi mencionado pela primeira vez em 1978, por Garry Thomson, em publicação que correlacionava arquitetura, condições ambientais e segurança, com o objetivo de assegurar a integridade dos acervos. A definição de conservação preventiva surgiu em seguida, com a publicação da Carta de Burra, em 1980, que a definiu como "a manutenção no estado da substância de um bem e a desaceleração do processo pelo qual ele se degrada" (CURY, 2004; apud: CARVALHO, 2014).

Porém, apenas em 1995, o ICOM (International Council of Museums) publicou um documento sobre 0 assunto:

\begin{abstract}
A conservação preventiva é um velho conceito no mundo dos museus, mas só nos últimos 10 anos que ela começou a se tornar reconhecida e organizada. Ela requer uma mudança profunda de mentalidade. Onde ontem se viam objetos, hoje devem ser vistas coleções. Onde se viam depósitos devem ser vistos edifícios. Onde se pensava em dias, agora se deve pensar em anos. Onde se via uma pessoa, devem ser vistas equipes. Onde se via uma despesa de curto prazo, se deve ver um investimento de longo prazo. Onde se mostram ações cotidianas, devem ser vistos programas e prioridades. A conservação preventiva significa assegurar a sobrevida das coleções. (GUICHEN, 1995, p.2)
\end{abstract}

\footnotetext{
${ }^{4}$ Ao contrário da conservação curativa, cujo foco de atuação está no objeto, a conservação preventiva pretende atuar sobre o seu entorno, que é entendido como a(s) barreira(s) de proteção contra possíveis ameaças de deterioração do acervo.
} 
Nesta mesma publicação, Périer-d'leteren (1995) define a preservação como "uma ação tomada para retardar ou prevenir a deterioração ou o dano aos bens culturais pelo controle do seu ambiente e/ou tratamento de sua estrutura de modo a mantê-los o mais próximo possível de um estado inalterado".

Também no livro 'Environmental Management - Guidelines for Museums and Galleries', de May Cassar (1995), a autora enfatiza o papel do edifício como a primeira linha de defesa para a conservação preventiva das coleções, destacando a importância de se ter condições ambientais estáveis, controladas e monitoradas e de se separar as áreas críticas de guarda de acervos das demais áreas do edifício.

Em 2008, durante a XV Conferência Trienal do Comitê para Conservação do ICOM, em Nova Delhi, a conservação preventiva passou a ser definida como:

o conjunto de medidas e ações que têm por objetivo evitar e minimizar futuras deteriorações ou perdas. Elas se inscrevem em um contexto ou ambiente de um bem cultural, porém, mais comumente no contexto de um conjunto de bens, seja qual for a sua antiguidade e o seu estado. Essas medidas e ações são indiretas - não interferem com os materiais e estruturas dos bens. Também não modificam a sua aparência (ICOM-CC, 2008)5 .

A definição foi revalidada pela Assembléia Geral do ICOM, no ano seguinte, em Shangai (CARVALHO, 2015). A preservação de edificações, entendida como o cuidado com a manutenção dos edifícios existentes, provavelmente é prática inerente às sociedades humanas e remonta, comprovadamente, a Vitrúvio. No entanto, é apenas no último quarto do século XIX, com Ruskin e Morris, que o tratamento conservativo foi sistematizado e diferenciado das ações de restauro (JOKILEHTO, 1999). As práticas de conservação do patrimônio edificado se desenvolveram ao longo do século XX, na Europa ocidental, principalmente após as grandes guerras, e estão documentadas nas cartas patrimoniais.

As chamadas cartas patrimoniais são documentos - em especial aquelas derivadas de organismos internacionais - cujo caráter é indicativo ou, no máximo, prescritivo. Constituem base deontológicab para as várias profissões envolvidas na preservação, mas não são receituário de simples aplicação (KÜHL, 2010, p. 287).

\footnotetext{
5 Para mais informações, ver: http://www.icom.org.br/wp-content/uploads/2014/03/PDF_Conceitos-Chave-de-Museologia.pdf ${ }^{6}$ Ramo da filosofia moral contemporânea, é a ciência que estuda os deveres e as obrigações individuais.
} 
Na primeira carta, de Atenas, de 1931, já aparece a recomendação para que fossem empregados os meios técnicos e científicos disponíveis para assegurar a conservação dos bens. Na carta mais recente, do ICOMOS, de 2003, tem-se que:

1.1. A conservação, o reforço e o restauro do patrimônio arquitetônico exigem uma abordagem multidisciplinar. (...)

1.6. A peculiaridade das estruturas do patrimônio, com a sua história complexa, exige a organização de estudos e de propostas em passos precisos que são semelhantes aos usados na medicina. Anamnese, diagnóstico, terapia e controle, correspondendo respectivamente às investigações de dados e de informações significativas, à individualização das causas dos danos e da degradação, à escolha das medidas curativas e ao controle da eficiência das intervenções. Para se conseguir uma eficácia de custos e um impacto mínimo sobre o patrimônio arquitetônico, usando-se os fundos disponíveis de uma forma racional, é geralmente necessário que o estudo repita estes passos num processo interativo. (...)

3.1. A terapia deve ser dirigida às causas da ruína e não aos seus sintomas.

3.2. A melhor terapia é a manutenção preventiva (ICOMOS, 2003).

Contudo, mesmo diante das evidências em favor da prevenção, planos para a gestão do patrimônio não são elaborados com frequência, e as justificativas mais usadas são: as pessoas responsáveis pela preservação e gestão do patrimônio cultural e suas coleções estão muito envolvidas nas questões do dia-a-dia e não têm tempo para antecipar problemas futuros; falta estrutura e/ou recursos financeiros para o planejamento ou; faltam informações e dados que possam ser analisados para que se possa priorizar ações de longo prazo para a preservação. No entanto, a experiência demonstra que o maior impedimento à gestão eficiente do patrimônio é a ausência de uma "cultura do risco" nas instituições culturais (IRM, 2012).

0 modo convencional de se controlar as características ambientais internas para prevenir danos às coleções sempre esteve associado a se encontrar a "fórmula ideal" (para temperatura, umidade, luz, etc.). É de 1942 a regra "mágica", conhecida como regra de Rawlins, que determina que espaços museológicos devem ser mantidos a $15^{\circ} \mathrm{C}$ de temperatura e $60 \%$ de umidade relativa (regra $60 / 60$, referindo-se a $60^{\circ} \mathrm{F}$ e $60 \%$ de umidade relativa). Quanto mais distante destas condições, acreditava-se, maiores os danos às coleções (MICHALSKI, 2007). Já na década de 1970, algumas críticas a esta abordagem começaram a ser feitas. É possível que esta abordagem não estivesse efetivamente preocupada com os documentos, mas sim com uma maior facilidade na gestão dos acervos para arquitetos, engenheiros, curadores e conservadores (ROGERS, 1976). 
Os manuais técnicos da ASHRAE (American Society of Heating, Refrigerating, and Air-Conditioning Engineers), por muito tempo, seguiram este mesmo raciocínio, determinando, como condição ideal para ambientes museológicos, $21^{\circ} \mathrm{C}$ de temperatura e $50 \%$ de umidade relativa. Somente na edição de 1999 , a entidade criou um capítulo específico para o tema: 'Chapter 23: Museums, Galleries, Archives, and Libraries'. E apenas em 2003 ela usou, pela primeira vez, o termo gerenciamento de risco, com a introdução do conceito de que existe um risco inerente a cada condição climática ${ }^{7}$, e que as flutuações admissíveis dependem também das condições financeiras e de pessoal da entidade (MICHALSKI, 2007; BR00KS, 2014). A sua mais nova versão, 'Chapter 24 (A.24). Museums, Galleries, Archives, and Libraries', de 2019, destaca que, nesta nova era de informação digital, é muito importante que a instituição esteja orientada à qualidade, com indicadores confiáveis de efetividade, autoridade e autenticidade.

De uma perspectiva institucional, a gestão integral de pessoas e patrimônio deve ser entendida dentro de um conceito mais amplo, o da preservação sustentável do patrimônio. Pode-se definir preservação sustentável como o conjunto de medidas que visam assegurar o melhor cuidado possível ao acervo, dentro das possibilidades próprias de cada instituição, de tal modo que, tanto as coleções, como a sua conservação, possam ser sustentadas ao longo do tempo, com o menor impacto possível para 0 planeta. Para que as medidas sejam efetivas, o empenho institucional deve se concentrar na coleta e no tratamento de dados, na realização de pesquisas, no uso das tecnologias disponíveis e no trabalho multi, inter e transdisciplinar. É importante que os resultados encontrados possam ser expressos de forma criativa, com liberdade para se experimentar soluções na busca por aquelas mais adaptadas a cada realidade específica (RIT, 2020)8.

Portanto, pode-se concluir que a conservação é uma ciência de natureza circular, que se iniciou de maneira "não profissional" com a milenar prática da guarda e do cuidado com aquilo que é caro a um grupo, sejam objetos religiosos, manifestações artísticas ou relíquias familiares, passou pelo surgimento dos gabinetes de curiosidades e, em sequência, dos museus (o primeiro, oficialmente, é o Ashmolean Museum da Universidade de Oxford, fundado em 1683), conectados ao desenvolvimento de práticas de conservação que incorporavam métodos para o reparo e o restauro do patrimônio, mediante a experimentação de técnicas e substâncias químicas inovadoras, e estratégias passivas para

\footnotetext{
7 the risks of each and every climate control option

8 Para mais informações, ver: https://ipisustainability.org
} 
o controle da qualidade ambiental, avançou para os conceitos de conservação preventiva desenvolvidos pós segunda guerra mundial, que associavam prevenção a um controle rígido da temperatura e da umidade relativa do ambiente interno, mediante o uso dos recém inventados sistemas de condicionamento de ar e fundamentado no conceito de uma condição "ideal" que simulasse 0 ambiente "modelo" para a preservação de objetos (imitando cavernas, castelos ou igrejas) e, por fim, retornou ao ponto inicial, porém, de uma perspectiva mais elevada, ou seja, de maior consciência e conhecimento técnico, com a preservação sustentável, que é o uso da ciência da conservação e dos princípios de sustentabilidade para se alcançar a melhor guarda e o melhor cuidado possível, sem esquecer o bem-estar das pessoas e a eficiência energética (STANIFORTH (ed.), 2013).

A preservação sustentável não exclui a conservação preventiva mas a complementa, ao indicar a importância de se compatibilizar as ações preventivas com os recursos disponíveis na instituição. Do mesmo modo, a conservação preventiva não exclui a necessidade de ações de restauro e de conservação curativa de bens, ao contrário, as torna mais racionais na medida em que minimiza o seu uso ao estritamente necessário, por serem elas ações que demandam muitos recursos (CARVALHO, 2014).

\subsubsection{Qualidade ambiental em áreas de guarda de acervos}

0 patrimônio cultural representa uma parte significativa da vida das comunidades e sua conservação deve ser um esforço deliberado na direção de se evitar a perda de identidade. Nas últimas décadas, diante de um cenário de mudanças e transformações, é crescente a discussão sobre o valor do patrimônio para seus usuários, as comunidades e os governos, bem como sobre a melhor maneira de preservá-lo e gerenciá-lo. Como o patrimônio é o reflexo da diversidade de valores, interesses e crenças, ele também tem potencial para gerar conflitos e discordâncias, o que, se não for bem administrado, pode vir a se tornar um obstáculo ao desenvolvimento. A gestão do patrimônio tem como um de seus principais desafios compreender o valor deste patrimônio para cada diferente grupo que compõe uma sociedade e, neste processo, é fundamental o diálogo e a reciprocidade (NOCCA, 2017).

Uma conservação orientada a valores depende do significado cultural deste patrimônio, o qual, por sua vez, é o resultado de "valores estéticos, históricos, científicos, espirituais e sociais mantidos pelas gerações passadas, presentes e futuras" (AVRAMANI et al., 2019). Os profissionais precisam, cada vez mais, lidar com um conjunto de variáveis complexas e interconectadas, que envolvem questões políticas, de meio-ambiente, de bem-estar das pessoas, de fomentação do turismo, bem como de 
salvaguarda de edifícios e coleções, além de estratégias para todos os públicos envolvidos: proprietários, funcionários e visitantes.

A preservação do patrimônio deve ir além da atual dicotomia entre valores utilitários (ou econômicos) e valores culturais (ou intangíveis), e precisa reconhecer e administrar os conflitos entre sociedade e ambiente (MALLARACH e VERSCHUUREN, 2019).

Um dos maiores desafios para a preservação do patrimônio neste cenário de mudanças são as crises climáticas globais, e seus impactos diretos e indiretos. Desde a década de 1970 a pegada ecológica global ultrapassa, todos os anos, a biocapacidade de regeneração do planeta. Atualmente, a situação mais dramática é observada nas regiões tropicais da América Latina, onde se registrou a maior perda de biodiversidade, causada tanto pela conversão de campos, florestas e áreas alagadas como pelas mudanças climáticas (WWF, 2020). 0 Millennium Ecosystem Assessment (2005) avaliou 24 funções dos ecossistemas e concluiu que $60 \%$ (15) são utilizados de maneira não sustentável, dentre elas "coleta de água pura, pesca extrativista, purificação do ar e da água, regulação climática local e regional, ameaças naturais e epidemias". Se essa tendência permanecer inalterada, é provável que aconteça um colapso ecológico global (Millennium Ecosystem Assessment, 2005).

Os eventos climáticos extremos são particularmente preocupantes para os edifícios porque ameaçam sua integridade, sua autenticidade, seu valor único e sua fruidez (MARKHAM et al., 2016).

Por outro lado, segundo o Banco Mundial, investir no patrimônio edificado pode ser uma resposta positiva à crise climática pois é um modo inerentemente melhor de produção, consumo e uso do solo, principalmente porque reaproveita a energia embutida no estoque edificado (HASSAN, 2013).

A economia de energia pode ser alcançada pelo uso de equipamentos mais eficientes, mas também, e com vantagens, através da gestão do patrimônio edificado e de mudanças no estilo de vida. 0 arquiteto Mark Alan Hewitt, em texto publicado na Common Edge (e traduzido pela Archdaily) intitulado "Why Reusing Buildings Should - and Must - be the Next Big Thing", comenta: 
Preservacionistas sugeriram que considerássemos a reutilização de estruturas existentes como uma estratégia de sustentabilidade, isso porque reformas desperdiçam menos energia, materiais e também produzem menos resíduos. Infelizmente, um dos principais selos de sustentabilidade e certificação de edifícios, o LEED, foi concebido para contemplar apenas novos edifícios, desconsiderando por completo as estruturas existentes. Reutilização adaptativa, ou seja, dar novos usos às estruturas existentes, não é visto como uma estratégia de sustentabilidade na industria da arquitetura e construção, pelo menos até os dias de hoje. É como um ponto cego, um pixel morto nas telas dos arquitetos e engenheiros.

(...)

Segundo estudo desenvolvido pela Arup Associates, em 2008, alcançaríamos a sustentabilidade se até 0 ano de 2050 apenas 15\% de tudo que se constrói no mundo fossem novos edifícios, os outros $85 \%$ passassem a ser reformas ou trabalhos relacionados à estruturas existentes (HEWIT, 2019).

Ao longo dos séculos XIX e XX, foi prática comum no setor cultural a instalação de parte significativa das instituições que abrigam acervos em edifícios históricos, eles mesmos parte do patrimônio cultural, porém, não projetados originalmente para a guarda e exibição de acervos. No entanto, na mudança para o século XXI, surgiu uma nova tendência mundial que vê os espaços de museus e bibliotecas não mais como uma simples envoltória, mas como uma atração cultural em si mesmo, repleto de possibilidades experimentais. Para tanto, era preciso projetar e construir edifícios novos, com arquiteturas marcantes e arrojadas, que pudessem ser internacionalmente reconhecidas (PADFIELD e LARSEN, 2004; MACLEOD, 2005). Curiosamente, neste quesito, o setor parece caminhar na contra-mão das boas práticas orientadas à sustentabilidade.

Porém, é preciso ter em conta que, se por um lado, o "reuso adaptativo" pode ser uma boa estratégia para preservar o patrimônio como um todo ao assegurar que um maior número de conjuntos arquitetônicos sejam poupados da demolição, ainda que a pressão especulativa pelo uso da terra seja sempre elevada, por outro lado, o uso de construções adaptadas impõe grandes desafios à conservação, tanto das coleções como do edifício, pois nem sempre as necessidades e restrições de um coincidem com as do outro (BULLEN e LOVE, 2011).

Edifícios históricos, cuja construção remonta a períodos anteriores à invenção de sistemas ativos para condicionamento e iluminação artificiais, frequentemente foram projetados fazendo uso de estratégias passivas para autorregulação das condições ambientais internas e tendem a possuir características construtivas que os tornam mais adaptados ao clima e menos dependentes da energia elétrica, tais como, por exemplo, em climas tropicais e sub-tropicais, posicionamento favorável no lote, materiais 
com elevada inércia térmica ${ }^{9}$ e boa resistência à água, baixa proporção de aberturas por fachada, varandas e beirais para menor incidência de luz natural direta, desvão do telhado e porão ventilados para redução da temperatura e da umidade, dentre outras (KLÜPPEL, 2009), soluções estas que, na maioria dos casos, também podem ser atributos positivos para a preservação de bens culturais, desde que corretamente considerados. Porém, é preciso ter em conta que os edifícios históricos são, quase na sua totalidade, protegidos por órgãos de preservação do patrimônio, o que implica em limites às possibilidades de alterações construtivas, principalmente aquelas que visam incorporar equipamentos à edificação. Neste caso, algumas estratégias também podem ser empregadas para diminuir a demanda por sistemas ativos e por consumo de energia, como, por exemplo: ajustar os critérios de desempenho do ambiente interno à(s) realidade(s) específica(s); implementar critérios mais amplos e flexíveis, desde que adequados aos objetos; escolher primeiro soluções passivas antes de empregar sistemas mecânicos; consertar ou aperfeiçoar a envolvente externa do edifício; incorporar instrumentos de gestão novos ou alternativos (HENRY, 2007). Outra opção que deve ser considerada é a "conservação minimalista" dos bens, que implica em "não se fazer nada", desde que esta seja uma decisão consciente, pautada por uma avaliação detalhada do estado de conservação dos itens (STANIFORTH, 2007).

0 desenvolvimento de uma política de preservação do patrimônio e a definição de estratégias de retrofit 10 e readequação do edifício dependem, em parte, de um prévio e continuado monitoramento do microclima interno das áreas com acervos. Para maior efetividade, deve-se ter especial atenção na escolha de sensores precisos e confiáveis e no posicionamento dos mesmos, de modo a assegurar a confiabilidade dos dados, eliminando ou reduzindo a possibilidade de interferências e garantindo que eles não causem danos à superfície onde forem instalados (MARTINEZ-MOLINA et al., 2018).

A bibliografia internacional sobre qualidade ambiental em áreas com acervos e seu monitoramento é bastante ampla e diversificada, demonstrando que, ao menos nos países desenvolvidos, este vem sendo um tema de pesquisa relevante, principalmente desde a segunda metade do século XX, quando

\footnotetext{
9 Termo que expressa dois fenômenos físicos: a diminuição da amplitude térmica, ou seja, da diferença entre o valor máximo e mínimo de temperatura interna em 24 horas e 0 atraso térmico, que é a quantidade de horas necessárias para que a temperatura interna se iguale à uma dada temperatura externa. A inércia térmica de um sistema construtivo está diretamente relacionada às características físico-químicas dos materiais de construção que o compõe (espessura, densidade, condutibilidade e capacidade térmica).
}

${ }^{10}$ Termo que expressa a atividade de modernização das facilidades, frequentemente associado aos conceitos de eficiência e sustentabilidade. 
do aprimoramento dos conceitos de conservação preventiva ("prevenir é melhor do que remediar"), que preconizam a avaliação dos riscos associados a ameaças aos acervos e vulnerabilidades no espaço construído, na busca pelas melhores condições possíveis para a salvaguarda do patrimônio $\left(\mathrm{CCl}_{\text {, }}\right.$ 2020)11. Os fatores ambientais - temperatura, umidade, ventilação, radiação e poluentes - estão diretamente relacionados a processos de degradação de materiais. Também tem relevância, no cenário atual, os aspectos correlacionados à sustentabilidade e, consequentemente, à eficiência energética do edifício. Um tópico que permanece desafiador para os profissionais da preservação é a interrelação entre a conservação e o conforto humano pois, ao prevalecerem as demandas para a salvaguarda do patrimônio, visitantes e funcionários muitas vezes experienciam algum grau de desconforto (Figura 04). Se este desconforto se encontra dentro de limites aceitáveis, bem como os efeitos das interrelações pessoas-objetos ainda é tema para maiores investigações (ULAS et al., 2014). La Gennusa et al. (2008), em um estudo comparativo das demandas ambientais para conforto térmico de pessoas e necessidades de conservação de bens culturais propôs o "índice de simultaneidade" (IS Simultaneousness Index), que procura expressar a relação entre um conforto compartilhado por usuários e obras de arte e o máximo conforto possível (Figura 05).

Figura 04. Comparação entre parâmetros para conforto humano e conservação de objetos

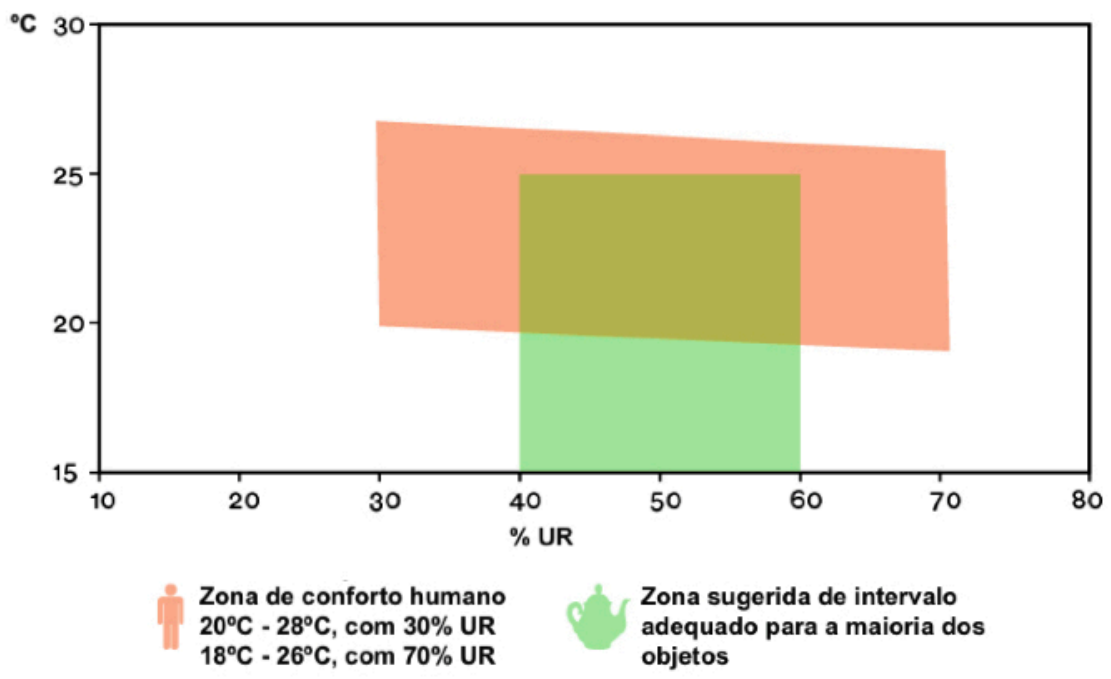

Fonte: traduzido de ULAS et al., 2014.

\footnotetext{
11 Para maiores informações, ver: https:/www.canada.ca/en/conservation-institute/services/preventive-conservation/guidelines-collections/basicrequirements-preventive-conservation.html, acesso em set. 2020.
} 
Figura 05. As zonas de sobreposição entre conforto humano e os requisitos de conservação dos objetos, para condições de inverno típico, por tipo de objeto

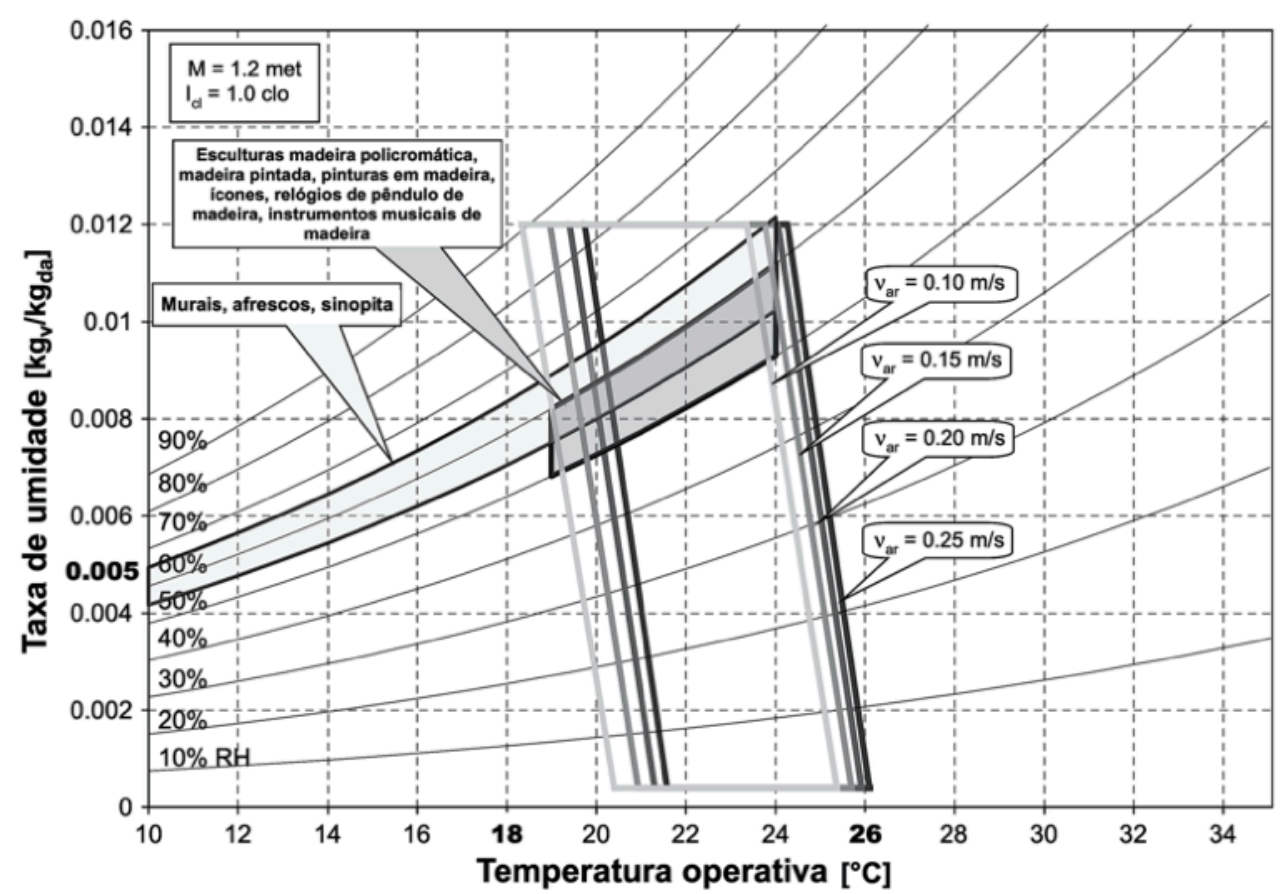

Fonte: traduzido e adaptado de LA GENNUSA et al., 2007.

Se o próprio edifício é parte do patrimônio, então, a qualidade ambiental interna é fator fundamental para sua preservação (KRAMER et al., 2016). Os parâmetros climáticos dos ambientes internos de museus, bibliotecas e arquivos - radiação e umidade - são os fatores mais importantes para a preservação das coleções (THOMSON, 1986).

\subsubsection{Radiação luminosa (parcialmente adaptado de ULAS et al., 2014)}

Em museus, bibliotecas e arquivos a luz é um recurso necessário (mesmo em áreas exclusivamente de guarda) e, simultaneamente, a causa de danos. Dependendo do tipo de material, estes danos podem ocorrer mesmo com níveis baixos de iluminação e seus efeitos são cumulativos (CASSAR, 1995). As principais fontes de iluminação são: a luz natural, do sol; e a luz artificial, das lâmpadas (incandescentes, fluorescentes, LED, etc.).

Toda radiação na frequência do visível vem acompanhada de alguma energia na frequência do infravermelho (IR) e do ultra-violeta (UV). Da radiaçã̃o total emitida pelo Sol, 9\% está no espectro do UV, $41 \%$ na luz visível e cerca de 50\% no IR. A radiação UV, por ser mais energética, é a causa dos maiores danos a acervos, seguida pela frequência do visível. A luz visível e o UV, quando interagem com a 
matéria, dão início a reações fotoquímicas cujo resultado é a modificação da estrutura química dos materiais, que se tornam frágeis, quebradiços, perdem ou alteram a cor. Estas reações têm maior probabilidade de serem iniciadas por interações com ondas nos comprimentos entre 320 e 500 nm, ou seja, entre o UV e a luz azul (Figura 06). A radiação IR, energia térmica, ao interagir com a matéria, produz agitação molecular (temperatura). A temperatura, em conjunto com a umidade, é a segunda maior causa de deterioração dos objetos. Além disso, muitas reações fotoquímicas são aceleradas pelo aumento da temperatura, fazendo com que as degradações por luz visível e UV sejam ainda maiores.

Figura 06. Espectro eletromagnético da radiação solar

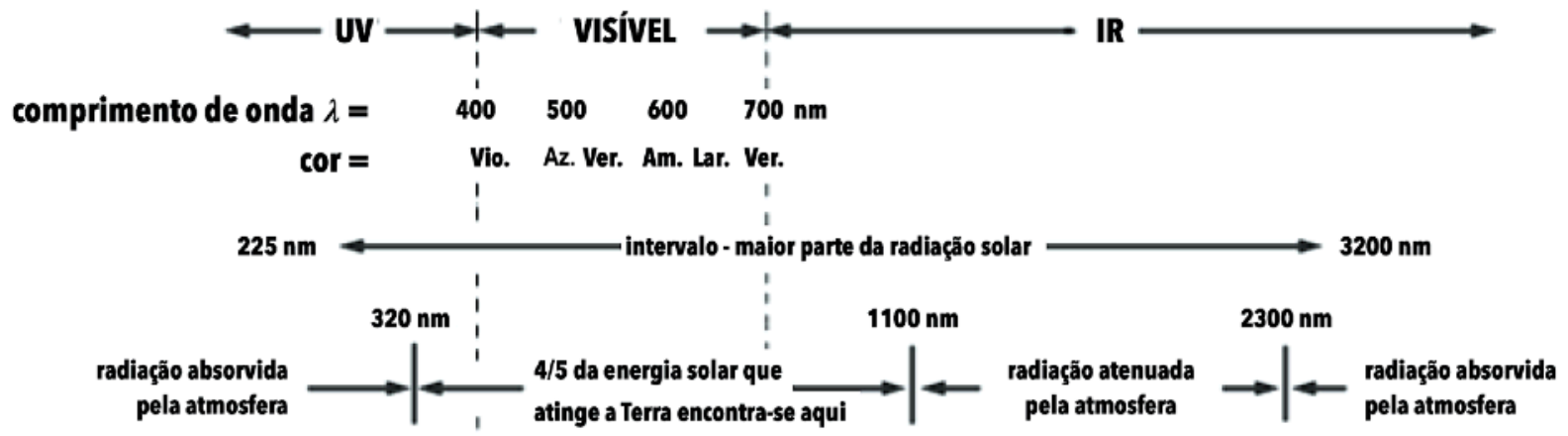

Fonte: traduzido e adaptado de ASU, 2020.

Ao mesmo tempo que é preciso minimizar a incidência de luz e os seus efeitos danosos, também é necessário garantir condições mínimas de conforto visual aos usuários. 0 ponto de equilíbrio entre as duas demandas deve ser a condição de menor impacto possível para ambos.

Para diminuir a taxa de deterioração e prolongar a vida útil do objeto é importante que ele seja exposto à luz apenas quando necessário e que esta luz tenha a de mais baixa intensidade possível e, de preferência, de uma fonte de baixa emissão de UV. Algumas estratégias podem ser utilizadas para minimizar os efeitos da luz sobre os acervos, tais como: modificar as exposições ou itens de uma exposição regularmente, alternando entre objetos expostos e armazenados; virar, com frequência, as páginas de livros, revistas e similares; caso o ambiente não tenha grande fluxo de usuários, instalar sensores ou interruptores nos ambientes e/ou junto aos armários e vitrines; eliminar toda a luz do ambiente (natural ou artificial) sempre que ele não estiver sendo usado (Museums Galleries Scotland, 2009).

A parcela de radiação UV presente nos equipamentos de iluminação, além de muito nociva para os objetos, não contribui com a qualidade visual e, portanto, deve ser minimizada e, se possível, eliminada. Para a iluminação natural, é muito importante a utilização de filtros de UV, tais como vidros 
laminados, películas auto-adesivas, vernizes absorventes de UV ou acrílicos e policarbonatos absorvedores de UV. Para a iluminação artificial, além dos filtros, é importante escolher lâmpadas com baixa emissão de UV. Como os filtros tradicionais costumam reduzir a quantidade de UV a valores inferiores a $75 \mu \mathrm{W} / \mathrm{lm}$ (microwatts por lúmen), este é o valor máximo aceito pela maioria das recomendações sobre o tema. No entanto, os filtros mais modernos de absorção de UV têm eficiência bastante superior, com redução para valores menores que $10 \mu \mathrm{W} / \mathrm{lm}$, logo eles devem ser preferidos, sempre que possível. É preciso também atenção especial à vida útil das películas protetoras, que costumam ser de 5 a 10 anos (Museums Galleries Scotland, 2009).

A parcela de radiação IR presente na iluminação corresponde à energia térmica emitida pela fonte de luz. 0 calor interfere na temperatura e na umidade relativa do clima interno e/ou do microclima, impactando nos processos de deterioração dos bens. É importante se ter atenção às características próprias da lâmpada (e do reator) e à distância entre a lâmpada e o objeto (Museums Galleries Scotland, 2009).

A intensidade luminosa de uma fonte pode ser medida com um luxímetro, a radiação UV, com um detector de UV e a radiação IR com um termômetro.

Nem sempre é fácil convencer funcionários e visitantes da importância de se proteger os objetos da luz. Além de conscientizar todos os envolvidos, também pode ser necessário, após um diagnóstico do estado de conservação dos itens, adotar medidas para mitigação de danos, tais como trocar objetos de lugar, mudar o tipo de acondicionamento e/ou fazer alterações no ambiente construído. Visando as melhores condições, tanto para acervos como para usuários, é importante, sempre que possível, separar os ambientes por funções e atividades.

A iluminação natural é a primeira e, ainda hoje, a mais complexa técnica de iluminação, dadas suas características dinâmicas com múltiplas variáveis, tanto ao longo de um dia como dos dias do ano. 0 organismo humano segue um ritmo, o ciclo circadiano12, que está em sintonia, principalmente, com a variação da luz e da temperatura ao longo de 24 horas. Assim, 0 uso da luz natural em museus, bibliotecas e arquivos pode trazer sensação de conforto e bem-estar para os usuários. Ela também contribui com economia no consumo de eletricidade, sendo, portanto, um fator agregador de eficiência

\footnotetext{
12 Processo endógeno do corpo humano que resulta em um período de vigília e outro de sono ao longo de um dia. Alterações nesse ritmo podem causar graves distúrbios à saúde. Iluminâncias superiores a 5.000 lux induzem um estado de vigília (fonte: https:// www.msdmanuals.com/pt-pt/profissional/distúrbios-neurológicos/transtornos-de-sono-e-vig\%C3\%ADlia/transtornos-do-sono-relacionados-a0ritmo-circadiano).
} 
energética e sustentabilidade ao ambiente construído. Por outro lado, nos ambientes que contêm materiais sensíveis à luz, o seu uso deve ser minimizado, evitado ou mesmo bloqueado. Se ela for uma fonte importante de iluminação que não pode ser dispensada, é preciso, então, prever estratégias para a difusão da luz ${ }^{13}$. Os papéis modernos, feitos a partir de pasta de madeira, sempre contém algum teor de lignina, que é uma substância muito reativa e suscetível à degradação fotoquímica. A degradação da lignina produz pigmentos, que amarelecem o papel, e ácidos, que rompem as fibras da celulose, deixando o papel quebradiço. Uma vez que esta reação foi iniciada, ela não pode mais ser interrompida naturalmente, mesmo que o material não esteja mais exposto à radiação.

Um projeto arquitetônico que prevê o uso da iluminação natural, deve considerar: mecanismos para eliminar toda luz solar direta; manter os objetos sensíveis o mais distante possível das aberturas para iluminação natural; utilizar filtros solares em todos os elementos envidraçados; priorizar elementos de proteção solar externos como brises, marquises, beirais, etc.; utilizar elementos de proteção internos como telas solares, cortinas, persianas e black-outs (CASSAR, 1995).

Como a luz natural não é constante e suficiente ao longo das 24 horas do dia, ela sempre precisará ser complementada pela iluminação artificial. A iluminação elétrica passou por um grande desenvolvimento tecnológico nas últimas décadas, o que ampliou suas possibilidades de uso junto ao patrimônio. Com o desenvolvimento das lâmpadas LED e dos filtros de UV já é possível criar, com a iluminação artificial, uma condição visual bastante adequada, tanto para os objetos como para as pessoas. Em um projeto de iluminação artificial, é importante: dar preferência para luzes de baixa potência; otimizar a quantidade e a distribuição das lâmpadas; preferir uma iluminação difusa; se possível, utilizar dimmers ao invés de interruptores (CASSAR, 1995). Tem-se, atualmente, sistemas LEDs / OLEDs ${ }^{14}$ desenvolvidos especificamente para uso em museus, bibliotecas e arquivos. Ao contrário das lâmpadas convencionais, LEDs são fontes pontuais de luz, o que permite um controle óptico mais preciso, tornando-os altamente ajustáveis. Além disso, a maioria dos LEDs emite uma quantidade muito menor de IR e UV, quando comparados a outros tipos de lâmpadas. Porém, LEDs com tecnologia mais antiga costumam ter um pico de energia na faixa do azul, o que pode ser danoso

\footnotetext{
13 Fenômeno de dispersão (alteração da trajetória) do raio luminoso ao atravessar um meio irregular (translúcido). 
ao acervo. Sempre que possível, deve-se especificar equipamentos mais modernos e especializados. 0 aspecto negativo desta tecnologia é que os melhores sistemas ainda possuem elevado custo inicial e, frequentemente, são considerados muito caros pela maioria das instituições culturais. Por outro lado, os produtos de boa qualidade costumam durar muitos anos, com iluminância constante e baixa manutenção, o que resulta em um bom custo-benefício ao longo da vida útil do equipamento. Por ser uma decisão complexa, sempre que possível ela deve ser feita por um especialista.

A iluminância [lux] é o fluxo luminoso, em lúmens [lm], proveniente de uma fonte e que incide sobre uma determinada superfície. Por convenção, a medida em lux é equivalente à quantidade de lúmens sobre uma área de $1 \mathrm{~m}^{2}$. A lei matemática que rege este fenômeno é a do inverso do quadrado da distância. Assim, por exemplo, se a iluminância medida a um metro da fonte for de 100 lux, a dois metros ela será um quarto deste valor ou 25 lux, e a três metros, um nono do valor ou 11 lux (Figura 07). Este princípio pode ajudar os conservadores a definir a distância entre o objeto e a fonte de luz.

Figura 07. Propagação da radiação a partir de uma fonte pontual S

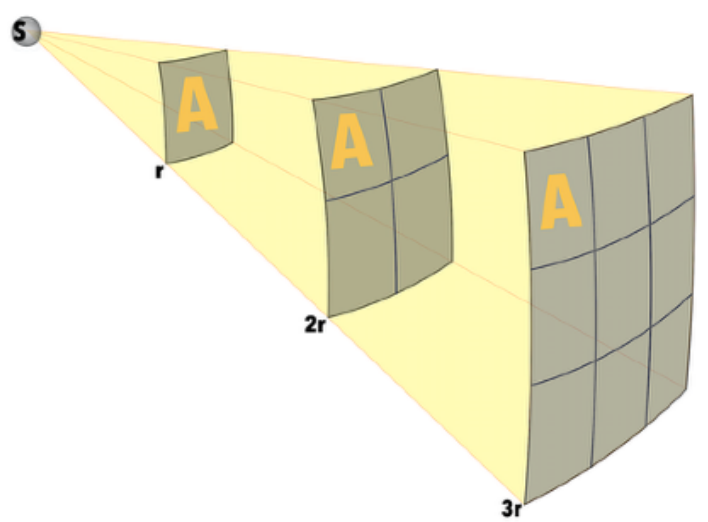

Fonte: a pesquisadora.

Não existe uma quantidade de luz que seja segura para materiais sensíveis. Pesquisas demonstraram que 50 lux é a quantidade mínima necessária para uma pessoa saudável enxergar formas e cores. Por isso, esta é a iluminância recomendada para os itens muito sensíveis. Para objetos moderadamente sensíveis, recomenda-se um máximo de 200 lux e, para aqueles insensíveis à luz, 300 lux. É importante que a iluminação de ambientes e mobiliários não tenha variações muito grandes na iluminância para não estressar a capacidade de adaptação visual dos usuários. 
A taxa de deterioração depende do comprimento da onda, da quantidade de luz que inside sobre o objeto e do tempo de exposição. Grosso modo, um objeto exposto a 100 lux por seis meses sofrerá 0 mesmo dano se exposto por dois meses a 300 lux. Por isso, as análises de exposição de um item à luz devem ser sempre anuais. Este cálculo é feito encontrando-se a média anual da iluminância incidente (se a iluminação for artificial este valor tende a ser constante) e multiplicando-a pelo total de horas de exposição ao longo de um ano (usualmente tem-se um calendário de horas de exposição já que é incomum 0 objeto ficar sob a luz 24 horas por dia, 7 dias da semana). As entidades de proteção do patrimônio recomendam 100.000 horas.lux de exposição para os itens muito sensíveis e 450.000 horas.lux para aqueles moderadamente sensíveis (Museums Galleries Scotland, 2009).

A iluminação artificial é recomendada sempre que possível dada sua regularidade e confiabilidade. No entanto, para que os atributos de qualidade possam ser alcançados é importante um bom projeto luminotécnico, fundamentado em diagnóstico e documentação, que considere tanto a conservação preventiva dos objetos como a experiência visual dos usuários. Um projeto de iluminação deve, pelo menos, considerar os seguintes fatores:

a. distribuição espectral: a luz visível é composta por um intervalo de radiação (espectro) sensível ao olho humano, que vai do vermelho $(750 \mathrm{~nm})$ ao violeta $(400 \mathrm{~nm})$. Dependendo da distribuição deste espectro, o resultado é uma experiência visual distinta (Figura 08). No caso de museus, bibliotecas e arquivos, recomenda-se avaliar a distribuição espectral da fonte de luz e verificar se existem emissões em comprimentos de onda potencialmente danosos a itens do acervo.

Figura 08. Espectros (gráfico) e imagens espectrais de uma lâmpada LED branca e uma lâmpada incandescente

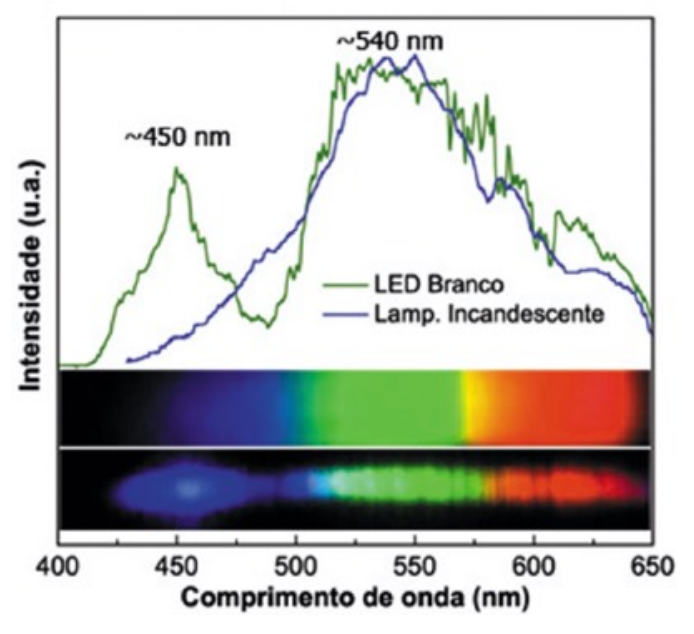

Fonte: AZEVEDO et al., 2019. 
b. temperatura de cor: tendo-se como referência a cor da radiação emitida por um corpo negro teórico quando aquecido a uma certa temperatura (em Kelvin), pode-se comparar esta temperatura de referência com a cor emitida por uma lâmpada. Assim, lâmpadas 'branco quente' são classificadas com temperatura de cor inferiores a 3.500K, 'branco neutro' entre 3.500 e $4.500 \mathrm{~K}$, e 'branco frio' acima de 4.500K (Figura 09). A temperatura de cor deve ser escolhida conforme o uso: cores mais quentes para ambiência e decoração, cores mais frias para precisão na execução de tarefas. Os fabricantes de lâmpadas costumam informar a temperatura de cor na embalagem do produto.

Figura 09. Efeito da temperatura de cor da lâmpada sobre flores

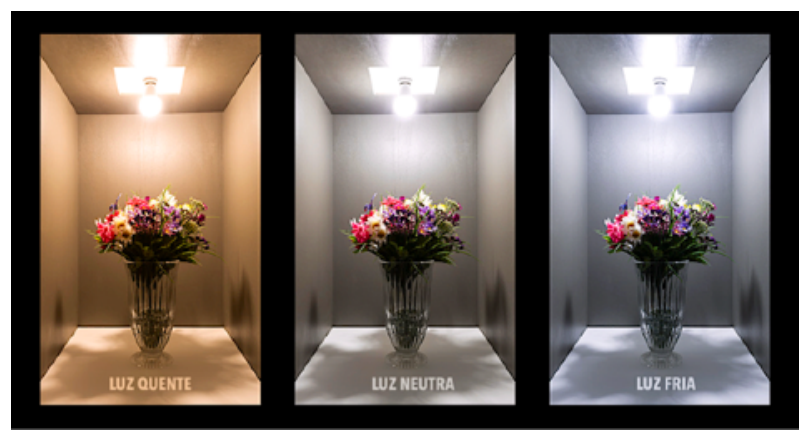

Fonte: adaptado de SUPERBRIGHTLEDS, 2020.

c. índice de reprodução de cor (IRC): o IRC classifica a fonte de luz em uma escala de 0 a 100 conforme a capacidade de uma fonte, em comparação a outras, de iluminar objetos de modo que eles sejam percebidos o mais próximo de suas cores originais. Em teoria, o IRC de duas lâmpadas só pode ser comparado se ambas tiverem a mesma temperatura de cor, mas, grosso modo, quanto mais alto 0 valor do IRC, melhor a qualidade da iluminação (Figura 10). Recomenda-se, para museus, bibliotecas e galerias, IRCs superiores a 90\%. Os fabricantes de lâmpadas também costumam trazer esta informação na embalagem do produto.

Figura 10. Qualidade visual associada a diferentes IRCS

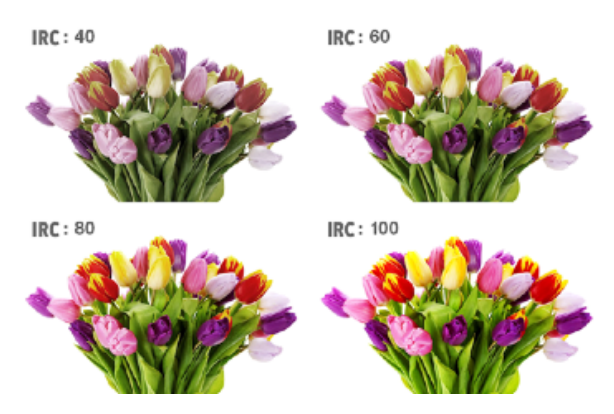

Fonte: traduzido de DMF, 2020. 
Além disso, características espaciais também devem ser consideradas no projeto luminotécnico:

a. fluxo luminoso: é quantidade de luz emitida por uma fonte em um segundo (Figura 11), medida em lúmens [Im].

Figura 11. Medidas básicas de luminotécnica

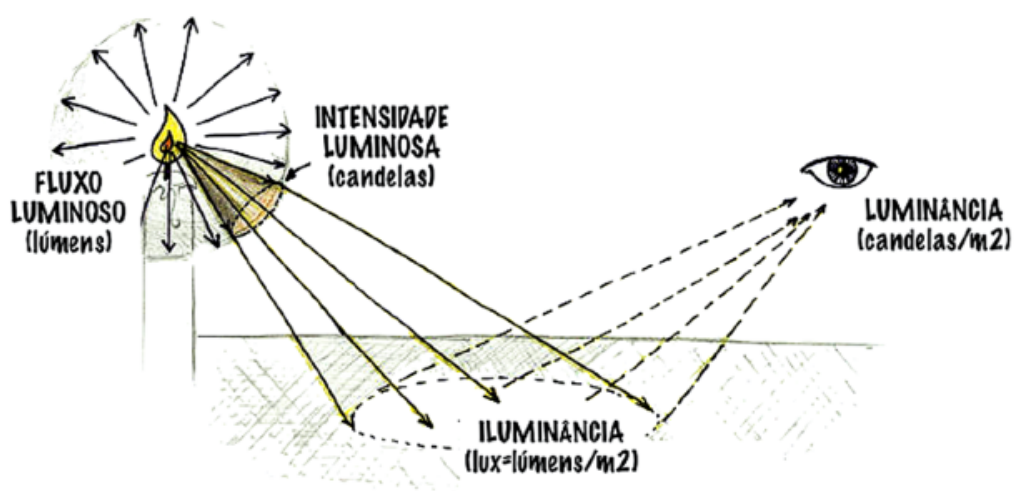

Fonte: traduzido de AUTODESK, 2018a.

b. distribuição da luz: dependendo das características da lâmpada e da luminária, o feixe luminoso terá uma distribuição específica, que pode ser representada pela curva fotométrica do sistema (Figura 12), com impactos diretos nas características visuais do ambiente iluminado.

Figura 12. Curva de distribuição da luz do conjunto lâmpada e luminária
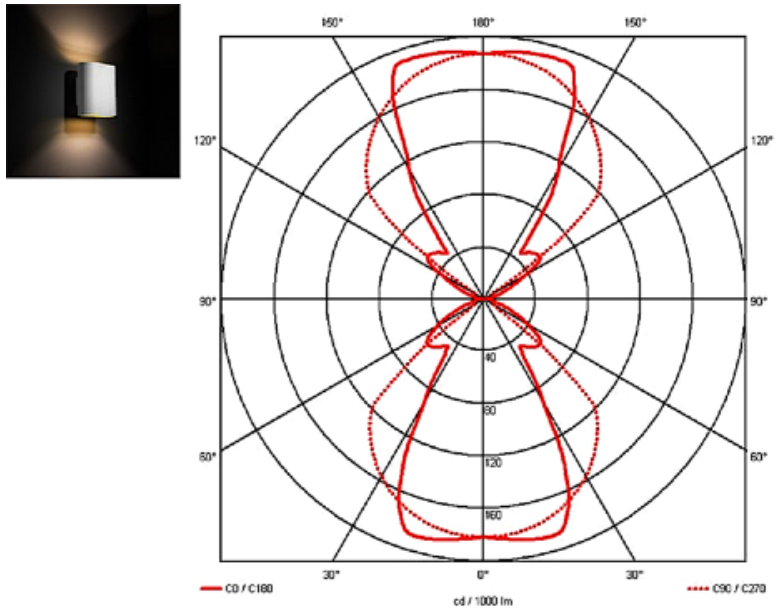

Fonte: DMLIGHTS, 2015.

c. geometria e materiais do espaço: a forma do ambiente, bem como as características reflexivas dos materiais de acabamento (refletâncias), influenciam no resultado final da iluminação e devem ser considerados de maneira criteriosa (Figura 13). 
Figura 13. Simulação com cálculo da iluminância [lux] para um ambiente modelo

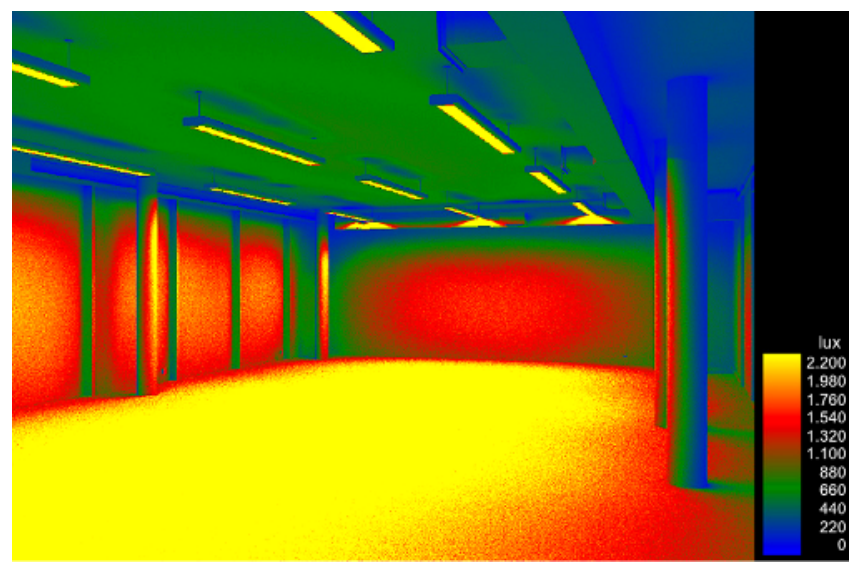

Fonte: traduzido de AUTODESK, 2018b.

Por fim, é preciso também ter atenção às características de funcionamento dos sistemas de iluminação:

a. eficácia luminosa [lm/W]: este fator traduz a relação entre a quantidade de luz (fluxo luminoso, em lúmens) produzida e a quantidade de energia (potência, em Watts) consumida. Quanto maior a quantidade de luz produzida por unidade de energia, mais energeticamente eficiente é a fonte luminosa. b. energia incorporada: as decisões projetuais, em uma análise pela perspectiva da sustentabilidade, devem considerar também a energia incorporada e os custos associados aos processos de produção, uso, descarte e reciclagem da lâmpada e/ou luminária.

c. sistemas de controle: com o desenvolvimento da tecnologia LED, as opções de esquemas de iluminação e de regulagem da intensidade da luz (dimerização) se ampliaram muito, permitindo que sejam previstos cenários personalizados e dinâmicos. Este atributo deve ser considerado pelo projetista no desenho de espaços que sejam os mais adaptados possível aos usos, às pessoas e aos acervos. Como a possibilidade de individualização e personalização pode resultar em esquemas complexos de iluminação, é importante assegurar ao usuário sistemas de controle precisos, seguros e fáceis de usar.

d. operação e manutenção: diferentes tipos de lâmpadas (e de reatores) possuem diferentes tempos de vida útil de projeto (VUP), o que precisa ser considerado em uma análise do tipo custo-benefício. Ao se decidir por um sistema, também é preciso verificar os fatores que foram considerados pelo fabricante quando do cálculo da VUP como a temperatura de operação, a taxa esperada de falha e a redução de emissão de luz ao longo da vida útil. 


\subsubsection{Radiação Térmica e Umidade (parcialmente adaptado de ULAS et al., 2014)}

A temperatura (T) e a umidade relativa (UR) são fatores essenciais na determinação do conforto do usuário. No entanto, as necessidades das coleções versus a dos seres humanos sempre resultarão em algum conflito, que precisará ser negociado.

Umidade relativa é a quantidade de vapor d'água existente no ar a uma dada temperatura em relação à máxima quantidade de vapor que o ar, naquela temperatura, pode conter. Seu valor é sempre expresso em porcentagem. A quantidade de vapor d'água que pode estar presente em um determinado volume de ar aumenta com a temperatura. Quanto mais quente, mais vapor 0 ar pode conter.

Ambientes isolados são aqueles que fazem uso de barreiras ao vapor (tintas, filmes, películas, materiais impermeáveis etc.), para reduzir ou eliminar a permeabilidade da envolvente ao vapor d'água. Caso um ambiente seja totalmente isolado e não permita o fluxo de vapor entre o lado externo e o interno, se a temperatura subir, a UR irá diminuir. E, se a temperatura cair, a UR irá aumentar, podendo até mesmo atingir a capacidade máxima do ar (UR $=100 \%$, o que resultará em condensaç̧ões ${ }^{15}$. Em espaços para a guarda de acervos (salas, mobiliários, vitrines e embalagens) com pouca troca entre 0 ar interno e externo, quando não condicionados artificialmente, observa-se, com frequência, variações bruscas na UR causadas pelo aumento ou diminuição da temperatura. Por outro lado, ambientes não isolados, com elevada permeabilidade ao vapor não devem fazer uso contínuo de sistemas de umidificação ou desumidificação do ar interno porque esta estratégia resulta em maior variação instantânea na UR interna e degradação dos materiais da envolvente pela indução de fluxo de vapor d'água entre as duas faces.

Valores muito altos ou muito baixos de T e UR afetam a estabilidade dos objetos, principalmente daqueles compostos por materiais orgânicos, que possuem maior propensão a absorver e eliminar água. Os principais riscos são: deformações, craquelamentos e rompimentos, degradação química e ataque por pragas e fungos.

Os materiais costumam ter suas reações químicas estabilizadas (em um ponto de equilíbrio químico) quando uma determinada condição climática se mantém constante. Do ponto de vista da degradação

\footnotetext{
15 Condensação é a passagem do estado gasoso (vapor d'água) para o estado líquido (água líquida). Para cada temperatura do ar corresponde uma quantidade máxima de vapor, para além da qual ocorre a condensação da água excedente. Quanto menor a temperatura, menor a quantidade de vapor que 0 ar pode conter. 0 resfriamento súbito do ar provoca condensação (chuva). Se 0 ar quente encontra uma superfície fria, pode ocorrer condensação junto a esta superfície.
} 
dos materiais, variações nos valores de T e UR, principalmente se forem bruscas, são mais danosas do que valores extremos porém constantes porque os objetos, nessa condição, não sofrem fadiga pelo estresse de dilatarem / contraírem, absorverem / perderem água repetidamente. Além disso, para os casos em que, dadas as características construtivas do ambiente, os valores de T e UR podem variar independentemente um do outro, valores extremos e flutuações na UR costumam ser mais danosos aos acervos do que valores extremos e flutuações na T. Da perspectiva da conservação preventiva, 0 foco deve ser sempre na estabilidade (HCC, 1998).

0 papel é o suporte mais comum em arquivos e bibliotecas, e é também encontrado com frequência em muitos museus. Ele é um material orgânico e higroscópico, sujeito a diversos processos de deterioração, sendo os mais importantes aqueles relacionados à degradação química da celulose (envelhecimento do papel) e aos danos por fungos. Michalski (1993) estudou o tempo de resposta do papel a variações na T e UR. Para uma única folha, a resposta é de alguns minutos; para livros expostos abertos, de algumas horas a três dias; e para livros guardados em armários fechados, de 6 a 9 meses. Se íntegra, a fibra da celulose é flexível e pode suportar, em grande medida, os impactos mecânicos da variação volumétrica resultante das flutuações de T e UR. Os danos mecânicos mais significativos são provocados pela guarda e o manuseio incorretos.

0 aumento na temperatura pode causar um aumento nas atividades biológicas, principalmente de insetos, e também acelerar processos de degradação química (em uma abordagem muito simplificada, pode-se considerar que a taxa de deterioração dobra a cada aumento de dez graus na temperatura). Flutuações no valor da temperatura podem causar dilatações e contrações excessivas, levando a deformações no objeto, principalmente se ele for composto por mais de um material.

Uma UR muito elevada pode estimular a proliferação de pragas e fungos; aumentar a corrosão de metais; desbotar tintas; deformar materiais como tecidos e couro; e fazer com que emulsões de gelatina e adesivos fiquem pegajosos. Já uma UR muito baixa faz com que os materiais se desidratem, causando deformações e craquelamentos; materiais muito finos podem perder água muito rapidamente e se encurvarem; objetos feitos de materiais compostos podem se deformar pelo diferencial de desidratação; e adesivos pode ressecar e se soltarem.

As principais causas de valores extremos e amplas flutuações nos valores de T e UR são: o macroclima regional; as condições climáticas internas; os climas localizados, conforme posição do ambiente dentro 
do edifício (por influência da orientação solar, distância até as aberturas, pavimento, etc.); os microclimas (armários, vitrines, embalagens, etc.) e os usuários (quantidade, hábitos, etc.). Os climas localizados e os microclimas costumam variar bastante dentro de um mesmo edifício.

Em edificações sem estratégias para isolamento térmico, como é o caso de muitos edifícios históricos, sabe-se que os valores de Te UR próximos às envolventes externas são diferentes das T e UR médias do ar interno. Nesta condição, mesmo os sistemas de condicionamento do ar mais avançados terão dificuldades para impedir a formação de climas localizados. A depender das condições de T e UR internas, nas zonas próximas às paredes externas também podem ocorrer condensações, formação de mofos e deterioração de materiais de construção.

Quando o edifício é parte do acervo, as condições climáticas internas precisam ser ajustadas para a preservação da construção e, no que concerne os objetos que demandam condições especiais, devem ser criados microclimas específicos. Recomenda-se que objetos frágeis sejam colocados próximos das paredes internas, no meio do ambiente ou em ambientes internos ao edifício. Não se deve encostar objetos nas paredes externas para evitar a formação de mofo no espaço entre a parede e o mobiliário / objeto.

É muito importante que o clima interno seja constantemente monitorado. Ao contrário de edifícios corporativos, onde diferenças climáticas podem ser bem toleradas pelos usuários, em museus, bibliotecas e arquivos é preciso entender como cada item reage ao clima e as consequências para a sua preservação. Para melhorar as condições de guarda, sempre que possível, devem ser criadas zonas tampão ${ }^{16}$ entre 0 objeto e 0 ambiente, 0 que pode ser feito com estratégias passivas e/ou ativas de controle climático.

0 trabalho em equipe é fundamental: as pessoas que cuidam do edifício e das facilidades devem decidir em conjunto com os responsáveis pelos acervos qual o local mais adequado para a guarda e exposição de cada objeto, conforme as características e limitações próprias de cada zona climática. 0 engenheiro ou arquiteto responsável pela gestão das facilidades deve ter especialização em sistemas para edifícios culturais. Copiar esquemas e estratégias utilizados em edifícios corporativos é "uma receita para o desastre" (MARTENS, 2012).

\footnotetext{
16 Zona tampão ou thermal buffer zone (TBZ) é uma estratégia para atenuação e homogeneização das cargas térmicas fazendo-se uso, para isso, de um ou mais espaços de transição entre duas zonas termicamente distintas. No caso dos edifícios, escadas, corredores, varandas, são alguns exemplos de espaços que podem funcionar como zonas tampão. No caso dos objetos, armários, vitrines, caixas, são exemplos de alguns elementos que podem ter a mesma funcionalidade.
} 
À primeira vista, pode parecer que o uso de condicionadores de ar é o método mais simples e efetivo para se obter uma condição climática estável. Existem dois tipos básicos de equipamentos para resfriamento do ar: 1. os climatizadores evaporativos (passa-se 0 ar por uma superfície molhada, o que reduz a temperatura ${ }^{17}$ e aumenta a umidade relativa; este sistema só pode ser usado em reservas técnicas se estiver associado a um sistema de desumidificação do ar); 2. os ar-condicionados (passa-se 0 ar por um gás refrigerante, 0 que diminui a temperatura e a umidade relativa ${ }^{18 ;}$ as condições climáticas internas podem variar bastante e, por isso, o seu funcionamento precisa ser permanentemente monitorado e ajustado). Porém, antes de se optar pela instalação de um destes equipamentos é preciso ter em conta que:

a. os custos de obtenção, operação e manutenção são elevados, e sua vida útil de projeto não é muito longa (por volta de 15 anos);

b. para que seja possível atingir o objetivo de se manter condições climáticas internas constantes ele provavelmente nunca poderá ser desligado, o que também têm impactos no consumo energético;

c. a manutenção do sistema deve ser muito bem feita para que ele não funcione fora das especificações programadas, não provoque flutuações excessivas de T e UR, e não contribua para a contaminação do ar por poluentes e microorganismos.

A UR é uma função da temperatura e sua uniformização dentro de um espaço ou edifício é um grande desafio. Os sistemas ativos de tratamento do ar normalmente são regulados para valores fixos de T e UR, o que faz com que o sistema tenha que constantemente realizar ajustes para assegurar que 0 ar interno se mantenha dentro da faixa de controle, resultando em permanente variação na quantidade de vapor d'água presente no ar. Por outro lado, se o termostato do sistema de AVAC (Aquecimento, Ventilação e Ar Condicionado) for ajustado para um valor fixo de temperatura de ponto de orvalho, 0 sistema tenderá a manter a umidade absoluta constante, ainda que a UR possa variar. A umidade absoluta é a quantidade de vapor d'água presente em um certo volume de ar, independentemente da temperatura. E é esta quantidade de vapor que efetivamente interfere na preservação dos materiais e

\footnotetext{
17 Parte da energia térmica presente no ar quente é 'gasta' na transformação da água líquida em vapor, o que resulta na diminuição do valor da temperatura e, portanto, no aumento da umidade relativa.

${ }^{18}$ Ao se passar 0 ar quente pelo gás refrigerante reduz-se a temperatura do ar, o que provoca a condensação de parte do vapor d'água, 0 qual é eliminado do sistema, resultando em um ar mais frio e mais seco.
} 
objetos (Figura 14). Assim, um sistema com controle do ponto de orvalho tende a manter um ambiente mais estável para as coleções e, simultaneamente, consome menos energia (Tabela 01).

Figura 14. Carta psicrométrica mostrando a temperatura de ponto de orvalho / umidade absoluta constante para umidade relativa variável

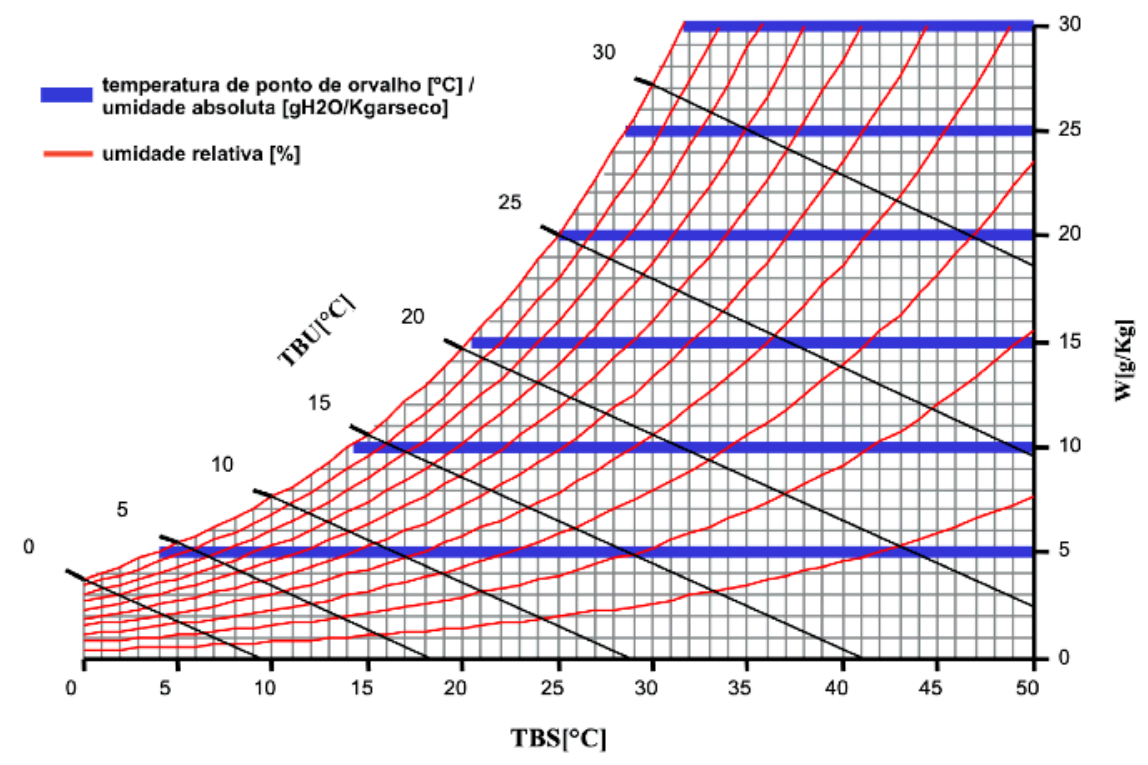

Fonte: AUT284, 2013.

Tabela 01: Exemplo de ponto de orvalho e quantidade de vapor constantes, com temperatura e umidade relativa variável

\begin{tabular}{c|c|c|c|c}
\hline $\begin{array}{c}\text { Temperatura de } \\
\text { bulbo seco }\left[{ }^{\circ} \mathbf{C}\right]\end{array}$ & $\begin{array}{c}\text { Umidade Relativa } \\
{[\%]}\end{array}$ & $\begin{array}{c}\text { Teor de umidade / } \\
\text { umidade absoluta }[\mathbf{g} / \mathbf{K g}]\end{array}$ & $\begin{array}{c}\text { Temperatura de } \\
\text { ponto de orvalho }\left[{ }^{\circ} \mathbf{C}\right]\end{array}$ & $\begin{array}{c}\text { Modo usual de } \\
\text { operação do sistema }\end{array}$ \\
\hline 24 & 44,3 & $\mathbf{8 , 2 6}$ & $\mathbf{1 1 , 1 1}$ & umidificação \\
\hline 23 & 47,0 & $\mathbf{8 , 2 6}$ & $\mathbf{1 1 , 1 1}$ & umidificação \\
\hline 22 & 50,0 & $\mathbf{8 , 2 6}$ & $\mathbf{1 1 , 1 1}$ & normal \\
\hline 21 & 53,1 & $\mathbf{8 , 2 6}$ & $\mathbf{1 1 , 1 1}$ & desumidificação \\
\hline 20 & 56,5 & $\mathbf{8 , 2 6}$ & $\mathbf{1 1 , 1 1}$ & desumidificação \\
\hline
\end{tabular}

Fonte: adaptado e traduzido de ULAS et. al., 2014.

A temperatura pode ser medida com termômetros analógicos ou digitais, ou dataloggers. A umidade relativa pode ser medida com higrômetros analógicos ou digitais, termohigrógrafos ou dataloggers. As vantagens de se usar dataloggers são que eles podem estar interligados a um sistema de alarme que avisa quando valores limites são ultrapassados e também podem fazer parte de um sistema com 
múltiplos sensores, instalados em diferentes locais, para avaliar climas localizados e/ou microclimas diversos. Por outro lado, suas desvantagens são que os dados precisam ser processados por um computador e a manutenção é mais cara e complexa do que a dos termohigrógrafos. A grande maioria dos equipamentos para medição de T e UR precisa ser calibrada com frequência para se assegurar a precisão dos dados registrados e é importante que eles sejam instalados em locais adequados, conforme recomendação de um especialista.

\subsubsection{Condicionamento ambiental}

Ao longo do século $X X$, pesquisas que correlacionavam a qualidade do ar interno com processos de degradação do patrimônio cultural estimularam a recomendação de uso de sistemas ativos de AVAC em detrimento de soluções passivas com o intuito de minimizar as interferências do ambiente externo (ASHRAE, 2015). Padfield e Larsen (2004), no artigo 'How to Design Museums with a Naturally Stable Climate', explicam esta escolha por outra perspectiva:

A crescente confiança em projetos auxiliados por computador traz outra razão do porquê técnicas passivas para o controle da umidade não foram adotadas pelos arquitetos modernos. 0 fluxo de calor através dos materiais e seu transporte pelo ar são fenômenos bem descritos. Por outro lado, o movimento do vapor d'água permanece um mistério. Muitos algoritmos computacionais foram escritos, mas os resultados obtidos não são totalmente convincentes. Isso porque todos eles se baseiam na premissa duvidosa que o vapor se move do mesmo modo que o calor. Mesmo que isso fosse verdade, outra questão é que, embora falhas na envolvente respondam, nos casos mais graves, por 30\% dos fluxos de calor, elas podem facilmente responder por até $98 \%$ do fluxo de vapor (PADFIELD e LARSEN, 2004; tradução da pesquisadora).

Além disso, o que se observou, em muitas instituições, foi a especificação preponderante de sistemas de condicionamento convencionais, não adequados à conservação por serem incapazes de manter os parâmetros ambientais dentro dos valores normativos (EN 15757:2010 e EN 16242:2012). Constatouse, então, que, frequentemente, era o próprio sistema de AVAC o responsável por processos de degradação do patrimônio (D'AGOSTINO et al., 2015).

Thomson, em 1986, já alertava para o uso excessivo de equipamentos para o condicionamento do ar e a iluminação artificial em edifícios culturais:

Há algo de deselegante na necessidade atual dessa massa de equipamentos consumindo energia para manter a UR e a iluminância constantes, algo de impróprio nessa despesa que está além da capacidade da maioria dos museus do mundo. Logo, a tendência precisa ser em direção a simplicidade, confiabilidade e baixo custo (THOMSON, 1986; tradução da pesquisadora). 
As condições ambientais adequadas para acervos culturais dependem da compreensão de alguns fatores:

a. os materiais que compõem cada item: orgânicos, inorgânicos ou compostos;

b. os fatores climáticos que interferem no comportamento dos materiais: temperatura, umidade, ponto de orvalho, ventilação e radiação luminosa;

c. os principais mecanismos de deterioração: mecânicos, físicos e químicos.

Para se atingir um bom desempenho ambiental, pode-se combinar soluções ativas com estratégias passivas para regulação dos climas e microclimas internos. Edifícios contemporâneos não costumam incorporar características construtivas voltadas ao conforto passivo, então, neste caso, é importante assegurar que eles possuam isolamento térmico adequado, minimizando, assim, o excesso de flutuações diárias e sazonais naturais do macroclima externo.

Além disso, uma disposição adequada das coleções dentro do edifício também pode ajudar. Por exemplo, os subsolos podem ser usados para a guarda de objetos resistentes a níveis mais elevados de UR, mas que se beneficiam de temperaturas mais baixas, desde que essa estratégia não prejudique a integridade do edifício. Ambientes naturalmente bem ventilados e protegidos da incidência direta do sol costumam ter valores medianos de umidade relativa, mas, neste caso, é preciso ter atenção aos poluentes e insetos. Um resultado semelhante pode ser alcançado com o uso de ventiladores colocados em paredes opostas às aberturas (que, neste caso, precisam ficar abertas). Nesta situação, é preciso avaliar cuidadosamente a intensidade e a orientação do vento, para que ele não danifique objetos mais leves e frágeis. 0 uso de vegetação pode ser uma estratégia para proteger paredes e coberturas da incidência direta do sol mas é preciso cuidado na escolha de espécies de plantas que não atraiam pragas e fungos. Também é possível minimizar o efeito de microclimas nocivos fazendo-se uso de materiais para conservação como a sílica ou embalagens de papel neutro (KOMPATSCHER et al., 2018).

0 Getty Conservation Institute (GCl), entre 1997 e 2002, financiou o desenvolvimento do projeto intitulado 'Collections in Hot \& Humid Environments' (GCl, 2021), que tinha por objetivo identificar, para edifícios históricos em climas tropicais, as principais espécies de microorganismos, controlar poluentes e incidência de luz e avaliar a eficácia de sistemas de condicionamento climático híbridos e sustentáveis, que utilizam ventilação mecânica controlada (exaustores e ventiladores, sensores de T e UR e filtros). Os resultados geraram um conjunto de recomendações que incluem a caracterização do clima e dos 
microclimas internos, testes laboratoriais, monitoramento das condições ambientais internas e utilização de estratégias passivas e ativas de ventilação específicas para cada condição avaliada.

A ideia de uma condição ambiental 'ideal' para a preservação do patrimônio evoluiu, ao longo do século XX, para um entendimento de que 'quanto mais estável, melhor'. No entanto, esta transformação conceitual não foi assimilada, na maioria das instituições culturais, pela perspectiva das coleções ou dos sistemas construtivos, mas sim da eficiência dos sistemas ativos de AVAC. Como consequência, muitas instituições ao redor do mundo interpretaram que a opção deveria ser, sempre que possível, pelos parâmetros prescritos pela classe AA da ASHRAE (a mais restritiva), acreditando que era este 0 significado de prover as melhores condições possíveis para os ambientes de guarda. Infelizmente, as consequências desta escolha não foram positivas, resultando em um consumo excessivo de energia, gastos exagerados com operação e manutenção e, nos edifícios históricos não isolados termicamente, graves problemas de condensação (BROWN e ROSE, 1996). Além disso, pesquisas posteriores demostraram que, em edifícios históricos, a obediência à norma não se traduziu em um ambiente interno estável, e que ambientes menos climatizados haviam conservado melhor as coleções (MARTENS, 2012).

Richard Kerschner (2007), embasado em sua prática profissional, observa que:

(...) Vinte e cinco anos atrás, os conservadores nos EUA com frequência citavam $20^{\circ} \mathrm{C}$ e $50 \%$ UR como os limites de segurança de temperatura e umidade para a preservação dos acervos. Esta era uma resposta que geralmente estava correta. Contudo, conforme eu pesquisava as normas ambientais para museus e edifícios históricos, e me familiarizava com as variadas coleções do Museu Shelborne e os edifícios que as abrigavam, eu comecei a perceber que estes requisitos restritivos não eram apenas pouco razoáveis para construções que incluíam uma ponte coberta e vários gal pões, mas eram, provavelmente, desnecessários para a preservação da maioria dos nossos artefatos. Conforme examinava as coleções nas diversas áreas expositivas e de guarda, eu percebi que a maioria dos objetos com 70 a 150 anos de idade estava em boa condição, apesar de muitos terem experienciado temperaturas extremas entre $-18^{\circ} \mathrm{C}$ e $32^{\circ} \mathrm{C}$ e UR extremas entre $10 \%$ e $95 \%$. Os artefatos em pior condição sofreram danos por permanecerem em condições desfavoráveis em áticos muito quentes, em porões muito úmidos, ou em ambientes muito secos como resultado de aquecimento no inverno sem umidificação (KERSCHNER, 2007; tradução da pesquisadora).

0 autor concluiu que foi preciso adotar uma abordagem que considerasse um intervalo de UR mais flexível; o emprego de estratégias bioclimáticas passivas para melhoria do desempenho dos edifícios sem descaracterizá-los, uma vez que eles também eram parte do patrimônio; a avaliação das ameaças às coleções caso a caso, conforme o tipo de material; e o monitoramento dos ambientes com sensores 
precisos. Os resultados se mostraram tão satisfatórios que, em 2000, ao planejarem a construção de um novo edifício para reserva técnica, decidiram empregar as mesmas estratégias passivas utilizadas nos edifícios históricos, combinando-as com estratégias ativas de umidificação / desumidificação, quando necessário. Medições posteriores demonstraram que esta abordagem foi adequada para os acervos e resultou em grande economia de energia elétrica.

Michalski (2007), a partir da sua experiência como consultor do CCl, cunhou o termo "flutuação comprovada", definida como o maior intervalo de flutuações de temperatura e/ou UR a que um objeto já foi exposto no passado. Assume-se que o risco de danos físicos para além do já acumulado por causa de flutuações dentro deste intervalo histórico é extremamente baixo. 0 conceito de flutuação comprovada elimina a necessidade de cálculos elaborados e oferece uma avaliação de riscos simplificada, baseada apenas nos registros climáticos. Este conceito foi amplamente utilizado em normas e recomendações para o controle das condições ambientais internas (BRATASZ, 2013).

A norma ASHRAE, no Capítulo 23 (2007), apresenta índices climáticos de referência para museus, galerias, bibliotecas e arquivos. Ela define classes de controle (Tabela 02 e Quadro 04), que vão de AA (controle preciso) a D (controle relaxado), e flutuações aceitáveis de curto (horárias e diárias) e de longo prazo (sazonais) para as diferentes classes. 0 setpoint ${ }^{19}$ pode ser um valor constante de $21^{\circ} \mathrm{C}$ e $50 \%$ de UR ou então a média anual a que a coleção está acostumada. Embora a T e UR médias sejam as mesmas para todas as classes climáticas, as variações sazonais permitidas e a largura da banda resultam que, para cada classe climática, haja uma recomendação diferente. A classe A, por exemplo, prevê duas opções: flutuações de UR de $\pm 5 \%$ e ajustes sazonais de $10 \%$ para cima e para baixo ou flutuações maiores, de $\pm 10 \%$ na UR, mas sem ajustes sazonais.

Tabela 02. Resumo dos valores de Te UR, segundo a ASHRAE (2015), para as condições climáticas internas

\begin{tabular}{c|c|c|c}
\hline Variável & Referência & Classe AA & Classe A \\
\hline$\left.T{ }^{\circ} \mathrm{C}\right]$ & 21 & $20-22$ & $19-23(\mathrm{a})$ \\
\hline UR $[\%]$ & 50 & $45-55$ & $40-60$ \\
\hline
\end{tabular}

(a) ajustado para $19-21^{\circ} \mathrm{C}$ no inverno e $21-23^{\circ} \mathrm{C}$ no verão

Fonte: traduzido e adaptado de KRAMER et al., 2016.

19 Setpoint é o valor-alvo programado para um sistema ativo com controle automático. 
Quadro 04. Recomendações ASHRAE (2007) para museus, galerias, bibliotecas e arquivos

\begin{tabular}{|c|c|c|c|c|c|}
\hline \multirow[b]{2}{*}{ Tipo } & \multirow{2}{*}{$\begin{array}{l}\text { Setpoint ou } \\
\text { valor anual }\end{array}$} & \multicolumn{3}{|c|}{$\begin{array}{l}\text { Flutuações máximas e gradientes } \\
\text { (espaços controlados) }\end{array}$} & \multirow{2}{*}{$\begin{array}{c}\text { Riscos e benefícios para } \\
\text { o acervo }\end{array}$} \\
\hline & & $\begin{array}{l}\text { classe de } \\
\text { controle }\end{array}$ & $\begin{array}{c}\text { flutuações / } \\
\text { gradientes (a) }\end{array}$ & $\begin{array}{c}\text { ajustes } \\
\text { sazonais no } \\
\text { setpoint }\end{array}$ & \\
\hline \multirow{4}{*}{$\begin{array}{l}\text { Museus em geral, } \\
\text { galerias, } \\
\text { bibliotecas e } \\
\text { arquivos } \\
\text { Todas as salas de } \\
\text { leitura e devolução, } \\
\text { salas para guarda de } \\
\text { acervos } \\
\text { quimicamente } \\
\text { estáveis, } \\
\text { especialmente se a } \\
\text { vulnerabilidade } \\
\text { mecânica for de alta } \\
\text { a média }\end{array}$} & \multirow{4}{*}{$\begin{array}{l}50 \% \text { UR (ou o } \\
\text { histórico das médias } \\
\text { anuais para coleções } \\
\text { permanentes) } \\
\text { Temperatura fixa } \\
\text { entre } 15 \text { e } 25^{\circ} \mathrm{C} \\
\text { Nota: ambientes de } \\
\text { exposição com itens } \\
\text { emprestados } \\
\text { precisam atender ao } \\
\text { setpoint especificado } \\
\text { no acordo de } \\
\text { empréstimo } \\
\text { (tipicamente } 50 \% \text { UR } \\
\text { e } 21^{\circ} \mathrm{C} \text {, } \\
\text { eventualmente } 55 \text { ou } \\
60 \% \text { UR) }\end{array}$} & $\begin{array}{l}\text { AA } \\
\text { Controle preciso, } \\
\text { sem variações } \\
\text { sazonais de UR }\end{array}$ & $\pm 5 \%$ UR, $\pm 2 \mathrm{~K}$ & UR não muda; $\pm 5 \mathrm{k}$ & $\begin{array}{l}\text { Nenhum risco de dano } \\
\text { mecânico para a maioria dos } \\
\text { artefatos e pinturas. Alguns } \\
\text { metais e minerais podem } \\
\text { degradar se } 50 \% \text { UR exceder a } \\
\text { UR crítica. Objetos } \\
\text { quimicamente instáveis se } \\
\text { deterioram em décadas. }\end{array}$ \\
\hline & & $\begin{array}{l}\text { A } \\
\text { Controle preciso, } \\
\text { gradientes ou } \\
\text { variações } \\
\text { sazonais, mas } \\
\text { não ambos }\end{array}$ & $\begin{array}{l}\text { As } \\
\pm 5 \% \text { UR, } \pm 2 K\end{array}$ & $\begin{array}{l}\text { UR não muda, }+5 K, \\
-10 K\end{array}$ & $\begin{array}{l}\text { Pequeno risco de dano } \\
\text { mecânico para artefatos muito } \\
\text { vulneráveis; nenhum risco de } \\
\text { dano mecânico para a maioria } \\
\text { dos artefatos, pinturas, } \\
\text { fotografias e livros. Objetos } \\
\text { quimicamente instáveis se } \\
\text { deterioram em décadas. }\end{array}$ \\
\hline & & $\begin{array}{l}\text { B } \\
\text { Controle preciso, } \\
\text { gradientes e } \\
\text { diminuição de T } \\
\text { no inverno }\end{array}$ & $\pm 10 \% \mathrm{UR}, \pm 5 \mathrm{~K}$ & $\begin{array}{c} \pm 10 \% \text { UR, }+10 \mathrm{~K} \\
\text { (não acima de } \\
\left.30^{\circ} \mathrm{C}\right),- \text { nK (o } \\
\text { quanto necessário } \\
\text { para manter o } \\
\text { controle da UR) }\end{array}$ & $\begin{array}{l}\text { Risco moderado de dano } \\
\text { mecânico para artefatos muito } \\
\text { vulneráveis; risco mínimo para } \\
\text { a maioria das pinturas e } \\
\text { fotografias; nenhum risco para } \\
\text { muitos artefatos e a maioria } \\
\text { dos livros. Objetos } \\
\text { quimicamente instáveis se } \\
\text { deterioram em décadas se T } \\
\text { frequentemente inferior a } \\
30^{\circ} \mathrm{C} \text {; períodos de inverno } \\
\text { frios podem dobrar a vida útil. }\end{array}$ \\
\hline & & $\begin{array}{l}\text { C } \\
\text { Prevenir todos } \\
\text { os extremos com } \\
\text { alto risco }\end{array}$ & \multicolumn{2}{|c|}{$\begin{array}{c}\text { Entre } 25 \text { e } 75 \% \text { UR ao longo do ano, } \\
\text { com T frequentemente abaixo de } 25^{\circ} \mathrm{Ce} \\
\text { raramente acima de } 30^{\circ} \mathrm{C}\end{array}$} & $\begin{array}{l}\text { Risco elevado de dano mecânico } \\
\text { para artefatos muito } \\
\text { vulneráveis; risco moderado } \\
\text { para a maioria das pinturas e } \\
\text { fotografias e alguns artefatos e } \\
\text { livros; risco mínimo para muitos } \\
\text { artefatos e livros. Objetos } \\
\text { quimicamente instáveis se } \\
\text { deterioram em décadas se T } \\
\text { frequentemente inferior a } 30^{\circ} \mathrm{C}_{\text {; }} \\
\text { períodos de inverno frios } \\
\text { podem dobrar a vida útil. }\end{array}$ \\
\hline
\end{tabular}

(a) o gradiente térmico descreve a variação no valor de T para uma determinada área ou volume. 
Quadro 04. Recomendações ASHRAE (2007) para museus, galerias, bibliotecas e arquivos (continuação)

\begin{tabular}{|c|c|c|c|c|c|}
\hline \multirow[b]{2}{*}{ Tipo } & \multirow{2}{*}{$\begin{array}{l}\text { Setpoint ou } \\
\text { valor anual }\end{array}$} & \multicolumn{3}{|c|}{$\begin{array}{l}\text { Flutuações máximas e gradientes } \\
\text { (espaços controlados) }\end{array}$} & \multirow{2}{*}{$\begin{array}{c}\text { Riscos e benefícios para } \\
\text { o acervo }\end{array}$} \\
\hline & & $\begin{array}{l}\text { classe de } \\
\text { controle }\end{array}$ & $\begin{array}{l}\text { flutuações / } \\
\text { gradientes }\end{array}$ & $\begin{array}{c}\text { ajustes } \\
\text { sazonais no } \\
\text { setpoint }\end{array}$ & \\
\hline $\begin{array}{l}\text { Museus em geral, } \\
\text { galerias, } \\
\text { bibliotecas e } \\
\text { arquivos } \\
\text { Todas as salas de } \\
\text { leitura e devolução, } \\
\text { salas para guarda de } \\
\text { acervos } \\
\text { quimicamente } \\
\text { estáveis, } \\
\text { especialmente se a } \\
\text { vulnerabilidade } \\
\text { mecânica for de alta } \\
\text { a média }\end{array}$ & $\begin{array}{l}50 \% \text { UR (ou o } \\
\text { histórico das médias } \\
\text { anuais para coleções } \\
\text { permanentes) } \\
\text { Temperatura fixa } \\
\text { entre } 15 \text { e } 25^{\circ} \mathrm{C} \\
\text { Nota: ambientes de } \\
\text { exposição com itens } \\
\text { emprestados } \\
\text { precisam atender ao } \\
\text { setpoint especificado } \\
\text { no acordo de } \\
\text { empréstimo } \\
\text { (tipicamente } 50 \% \text { UR } \\
\text { e } 21^{\circ} \mathrm{C} \text {, } \\
\text { eventualmente } 55 \text { ou } \\
60 \% \text { UR) }\end{array}$ & $\begin{array}{l}\text { D } \\
\text { Prevenir UR }\end{array}$ & Com segurançc & baixo de $75 \%$ UR & $\begin{array}{l}\text { Risco elevado de dano } \\
\text { mecânico eventual ou } \\
\text { cumulativo para a maioria dos } \\
\text { artefatos e pinturas: trincas por } \\
\text { baixa umidade; delaminações } \\
\text { e deformações por excesso de } \\
\text { umidade. Crescimento de } \\
\text { fungos e corrosões são } \\
\text { evitados. Objetos } \\
\text { quimicamente instáveis se } \\
\text { deterioram em décadas se T } \\
\text { frequentemente inferior a } \\
30^{\circ} \mathrm{C} \text {; períodos de inverno frios } \\
\text { podem dobrar a vida útil. }\end{array}$ \\
\hline \multirow[t]{2}{*}{$\begin{array}{l}\text { Bibliotecas e } \\
\text { arquivos } \\
\text { Guarda de acervos } \\
\text { quimicamente } \\
\text { instáveis }\end{array}$} & $\begin{array}{l}\text { Câmara fria: } \\
-20^{\circ} \mathrm{C} ; 40 \% \text { UR }\end{array}$ & $\pm 10 \%$ UR $; \pm 2 \mathrm{~K}$ & & & $\begin{array}{l}\text { Objetos quimicamente } \\
\text { instáveis íntegros por } \\
\text { milênios. Pequenas flutuações } \\
\text { de UR não afetam a maioria } \\
\text { dos objetos devidamente } \\
\text { embalados para estas } \\
\text { temperaturas (o período fora } \\
\text { da câmara é determinante } \\
\text { para a vida útil). }\end{array}$ \\
\hline & $\begin{array}{l}\text { Câmara fresca: } \\
10^{\circ} \mathrm{C} ; 30 \text { a } 50 \% \text { UR }\end{array}$ & \multicolumn{3}{|c|}{$\begin{array}{l}\text { (Mesmo se alcançado apenas durante a estação de inverno, } \\
\text { há vantagens globais para estas coleções, desde que não } \\
\text { haja umidade excessiva) }\end{array}$} & $\begin{array}{l}\text { Objetos quimicamente instáveis } \\
\text { íntegros por séculos ou mais. } \\
\text { Livros e papéis costumam ter } \\
\text { baixa vulnerabilidade mecânica } \\
\text { a flutuações. }\end{array}$ \\
\hline $\begin{array}{l}\text { Itens especiais em } \\
\text { metal }\end{array}$ & $\begin{array}{l}\text { Sala seca: } \\
0 \text { a } 30 \% \text { UR }\end{array}$ & \multicolumn{3}{|c|}{$\begin{array}{l}\text { UR não pode exceder valores críticos, tipicamente } \\
\qquad 30 \% \text { UR }\end{array}$} & - \\
\hline
\end{tabular}

Fonte: traduzido e adaptado de MARTENS, 2012.

A norma ASHRAE foi sendo aprimorada ao longo das décadas de modo a incorporar as descobertas e discussões internacionais sobre qualidade e desempenho ambiental em edifícios culturais (Quadro 05). Ela aborda: os intervalos de variação para o setpoint de cada classe a partir do valor de referência de 50\% de UR; o risco estimado para cada classe; e uma grande variedade de opções de ajustes visando à eficiência energética. Estas especificações não são prescritivas, mas informativas. No entanto, 
é preciso salientar que apenas profissionais especializados são capazes de traduzir, para um determinado edifício com um acervo específico, os valores indicados por classe e os riscos associados a cada escolha pois fatores como o estado de conservação dos objetos, características construtivas e dos sistemas ativos, características climáticas externas e do entorno, quantidade de visitantes, dentre outros, alteram as demandas (KRAMER et al., 2016). Além disso, é preciso considerar as condições de conforto tanto para as obras como para as pessoas. A norma recomenda que os valores de umidade relativa sejam ajustados para as demandas das coleções e os valores de temperatura para as demandas dos usuários (KRAMER et al., 2015).

Quadro 05. Seleção de normas e recomendações internacionais para T e UR entre 1978 e 2010

\begin{tabular}{|c|c|c|c|c|c|c|c|}
\hline \multirow[b]{2}{*}{ Ano } & \multirow{2}{*}{$\begin{array}{l}\text { Entidade } \\
\text { responsável } \\
\text { pela norma }\end{array}$} & \multirow[b]{2}{*}{$\begin{array}{c}\text { Temperatura } \\
{\left[{ }^{\circ} \mathrm{C}\right]}\end{array}$} & \multicolumn{3}{|c|}{ UR [\%] } & \multirow[b]{2}{*}{ Notas } & \multirow[b]{2}{*}{ Referências } \\
\hline & & & $\begin{array}{c}\text { média } \\
\text { de longo } \\
\text { prazo }\end{array}$ & $\begin{array}{c}\text { ciclo } \\
\text { sazonal }\end{array}$ & $\begin{array}{c}\text { flutuações } \\
\text { de curto } \\
\text { prazo }\end{array}$ & & \\
\hline \multirow[t]{2}{*}{1978} & \multirow[t]{2}{*}{$\begin{array}{c}\text { livro 'The Museum } \\
\text { Environment' }\end{array}$} & $\begin{array}{c}19 \text { (inverno) até } \\
24 \text { (verão) }\end{array}$ & 50 ou 55 & - & \pm 5 & $\begin{array}{l}\text { Classe } 1 \text { - adequada para os } \\
\text { principais museus nacionais, } \\
\text { antigos ou modernos, e } \\
\text { também para os principais } \\
\text { edifícios novos para museus }\end{array}$ & \multirow[b]{2}{*}{$\begin{array}{c}\text { THOMPSON, } \\
1986\end{array}$} \\
\hline & & $\begin{array}{c}\text { suficientemente } \\
\text { constante para } \\
\text { estabilizar a UR }\end{array}$ & \multicolumn{3}{|c|}{$40-70$} & $\begin{array}{l}\text { Classe } 2 \text { - pensada para evitar } \\
\text { os danos mais significativos e } \\
\text { também reduzir custos e } \\
\text { modificações ao mínimo. Por } \\
\text { exemplo, casas-museu e igrejas } \\
\text { devem seguir as } \\
\text { recomendações desta classe }\end{array}$ & \\
\hline 1979 & $\mathrm{CCl}$ & $\begin{array}{c}21 \text { (variação } \\
\text { sazonal permitida } \\
\text { entre } 20 \text { e } 25 \text { ) }\end{array}$ & $47-53$ & $38-55$ & \pm 2 & $\begin{array}{l}\text { A variação sazonal permitida no } \\
\text { setpoint é de } 1^{\circ} \mathrm{C} \text { e } 5 \% \text { UR ao } \\
\text { mês. Variações ocasionais de } \pm \\
5 \% \text { UR são toleráveis, desde } \\
\text { que excepcionais }\end{array}$ & $\begin{array}{l}\text { LAFONTAINE, } \\
1979\end{array}$ \\
\hline 1994 & National Trust & $5-22$ & 58 & $\begin{array}{r}50-65 \\
\text { ala }\end{array}$ & $\begin{array}{l}\text { (nível de } \\
\text { me 1) }\end{array}$ & $\begin{array}{l}\text { A estratégia recomendada } \\
\text { pressupõe controle da UR o } \\
\text { mais constante possível, } \\
\text { principalmente mediante } \\
\text { ajustes na taxa de aquecimento }\end{array}$ & $\begin{array}{l}\text { STANIFORTH } \\
\text { et al., } 1994\end{array}$ \\
\hline
\end{tabular}


Quadro 05. Seleção de normas e recomendações internacionais para Te UR entre 1978 e 2010 (continuação)

\begin{tabular}{|c|c|c|c|c|c|c|c|}
\hline \multirow[b]{2}{*}{ Ano } & \multirow{2}{*}{$\begin{array}{l}\text { Entidade } \\
\text { responsável } \\
\text { pela norma }\end{array}$} & \multirow[b]{2}{*}{$\begin{array}{c}\text { Temperatura } \\
{\left[{ }^{\circ} \mathrm{C}\right]}\end{array}$} & \multicolumn{3}{|c|}{ UR [\%] } & \multirow[b]{2}{*}{ Notas } & \multirow[b]{2}{*}{ Referências } \\
\hline & & & $\begin{array}{l}\text { média } \\
\text { de longo } \\
\text { prazo }\end{array}$ & $\begin{array}{c}\text { ciclo } \\
\text { sazonal }\end{array}$ & $\begin{array}{l}\text { flutuações } \\
\text { de curto } \\
\text { prazo }\end{array}$ & & \\
\hline \multirow[t]{6}{*}{1999} & \multirow{6}{*}{$\begin{array}{l}\text { American Society } \\
\text { of Heating, } \\
\text { Refrigerating, and } \\
\text { Air-Conditioning } \\
\text { Engineers Inc. } \\
\text { (ASHRAE) }\end{array}$} & \multirow{6}{*}{$15-25$} & \multirow{3}{*}{$\begin{array}{l}50 \text { ou } \\
\text { média } \\
\text { histórica } \\
\text { anual }\end{array}$} & não & \pm 5 & $\begin{array}{l}\text { Classe de controle AA - Sem } \\
\text { risco de dano mecânico para a } \\
\text { maioria dos artefatos e pinturas }\end{array}$ & \multirow{6}{*}{$\begin{array}{l}\text { ASHRAE, } \\
2007\end{array}$} \\
\hline & & & & não & \pm 10 & & \\
\hline & & & & $\begin{array}{l}+10 \text { no } \\
\text { verão } \\
-10 \text { no } \\
\text { inverno }\end{array}$ & \pm 5 & $\begin{array}{l}\text { Classe de controle A - Pequeno } \\
\text { risco de dano mecânico para } \\
\text { artefatos muito vulneráveis }\end{array}$ & \\
\hline & & & \multirow{3}{*}{$\begin{array}{l}50 \text { ou } \\
\text { média } \\
\text { histórica } \\
\text { anual }\end{array}$} & $\begin{array}{l}+10 \text { no } \\
\text { verão } \\
-10 \text { no } \\
\text { inverno }\end{array}$ & \pm 10 & $\begin{array}{l}\text { Classe de controle B - Risco } \\
\text { moderado de dano mecânico } \\
\text { para artefatos muito } \\
\text { vulneráveis }\end{array}$ & \\
\hline & & & & \multicolumn{2}{|c|}{$25-75$} & $\begin{array}{l}\text { Classe de controle C - Risco } \\
\text { elevado de dano mecânico para } \\
\text { artefatos muito vulneráveis }\end{array}$ & \\
\hline & & & & \multicolumn{2}{|c|}{ abaixo de 75} & $\begin{array}{l}\text { Classe de controle D - Risco } \\
\text { elevado de dano mecânico } \\
\text { súbito ou cumulativo para a } \\
\text { maioria dos artefatos e pinturas } \\
\text { por trincas devido à baixa } \\
\text { umidade }\end{array}$ & \\
\hline 2006 & National Trust & $5-22$ & $50-65$ & - & - & $\begin{array}{l}0 \text { setpoint anterior fixado em } \\
58 \% \text { UR foi substituído por um } \\
\text { intervalo alvo. } 0 \text { setpoint de UR } \\
\text { deve ser ajustado para cada } \\
\text { ambiente e depende das } \\
\text { condições às quais o acervo } \\
\text { está aclimatado }\end{array}$ & $\begin{array}{l}\text { STANIFORTH, } \\
2006\end{array}$ \\
\hline 2007 & $\begin{array}{l}\text { Smithsonian } \\
\text { Institution }\end{array}$ & 21 & 45 & - & \pm 8 & - & $\begin{array}{l}\text { ERHARDT et } \\
\text { al., } 2007\end{array}$ \\
\hline 2009 & $\begin{array}{l}\text { National Museum } \\
\text { Directors' } \\
\text { Conference UK }\end{array}$ & $16-25$ & & $40-60$ & & $\begin{array}{l}\text { Especificações para a maioria } \\
\text { dos objetos com material } \\
\text { higroscópico. Algumas } \\
\text { excessões listadas, como } \\
\text { materiais muito sensíveis que } \\
\text { requerem controle de UR } \\
\text { específico e preciso }\end{array}$ & NMDC, 2009 \\
\hline
\end{tabular}

(continua) 
Quadro 05. Seleção de normas e recomendações internacionais para Te UR entre 1978 e 2010 (continuação)

\begin{tabular}{|c|c|c|c|c|c|c|c|}
\hline \multirow[b]{2}{*}{ Ano } & \multirow{2}{*}{$\begin{array}{l}\text { Entidade } \\
\text { responsável } \\
\text { pela norma }\end{array}$} & \multirow[b]{2}{*}{$\begin{array}{c}\text { Temperatura } \\
{\left[{ }^{\circ} \mathrm{C}\right]}\end{array}$} & \multicolumn{3}{|c|}{ UR [\%] } & \multirow[b]{2}{*}{ Notas } & \multirow[b]{2}{*}{ Referências } \\
\hline & & & $\begin{array}{c}\text { média } \\
\text { de longo } \\
\text { prazo }\end{array}$ & $\begin{array}{c}\text { ciclo } \\
\text { sazonal }\end{array}$ & $\begin{array}{c}\text { flutuações } \\
\text { de curto } \\
\text { prazo }\end{array}$ & & \\
\hline 2010 & $\begin{array}{c}\text { European } \\
\text { standard EN } \\
15757: 2010\end{array}$ & sem especificação & $\begin{array}{c}\text { média } \\
\text { histórica } \\
\text { anual }\end{array}$ & $\begin{array}{c}\text { ciclo } \\
\text { histórico } \\
\text { sazonal* }\end{array}$ & $\begin{array}{c} \pm 10 \\
\text { ou intervalo } \\
\text { pretendido, } \\
\text { calculado a } \\
\text { partir do } \\
\text { histórico } \\
\text { climático ** } \\
\text { (o que for } \\
\text { maior) }\end{array}$ & $\begin{array}{l}\text { * Este ciclo é obtido calculando- } \\
\text { se, para cada UR medida, a } \\
\text { média móvel centrada, que é a } \\
\text { média das URs medidas nos } 15 \\
\text { dias anteriores e posteriores à } \\
\text { data para a qual a média está } \\
\text { sendo calculada. } \\
\text { ** Os limites superiores e } \\
\text { inferiores do intervalo } \\
\text { pretendido de flutuação da UR } \\
\text { são, respectivamente, o } 7^{\circ} \text { e } 0 \\
93^{\circ} \text { percentil das flutuações } \\
\text { medidas para o período } \\
\text { monitorado. A flutuação é } \\
\text { calculada para a média móvel } \\
\text { centrada, ou seja, para o ciclo } \\
\text { sazonal e não para a média } \\
\text { anual. }\end{array}$ & $\begin{array}{c}\text { EN } \\
15757: 2010\end{array}$ \\
\hline
\end{tabular}

Fonte: traduzido e adaptado de BRATASZ, 2013.

Em 2010, durante o evento Rethinking the Museum Climate, foi proposto que o grupo de trabalho, conhecido como Boston Roundtable, re-examinasse as demandas energéticas dos ambientes internos de áreas com acervos em resposta a um crescente movimento por uma gestão mais eficiente da qualidade do ambiente interno, que ficou conhecido como 'museus verdes'20 (BRATASZ, 2013). No mesmo ano, a AIC (American Institute for Conservation) e a IIC (International Institute for Conservation) organizaram uma mesa-redonda que ficou conhecida como "The Plus/Minus Dilemma: The Way Forward in Environmental Guidelines"21. A conclusão do encontro foi que, ao longo das quatro décadas anteriores, os parâmetros ambientais propostos para acervos eram excessivamente rígidos e estavam demasiadamente associados a um controle fino de T e UR por meio de sistemas ativos de condicionamento de ar, o que podia ser explicado pelo baixo custo da energia elétrica na época, a

\footnotetext{
20 Green Museums. Propunha-se reduzir o consumo de energia e a pegada de carbono sem reduzir ou até mesmo aumentando o padrão de excelência na conservação do acervo.

21 "O Dilema do Mais ou Menos: o Caminho a se Seguir nas Diretrizes Ambientais"; tradução da pesquisadora. A discussão pode ser assistida em: https://www.youtube.com/watch?v=QCLxQIZcTmE, acesso em nov. 2020.
} 
ausência de preocupações com mudanças climáticas e o desenvolvimento de tecnologias focadas mais na capacidade de controle do equipamento do que na eficiência do sistema (IIC, 2020)22.

A conclusão dos dois encontros foi que, para a maioria dos materiais:

a. a UR recomendada deve permanecer entre 45 e 55\%, com flutuação máxima de $\pm 5 \%$, ou seja, para o período de um ano, a UR mínima recomendada é de $40 \%$ e a máxima, de $60 \%$;

b. a T recomendada deve estar dentro do intervalo de 15 a $25^{\circ} \mathrm{C}$, com a menor flutuação possível;

c. alguns materiais precisam receber atenção individualizada;

d. as condições ambientais para empréstimo de itens devem sempre ser decididas em conjunto com os conservadores.

A partir destas conclusões, o grupo de trabalho do AIC e IIC decidiu se unir ao CCI (Canadian Conservation Institute) e à comunidade européia para, em conjunto, propor alterações à norma ASHRAE. Os parâmetros para controle climático foram discutidos e ratificados em um encontro internacional em 2012 (AIC, 2020)23.

Em setembro de 2014, duas conferencias internacionais, uma do ICOM-CC (International Council of Museums-Committee for Conservation), em Melbourne, e outra do IIC, em Hong Kong, se dispuseram a discutir os parâmetros ambientais para conservação do patrimônio cultural e, ao final, concordaram com a seguinte declaração:

\section{Sustentabilidade e gestão:}

- a questão da sustentabilidade em museus é muito mais ampla do que a discussão sobre normas ambientais e precisa ser entendido como um critério-chave para princípios futuros;

- museus e instituições com acervos precisam minimizar a pegada de carbono e 0 impacto ambiental como forma de mitigar a mudança climática e, para isso, devem reduzir 0 consumo de energia e explorar fontes alternativas renováveis;

- a preservação das coleções deve ser alcançada por meios que não pressuponham 0 condicionamento do ar (AVAC). Sempre considerar a possibilidade de se usar métodos passivos, tecnologias cuja manutenção seja simples, circulação de ar e outras soluções com baixo consumo energético;

- a gestão de riscos deve ser incorporada aos processos de gestão institucional.

\footnotetext{
22 Para maiores informações, ver: https://www.iiconservation.org/archives/dialogues/plus-minus

${ }^{23}$ Para maiores informações, ver: https://www.conservation-wiki.com/wiki/Environmental_Guidelines
} 
Ambiente:

- é de amplo conhecimento que os requisitos ambientais para acervos e materiais são uma questão complexa; os conservadores e cientistas da conservação devem ativamente procurar esclarecer e desvendar essas complexidades;

- os requisitos para os fatores ambientais de guarda e exposição permanente devem poder ser alcançados com o clima local. (...)

Diretrizes atuais:

- as diretrizes provisórias acordadas entre AIC, AICCM, grupo Bizot etc. precisam se tornar diretrizes permanentes, e não provisórias. Entende-se que são parâmetros para empréstimos para exposições internacionais. (ICOM/IIC, 2014; tradução da pesquisadora.)

Além dos resultados destas conferências, o grupo Bizot (The International Group of Organizers of Major Exhibitions - Groupe Bizot) também havia proposto diretrizes provisórias para materiais higroscópicos (Bizot Interim Guidelines for Hygroscopic Materials, 2014):

a. temperatura (T) estável, com valor dentro do intervalo de 16 a $25^{\circ} \mathrm{C}$;

b. umidade relativa (UR) estável, com valor dentro do intervalo de 40 a 60\%, e flutuações menores que $\pm 10 \%$ em 24 horas, desde que dentro do intervalo;

c. objetos mais sensíveis precisam de um controle de UR específico e rigoroso, a depender do material, das condições de conservação e da história do item. Uma avaliação técnica de um conservador é fundamental para definir as condições ambientais adequadas e os requisitos para empréstimo;

d. requisitos específicos de T e UR para coleções frágeis ou sensíveis devem ser especificadas por um especialista;

e. para os itens que demandam um controle específico e mais rigoroso, isto pode ser alcançado com o uso de microclimas específicos;

f. os demais requisitos ambientais como níveis de iluminação e fluxo de ar devem ser especificados por um conservador especialista (ICOM-CC, 2020)24.

A Australian Institute for Conservation of Cultural Material (AICCM) tem buscado parâmetros de temperatura e umidade relativa que sejam seguros para a maior parte dos materiais e, simultaneamente, mais flexíveis, para que possam ser alcançados por um número maior de instituições culturais. Assim, eles recomendam, como diretrizes provisórias para a guarda e a exibição (AICCM, 2020):

\footnotetext{
${ }^{24}$ Maiores informações em: http://www.icom-cc.org/332/-icom-cc-documents/declaration-on-environmental-guidelines/\#.X6v5gi_5TMI
} 
a. temperatura entre 15 e $25^{\circ} \mathrm{C}$, com flutuação máxima de $\pm 4^{\circ} \mathrm{C}$ em 24 horas;

b. umidade relativa entre 45 e 55\%, com flutuação máxima de \pm 5\% em 24 horas;

c. em edifícios não isolados termicamente, com flutuação sazonal, umidade relativa entre 40 e 60\%, com variação a mais lenta possível para evitar fadiga nos materiais.

Deve-se salientar que os parâmetros ambientais preconizados pelos organismos internacionais foram estabelecidos a partir da coleta de dados e da observação das condições de conservação de acervos ao longo de muitos anos, em variadas instituições, em países desenvolvidos localizados em regiões de clima temperado; países em desenvolvimento, localizados em regiões tropicais ou equatoriais não possuem informação consolidada nem parâmetros de desempenho adaptados às necessidades do seu patrimônio (ATKINSON, 2014). Portanto, instituiç̧ões localizadas nestas regiões do globo devem interpretar as recomendações disponíveis com cautela, sempre que possível a partir de um profundo conhecimento das suas condições e características específicas (Figura 15).

Figura 15. Comparação entre as diretrizes de Te UR de: AICCM, HCC (Heritage Collections Council), Grupo

\section{Bizot e ASHRAE}

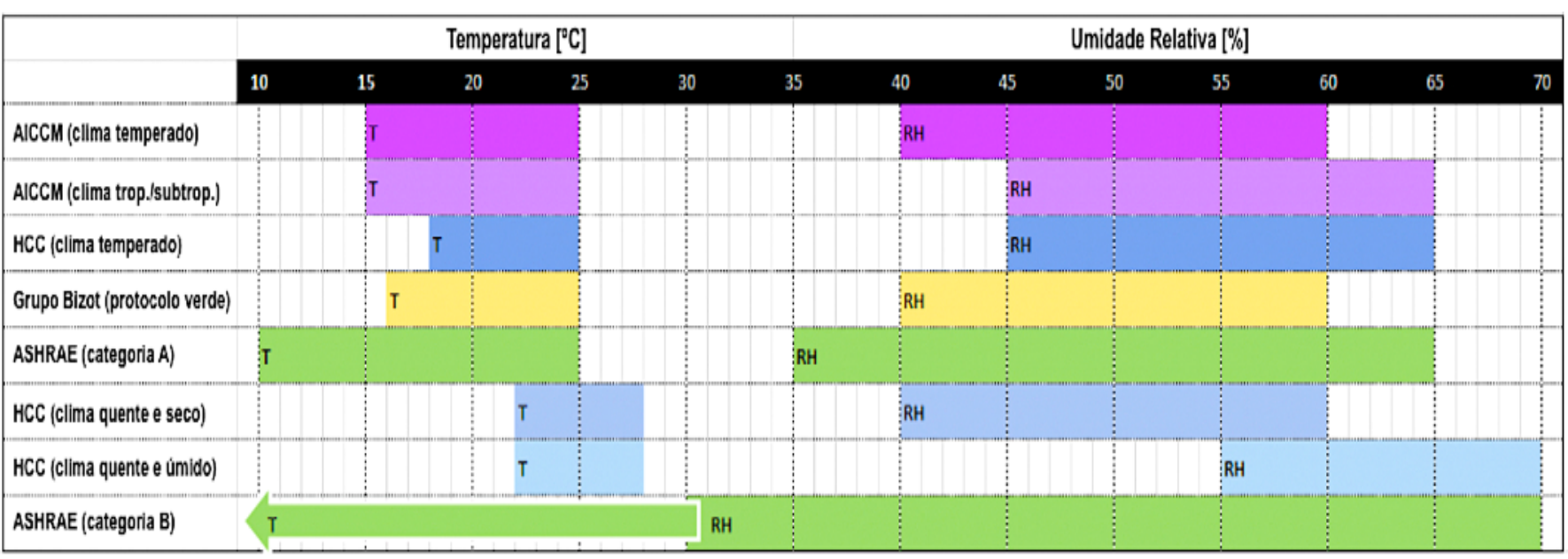

Fonte: traduzido de AICCM, 2020.

Com o início do século XXI e de demandas mais prementes orientadas à sustentabilidade e, consequentemente, à eficiência energética, ampliou-se a necessidade de se lidar com decisões difíceis e complexas. Por isso, existe crescente demanda por estudos que correlacionem as condições específicas de uma instituição (clima e entorno, características construtivas, características do acervo) com as classes ASHRAE e o consumo energético (MICHALSKI, 2007; KRAMER et al., 2016). 
0 programa da União Europeia 'Climate for Culture: damage risk assessment, economic impact and mitigation strategies for sustainable preservation of cultural heritage in times of climate change,'25 desenvolvido entre 2009 e 2014 tinha por objetivo simular a resposta de modelos construtivos de edifícios históricos a cenários de evolução das mudanças climáticas (conforme projeções do IPCC26 até 2100), no continente europeu e norte da África, para identificar, com elevada confiabilidade, os possíveis riscos de danos para cada condição específica, bem como os impactos econômicos associados. 0 programa financiou 74 estudos de caso (castelos, igrejas, monastérios, museus, monumentos, palácios e residências), distribuídos por 20 países e quatro zonas climáticas distintas, e concluiu que:

a. a simulação dos processos de sorção ${ }^{27}$ de umidade pelas camadas de materiais que compõem um objeto, a uma determinada temperatura, pode auxiliar na compreensão das deformações elásticas e, portanto, na definição de intervalos mais ou menos restritivos de umidade relativa para uma coleção específica.

b. objetos formados por materiais higroscópicos devem seguir a norma BS/EN 15757:2010 Conservation of cultural property. Specifications for temperature and relative humidity to limit climateinduced mechanical damage in organic hygroscopic materials, que aconselha a prévia aclimatação dos objetos às flutuações sazonais de T e UR de um edifício histórico. Para estes edifícios, recomenda-se sistemas de umidificação e desumidificação com setpoint variável, ajustados pela média móvel, conforme a estação do ano.

c. a avaliação dos riscos para crescimento de mofo deve seguir o modelo preditivo proposto por Krus et al. (2007), que especifica uma LIM (Lowest Isopleth for Mould / Menor Isopleta para Mofo) de projeto, conforme o material de construção utilizado (Figura 16).

\footnotetext{
25 Clima para a Cultura: avaliação de risco de dano, impacto econômico e estratégias de mitigação para uma preservação sustentável do patrimônio cultural em tempos de mudança climática. 0 projeto completo pode ser visto em: https://www.climateforculture.eu.

26 Intergovernmental Panel on Climate Change / Painel Intergovernamental para Mudanças Climáticas

27 Processos de absorção e adsorção de água capazes de causar degradação hidrolítica do material.
} 
Figura 16. Diagramas com as isopletas ${ }^{28}$ de Te UR para formação de mofo ${ }^{29}$ em substrato 0 (meio de cultura ótimo); substrato I (papel de parede, gesso, papelão, matérias-primas biodegradáveis, materiais com juntas permanentemente elásticas); substrato II (rebocos, materiais minerais, algumas madeiras, isolantes não pertencentes a I); e substrato K (fungos reconhecidos pela literatura como perigosos para a saúde humana).

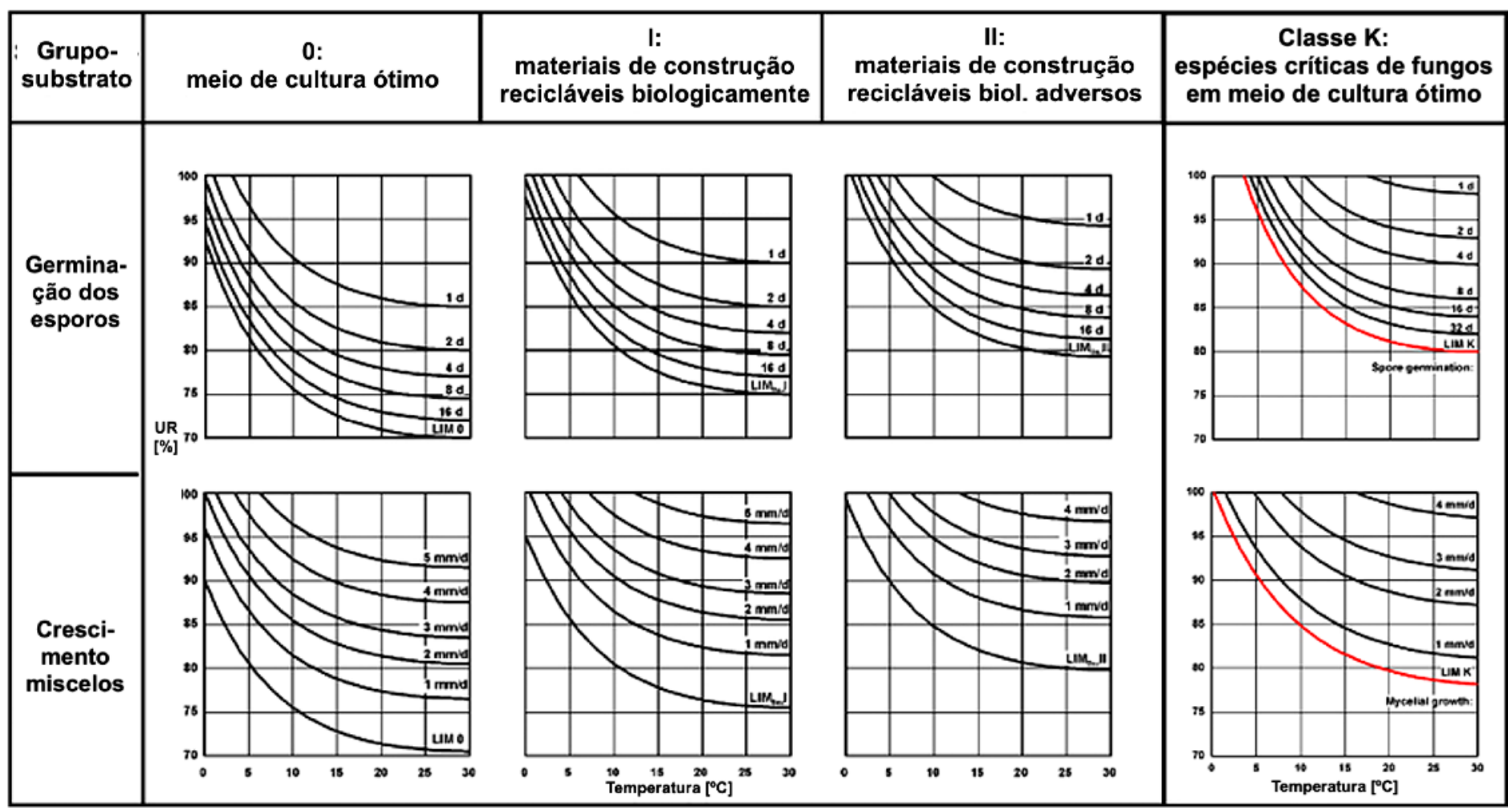

Fonte: traduzido de KRUS et al., 2007.

Uma das principais questões atualmente, quando se pensa em preservação do patrimônio é: como compatibilizar duas condições aparentemente opostas, preservar o máximo possível, assegurando a melhor qualidade ambiental e, simultaneamente, consumindo o mínimo possível de energia? Na tentativa de responder a este dilema o IPI (Image Permanence Institute) publicou, em 2012, o "IPI's Guide to Sustainable Preservation Practices for Managing Storage Environments" com sugestões práticas de como as instituições culturais podem agir para assegurar áreas de guarda sustentáveis e com qualidade ambiental. Estas sugestões têm o mérito de serem relevantes para uma ampla gama de condições climáticas, construtivas e de acervos.

${ }^{28}$ Curva de uma função que contém duas variáveis com valores constantes.

290 estudo considerou mais de 150 espécies de fungos encontrados na Alemanha. 
A abordagem considera três princípios fundamentais:

a. as condições ambientais podem sofrer variações sazonais. Valores fixos de T e UR não se mostraram adequados. Uma gestão ambiental flexível e holística demonstrou ser mais bem sucedida;

b. uma gestão dos sistemas mecânicos que se baseia apenas em manutenções corretivas não leva em conta que a diminuição da eficiência do sistema pelo desgaste do equipamento (operação sub-ótima) reduz a qualidade ambiental e aumenta os custos de operação;

c. a gestão estratégica da qualidade ambiental e dos riscos deve considerar simultaneamente a gestão das facilidades, dos espaços físicos e dos itens do acervo.

As soluções para a preservação sustentável do patrimônio serão sempre individuais mas alguns fatores precisam ser considerados em quaisquer análise:

- a região geográfica, o entorno e as características climáticas locais;

- as características construtivas do edifício;

- as necessidades específicas de cada coleção;

- as características dos sistemas ativos existentes;

- o grau de especialização dos profissionais envolvidos na conservação dos acervos e na gestão das facilidades.

A implementação de melhorias deve estar fundamentada na compreensão de que mudanças institucionais não podem ser feitas aleatoriamente, mas devem seguir um passo-a-passo que se inicia com a documentação dos riscos e dos dados ambientais; segue para a análise dos dados coletados e a proposição de soluções; avança para a experimentação de procedimentos e avaliação dos resultados; e finaliza com a adoção de novos protocolos para monitoramento e manutenção das áreas de guarda. Este procedimento é cíclico e deve ser repetido sempre que for necessário.

0 IPI (2012) recomenda também seis atividades de gestão que podem ser adaptadas a quaisquer instituição cultural:

1. documentar as características de desempenho dos sistemas de condicionamento ambiental;

2. definir, em conjunto, quais as melhores características ambientais para os acervos;

3. definir, em conjunto, quais as melhores características ambientais para os usuários;

4. definir, em conjunto, e a partir das informações de 1 a 3, qual 0 ambiente 'ideal' para 0 armazenamento de cada tipo de objeto;

5. definir as métricas que serão usadas para medir os ambientes; 
6. medir regularmente os ambientes 'reais' e comparar os resultados com os índices definidos como 'ideais' e, se necessário, fazer ajustes aos ambientes.

Por fim, o IPI salienta que, apesar de ser comum uma resistência inicial a trabalhos colaborativos e em equipe, frequentemente entendidos como "mais reuniões e tarefas", uma vez superada esta dificuldade inicial, a implantação de atividades regulares de gestão orientadas à preservação sustentável têm demonstrado resultar em uma otimização do tempo e das tarefas, maior eficiência no uso dos sistemas ativos, maior qualidade ambiental interna e, muitas vezes, considerável economia de energia. É comum também a percepção de melhorias na qualidade do ambiente de trabalho, com melhor comunicação entre todos os setores, maior organização na execução das tarefas e distribuição mais adequada das responsabilidades entre os membros das equipes. Um passo inicial importante é a instituição escolher, para líder das equipes, pessoas que tenham perfil para organizar reuniões, incentivar a participação de todos e estimular propostas. Os líderes também precisam ser pessoas interessadas nas atividades e nas dificuldades dos outros setores para que as soluções sejam holísticas e não segmentadas (IPI, 2012).

Tendo-se como pressuposto o consenso do ICOM/IIC de 2014 de priorizar as estratégias passivas em detrimento do condicionamento do ar por sistemas ativos, uma vez que esta abordagem traz menor impacto energético, menor dependência de manutenções caras e complexas e maior previsibilidade ambiental para os acervos, deve-se considerar também que as instituições culturais abrigadas em edifícios históricos, na maioria das vezes, já possuem características construtivas em consonância com estas estratégias. Uma equipe técnica especializada, formada por arquitetos, engenheiros e conservadores, de posse de um histórico de medições climáticas, deve avaliar as condições específicas de cada ambiente. É importante destacar que as soluções precisam ser desenhadas caso a caso, e devem levar em conta as características construtivas do edifício e os materiais que compõem os acervos. Na gestão da qualidade sustentável dos ambientes para guarda ou exposição de acervos é importante considerar (ULAS et al., 2014):

a. materiais: os materiais de construção podem influenciar positiva ou negativamente na qualidade e na estabilidade ambiental interna. Alguns materiais liberam gases perigosos, como os VOCs, outros favorecem a proliferação de microorganismos; alguns têm propriedades de isolamento térmico, outros são bons condutores de calor; alguns são impermeáveis e agem como barreira à passagem do vapor d'água, outros, ao contrário, precisam permitir a passagem de vapor para não se deteriorarem. É 
importante compreender e respeitar as necessidades próprias dos materiais existentes; cuidar para que novos materiais não sejam incompatíveis com os antigos nem com os itens dos acervos; e comprálos localmente, reciclar e reutilizar, sempre que possível.

b. ventilação: 0 ar externo nem sempre está na temperatura e umidade adequadas, além de transportar poluentes e microorganismos. A ventilação natural demanda a compreensão de quando abrir e fechar os caixilhos, respeitando-se as vazões mínimas previstas em norma. É recomendável que 0 ar externo seja filtrado para minimizar a entrada de partículas indesejadas. 0 uso de ventiladores estrategicamente posicionados pode ajudar na dissipação de bolsões de ar estagnado e impedir a formação de microclimas incorretos. Os equipamentos de AVAC devem tratar 0 ar externo por meio de sistemas de filtragem apropriados, e não apenas recircular 0 ar interno, evitando, assim, a proliferação de microorganismos patogênicos.

c. sistemas ativos: uma vez esgotadas todas as possibilidades de estratégias passivas para condicionamento ambiental, pode-se constatar a necessidade de complementação com equipamentos mecânicos. Se a equipe de especialistas concluir que este é o caso, é importante refletir sobre algumas questões específicas:

- quais ambientes ou zonas efetivamente precisam de sistemas ativos de condicionamento?

- se o edifício é histórico, os materiais e sistemas construtivos resistirão às novas condições climáticas?

- qual o período (do ano, do mês e do dia) de real necessidade de utilização do equipamento?

- quais os recursos financeiros disponíveis para a manutenção dos sistemas ativos?

- qual a facilidade de manutenção, no que tange a equipes especializadas e peças de reposição?

Além disso, é muito importante que seja feito o esforço para manter os sistemas ativos o mais simples possível. A experiência têm demonstrado que sistemas complexos, automatizados ou robotizados são de manutenção difícil e cara e, quando quebram, não permitem flexibilidade de opções para a mitigação do problema.

d. resfriamento e desumidificação: equipamentos centrais para condicionamento do ar, que utilizem água gelada para resfriamento tendem a resultar em valores de T e UR mais estáveis, desde que o sistema seja corretamente dimensionado, tanto para a carga de pico como para todas as faixas de operação determinadas. Os sistemas devem ser desenhados e especificados para manter T e UR estáveis antes de assegurar o conforto humano, e isto é mais facilmente alcançado fixando-se e controlando-se a 
temperatura de ponto de orvalho (o que também assegura mudanças mais lentas e graduais, adequadas para os objetos). Sempre que possível, a desumidificação deve fazer parte do sistema de AVAC (desumidificação dessecante e/ou serpentinas de água gelada), em detrimento a equipamentos separados, portáteis, os quais devem ser utilizados apenas como solução temporária ou esporádica.

Os desumidificadores portáteis devem ter seus drenos conectados a uma rede de drenagem que conduza toda a água para fora das áreas de guarda ou de exposição; a água armazenada no equipamento é um grande risco para os acervos.

Importante ressaltar que tanto edifícios históricos como contemporâneos que não utilizam estratégias para isolamento do meio externo (isolantes térmicos e/ou elevada inércia térmica, barreiras ao vapor, barreiras às pontes térmicas e caixilhos de alta eficiência) provavelmente não possuem as condições necessárias para o funcionamento ótimo de sistemas ativos de resfriamento e desumidificação, o que pode resultar em elevado consumo energético, grandes flutuações de T e UR, danos aos materiais e sistemas construtivos e danos a objetos do acervo. Este aspecto deve ser cuidadosamente considerado pelos especialistas quando da especificação de sistemas ativos.

Em edifícios sem controle climático, é importante entender a influência da inércia térmica e da inércia ao vapor das envolventes externas. No entanto, muitas vezes, as instituições possuem um grande histórico de dados de T e UR dos ambientes internos mas não possuem dados do clima externo, o que inviabiliza a avaliação do desempenho das envolventes na qualidade ambiental (PADFIELD e LARSEN, 2004).

e. aquecimento: em climas tropicais e subtropicais dificilmente há necessidade de sistemas ativos para aquecimento. No entanto, caso a análise das condições locais demonstrem a relevância de uso destes sistemas, deve-se preferir equipamentos que utilizam água quente pois eles garantem maior estabilidade nos valores de T e UR e uma taxa de mudança mais lenta e constante. 0 uso de pisos e paredes radiantes, por meio de passagem de dutos de água quente, vêm sendo adotado como estratégia energeticamente eficiente e sustentável para garantir temperaturas estáveis em áreas de guarda e de exposição, no entanto, é preciso assegurar elevada robustez e confiabilidade do sistema para minimizar os riscos aos acervos.

6. umidificação: os sistemas de umidificação ultrassônica são os mais eficientes, seguidos dos de geração de vapor por eletrodos. Deve-se evitar os sistemas de umidificação por spray pois a prática 
demonstra que eles são ineficientes, além de perigosos porque podem espalhar microorganismos patogênicos (como a legionela).

7. manutenção: os sistemas ativos e passivos devem ser desenhados e especificados prevendo-se um funcionamento contínuo e constante, sendo assim, é importante que sejam considerados e especificados os requisitos, os protocolos e a frequência das manutenções preventivas como parte de um plano para a gestão das facilidades.

\subsubsection{Taxa de degradação de materiais orgânicos}

O IPI (Image Permanence Institute) desenvolveu um método para avaliação da eficiência de uma área de guarda na preservação de seus objetos. Ele consiste no cálculo de um índice, denominado Índice de Preservação (PI - Preservation Index) ou Índice de Preservação Ponderado no Tempo (TWPI - Time Weighted Preservation Index), que procura traduzir o efeito de T e UR na taxa de degradação de materiais orgânicos. Inicialmente, o IPI avaliou o comportamento do acetato de celulose (filmes e negativos fotográficos) em ambientes variados e, a partir de uma análise quantitativa dos dados, deduziu a fórmula matemática que correlaciona a agressividade do ambiente com a taxa de decomposição do material. Esta fórmula foi reduzida a um único valor para cada condição ambiental específica (PI), ajustado para cada tipo de material. Em ambientes que sofrem influência do clima externo (T e UR variável), este índice (Tabela 03) foi ponderado para um valor médio (TWPI) ao longo do tempo (NISHIMURA, 2011).

A expectativa de vida (PI ou TWPI) é dada em anos. Isso foi feito para que houvesse um maior impacto psicológico: uma previsão de preservação de, por exemplo, 30 anos parece mais 'real' do que uma taxa de deterioração de 3\% ao ano (PADFIELD, 2004). 0 IPI também desenvolveu um kit contendo dataloggers para medição de T e UR e um software que calcula o PI e o TWPI a partir do banco de dados climáticos.

Tabela 03. TWPI e o efeito do ambiente nas reações químicas espontâneas ou envelhecimento natural

\begin{tabular}{c|l}
\hline Valor de TWPI (anos) & \multicolumn{1}{c}{ Interpretação } \\
\hline $1-45$ & ambiente pobre; rápido envelhecimento \\
\hline $45-75$ & ambiente regular \\
\hline $75-100$ & ambiente bom \\
\hline$>100$ & ambiente excelente \\
\hline
\end{tabular}

Fonte: traduzido e adaptado de NISHIMURA, 2011. 
Para Padfield (2004), o cálculo de PI/TWPI proposto pelo IPI é controverso porque, ao invés de utilizar as já conhecidas e comprovadas equações de ação das massas e de Arrhenius30, eles utilizam um cálculo empírico baseado na taxa de degradação observada para o acetato de celulose e depois ajustada para outros materiais orgânicos. Na opinião de Padfield, não há porque utilizar o método proposto pelo IPI uma vez que já existe um modelo matemático que pode ser aplicado a qualquer reação química conhecida. Além disso, a interpolação do valor empírico do acetato para outras matérias orgânicas carece de validade e precisão, e pode levar a instituição a tomar decisões incorretas. No caso do TWPI, segundo Padfield (2004), o valor ponderado só tem validade se o cálculo for feito para um período de tempo de múltiplos de um ano completo. Se, inadvertidamente, for utilizado, por exemplo, um intervalo de tempo que contenha dois verões e um inverno, a taxa de deterioração parecerá maior e vice-versa, na situação oposta.

0 autor também acredita que apresentar a taxa de preservação dos objetos em anos não expressa corretamente a cinética das reações químicas, fenômeno muito complexo e que depende das características fisico-químicas de cada material, e da estabilidade (ou não) das condições ambientais ao longo do tempo. Por fim, ele critica o IPI por ter desenvolvido uma metodologia 'própria', cuja finalidade parece ser apenas a de vender um sistema de hardware e software de domínio privado, "se esforçando para comercializar um conceito simples como uma ferramenta de gestão complicada e cara" (PADFIELD, 2004; tradução da pesquisadora).

Padfield (2004) argumenta que, apesar de ser relativamente fácil calcular a vida útil de projeto de um material, é muito difícil prever efetivamente quanto tempo um objeto vai durar. Assim, ele propõe, como alternativa à metodologia do IPI, que seja identificada a taxa de reação dos materiais e se deixe a cargo do conservador avaliar qual o nível de degradação a partir do qual o uso do objeto ficaria inviável. Para tanto, ele propõe o uso de 'isoburns' (linhas de mesma taxa de degradação), que são curvas que correlacionam T e UR para uma mesma taxa de hidrólise, considerando-se uma energia de ativação constante de $100 \mathrm{~kJ} / \mathrm{mol}$ (Figura 17). Para ambientes condicionados, a combinação de uma temperatura de ponto de orvalho baixa e uma taxa de degradação baixa é recomendada.

\footnotetext{
${ }^{30}$ A lei de ação das massas é um modelo matemático que descreve a velocidade de uma reação química (cinética da reação) como sendo proporcional à concentração dos reagentes. A equação de Arrhenius permite encontrar a constante de velocidade ou a energia de ativação de uma dada reação química para uma temperatura específica.
} 
Figura 17. Linhas de igual taxa de degradação ou 'Isoburns', com a linha de ponto de orvalho de $4^{\circ} \mathrm{C}$ sobreposta

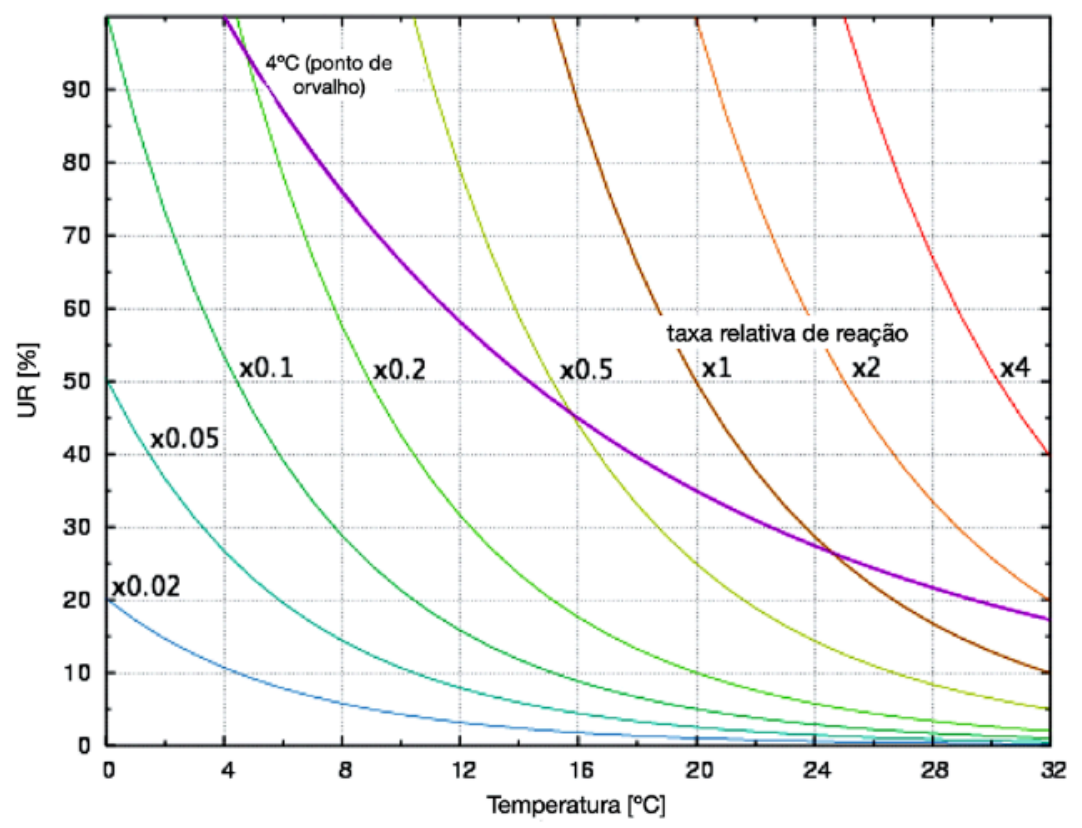

Fonte: traduzido de PADFIELD, 2004.

0 valor de $4^{\circ} \mathrm{C}$ de ponto de orvalho foi utilizado como referência por ser ele o menor possível para arcondicionados tradicionais refrigerados a água. Qualquer combinação de T e UR ao longo da linha lilás tem uma temperatura de ponto de orvalho de $4^{\circ} \mathrm{C}$. Portanto, tomando-se esta linha como referência, nota-se que as combinações de T mais baixas e UR mais altas resultam em uma menor taxa relativa de reação de degradação por hidrólise, isso porque uma umidade absoluta constante e baixa (cerca de 6,2 $\mathrm{g} / \mathrm{m}^{3}$ ) e uma temperatura baixa reduzem a velocidade da reação (por exemplo, $\mathrm{T}=10^{\circ} \mathrm{C}$ e UR $=66 \%$, taxa relativa de reação de $0,3 \%$ ). Esta análise demonstra o perigo de se avaliar a qualidade ambiental apenas a partir dos dados de T e UR. A temperatura de ponto de orvalho e, portanto, a umidade absoluta são informações fundamentais em uma avaliação do risco de degradação de acervos. Para edifícios históricos não condicionados, a temperatura de ponto de orvalho varia conforme o clima externo, o que torna esta análise bastante complexa.

0 teor de umidade é o parâmetro mais importante para a preservação de materiais higroscópicos (como os papéis), no entanto, mensurar a quantidade de água presente dentro do material não é tarefa simples e, por esta razão, costuma-se utilizar a UR como parâmetro de referência. No entanto, o teor de umidade não é função apenas da UR, mas também da T e da pressão atmosférica ${ }^{31}$. É muito

\footnotetext{
${ }^{31}$ A pressão atmosférica pode ser considerada constante para uma dada localidade mas ela varia com a altitude e, portanto, precisa ser levada em conta quando um item é transportado de uma cidade ou região para outra.
} 
importante que uma redução na T seja acompanhada de uma redução na UR (recomenda-se redução de 3 a 4\% de UR para cada diminuição de $10^{\circ} \mathrm{C}$ de T), de modo que a quantidade de vapor d'água presente no ar se mantenha equilibrada (MCCORMICK-GO0DHART, 1996).

Os intervalos recomendados para T e UR têm dois objetivos principais: 0 armazenamento seguro e 0 uso seguro dos objetos. Por seguro, deve-se entender a segurança física e química dos materiais que compõem os acervos (MCCORMICK-GOODHART, 1996). Objetos suportam algum grau de deformação plástica ao longo dos ciclos de variação sazonais, a depender do grau de fragilidade dos materiais. Porém, em uma escala microscópica, a deformação plástica também pode resultar em microdegradações que, com o passar do tempo, podem causar rachaduras e delaminações 32 .

0 limite de elasticidade é o valor de máxima mudança dimensional (expansão ou contração) que um objeto pode suportar, a partir do qual esta mudança se torna permanente. A pesquisa de McCormickGoodhart (1996) para uma ampla gama de materiais orgânicos demonstrou que, adotando-se um valor conservador de alongamento máximo aceitável de 0,4\%, é possível estimar, com elevada confiabilidade, os intervalos seguros de T e UR para o material. A pesquisa mostrou que os maiores danos são observados quando o objeto é impedido de se movimentar em alguma direção (movimentação uniaxial), seja porque ele está contido por uma estrutura auxiliar, seja porque ele está interligado a outro material ou objeto com coeficiente de dilatação diferente. As tensões resultantes de movimentações desiguais entre materiais se provou tão danosa quanto o manuseio incorreto do objeto. 0 pesquisador também concluiu que, apesar dos materiais antigos, como resultado do processo de enrijecimento natural, se tornarem mais frágeis ao manuseio, eles costumam ser tanto ou mais elásticos que os materiais novos e podem suportar variações sazonais ou diárias de Te UR, desde que dentro do intervalo de segurança e, portanto, não precisam, necessariamente, ser armazenados em condições diferentes daquelas adequadas para seus correspondentes novos.

32 Delaminação é o processo de separação entre as camadas, ou lâminas, que compõem o material. 


\subsubsection{O papel e o livro}

0 papel é um suporte muito comum em coleções museológicas, bibliográficas e arquivísticas. Ele é entendido como uma fina lâmina composta por materiais orgânicos (polímeros), de origem vegetal (papiro, papéis de trapo, papéis ácidos, neutros ou alcalinos) ou animal (pergaminho, velino, couro), que recebe aditivos de modo a permitir a escrita (ou impressão). Como todo composto orgânico, é bastante sensivel às flutuações climáticas (de temperatura, umidade e radiação) e propenso a degradações por processos mecânicos, químicos e biológicos.

A palavra 'papel' tem sua origem no latim papyrus, a partir do grego papurus, em referência à fibra da planta Cyperus papyrus, utilizada no Egito, pelo menos desde 2.500 a.E.C., na fabricação de longas lâminas delgadas. Antes da invenção do papiro, grupos humanos já faziam uso de uma grande variedade de materiais como suporte para a escrita, incluindo pedras, argila, tijolos, cascas, madeiras, linho, cera, metal, marfim, ossos, couros, dentre outros (REED, 1972).

No século II a.E.C., para evitar que a Biblioteca de Alexandria fosse superada em quantidade de textos pela biblioteca de Pérgamo, o rei do Egito, Ptolomeu IV, proibiu a exportação do papiro, provocando uma grande escassez deste material. Eumenes II, rei de Pérgamo, exigiu, segundo a versão mais famosa desta lenda, que seus sábios descobrissem um substituto para o papiro. Como eles eram criadores de ovinos, desenvolveram um método para tratar a pele animal de modo a permitir a escrita. Inventaram ou, segundo alguns teóricos, aprimoraram, o pergaminho, material que se mostrou mais resistente e durável que o papiro.

Tanto o papiro como o pergaminho tinham os seus pedaços colados para formar rolos, que são longas faixas de material enroladas em torno de uma haste e escritas em colunas, em apenas uma das faces. Para ser lido, o rolo precisa ser segurado com as duas mãos, o que dificulta a consulta a mais de um trecho simultaneamente ou a anotação junto ao texto.

No Império Romano, durante o primeiro século da Era Comum, para facilitar o manuseio de textos jurídicos, decidiu-se dobrar o pergaminho em quatro ou oito partes, formando assim um caderno, que era chamado de volumen. Algumas vezes esses cadernos eram agrupados (costurados) para facilitar a organização por assunto, e este conjunto recebeu o nome de codex (códice).

Segundo Chartier (1998), o formato de rolo facilitava leituras contínuas, em voz alta, já a estrutura em páginas do códice permitia outras práticas, dentre elas a leitura silenciosa. 0 códice medieval era 
confeccionado manualmente no scriptorium, onde trabalhavam profissionais altamente especializados na reprodução do texto escrito ou na elaboração de ilustrações e iluminuras. Os manuscritos monásticos foram produzidos exclusivamente nos mosteiros desde a queda do Império Romano no Ocidente até o século XII, e continuaram a ser feitos, sem exclusividade, dos séculos XIII ao XVI. Já os manuscritos laicos foram fabricados em oficinas de copistas e iluminadores especializados desde 0 surgimento das universidades, no século XIII, até a invenção da prensa (FEBVRE e MARTIN, 2017).

0 pergaminho foi praticamente o único suporte utilizado no Ocidente para a produção de manuscritos, sendo substituído, paulatinamente, pelo papel quando do surgimento da imprensa, no século XV.

0 papel, provavelmente, foi inventado na China. 0 primeiro registro do uso deste material é de 105 E.C.. 0 oficial chinês T'sai Lun desenvolveu um papel feito a partir da mistura de casca de amoreira, bambu, redes de pesca (cânhamo), e qualquer outra fibra vegetal disponível, batidas com água para formar uma pasta, que era então peneirada para criar uma fina película uniforme e exposta ao sol para secar.

Em 751 E.C., os árabes venceram os chineses na Batalha de Talas, no entreposto comercial de Samarcanda, o que Ihes permitiu quebrar o monopólio chinês da fabricação do papel. Samarcanda passou a ser conhecida como sinônimo de papel de alta qualidade, feito a partir de fibras de linho. Este conhecimento foi aos poucos sendo difundido por todo o império mouro e chegou à Península Ibérica no século XI (Figura 18).

Figura 18. A rota do papel do Oriente ao Ocidente

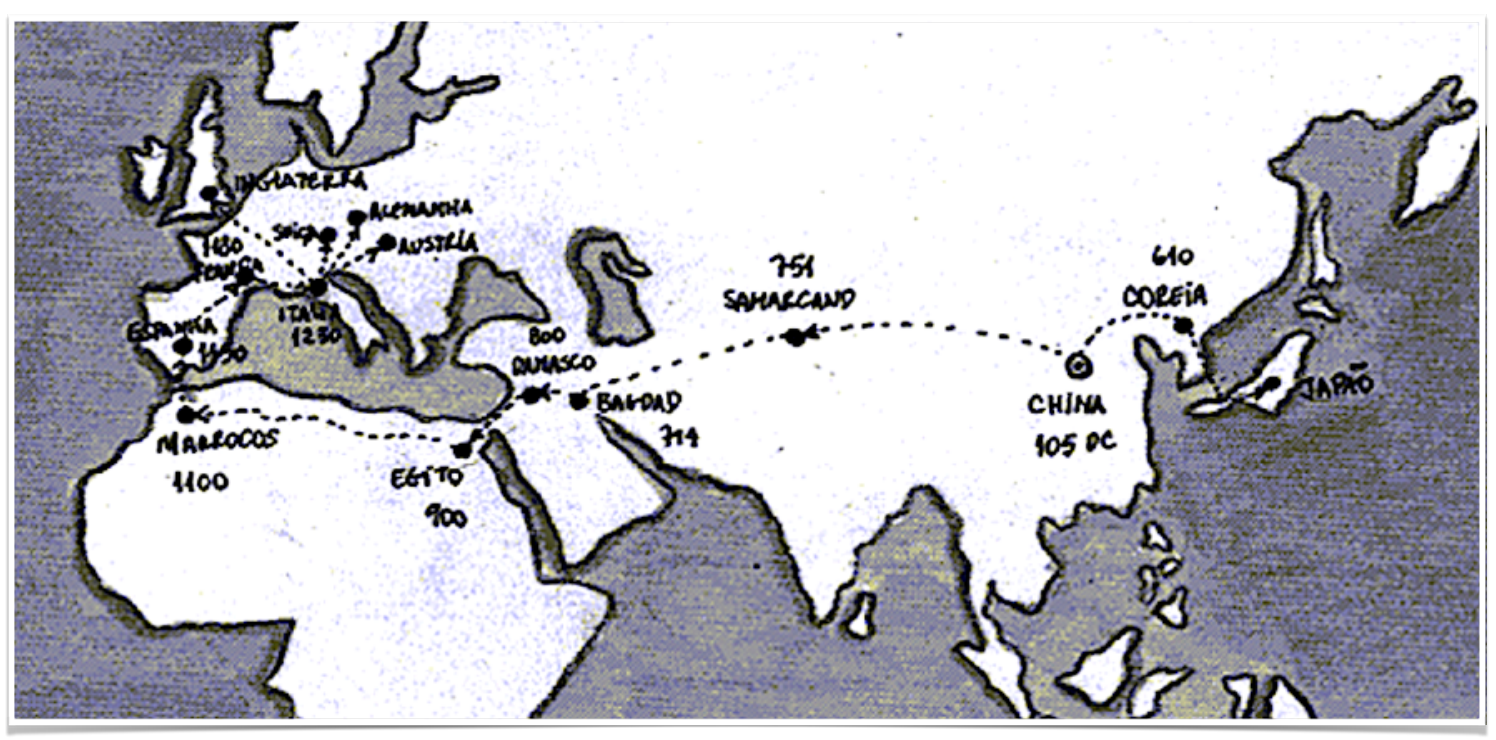

Fonte: CABRALES, 2019. 
Entre os séculos XIII e XV o papel coexistiu com o pergaminho. Os primeiros papéis eram, por um lado, frágeis, rugosos e com maior porosidade à tinta (pior para ornamentação com pigmentos), por outro lado, mais leves e manejáveis. Por terem menor resistência e rasgarem com facilidade, foram, inicialmente, usados apenas para rascunhos e mensagens que deveriam ser rapidamente descartadas. O surgimento de universidades por toda a Europa e, consequentemente, das suas bibliotecas (Bologna em 1089, Oxford em 1096, Paris em 1150, Palência em 1208 e Coimbra em 1290) e de uma burguesia que demandava por obras 'de distração', associada à recém criada indústria tipográfica, fez do papel o suporte mais adequado às novas necessidades, uma vez que o pergaminho não podia ser produzido em larga escala (FEBVRE e MARTIN, 2017).

Além disso, o papel foi sendo aprimorado ao longo do século XIV. 0 uso do trapo de pano de roupa (de cânhamo e linho), barato e abundante, deu ao papel maior qualidade e menor custo, e a substituição das colas vegetais usadas pelos chineses pelas colas e gelatinas animais deram ao papel um aspecto acetinado. A invenção da impressão com tipos móveis possivelmente ocorreu na China por volta de 1045 E.C., mas utilizava blocos de madeira, pouco duráveis para a produção em larga escala. A prensa com tipos metálicos também não foi uma invenção europeia; ela muito provavelmente ocorreu na Coreia, por volta de 1230. No entanto, Gutenberg, ao longo das décadas de 1430 a 1450, parece ter combinado os elementos certos para que a invenção se disseminasse: blocos metálicos muito precisos, que resultavam em textos com grande qualidade visual; prensa com rosca, que dava velocidade ao processo de impressão; e tintas à base de óleo de linhaça e preto de fumo, que não borravam o papel. Além disso, havia um ambiente propício ao consumo de material impresso: o renascimento, a reforma protestante e a demanda por textos 'populares', nas recém criadas línguas nacionais (SPALDING, 2011).

0 primeiro livro impresso, produzido por volta de 1455, é conhecido como a Bíblia de Gutenberg ou Bíblia de 42 linhas (ou B42). É um incunábulo, ou seja, um livro impresso cujos tipos imitavam as características dos manuscritos, contendo também, muitas vezes, ilustrações e iluminuras. A maior parte dos exemplares remanescentes (36) são feitos de papel de trapo de excelente qualidade, mas existem também 12 cópias feitas em velino.

A Biblioteca Nacional do Rio de Janeiro possui uma cópia da Bíblia de Mogúncia, incunábulo impresso em 1462 por Johann Fust e Peter Schoffer, ex-sócios de Gutenberg. 
Com a crescente demanda por livros, no início do século XVII, a indústria papeleira passou por uma grave crise causada pela escassez de matéria-prima. Na França, por exemplo, ela foi tão séria que se proibiu a exportação de 'velhos panos'.

A escassez de matéria-prima forçou a indústria a buscar novas tecnologias. Em 1719, Réaumur demonstrou que era possível fabricar papel a partir de fibras de madeira. Ao longo do século XVIII foram feitas diversas experiências com muitas espécies: palmeiras, espartos, aloés, urtigas, amoreiras, alteias, etc.. Em 1844 Keller decidiu misturar trapos à pasta mecânica de madeira que vinha sendo aprimorada, solução esta que foi amplamente usada ao longo de todo o século XIX. A partir de 1860 começou-se a utilizar também a palha para a fabricação de papel-jornal. A matéria-prima continuamente em falta fez com que a qualidade do papel decaísse ano após ano, suscitando muitas queixas quanto à má qualidade dos papéis (FEBVRE e MARTIN, 2017).

0 século XIX, pós Revolução Industrial, é marcado pelo aparecimento da produção literária de massa, em larga escala, dos mais variados gêneros, em múltiplos meios. Surgem jornais com publicações diárias. 0 The Times foi o primeiro, fundado em Londres em 1785 (SPALDING, 2011).

Para Chartier (1998) é possível identificar três grandes revoluções na história do livro: a primeira é a passagem do formato de rolo para o de códice; a segunda é a passagem do manuscrito para o livro impresso; por fim, a terceira é a passagem do livro em papel para o texto digital. Estas três revoluções têm em comum a completa transformação, tanto da base de registro da escrita como dos hábitos de leitura.

A percepção de que a cópia do material impresso para o meio digital poderia ser usada como instrumento para preservação e disponibilização de acesso de antigas obras em papel surgiu em 1971 quando Michael Hart criou o Projeto Gutenberg, na Universidade de Illinois. Em 1998 surgiram os primeiros 'livros eletrônicos' (os e-books).

Por enquanto, a demanda por papel continua alta, o que resulta em uma sempre crescente necessidade de se obter mais folhas com menor custo. A durabilidade do papel é uma questão que permanece em segundo plano. Se, por um lado, árvores folhosas como o pinus e o eucalipto são uma fonte abundante de celulose (a matéria-prima para fabricação do papel), por outro lado, dada a constituição física da árvore, a celulose está entremeada por outras substâncias, o que exige processos físico-químicos bastante agressivos para a sua extração, e são, eles mesmos, a causa da instabilidade do papel (CASSARES e TANAKA, 2008). 


\subsubsection{Características fisico-químicas do papel}

0 princípio da fabricação do papel é a tendência natural das fibras celulósicas de se unirem e assim permanecerem após secas. As etapas para se fabricar papel são: 1. extração da celulose da planta ou da madeira; 2. polpação da celulose por energia mecânica, térmica e/ou química; 3. lavagem; 4. branqueamento (se for o caso); 5. refino da pasta; 6. adição de cargas e de colagem interna; 7. formação das folhas; 8. secagem e colagem superficial; 9. acabamento (Figura 19).

Figura 19. Etapas da fabricação artesanal do papel
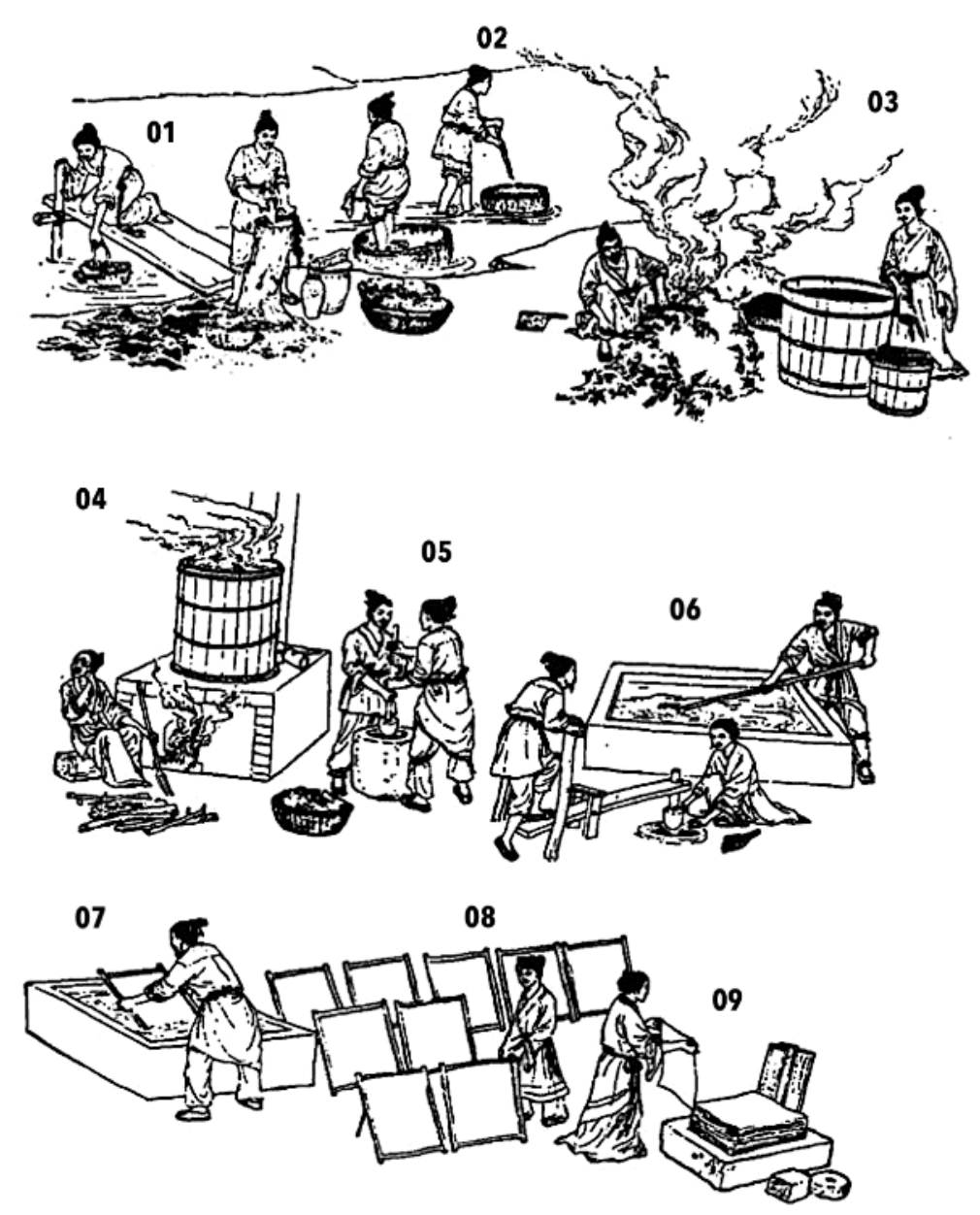

Fonte: GLOGSTER, 2015.

Atualmente, $90 \%$ de todo papel fabricado para impressão e escrita utiliza pasta de fibras derivadas de madeira (eucalipto e pinus), principalmente a pasta kraft (para papel para imprimir e escrever) e a pasta mecânica de alto rendimento (para papel jornal) (AREA e CHERADAME, 2011). 
Os principais processos para a fabricação da pasta celulósica de madeira são (Figura 20):

1. processo mecânico: desenvolvido em 1847 na Alemanha, por Friedrich Keller, e na Nova Escócia, por Charles Fenerty, utiliza apenas energia mecânica com pouca ou nenhuma adição de substâncias químicas. Para a fabricação da polpa celulósica, cavacos de madeira são prensados entre discos de pedra (tradicional) ou de aço (moderno) que giram para provocar o desfibramento da madeira, resultando em uma massa conhecida como pasta mecânica de alto rendimento. Neste processo a lignina 33 não é removida e o papel resultante amarelece com o passar do tempo (reversão da alvura);

2. processo químico: cavacos de madeira são combinados a substâncias químicas em um digestor e submetidos a elevada temperatura e pressão para separar a lignina e a hemicelulose da celulose. Os produtos da hidrólise da lignina e das hemiceluloses, assim como os extratíveis, permanecem em solução, formando o que é denominado licor negro. Esse processo pode ocorrer em dois meios, alcalino (soda e kraft) ou ácido (sulfito), dependendo da técnica utilizada:

- pasta química soda: processo desenvolvido na Inglaterra em 1852 por Charles Watt e Hugh Burgess, combina a madeira com o reagente $\mathrm{NaOH}$ (soda) durante o cozimento para remover a lignina e individualizar as fibras;

- pasta sulfito ou bissulfito (deu origem ao nome ainda hoje, erroneamente, utilizado de 'papel sulfite'): processo desenvolvido nos Estados Unidos em 1867 por Benjamin Tilghman, em que se cozinha os cavacos de madeira com $\mathrm{SO}_{2}$ mais as bases $\mathrm{Mg}(\mathrm{OH})_{2}$, $\mathrm{Ca}(\mathrm{OH})_{2}$ e/ou $\mathrm{NH}_{4}(\mathrm{OH})$ a uma pressão entre 6,1 e $7,5 \mathrm{~atm}$ e temperatura de 125 a $160^{\circ} \mathrm{C}$ por um período de 6 a 12 horas para remover a lignina. A polpa obtida por esse processo foi muito utilizada, entre o final do século XIX e os anos 1980, na produção de papéis brancos. Atualmente cerca de 10\% da celulose produzida no mundo ainda é celulose sulfito (KLOCK et al., 2013);

- pasta kraft ou sulfato: processo desenvolvido na Alemanha em 1883 por Karl Dahl, combina $\mathrm{NaOH}$ e $\mathrm{Na}_{2} \mathrm{~S}$ aos cavacos de madeira durante o cozimento, sob uma pressão de 6,8 a 9,2 atm e temperatura de 170 a $177^{\circ} \mathrm{C}$, por 2 a 5 horas, para se obter a polpa de celulose. É o processo mais utilizado atualmente na fabricação da pasta de celulose.

\footnotetext{
${ }^{33} \mathrm{~A}$ fibra vegetal de madeiras é uma estrutura lignocelulósica composta por parede celular e lúmen. A parede celular contém lignina, celulose e hemicelulose. Também compõem a fibra outras substâncias como sais minerais (principalmente $\mathrm{Ca}, \mathrm{K}, \mathrm{Mg}$ ) e extrativos (resinas, ceras, gorduras, açúcares e/ou taninos). A celulose é um homopolissacarídeo não-ramificado constituído unicamente por moléculas de glicose unidas entre si por ligações glicosídicas. A hemicelulose é um heteropolissacarídeo formado por vários açúcares ligados entre si principalmente por ligações glicosídicas. A lignina é um polímero aromático composto por diferentes monômeros de fenilpropano, cuja função é fornecer rigidez à planta.
} 
Figura 20. Tipos de pasta de celulose (\%) produzidos no Brasil, em 2015

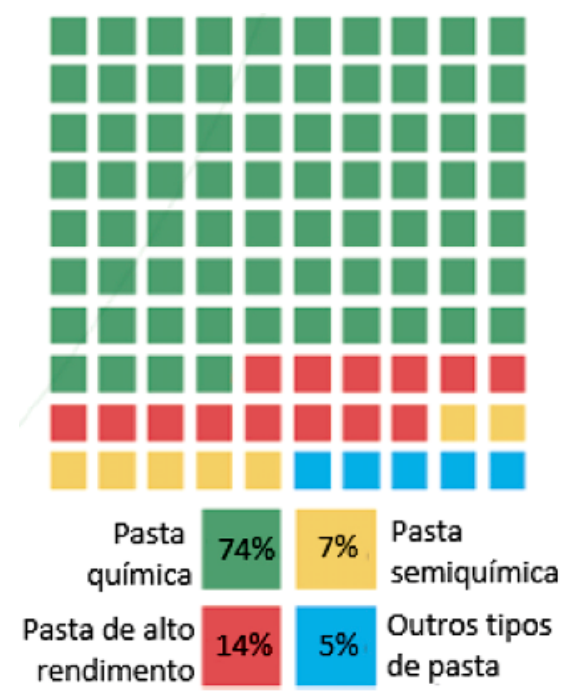

Fonte: GEDF-CD/FIEP (2016) a partir dos dados da FAO (2016); apud: EPE, 2018.

As fibras de madeira mais utilizadas atualmente na fabricação de papel são de três tipos (Quadro 06):

1. celulose de fibra curta: extraída do eucalipto, por ter boa capacidade absorvente é adequada para papéis tissue, de imprimir e escrever, e especiais;

2. celulose de fibra longa: proveniente do pinus, é combinada à celulose de fibra curta para garantir resistência, maciez e opacidade aos papéis tissue, de imprimir e escrever, especiais e de embalagem; 3. celulose de fibra longa tipo fluff: também retirada do pinus, passa por processamento especial para maior e mais rápida capacidade de absorção. É usada na fabricação de fraldas e absorventes.

Quadro 06. Características da fibra de Pinus e de Eucalipto

\begin{tabular}{l|c|c} 
Nome: & Pinus sp. - Pinaceae & Eucalyptus sp. - Myrtaceae \\
\hline Espécies mais usadas: & P. elliottii e P. taeda & E. grandis, E. saligna, E. urophylla \\
\hline Fibra: & longa & curta \\
\hline Comprimento médio da fibra: & $3,34 \mathrm{~mm}$ & $1 \mathrm{~mm}$ \\
\hline Largura média da fibra: & $46,75 \mu \mathrm{m}$ & $20 \mu \mathrm{m}$ \\
\hline Idade da árvore para corte: & 15 a 20 anos & 3 a 7 anos
\end{tabular}

Fonte: adaptado de UFPR, 2018. 
Na fabricação de papéis também podem ser utilizadas fibras de plantas que não formam madeira, no entanto, atualmente, elas constituem apenas $5 \%$ do total de fibras utilizadas.

As características da fibra influenciam na resistência do papel:

a. o maior comprimento das fibras produz uma maior resistência intrínseca e uma maior quantidade de ligações interfibras, o que aumenta a resistência à tração e ao arrebentamento;

b. a espessura da parede e o grau de polimerização da celulose também aumentam a resistência ao rasgo.

\subsubsection{Degradação da celulose}

Existem duas maneiras principais de se degradar a cadeia celulósica: quimicamente e enzimaticamente.

\section{A. Degradação química}

As alterações químicas que podem ocorrer ao longo da vida útil de um papel envolvem processos complexos, com multi-parâmetros, que estão diretamente relacionados à morfologia da fibra de celulose (presença de regiões amorfas e cristalinas) e ao pH do papel (ácido ou alcalino). Umidade, temperatura, radiação e poluição são os fatores que iniciam mecanismos de degradação por hidrólise e oxidação ácida ou por ligações cruzadas (AREA e CHERADAME, 2011).

Os grupos hidroxilas ${ }^{34}$ do monômero ${ }^{35}$ de glicose 36 podem formar ligações de hidrogênio, o que contribui para a rigidez e a resistência da estrutura fibrilar da celulose e são a causa da sua afinidade pela água. As hidroxilas também determinam a reatividade da celulose. Estas reações levam à introdução de novas funções químicas na molécula de celulose, e podem alterar suas propriedades físico-químicas. Os produtos de tais reações são chamados 'derivados de celulose' (Figura 21). As reações de derivatização37 mais comuns são: esterificação, eterificação, oxidaç̧ão, grafitização por copolimerização e ligações cruzadas.

\footnotetext{
${ }^{34}$ Radical $\mathrm{OH}^{-}$

35 Os meros são as unidades básicas que se repetem em um polímero. Monômero é uma molécula formada por um mero, os quais, por reações de polimerização, formam polímeros (macromoléculas).

${ }^{36}$ Carboidrato não polimerizado (monossacarídeo). Fórmula molecular $\mathrm{C}_{6} \mathrm{H}_{12} \mathrm{O}_{6}$.

37 Reações que transformam uma substância química em outra de estrutura semelhante (derivado).
} 
Figura 21. Modificações químicas da celulose

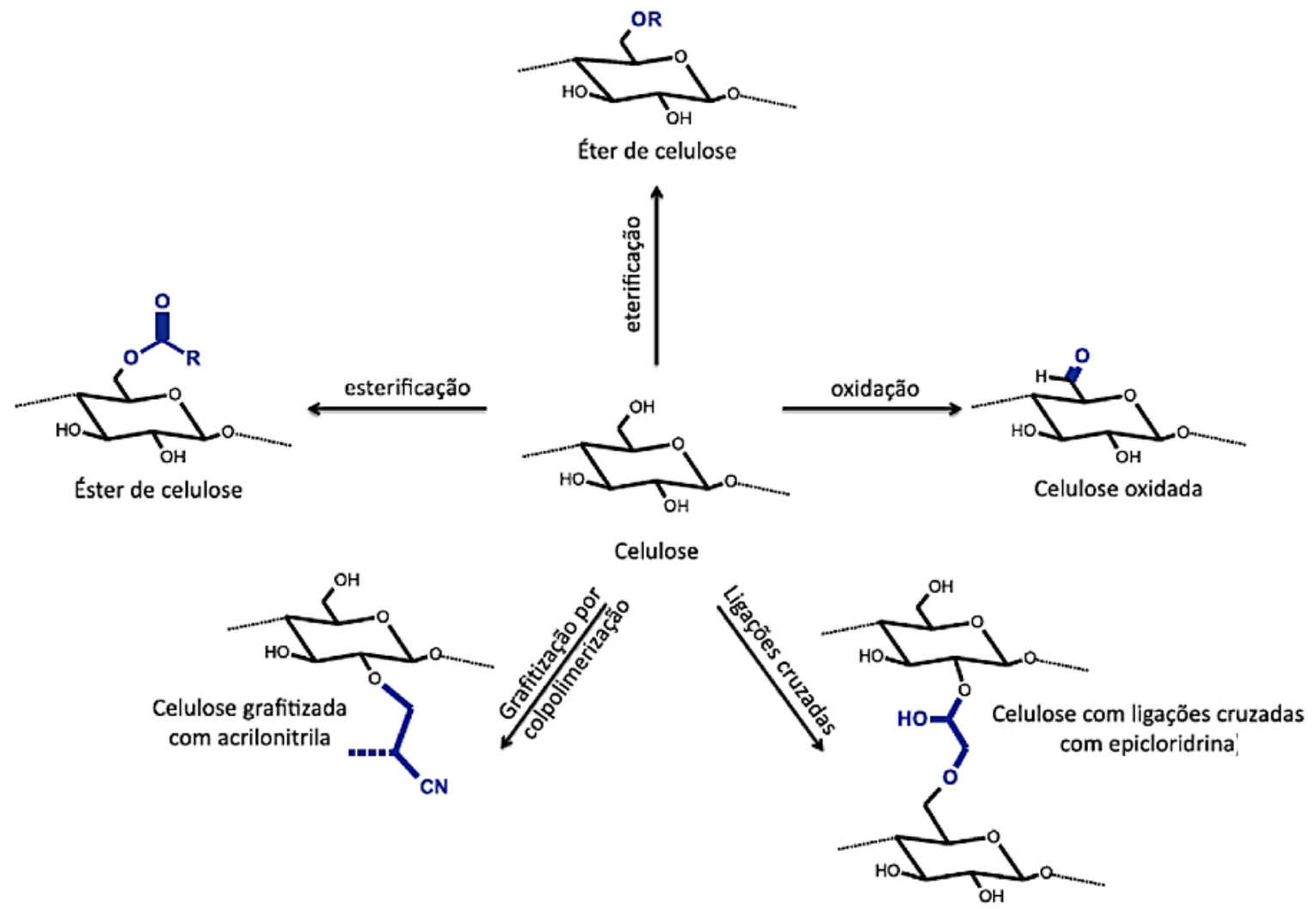

Fonte: CELULOSEONLINE, 2016.

A hidrólise é uma reação de decomposição ou alteração de uma substância em meio aquoso. No papel, a ação da água resulta em uma redução no grau de polimerização da cadeia de celulose pelo rompimento de ligações de hidrogênio em regiões amorfas e na consequente perda de resistência física (Figura 22). A hidrólise catalisada por ácidos da própria cadeia de celulose encurta o comprimento das fibras, sendo a mais importante reação química no processo de envelhecimento do papel (CARTER, 1996). A hidrólise ácida também aumenta a cristalinidade da fibra, processo responsável pela diminuição da flexibilidade do papel.

Figura 22. Representação esquemática da hidrólise progressiva de macromoléculas de celulose (linhas contínuas) em uma estrutura porosa e aberta (linhas tracejadas)
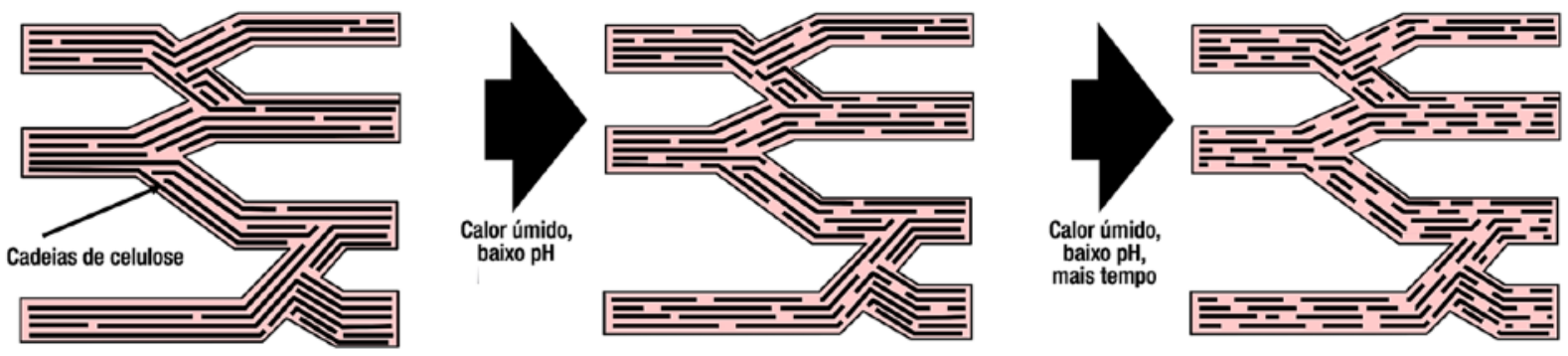

Fonte: HUBBE, 2010. 
A oxidação é uma reação que altera a cadeia celulósica introduzindo grupos laterais aldeídos e cetonas, o que torna a molécula mais facilmente hidrolisável. Os danos oxidativos levam a amarelecimento, escurecimento e fragilização do papel (HOLIK, 2006).

Um meio ácido ou alcalino combinado à ação da temperatura ou da radiação UV pode catalisar reações de oxidação. A auto-oxidação da celulose ocorre por reação das fibras com radicais livres (formados em outros processos de oxidação da celulose) ou dentro da fibra por ligações cruzadas $^{38}$ nos grupos cetona, aldeído e hidroxila, resultando em ácidos fórmico, acético, láctico e oxálico. Processos oxidativos também podem estar relacionados aos agentes químicos utilizados para branqueamento da pasta de madeira.

A oxidação pelo oxigênio atmosférico ou foto oxidação depende da presença de luz (principalmente de radiação UV) e temperatura elevada, e é favorecida por catalisadores como íons metálicos ( $\mathrm{Cu}^{+2}$ ou Fe+3) ou gases poluentes $\left(\mathrm{O}_{3}, \mathrm{SO}_{2}\right.$ e $\mathrm{NO}_{x}$ ). Esta é a principal forma de oxidação da celulose (AREA e CHERADAME, 2011).

A foto oxidação da lignina, encontrada principalmente na pasta mecânica de alto rendimento, favorece a formação de grupos cromóforos (responsáveis pelo amarelecimento do papel) que possuem 'afinidade' pela luz, ou seja, quando o papel é exposto à luz, esses grupos se formam a taxas cada vez mais elevadas. Os grupos cromóforos também participam na hidrólise ácida da celulose.

A foto oxidação da fibra de celulose parece estar relacionada a um aumento de ligações cruzadas nas cadeias celulósicas, principalmente pela ação energética da radiação UV, o que leva a um aumento da cristalinidade das fibras, reduzindo a flexibilidade do papel, tornando-o frágil e quebradiço. A ligação cruzada (crosslinking) é a principal rota de modificação do esqueleto da celulose (KLEMM et al., 1998). Nesse tipo de reação ocorre a formação de ligações covalentes ${ }^{39}$ entre duas cadeias poliméricas de celulose (Figura 23). Tais ligações são mais fortes que as de hidrogênio, presentes na cadeia de celulose não modificada. Alguns estudo têm buscado meios para reverter os processos de cristalização das fibras, porém, sem sucesso. Análises por Difração de Raio X demonstraram que os tratamentos

\footnotetext{
38 Cadeias poliméricas lineares ou ramificadas podem se unir por meio de ligações covalentes (crosslinking), resultando em cadeias tridimensionais, maiores e mais rígidas.

39 Tipo de ligação química entre átomos não metálicos em que ocorre o compartillhamento dos elétrons.
} 
restaurativos atuais para branqueamento e desacidificação do papel não influenciaram na cristalinidade e, portanto, não reduziram a fragilidade do papel (CARTER, 1996).

Figura 23. Modelo esquemático das alterações propostas em fibras de pasta kraft. As áreas sombreadas indicam a formação de ligações covalentes no material celulósico.
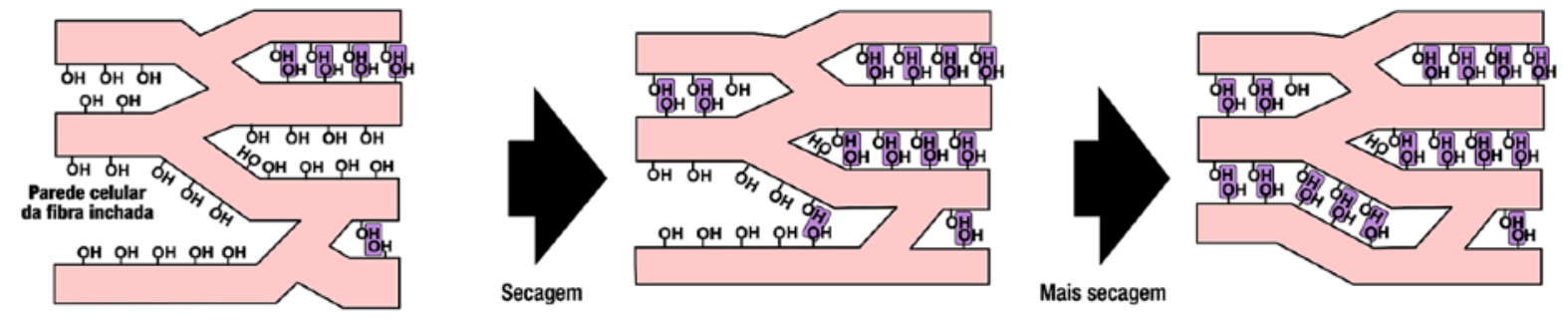

Fonte: HUBBE, 2010.

\section{B. Degradação bioquímica}

0 processo enzimático utilizado por fungos e bactérias para hidrolisar a celulose envolve um conjunto de enzimas chamadas celulases. Pesquisas indicam que as celulases desempenham diferentes funções cooperativamente na hidrólise da celulose: algumas clivam 40 a cadeia de celulose em fragmentos contendo 4 a 5 glicoses, algumas degradam esses fragmentos em unidades menores de duas glicoses (chamadas celobiose), e outras, finalmente, transformam as celobioses em glicose simples. No entanto, pesquisas sobre a hidrólise enzimática ainda estão em estágios iniciais e muitos mecanismos deste processo seguem sem resposta (JIN, 2010).

\subsubsection{Degradação do papel}

0 envelhecimento do papel pode ser:

a. natural: com o passar do tempo a celulose se torna mais cristalina e rígida, deixando o papel descolorido e quebradiço.

b. acelerado: ambientes com elevada temperatura e umidade relativa, bem como a exposição à radiação luminosa (luz visível e UV) e a poluentes podem iniciar reações de degradação. Estas reações, dependendo das condições e da duração de exposição, podem produzir compostos químicos diferentes daqueles encontrados no envelhecimento natural (REYDEN, 1992).

40 Quebram a cadeia polimérica. 
Uma das maneiras de se medir a qualidade do papel é pelo comprimento das fibras de celulose: quanto mais longas, mais duráveis, resistentes e flexíveis elas são. Um papel com fibras curtas pode ser consequência da fonte (celulose de eucalipto) ou de processos de degradação (Library of Congress, 2016). Existem duas forças de ligação que mantém a integridade da fibra de celulose: a força de ligação interna à fibra e a força de ligação entre fibras. Os mecanismos de deterioração estão associados ao encurtamento das fibras pelo decréscimo das forças de ligação entre as fibras.

Componentes lignocelulósicos são mais reativos do que a celulose, por isso muitos pesquisadores acreditam que eles devem estar diretamente associados a processos de degradação (BURGERSS e BINNIE, 1990). Além disso, a própria celulose, por causa das fortes ligações intermoleculares, transforma grupos hidroxilas em grupos ácidos, o que pode explicar o porquê dos papéis terem pH cada vez mais baixos com o passar dos anos (Library of Congress, 2016).

Os papéis de trapo apresentam taxa de degradação muito menor que os papéis modernos. Algumas hipóteses correlacionam esta característica com a menor presença de lignina na fibra. Outra explicação possível é que a fermentação dos trapos seguida de adição de cal apagada (hidróxido de cálcio) e maceração da pasta faz com que partículas de carbonato de cálcio e de magnésio fiquem aderidas às fibras, neutralizando os ácidos que se formam no processo natural de envelhecimento do papel e diminuindo, assim, a taxa de degradação.

Os papéis de pasta mecânica apresentam rápido amarelecimento (reversão da alvura) uma vez que os compostos lignocelulósicos não são removidos da polpa. Muitas pesquisas vêm sendo feitas na tentativa de comprovar que a presença da lignina é a responsável pelos processos de degradação, porém, alguns resultados parecem indicar que o amarelecimento do papel não está diretamente relacionado à perda de resistência do material (AREA e CHERADAME, 2011). Zou et al. (apud AREA e CHERADAME, 2011) concluíram que a existência de até $28 \%$ de lignina na pasta celulósica não traz perda significativa de resistência ao papel ao longo do seu processo de envelhecimento.

Também foram feitas pesquisas que parecem comprovar que pastas de madeira (pinus e eucalipto) são inerentemente ácidas e é este atributo que desencadeia reações com a lignina residual (principalmente quando combinada ao cloro), que estão associadas à degradação e à fragilidade deste tipo de papel (HOLIK, 2006). 
Os papéis atuais (após a década de 1980) são quase todos fabricados a partir de pasta alcalina (kraft) de eucalipto, ou seja, possuem fibras curtas e lignina residual associadas a cargas metálicas e polímeros sintéticos (colas), combinação que também pode estar relacionada a uma maior taxa de degradação (SENAl, 2016). Além disso, a pressão de órgãos ambientais e de saúde do trabalhador por processos de branqueamento livres de cloro resulta em uma pasta com maior quantidade de lignina residual (HEINEMANN, 2006). Segundo Carter (1996), experimentos com peróxido de hidrogênio $\left(\mathrm{H}_{2} \mathrm{O}_{2}\right)$ para 0 branqueamento de linter de algodão resultaram em menor degradação oxidativa da celulose do que 0 método mais usual com hipoclorito de sódio ( $\mathrm{NaClO}$ ), que é o responsável por tornar o meio ácido.

Outra linha de investigação correlaciona a substituição das colas de origem animal dos papéis de trapo pelas colas feitas a base de alúmen $\left(\mathrm{Al}_{2}\left(\mathrm{SO}_{4}\right)_{3} \cdot 18 \mathrm{H}_{2} \mathrm{O}\right)$ e breu. 0 alumínio presente no alúmen torna 0 meio ácido, catalisando a despolimerização da cadeia celulósica, principalmente no papel de madeira, mais suscetível a este tipo de reação do que a fibra de plantas (HOLIK, 2006). As atuais colas sintéticas utilizam carga de carbonato de cálcio para torná-las neutras ou levemente alcalinas com o propósito de adicionar uma 'reserva alcalina' ao papel na tentativa de neutralizar as reações ácidas inerentes aos processos de envelhecimento. A efetividade desta solução ainda precisará ser comprovada na prática.

$\mathrm{Na}$ busca por respostas, outros estudos tentam correlacionar o papel alcalino com os poluentes atmosféricos (REYDEN, 1992), pois existe uma possibilidade de que estes papéis tenham maior afinidade por dióxido de enxofre e dióxido de nitrogênio (GCI Newsletter, 1990). Pesquisas realizadas por Seery (2013) demonstraram que o dióxido de nitrogênio $\left(\mathrm{NO}_{2}\right)$ e o dióxido de enxofre $\left(\mathrm{SO}_{2}\right)$, comumente encontrados no ar das grandes cidades, quando presentes nas áreas de guarda e em contato com a umidade existente no ar e no papel, formam, respectivamente, ácido nítrico e ácido sulfúrico, aumentando a acidez do meio e favorecendo a hidrólise e a oxidação. Além disso, o dióxido de nitrogênio pode oxidar os grupos hidroxilas da celulose formando ácidos carboxílicos, responsáveis por processos de acidificação.

Aparentemente, os processos de degradação por foto oxidação parecem ser mais intensos quanto maior 0 teor de lignina residual, mas, para que ela ocorra, é necessária a catalisação por poluentes atmosféricos. Alguns testes de envelhecimento demonstraram que a presença de umidade na folha de papel favorece a hidrólise ácida, acelerando a deterioração do material do centro para as bordas (Library of Congress, 2016). 
Pode-se, portanto, concluir que a maior parte dos processos de degradação do papel estão diretamente relacionados às condições ambientais das áreas de guarda. Todos os tipos de papel parecem se beneficiar do armazenamento em um ambiente com temperaturas mais baixas, umidades relativas medianas, pouca ou nenhuma incidência luminosa e ausência de poluentes.

Da perspectiva da qualidade do papel, as recomendações atuais para fabricação de papel permanente 41 são: ter fibras longas; ser alcalino; possuir reserva alcalina; e ter, no máximo, 1\% de lignina residual. Porém, não há como comprovar que estas recomendações irão efetivamente garantir uma maior durabilidade. É preciso que muitas outras pesquisas sejam realizadas e novos testes sejam desenvolvidos para uma maior compreensão dos processos físico-químicos associados à deterioração de toda a enorme diversidade de tipos de papéis utilizados atualmente (AREA e CHERADAME, 2011).

\subsubsection{Danos ao papel}

Os danos a documentos com suporte em papel, segundo classificação apresentada por DER MOST et al. (2010) em 'Archives Damage Atlas - a tool for assessing damage', podem ser: à capa e ao miolo; químicos; mecânicos; por pragas; por água; ou por mofo. Suas características e consequências estão descritos nos Quadros 07 a 12, a seguir.

Quadro 07. Danos à capa e ao miolo

\begin{tabular}{l|l|l|}
\hline \multicolumn{1}{c|}{ Danos à capa e ao miolo } & \multicolumn{1}{|c|}{ Tipos de danos } \\
\hline \multirow{2}{*}{$\begin{array}{l}\text { Consequências: dissociações, perda } \\
\text { total ou parcial, ondulações, } \\
\text { riscos, manchas, rugas, furos, rasgos }\end{array}$} & $\begin{array}{l}\text { Deformações: } \\
\text { Te UR incorretas; uso, armazenamento e/ou } \\
\text { transporte inadequados. }\end{array}$ & $\begin{array}{l}\text { Desgastes na costura: } \\
\text { a costura pode se deteriorar por envelhecimento } \\
\text { natural da linha, manuseio e/ou armazenamento } \\
\text { incorreto, ou Te UR incorretas. }\end{array}$ \\
\hline & \begin{tabular}{ll} 
Fonte: PAGLIONE, 2017. \\
\hline
\end{tabular} & \\
\hline
\end{tabular}

(continua)

41 U.S. Permanent Paper Law (P.L. 101-423) é uma resolução conjunta (dos EUA) que recomenda o uso de papéis 'acid-free' ou alcalinos (padronizados pela norma Joint Committee on Printing JCP A 270) para registros federais, livros e outros documentos que se pretenda de "valor permanente" nos Estados Unidos. 
Quadro 07. Danos à capa e ao miolo (continuação)

\begin{tabular}{|c|c|c|}
\hline Danos à capa e ao miolo & Tipos de danos & Imagem ilustrativa \\
\hline \multirow{4}{*}{$\begin{array}{l}\text { Consequências: dissociações, perda } \\
\text { total ou parcial, ondulações, } \\
\text { riscos, manchas, rugas, furos, rasgos }\end{array}$} & $\begin{array}{l}\text { Desgastes na lombada: } \\
\text { deformações ou dissociação estão frequentemente } \\
\text { associadas ao manuseio ou armazenamento } \\
\text { incorreto, mas também podem ser causadas porT, } \\
\text { UR ou luz e UV incorretas. }\end{array}$ & $\begin{array}{l}\text { Fonte: DER MOST et al., } 2010 . \\
\text { Fin }\end{array}$ \\
\hline & $\begin{array}{l}\text { Costura solta / perda de suporte: } \\
\text { os materiais e/ou o processo de fabricaçãa, o uso ou } \\
\text { armazenamento incorreto e a exposição a T, UR ou } \\
\text { luz e UV incorretas podem levar à deterioração de } \\
\text { uma ou ambas as pastas da capa. }\end{array}$ & Fonte: PAGLIONE, 2017. \\
\hline & $\begin{array}{l}\text { Fragmentos soltos: } \\
\text { uso, armazenamento e transporte incorretos podem } \\
\text { levar à dissociação de partes do documento. } \\
\text { Este dano quase sempre está associado a algum } \\
\text { outro processo de deterioração. }\end{array}$ & Fonte: DER MOST et al., 2010. \\
\hline & $\begin{array}{l}\text { Danos à superfície: } \\
\text { os materiais e/ou o processo de fabricação, o uso, } \\
\text { armazenamento e/ou transporte incorretos e a } \\
\text { exposição a T, UR ou luz e UV incorretas podem } \\
\text { levar à deterioração superficial do documento. }\end{array}$ & Fonte: PAGLIONE, 2017 . \\
\hline
\end{tabular}

Fonte: traduzido e adaptado de DER MOST et al., 2010 e PAGLIONE, 2017.

Quadro 08. Danos químicos

\begin{tabular}{|c|c|c|}
\hline Danos químicos & Tipos de danos & Imagem ilustrativa \\
\hline $\begin{array}{l}\text { Consequências: perda total ou parcial, } \\
\text { dissociações, descolorações, manchas, } \\
\text { furos, rasgos }\end{array}$ & $\begin{array}{l}\text { Fogo: } \\
\text { é um tipo de oxidação. A celulose é uma molécula } \\
\text { compostas apenas por } \mathrm{C}, \mathrm{O} \text { e H, por isso, a sua } \\
\left.\text { combustão (reação com } \mathrm{O}_{2}\right) \text { é completa, ou seja, ela } \\
\text { é totalmente transformada em dióxido de carbono } \\
\left(\mathrm{CO}_{2}\right) \text { e água }\left(\mathrm{H}_{2} \mathrm{O}\right) \text {. }\end{array}$ & Fonte: PAGLIONE, 2017. \\
\hline
\end{tabular}

(continua) 
Quadro 08. Danos químicos (continuação)

\begin{tabular}{|c|c|}
\hline Danos químicos & Tipos de danos \\
\hline & $\begin{array}{l}\text { Foxing: } \\
\text { formação de pontos acastanhados na totalidade ou } \\
\text { em parte da superfície do papel por processo químico } \\
\text { cujas causas não são bem conhecidas. Hipóteses: } \\
\text { a. oxidação de partículas metálicas (impurezas) } \\
\text { resultantes do processo de fabricação do papel. } \\
\text { b. sais metálicos (como sulfato de alumínio) } \\
\text { associados às fibras, que oxidam na presença de } \\
\text { umidade. } \\
\text { c. degradação bioquímica associada a fungos. } \\
\text { d. Reação de Maillard: escurecimento não enzimático } \\
\text { na presença de calor e umidade. } \\
\text { Existem discussões sobre a possibilidade de se usar } \\
\text { Espectroscopia Raman na detecção dos compostos. }\end{array}$ \\
\hline & $\begin{array}{l}\text { Corrosão da tinta ferrogálica / corrosão do } \\
\text { cobre: } \\
\text { reação contínua, acentuada por umidade, ácidos e } \\
\text { oxidação (piores casos são encontrados em países } \\
\text { tropicais), que causam a despolimerização do } \\
\text { suporte e a descoloração da tinta (ver maiores } \\
\text { detalhes em Observação 1). }\end{array}$ \\
\hline
\end{tabular}

Consequências: perda total ou parcial, dissociações, descolorações, manchas, furos, rasgos

\section{Fitas e outros adesivos:}

fitas adesivas usadas para anexar um elemento à obra ou para reparar e proteger documentos, bem como post-its e outros materiais colantes.

As colas reagem com o papel provocando danos químicos. Inicialmente a área em contato com a cola pode sofrer descoloração. Com o passar do tempo, a cola pode impregnar o papel e enrijecer, se separando da fita, que deixa de exercer a função pretendida e cria uma área escura sobre o papel. Processos de oxidação da cola podem deixá-la quebradiça, juntamente com o papel. As colas antigas são ácidas, o que favorece processos de hidrólise e oxidação do papel. Colas modernas são alcalinas e podem ter tanta afinidade com a celulose que é impossível removê-las (reação não reversível).

\section{Ferrugem:}

oxidação do ferro (e, por analogia, corrosão de outros metais) em presença de oxigênio e umidade. É bastante frequente que documentos tenham associados a eles elementos metálicos: grampos, clipes e outros, que oxidam com o passar do tempo. 0 metal oxidado se deposita nas fibras do papel e, em meio ácido, age como catalisador de reações de despolimerização da celulose. Em casos extremos, 0 processo pode levar ao rompimento das fibras e à perda de partes do documento.
Imagem ilustrativa

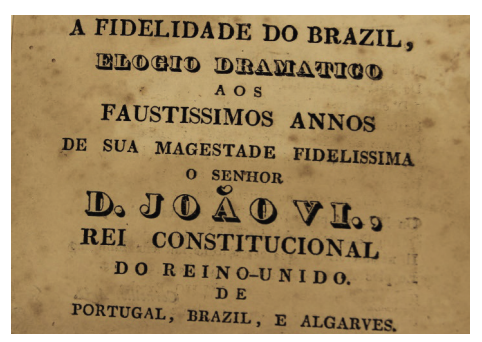

Fonte: PAGLIONE, 2017.

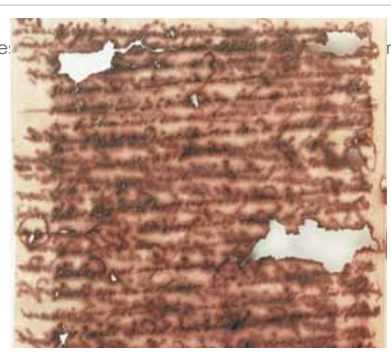

Fonte: DER MOST et al., 2010.

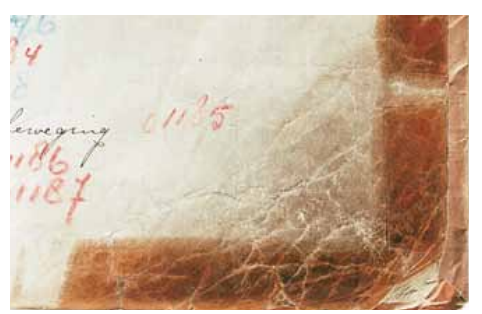

Fonte: DER MOST et al., 2010.

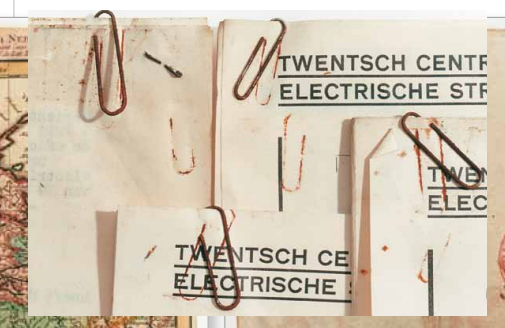

Fonte: DER MOST et al., 2010. 


\begin{tabular}{|c|c|c|}
\hline Danos químicos & Tipos de danos & Imagem ilustrativa \\
\hline & $\begin{array}{l}\text { Acidificação: } \\
\text { resultado principalmente do processo de fabricação } \\
\text { do papel. } \\
\text { Praticamente todo papel de madeira fabricado até } \\
1980 \text { possui pH menor do que } 7 \text {. Além disso, todo } \\
\text { papel vegetal é ácido (óleos e ácidos são usados } \\
\text { para quebrar a fibra celulósica e torná-lo } \\
\text { translúcido). } \\
\text { As reações de acidificação do papel fazem com que } \\
\text { ele se torne frágil e quebradiço e liberam um odor } \\
\text { característico, avinagrado, muito presente em áreas } \\
\text { de guarda de acervos. As condições de } \\
\text { armazenamento podem acelerar o processo de } \\
\text { degradação. }\end{array}$ & 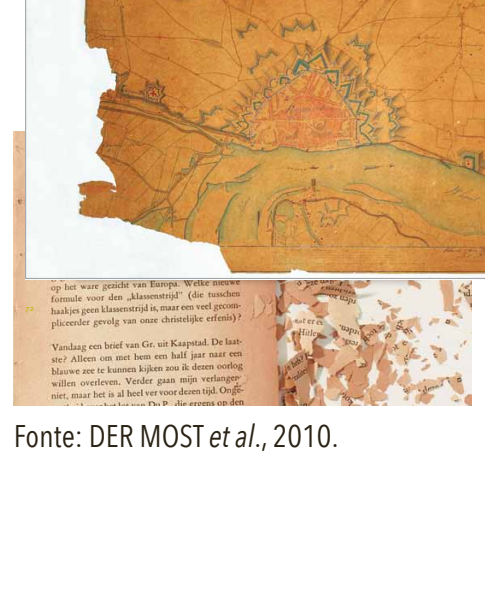 \\
\hline $\begin{array}{l}\text { Consequências: perda total ou parcial, } \\
\text { dissociações, descolorações, manchas, } \\
\text { furos, rasgos }\end{array}$ & $\begin{array}{l}\text { Intervenções anteriores: } \\
\text { o desenvolvimento das técnicas de restauro } \\
\text { aplicadas a bens culturais trouxe propostas de } \\
\text { intervenções químicas com o objetivo de estabilizar } \\
\text { e recuperar documentos. Infelizmente, não era } \\
\text { possível saber, naquele momento, quais as } \\
\text { consequências de longo prazo dessas intervenções } \\
\text { e, muitas delas, se mostraram danosas. Esta é uma } \\
\text { das razões de porquê, atualmente, se preconizar } \\
\text { primeiro o cuidado com a qualidade do ambiente } \\
\text { de guarda, depois, se necessário, procedimentos de } \\
\text { higienização e pequenos reparos e, apenas quando } \\
\text { extremamente necessário, intervenções } \\
\text { restaurativas. Novos processos para tratamento } \\
\text { químico de acervos continuam sendo } \\
\text { desenvolvidos com a promessa de resultados } \\
\text { positivos sem efeitos colaterais adversos mas, por } \\
\text { hora, não é possível afirmar que 'ingredientes } \\
\text { mágicos' (que não causem danos nem às obras } \\
\text { nem aos trabalhadores) tenham sido encontrados. }\end{array}$ & 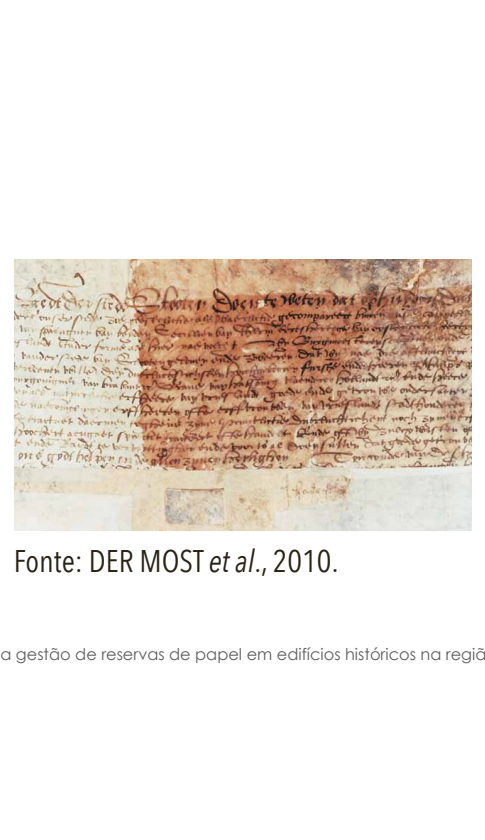 \\
\hline
\end{tabular}

Fonte: traduzido e adaptado de DER MOST et al., 2010 e PAGLIONE, 2017.

Observação 1: Os principais ingredientes da tinta ferrogálica são sulfato ferroso (ou vitríolo verde, $\mathrm{FeSO}_{4}$ ) e extrato de noz de gália (ácido gálico $-\mathrm{C}_{6} \mathrm{H}_{2}(\mathrm{OH})_{3} \mathrm{COOH}$ ). A proporção 3:1 parece ser a mais estável. Em alguns casos, o sulfato ferroso foi substituído por ou adicionado a sulfato de cobre (ou vitríolo azul, $\mathrm{CuSO}_{4}$ ), com menor eficiência (DA COSTA et al., 2013). São ingredientes secundários: água, goma arábica, ácido sulfúrico $\left(\mathrm{H}_{2} \mathrm{SO}_{4}\right)$ e ácido clorídrico $(\mathrm{HCl})$, usado para prevenir a formação de sedimentos. A tinta ferrogálica é uma tinta ácida. 
A maioria dos manuscritos ocidentais foram escritos com tintas ferrogálicas. Estas tintas podem danificar o papel por meio de dois mecanismos principais: a hidrólise ácida, aumentada pela umidade; e a despolimerização oxidativa, provocada pela presença de oxigênio e íons ferro (II) livres.

A degradação de papel Whatman sem colagem (papel de referência) impregnado com diferentes combinações de sulfato de ferro, ácido gálico e goma arábica foi estudada em temperatura ambiente para avaliar a importância relativa de cada mecanismo. As amostras foram armazenadas em várias condições, incluindo uma atmosfera seca e/ou sem oxigênio. Os resultados indicaram que quantidades residuais de oxigênio (menos de 0,1\%) promovem a despolimerização da celulose, enquanto o nível de umidade relativa não teve impacto.

Quanto à oxidação do ferro, ela ocorre apenas na presença simultânea de oxigênio e vapor d'água, sugerindo a ocorrência de mecanismos oxidativos similares à corrosão. Finalmente, a presença de ácido gálico tem uma forte influência, que é apenas parcialmente explicada pela sua capacidade de reduzir o ferro (III) em ferro (II) (ROUCHON et al., 2011).

Tintas a base de cobre resultam em tons de verdes e azuis. Menos comum em manuscritos, elas são encontradas principalmente em mapas e desenhos antigos. A corrosão da tinta a base de cobre tem processo similar à da tinta ferrogálica. Como resultado da oxidação do cobre na presença de umidade e oxigênio, tem-se a descoloração da tinta com a transformação da cor em preto.

Quadro 09. Danos mecânicos

\begin{tabular}{|c|c|c|}
\hline Danos mecânicos & Tipos de danos & Imagem ilustrativa \\
\hline $\begin{array}{l}\text { Consequências: } \\
\text { dissociações, perda total ou parcial, } \\
\text { riscos, manchas, vincos, dobras, rugas, } \\
\text { furos, rasgos, cortes }\end{array}$ & $\begin{array}{l}\text { Por uso: } \\
\text { é muito comum que, durante o uso, documentos } \\
\text { sofram com ações descuidadas: anotações e grifos; } \\
\text { dobras na capa ou nas folhas para facilitar a leitura; } \\
\text { adição de elementos os mais variados para marcar } \\
\text { páginas ou apenas como recordação, mas quase } \\
\text { sempre danosos ao papel; vincos, dobras, rugas e } \\
\text { rasgos causados por descuido no manuseio; recortes } \\
\text { feitos propositalmente; dentre outras possibilidades. } \\
\text { Dentro dos ambientes de guarda também podem ser } \\
\text { realizados procedimentos que causam danos ao } \\
\text { documento: furos ou recortes para adição de capas e } \\
\text { pastas; uso de embalagens inadequadas (muito } \\
\text { grandes ou muito pequenas) para o } \\
\text { acondicionamento; anotação de informações a } \\
\text { caneta e carimbos para catalogação; dentre outros. }\end{array}$ & Fonte: DER MOST et al., 2010. \\
\hline
\end{tabular}




\begin{tabular}{l|l|l|}
\hline \multicolumn{1}{c|}{ Danos mecânicos } & \multicolumn{1}{c|}{ Imagem ilustrativa } \\
\hline $\begin{array}{l}\text { Consequências: } \\
\text { dissociações, perda total ou parcial, } \\
\begin{array}{l}\text { riscos, manchas, vincos, dobras, rugas, } \\
\text { furos, rasgos, cortes }\end{array}\end{array}$ & $\begin{array}{l}\text { Por vandalismo: } \\
\text { o vandalismo contra documentos pode ter o intuito } \\
\text { de danificar o material propositalmente ou roubar } \\
\text { algum item de valor, subtraindo-o da coleção ou } \\
\text { rasgando ou recortando o elemento que se deseja } \\
\text { roubar. }\end{array}$ & Fonte: DER MOST et al., 2010. \\
\hline
\end{tabular}

Fonte: traduzido e adaptado de DER MOST et al., 2010 e PAGLIONE, 2017.

$$
\text { Quadro 10. Danos por pragas }
$$

\begin{tabular}{|c|c|c|}
\hline Danos por pragas & Tipos de danos & Imagem ilustrativa \\
\hline \multirow{3}{*}{$\begin{array}{l}\text { Consequências: dissociações, perda } \\
\text { total ou parcial, manchas, furos, rasgos }\end{array}$} & $\begin{array}{l}\text { Insetos (baratas, brocas, cupins e traças): } \\
\text { muitos insetos são especializados na decomposição } \\
\text { de troncos e follhas, o mesmo material de que são } \\
\text { feitos os papéis. } \\
\text { As condições que os insetos precisam para sobreviver } \\
\text { são: alimento (principalmente celulose, mas } \\
\text { também poeira e restos de comida) e quantidades } \\
\text { mínimas de oxigênio, calor e umidade (ver maiores } \\
\text { detalhes em Observação 2). }\end{array}$ & Fonte: DER MOST et al., 2010. \\
\hline & $\begin{array}{l}\text { Roedores: } \\
\text { são encontrados principalmente em ambientes com } \\
\text { acesso a um local escuro, ao abrigo das intempéries e } \\
\text { dos predadores. } \\
\text { Assim como os insetos, eles precisam de alimento, } \\
\text { água, oxigênio e calor. Porém, ao contrário dos } \\
\text { insetos, eles não se alimentam de celulose, mas } \\
\text { utilizam o papel na construção dos ninhos. Enquanto } \\
\text { caminham pelas áreas de guarda podem urinar } \\
\text { sobre o acervo, deteriorando itens e trazendo risco de } \\
\text { doenças aos usuários. }\end{array}$ & $\begin{array}{l}\text { Fonte: https://blogs.bl.uk/collectioncare/ } \\
\text { 2013/08/the-bookie-monster-attack-of-the- } \\
\text { creepy-crawlies.html, acesso em fev. } 2019\end{array}$ \\
\hline & $\begin{array}{l}\text { Outros animais (pássaros, morcegos, gatos, etc.): } \\
\text { quando as áreas de guarda não estão bem fechadas } \\
\text { e controladas, diversos animais podem ver nestes } \\
\text { ambientes locais de abrigo bastante adequados. Eles } \\
\text { não se alimentam nem utilizam o papel, mas podem } \\
\text { levar alimentos para dentro do espaço, estocar a } \\
\text { comida, se alimentar e defecar junto aos acervos. } \\
\text { Também podem espalhar urina para demarcar o } \\
\text { território. Todos estes hábitos trazem danos ao } \\
\text { patrimônio edificado e aos objetos. }\end{array}$ & $\begin{array}{l}\text { Fonte: https://americanlibrariesmagazine.org/ } \\
\text { 2017/01/03/library-cats-leave-some-sneezing- } \\
\text { others-feline-fine/,acesso em jan. } 2021\end{array}$ \\
\hline
\end{tabular}

Fonte: traduzido e adaptado de DER MOST et al., 2010 e PAGLIONE, 2017. 
Observação 2: Dentre os inúmeros insetos que podem ser encontrados dentro de uma área de guarda, alguns são especialmente preocupantes pelos danos que podem causar aos acervos. As baratas podem se alimentar de papel, mas não têm preferência por este material. Elas costumam ser atraídas pela presença de lixo orgânico em áreas próximas ao acervo. Brocas e traças depositam seus ovos em locais escuros e úmidos, junto a uma fonte de alimento. Apenas as larvas se alimentam de papel. Os cupins são insetos sociais, que vivem em colônias. Algumas espécies se alimentam de árvores (arbóreos), outras de madeira seca. Ambos provocam infestações localizadas. As piores espécies são as de subsolo porque fazem longos caminhos (com vários quilômetros) na busca por alimentos, destruindo edifícios, mobiliários e acervos. 0 combate a insetos exige inspeção constante e ação especializada, adequada a cada espécie que se deseja controlar. Podem ser utilizadas barreiras de proteção no entorno do edifício e iscas em locais estratégicos. Para que a resposta seja a mais adequada e segura, com o menor impacto possível ao meio ambiente, é fundamental que as instituições culturais tenham um plano de manejo integrado de pragas (IPM - Integrated Pest Management).

Não se deve consumir alimento nem armazenar lixo orgânico perto ou dentro de reservas técnicas. Quando os documentos já estão infestados, a câmara de anóxia tem se mostrado o tratamento mais eficaz. No passado, para o controle de insetos, era comum a prática de se depositar venenos diretamente sobre as páginas de papel. Muitos documentos foram contaminados deste modo. Ainda hoje isto causa danos à saúde de trabalhadores e pesquisadores em museus, bibliotecas e arquivos. Ao se observar a presença de pó branco ou de papéis pegajosos ao toque, o material deve ser isolado e enviado para uma análise química. Ainda não existe uma técnica para descontaminar o material, e a recomendação é que o documento seja digitalizado e o original armazenado em local seguro, devidamente identificado, sendo manipulado apenas em casos de extrema necessidade, mediante 0 uso de todos os equipamentos de proteção individual (EPI). 


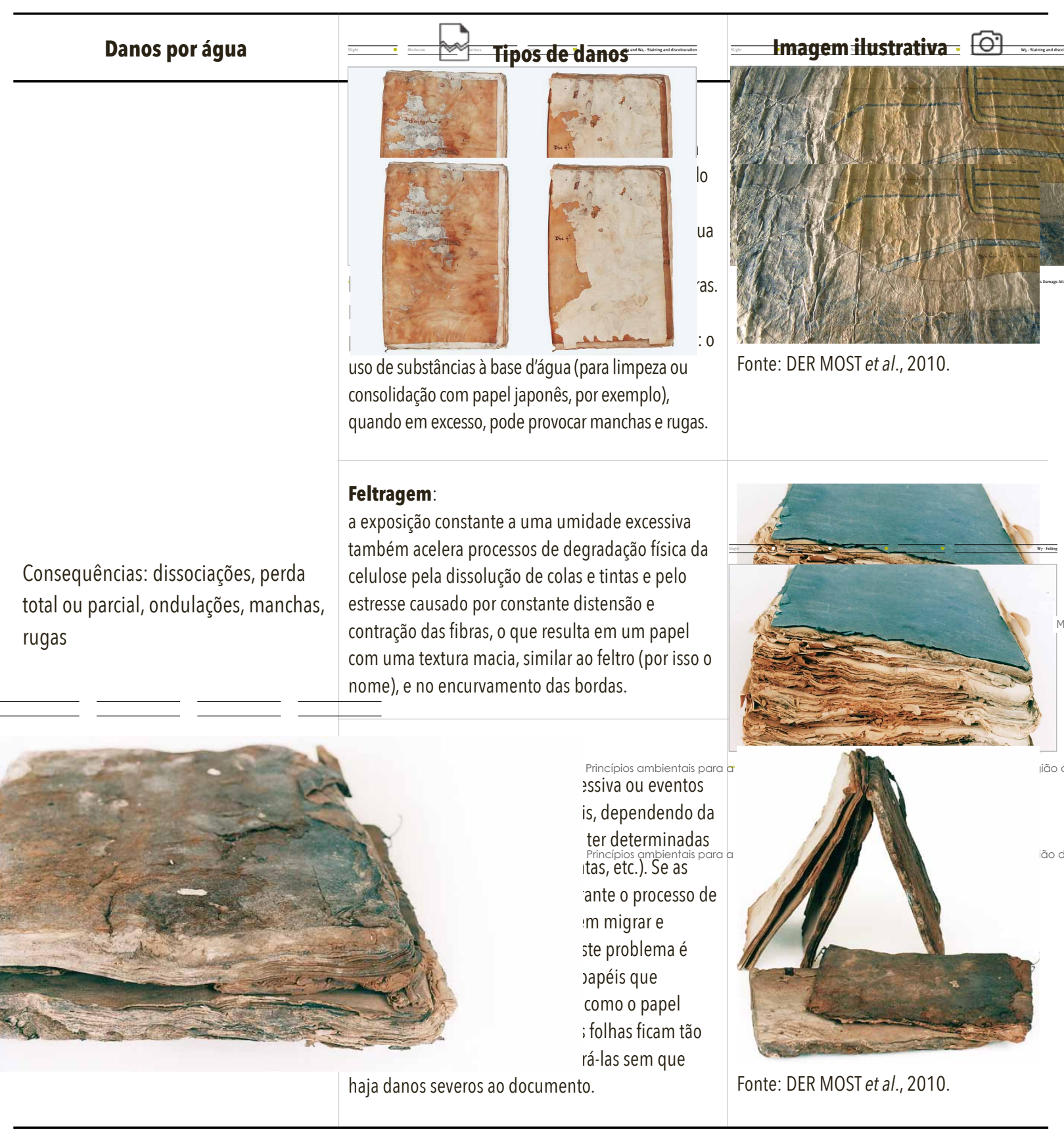

Fonte: traduzido e adaptado de DER MOST et al., 2010 e PAGLIONE, 2017. 
Quadro 12. Danos por mofo

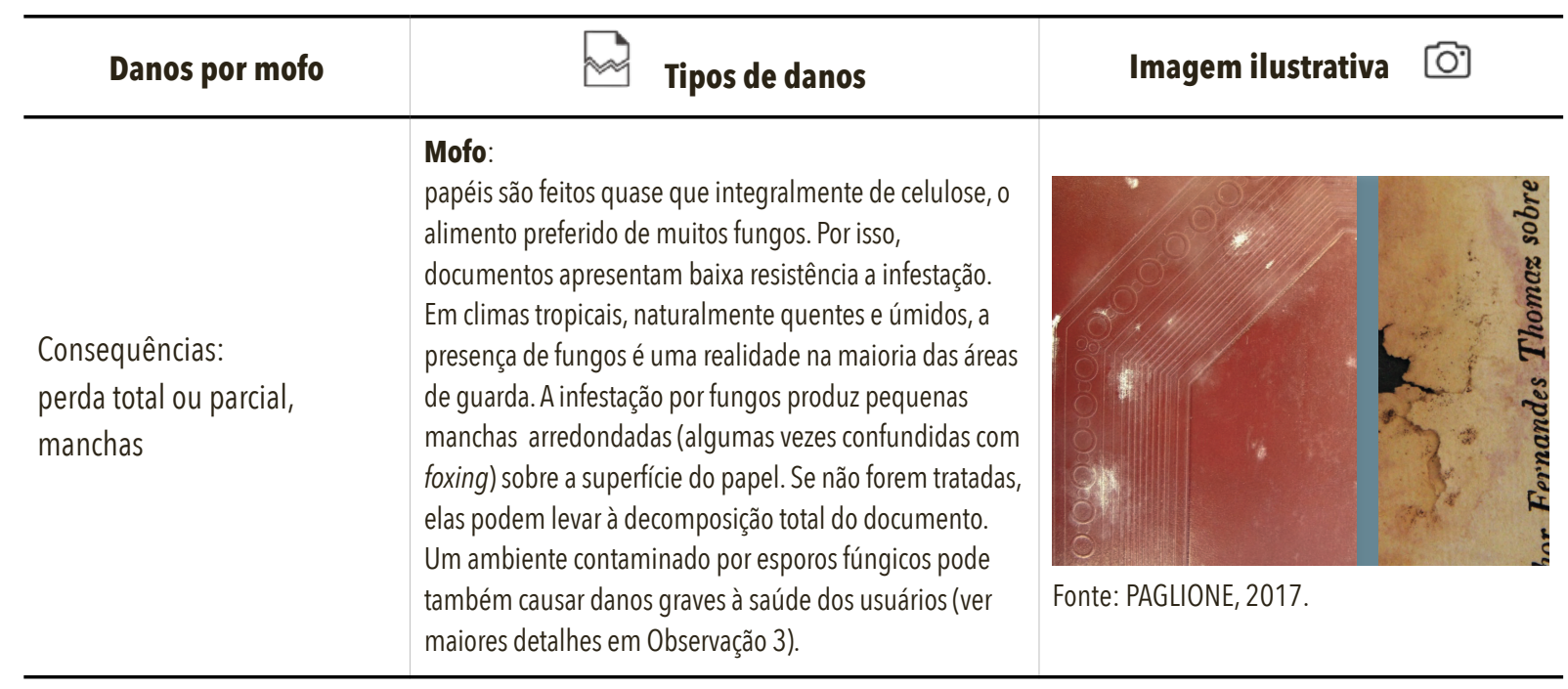

Fonte: traduzido e adaptado de DER MOST et al., 2010 e PAGLIONE, 2017.

Observação 3: 0 esporo, célula reprodutiva dos fungos, é uma estrutura muito resistente, difícil de ser eliminada, e pode ser encontrada em todo e qualquer ambiente. Os fungos liberam, ao longo de sua vida, milhões de esporos que são transportados pelas correntes de ar e se depositam sobre todo tipo de superfície. Quando o esporo encontra condição adequada (alimento, calor e umidade), ele germina, formando o micélio (conjunto de hifas, responsáveis pela alimentação do fungo). 0 micélio é, na maioria dos casos, transparente e fica dentro do substrato, não podendo ser visto a olho nu. Se a T estiver suficientemente elevada (varia conforme a espécie, mas, frequentemente, acima de $24^{\circ} \mathrm{C}$ ), bem como a UR (para a maioria deles, acima de 65\%), o micélio produz uma estrutura reprodutora chamada corpo de frutificação, que é a parte visível do fungo (usualmente possui uma coloração característica, conforme a espécie). Quando esta estrutura tem uma aparência algodonosa ou aveludada, ela é chamada de mofo. A presença de mofo é indicação de que o fungo está se reproduzindo, ou seja, lançando novos esporos no ambiente. Para controlar infestações por fungos é importante garantir que os ambientes mantenham uma UR constante, abaixo de 65\%, e tenham uma boa taxa de ventilação para reduzir a deposição de esporos sobre os objetos. 0 tratamento mais simples para documentos contaminados é por aspiração, com aspirador com filtro HEPA42, desde que em ambiente bem ventilado e por pessoas treinadas, utilizando os EPIs obrigatórios. No entanto, qualquer tratamento disponível será pouco efetivo se os objetos retornarem às mesmas condições ambientais em que se encontravam antes.

\footnotetext{
42 High Efficiency Particulate Air. São filtros de alta eficiência, com malhas especiais, que permitem a retenção de até 99,7\% das impurezas
} presentes no ar, incluindo micropartículas como ácaros, vírus e bactérias. 


\subsubsection{Gestão do patrimônio e gestão de riscos}

A grande quantidade de museus criados ao longo do século XX, com o consequente acúmulo de itens e coleções, frequentemente armazenados em locais inadequados, foi, e é, causa de danos irreparáveis a muitos bens culturais (D'AGOSTINO et al., 2015). Como observou Guichen (1995), "um mau restaurador destrói um item por mês. Um mau conservador pode destruir uma coleção inteira em um ano". Para se evitar que processos de deterioração se iniciem ou se intensifiquem, é preciso um profundo conhecimento das causas e dos mecanismos envolvidos (THOMSON, 1986).

Assim, na tentativa de se estabelecer políticas de prevenção de danos, métodos, normas e recomendações vêm sendo propostos por diversos organismos multinacionais e instituições de pesquisa. 0 desenvolvimento de uma política de conservação preventiva depende de "conhecimento detalhado do acervo sob a guarda de uma determinada instituição, de seu(s) valor(es) e uso(s), bem como dos riscos de deterioração e perda de valor a que está sujeito" (HOLLÓS e PEDERSOLI JR., 2009). Para uma gestão adequada do patrimônio cultural é preciso compreender os riscos, fazer escolhas e estabelecer prioridades, o que não é um processo fácil pois depende de conhecimento aprofundado e multidisciplinar e de trabalho em equipe. Quanto mais consciente for este processo, mais ele resultará em uma proteção efetiva de coleções, monumentos, edifícios e sítios (PEDERSOLI JR. et al., 2016).

A gestão do patrimônio precisa ser multidimensional, o que demanda a contínua produção de indicadores quantitativos, qualitativos, monetários e não-monetários (NOCCA, 2017). A campanha Transforming Our World da Agenda 2030 explica que:

(...) o desenvolvimento cultural e sustentável precisa estar embasado em pesquisa e em indicadores. Há demanda por indicadores confiáveis e inclusivos que avaliem se os objetivos culturais foram implementados.

(...) é preciso desenvolver indicadores culturais e um conjunto de informações confiáveis que permitam uma melhor compreensão quantitativa e qualitativa do papel da cultura no desenvolvimento sustentável. (UNESCO, 2015; tradução da pesquisadora)

Além disso, tanto a Agenda 2030 (UNESCO, 2015) quanto a New Urban Agenda (UNESCO, 2016) reforçam que é preciso ir além de princípios e se chegar à ação. Porém, apesar da ampla bibliografia sobre a relevância das ações de planejamento e de conservação do patrimônio cultural para uma sociedade, ainda faltam maiores evidências empíricas que demonstrem como executá-las em uma abordagem holística (NOCCA, 2017). 


\subsubsection{Gestão}

0 termo gestão, como entendido pela Teoria Geral da Administração (TGA), compreende o conjunto de princípios, proposições e técnicas que permitem conhecer e administrar organizações (CHIAVENATO, 2003). Kast e Rosenzweig (1985) definiram gestão como um trabalho mental (pensar, intuir, sentir) realizado por pessoas dentro de um contexto organizacional, que envolve:

a. a coordenação de recursos humanos, materiais e financeiros visando atingir, de maneira efetiva e eficiente, metas organizacionais;

b. a relação da instituição com o ambiente externo e a resposta a demandas sociológicas;

c. o desenvolvimento de um ambiente organizacional no qual as pessoas podem atingir seus objetivos individuais e coletivos;

d. a realização de certas funções específicas como definição de metas, planejamento, destinação de recursos, organização, implementação e controle;

e. a execução de regras interpessoais, divisionais e de informação.

Os fundamentos da gestão não são novos. Pelo menos desde os primórdios do capitalismo mercantil, na Florença do século XIV, já havia teorias econômicas que tentavam organizar ações e decisões (SANTOS, 1999). 0 que se modificou com o passar do tempo foram os instrumentos, por isso, é importante destacar que, ainda que gestão seja uma ideia antiga, ela só faz sentido se os instrumentos estiverem atualizados às necessidades do presente.

Na década de 1920, surgem as primeiras pesquisas relacionando gestão com psicologia industrial e teorias sociológicas. Os estudos do psicólogo ambiental Elton Mayo deram origem ao "Movimento das Relações Humanas". Ele realizou uma série de experimentos, conhecidos como Experiências Hawthorne, entre 1923 e 1926, em uma fábrica da Western Electric Company, em que correlacionou a qualidade ambiental (níveis de iluminação) com a produtividade e a estabilidade emocional dos funcionários. Suas conclusões o levaram a propor a Teoria das Relações Humanas, que afirmava que o comportamento humano não podia ser reduzido ao comportamento de uma máquina e que as relações psicológicas e sociais têm uma influência muito maior sobre as pessoas do que o espaço físico, sendo o conflito a indicação de uma chaga social, e a cooperaç̧ão, de um estado de bem-estar (MOTTA, 2006). 
As Experiências Hawthorne foram o embrião de muitas pesquisas posteriores que demonstraram que as pessoas trabalham por um conjunto complexo de motivos e não apenas pela recompensa financeira e, por isso, o ambiente de trabalho deve conter um sistema de normas e valores que preencham as necessidades sociais e psicológicas e proporcionem o reconhecimento do grupo no qual a pessoa está inserida (AMARATUNGA, 2001).

A Teoria Geral de Sistemas (TGS), desenvolvida pelo biólogo Ludwig von Bertalanffy, na década de 1960, propôs que se utilizasse um grande conjunto de instrumentos de análise (quantitativa e comportamental) para se compreender uma organização. Segundo esta teoria, todo sistema organizacional é composto por partes, que formam seu ambiente interno, e por uma fronteira, que 0 separa do ambiente externo (MULLINS, 1996). Existe uma interdependência entre as partes, as quais, mesmo diante de forças internas ou externas aplicadas a elas, tendem a permanecer ou retornar a um estado de equilíbrio. A TGS introduziu o conceito de resposta (feedback), que é o processo para se obter informações de como o sistema está se comportando, de modo a guiar e controlar suas operações (AMARATUNGA, 2001).

Ainda na década de 1960, pesquisas de Chandler, Burns e Stalker, Emery e Trist, Lawrence e Lorsch resultaram na Teoria da Contingência, que propunha utilizar instrumentos de diagnóstico (propostos pela TGS) para determinar a melhor combinação de desenho organizacional, o qual deveria variar conforme: 0 ambiente externo; fatores tecnológicos; habilidades humanas; e motivações. Segundo esta teoria, não existe uma fórmula universal de gestão uma vez que o número de variáveis e de tipos de organizações é muito grande (COLE, 1996).

Os mais recentes estudos em gestão organizacional buscam responder às demandas do que vem sendo chamado de quarta revolução industrial ou indústria 4.0 (Figura 24), termo criado pelo Programa Estratégico de Alta Tecnologia do governo alemão, que procura explicar a mais nova era industrial, ainda em formação, na qual a automação pretende responder, sem a presença de pessoas ('smart industry'), em escala industrial, a demandas individuais fazendo uso, para isso, de sistemas ciber-físicos (IEDI, 2017). 
Figura 24. Indústria 4.0 ou Industrial Internet of Things (IloT)

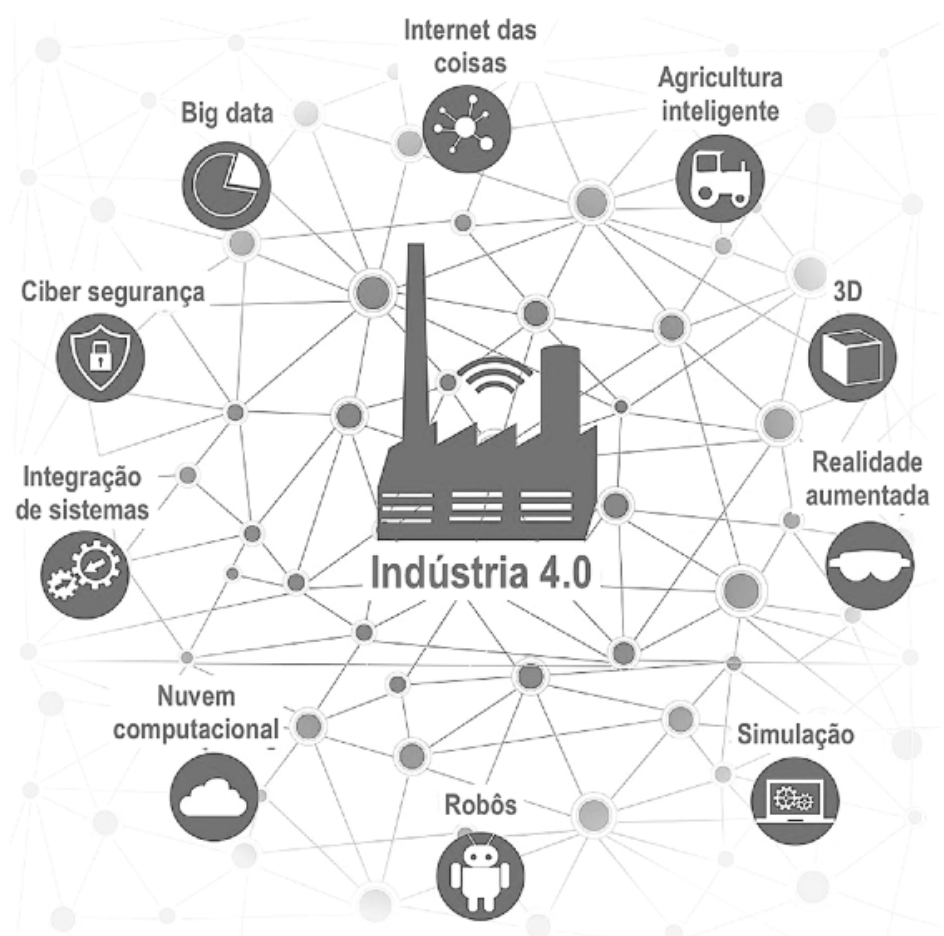

Fonte: traduzido de DESIGNSPARK, 2018.

\subsubsection{Gestão Estratégica}

A Gestão Organizacional Estratégica (Strategic Enterprise Management - SEM), conforme definida pela TGA, é um conjunto de técnicas e instrumentos para auxiliar na avaliação institucional e na tomada de decisões. Segundo Sampaio (2004), a gestão estratégica é um sistema multimétodos que utiliza instrumentos de gestão operacional para a administração de: (a) projetos (conjunto de ações); (b) atores (esferas interessadas); e (c) indicadores de efetividade (eficiência e eficácia), visando o desenvolvimento sustentável de uma determinada organização.

Nutt e Backoff (1993, apud: SWEENEY et al., 2018) acrescentam que a gestão para o desenvolvimento sustentável deve abranger três fases (Figura 25):

1. o planejamento das estratégias;

2. a execução, 0 acompanhamento, 0 controle e a avaliação;

3. a análise do ambiente interno e externo à organização.

A gestão organizacional estratégica inicia-se com o planejamento, etapa na qual se faz o diagnóstico das possíveis deficiências da instituição, a partir de exercícios de reflexão com pessoas-chave. Tendo-se um diagnóstico, definem-se estratégias para responder às deficiências identificadas, as quais devem conter 
planos de ação detalhados com metas quantitativas e qualitativas. Essas metas devem estar condicionadas a um cronograma e um orçamento de longo prazo e devem prever mecanismos para acompanhamento e avaliação dos resultados práticos atingidos. Sempre que se verificar que uma ação se tornou ineficiente ou desatualizada, ela deve ser revisada e alterada em uma nova etapa de planejamento (COSTA, 2010).

Figura 25. As três fases da gestão organizacional estratégica

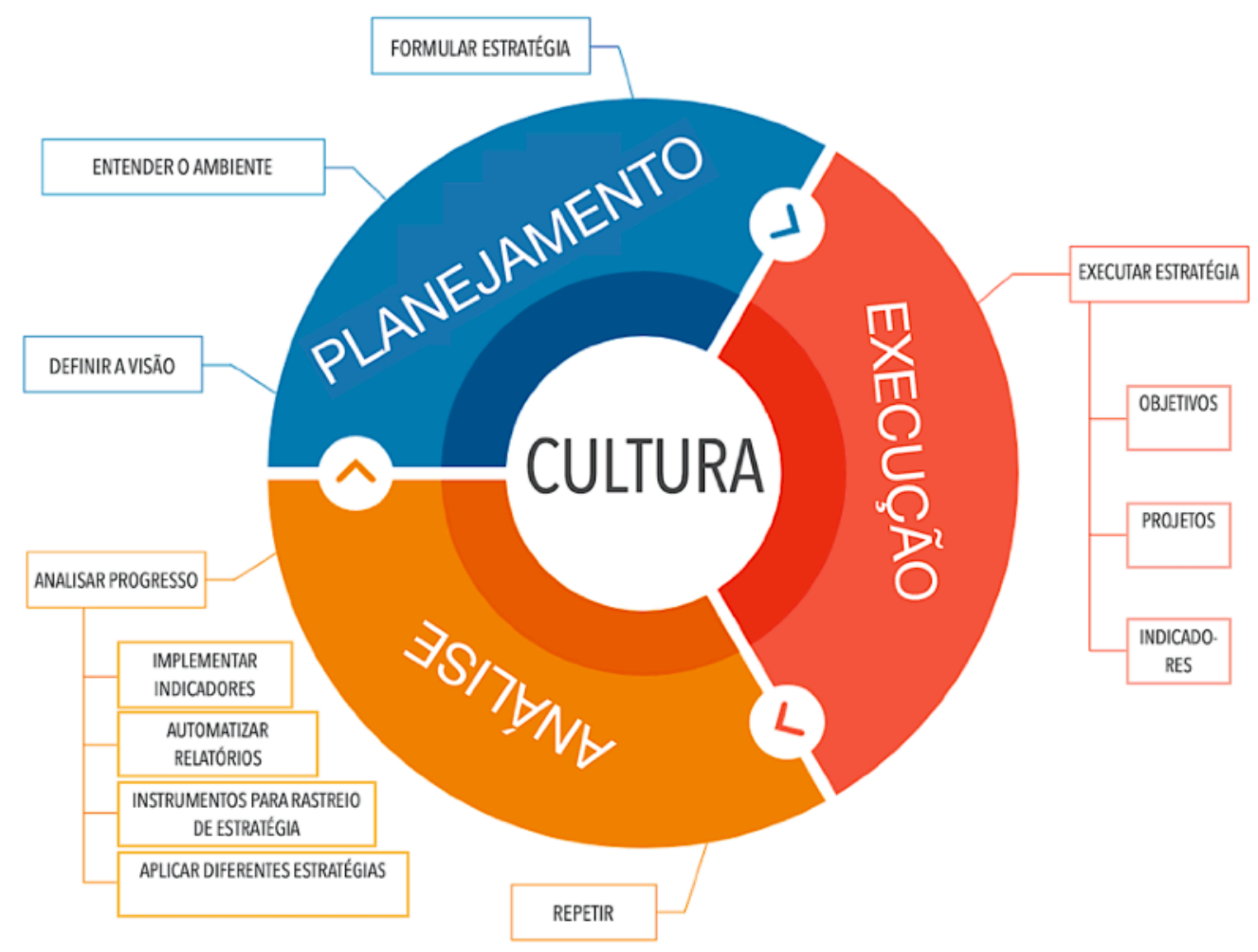

Fonte: traduzido de WRIGHT, 2019.

Sampaio (2004) complementa que o diagnóstico deve identificar as vulnerabilidades (ou riscos); as oportunidades (opportunities) e as ameaças (threats) provenientes do ambiente externo à instituição; e os pontos fortes (strenghts) e fracos (weaknesses) do seu ambiente interno. Pontos fortes e fracos, oportunidades e ameaças são chamados de questões estratégicas. 0 diagnóstico dos riscos e das questões estratégicas deve resultar em ações específicas para a instituição, as quais precisam ser agrupadas em projetos que devem ser acompanhados, controlados e avaliados de modo a retroalimentar o processo.

É importante compreender a diferença entre projetos e processos. Projetos são conjuntos de ações planejadas para se atingir um fim específico. Cada projeto é único e tem começo, meio e fim. Processos 
são atividades da rotina institucional que contêm ações que devem ser repetidas, da melhor maneira possível, na execução das tarefas.

Para se identificar problemas e estimular a proposição de soluções criativas e a escolha daquelas mais viáveis, podem ser utilizados instrumentos provenientes do design thinking como o brainstorming, 0 brainwriting e o mind mapping (SOUTO-MAIOR, 2012). Brainstorming também conhecida como tempestade de ideias é uma técnica de dinâmica de grupo em que pessoas são convidadas a, em conjunto, expressar suas ideias (palavras-chave) sobre um problema e propor soluções. Uma ampla variedade de alternativas e a livre expressão da criatividade devem ser estimuladas, mas julgamentos críticos não. A partir das ideias levantadas, cabe ao grupo buscar um consenso e propor ações. Muito similar ao brainstorming, o brainwriting propõe que os participantes, ao invés de verbalizarem suas ideias para o líder do grupo, as registrem por escrito. Mind mapping ou mapa mental é um diagrama que procura correlacionar os problemas e soluções identificados pelo brainstorming ou brainwriting. Outra opção de dinâmica de planejamento estratégico é a Metodologia dos Cinco Por Quês, desenvolvida pela Toyota Production System com o intuito de aprimorar processos. 0 primeiro passo é selecionar um problema, a partir da perspectiva do usuário. Em seguida, para o problema dado, faz-se, para o grupo participante, uma pergunta que comece com 'por que ... ?'. A resposta deve ser curta e objetiva. As palavras-chave da resposta devem compor um segundo 'por que ... ?', e assim sucessivamente, cinco vezes. Os teóricos deste método acreditam que ele permite estruturar as respostas e encontrar o encadeamento de condicionantes que são responsáveis pelo problema, auxiliando na proposição de soluções mais objetivas. 0 resultado da aplicação deste método é um conjunto de ações, que devem ser testadas e aprimoradas para maior efetividade. Não se recomenda dinâmicas para vários problemas simultaneamente pois isso dificulta a avaliação posterior de quais, dentre as ações propostas, foram realmente efetivas (IPI, 2020).

0 diagnóstico das questões estratégicas pode fazer uso de um instrumento para análise de cenários conhecido como Análise ou Matriz SWOT43 (Figura 26), cujo objetivo é identificar e agrupar os fatores positivos e negativos, tanto do ambiente interno como externo à instituição (PANAGIOTOU, 2003; PENG \& VLAS, 2017).

\footnotetext{
43 SWOT, acrônimo para Strenghts, Weaknesses, Opportunities and Threats. Muitas vezes é traduzida para o português como FOFA, acrônimo para
} Forças, Oportunidades, Fraquezas e Ameaças. 
Figura 26. Análise SWOT

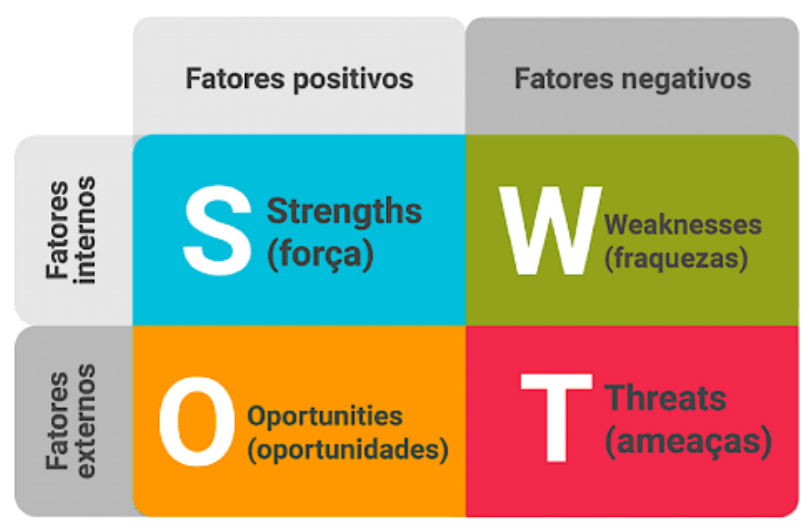

Fonte: CASAROTTO, 2019.

Os resultados da aplicação de instrumentos de planejamento estratégico podem ser organizados em matrizes de priorização (de projetos ou de processos). Uma matriz é um instrumento para classificar itens (riscos, propostas, ações, etc.) por ordem de importância. Alguns exemplos de matrizes são: Matriz GUT - Gravidade, Urgência e Tendência (Figura 27), Matriz RICE (Reach/Alcance, Impact/Impacto, Confidence/Confiança e Effort/Esforço), Matriz BASICO (Benefícios para a Organização, Abrangência dos Resultados, Satisfação do Cliente interno, Investimento Requerido, Cliente Externo Satisfeito, Operacionalidade Simples), Matriz Custo x Benefício (Figura 28), Matriz Urgência x Importância ou de Eisenhower (Figura 29), Matriz Esforço x Impacto (Figura 30).

Figura 27. Matriz GUT

\begin{tabular}{|c|ccc|}
\hline Nota & Gravidade & Urgência & Tendência \\
\hline $\mathbf{5}$ & extremamente grave & ação imediata & irá piorar rapidamente \\
\hline $\mathbf{4}$ & muito grave & muito urgente & irá piorar a curto prazo \\
\hline $\mathbf{3}$ & grave & urgente & irá piorar a médio prazo \\
\hline $\mathbf{2}$ & pouco grave & pouco urgente & irá piorar a longo prazo \\
\hline $\mathbf{1}$ & sem gravidade & pode esperar & não vai mudar \\
\hline
\end{tabular}

Fonte: adaptado de CAMARG0, 2018. 
Figura 28. Matriz Custo x Benefício

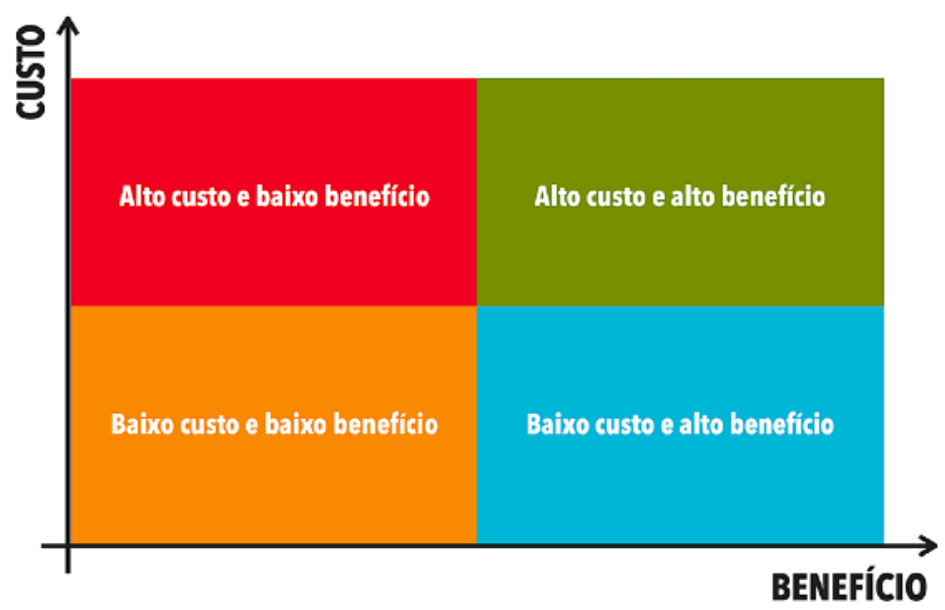

Fonte: adaptado de CAMARG0, 2018.

Figura 29. Matriz Urgência x Importância

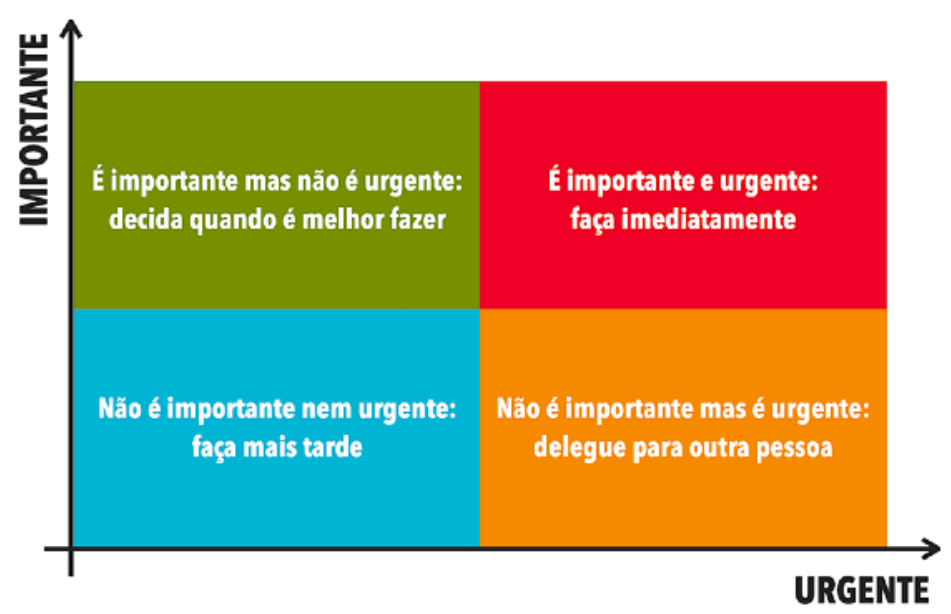

Fonte: adaptado de NA PRÁTICA, 2021.

Figura 30. Matriz Esforço x Impacto

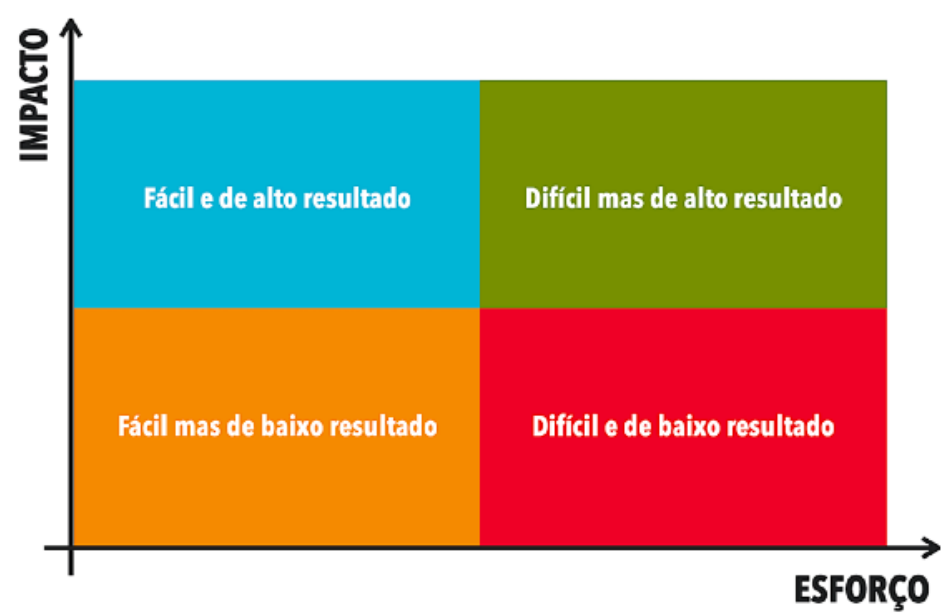

Fonte: adaptado de CAMARG0, 2018. 
Para que as ações identificadas tenham qualidade, a instituição deve nomear líderes que coordenem os projetos (gerência por projeto) e congreguem todas as esferas interessadas a participar (são os arranjos institucionais; segundo Gondim, 1994), utilizando parâmetros e critérios que contenham indicadores de desempenho (KAPLAN e NORTON, 1997), de modo que se possa medir a eficiência dos processos, a eficácia dos resultados e, assim, a efetividade das ações escolhidas.

A gestão de uma instituição cultural pode fazer uso do sistema de planejamento organizacional estratégico para definir seus planos (diretor, de manutenção, de emergência, etc.). Cada plano deve identificar os riscos (externos e internos) e definir as políticas institucionais (projetos e processos). As políticas devem prever medidas de avaliação do desempenho. As atividades podem se beneficiar do desenvolvimento tecnológico mediante o uso de ferramentas computacionais para gestão documental com a finalidade de criar e aprimorar protocolos (conjunto de procedimentos), facilitando a coleta e 0 tratamento dos dados e a posterior tomada de decisão, possibilitando o armazenamento de grandes quantidades de dados, e permitindo análises comparativas e extrapolações, além do compartilhamento de dados e soluções com outras instituições similares.

\subsubsection{Design thinking}

0 design thinking, termo ainda sem tradução adequada para o português, é um sistema de gestão organizacional desenvolvido para agregar inovação a serviços, produtos ou marcas, que propõe métodos para a solução de problemas complexos, utilizando instrumentos para a geração de ideias que consideram o usuário final mediante a organização de equipes interdisciplinares (BROWN, 2017). No método linear de pensamento, a solução de problemas costuma alternar entre um modo de pensar exclusivamente racional e analítico e um modo baseado apenas na intuição e na inspiração. 0 design thinking, por outro lado, propõe um caminho que seja uma combinação dos dois anteriores, fazendo uso do pensamento integrativo, proveniente do design, para construir mapas mentais (mind mapping), que são um instrumento para visualizar as conexões entre as diversas partes de um sistema e, assim, encontrar estratégias alternativas e inovadoras para solucionar problemas. Os mapas mentais permitem uma abordagem experimental, em um trabalho coletivo e com descobertas inesperadas (Figura 31). 
Figura 31. Mapas mentais

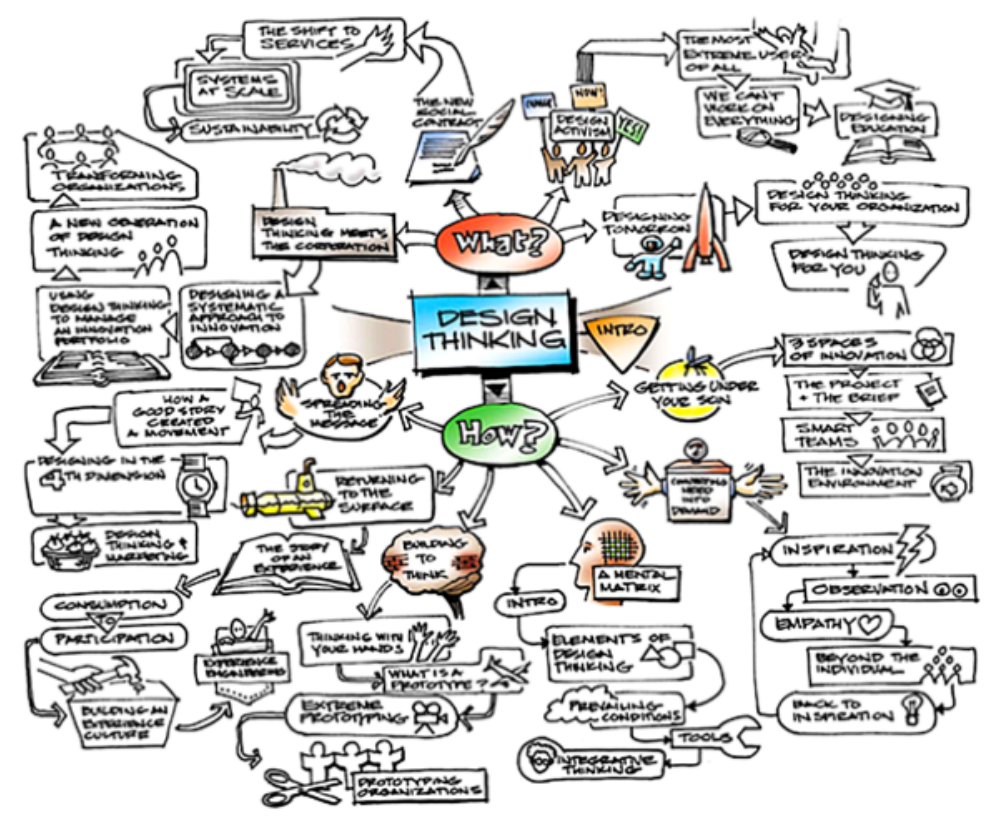

Fonte: BROWN, 2017.

Para que as conclusões sejam válidas, cada proposta precisa passar por três critérios de restrição (Figura 32):

1. ela é funcionalmente possível?

2. ela é viável, ou seja, sustentável para a instituição?

3. ela faz sentido para as pessoas?

Se a resposta for positiva para as três restrições, tem-se uma solução válida para um determinado problema (BROWN, 2017).

Figura 32. 0 processo para encontrar respostas a um problema

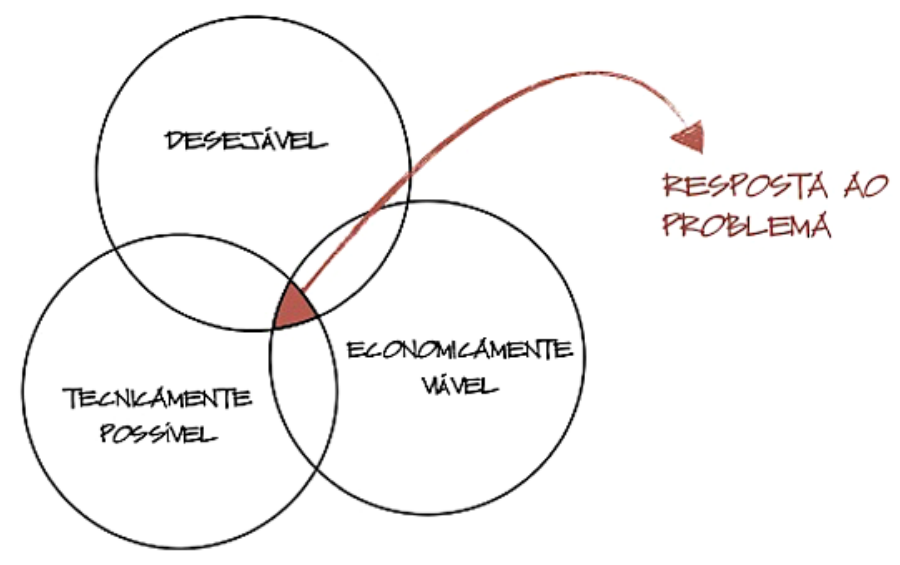

Fonte: OLOGIA, 2010 
Um projeto deve ser um meio para se chegar a um resultado concreto. Sendo assim, ele precisa ter metas claras, prazos finais bem definidos e maneiras de se avaliar a progressão dos trabalhos. Além disso, é preciso definir a equipe de projeto. Equipes interdisciplinares (em substituição ao modelo tradicional multidisciplinar $)^{44}$ são fundamentais pois cada especialista trará o seu ponto de vista. No entanto, isto exige profissionais que são conhecidos como "em forma de T", ou seja, na linha vertical, grande competência em sua área de conhecimento e, na linha horizontal, grande interesse por outras áreas do conhecimento.

0 design thinking propõe também que o modelo de uma única grande equipe de trabalho (modelo este que costuma trazer problemas políticos e burocráticos) seja substituído por várias equipes menores, cada uma com metas e prazos bem definidos. Nesta proposta, a incorporação de novas tecnologias para a gestão da informação e da comunicação é fundamental para que as pequenas equipes possam trabalhar em rede, compartilhando diagnósticos e resultados (Figura 33).

Figura 33. Trabalho em rede

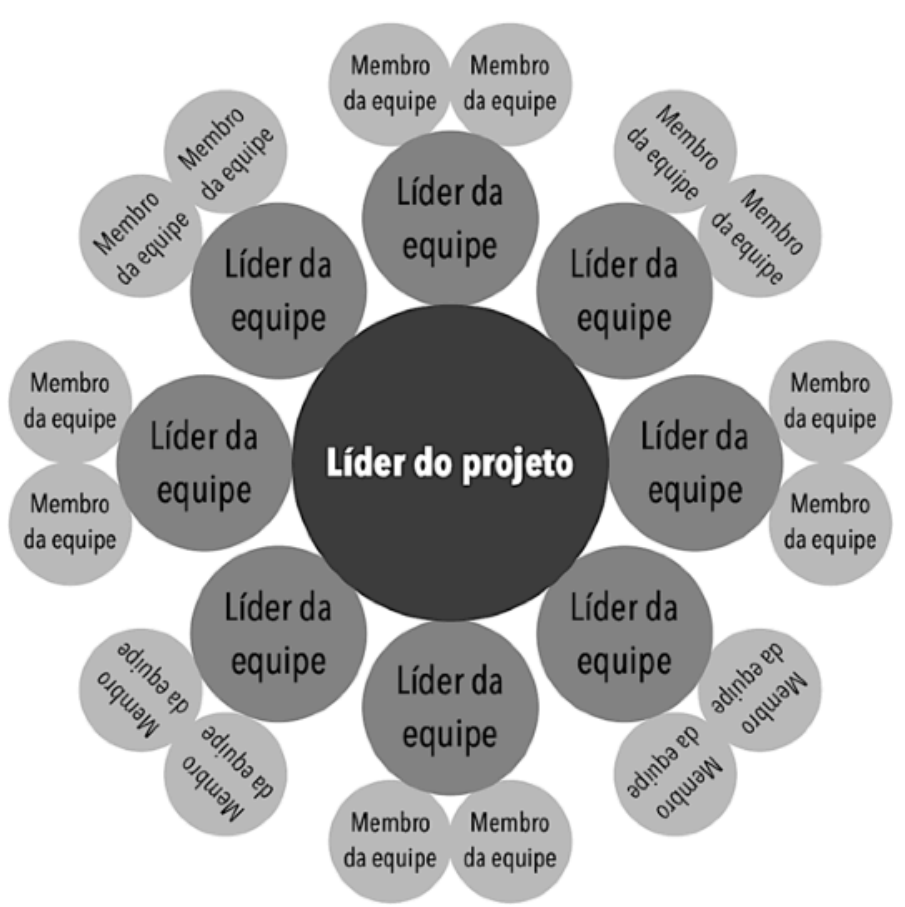

Fonte: a pesquisadora.

\footnotetext{
${ }^{44}$ No modelo multidisciplinar as pessoas normalmente realizam seus trabalhos independentemente e, posteriormente, cedem, a contragosto, em prol de um resultado final unificado. Em um trabalho interdisciplinar todos constroem as propostas em conjunto, sendo também corresponsáveis pelos resultados (BROWN, 2017).
} 
Na perspectiva do design thinking, o bem-estar das pessoas é atingido quando a instituição como um todo é criativa. A criatividade é entendida, neste contexto, como a percepção de que a experimentação, 0 risco e a iniciativa são atributos benéficos. A cultura institucional que inclui a permissão para falhar resulta em um ambiente psicológico (e, portanto, físico) mais relaxado e mais integrado (em oposição ao ambiente tradicional, rígido e fragmentado). No entanto, ressalta Brown (2017), esta mudança orientada à criatividade não é fácil e exige das instituições que repensem seus procedimentos e incluam uma cultura de bem-estar por meio de atividades e ambientes (adaptáveis, reconfiguráveis) nos quais as pessoas se sintam autorizadas a, diante de um problema, exercitar colaborativamente as habilidades da inspiração, idealização e implementação de soluções inesperadas e criativas.

\subsubsection{Gestão de riscos ao patrimônio}

A gestão de riscos ao patrimônio é uma ideia, em certa medida, emprestada das teorias econômicas de prevencionismo e particularmente inspirada na norma australiana e neozelandesa para gestão de riscos, AS/NZS 4360. Esta norma, criada em 1995, tinha como público-alvo as companhias de seguros e definia que "risco é a chance de que algo ocorra que terá um impacto nos objetivos" e que gestão de riscos é o processo utilizado "para identificar e explorar oportunidades para aprimorar os resultados organizacionais assim como reduzir as consequências negativas" (traduzido de AS/NZS 4360:2004). Assim, mensurar riscos significa estimar qual a probabilidade de que um evento adverso ocorra e, se ele ocorrer, qual o impacto esperado sobre o objeto da análise. No entanto, uma definição de risco mais universal e objetiva ainda está por ser criada (AVEN, 2010).

Eventos adversos, também chamados de perigos, são todos aqueles potencialmente prejudiciais, tenham eles causa natural ou humana, que podem provocar ferimentos ou perdas de vidas; danos a propriedades; perturbações econômicas e sociais; ou degradação ambiental (UNISDR, 2009). A suscetibilidade aos efeitos prejudiciais de um perigo é chamada de vulnerabilidade (física, social, econômica e ambiental) e a capacidade para se lidar com as consequências de um perigo (danos e perdas) é entendida como resiliência (MANYENA, 2006).

Quando o conceito de risco é aplicado ao patrimônio, ele se traduz como a "perda de valor esperada para um bem cultural" (PEDERSOLI JR. et al., 2016). Os riscos associados ao patrimônio podem ser divididos em: 
a. repentinos e catastróficos: terremotos, inundações, incêndios, guerras, dentre outros;

b. graduais e cumulativos: degradações químicas, físicas ou biológicas, problemas de gestão, e outros. Metodologias para a redução do risco de desastres (Disaster Risk Reduction - DRR) e gestão do risco de desastres (Disaster Risk Management - DRM) vêm sendo desenvolvidas com o objetivo de se encontrar mecanismos para minimizar seus impactos. Em 2005, durante a World Conference on Disaster Reduction da ONU foi produzido o 'Quadro de Ação de Hyogo' (Hyogo Framework for Action - HFA) para 2005 a 2015, que estabeleceu cinco prioridades, sendo a segunda a avaliação e o monitoramento de riscos (UNISDR, 2005). Em 2015, o HFA foi substituído pelo 'Quadro de DRR de Sendai' (Sendai Framework for Disaster Risk Reduction) para 2015 a 2030, que estabeleceu sete metas compreendidas em quatro ações prioritárias voltadas para a DRR: compreender o risco de desastres; fortalecer a governança em risco de desastres para poder gerenciar os riscos; investir na redução de desastres orientada à resiliência; e aumentar a preparação a desastres, para uma resposta efetiva e para se "refazer melhor" quando for preciso recuperar, reabilitar ou reconstruir (UNDRR, 2015). Dentre outros aspectos, os Quadros de Hyogo e de Sendai destacam a importância de se avaliar o impacto de perigos potenciais sobre o patrimônio cultural, dado seu valor insubstituível para a sociedade (UNDRR, 2013). Mesmo com a mobilização mundial em torno da preservação do patrimônio, diversas perdas continuam a acontecer todos os anos, sejam elas causadas por ações humanas ou por desastres naturais. A avaliação, gestão e redução de riscos nem sempre estão ao alcance do recursos institucionais (KINCAID, 2012). Além disso, o cálculo da probabilidade de um evento ocorrer será tanto mais preciso quanto maior a quantidade e a confiabilidade dos dados disponíveis (por exemplo, faltam dados relativos a determinados comportamentos humanos) e a regularidade no padrão de ocorrência (por exemplo, as incertezas associadas às mudanças climáticas). Assim, especificamente para o caso do patrimônio cultural, sua complexidade e a ausência de amplas bases de dados confiáveis torna muito difícil estabelecer, com precisão, suas vulnerabilidades (SMITH, 2013). No que tange a métodos de cálculo da resiliência das instituições frente a um desastre - educação e treinamento; tempo esperado; recursos necessários; e valor do bem - também não existe ainda muita informação disponível (CIMELLARO et al., 2010; ROMÃO et al., 2016). 
Para que uma avaliação de riscos adaptada ao patrimônio cultural seja confiável, é preciso que os procedimentos tenham fácil compreensão e execução, e que ela seja refeita periodicamente, criando um histórico de dados confiáveis ao longo dos anos. Resultados efetivos dependem de: modelos embasados em uma quantidade suficiente de informações precisas; base de dados correta sobre os itens em risco; instrumentos adequados para se avaliar as vulnerabilidades existentes; modelos adequados para a análise das consequências multidimensionais de um evento adverso; recursos humanos, econômicos e temporais para a execução das tarefas propostas (ROMÃo et al., 2016).

Na maioria dos casos, as instituições culturais precisam avaliar e monitorar um grande número de itens e coleções e, dadas as prováveis restrições de recursos, é importante que elas possam, em um primeiro momento, contar com metodologias simples, de análise preliminar dos riscos, que permitam compreender as prioridades e estabelecer os fundamentos para avaliações mais detalhadas. Para esta situação, o uso de instrumentos qualitativos de análise (identificação das ocorrências e proposição de soluções) pode ser a melhor maneira de se atender às demandas (ROMÃO et al., 2016). Além disso, resultados simples e objetivos podem ser mais facilmente comunicados a tomadores de decisão e formuladores de políticas (COX et al., 2005). Tem-se também que, em muitos casos, o uso de métodos quantitativos de avaliação de riscos é demasiadamente complexo, caro ou carece de dados confiáveis disponíveis (RAUSAND e HAUGEN, 2020).

ROMÃo et al. (2016) propõem um sistema simplificado de avaliação de risco (Figura 34) cujo objetivo é auxiliar instituições com grandes acervos, possibilitando que elas façam uma triagem preliminar dos itens em dois grupos: aqueles que exigem poucos cuidados e aqueles que precisam de avaliações mais detalhadas. Essa estratégia permite um melhor uso dos recursos disponíveis e foco nas situações de maior perigo. Para isso, é proposta uma análise qualitativa, com base em fluxogramas estruturados, dos seguintes aspectos: a probabilidade de um perigo; as consequências deste perigo; as vulnerabilidades e o valor de cada item; e a capacidade de recuperação institucional depois de um evento adverso. A metodologia proposta estabelece a possibilidade de um elemento do patrimônio ter risco desprezível $\left(R_{0}\right)$ ou então algum grau de risco, dividido em cinco classes de vulnerabilidade crescente $\left(V_{1}\right.$ a $\left.V_{V}\right)$. 
Figura 34. Metodologia para análise simplificada de riscos proposta por Romão et al. (2016): avaliação do nível de vulnerabilidade de um elemento do patrimônio cultural

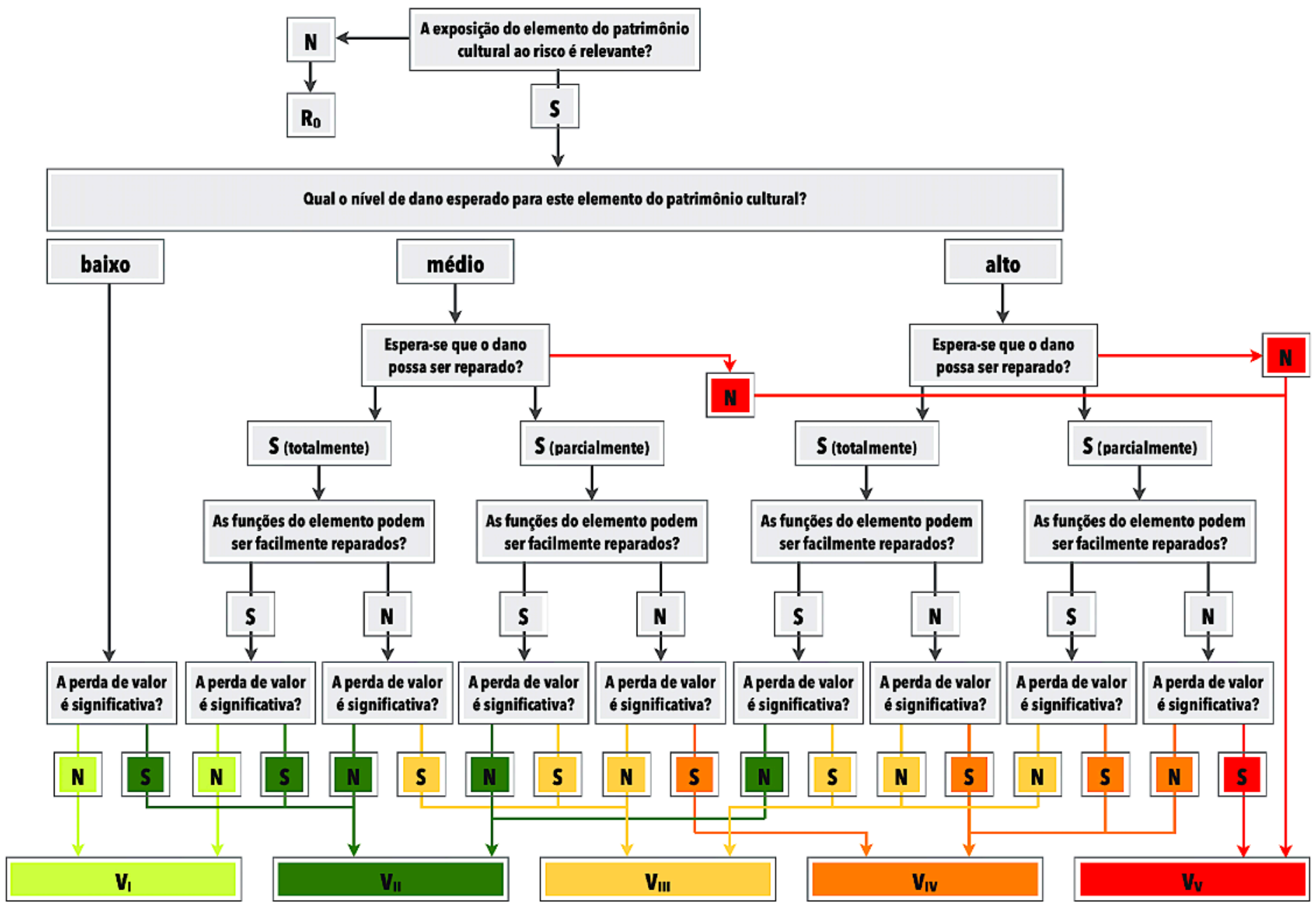

Legenda:

\section{S: $\operatorname{sim}$}

$\mathbf{R}_{\mathbf{0}}$ : risco desprezível

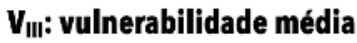

\section{N: não}

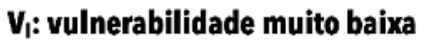
VIv: vulnerabilidade alta
$V_{\|}$: vulnerabilidade baixa $V_{\mathrm{v}}$ : vulnerabilidade muito alta

Fonte: traduzido e adaptado de Romão et al. (2016)

A gestão de riscos é um processo contínuo de identificação, atuação, monitoramento e ajuste das ações propostas com o intuito de minimizar impactos negativos nos objetivos propostos (Figura 35). Devido à sua importância para os mais variados setores econômicos, diversos sistemas multimétodos foram propostos, dentre eles destaca-se, a norma ISO 31000 - Risk Management - Guidelines (2018). 
Figura 35. As etapas do processo de gestão de riscos

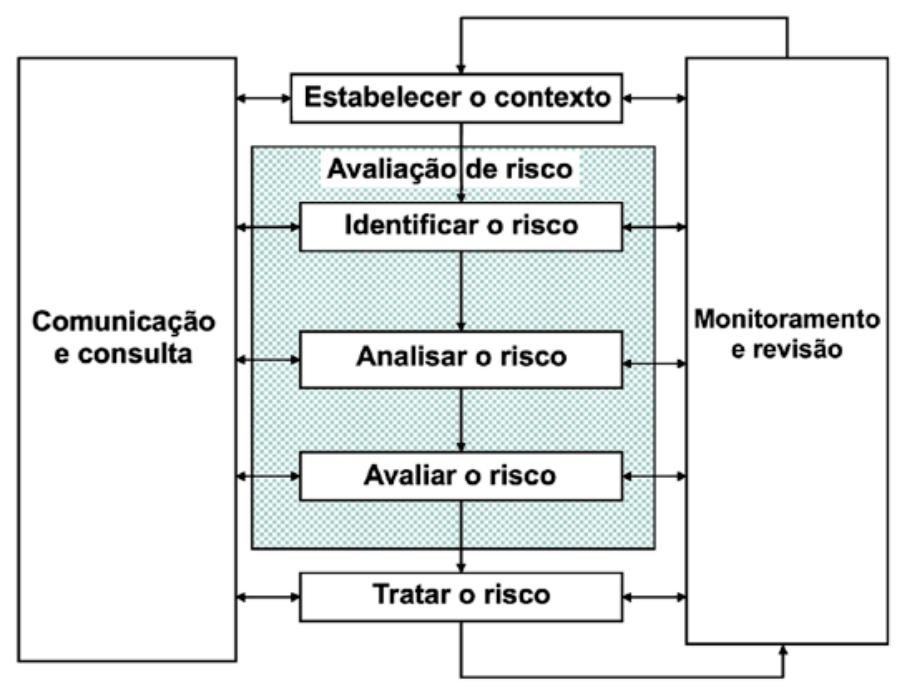

Fonte: adaptado e traduzido de ISO 31000:2009

0 método para gerenciar riscos ao patrimônio cultural, inspirado na norma AS/NZS 4360 e adaptado da norma ISO 31000, foi desenvolvido, na década de 1990, pelo ICCROM em conjunto com o CCI (Canadian Conservation Institute) e o ICN (Netherlands Institute for Cultural Heritage), tendo sido inicialmente pensado para as coleções de museus e, posteriormente, ampliado a todo conjunto do patrimônio cultural (CARVALHO, 2011), uma vez que o controle ambiental da edificação como um todo é mais eficiente do que a proteção do acervo apenas (TOLED0, 2010).

0 CCl, em 1996, criou a divisão de Serviços de Conservação Preventiva (Preventive Conservation Services - PCS) com o objetivo de definir as melhores estratégias para o gerenciamento ambiental de acervos. A gestão ambiental de áreas com acervos exige o conhecimento das variáveis climáticas correspondentes à latitude e à posição geográfica do edifício (macroclima), assim como das características próprias dos ambientes com acervos: sala (clima interno) e armário, vitrine, caixa, etc. (microclima). Este controle pode ser feito por sistemas passivos (manuais, naturais), mecânicos (ativos, forçados, artificiais) e/ou híbridos (alternativos, customizados). Os sistemas híbridos têm ganhado destaque por demonstrarem ser mais eficazes e sustentáveis (TOLED0, 2010).

Michalski (2004), como parte das pesquisas do PCS, identificou nove agentes de deterioração dos bens culturais: pragas, temperatura incorreta, umidade relativa incorreta, luz visível e UV, poluentes, fogo, água, forças físicas e atos criminosos. 
0 processo de avaliação e gerenciamento de riscos é cíclico e dividido em cinco etapas: (a) caracterizar o edifício e as coleções; (b) identificar os riscos; (c) analisar os riscos, dando a eles uma escala de importância; (d) determinar critérios de ação; e (e) tratar os riscos (Figura 36). Duas outras etapas permeiam todo o processo: a documentação dos trabalhos e o monitoramento dos dados $(\mathrm{CCl}, 2018)^{45}$.

Figura 36. As etapas da gestão de riscos, adaptadas da norma ISO 31000 para o patrimônio cultural

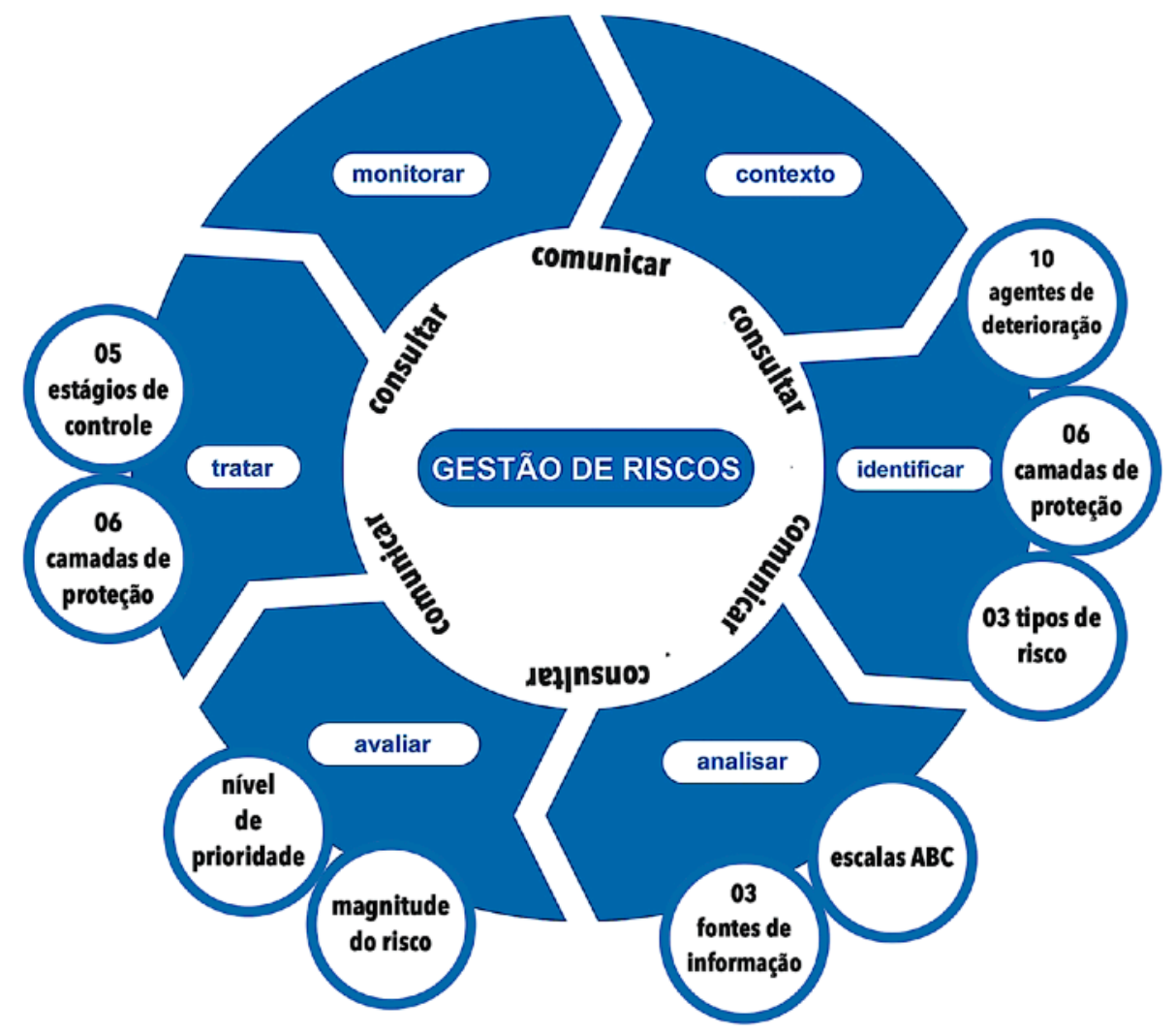

Fonte: adaptado de PEDERSOLI JR. et al., 2016.

As etapas propostas para a gestão de riscos a acervos são (PEDERSOLI JR. et al., 2016):

1. contexto: compreender os elementos específicos que caracterizam os aspectos políticos, organizacionais, administrativos, financeiros, legais, sócio-culturais e físicos do ambiente interno e externo da instituição.

2. identificar: verificar tudo "o que pode dar errado e causar dano ou perda de valor a um bem cultural", comunicar e treinar todos os funcionários quanto aos riscos existentes. Devem ser identificados:

45 Para mais informações, ver:https://www.canada.ca/en/conservation-institute/services/risk-management-heritage-collections.html 
a. os dez agentes de deterioração46 (Figura 37):

- forças físicas: eventos climáticos, uso e transporte inadequado, superpopulação, e outros;

- crimes: roubo, vandalismo, terrorismo, pichações, outros atos criminosos;

- fogo: possíveis causas de incêndio (balões, velas, curto circuito, reformas e outros) dentro e fora da instituição;

- água: possíveis causas de danos por água (vazamentos, inundações, temporais, combate a incêndio, e outros) dentro e fora da instituição;

- pragas: fungos e bactérias, insetos, aves e mamíferos;

- poluentes: material particulado, gases, líquidos, adesivos produzidos no ambiente interno ou externo;

- luz e UV: possíveis fontes de iluminação natural ou artificial com intensidade incorreta;

- temperatura incorreta: possíveis causas de temperatura elevada ou acentuada variação térmica;

- UR incorreta: possíveis causas de umidade relativa muito alta ou muito baixa ou acentuada variação nos níveis de UR;

- dissociação: falhas em gestão, documentação, guarda, transporte ou exposição de um item.

Figura 37. Exemplo de matriz de hierarquização dos riscos por agente de deterioração realizado pela Divisão de Coleções Especiais da Biblioteca Universitária da Universidade Federal de Minas Gerais (UFMG)

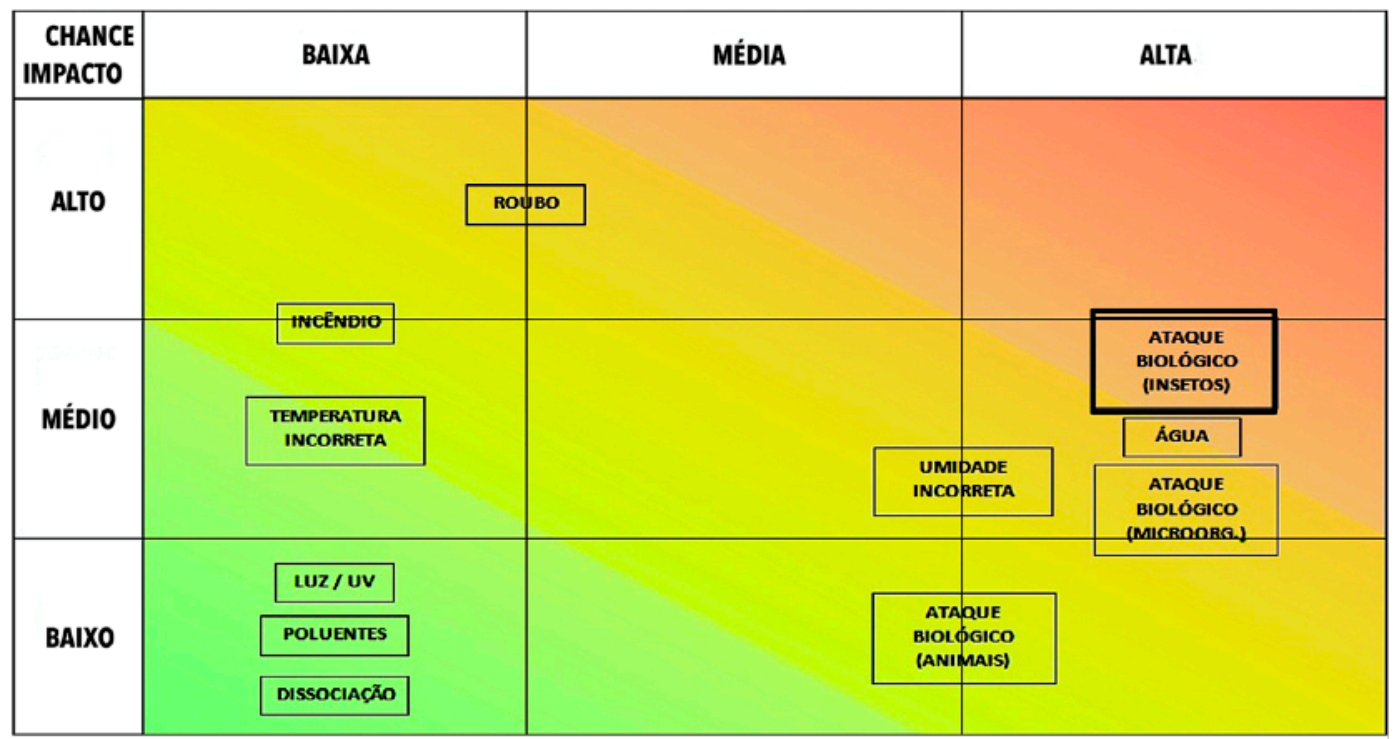

Fonte: GONÇALVES, 2012.

46 Pedersoli Jr., enquanto pesquisador do CCl, acrescentou, aos nove agentes de deterioração definidos por Michalski um décimo agente: a dissociação. 
b. as seis camadas de proteção:

- suporte: características do material (papel, madeira, plástico, metal, pedra, hard-disk, dentre outros); - armazenamento: características da embalagem, estante, vitrine, dentre outros;

- sala: características do ambiente onde o item está exposto ou guardado;

- edifício: características da construção para guarda e/ou exposição do bem;

- localização: características do terreno e seu entorno;

- região: características da cidade, região do país.

c. os três tipos de risco:

- eventos raros: não esperados no tempo de uma geração, não fazem parte da experiência dos funcionários;

- eventos frequentes: esperados em toda geração, fazem parte da experiência dos funcionários;

- processos cumulativos: frequentemente associados ao 'envelhecimento' do bem, podem ser contínuos ou intermitentes.

3. analisar: criar uma escala de dimensão do risco e de prioridades. Deve-se analisar:

a. as escalas numéricas $A B C$ de magnitude do risco (MR), descritas a seguir:

$-M R=A+B+C($ risco máximo possível $M R=15)$;

- a escala A quantifica a frequência de ocorrência de um evento ou a taxa de ocorrência de um processo (a cada 1 ano, 3 anos, ..., 10.000 ou 30.000 anos) e atribui um valor entre 5 e 1/2;

- a escala B quantifica o tamanho da perda de valor de um item quando afetado por um risco (entre $100 \%$, tudo e $0 \%$, nada) e atribui um valor entre 5 e $1 / 2$;

- a escala C quantifica o tamanho da perda de valor do patrimônio cultural como um todo quando um item deste conjunto é danificado ou perdido (entre 100\%, todo e 0\%, nenhum) e atribui um valor entre 5 e 1/2.

b. as três fontes de informação sobre causas de riscos:

- estatísticas regionais: tabelas climáticas, GIS (Geographic Information Systems), dados estatísticos (de governos, ongs, outras instituições), dentre outros;

- conhecimento local: pesquisas (entrevistas e questionários), conversas, documentação do edifício e seu entorno, dentre outros;

- conhecimento técnico-científico: literatura técnica-científica, projetos da edificação, normas e regulamentos, dentre outros. 
4. avaliar: ao se classificar os riscos identificados para as seis camadas de proteção quanto a perda de valor (Tabela 04) e nível de prioridade (Tabela 05), conforme a magnitude de risco calculada pela escala $A B C$, é possível decidir qual o plano de ação mais adequado à preservação de um acervo específico (Figura 38).

a. perda de valor

Tabela 04. Perda de valor conforme a magnitude do risco (MR)

\begin{tabular}{|c|c|}
\hline MR & Perda esperada de valor para o bem \\
\hline 15 & $100 \%$ em 1 ano \\
\hline 14,5 & $30 \%$ ao ano \\
\hline 14 & $10 \%$ ao ano $=100 \%$ em 10 anos \\
\hline 13,5 & $3 \%$ ao ano $=100 \%$ em 30 anos \\
\hline 13 & $10 \%$ em 10 anos $=100 \%$ em 100 anos \\
\hline 12,5 & $3 \%$ em 10 anos $=100 \%$ em 300 anos \\
\hline 12 & $1 \%$ em 10 anos $=10 \%$ em 100 anos \\
\hline 11,5 & $0,3 \%$ em 10 anos $=3 \%$ em 100 anos \\
\hline 11 & $1 \%$ em 100 anos \\
\hline 10,5 & $0,3 \%$ em 100 anos \\
\hline 10 & $0,1 \%$ em 100 anos $=1 \%$ em 1.000 anos \\
\hline 9,5 & $0,03 \%$ em 100 anos $=0,3 \%$ em 1.000 anos \\
\hline 9 & $0,1 \%$ em 1.000 anos $=1 \%$ em 10.000 anos \\
\hline \multicolumn{2}{|l|}{8,5} \\
\hline 8 & $0,01 \%$ em 1.000 anos $=0,1 \%$ em 10.000 anos \\
\hline \multicolumn{2}{|l|}{7,5} \\
\hline 7 & $0,001 \%$ em 1.000 anos \\
\hline \multicolumn{2}{|l|}{6,5} \\
\hline 6 & 0,0001\% em 1.000 anos \\
\hline \multicolumn{2}{|l|}{5,5} \\
\hline 5 & 0,00001\% em 1.000 anos \\
\hline
\end{tabular}

Fonte: adaptado de PEDERSOLI JR. et al., 2016. 
b. nível de prioridade

Tabela 05. Nível de prioridade conforme a magnitude do risco (MR)

\begin{tabular}{|c|c|}
\hline MR & Perda esperada de valor para o bem \\
\hline 15 & \multirow{4}{*}{$\begin{array}{l}\text { Prioridade catastrófica: todos ou quase todos os bens correm } \\
\text { o risco de serem perdidos nos próximos anos. }\end{array}$} \\
\hline 14,5 & \\
\hline 14 & \\
\hline 13,5 & \\
\hline 13 & \multirow{4}{*}{$\begin{array}{l}\text { Prioridade extrema: danos significativos ou perda total de } \\
\text { parte dos bens é provável na próxima década; perda total é } \\
\text { possível em um século. }\end{array}$} \\
\hline 12,5 & \\
\hline 12 & \\
\hline 11,5 & \\
\hline 11 & \multirow{4}{*}{$\begin{array}{l}\text { Prioridade alta: perdas significativas de uma pequena parte } \\
\text { dos bens ou pequenas perdas em boa parte do acervo são } \\
\text { esperadas para o próximo século. }\end{array}$} \\
\hline 10,5 & \\
\hline 10 & \\
\hline 9,5 & \\
\hline 9 & \multirow{4}{*}{$\begin{array}{l}\text { Prioridade média: pequenos danos ou perdas ao longo de } \\
\text { vários séculos ou perdas significativas de uma pequena } \\
\text { parte dos bens ao longo de vários milênios. }\end{array}$} \\
\hline 8,5 & \\
\hline 8 & \\
\hline 7,5 & \\
\hline 7 & \multirow{5}{*}{$\begin{array}{l}\text { Prioridade baixa: danos ou perdas mínimas ou } \\
\text { insignificantes ao longo de vários milênios. }\end{array}$} \\
\hline 6,5 & \\
\hline 6 & \\
\hline 5,5 & \\
\hline 5 & \\
\hline
\end{tabular}

Fonte: adaptado de PEDERSOLI JR. et al., 2016. 
Figura 38. Exemplo de avaliação pela escala $\mathrm{ABC}$, para cada risco identificado em uma instituição cultural

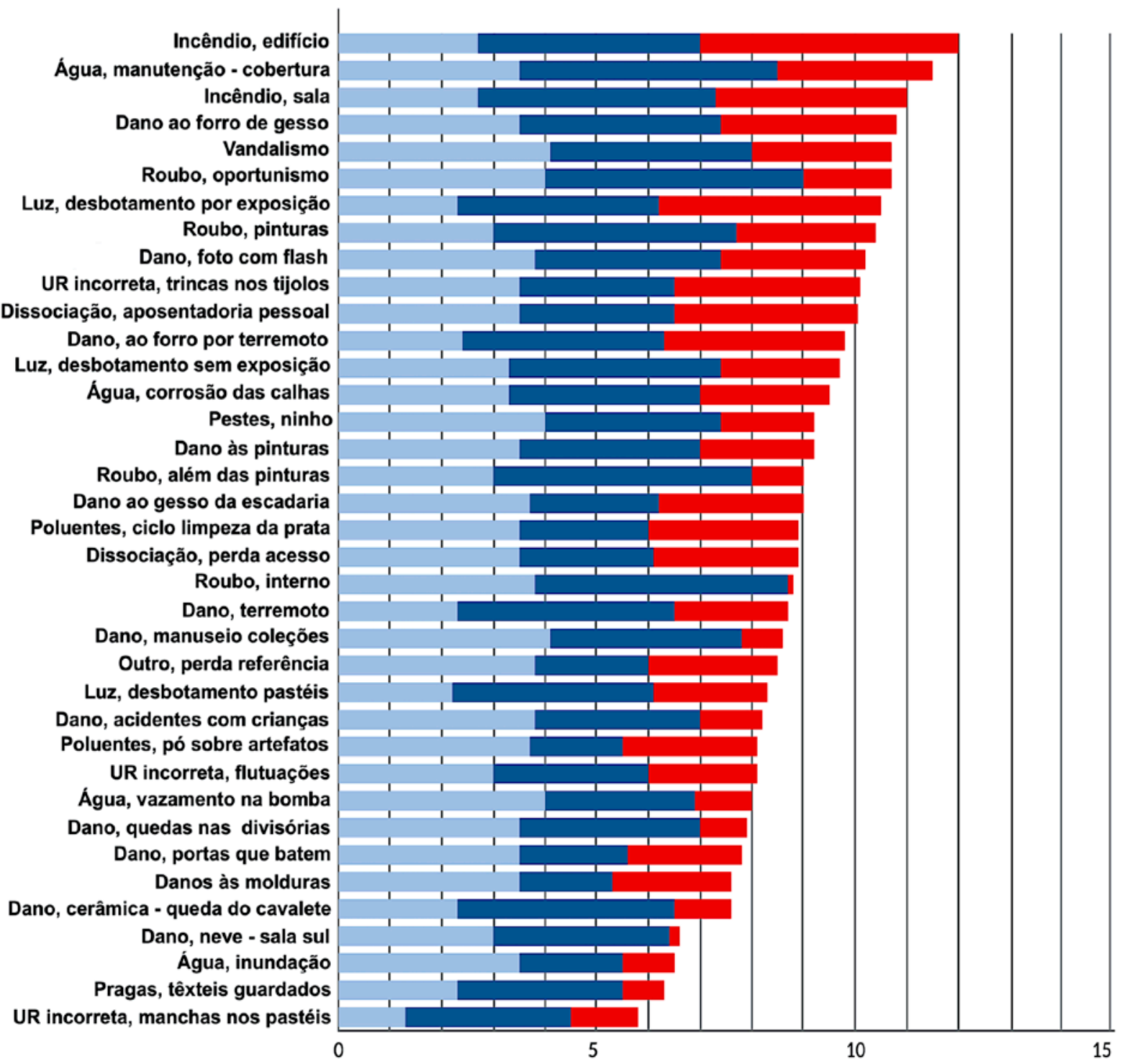

escala A: Qual a frequência de ocorrência do evento?

Em quantos anos se acumula um determinado nível de dano?

escala B: Fração da perda de valor para cada item afetado

escala C: Porcentagem do valor do patrimônio afetado

Fonte: adaptado de PEDERSOLI JR. et al., 2016.

5. tratar: propor medidas efetivas que possam mitigar ou eliminar os riscos observados. Deve-se verificar:

a. as seis camadas de proteção (suporte, armazenamento, sala, edifício, localização e região):

considerar, para cada uma das seis camada, quais medidas podem ser adotadas para minorar os

riscos aos objetos. 
b. os cinco estágios de controle:

- evitar situações que causem ou elevem o risco; é o estágio mais simples e mais efetivo de todos;

- bloquear os dez agentes de deterioração, criando uma barreira de proteção entre os agentes e os objetos;

- detectar os efeitos dos agentes de deterioração sobre os bens, monitorando os objetos e agindo assim que um problema é identificado;

- responder a um dano presente, o que inclui o planejamento e a preparação para uma resposta rápida e efetiva;

- recuperar o bem que sofreu um dano ou uma perda, quando os estágios anteriores falharam.

6. monitorar: verificar regularmente as medidas implementadas e, quando necessário, fazer mudanças e ajustes para aprimorar os resultados.

0 monitoramento dos riscos deve fazer uso de instrumentos que permitam avaliar os procedimentos, planejar melhorias e adotar medidas orientadas à prevenção e redução da chance de que algo aconteça causando danos e perda de valor para acervos, bem como à mitigação dos perigos e efeitos negativos que não puderam ser evitados (IBRAMa; IBRAMb, 2017). Como resultado da aplicação dos instrumentos de monitoramento, tem-se relatórios técnicos periódicos com a análise dos dados coletados.

Spinelli e Pedersoli Jr., no Plano de Gerenciamento de Riscos: salvaguarda e emergência (2010) para a Biblioteca Nacional, no Rio de Janeiro, descrevem quais os requisitos necessários à implantação de um plano de gestão de riscos bem sucedido:

a. comprometimento institucional em todos os níveis, em particular da presidência e dos demais responsáveis pelos diferentes setores da instituição;

b. atitude proativa de todos os funcionários para que se desenvolva uma "cultura de gerenciamento de riscos" na instituição;

c. constituição formal de uma equipe interna interdisciplinar para a implantação do gerenciamento de riscos na instituição;

d. disponibilização de recursos financeiros para a implementação de medidas de tratamento de riscos, conforme os graus de urgência e de prioridade determinados pela avaliação dos riscos; 
e. monitoramento, documentação e revisão contínuos da aplicação do plano, cuja atualização sistemática deve ser feita conforme a necessidade ou com a periodicidade preestabelecida (por exemplo, a cada seis meses);

f. comunicação e consulta contínuas a todas as partes envolvidas e interessadas, assegurando ampla inclusão, participação ativa ao longo do processo e uso da informação e do conhecimento disponíveis. A avaliação de um patrimônio cultural têm como resultado um mapa com o valor de cada item do acervo (MICHALSKI, 2004). A partir da análise dos riscos, devem ser feitos cenários de atuação, comparando-se a importância do risco com as incertezas associadas a ele. Também deve ser elaborado um Plano de Emergência, a ser publicado na forma de um manual para que todos os funcionários tenham conhecimento de como agir no caso de um evento adverso.

0 Plano de Emergência deve abordar as quatro áreas da proteção (DORGE e JONES, 1999):

1. prevenção: 0 que pode ser feito para minimizar perigos e efeitos negativos a usuários (visitantes e funcionários), coleções e edificações;

2. preparação: quais as medidas necessárias para se equipar a instituição e treinar as pessoas que precisarão lidar com a emergência;

3. resposta: quais as atitudes a serem tomadas, caso um evento adverso ocorra, para minimizar ferimentos e perdas;

4. recuperação: como preparar e treinar os funcionários para que, após um evento adverso, a situação possa retornar à normalidade.

Um Plano de Emergência deve conter uma descrição dos princípios e objetivos que o norteiam, das responsabilidades do corpo diretivo e, dentre as equipes de resposta, quem são os líderes, quem deve ser acionado e quando, e o que cada um deve fazer, dependendo do grau da emergência. Para que seja efetivo, o Plano precisa ter o conhecimento e o apoio de todos na instituição, deve ser simples, se concentrando nas ações mais importantes, deve ser flexível, pois em uma emergência sempre existem situações inesperadas, deve ser realista quanto à capacidade técnico-financeira da instituição e deve ser testado frequentemente, por meio de simulados, e ajustado, quando necessário, afinal, em instituições culturais, pessoas, acervos e exposições se modificam com frequência (DORGE e JONES, 1999). 
Um Plano de Emergência pode fazer parte de um plano maior, de Gestão de Riscos, que deve conter:

a. contexto institucional: análise detalhada das características próprias da instituição, com base nos documentos:

- Plano Institucional (Museológico), que identifica a missão da instituição, tanto para o público interno quanto para o externo, e guia os procedimentos administrativos em geral, e a gestão de riscos em particular;

- diagnóstico das características geográficas, climáticas e construtivas.

b. identificação dos riscos e das formas de controle e tratamento.

c. definição de normas de conduta e procedimentos essenciais para a normatização da gestão de riscos (IBRAMa, 2017).

Um Plano de Gestão de Riscos só será efetivo se for um trabalho interdisciplinar (curadoria, documentação, exposição, conservação/restauração, segurança e gestão), visando garantir as melhores condições para a segurança e a preservação dos acervos.

Entre 2007 e 2011, o CCl, em conjunto com o ICCROM (2018), desenvolveram um método simplificado do tipo passo-a-passo para a reorganização de reservas técnicas de pequeno porte (até $250 \mathrm{~m}^{2}$ e 5 funcionários), mas que pode ser adaptado para espaços maiores desde que eles sejam setorizados, chamado de RE-ORG. 0 objetivo era contribuir com uma primeira aproximação na direção de uma gestão mais eficiente das áreas de guarda de acervos em museus, galerias, bibliotecas e arquivos e da mitigação dos riscos. Este método faz uso de tecnologias digitais ${ }^{47}$ para receber 0 feedback das instituições participantes e, assim, ser atualizado periodicamente.

Os autores observam que, muitas vezes, os tomadores de decisões têm dificuldades em perceber a relevância de se avaliar riscos e introduzir melhorias nas áreas de guarda de acervos. Eles apontam três situações principais (CCI / ICCROM, 2018):

a. os tomadores de decisão não estão cientes dos riscos ou não os percebem como tal: neste caso, recomenda-se que a instituição utilize o 'Instrumento para Auto-Avaliação dos Acervos em Reservas Técnicas'48, que é um checklist para verificação rápida da escala de risco e da necessidade ou não de

\footnotetext{
${ }^{47}$ Mais informações em: https://www.iccrom.org/themes/preventive-conservation/re-org/method, acesso em nov. 2020.

480 checklist pode ser encontrado no endereço: https://www.iccrom.org/sites/default/files/2017-11/en_0_selfevaluation_nov2017.pdf, , acesso em nov. 2020.
} 
se realizar o método RE-ORG completo. Ele é dividido em quatro componentes: gestão; edifício \& espaços; mobiliário \& pequenos equipamentos; e acervo, cada uma com 8 a 10 afirmações. Para cada afirmação, o avaliador deve selecionar a opção de resposta mais adequada. Para cada opção, corresponde uma pontuação. 0 total de pontos indica a escala de risco, por seção e total. 0 resultado pode ser apresentado aos tomadores de decisão;

b. os tomadores de decisão não querem chamar atenção para eventuais problemas em um setor que está oculto dos olhares públicos: neste caso, é preciso conscientizá-los de que reservas técnicas ao redor do mundo enfrentam os mesmos desafios, o que pode ser comprovado pela pesquisa 'ICCROM-UNESCO Pesquisa Internacional sobre Reservas Técnicas 2011', realizada em 1.490 museus de 136 países $49 ;$

c. os tomadores de decisão acreditam que melhorias custam muito caro e que a instituição não tem condições de arcar com elas: neste caso, o método RE-ORG pode auxiliar na identificação dos riscos, na definição das prioridades, na busca por soluções criativas e em uma melhor alocação dos recursos disponíveis.

0 método RE-ORG apresenta instruções de como a equipe de trabalho deve proceder para avaliar a reserva técnica da sua instituição. 0 método está dividido em quatro fases (CCI / ICCROM, 2018):

- fase 1 - preparação: definir equipes e espaços de trabalho; reunir documentos, materiais, plantas arquitetônicas; documentar e registrar visualmente a situação presente da reserva técnica.

- fase 2 - relatório sobre a situação atual da reserva técnica: preparar relatório com a análise dos dados e registros coletados na fase anterior, a ser entregue para diretores e tomadores de decisão.

- fase 3 - plano de ação para a reserva técnica: a partir do diagnóstico presente no relatório elaborado na fase anterior, planejar passo-a-passo as ações para a reorganização da reserva técnica.

- fase 4 - implementação da reorganização da reserva técnica: executar o plano de ação e documentar todas as atividades realizadas; entregar para a direção um relatório das atividades; iniciar o plano de monitoramento continuado das mudanças realizadas (Figura 39).

\footnotetext{
49 Resultados disponíveis em: https://www.iccrom.org/sites/default/files/ICCROM-UNESCO\%20International\%20Storage\%20Survey\%202011_en.pdf, acesso em jun. 2020.
} 
Figura 39. Exemplo de registro do antes e depois da aplicação do método RE-ORG no Centro Nacional de Artes Indira Gandhi, em Nova Déli. 0 projeto foi realizado em 10 dias com uma equipe de 10 pessoas
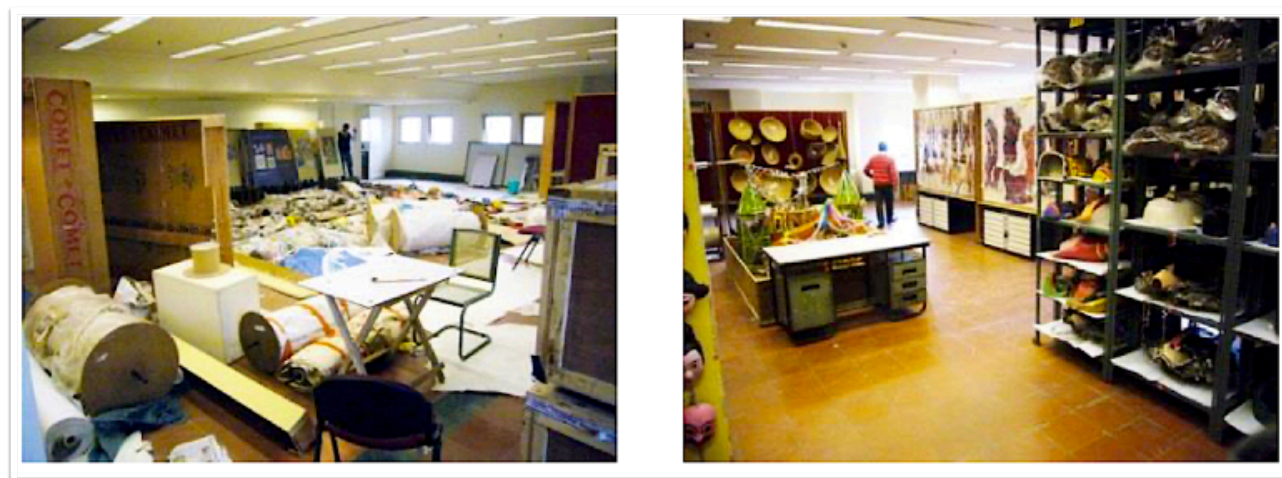

Fonte: CCI / ICCROM, 2018.

A avaliação utiliza dez critérios de qualidade:

1 - presença (ou não) de funcionário treinado responsável pelo espaço;

2 - todos os itens guardados estão (ou não) inventariados;

3 - existe (ou não) áreas de apoio dedicadas (escritórios, laboratórios, depósitos, etc.);

4 - nenhum (ou algum) objeto está apoiado diretamente sobre o piso;

5 - todos os objetos estão (ou não) identificados (e podem ser encontrados em até três minutos);

6 - todos os objetos podem (ou não) ser removidos da sala sem que seja preciso mover mais do que dois outros itens;

7 - todos os objetos estão (ou não) organizados por categorias;

8 - políticas e procedimentos existem e são aplicados (ou não);

9 - edifício e área de guarda oferecem (ou não) proteção adequada;

10 - nenhum (ou algum) objeto apresenta processo de deterioração e encontra-se (ou não) disponível para exposição ou outra atividade institucional.

Se os critérios 1 a 7 não estiverem sendo atendidos, uma reorganização do espaço no curto prazo pode ser suficiente. Já os critérios 8 a 10, quando não atendidos, podem exigir intervenções mais complexas, de médio ou longo prazo. 
0 RE-ORG divide a reserva técnica em quatro componentes de avaliação (Figura 40):

- acervo: dados qualitativos e quantitativos sobre as coleções podem auxiliar na identificação de necessidades específicas;

- mobiliário e pequenos equipamentos: a avaliação da adequação de mobiliários e equipamentos pode ajudar a criar um espaço mais eficiente;

- edifício e espaços: a avaliação do edifício permite identificar riscos potenciais e a avaliação dos espaços pode ajudar a aprimorar o leiaute;

- gestão: a avaliação de políticas e procedimentos, funções e responsabilidades pode auxiliar no aprimoramento das atividades institucionais.

Figura 40. As quatro componentes de avaliação

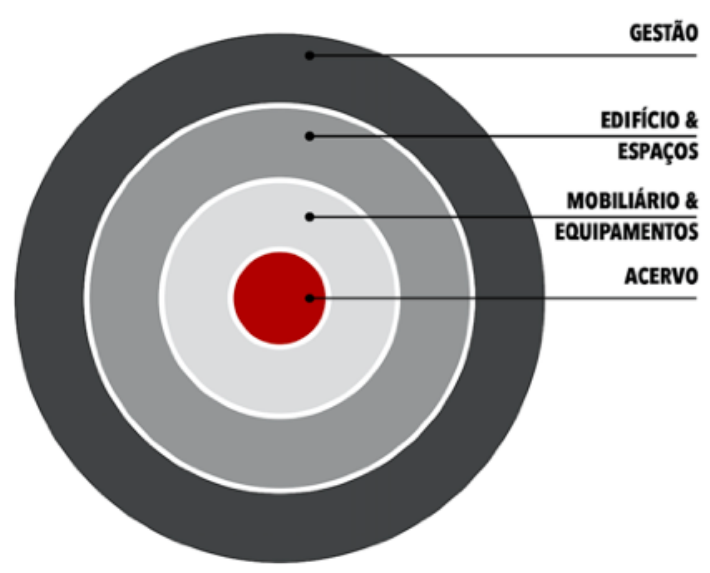

Fonte: traduzido de CCI / ICCROM, 2018

Como parte da gestão de riscos aos acervos, a instituição precisa ser capaz de definir e assegurar condições de guarda adequadas. No entanto, o diagnóstico das condições ambientais para espaços de armazenamento e exposição são extremamente complexas. Apesar da existência de normas e regulamentos, percebe-se ainda uma ausência de protocolos e estratégias que sejam de fácil uso, considerem todas as variáveis e permitam ao conservador monitorar e controlar com efetividade as condições dos ambientes e das coleções (D'AGOSTINO et al., 2015).

Tem-se, a seguir, dois exemplos de propostas de procedimentos para diagnóstico ambiental de áreas com acervos. 
Martens (2012) propõe uma metodologia para avaliação climática de ambientes para a guarda e exposição de coleções que se inicia pela análise dos dados de T e UR internos. Os valores obtidos para um ano (ou mais) são anotados sobre a carta psicrométrica (Figura 41) e correlacionados com uma matriz da distribuição dos dados climáticos ao longo do período da análise.

Figura 41. Exemplo de gráfico para avaliação do clima interno

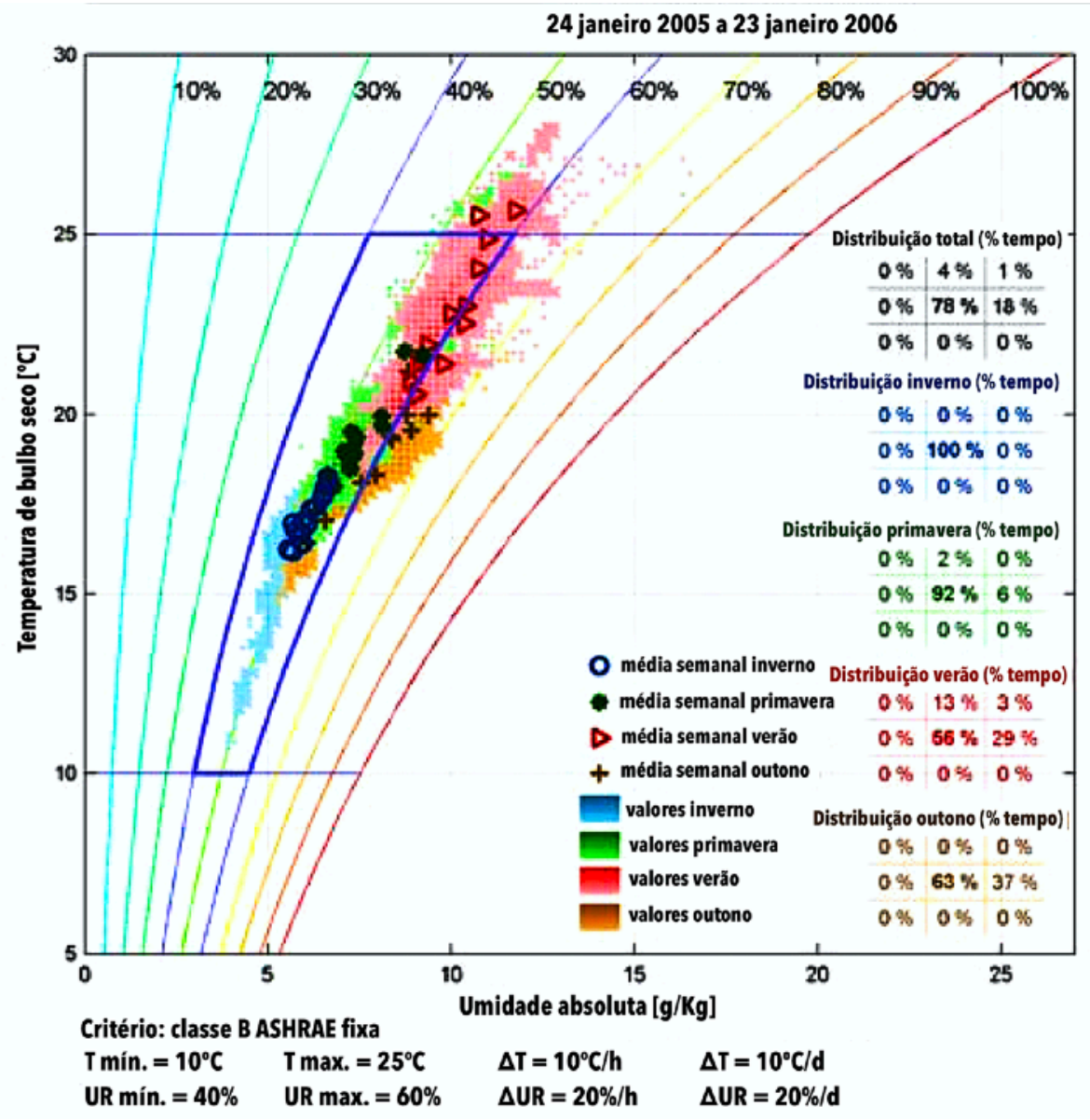

Fonte: traduzido de MARTENS, 2012

A área demarcada em azul sobre a carta psicrométrica indica o intervalo de T e UR fixados pela classe de controle ASHRAE escolhida pela análise, neste exemplo a classe B.

Ao lado da carta são apresentadas matrizes $3 \times 3$ da distribuição dos dados para cada estação do ano. Cada célula indica a quantidade de dados contidos em uma condição específica, conforme explicado no Quadro 13, a seguir: 
Quadro 13. Matriz de classificação dos dados climáticos, a partir das recomendações da norma ASHRAE

\begin{tabular}{l|l|l}
$\begin{array}{l}\text { Muito seco e muito quente } \\
\text { T }>\text { Tmax. norma } \\
\text { UR }<\text { URmin. norma }\end{array}$ & $\begin{array}{l}\text { Muito quente } \\
\text { T }>\text { Tmax. norma } \\
\text { URmin. norma } \leq \text { UR } \leq \text { URmax. norma }\end{array}$ & $\begin{array}{l}\text { Muito úmido e muito quente } \\
\text { T }>\text { Tmax. norma } \\
\text { UR }>\text { URmax. norma }\end{array}$ \\
\hline $\begin{array}{l}\text { Muito seco } \\
\text { Tmin. norma } \leq \text { T } \leq \text { Tmax. norma } \\
\text { UR }<\text { URmin. norma }\end{array}$ & $\begin{array}{l}\text { Adequado } \\
\text { Tmin. norma } \leq T \leq \text { Tmax. norma } \\
\text { URmin. norma } \leq \text { UR } \leq \text { URmax. norma }\end{array}$ & $\begin{array}{l}\text { Muito úmido } \\
\text { Tmin. norma } \leq T \leq \text { Tmax. norma } \\
\text { UR }>\text { URmax. norma }\end{array}$ \\
\hline $\begin{array}{l}\text { Muito seco e muito frio } \\
\text { T<Tmin. norma } \\
\text { UR }<\text { URmin. norma }\end{array}$ & $\begin{array}{l}\text { Muito frio } \\
\text { T }<\text { Tmin. norma } \\
\text { URmin. norma } \leq \text { UR } \leq \text { URmax. norma }\end{array}$ & $\begin{array}{l}\text { Muito úmido e muito frio } \\
\text { T }<\text { Tmin, norma } \\
\text { UR }>\text { URmax. norma }\end{array}$
\end{tabular}

Fonte: traduzido e adaptado de MARTENS, 2012.

Martens (2012) sugere que, em seguida, seja feita uma segunda matriz, dos riscos ao acervo, para cada ambiente avaliado, que contenha, no eixo "y", os tipos de materiais de suporte presentes na sala (papel, madeira, pintura, escultura, tecido, etc.) e, no eixo " $x$ ", os possíveis agentes (causas) de deterioração mecânica, biológica e/ou química identificados (Figura 42). Para cada célula da matriz, a partir da análise realizada, anota-se o risco determinado, conforme a escala: seguro; risco baixo (RB); risco médio (RM); ou risco alto (RA). Para cada nível de risco propõe-se que seja associada uma cor específica.

Figura 42. Exemplo de matriz de risco, a partir de modelo sugerido por Martens (2012)

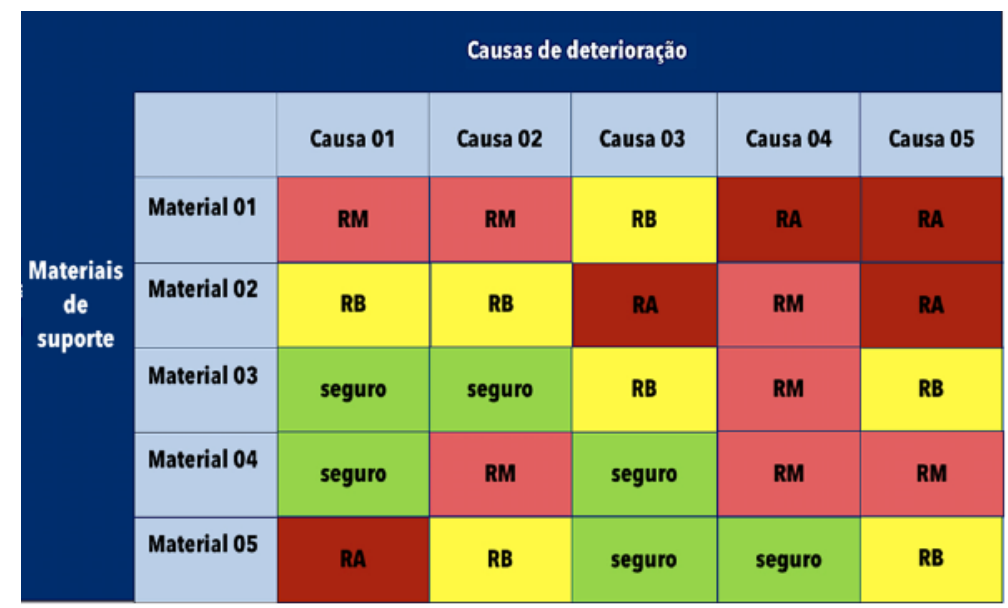

Fonte: a pesquisadora

Após a análise matricial dos riscos aos acervos, o autor sugere que sejam empregadas simulações computacionais para testar o desempenho termo-energético de alternativas construtivas para mitigar ou eliminar os riscos identificados. A partir destas simulações pretende-se avaliar dois quesitos: 0 desempenho da envolvente externa ( $\mathrm{DdE}$ ) e o nível de controle dos sistemas de condicionamento 
$(\mathrm{NdC})$. Deve-se ter em conta que a qualidade dos resultados obtidos é altamente dependente da precisão do arquivo de dados climáticos (macroclima externo) e da acurácia do modelo utilizado.

Outro exemplo de protocolo para a avaliação de condições microclimáticas, especialmente em museus com poucos recursos econômicos, e para a gestão e prevenção de riscos foi proposto por D'Agostino et al. (2015), mediante adaptação da estratégia SOBANE (Screening/Seleção, Observation/Observação, Analysis/Análise, Expertise/Especialista).

0 protocolo SOBANE (Figura 43) não é um método, um instrumento ou um checklist, mas sim uma estratégia orientada à solução, através de uma organização eficiente, durável e econômica dos esforços voltados à saúde e segurança no ambiente de trabalho (MALCHAIRE, 2006).

Figura 43. Esquema da estratégia SOBANE

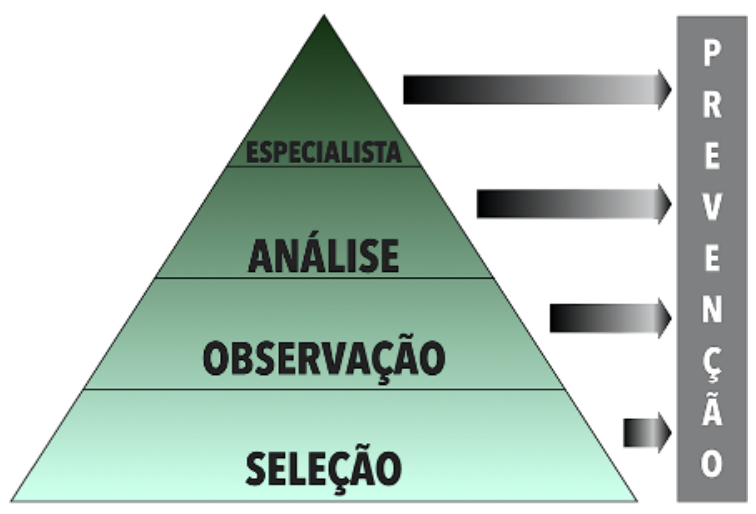

Fonte: adaptado e traduzido de D'AGOSTINO et al., 2015.

Este protocolo contempla quatro níveis de atuação (Quadro 14):

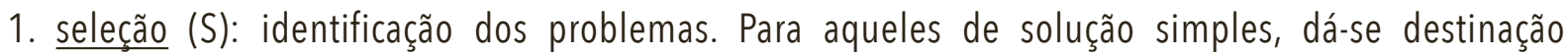
imediata, os demais devem avançar para os próximos níveis;

2. observação (OB): coleta de informações preliminares sobre condições climáticas, fontes de aquecimento e resfriamento e condições de trabalho para a solução de problemas pouco complexos;

3. análise (AN): contratação de profissionais especializados em ferramentas e técnicas que permitam a análise e a solução de problemas mais complexos;

4. especialista (E): contratação de profissionais altamente especializados (experts) que possam recomendar as melhores práticas para a identificação dos riscos e a solução de problemas muito complexos. 
Quadro 14. Especificidades de cada nível do protocolo SOBANE

\begin{tabular}{l|c|c|c}
\hline \multicolumn{1}{c|}{ 1. Seleção (S) } & 2. Observação (OB) & 3. Análise (AN) & 4. Especialista (E) \\
\hline a. Quando? & $\begin{array}{c}\text { quando o problema é } \\
\text { detectado }\end{array}$ & casos mais complicados & casos muito complexos \\
\hline b. Como? & observações qualitativas & medições simples & medições complexas \\
\hline c. Quanto? & baixo custo & médio custo & alto custo \\
\hline $\begin{array}{l}\text { d. Por quem? } \\
\text { funcionários e gestores } \\
\text { da instituição }\end{array}$ & $\begin{array}{c}\text { funcionários e gestores da } \\
\text { instituição + especialistas }\end{array}$ & instituição + especialistas + experts \\
\hline $\begin{array}{l}\text { e. Conhecimento dos } \\
\text { sistemas institucionais }\end{array}$ & Competências: & baixo \\
\hline $\begin{array}{l}\text { f. Habilidade de } \\
\text { engenheiros e arquitetos }\end{array}$ & alto & médio \\
\hline $\begin{array}{l}\text { g. Habilidade da equipe de } \\
\text { conservação }\end{array}$ & médio & alto & alto
\end{tabular}

Fonte: traduzido e adaptado de D'AGOSTINO et al., 2015.

A aplicação do protocolo SOBANE deve observar as características próprias dos três sistemas institucionais: das envolventes externas do edifício, das coleções e dos usuários. As envolventes formam um sistema rígido, difícil de ser alterado, que está diretamente relacionado a características ambientais específicas. As coleções comportam uma grande variedade de materiais, cada um com uma história particular e com respostas diferentes às características ambientais. Os usuários (funcionários e visitantes) demandam condições adequadas de conforto, segurança e acessibilidade, nem sempre convergentes com as demandas dos objetos, e, além disso, são fonte de poluentes, calor e umidade.

0 protocolo SOBANE adaptado à preservação de acervos correlaciona os dados de qualidade ambiental - parâmetros termohigrométricos internos e externos, de concentração de poluentes e partículas e de iluminação - com os sistemas construtivos passivos e ativos, o estado de conservação dos bens e os planos de gestão. Para que fosse amigável, ele foi dividido em cinco fases, cada uma executada através de um checklist (D'AGOSTINO et al., 2015):

1. 0 nível seleção (S) não utiliza nenhuma fase; 
2. o nível observação (OB) utiliza duas fases:

I - caracterização do edifício e dos sistemas ativos e identificação das fontes de poluição;

II - caracterização dos bens e do seu estado de conservação.

3. o nível análise (AN) faz uso de mais duas fases:

III - plano de avaliação com locação de sensores para medição da qualidade ambiental;

IV - medições com instrumentos, avaliação dos parâmetros e análise dos resultados.

4. 0 nível especialista (E) usa uma fase:

V - estudos físicos, químicos e biológicos complementares e análise dos resultados.

Por fim, os autores recomendam que as soluções propostas sejam simuladas em softwares de análise de transferência de massa e calor e das condições de iluminação. Todos os dados coletados e tratados devem ser arquivados como referência para análises futuras.

Museus, bibliotecas e arquivos são instituiç̧ões com características (coleções, edificações, públicos, recursos técnico-financeiros, etc.), dimensões (pequenas, médias ou grandes) e abrangência (locais, regionais ou nacionais) bastante diversificadas. A gestão da qualidade ambiental destas instituições deve fazer uso de técnicas e métodos provenientes das mais diversas áreas do conhecimento, adaptadas à realidade de cada caso. Tem-se, atualmente, muitos sistemas para a gestão de riscos disponíveis e ao alcance dos gestores (D'AGOSTINO et al., 2015).

Hawks e Waller (2013) refletiram sobre correlações entre sistemas para a gestão de riscos ao patrimônio e às pessoas. A gestão de riscos ao patrimônio tem por objetivo evitar perdas e danos aos valiosos itens das coleções, já a gestão de riscos a pessoas tem por propósito assegurar a saúde e evitar acidentes. A gestão integrada destes riscos pode trazer benefícios pela sobreposição de medidas que visam a preservação de um, a saúde do outro e a segurança de ambos ${ }^{50}$. Algumas soluções são naturalmente solidárias como, por exemplo, o uso de EPIs, que protege as pessoas de acervos contaminados e os acervos de contaminação pelos usuários. No entanto, nem todas as situações possuem esta sinergia como, por exemplo, a decisão de se manter acervos com materiais biológicos potencialmente perigosos à saúde humana. Nestes casos, o trabalho conjunto de especialistas das

\footnotetext{
50 Ver interessante representação artística da correlação entre sistemas de gestão de riscos a pessoas e coleções em: http://protectheritage.com/ Lisbon2011/wp-content/uploads/2011/11/A-Tale-of-Two-Systems-Poster-Reduced-file-size.pdf, acesso em dez. 2020.
} 
múltiplas especialidades envolvidas pode ajudar a resolver conflitos e encontrar um ponto de equilíbrio entre as duas demandas.

0 Getty Conservation Institute $(\mathrm{GCl})$ abordou a interrelação entre métodos para a gestão de riscos e a atribuição de valores pela primeira vez no ano 2000 (AVRAMANI et al., 2000). À época, percebeu-se que os instrumentos utilizados para diagnóstico focavam essencialmente nos aspectos físicos dos acervos e, assim, deixavam escapar o mais importante: 0 valor que as pessoas (partes interessadas) atribuíam ao patrimônio, que é a razão de ser de sua preservação (Figura 44). Na opinião dos autores, isso podia ser explicado pela fragmentação e o desequilíbrio entre as diferentes disciplinas que compõem o corpo de conhecimentos da conservação preventiva. Saberes provenientes das ciências, da documentação e da catalogação evoluíram muito mais do que aqueles oriundos da economia, sociologia ou política, por exemplo.

Figura 44. Prática corrente: as diferentes atividades são realizadas separadamente, sem integração e sem um contexto social. Prática sugerida: integração e coesão entre as atividades de conservação, o contexto social e os interesses de todas as partes envolvidas

Prática corrente da conservação preventiva:

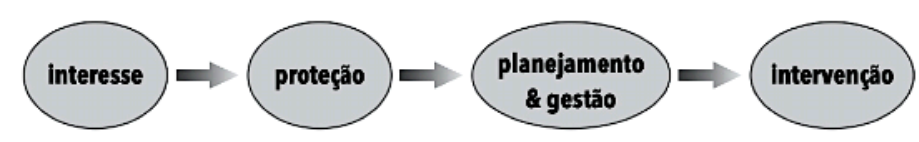

Prática potencial da conservação preventiva:

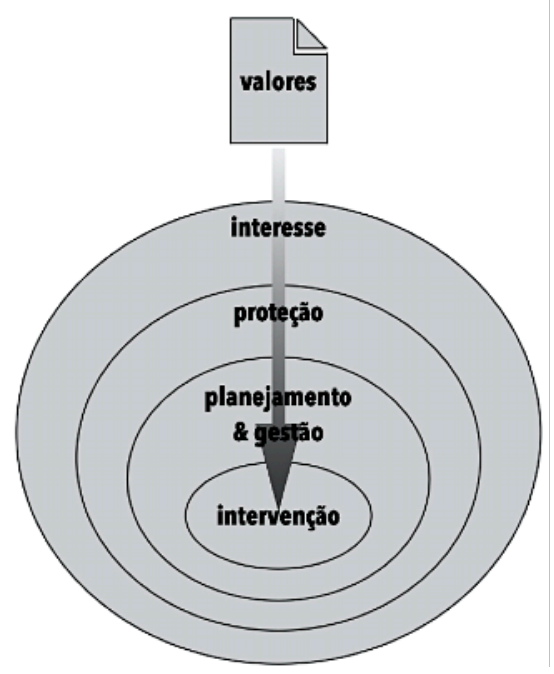

Fonte: traduzido e adaptado de AVRAMANI et al., 2000

Em 2017, o GCl organizou o Encontro 'Valores na gestão do patrimônio: abordagens emergentes e direções de pesquisa', no qual foram apresentadas e debatidas pesquisas e estudos de caso sobre a gestão de valores para o patrimônio cultural. Como resultado, foi sugerida uma agenda de ações futuras (AVRAMANI et al., 2019): 
a. teoria (visões de mundo e conceitos): desenvolver metodologias e conceitos-chave para a valorização do patrimônio em todas as suas dimensões, e publicá-las;

b. política (governança): desenvolver e publicar orientações de como as instituições podem aplicar à sua gestão políticas e processos baseados em valores;

c. recursos (estruturas, instrumentos): desenvolver e publicar métodos e instrumentos adaptados à conservação do patrimônio, nas mais diversas tipologias institucionais, para identificar, avaliar e gerenciar valores, e para administrar conflitos;

d. educação (capacitação, conscientização): desenvolver material didático para capacitação e/ou conscientização de todas as partes envolvidas;

e. colaboração interdisciplinar: desenvolver diretrizes para a colaboração entre as diversas especialidades, voltadas a uma gestão baseada em valores e fundamentada na integração natureza e cultura.

Em 2019, o GCl concluiu que, para além dos valores sociais identificados em 2000, outros aspectos surgiram ou ganharam maior relevância na atribuição de valores para a gestão do patrimônio cultural (BUCKLEY, 2019):

a. direitos humanos: com destaque para os direitos de identidade e os direitos dos povos originais. $\mathrm{Na}$ gestão do patrimônio, os tomadores de decisão devem ter especial atenção para não violar ou negligenciar os direitos de nenhum grupo humano. Esta consciência pode ser uma chave impulsionadora de mudanças na sociedade (DISKO e TUGENDHAT, 2014);

b. crises ambientais globais: cada vez mais as políticas públicas precisarão estar orientadas pela crise climática e seus efeitos irreversíveis sobre o planeta. Estes efeitos impactam de maneira mais profunda e complexa o patrimônio edificado e o patrimônio intangível;

c. díade natureza-cultura: na modernidade ocidental existe, tradicionalmente, uma cisão entre natureza e cultura, que conduz à defesa de uma 'natureza sem pessoas' e uma 'cultura sem natureza' (BYRNE et al., 2013). É preciso superar essas crenças para que seja possível incorporar, na gestão do patrimônio, os conceitos de herança local;

d. paisagem urbana histórica: desde que a UNESCO (2011) destacou a importância de se conservar 0 patrimônio urbano (e seus valores intangíveis), este têm sido um grande desafio e uma fonte para inovação e envolvimento da comunidade; 
e. tecnologias digitais e ciência cidadã: 0 uso da tecnologia revolucionou o mundo de muitas maneiras diferentes. Na gestão do patrimônio, propiciou novos instrumentos para avaliação, documentação e utilização dos acervos. Também "descortinou novas formas de consumo e produção do patrimônio relacionadas a interpretações e conteúdos" (LEWI et al., 2016);

f. discurso crítico do patrimônio: são inúmeros os trabalhos acadêmicos que tratam do patrimônio cultural (HARRISON, 2013). No entanto, uma relação mais aprofundada e colaborativa entre acadêmicos e profissionais da conservação ainda está por ser estabelecida.

Henderson (2018), em artigo intitulado 'Managing Uncertainty for Preventive Conservation' complementa a análise do $\mathrm{GCl}$ ao tratar de um aspecto muito importante mas ainda pouco abordado pelas metodologias de conservação preventiva de acervos: a gestão das incertezas, condição inerente a toda análise de riscos e tomada de decisão.

Usualmente, as ações para preservação do patrimônio são decididas a partir da análise dos dados coletados, que traduzem padrões presentes e passados. Esta é uma simplificação que funciona bem em um cenário de estabilidade, ou seja, quando o futuro é uma continuidade do padrão observado. No entanto, este método não funciona tão bem quando se está diante de um cenário de mudanças. E oS tempos atuais são marcados pela mudança: climática, econômica, política, ambiental etc., o que torna o futuro bastante incerto e impacta diretamente nas decisões.

Tradicionalmente, os efeitos adversos são determinados a partir de uma análise qualitativa dos perigos e seus impactos. Na avaliação clássica, os riscos são compreendidos como uma medida quantitativa, produto dos perigos esperados pela probabilidade deles ocorrerem. No entanto, nesta abordagem, valores morais, éticos, sociais, políticos, dentre outros, não são considerados.

Há uma sutil diferença entre perigo e risco. Um perigo se transforma em um risco quando se conhece sua natureza e probabilidade de ocorrência (BORA, 2006). Perigos e riscos podem ser minimizados preenchendo-se as lacunas de conhecimento. Por outro lado, a ignorância pode ser mais desafiadora, principalmente quando ela não pode ser reduzida (ignorância fechada), seja por causa dos limites do aparelho cognitivo humano, pela aleatoriedade dos eventos ou pela rejeição ou negação a um conhecimento possível (conhecido como Efeito Galileu). A principal atitude possível frente à ignorância é transformá-la de fechada em aberta, o que implica em identificar e reconhecer a ignorância e reconhecer a necessidade de se pesquisar e aprender (Figura 45) (GROSS, 2007). 


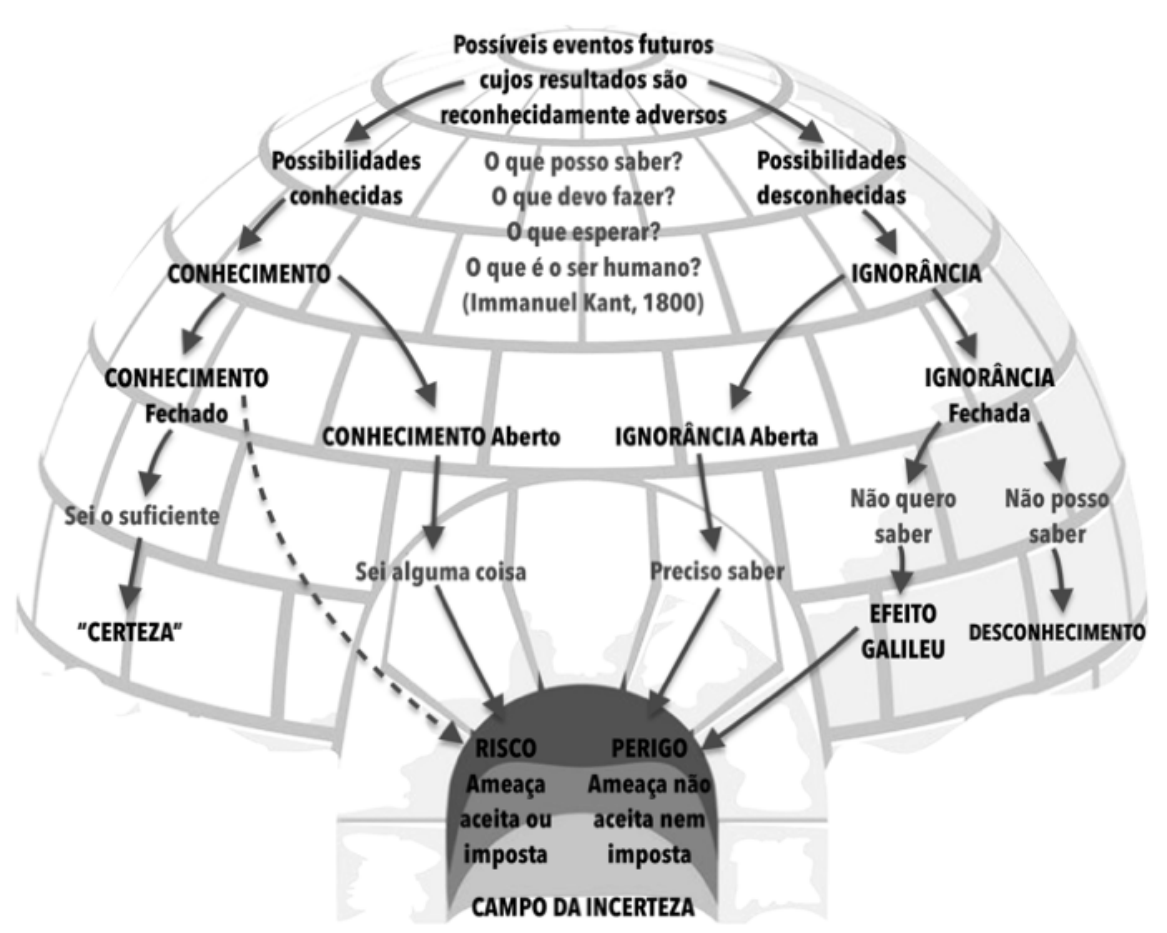

Fonte: traduzido e adaptado de TANNERT et al., 2007

Mesmo quando existe considerável conhecimento para uma avaliação dos riscos, sempre há algum grau de ignorância remanescente, que são as incertezas quanto aos resultados possíveis. As incertezas podem ser divididas em dois grupos fundamentais: objetivas e subjetivas. As incertezas objetivas são aquelas que podem ser minimizadas pela pesquisa e pelo conhecimento, o que é, portanto, um dever moral. As incertezas subjetivas são aquelas para as quais não é possível aplicar regras morais claras. Elas podem ser divididas em dois sub-grupos: aquelas que podem ser guiadas por regras morais gerais e aquelas que são guiadas pela intuiçã̃o (convicções morais fundamentais internalizadas ou subconscientes) (TANNERT et al., 2007).

Na cultura científica ocidental, tradicionalmente, a incerteza é entendida como um problema a ser eliminado. Como as incertezas nunca podem ser completamente removidas das predições futuras, esta abordagem pode resultar em um viés heurístico, que é quando os tomadores de decisão, de maneira consciente ou inconsciente, adotam simplificações ou "atalhos mentais", baseados em suas crenças e julgamentos pessoais, na tentativa de excluir cenários indesejados (KAHNEMAN, 2012).

Uma abordagem mais adequada se inicia com a compreensão das diferenças entre sistemas complicados e complexos. Sistemas complicados são aqueles que dependem de muitas partes para 
funcionar, mas cujo resultado é previsível e conhecido (como, por exemplo, mecanismos e máquinas). Sistemas complexos são aqueles cujos resultados não podem ser totalmente previstos (GLOUBERMAN e ZIMMERMAN, 2002). Nos sistemas complexos, como é o caso do patrimônio cultural, os resultados dependem das interrelações entre agentes, padrões e relacionamentos (HENDERSON, 2018). Identificar o contexto de incertezas inerente ao problema em análise pode auxiliar o tomador de decisão, pois permite que ele considere uma maior variedade de respostas adequadas, tanto para os aspectos físicos como humanos da questão (Quadro 15). Além disso, é importante sempre aplicar o princípio da precaução, o que implica em abordar as incertezas de maneira proativa (PETERSON, 2007), ou seja, quando se está diante de graves ameaças, a ausência de plena certeza científica não pode ser usada como justificativa para se adiar a tomada de decisões preventivas (TANNERT et al., 2007).

Quadro 15. Formas de incertezas no contexto da conservação preventiva, segundo Hoogduin (2015), Lane e Maxfield (2005), Lander (2018), Bradley e Drechsler (2013)

\begin{tabular}{|c|c|c|}
\hline Tipo de incerteza & Significado & Exemplo e solução \\
\hline $\begin{array}{l}\text { Estatística / aleatória / } \\
\text { estado / risco }\end{array}$ & $\begin{array}{l}\text { Quando a incerteza pode ser expressa por uma } \\
\text { probabilidade ou por distribuições }\end{array}$ & $\begin{array}{l}\text { Predições de risco de incêndio podem ser baseadas na } \\
\text { probabilidade de ocorrência e nas consequências potenciais. } \\
\text { A gestão formal do risco pode utilizar esta avaliação para } \\
\text { orientar investimentos de modo a maximizar os benefícios } \\
\text { potenciais para o acervo. }\end{array}$ \\
\hline $\begin{array}{l}\text { Epistemológica / } \\
\text { sistemática / factual }\end{array}$ & $\begin{array}{l}\text { Expressa coisas que poderiam ser conhecidas } \\
\text { mas não são }\end{array}$ & $\begin{array}{l}\text { A resposta de um artefato específico a um padrão de umidade. } \\
\text { Pesquisas são uma resposta efetiva. }\end{array}$ \\
\hline Verdadeira & $\begin{array}{l}\text { Quando não há certeza da veracidade ou da } \\
\text { clareza de uma dada premissa. Em alguns } \\
\text { casos, pode ser definida estatisticamente }\end{array}$ & $\begin{array}{l}\text { Não saber se um item que está passando por um processo de } \\
\text { conservação é o original ou uma réplica. } \\
\text { Uma prática cautelosa pode ser necessária. }\end{array}$ \\
\hline Semântica & $\begin{array}{l}\text { Diferentes experiências da realidade. } \\
\text { Incertezas semânticas podem ser observadas } \\
\text { quando se percebe que algo que era } \\
\text { considerado a realidade, na verdade, era } \\
\text { apenas uma interpretação pessoal (por } \\
\text { exemplo, quando um viés cultural mascara } \\
\text { atitudes colonialistas) }\end{array}$ & $\begin{array}{l}\text { Uma estratégia de conservação preventiva baseada na suposição } \\
\text { de que preservar o item é uma questão crítica, enquanto outras } \\
\text { pessoas consideram que preservar as habilidades para a } \\
\text { conservação do artefato é o que importa. } \\
0 \text { engajamento das partes interessadas expõe as divisões } \\
\text { semânticas, criando a oportunidade de resolvê-las. }\end{array}$ \\
\hline Atribuição & Significado indefinido mas compartilhado & $\begin{array}{l}\text { Incertezas de atribuição podem ser usadas para descrever } \\
\text { divergências em hipóteses e práticas entre conservadores de } \\
\text { diferentes especialidades, como, por exemplo, a criação de uma } \\
\text { cópia, que é vista como conservação preventiva básica para } \\
\text { livros, mas como falsificação para edifícios. } \\
\text { A comunicação expõe as inconsistências. }\end{array}$ \\
\hline
\end{tabular}


Quadro 15. Formas de incertezas no contexto da conservação preventiva, segundo Hoogduin (2015), Lane e

$$
\text { Maxfield (2005), Lander (2018), Bradley e Drechsler (2013) (continuação) }
$$

\begin{tabular}{|c|c|c|}
\hline Tipo de incerteza & Significado & Exemplo e solução \\
\hline Ética / normativa & $\begin{array}{l}\text { Não se sabe como as pessoas irão valorar as } \\
\text { consequências das ações. Algumas consequências } \\
\text { podem ser vistas como falta de sorte e outras } \\
\text { como negligência. Mesmo quando a } \\
\text { probabilidade de um resultado é conhecida, a } \\
\text { resposta emocional a ele pode ser desconhecida }\end{array}$ & $\begin{array}{l}0 \text { dano resultante de se manter um objeto disponível para o } \\
\text { manuseio pode ser visto como um pequeno preço a se pagar } \\
\text { para ampliar o acesso à obra ou como negligência no cuidado } \\
\text { com o item. } \\
\text { A incerteza apenas poderá ser verificada após a consequência. } \\
\text { Diálogo e prevenção podem mitigar os danos. }\end{array}$ \\
\hline Ontológica & $\begin{array}{c}\text { Não se sabe o que não se sabe. Incertezas } \\
\text { ontológicas existem, sejam elas reconhecidas } \\
\text { ou não }\end{array}$ & $\begin{array}{l}\text { Ao se planejar a capacidade de armazenamento para a } \\
\text { ampliação do acervo, mesmo que se use padrões estatísticos de } \\
\text { crescimento, pode haver a incerteza ontológica de que um } \\
\text { doador secretamente considera enviar um grande acervo para a } \\
\text { instituição. } \\
\text { Planos de contingenciamento podem ser suficientes. }\end{array}$ \\
\hline Modal / estado-espaço & $\begin{array}{l}\text { Incertezas quanto às possibilidades ou quanto } \\
\text { ao que pode vir a acontecer }\end{array}$ & $\begin{array}{l}\text { Buscar estratégias preventivas em um conjunto muito pequeno } \\
\text { de opções, como controle mecânico do clima, e desconhecer } \\
\text { outras possibilidades. } \\
\text { Pessoas inovadoras podem encontrar novas formas criativas e } \\
\text { opções não consideradas previamente. }\end{array}$ \\
\hline Empírica / estado & $\begin{array}{l}\text { Incertezas quanto ao funcionamento do } \\
\text { contexto, que pode ser expresso por diferentes } \\
\text { níveis de severidade }\end{array}$ & $\begin{array}{l}\text { Não saber todos os materiais que compõem as coleções. } \\
\text { Identificar, para a situação presente, os elementos } \\
\text { desconhecidos. }\end{array}$ \\
\hline Efetiva & $\begin{array}{l}\text { Como o funcionamento do contexto pode } \\
\text { impactar na área de interesse }\end{array}$ & $\begin{array}{l}\text { Não saber o que pode acontecer com os objetos se os } \\
\text { parâmetros de controle da UR forem relaxados. } \\
\text { Identificar o que não se sabe sobre o que pode vir a acontecer. }\end{array}$ \\
\hline Opção & $\begin{array}{l}\text { Como o contexto irá responder às mudanças } \\
\text { fomentadas / às consequências das ações }\end{array}$ & $\begin{array}{l}\text { Não saber se os novos parâmetros mais relaxados de UR serão } \\
\text { aclamados como altamente sustentáveis ou como terrivel } \\
\text { negligência. } \\
\text { Identificar o que não se sabe sobre como eventos futuros } \\
\text { podem impactar as dúvidas. }\end{array}$ \\
\hline
\end{tabular}

Fonte: traduzido e adaptado de HENDERSON, 2018.

Lidar com incertezas é, principalmente, lidar com pessoas e suas emoções (satisfações e frustrações). Isso significa que é preciso investir em conhecimento, treinamento e comunicação. Também é importante que ideias inovadoras e criativas possam ser bem acolhidas pelas equipes (HENDERSON, 2018).

As incertezas (de atribuição, semânticas e éticas) estão diretamente relacionadas à habilidade de comunicação sobre valores, significados e usos das coleções entre todas as partes interessadas. Diante 
de um conflito, a postura tradicional é se buscar uma solução 'vencedora'; por outro lado, em uma abordagem voltada à gestão das incertezas, entende-se que todas as perspectivas podem ter validade, que é preciso integrar mais de uma solução e procurar alternativas criativas.

As incertezas por desconhecimento podem ser mitigadas, mas não eliminadas, mediante consulta a especialistas (KLEIN, 1999). Incertezas estatísticas ou epistemológicas podem ser reduzidas, mas não eliminadas, com coleta e tratamento de dados. As instituições devem ter cuidado com a 'sensação' que grandes bancos de dados produzem de que tudo pode ser 'conhecível' (HENDERSON, 2018).

Uma atitude prudente diante de fatores desconhecidos é incorporar estratégias de amortecimento ou de redundância (físicas e/ou administrativas), de modo que a instituição tenha algum tempo para decidir quais atitudes tomar quando diante de um evento adverso. Algumas pesquisas indicam que incorporar, nos planos de gestão de risco, a certeza de que haverá situações inesperadas parece reduzir

a chance de que elas ocorram por causa da maior atenção das equipes a esta probabilidade (HENDERSON, 2018).

Em um paralelo com a medicina, onde a aceitação e a convivência com as incertezas está melhor equacionada, a conservação preventiva pode fazer uso de um planejamento com foco nos processos (e não nos resultados), que estabeleça metas e celebre as pequenas respostas positivas, em ciclos continuados de diagnósticos e ações (UNESCO e ICCROM 2018).

\subsubsection{Gestão do edifício}

Vive-se, atualmente, em um período caracterizado por grande insustentabilidade (ambiental, social e econômica) e isto pode estar diretamente correlacionado a uma percepção bastante disseminada de falta de bem-estar (UNESCO, 2012).

Se o patrimônio cultural é entendido como um bem comum, atividades que o preservem e 0 valorizem, precisam ser percebidos como um benefício para a sua comunidade. Para que isso possa ser medido, faz-se necessário o desenvolvimento de instrumentos que avaliem o impacto do patrimônio no bem-estar de uma população (NOCCA, 2017).

Sabe-se, por exemplo, que "se engajar com a cultura (visitar, assistir e participar) aumenta significativamente o nível geral de satisfação com a vida" (Department for Culture, Media \& Sport, 2016; tradução da pesquisadora). 0 bem-estar ou satisfação com a vida está relacionado à percepção de que as necessidades e os direitos que um ser humano considera fundamentais para viver 
adequadamente foram atendidos. É um conceito multidimensional, que varia no espaço e no tempo e se altera com a cultura.

Assim, para se medir o bem-estar de uma pessoa, é preciso avaliar o contexto em que essa pessoa vive. A 'qualidade de vida' está frequentemente associada a conforto, saúde, segurança, expectativas e satisfações. Todos estes parâmetros também estão interrelacionados com 0 ambiente: a recuperação do bem-estar humano impacta 0 ambiente e a recuperação ambiental impacta o bem-estar do ser humano (NOCCA, 2017).

Esta correlação, e o real benefício de se investir em cultura, é apenas fracamente percebido pelas sociedades contemporâneas. Usa-se como argumento a falta de recursos (financeiros, humanos, etc.) para se justificar a falta de empenho. No entanto, estes argumentos apenas demonstram que as comunidades continuam presas a uma visão linear dos processos econômicos. Em uma visão circular, é possível perceber o valor de uso de se conservar o patrimônio como um símbolo 'vivo', que produz riquezas econômicas e sociais, principalmente pela perspectiva do bem-estar. Assim, em uma visão circular da economia, a conservação, a manutenção, o reuso, a restauração e a reabilitação, que promovem valorização e regeneração da paisagem urbana, são palavras-chave e os instrumentos para avaliação do patrimônio em uso são fundamentais na tomada de decisões que possam ampliar a vida útil destes recursos ao longo do tempo (NOCCA, 2017).

\subsubsection{Avaliação do Desempenho de Edifícios e Avaliação Pós-Ocupação(APO)}

Durante o século XX, e paralelamente ao desenvolvimento dos métodos de gestão e de conservação preventiva do patrimônio cultural, no âmbito da arquitetura, também houve avanços com o intuito de aprimorar a qualidade do ambiente construído, atendendo, assim, às necessidades dos usuários.

0 ser humano constrói cidades e edificações para satisfazer suas necessidades físicas de proteção ao meio externo e psicológicas de contato com a beleza. A arquitetura de qualidade pode ser entendida, portanto, como aquela que proporciona bem-estar e harmonia a seus ocupantes, satisfazendo às necessidades ambientais e comportamentais do usuário (ORNSTEIN e ROMÉRO, 2003).

Os processos industrializados demandam qualidade e precisão associadas a rapidez e baixo custo. Há várias décadas, principalmente nos países desenvolvidos, são utilizados sistemas multimétodos para avaliação de processos e produtos visando à satisfação do usuário e à aferição do cumprimento das metas estabelecidas (ORNSTEIN, 2017). Por outro lado, e na tentativa de trazer maior qualidade ao 
setor da construção, há mais de meio século, pesquisadores se dedicam a estudar mecanismos de gestão da qualidade da construção que considerem todo o seu ciclo de vida: projeto, construção, uso e demolição. Dentre estes mecanismos, encontram-se as certificações, as normas e os sistemas de avaliação do ambiente construído.

A Avaliação do Desempenho de Edifícios (BPE - Building Performance Evaluation), que compartilha métodos e instrumentos provenientes da gestão de riscos ao patrimônio, têm por objetivos a análise, 0 diagnóstico e a proposição de recomendações, realizados por especialistas, para a eliminação ou mitigação das vulnerabilidades identificadas.

A Avaliação do Desempenho do Edifício é definida como:

uma abordagem sistemática que engloba diversas atividades, dentre elas pesquisa, medição, comparação, avaliação, e resposta, que são realizadas ao longo de todas as fases do ciclo de vida de uma edificação, o que inclui: estudo de viabilidade, programa de necessidades, projeto, construção, ocupação e reciclagem (PREISER et al., 2012; tradução da pesquisadora).

Quando esta avaliação é feita em edifícios já construídos e em uso, ela recebe o nome de Avaliação Pós-Ocupação (APO), que é definida como "o processo de avaliar edifícios de modo sistemático e rigoroso depois que ele já foi construído e ocupado por um certo tempo" (traduzido de PREISER et al., 1988). A APO começou a ser bastante utilizada nos Estados Unidos no final da década de 1960 com 0 intuito de se medir a interrelação entre ambientes e seres humanos (ROMÉRO e ORNSTEIN, 2003) e foi sendo aprimorada ao longo das décadas seguintes para se transformar em uma avaliação orientada ao processo51, que considera não apenas o edifício isoladamente, mas também os aspectos sociais, econômicos, culturais, históricos e até mesmo políticos em que ele está inserido (ONO et al., 2018). A APO "se concentra nas necessidades dos usuários do edifício, dentre elas: saúde, proteção e segurança; funcionalidade e eficiência do fluxo de trabalho; desempenho e adequação social, psicológica e cultural, o que inclui qualidade visual-estética e satisfação" (traduzido de PREISER et al., 2005).

A Avaliação Pós-Ocupação (APO) é, portanto, uma abordagem multimétodos de avaliação do ambiente construído desde que ele foi ocupado até o final da sua vida útil, que faz uso de técnicas e instrumentos quantitativos e qualitativos para análise, diagnóstico, proposição de ações e aprendizado de boas práticas, a partir de dados sobre fatores socioeconômicos, infraestrutura e superestrutura urbanas dos sistemas construtivos, conforto ambiental, conservação de energia e fatores estéticos,

\footnotetext{
51 process-oriented assessment
} 
funcionais e comportamentais, levando em consideração o ponto de vista dos próprios avaliadores, projetistas e clientes, e também dos usuários (Figura 46) (ORNSTEIN e ROMÉRO, 2003).

Figura 46. Abordagem multimétodo na aplicação da APO

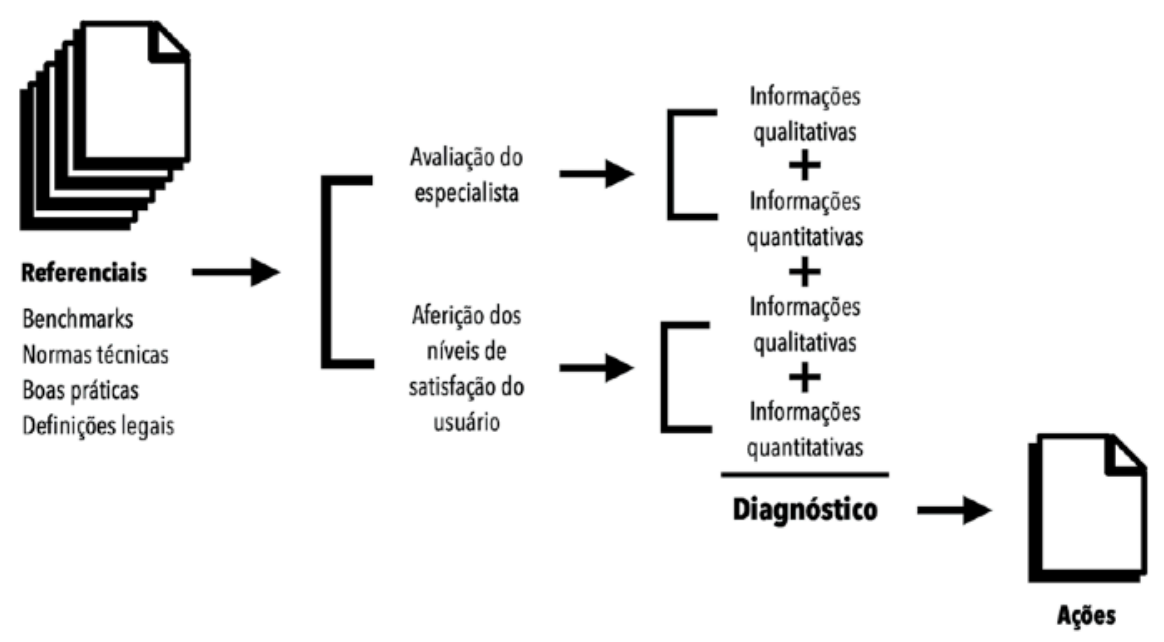

Fonte: ONO et al., 2018.

Para que o resultado seja uma arquitetura de qualidade, os profissionais envolvidos precisam conhecer todas as atividades correlacionadas, do pré-projeto até o final da vida útil do edifício (ONO et al., 2015). A utilização de APOs traz benefícios de curto (imediato), médio (até 5 anos) e longo (de 10 a 25 anos) prazo, que podem ser mais claramente percebidos nos setores em que as características de uso e operação se repetem com frequência, como museus, escolas, hospitais, habitações de interesse social, dentre outros (FFC, 2001), pois permite compreender o projeto e seus processos (PREISER e SCHARAMM, 2005) à luz de decisões racionais, emocionais e intuitivas (KOWALTOWSKI et al., 2013), na busca por atributos que expressem a qualidade do ambiente construído (ABIKO e ORNSTEIN, 2002), ou seja, o seu desempenho em uso (ONO et al., 2018). Estes atributos podem ser identificados, em grande medida, por meio de metodologias provenientes da psicologia ambiental, que traduzem 0 comportamento do usuário quando em contato com as diversas tipologias construtivas (BECHTEL et al., 1987), e são conhecidas como relações entre ambiente e comportamento, ou RACs (ORNSTEIN, 1996).

0 desempenho dos edifícios é avaliado, diariamente, de forma inconsciente e não explícita. Quando, em um determinado ambiente, são ouvidas conversas e ruídos de outros ambientes, a performance acústica do recinto está sendo avaliada. Da mesma forma, a temperatura do recinto, a qualidade da iluminação natural/artificial, do mobiliário, dos acabamentos e a visão do exterior através das aberturas, são avaliados informalmente. Enquanto esperamos um elevador, podemos julgar o tempo de espera. Os critérios de avaliação usados neste caso são originados em expectativas que são baseadas em situações vivenciadas (RHEINGANTZ et al., 1997). 
A principal característica da APO em relação aos outros mecanismos de gestão da qualidade do ambiente construído é a participação do usuário nesse processo. Se, por um lado, o especialista contribui com 0 conhecimento técnico (estabilidade, estanqueidade, segurança contra incêndio, conforto ambiental, adequação ao uso, dentre outros), por outro, o usuário pode esclarecer questões relacionadas à sua cultura (valores, comportamentos, interesses, percepções, etc.) (ORNSTEIN, BRUNA e ROMÉRO, 1995).

Há décadas a APO vem sendo usada, principalmente nos países desenvolvidos, com o objetivo de atender às normas vigentes e satisfazer às expectativas dos usuários de habitabilidade, conforto e bem-estar (ORNSTEIN, 2017).

Nos anos 1960 e 1970, ainda nos EUA, pesquisas deram origem a uma nova área de estudo dentro da psicologia humana, que viria ser conhecida como psicologia ambiental e tinha por objetivo estudar a interação entre o ambiente construído e a saúde física e mental de seus ocupantes. Os estudos de Sommer (1969), por exemplo, identificaram o efeito negativo de ambientes monótonos, que podiam transparecer na forma de manifestações psicológicas, tais como apatia e indiferença (FRANÇA, 2011).

Assim, uma vez que a APO também considera o conforto psicológico do usuário, muitos dos instrumentos da psicologia ambiental foram adequados e incorporados de modo a permitir uma maior compreensão de como o usuário influencia ou é influenciado pelo ambiente, e suas consequências, tanto para o ser humano como para o edifício (ORNSTEIN et al., 1995).

No Brasil, a APO foi inicialmente empregada pelo Instituto de Pesquisas Tecnológicas do Estado de São Paulo (IPT), em meados da década de 1970, para avaliação da qualidade e da satisfação do usuário em conjuntos habitacionais paulistas e, similar ao ocorrido nos EUA, teve seu uso ampliado para outros setores interessados em gestão da qualidade e da produtividade (SIMÕES, 2004).

Como metodologia para a pesquisa da relação "especialistas versus usuários", ela vem sendo empregada nas universidades brasileiras desde 1980, contribuindo para o desenvolvimento do estudo e ensino de disciplinas no campo da Tecnologia da Arquitetura (ORNSTEIN, 2017).

Nos últimos anos, a utilização da APO no Brasil ganhou novo espaço, principalmente nos setores residencial (HIS), educacional, hospitalar e de serviços, notadamente após a criação da norma brasileira de desempenho para a construção civil (ABNT, 2008). 
Por outro lado, sabe-se que muitos projetistas (engenheiros e arquitetos) brasileiros ainda se mantêm distanciados do edifício projetado após a conclusão da obra, ficando alheios aos aspectos relacionados à sua manutenção e operação (MELHADO e MESQUITA, 2006).

A durabilidade de um edifício, frente aos desgastes de seus equipamentos, instalações e necessidades de manutenção, é um fator de grande importância, especialmente em se tratando de edifícios públicos. No entanto, limitações do programa e das técnicas construtivas, falhas no projeto, na execução ou nos materiais e ausência de manutenção são possíveis causas de problemas de qualidade no ambiente construído. 0 desafio está em identificá-las para que possam ser minimizadas ou mesmo corrigidas. Neste contexto, os estudos que envolvem a aplicação de APOs são muito relevantes para 0 diagnóstico de aspectos relacionados à funcionalidade dos edifícios, e para a realimentação dos processos criativos de projeto (FRANÇA, 2011).

A funcionalidade do ambiente construído (adequação às especificidades) está diretamente relacionada à qualidade do projeto arquitetônico, consequentemente, a um programa de necessidades adequado, ou seja, que compreenda: as características e necessidades dos usuários; as atividades específicas realizadas em cada ambiente; os mobiliários adequados, por uso e por público; as dimensões e características das áreas para armazenamento; as especificidades dos acessos e fluxos de pessoas e bens; e as normas técnicas e leis vigentes que devem ser obedecidas (KOWALTOWSKI, 1999).

Ainda que o meio acadêmico tenha compreendido, há várias décadas, a necessidade de uma visão circular, orientada ao processo de projeto, construção, ocupação e uso / operação / manutenção, e requalificação, reforma ou reciclagem, o mercado da construção civil ainda encontra dificuldades para se desvencilhar de uma visão mais convencional e linear das etapas de construção de edifícios (Figuras 47 e 48).

Figura 47. Visão convencional e linear do processo

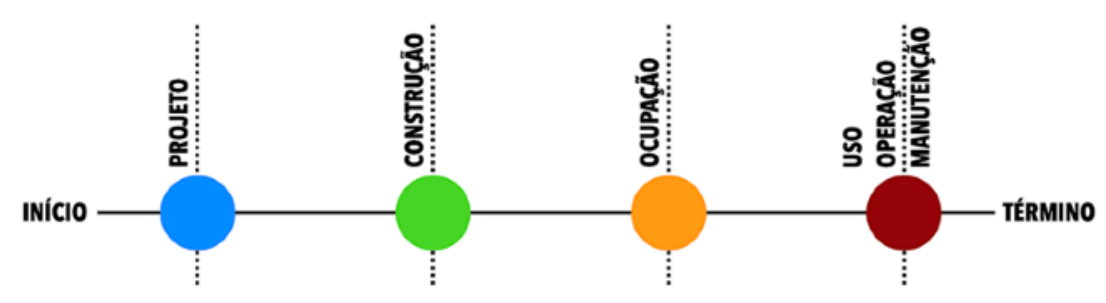

Fonte: ORNSTEIN, 2017. 


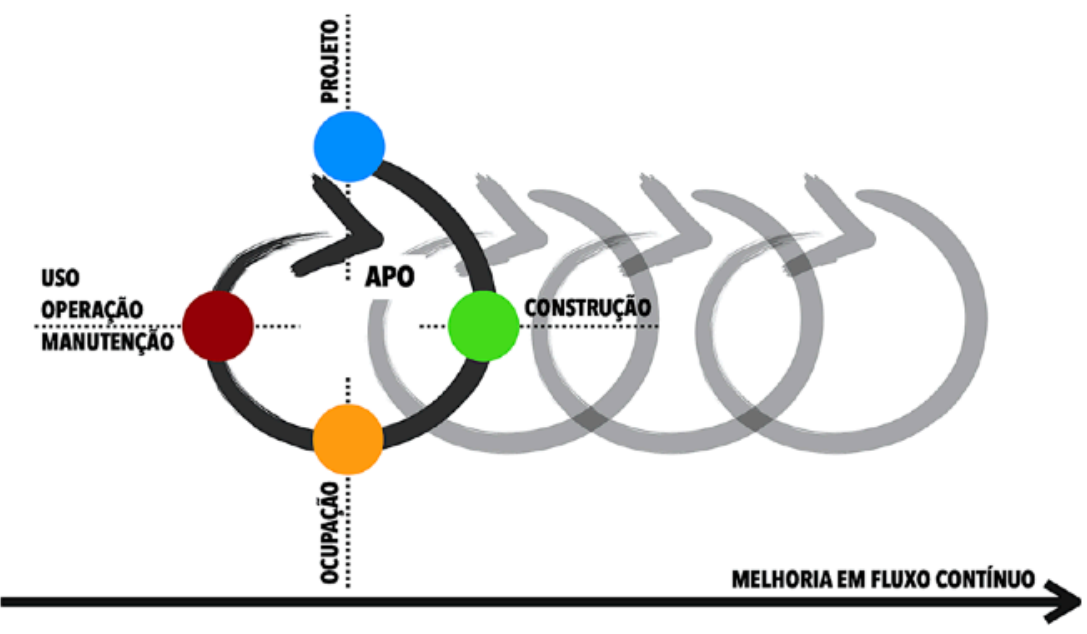

Fonte: ORNSTEIN, 2017.

A APO pode auxiliar em uma mudança de visão pois propõe o uso de uma grande variedade de métodos, muitas vezes emprestados de outras áreas do conhecimento, que podem ser escolhidos e combinados conforme 0 estudo de caso com o intuito de se aferir a eficácia das etapas do projeto, da construção, da ocupação e do uso, na busca pela melhoria na qualidade do ambiente construído. A APO também pode contribuir com o aprimoramento de cada uma dessas etapas ao longo de toda a vida útil da edificação por meio de diagnósticos e recomendações que podem orientar procedimentos de operação, manutenção preventiva ou corretiva, reforma ou ampliação mais adequados (Figura 49). Os resultados obtidos, se organizados de modo sistêmico, podem, no médio e longo prazo, formar bancos de dados (de soluções adequadas e inadequadas) que servem de referência (benchmarks) para projetos semelhantes futuros (ONO et al., 2015). Além disso, o conhecimento adquirido com a avaliação dos aspectos positivos e negativos das soluções construtivas também pode contribuir para 0 aperfeiçoamento das normas técnicas, as quais, por sua vez, devem ser usadas para auxiliar em uma melhor avaliação do ambiente construído (VILLA e ORNSTEIN, 2013; FINCH, 2012; RHEINGANTZ et al., 2009; VOORDT e WEGEN, 2005; PREISER e VISCHER, 2005; ROMÉRO e ORNSTEIN, 2003; THOMSEN, 2002). 
Figura 49. As atividades de APO ao longo do ciclo de vida do edifício

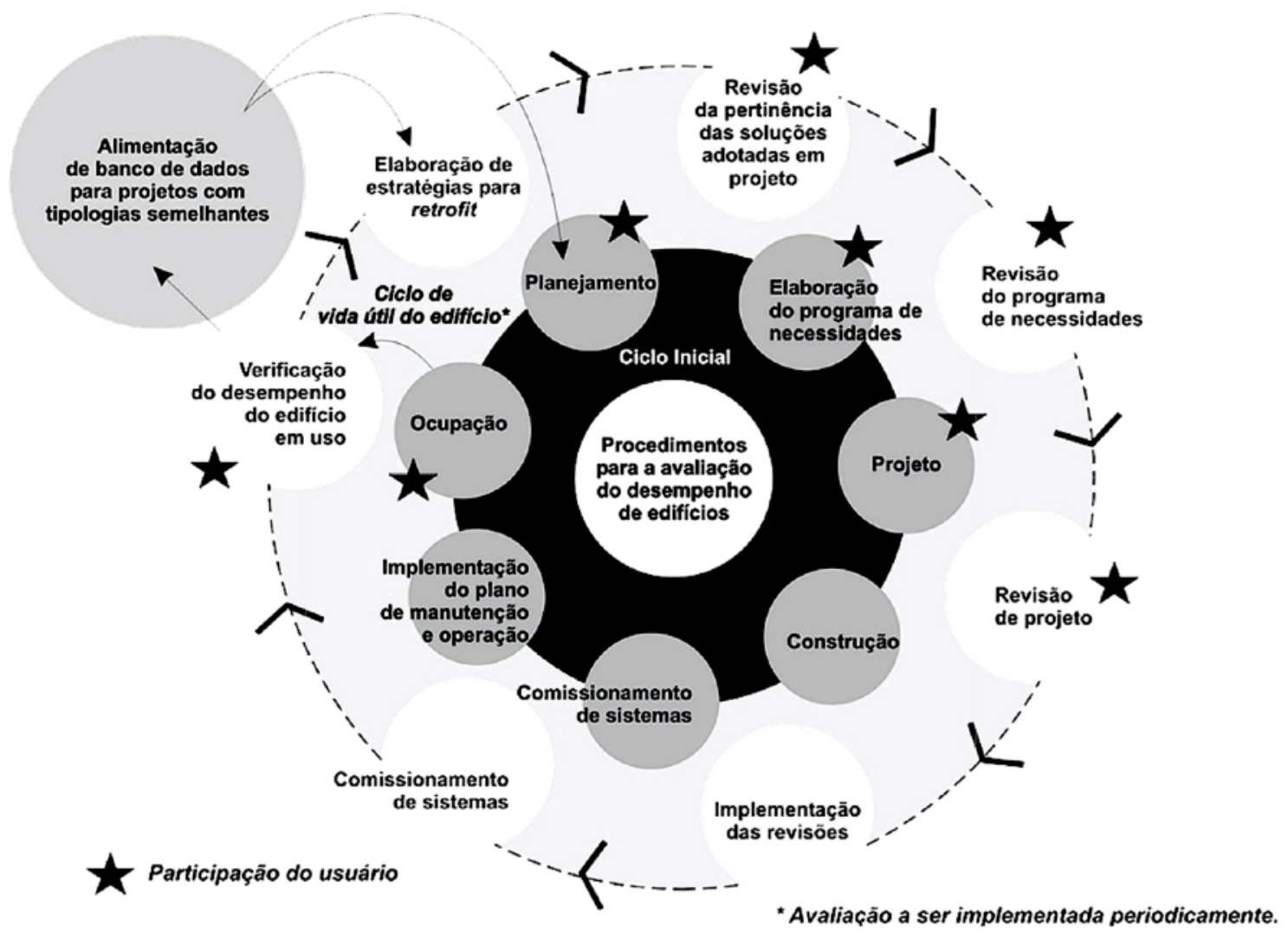

Fonte: FRANÇA, 2011.

A aplicação dos instrumentos de APO exige, segundo França (2011), atenção às etapas de planejamento e de definição dos instrumentos que se adequam à análise pretendida. É importante se ter clareza das metas pretendidas para que o conjunto de resultados permita uma avaliação crítica do estudo de caso e, assim, traga contribuições, tanto para o objeto de estudo, quanto para pesquisas futuras relacionadas ao tema.

Atualmente, a APO dispõe de muitas técnicas com variados instrumentos quantitativos e qualitativos que, comprovadamente, podem ser utilizados, conforme o estudo de caso, para avaliar a qualidade do ambiente em uso (Figura 50). Dentre os instrumentos, destacam-se (ORNSTEIN, 2004; VILLA, 2016):

a. as-built com posicionamento de elementos relevantes;

b. visitas técnicas, que podem ser feitas em conjunto com walkthroughs, checklists dos aspectos construtivos e funcionais e registros visuais (fotografias, vídeos, desenhos etc.);

c. medições e/ou simulações das condições de conforto ambiental, funcionalidade e ergonomia;

d. observação de comportamentos do usuário e elaboração de mapas comportamentais; 
e. entrevistas estruturadas ou semiestruturadas com pessoas-chave da instituição;

f. questionários para aferição da satisfação dos usuários, com respostas de múltipla escolha, escala de valores e/ou respostas abertas;

g. grupos focais ou outras dinâmicas de grupo, com atividades para conjuntos de 6 a 12 pessoas que compartilham das mesmas características;

h. desenhos, poemas de desejos, dentre outras atividades para públicos especiais (crianças, idosos, dentre outros).

Figura 50. Metodologia da APO

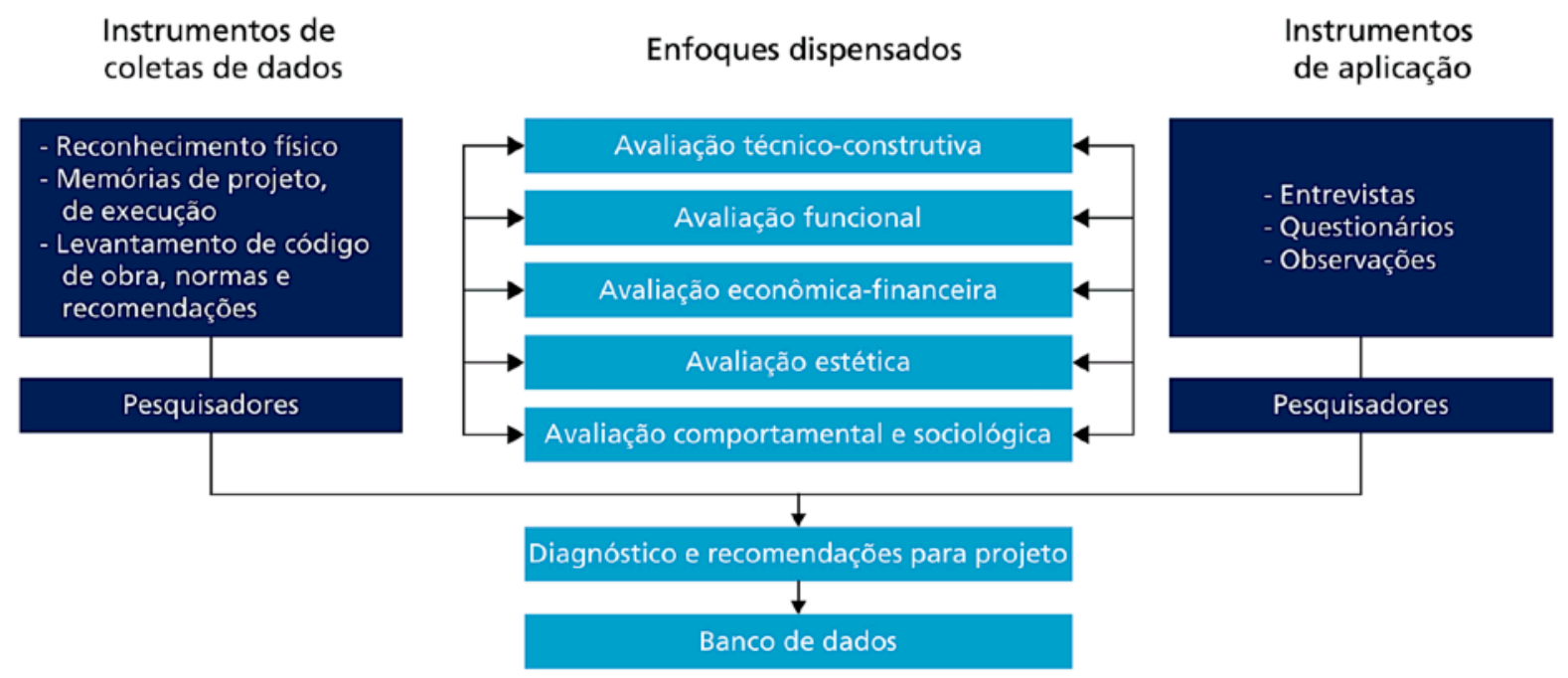

Fonte: VILLA, 2016.

Tipicamente, uma vez que a construção de um edifício tenha sido encerrada e ele começou a ser ocupado, surgem dúvidas que, com frequência, costumam ficar sem resposta, tais como (HEFCE, 2006):

- o edifício está funcionando conforme o esperado?

- as demandas e necessidades dos usuário permaneceram as mesmas ou se alteraram?

- surgiram dificuldades que precisam de resolução imediata?

- quão eficaz foi o processo de projeto e de construção?

- quais experiências devem ou não devem ser replicadas em projetos semelhantes futuros?

Vários instrumentos de avaliação de desempenho, objetivos e subjetivos, podem ser usados para coletar informações e responder a estas perguntas, desde que o processo como um todo seja adequadamente planejado. No livro 'Avaliação pós-ocupação na arquitetura, no urbanismo e no design: da teoria à prática' (ONO et al., 2018), as autoras propõem um encadeamento de ações e informações, que podem 
auxiliar no planejamento das etapas de execução de uma APO. 0 plano estratégico da APO, adaptado por esta pesquisa para instituições culturais, está descrito na Figura 51 e no Quadro 16.

Figura 51. Fluxograma das etapas de AP0 adaptado para esta pesquisa

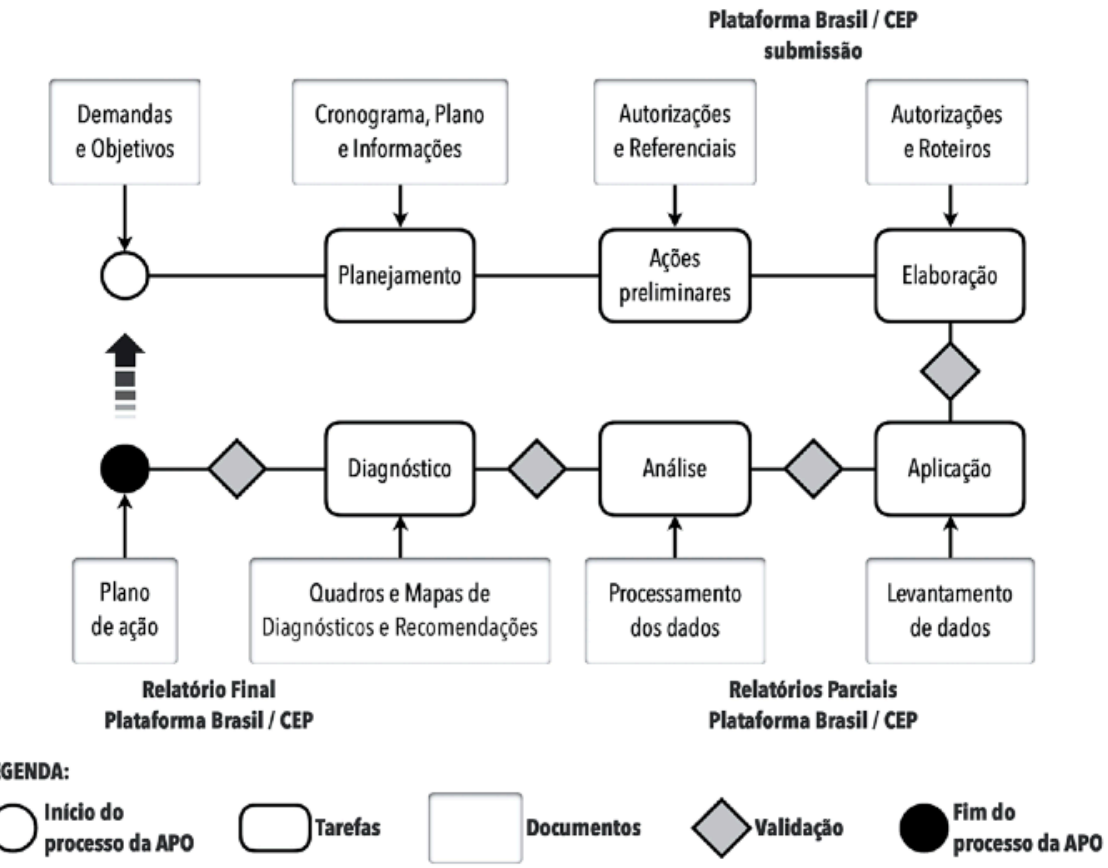

Fonte: adaptado de ONO et al., 2018.

Quadro 16. Plano estratégico para aplicação da APO, adaptado para esta pesquisa

\begin{tabular}{|c|c|c|c|}
\hline 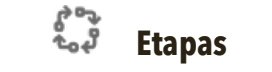 & 二 & (D) Ações & Informações \\
\hline \multirow{2}{*}{$\begin{array}{l}\text { 1. Início do } \\
\text { processo: } \\
\text { demanda por } \\
\text { utilização da APO }\end{array}$} & Demanda & $\begin{array}{c}\text { definir o(s) problema(s), a(s) } \\
\text { questão(ões) ou a(s) estratégia(s) } \\
\text { institucional(is) que motivam a } \\
\text { realização da APO }\end{array}$ & $\begin{array}{l}\text { referências bibliográficas, contato com } \\
\text { instituições e especialistas } \\
\text { documentos: planos e políticas; } \\
\text { organograma institucional; plantas } \\
\text { arquitetônicas; etc. }\end{array}$ \\
\hline & Objetivos & $\begin{array}{l}\text { definir os objetivos institucionais } \\
\text { pretendidos }\end{array}$ & $\begin{array}{l}\text { reunir os dados existentes na instituição } \\
\text { sobre gestão, conservação, manutenção e } \\
\text { monitoramento }\end{array}$ \\
\hline \multirow{4}{*}{$\begin{array}{l}\text { 2. Planejamento } \\
\text { (projeto da APO) }\end{array}$} & \multirow{4}{*}{$\begin{array}{l}\text { Cronograma das } \\
\text { atividades }\end{array}$} & $\begin{array}{l}\text { estabelecer prazo para coleta de dados } \\
\text { / aplicação dos instrumentos }\end{array}$ & \multirow{4}{*}{$\begin{array}{l}\text { período de tempo definido pela equipe } \\
\text { responsável pela elaboração do projeto da } \\
\text { APO em conjunto com a(s) equipe(s) } \\
\text { responsável(is) pela aplicação da APO }\end{array}$} \\
\hline & & $\begin{array}{l}\text { estabelecer prazo para tratamento e } \\
\text { análise dos dados }\end{array}$ & \\
\hline & & $\begin{array}{l}\text { estabelecer prazo para diagnósticos e } \\
\text { recomendações / plano de ação e de } \\
\text { monitoramento dos resultados }\end{array}$ & \\
\hline & & estabelecer prazo para relatório final & \\
\hline
\end{tabular}


Quadro 16. Plano estratégico para aplicação da APO, adaptado para esta pesquisa (continuação)

\begin{tabular}{|c|c|c|c|}
\hline हొః Etapas & Procedimentos & ( $)$ Ações & Informações \\
\hline \multirow{5}{*}{$\begin{array}{l}\text { 2. Planejamento } \\
\text { (projeto da APO) }\end{array}$} & \multirow{3}{*}{ Plano estratégico } & $\begin{array}{l}\text { identificar os recursos humanos } \\
\text { necessários }\end{array}$ & $\begin{array}{c}\text { definir equipe e/ou profissional responsável } \\
\text { por cada uma das atividades previstas }\end{array}$ \\
\hline & & $\begin{array}{c}\text { identificar os recursos técnicos } \\
\text { necessários }\end{array}$ & $\begin{array}{l}\text { descrever as ferramentas e os materiais } \\
\text { necessários para a aplicação da APO }\end{array}$ \\
\hline & & $\begin{array}{l}\text { identificar os métodos e técnicas a } \\
\text { serem empregados }\end{array}$ & $\begin{array}{c}\text { definir os instrumentos qualitativos e } \\
\text { quantitativos para coleta de dados } \\
\text { definir os métodos e técnicas para análise } \\
\text { dos resultados }\end{array}$ \\
\hline & \multirow{2}{*}{$\begin{array}{l}\text { Levantamento de } \\
\text { informações }\end{array}$} & $\begin{array}{l}\text { descrever os padrões de uso e } \\
\text { ocupação }\end{array}$ & $\begin{array}{l}\text { uso e ocupação de: áreas de guarda e/ou } \\
\text { exposição; áreas de apoio; áreas } \\
\text { administrativas }\end{array}$ \\
\hline & & realizar análise documental & $\begin{array}{l}\text { informações construtivas, das facilidades e } \\
\text { dos mobiliários; } \\
\text { dados climáticos internos e externos }\end{array}$ \\
\hline \multirow{6}{*}{$\begin{array}{l}\text { 3. Ações } \\
\text { preliminares }\end{array}$} & \multirow[t]{2}{*}{ Autorizações } & $\begin{array}{l}\text { submeter o projeto da APO à Plataforma } \\
\text { Brasil: pesquisas e dinâmicas com } \\
\text { usuários precisam ser submetidas e } \\
\text { aprovadas por um Comitê de Ética em } \\
\text { Pesquisa (CEP) } \\
\text { [Ressalva: conforme Resolução n } 510 \\
\text { de 2016: Parágrafo único, pesquisa de } \\
\text { opinião pública com participantes não } \\
\text { identificados não serão registradas nem } \\
\text { avaliadas pelo sistema CEP/CONEP.] }\end{array}$ & $\begin{array}{l}\text { projeto da APO contendo: Modelo de } \\
\text { Solicitação de Autorização do responsável } \\
\text { pela instituição; Modelo do Termo de } \\
\text { Consentimento Livre e Esclarecido (TCLE) e/ } \\
\text { ou Modelo do Termo de Assentimento Livre } \\
\text { e Esclarecido (TALE), para cada tipo de } \\
\text { usuário; roteiros dos instrumentos de } \\
\text { avaliação da percepção dos usuários } \\
\text { (entrevistas, questionários, dinâmicas, etc.) }\end{array}$ \\
\hline & & solicitar autorizações na instituição & $\begin{array}{c}\text { autorização de diretores, gestores e/ou } \\
\text { demais responsáveis pela instituiç̧ão, seus } \\
\text { espaços edificados e seus acervos }\end{array}$ \\
\hline & \multirow{4}{*}{ Referenciais } & benchmarks & $\begin{array}{l}\text { estudos de caso nacionais e internacionais } \\
\text { de referência }\end{array}$ \\
\hline & & normas técnicas & $\begin{array}{l}\text { normas nacionais e internacionais de } \\
\text { referência para espaços com acervos }\end{array}$ \\
\hline & & boas práticas & $\begin{array}{l}\text { recomendações de instituições de pesquisa } \\
\text { e de organismos nacionais e internacionais }\end{array}$ \\
\hline & & definiç̧ões legais & $\begin{array}{l}\text { atribuições de museus, bibliotecas e } \\
\text { arquivos; cartas do IPHAN e do IBRAM; } \\
\text { cartas internacionais; etc. }\end{array}$ \\
\hline \multirow[b]{2}{*}{ 4. Elaboração } & \multirow[b]{2}{*}{ Autorizações } & $\begin{array}{l}\text { encaminhar Solicitação de Autorização } \\
\text { para cada responsável }\end{array}$ & \multirow[b]{2}{*}{ Após autorização do CEP } \\
\hline & & $\begin{array}{l}\text { finalizar TCLE (para adultos capazes) e/ } \\
\text { ou TALE (para pessoas legalmente } \\
\text { incapazes) para cada participante }\end{array}$ & \\
\hline
\end{tabular}


Quadro 16. Plano estratégico para aplicação da APO, adaptado para esta pesquisa (continuação)

\begin{tabular}{|c|c|c|c|}
\hline$\oint^{\circ}$ & Procedimentos & Ações & Informações \\
\hline \multirow[t]{2}{*}{ 4. Elaboração } & \multirow[t]{2}{*}{ Roteiros } & $\begin{array}{l}\text { finalizar os roteiros dos instrumentos } \\
\qquad \begin{array}{c}\text { de avaliação da percepção dos } \\
\text { usuários }\end{array}\end{array}$ & $\begin{array}{l}\text { pré-testar cada roteiro, se necessário, } \\
\text { fazer ajustes (quantas vezes for preciso } \\
\text { para que não haja dúvidas, erros de } \\
\text { interpretação ou vieses) }\end{array}$ \\
\hline & & $\begin{array}{l}\text { finalizar roteiros e checklists para } \\
\text { avaliação do ambiente construído }\end{array}$ & $\begin{array}{l}\text { especificar os itens a serem verificados, as } \\
\text { ferramentas que serão utilizadas, e as } \\
\text { informações que devem ser coletadas }\end{array}$ \\
\hline \multirow{4}{*}{ 5. Aplicação } & \multirow{4}{*}{ Levantamentos de dado } & receber autorização dos responsáveis & $\begin{array}{c}\text { assinatura de cada responsável, autorizando } \\
\text { a aplicação da APO }\end{array}$ \\
\hline & & $\begin{array}{l}\text { entregar TCLE / TALE a cada } \\
\text { participante }\end{array}$ & $\begin{array}{l}\text { assinatura dos participantes com o seu } \\
\text { consentindo }\end{array}$ \\
\hline & & $\begin{array}{l}\text { aplicar instrumentos para avaliação da } \\
\text { percepção dos usuários }\end{array}$ & realizar cada atividade conforme definido \\
\hline & & $\begin{array}{l}\text { aplicar instrumentos para avaliação do } \\
\text { ambiente construído }\end{array}$ & nas etapas de Planejamento e Elaboração \\
\hline \multirow{4}{*}{ 6. Análise } & \multirow[t]{3}{*}{$\begin{array}{l}\text { Análise dos resultados - } \\
\text { Processamento dos } \\
\text { dados coletados }\end{array}$} & analisar dados climáticos & $\begin{array}{l}\text { processamento dos dados, elaboração de } \\
\text { diagramas e gráficos comparativos dos valores } \\
\text { encontrados com os parâmetros definidos } \\
\text { pela instituição e/ou as recomendações de } \\
\text { boas práticas; } \\
\text { simulação computacional das condições } \\
\text { ambientais e de alternativas projetuais para } \\
\text { melhoria do desempenho }\end{array}$ \\
\hline & & $\begin{array}{l}\text { analisar dados coletados na avaliação } \\
\text { do ambiente construído }\end{array}$ & \multirow{2}{*}{$\begin{array}{l}\text { sistematização os dados coletados (mapas, } \\
\text { gráficos, diagramas, matrizes, etc.), } \\
\text { compará-los com os referenciais escolhidos } \\
\text { e as normas técnicas, identificar } \\
\text { vulnerabilidades }\end{array}$} \\
\hline & & $\begin{array}{l}\text { analisar dados coletados sobre a } \\
\text { percepção dos usuários }\end{array}$ & \\
\hline & Relatórios parciais & $\begin{array}{l}\text { submeter, à Plataforma Brasil, os } \\
\text { resultados parciais da aplicação dos } \\
\text { instrumentos com os usuários }\end{array}$ & $\begin{array}{l}\text { comunicar alterações, dificuldades e/ou } \\
\text { cumprimento das metas pretendidas }\end{array}$ \\
\hline 7. Diagnóstico & $\begin{array}{l}\text { Diagnósticos e } \\
\text { recomendações }\end{array}$ & $\begin{array}{l}\text { construir os Quadros-síntese de } \\
\text { Diagnósticos e Recomendações (QDR) }\end{array}$ & $\begin{array}{l}\text { matrizes resumo dos principais dados } \\
\text { coletados e analisados, tais como: } \\
\text { ocorrências identificadas, instrumentos } \\
\text { utilizados, sistema construtivo associado, } \\
\text { critérios de desempenho, riscos ao edifício } \\
\text { e às coleções, normas e os parâmetros } \\
\text { considerados na análise, recomendações } \\
\text { para solução da ocorrência ou mitigação de } \\
\text { danos, escala relativa de danos ao edifício } \\
\text { e/ou às coleções, prazos e custos relativos } \\
\text { para a implantação das recomendações, } \\
\text { dentre outros }\end{array}$ \\
\hline
\end{tabular}


Quadro 16. Plano estratégico para aplicação da APO, adaptado para esta pesquisa (continuação)

\begin{tabular}{|c|c|c|c|}
\hline$\varliminf_{0}^{\circ} \quad$ Etapas & 二 & (V) Ações & Informações \\
\hline 7. Diagnóstico & $\begin{array}{l}\text { Diagnósticos e } \\
\text { recomendações }\end{array}$ & $\begin{array}{l}\text { construir os Mapas de Diagnósticos e } \\
\text { Recomendações (MDR) }\end{array}$ & $\begin{array}{c}\text { quadros e legendas contendo as principais } \\
\text { informações dos QDR anotados nas plantas } \\
\text { arquitetônicas do edifício }\end{array}$ \\
\hline \multirow[t]{2}{*}{$\begin{array}{l}\text { 8. Fim do processo: } \\
\text { encerramento da } \\
\text { APO }\end{array}$} & \multirow[t]{2}{*}{ Plano de ação } & \multirow[t]{2}{*}{ elaboração do Relatório Final } & $\begin{array}{l}\text { apresentação das conclusões da APO aos } \\
\text { tomadores de decisão, contendo plano } \\
\text { de ação (para a gestão, o edifício, os } \\
\text { acervos e os ambientes internos) e } \\
\text { métrica para monitoramento dos } \\
\text { resultados e possíveis ajustes }\end{array}$ \\
\hline & & & $\begin{array}{l}\text { submissão de relatório final à Plataforma } \\
\text { Brasil }\end{array}$ \\
\hline
\end{tabular}

Fonte: a pesquisadora.

Toda vez que uma APO faz uso de instrumentos para a coleta de dados de usuários, é muito importante o planejamento do enquadramento ético das atividades, ou seja, a definição de quais são os objetivos pretendidos, quais os métodos que serão utilizados, quais os benefícios previstos, quais os riscos potenciais (mesmo que mínimos) e quais os possíveis incômodos associados.

A Plataforma Brasil é o sistema eletrônico do governo federal (Ministério da Saúde) responsável pelo recebimento dos projetos de pesquisa que envolvem seres humanos e a distribuição deles para um dos diversos Comitês de Ética em Pesquisa (CEP) existentes no país. A equipe responsável pelo planejamento da APO deve encaminhar uma solicitação contendo: a descrição de quais os instrumentos que serão utilizados e qual a amostra / os participantes previstos; os modelos das autorizações necessárias (diretores, chefes ou outros responsáveis); os modelos dos Termos de Consentimento Livre e Esclarecido (TCLE) e, se for o caso, dos Termos de Assentimento Livre e Esclarecido (TALE); e os roteiros das atividades previstas.

0 TCLE é o documento que registra que o participante concordou com a atividade, sem que houvesse para isso quaisquer vício (simulação, fraude ou erro), dependência, subordinação ou intimidação. Precisa ser redigido de forma clara, no formato de uma carta-convite. Deve conter as principais informações sobre a pesquisa: os dados para contato com o(s) pesquisador(es), os objetivos da pesquisa, seus riscos e benefícios, o número de protocolo (CAAE) de autorização do CEP, os dados para contato com o CEP, e as instruções para o caso de desistência. 
O TALE é o documento de anuência de participantes legalmente incapazes, como crianças, adolescentes ou pessoas com deficiência intelectual. Deve conter as mesmas informações do TCLE, porém elaborado em linguagem acessível, respeitando as singularidades de cada grupo. Os responsáveis legais também precisam consentir mediante a assinatura do TCLE correspondente. Cabe ao pesquisador definir quais os grupos que serão contemplados pelo estudo e os TALEs adaptados a cada um.

0 planejamento de uma APO se inicia com a definição de qual período, dentre três distintos, ela se enquadra (HEFCE, 2006):

a. avaliação operacional ( 3 a 6 meses após a ocupação do edifício): avaliação do processo de execução e entrega da obra, documentação de decisões e alterações feitas no canteiro, identificação de problemas iniciais, durante o processo de ocupação, que precisam de solução imediata (Quadro 17).

Quadro 17. Avaliação operacional: de 3 a 6 meses após a ocupação do edifício

\begin{tabular}{l|l} 
Horizonte temporal: & Revisão do processo de projeto \\
\hline Objetivo principal: & - o processo como um todo, desde a contratação do projeto até a entrega da obra \\
\hline Objetivos amplos: & $\begin{array}{l}\text { - visão preliminar do desempenho técnico-funcional e da qualidade do ambiente construído } \\
\text { - oportunidade para pequenos ajustes e correção imediata de problemas } \\
\text { - resposta rápida aos usuários }\end{array}$ \\
\hline Gestão da informação: & $\begin{array}{l}\text { - apenas para uso interno (pela instituição ou organização da qual ela faz parte) } \\
\text { - revisão do processo: conclusões podem auxiliar na melho ria de projetos similares futuros } \\
\text { - revisão da construção: pequenos ajustes no uso e ocupação do edifício }\end{array}$ \\
\hline Abordagem: & Avaliação indicativa
\end{tabular}
Fonte: traduzido e adaptado de HEFCE, 2006.

b. avaliação projetual (12 a 18 meses após a ocupação): feedback das soluções de projeto (sistemas construtivos, equipamentos, mobiliário, etc.) após um ciclo completo de um ano de ocupação e uso do edifício, seus espaços e sistemas (Quadro 18).

Quadro 18. Avaliação projetual: de 12 a 18 meses após a ocupação do edifício

\begin{tabular}{l|l} 
Horizonte temporal: & Revisão do processo de ocupação e uso do edifício \\
\hline Objetivo principal: & $\begin{array}{l}\text { - avaliação do desempenho de áreas / funções específicas } \\
\text { - avaliação do desempenho técnico-funcional } \\
\text { - identificação da necessidade de ajustes e correções nos ambientes e nas facilidades } \\
\text { - avaliação dos custos de uso e operação }\end{array}$
\end{tabular}


Quadro 18. Avaliação projetual: de 12 a 18 meses após a ocupação do edifício (continuação)

\begin{tabular}{l|l} 
Gestão da informação: & $\begin{array}{l}\text { - para uso interno (instituição / organização) e externo (equipes de projeto) } \\
\text { - revisão do processo: auxiliar no planejamento de projetos futuros similares } \\
\text { - revisão da construção: pequenos ajustes no edifício }\end{array}$ \\
\hline Abordagem: & Avaliação investigativa / diagnóstica
\end{tabular}

Fonte: traduzido e adaptado de HEFCE, 2006.

c. avaliação estratégica (após 18 de meses ou mais de ocupação; ao longo de toda a vida útil do edifício): a APO é uma das abordagens pertinentes para a revisão de longo prazo de decisões e soluções construtivas, uma vez que padrões de uso e ocupação podem se alterar com o tempo, manifestações patológicas 52 podem aparecer, e equipamentos podem ficar obsoletos (Quadro 19).

Quadro 19. Avaliação estratégica: a cada n53 anos, conforme planejamento institucional estratégico

\begin{tabular}{l|l} 
Horizonte temporal: & Revisão de longo prazo; olha para o passado mas também para o futuro \\
\hline Objetivo principal: & $\begin{array}{l}\text { - avaliação de resposta do edifício a mudanças organizacionais } \\
\text { - avaliação de como o edifício pode responder à projeção de demandas futuras } \\
\text { - revisão do plano de gestão institucional e do plano de gestão das facilidades, após vários } \\
\text { anos de experiência com o edifício }\end{array}$ \\
\hline Gestão da informação: & $\begin{array}{l}\text { - para uso interno (informações sensíveis que não podem ser compartilhadas com o } \\
\text { público) e externo (público) } \\
\text { - qual o próximo projeto? (planejamento institucional estratégico) }\end{array}$ \\
\hline Abordagem: & Avaliação investigativa
\end{tabular}

Fonte: traduzido e adaptado de HEFCE, 2006.

Durante o planejamento de uma APO, também é preciso decidir quais as grandes áreas que serão foco da avaliação (HEFCEA, 2006):

a. avaliação com foco no processo: medição da efetividade das decisões tomadas e dos trabalhos realizados, desde a solicitação do projeto arquitetônico até a entrega e ocupação do edifício (Quadro 20).

\footnotetext{
52 Manifestações patológicas são inadequações construtivas associadas a riscos de danos ou perdas. As manifestações patológicas podem ter como causa falhas ou anomalias no projeto, na execução, no material ou componente, e/ou na manutenção (SIMÕES, 2004).

530 planejamento institucional estratégico costuma ter um horizonte temporal fixo, ou seja, propõe metas a serem cumpridas ao longo de $\mathrm{N}$ anos (definido pela instituição, usualmente entre 5 e 20 anos), ao final do qual as metas devem ser avaliadas, revistas e ajustadas para um novo ciclo. Como parte do planejamento estratégico, podem ser previstas APOs a cada n anos (definido pela instituição, usualmente entre 3 e 5 anos).
} 
Quadro 20. Os aspectos considerados em uma avaliação com foco no processo

\begin{tabular}{l|l} 
Demanda: & $\begin{array}{l}\text { O modo como a equipe planejou as demandas (Programa de Necessidades e Estudo de } \\
\text { Viabilidade) e o impacto destas escolhas no projeto e na gestão financeira. }\end{array}$ \\
\hline Contratação: & $\begin{array}{l}\text { O modo como a equipe fez a gestão da seleção, contratação e avaliação técnica dos } \\
\text { prestadores de serviço, incluindo o atendimento a prazos e custos. }\end{array}$ \\
\hline Projeto: & $\begin{array}{l}\text { O modo como a equipe desenvolveu, compatibilizou e aprimorou o projeto arquitetônico e } \\
\text { seus projetos complementares, bem como os aspectos relativos à gestão financeira do } \\
\text { processo. }\end{array}$ \\
\hline Construção: & $\begin{array}{l}\text { O modo como as etapas de obra, do terrapleno até a entrega, foram administradas, } \\
\text { incluindo a gestão das equipes e dos recursos. }\end{array}$ \\
\hline Comissionamento: & $\begin{array}{l}0 \text { modo como foi feita a gestão do comissionamento do edifício, incluindo a inspeção final } \\
\text { pré-entrega da obra, os últimos ajustes e o as-built. }\end{array}$ \\
\hline Ocupação: & $\begin{array}{l}0 \text { modo como o processo de entrega da obra foi conduzido, incluindo ajustes / } \\
\text { modificações de última hora e os processos de limpeza e realocação de equipamentos. }\end{array}$
\end{tabular}

Fonte: traduzido de HEFCEA, 2006.

b. avaliação com foco no desempenho funcional: medição da efetividade do edifício em responder às demandas organizacionais e às necessidades dos usuários (Quadro 21).

Quadro 21. Os aspectos considerados em uma avaliação com foco no desempenho funcional

\begin{tabular}{l|l} 
Valor estratégico: & Atendimento aos objetivos institucionais \\
\hline Estética e imagem: & Atendimento às expectativas: harmonioso, neutro, icônico, marcante, etc. \\
\hline Ambiente: & Dimensões, ergonomia, acessibilidade, etc. \\
\hline Conforto: & Aspectos ambientais: iluminação, térmica, ventilação, acústica, etc. \\
\hline Facilidades: & Sistemas e equipamentos: adequação ao uso, capacidade, posicionamento, etc. \\
\hline Serviços: & Manutenção, limpeza, segurança, etc. \\
\hline Custos operacionais: & Custos de: energia, água e esgoto, aluguel, seguro, etc. \\
\hline Custos ao longo da vida útil: & Custos de: construção, operação, manutenção e reparos, alteração e demolição \\
\hline Gestão operacional: & $\begin{array}{l}\text { Demanda por alocação de espaços, sistemas de apoio aos usuários, políticas e } \\
\text { manuais, treinamentos e simulados, etc. }\end{array}$
\end{tabular}

Fonte: traduzido de HEFCEA, 2006. 
c. avaliação com foco no desempenho técnico: medição do desempenho dos sistemas físicos (Quadro 22).

Quadro 22. Os aspectos considerados em uma avaliação com foco no desempenho técnico

\begin{tabular}{l|l} 
Sistemas físicos: & Iluminação, ventilação, aquecimento, resfriamento, etc. \\
\hline Características ambientais: & Consumo de energia, consumo de água, níveis de poluentes, etc. \\
\hline Adaptabilidade: & Capacidade dos sistemas de se adaptarem à necessidade de mudanças \\
\hline Durabilidade: & $\begin{array}{l}\text { Robustez, rotina de manutenção simples ou complexa, frequência de inoperação por } \\
\text { problemas técnicos, etc. }\end{array}$
\end{tabular}

Fonte: traduzido de HEFCEA, 2006.

A APO deve ser entendida como um compromisso institucional com a qualidade, sendo assim parte de um processo de melhoria continuada. A documentação sistemática de todas as etapas deve resultar em um histórico das decisões adotadas, o que facilita análises comparativas e encaminhamentos futuros. Os usuários são parte importante de uma APO porque: são fonte de informação; devem ser incluídos no processo para que se sintam confiantes com os resultados; e/ou integram a equipe de trabalho (Quadro 23).

Quadro 23. Quem deve participar de uma APO (adaptado para instituições culturais)

\begin{tabular}{|c|c|}
\hline Quem? & Considerações \\
\hline \multicolumn{2}{|l|}{ Equipe de trabalho } \\
\hline Avaliadores/Consultores & $\begin{array}{l}\text { - definir funções e expectativas } \\
\text { - registrar informações relevantes } \\
\text { - juntar referências e documentos } \\
\text { - informar decisões do planejamento da APO }\end{array}$ \\
\hline Especialistas & - definir especialidades relevantes e responsabilidades \\
\hline \multicolumn{2}{|l|}{ Usuários } \\
\hline Visitantes & $\begin{array}{l}\text { - quais os grupos representativos? } \\
\text { - quando estão disponíveis? } \\
\text { - qual a melhor forma de envolvê-los nas atividades (questionários, dinâmicas, jogos, ...)? } \\
\text { - qual a amostra representativa? }\end{array}$ \\
\hline Funcionários & $\begin{array}{l}\text { - quais funcionários são representativos? } \\
\text { - quando estão disponíveis? }\end{array}$ \\
\hline Outros (pesquisadores, etc.) & - quais os grupos representativos? \\
\hline A instituição como cliente & - quais funções precisam estar incluídas? \\
\hline
\end{tabular}

Fonte: traduzido e adaptado de HEFCE, 2006. 
0 Conselho para Financiamento do Ensino Superior da Inglaterra (HEFCEA, 2006) sugere que 0 planejamento de uma APO considere utilizar um dentre três níveis de investigação (mais um nível de pré-avaliação), conforme as necessidades específicas da instituição:

- nível zero: ainda na etapa de planejamento da APO, é possível conduzir uma pré-avaliação do ambiente construído para orientar a equipe na definição dos objetivos pretendidos com esta abordagem. Para isso, frequentemente, se faz uso de conversas informativas e visitas de reconhecimento.

- nível um - avaliação indicativa: abordagem ampla e generalista, com a função de identificar os principais pontos fortes e fracos da instituição, permitindo separar as ocorrências de baixa vulnerabilidade daquelas de alta vulnerabilidade, as quais demandarão avaliações mais aprofundadas. Neste nível costuma-se combinar algumas entrevistas semi-estruturadas ou estruturadas com visita(s) técnica(s) exploratória(s). Conforme o caso, também pode(m) ser empregado(s) questionário(s) curto(s) e simples.

- nível dois - avaliação investigativa: abordagem mais completa para uma avaliação mais aprofundada das principais questões previamente identificadas. Neste nível podem ser utilizadas visitas técnicas estruturadas (walkthroughs com checklists), bem como questionários combinados com dinâmicas de grupo e entrevistas estruturadas.

- nível três - avaliação diagnóstica: abordagem bastante aprofundada, com análise completa do desempenho do edifício, pela perspectiva de especialistas e usuários. Contempla, além das visitas técnicas estruturadas, medições (de sistemas construtivos e da qualidade do ambiente interno), avaliação dos sistemas ativos, simulações energéticas, dentre outros, bem como entrevistas estruturadas e questionários extensos e detalhados, combinados a outras dinâmicas planejadas para grupos específicos.

É preciso também que o planejamento da APO considere um dentre dois caminhos possíveis: utilizar uma abordagem metodológica de APO já estabelecida ou desenvolver uma abordagem personalizada, sob medida para a instituição (Quadro 24). 
Quadro 24. Vantagens e desvantagens de se utilizar uma abordagem metodológica de APO estabelecida ou personalizada

\begin{tabular}{|c|c|}
\hline \multicolumn{2}{|l|}{ Métodos existentes } \\
\hline 1 Vantagens: & Desvantagens: \\
\hline $\begin{array}{l}\text { - testado } \\
\text { - pronto para o uso } \\
\text { - fundamentado em pesquisas rigorosas } \\
\text { - benchmarks (comparação com instituições similares que } \\
\text { utilizaram a mesma metodologia) }\end{array}$ & $\begin{array}{l}\text { - pode ter custo elevado } \\
\text { - pode não se adaptar a situações específicas } \\
\text { - os resultados podem ter como proprietário o desenvolvedor } \\
\text { do método } \\
\text { - custo dos especialistas em aplicação do método }\end{array}$ \\
\hline \multicolumn{2}{|l|}{ Métodos sob medida } \\
\hline Vantagens: & Desvantagens: \\
\hline $\begin{array}{l}\text { - adaptado a demandas específicas } \\
\text { - pode ter custo menor } \\
\text { - todo o processo sob controle da instituição }\end{array}$ & $\begin{array}{l}\text { - tempo necessário para planejar e configurar as etapas de } \\
\text { trabalho } \\
\text { - experiência da equipe de planejamento } \\
\text { - pode custar mais que um método já estabelecido }\end{array}$ \\
\hline
\end{tabular}

Fonte: traduzido e adaptado de HEFCEA, 2006.

Por fim, o HEFCEA (2006) recomenda que sejam escolhidos os instrumentos de avaliação que serão utilizados, dentre os muitos disponíveis. Para isso, alguns fatores devem ser considerados:

a. o foco e o nível de avaliação escolhido;

b. a quantidade de informação disponível;

c. os recursos disponíveis;

d. o prazo para realização dos trabalhos;

e. 0 nível de especialização dos avaliadores;

f. a existência ou não de avaliações prévias (e o nível delas).

Os principais instrumentos utilizados em uma APO, suas vantagens e desvantagens podem ser encontradas nos Quadros 25 a 31, a seguir. 
Quadro 25. Características, vantagens e desvantagens da aplicação do instrumento visitas técnicas

\begin{tabular}{|c|c|c|c|}
\hline Instrumento & Características & Vantagens & Desvantagens \\
\hline $\begin{array}{l}\text { Visitas técnicas / } \\
\text { walkthrough com } \\
\text { checklist e registro } \\
\text { visual }\end{array}$ & $\begin{array}{l}\text {-um dos instrumentos de observação exploratória direta } \\
\text { mais utilizados em APO; } \\
\text { - tem por finalidade permitir uma melhor compreensão } \\
\text { da área de estudo, através da identificação de suas } \\
\text { características técnico-construtivas, bem como de uso e } \\
\text { ocupação dos espaços; } \\
\text { - sempre que possível, deve ser realizada em conjunto } \\
\text { com funcionários que possam esclarecer os problemas } \\
\text { técnicos existentes e o histórico de intervenções e } \\
\text { manutenções realizadas; } \\
\text { - importante que sejam feitos registros visuais e } \\
\text { anotações in-loco, sobre a planta do edifício, do local e } \\
\text { do tipo de ocorrência identificada; } \\
\text { - o walkthrough é uma visita técnica estruturada, com } \\
\text { percursos definidos segundo os objetivos da análise, } \\
\text { concentrando-se na observação e no registro dos fatores } \\
\text { técnicos e funcionais dos ambientes a partir de plantas, } \\
\text { checklists (listas para verificação estruturada de } \\
\text { requisitos previamente definidos na etapa de } \\
\text { planejamento), anotações visuais, dentre outras técnicas. }\end{array}$ & $\begin{array}{l}\text { - pode ser feito por } \\
\text { pessoas pouco } \\
\text { especializadas, desde que } \\
\text { treinadas para identificar } \\
\text { as manifestações } \\
\text { patológicas; } \\
\text { - pode ser feito sem } \\
\text { qualquer impacto para o } \\
\text { funcionamento da } \\
\text { instituição; } \\
\text { - permite uma avaliação } \\
\text { dos ambientes com } \\
\text { poucos vieses e } \\
\text { distorções; } \\
\text { - se previsto no } \\
\text { planejamento, pode } \\
\text { fornecer, além dos dados } \\
\text { qualitativos, dados } \\
\text { quantitativos. }\end{array}$ & $\begin{array}{l}\text { - exige aplicação rigorosa, } \\
\text { e pode demandar } \\
\text { observações em dias e } \\
\text { horários específicos; } \\
\text { - desenvolver um } \\
\text { procedimento } \\
\text { personalizado pode ser } \\
\text { difícil e demandar } \\
\text { conhecimento } \\
\text { especializado; } \\
\text { - utilizar um modelo } \\
\text { pronto pode ser mais } \\
\text { simples mas pode não } \\
\text { contemplar todas as } \\
\text { necessidades de } \\
\text { avaliação. }\end{array}$ \\
\hline
\end{tabular}

Fonte: a pesquisadora, a partir de informações de SIMÕES, 2004; HEFCEA, 2006; PINHEIRO e GUNTHER, 2008; RHEINGANTZ et al., 2009; MATAR, 2011 e ONO et al., 2018.

Quadro 26. Características, vantagens e desvantagens da aplicação do instrumento medições e análises

\begin{tabular}{|c|c|c|c|}
\hline 圈 Instrumento & Características & Vantagens & Desvantagens \\
\hline $\begin{array}{c}\text { Medições e } \\
\text { análises técnicas }\end{array}$ & $\begin{array}{l}\text { - dados sobre desempenho de sistemas } \\
\text { construtivos (estruturas, vedos, etc.), } \\
\text { desempenho do ambiente interno } \\
\text { (temperatura, iluminação, poluentes, } \\
\text { etc.), ou desempenho energético; } \\
\text { - processo sistemático e/ou contínuo de } \\
\text { medição e monitoramento dos } \\
\text { parâmetros de desempenho entendidos } \\
\text { como representativos da qualidade da } \\
\text { construção e do ambiente interno; } \\
\text { - exige planejamento especializado dos } \\
\text { pontos de medição, da frequência e da } \\
\text { duração das atividades; } \\
\text { - exige a aplicação das normas técnicas } \\
\text { e das boas práticas para a coleta e } \\
\text { tratamento dos dados; } \\
\text { - exige o conhecimento das demandas } \\
\text { técnicas específicas de cada } \\
\text { equipamento de medição. }\end{array}$ & $\begin{array}{l}\text { - dados quantitativos } \\
\text { objetivos; } \\
\text { - os dados podem ser } \\
\text { associados a um } \\
\text { ambiente ou local } \\
\text { específico; } \\
\text { - permite entender o } \\
\text { padrão de } \\
\text { comportamento dos } \\
\text { parâmetros } \\
\text { construtivos, } \\
\text { ambientais e } \\
\text { energéticos, ao longo } \\
\text { dos dias, meses e anos. }\end{array}$ & $\begin{array}{l}\text { - as medições e as análises precisam ser feitas } \\
\text { por profissionais treinados / especializados; } \\
\text { - em alguns casos, pode ser necessária a } \\
\text { contratação de consultores externos; } \\
\text { - é preciso ter o equipamento adequado para } \\
\text { cada tipo de medição; } \\
\text { - algumas medições precisam ser feitas por } \\
\text { longos períodos de tempo, e os } \\
\text { equipamentos precisam permanecer no local, } \\
\text { funcionando adequadamente, sem que haja } \\
\text { interrupções na coleta dos dados; } \\
\text { - dadas as dificuldades envolvidas na coleta e } \\
\text { no tratamento dos dados, há sempre uma } \\
\text { possibilidade de vieses e distorções na análise } \\
\text { dos resultados pois nem sempre é possivel } \\
\text { afirmar, dentre as diversas causas internas e } \\
\text { externas, quais as que estão impactando mais } \\
\text { intensamente nos resultados. }\end{array}$ \\
\hline
\end{tabular}

Fonte: a pesquisadora, a partir de informações de SIMÕES, 2004; HEFCEA, 2006; PINHEIRO e GUNTHER, 2008; RHEINGANTZ et

$$
\text { al., 2009; MATTAR, } 2011 \text { e ONO et al., } 2018 .
$$


Quadro 27. Características, vantagens e desvantagens da aplicação do instrumento observações dos usuários

\begin{tabular}{|c|c|c|c|}
\hline Instrumento & Características & Vantagens & Desvantagens \\
\hline $\begin{array}{l}\text { Observações dos } \\
\text { usuários (mapas } \\
\text { comportamentais) }\end{array}$ & $\begin{array}{l}\text { - observação de comportamentos não- } \\
\text { verbais, gestos, posturas, etc., que devem ser } \\
\text { registrados visualmente (desenhos, fotos, } \\
\text { filmes, etc.) e anotados sobre a planta do } \\
\text { pavimento; } \\
\text { - deve ser feita simultaneamente por mais de } \\
\text { um avaliador, treinados para que suas } \\
\text { presenças interfiram o mínimo possível nos } \\
\text { resultados; } \\
\text { - pode ser casual (sem categorias ou sistemas } \\
\text { de pontuação pré-fixadas) ou sistemática } \\
\text { (cada comportamento é qualificado segundo } \\
\text { um sistema de pontuação, definido na etapa } \\
\text { de planejamento); } \\
\text { - podem ser usados para confirmar ou refutar } \\
\text { conceitos provenientes da literatura. }\end{array}$ & $\begin{array}{l}\text { - são bastante úteis na } \\
\text { identificação de } \\
\text { comportamentos, } \\
\text { atividades e interações } \\
\text { entre usuários e o } \\
\text { ambiente construído; } \\
\text { - permitem descobertas } \\
\text { inesperadas e } \\
\text { surpreendentes. }\end{array}$ & $\begin{array}{l}\text { - a presença dos avaliadores pode ter } \\
\text { impacto nos resultados; } \\
\text { - pode ser necessário realizar } \\
\text { múltiplas observações em dias e } \\
\text { horários diferentes; } \\
\text { - nem sempre é possível captar todos } \\
\text { os comportamentos, nem estabelecer } \\
\text { padrões de correlação entre } \\
\text { comportamentos e o ambiente } \\
\text { construído; } \\
\text { - para reduzir vieses e distorções, os } \\
\text { resultados precisam estar sempre } \\
\text { associados a outros instrumentos, tais } \\
\text { como visitas técnicas, entrevistas e } \\
\text { questionários. }\end{array}$ \\
\hline
\end{tabular}

Fonte: a pesquisadora, a partir de informações de SIMÕES, 2004; HEFCEA, 2006; PINHEIRO e GUNTHER, 2008; RHEINGANTZ et al., 2009; MATAR, 2011 e ONO et al., 2018.

Quadro 28. Características, vantagens e desvantagens da aplicação do instrumento dinâmicas de grupo

\begin{tabular}{|c|c|c|c|}
\hline 圈 Instrumento & Características & Vantagens & Desvantagens \\
\hline $\begin{array}{c}\text { Dinâmicas de } \\
\text { grupo }\end{array}$ & $\begin{array}{l}\text { - aconselha-se grupos de, no máximo, oito pessoas; } \\
\text { - os grupos devem contemplar pessoas de diferentes } \\
\text { áreas, para que elas contribuam com perspectivas e } \\
\text { experiências diversas para uma mesma questão; } \\
\text { - o tema / foco da dinâmica deve ser divido em } \\
\text { subtópicos; } \\
\text { - as atividades de cada subtópico não devem durar } \\
\text { mais do que uma hora; } \\
\text { - o facilitador deve decidir, em conjunto com o grupo, } \\
\text { os principais aspectos identificados, para os quais o } \\
\text { grupo deve buscar soluções; } \\
\text { - as respostas dos participantes devem ser registradas } \\
\text { de modo que todos possam ver e participar } \\
\text { (flipcharts, quadros brancos, etc.); } \\
\text { - é preciso separar um tempo para resumir e concluir } \\
\text { a atividade; } \\
\text { - os resultados devem ser compilados em um } \\
\text { relatório a ser entregue a todos os participantes. }\end{array}$ & $\begin{array}{l}\text { - as dinâmicas podem ajudar } \\
\text { a identificar e explorar } \\
\text { problemas, bem como } \\
\text { possíveis soluções; } \\
\text { - permitem descobertas } \\
\text { inesperadas e } \\
\text { surpreendentes. }\end{array}$ & $\begin{array}{l}\text { - são demoradas, uma } \\
\text { dinâmica deve durar pelo } \\
\text { menos meio dia; } \\
\text { - os resultados precisam } \\
\text { estar sempre associados a } \\
\text { outros instrumentos, tais } \\
\text { como visitas técnicas, } \\
\text { entrevistas e } \\
\text { questionários. }\end{array}$ \\
\hline
\end{tabular}

Fonte: a pesquisadora, a partir de informações de SIMÕES, 2004; HEFCEA, 2006; PINHEIRO e GUNTHER, 2008; RHEINGANTZ et al., 2009; MATTAR, 2011 e ONO et al., 2018. 
Quadro 29. Características, vantagens e desvantagens da aplicação do instrumento entrevistas

\begin{tabular}{|c|c|c|c|}
\hline Instrumento & Características & Vantagens & Desvantagens \\
\hline Entrevistas & 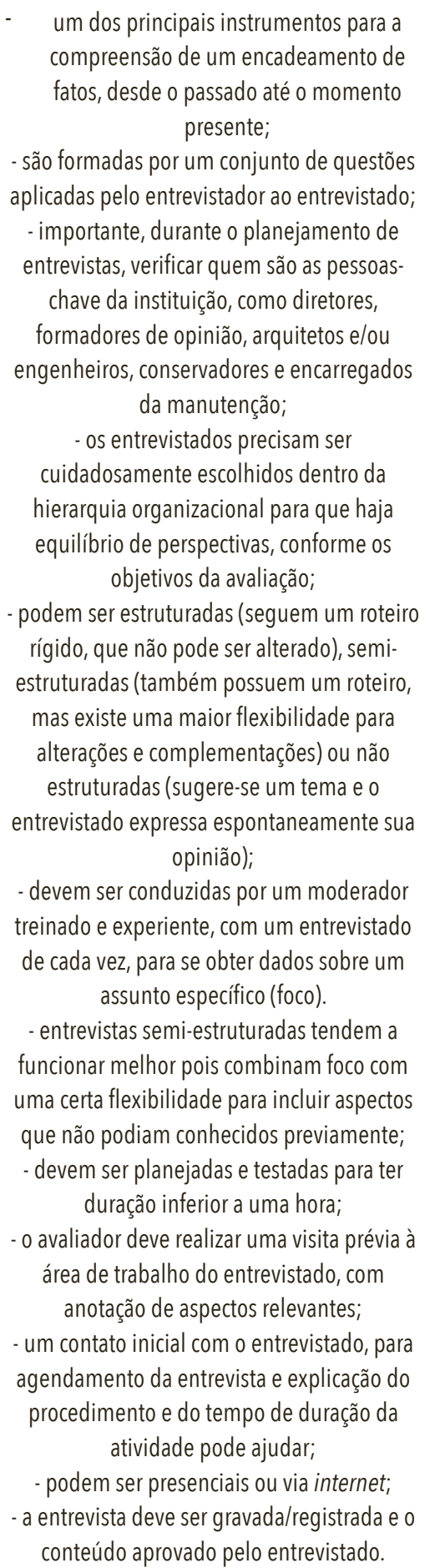 & $\begin{array}{l}\text { - permite obter informações } \\
\text { bastante específicas e } \\
\text { detalhadas; } \\
\text { - permite captar a percepção de } \\
\text { usuários muito específicos; } \\
\text { - é mais fácil de organizar do } \\
\text { que dinâmicas de grupo. }\end{array}$ & $\begin{array}{c} \\
\\
\text { pessoa treinada, e capaz de } \\
\text { manter a objetividade; } \\
\text { - opiniões específicas não } \\
\text { podem ser generalizadas; } \\
\text { - não é possível fazer } \\
\text { comparações entre as } \\
\text { respostas; } \\
\text { - devem ser conduzidas por } \\
\text { - não há anonimato entre o } \\
\text { entrevistador e o entrevistado, } \\
\text { o que pode resultar em vieses } \\
\text { nas respostas; } \\
\text { - precisa de recursos } \\
\text { (humanos, temporais e } \\
\text { financeiros) para a adequada } \\
\text { preparação, coleta e análise } \\
\text { dos dados. }\end{array}$ \\
\hline
\end{tabular}

Fonte: a pesquisadora, a partir de informaç̃ões de SIMÕES, 2004; HEFCEA, 2006; PINHEIRO e GUNTHER, 2008; RHEINGANTZ et al., 2009; MATTAR, 2011 e ONO et al., 2018. 
Quadro 30. Características, vantagens e desvantagens da aplicação do instrumento questionários

\begin{tabular}{|c|c|c|c|}
\hline 圈 Instrumento & Características & Vantagens & Desvantagens \\
\hline Questionários & 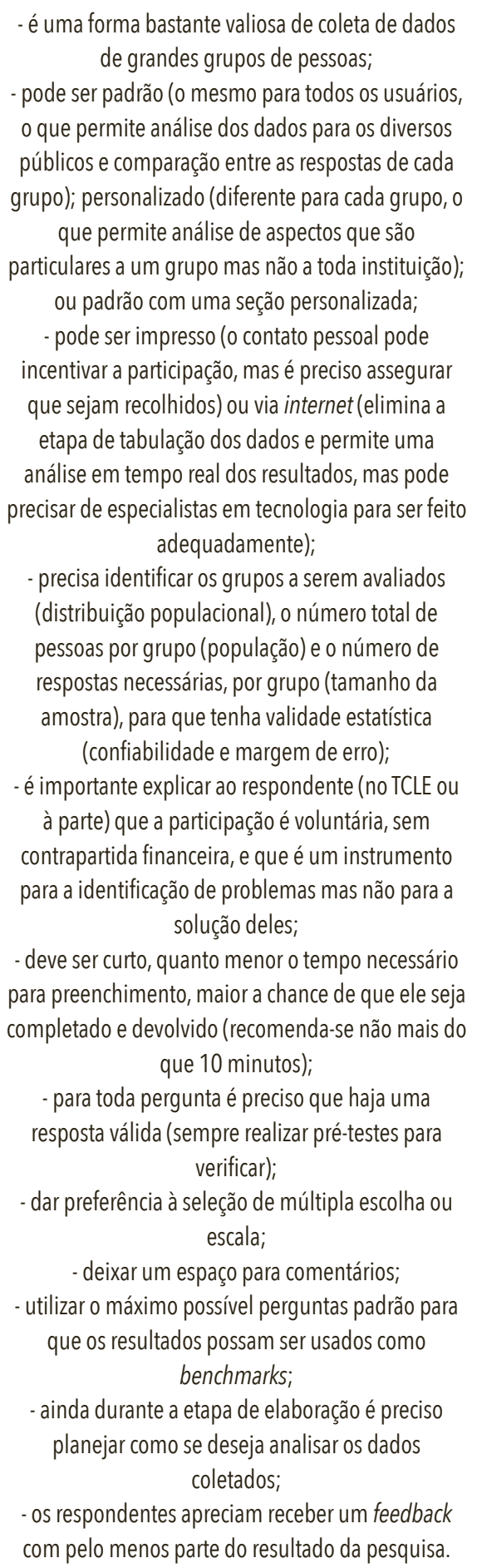 & $\begin{array}{c}\text { - pode fornecer uma ampla } \\
\text { base de dados } \\
\text { quantitativos, pela } \\
\text { perspectiva dos usuários, o } \\
\text { que permite uma análise } \\
\text { detalhada de múltiplas } \\
\text { variáveis; } \\
\text { - a intensidade dos } \\
\text { problemas pode ser } \\
\text { mapeada por zonas do } \\
\text { edifício; } \\
\text { - permite o anonimato do } \\
\text { respondente; } \\
\text { - permite pesquisas } \\
\text { comparativas entre edifícios } \\
\text { (benchmarking) ou ao } \\
\text { longo do tempo, de modo a } \\
\text { se encontrar tendências. }\end{array}$ & $\begin{array}{l}\text { - precisa ser planejado por } \\
\text { um especialista habilidoso } \\
\text { e ser pré-testado; } \\
\text { - precisa de recursos } \\
\text { (humanos, temporais e } \\
\text { financeiros) para a } \\
\text { adequada preparação, } \\
\text { coleta e análise dos dados; } \\
\text { - preparar, aplicar e analisar } \\
\text { questionários demanda } \\
\text { muito tempo e isto não } \\
\text { pode ser subestimado; } \\
\text { - precisa de gestão } \\
\text { especializada para } \\
\text { assegurar que a devolução } \\
\text { seja em quantidade } \\
\text { suficiente para se atingir a } \\
\text { amostra necessária; } \\
\text { - precisa de pessoas } \\
\text { treinadas para correta } \\
\text { análise e interpretação das } \\
\text { respostas. }\end{array}$ \\
\hline
\end{tabular}

Fonte: a pesquisadora, a partir de informações de SIMÕES, 2004; HEFCEA, 2006; PINHEIRO e GUNTHER, 2008; RHEINGANTZ et al., 2009; MATTAR, 2011 e ONO et al., 2018. 
Quadro 31. Características, vantagens e desvantagens da aplicação do instrumento grupos focais

\begin{tabular}{|c|c|c|c|}
\hline 圈 Instrumento & Características & Vantagens & Desvantagens \\
\hline Grupos focais & 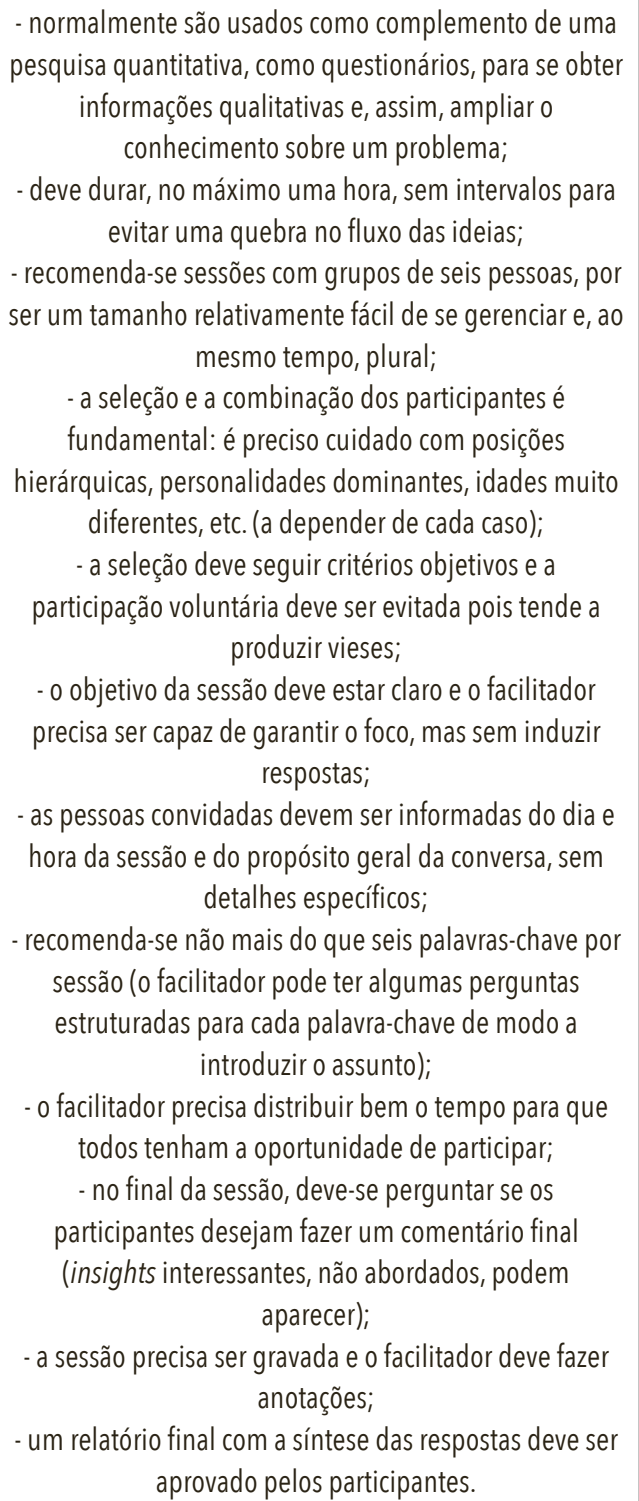 & $\begin{array}{l}\text { - mais fácil e rápido de se } \\
\text { preparar do que } \\
\text { entrevistas; } \\
\text { - permite entender } \\
\text { detalhes sobre um } \\
\text { determinado assunto; } \\
\text { - envolve um grupo } \\
\text { relativamente pequeno de } \\
\text { pessoas; } \\
\text { - a interação entre os } \\
\text { participantes cria } \\
\text { oportunidades de novas } \\
\text { descobertas; } \\
\text { - maior flexibilidade, uma } \\
\text { vez que novas perguntas } \\
\text { podem ser acrescentadas } \\
\text { à medida que são feitas } \\
\text { descobertas; } \\
\text { - permite maior } \\
\text { compreensão do grau de } \\
\text { importância atribuído por } \\
\text { usuários a cada tópico } \\
\text { abordado no questionário. }\end{array}$ & $\begin{array}{l}\text { - o facilitador precisa ser } \\
\text { especialista neste } \\
\text { instrumento; } \\
\text { - os dados qualitativos } \\
\text { obtidos não podem ser } \\
\text { tratados estatisticamente; } \\
\text { - a seleção dos } \\
\text { participantes é crítica; } \\
\text { - pode haver vieses e } \\
\text { distorções pois é preciso } \\
\text { se expor ao grupo, o que } \\
\text { pode inibir alguns } \\
\text { participantes quanto a } \\
\text { dizer o que realmente } \\
\text { pensam. }\end{array}$ \\
\hline
\end{tabular}

Fonte: a pesquisadora, a partir de informações de SIMÕES, 2004; HEFCEA, 2006; PINHEIRO e GUNTHER, 2008; RHEINGANTZ et al., 2009; MATTAR, 2011 e ONO et al., 2018.

Em uma APO, a mescla de métodos qualitativos e quantitativos de avaliação possibilita a coleta de diferentes tipos de dados, o que permite contrabalancear possíveis desvios ou tendências nos resultados. Além disso, os instrumentos precisam passar por um rigoroso controle de qualidade, que garanta a confiabilidade dos resultados obtidos. Para tanto, eles devem, antes de aplicados em larga escala, ser submetidos a uma (ou mais) etapa(s) de pré-teste, seguido da revisão do roteiro e assim sucessivamente até que se tenha confiança de que o instrumento está suficientemente afinado para captar, de forma clara 
e objetiva, as informações necessárias, conforme as metas pretendidas (ROSSI e FREEMAN, 1989; ONO et al., 2015). Um pré-teste cuidadoso pode, inclusive, alertar para problemas nas premissas consideradas ou nos procedimentos metodológicos escolhidos, os quais podem ser corrigidos ainda nesta fase inicial da avaliação, minimizando a necessidade de retrabalhos posteriores (ZEISEL, 2006).

Os instrumentos de entrevistas e questionários podem prever questões abertas (livre resposta) ou fechadas (escolha dentre alternativas). As questões fechadas podem ser dicotômicas (do tipo sim ou não), de múltipla escolha (várias alternativas) ou escalonadas. As escalas podem ser nominais (categorias mutuamente excludentes); ordinais (categorias ordenadas); de intervalo (variável com valores arbitrários); de frequência (ocorrência de um evento); de classificação (de Thurstone e de Likert); ou de diferencial semântico (escala de gradação por pontos).

Em um estudo comparativo entre sistemas de classificação qualitativos e quantitativos para análise de riscos, Cox et al. (2005) concluíram que, em sistemas simplificados qualitativos, que utilizam a escala de Likert54, podem ocorrer dois tipos de vício, aos quais deve-se ter especial atenção:

a. classificações invertidas: situações em que a avaliação qualitativa concluiu que a ocorrência tinha, por exemplo, risco 'alto' mas a avaliação quantitativa demonstrou que o risco era 'baixo', ou vice-versa; b. classificações não-informativas: situações em que a avaliação qualitativa atribuiu um mesmo nível de risco (por exemplo, 'alto') a ocorrências que, em uma análise quantitativa, receberam níveis de risco distintos. Quando um grande número de ocorrências recebe uma mesma classificação, esta análise é não-informativa pois não é possível se depreender dela nenhuma escala de prioridades.

Portanto, apesar de suas características atraentes de construção de consenso, flexibilidade e processo aparentemente cuidadoso quanto aos requisitos de entrada, os sistemas de classificação qualitativa, conforme propostos atualmente, muitas vezes não fornecem informações suficientes para distinguir com precisão entre riscos quantitativamente pequenos e quantitativamente grandes. (...) Essas limitações sugerem que é importante que se continue o desenvolvimento e a aplicação de métodos de avaliação de risco quantitativos práticos, uma vez que as escalas qualitativas nem sempre são confiáveis (COX et al., 2005; tradução da pesquisadora).

França (2011) explica que, após a coleta dos dados, é preciso fazer o tratamento das informações em uma etapa que é chamada de diagnóstico. Nesta etapa é preciso confrontar os dados técnicos (ambientais e da

\footnotetext{
${ }^{54} \mathrm{~A}$ escala de Likert é aquela que utiliza categorias de classificação para avaliar uma variável, como, por exemplo, bom - regular - ruim. Pesquisas recentes discutem a eficácia desta escala: se ela contém números ímpares, a categoria central pode representar um viés de indecisão; se ela contém números pares, pode induzir a um viés positivo ou negativo.
} 
edificação) com aqueles obtidos por observação e interação com o usuário. Isto permite uma análise bastante fundamentada, com recomendações que contenham elevado grau de confiabilidade.

Os diagnósticos podem ser apresentados, para melhor compreensão dos dados da análise, na forma de Quadros-sínteses e Mapas de Diagnósticos e Recomendações.

0 Quadro-síntese de Diagnósticos e Recomendações (ODR) é uma tabela resumo de todas as ocorrências observadas, com base nas informações coletadas por meio dos vários instrumentos. Essas ocorrências podem ser categorizadas, descritas, classificadas quanto ao risco e correlacionadas com recomendações técnicas para solução do problema ou mitigação dos riscos. 0 quadro também pode trazer outras informações como o(s) instrumento(s) utilizado(s) para diagnosticar cada ocorrência, as normas técnicas que nortearam a análise, os prazos e recursos financeiros necessários para se executar cada recomendação (Figura 52).

Figura 52. Exemplo de um Quadro-síntese de Diagnósticos e Recomendações (QDR)

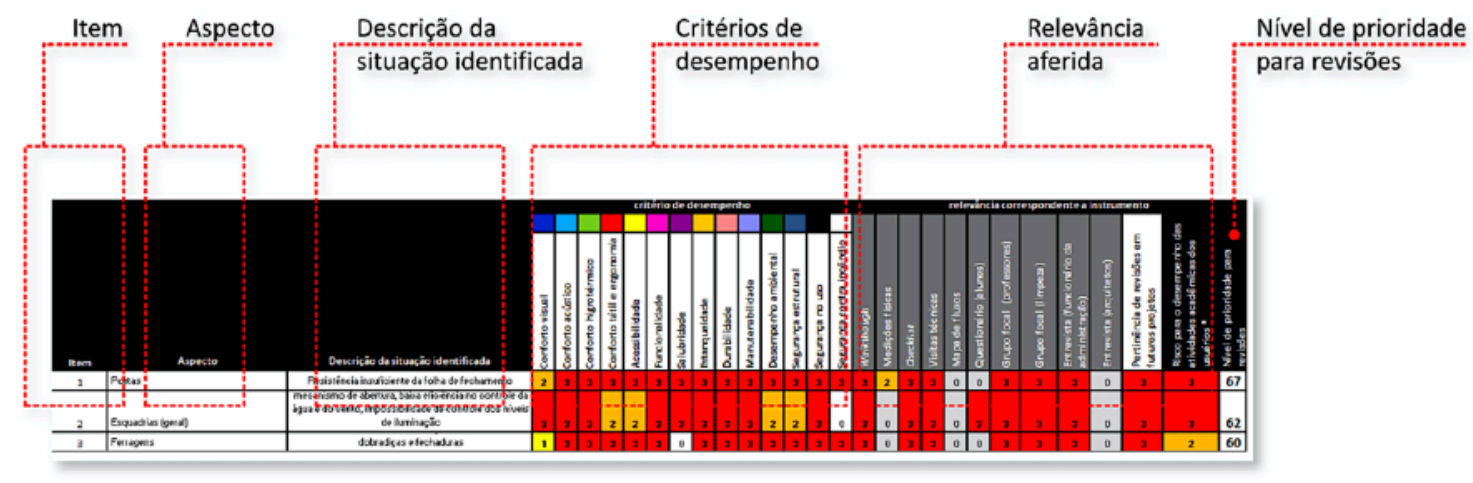

Legenda: Atribuição de valores de relevância

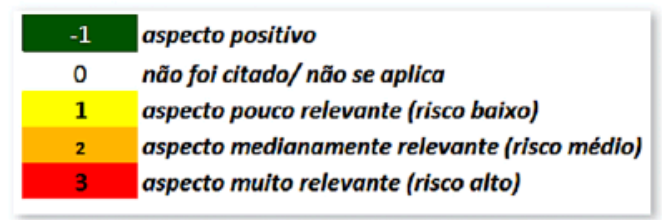

Fonte: FRANÇA, 2011.

O Mapa de Diagnósticos e Recomendações (MDR) é a síntese das ocorrências observadas, anotadas nas plantas baixas dos pavimentos, com o objetivo de facilitar a leitura e a compreensão dos resultados. Ele deve ser produzido em acordo com a demanda da instituição podendo conter, por exemplo, as ocorrências observadas, a(s) recomendação(ões) de intervenção proposta(s), o(s) instrumento(s) utilizado(s) na sua identificação, a análise do(s) risco(s), a fundamentação normativa, o prazo para a 
solução, os recursos financeiros necessários, dentre outros. Frequentemente utiliza-se legendas gráficas e escalas de cores para uma melhor visualização dos resultados (Figura 53).

Figura 53. Exemplo de Mapa de Diagnósticos e Recomendações (MDR) aplicado a um museu

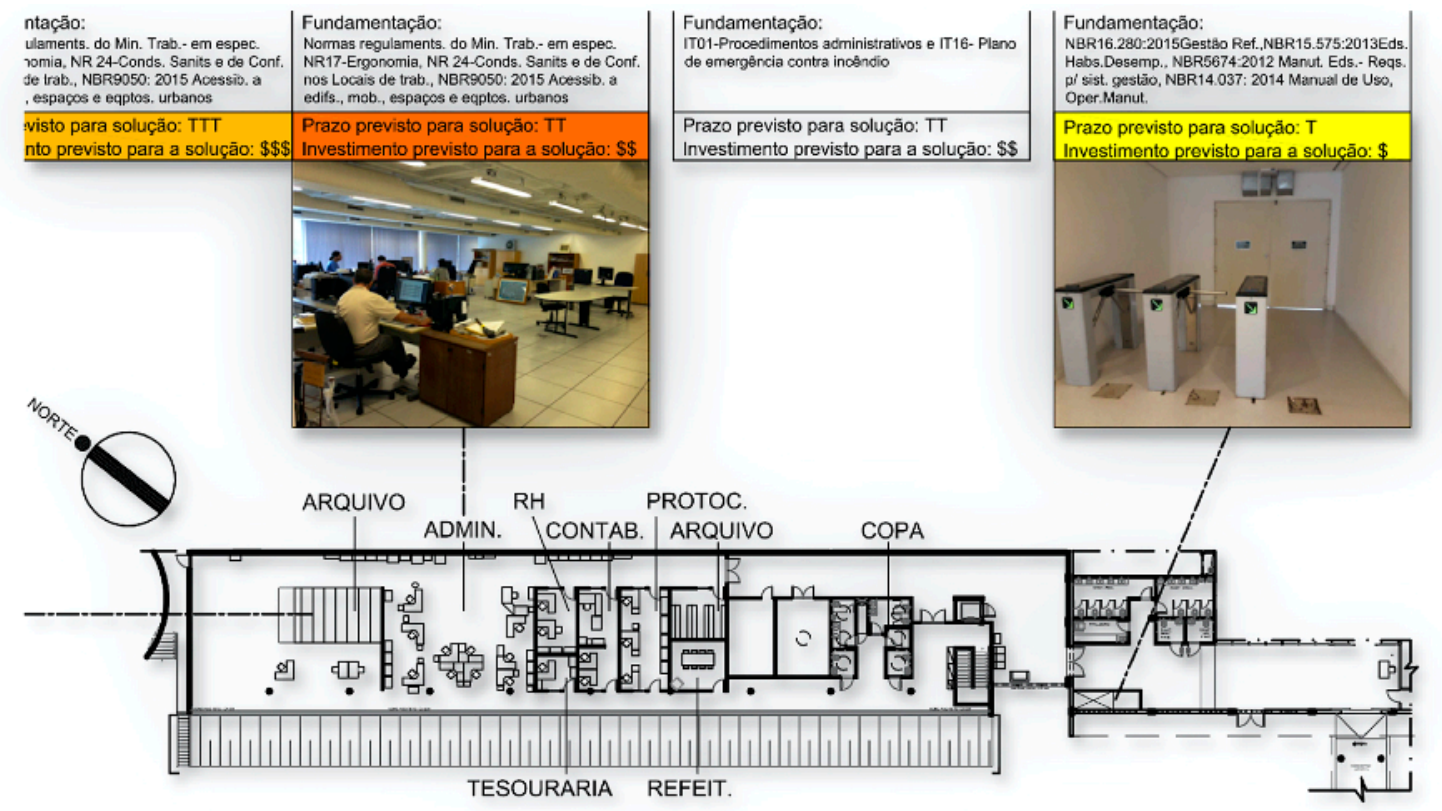

LEGENDA DO MAPA:

\begin{tabular}{|l|}
\hline Aspectos: \\
\hline \\
\hline \\
Sinalização \\
Manutenção \\
Manifestações patológicas \\
Infraestrutura \\
Segurança contra incêndio \\
Acessibilidade
\end{tabular}

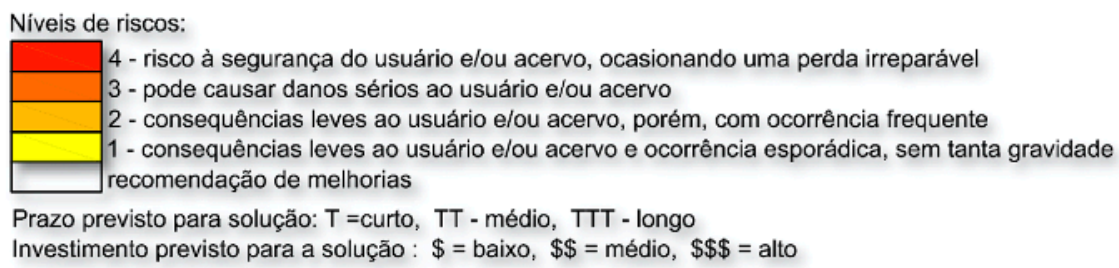

Fonte: SAFT et al., 2018.

Hadjri e Crozier (2009) discutem que, apesar da APO estar sendo constantemente discutida e aprimorada no meio acadêmico há muitas décadas, e os resultados demonstrarem que sua aplicação traz muitos benefícios sob os mais diversos pontos de vista (econômicos, sociais, ambientais, psicológicos, etc.), ainda assim, ela continua sendo uma atividade pouco utilizada pelo mercado da construção civil. Eles apontam algumas razões para este paradoxo:

1. a APO não faz parte do currículo de muitos cursos de graduação em arquitetura e urbanismo;

2. nem sempre há clareza quanto a quem deve pagar pela aplicação de uma APO;

3. profissionais do setor da construção civil nem sempre se sentem confiantes quanto a se responsabilizarem pela aplicação de instrumentos de APO. 
Por outro lado, a APO não deve ser compreendida como uma atividade isolada, um fim em si mesmo, mas como parte da política de gestão do ambiente construído de uma organização. É importante se ter clareza das metas pretendidas para que o conjunto de resultados permita uma análise crítica dos dados e, assim, traga contribuições efetivas, tanto para o objeto de estudo, quanto para projetos futuros similares.

0 plano diretor de instituições culturais deve prever políticas e ações de avaliação e monitoramento do edifício que garantam tanto a sua preservação e manutenção como a conservação preventiva de seus acervos. Funcionários responsáveis pelo comissionamento ou pela gestão de facilidades (FM) podem utilizar os múltiplos instrumentos de APO para monitorar, controlar e avaliar as ações propostas. A gestão documental deve considerar protocolos para a coleta e o tratamento dos dados, fundamentando, assim, a tomada de decisões ao longo de toda a vida útil do edifício, e indicando possibilidades de pesquisas científicas e ações futuras que permitam a contínua melhoria da qualidade ambiental, tanto para os acervos, quanto para funcionários e visitantes. Estas informações podem estar vinculadas a uma plataforma BIM (Building Information Model) adaptada ao patrimônio (HBIM), o que permite a construção de um modelo virtual do edifício e a correlação dos elementos construtivos com informaç̧ões técnicas e de desempenho que podem ser monitoradas ao longo de toda a vida do edifício.

\subsubsection{Avaliação de riscos em edifícios históricos}

As complexidades técnicas e estruturais e o estado de conservação dos materiais de construção tornam bastante desafiadora a avaliação das vulnerabilidades de edifícios históricos. Os riscos a estes edifícios significam não apenas a possibilidade de perda material, mas também de perda de significado cultural e, ao contrário dos edifícios contemporâneos, essas perdas não podem ser reparadas por meio de simples pagamento de seguros (D'AYALA et al., 2006).

D’Ayala et al. (2006) propõem um modelo metodológico para Avaliação dos Múltiplos Perigos de Vulnerabilidade (MHAV - Multi-Hazard Assessment of Vulnerability) por eventos naturais potencialmente destrutivos (terremotos, vendavais, inundações e raios), adaptado a edifícios históricos, com uma abordagem em três níveis:

- nível 1: triagem para identificação dos principais perigos; aqueles classificados como de maior risco devem seguir para o próximo nível. 
- nível 2: calcula as perdas esperadas (monetárias e de significado) para um determinado desastre, mediante identificação dos elementos construtivos mais vulneráveis.

- nível 3: estudo analítico aprofundado do risco de dano e perda de elementos construtivos únicos e insubstituíveis.

0 modelo propõe:

- a classificação da relevância de um determinado perigo em um local específico (por meio de mapeamento SIG55; avaliação empírica; escala de danos; e modelagem probabilística);

- a definição do grau de vulnerabilidade física das diferentes tipologias de edifícios históricos para os diferentes perigos (por meio de pontuação para fatores como a presença ou não de soluções tipológicas de adaptação a perigos naturais frequentes; 0 aumento dos riscos por mudanças climáticas e humanas do entorno; falhas em manutenções ou reformas; o grau de vulnerabilidade por características próprias de um material e/ou sistema construtivo; o estado atual de dano de um sistema construtivo);

- métodos para determinar a significância e o valor patrimonial dos edifícios históricos e quantificar perdas significativas (é um calculo empírico, facilmente manipulável; propõe-se que os vieses sejam minimizados pelo uso combinado dos métodos quantitativos de valoração contingente ${ }^{56}$, da crítica social do julgamento ${ }^{57}$ e de pontuação composta ${ }^{58}$, ajustados ao grupo social local).

Na definição dos pesos para cada uma das variáveis foram utilizadas escalas relativas (de 1 a $5 ;-1,0$, 1; ou de 1 a 10; conforme o caso), como proposto na metodologia de gestão de riscos ao patrimônio histórico do governo australiano ${ }^{59}$. Em circunstâncias localizadas e específicas, recomenda-se a validação desta escala por meio da técnica de Delphi60.

\footnotetext{
55 Sistemas de Informações Geográficas. Também conhecido pela sigla em inglês GIS (Geographic Information System)

56 Mede o quanto um indivíduo considera relevante um determinado fator para o seu bem-estar.

${ }^{57}$ Avalia prioridades através da medição do julgamento que as diversas partes interessadas fazem das diferentes variáveis.

58 Proposta pelo Departamento de Planejamento da cidade de Vancouver, mede a pontuação acumulada dos fatores de risco para edifícios históricos segundo quatro critérios: história arquitetônica, história cultural, contexto e integridade. Disponível em: https://vancouver.ca/files/cov/ heritage-register-evaluation-methodology.pdf, acesso em dez. 2020.

59 Para maiores informações, ver os planos de emergência propostos pela FEMA - Federal Emergency Management Agency (https:// www.fema.gov/pdf/plan/slg101.pdf), acesso em dez. 2020.

60 Método para obtenção de consenso na avaliação de riscos. Propõe que um questionário (individual e anônimo) seja aplicado a um grupo estruturado de especialistas. As respostas são compiladas e encaminhadas aos especialistas, que, individualmente e de forma anônima, podem rever ou sustentar suas opiniões, e assim em ciclos sucessivos até que se atinja um consenso.
} 
A avaliação das vulnerabilidades físicas de estruturas históricas é uma atividade fundamental em uma análise dos riscos com vistas à preservação do patrimônio cultural edificado. Tem-se, a seguir, a descrição de duas propostas metodológicas de avaliação de riscos de degradação física em edifícios históricos.

Paupério et al. (2011) descrevem uma metodologia para avaliação dos riscos à estabilidade estrutural de edifícios históricos, desenvolvida pelo grupo de pesquisa da Universidade do Porto, em colaboração com outras instituições. Propõe-se que a avaliação seja iniciada pela inspeção visual do edifício, cuja efetividade depende, em grande medida, da experiência e do conhecimento técnico daqueles que a realizam. Ela deve conter: definição geométrica da construção existente; identificação dos esquemas de funcionamento estrutural; definição dos elementos estruturais-chave; e identificação de todas as manifestações patológicas, com registo fotográfico detalhado e posicionamento das peças anotadas na planta baixa do edifício. Em seguida, propõe-se proceder a análise dos dados coletados, que devem ser compilados em um Relatório de Inspeção. As manifestações patológicas identificadas, suas possíveis causas e as recomendações para mitigação podem ser resumidas em Mapas de Danos. Em casos específicos, pode ser recomendada a instalação de equipamentos de monitoramento com o intuito de identificar se as manifestações patológicas estão estáveis ou ativas (progredindo com o passar do tempo). Em casos muito específicos, também pode ser necessária a realização de ensaios, in sito ou em laboratório, com técnicas não destrutivas ou minimamente destrutivas. 0 grupo de pesquisa propõe 0 desenvolvimento de um programa computacional baseado em SIG para inspeção técnica do edifício e registro detalhado dos sistemas e materiais construtivos e dos danos existentes. 0 programa também permite a análise, o armazenamento e o mapeamento de uma grande quantidade de dados, realizando, de forma automática, os Mapas de Danos, o que diminui consideravelmente o tempo necessário para processamento das informações coletadas. Esta técnica permite também a criação de bancos de dados de inspeções sucessivas e o acompanhamento dos danos ativos.

Cavalagli et al. (2019) propõem uma metodologia similar, porém, voltada para o mapeamento dos riscos de degradação dos materiais de construção em edifícios históricos, com avaliação das interações entre os efeitos das mudanças climáticas e os possíveis danos estruturais, mediante os seguintes procedimentos: inspeções técnicas preliminares in loco; identificação de processos de degradação; calibração e simulação do modelo numérico de predição de resposta termo-estrutural do edifício; e 
predição das degradações e dos potenciais riscos estruturais para cada cenário climático. Ao final, propõe-se um Mapa de Riscos hierarquizado, do maior para o menor risco de dano (Figura 54).

Figura 54. Mapa de Riscos com escala de degradação para a fachada principal do Palácio Consoli, considerando a interação entre mudança climática e risco de dano estrutural

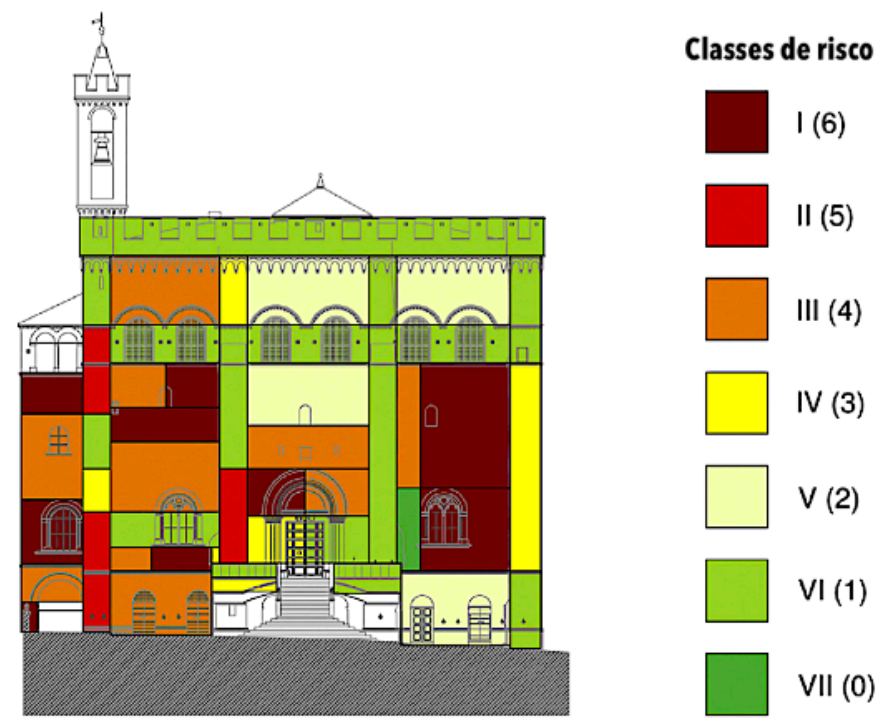

Fonte: traduzido de CAVALAGLI et al., 2019.

No Brasil, o IPHAN em parceria com o Programa Monumenta61 (CARVALHO, 2014), editou uma série de manuais práticos para a conservação de sítios e imóveis históricos. Dentre estes documentos, destacase o Manual de Conservação Preventiva para Edificações, cujo objetivo é auxiliar profissionais e proprietários na identificação de problemas que possam causar danos ao edifício (KLÜPPEL e SANTANA, 2000). Ele contempla um amplo conjunto de fichas para inspeção e identificação de ameaças presentes no entorno da edificação e de manifestações patológicas frequentemente associadas a técnicas e materiais construtivos tradicionais brasileiros, bem como sugestões de tratamentos para a mitigação ou resolução dos problemas identificados.

\footnotetext{
61 Programa de preservação do patrimônio cultural brasileiro desenvolvido pelo Ministério da Cultura (MinC) em parceria com o Banco Interamericano para o Desenvolvimento (BID), iniciado em 2000, tinha como prioridades: (a) preservar áreas prioritárias do patrimônio histórico e artístico urbano sob proteção federal [IPHAN]; (b) aumentar a conscientização da população brasileira acerca desse patrimônio; (c) aperfeiçoar a gestão desse patrimônio e o estabelecimento de critérios para a implementação de prioridades de conservação. (PROGRAMA MONUMENTA, 2005, p. 6, apud: DUARTE JUNIOR, 2010).
} 


\subsubsection{Documentação digital}

Nas últimas décadas, o patrimônio histórico e cultural vêm sendo constantemente apontado como um fator estratégico para o desenvolvimento econômico sustentável e uma maior coesão e inclusão social (BERNARDES et al., 2014). Porém, a recuperação e a manutenção destes edifícios é uma tarefa complexa e onerosa e as metodologias para a gestão do patrimônio edificado, na prática, não têm respondido de modo eficiente (FORSTER e KAYAN, 2009). Além disso, a quantidade de dados produzidos ao longo da vida útil de um edifício histórico é muito grande: informações sobre projetos de construção, reformas, adaptações, restauros, manutenções, instalação de equipamentos, montagem de exposições, dentre outros. Armazená-los corretamente é um grande desafio, mas também fundamental para que seja possível o acesso futuro a esta documentação (RODRIGUES et al., 2019).

Existe também a relevância de se documentar o próprio patrimônio cultural, conceito que se tornou bastante estabelecido principalmente em decorrência dos desastres (naturais e humanos) experienciados nas últimas décadas. É crescente o apelo internacional pela preservação do patrimônio também em meios digitais (confiáveis e padronizados) para que, em último caso, ao menos estas informações sobrevivam e possam ser transmitidas às futuras gerações. Como consequência, existem diversos projetos em andamento cujo objetivo é produzir modelos tridimensionais, em muito alta qualidade, de edifícios e sítios históricos. Porém, falta ainda um maior desenvolvimento de normas e padrões que regulamentem a documentação digital (RIZZI et al., 2011).

As tecnologias digitais para modelamento arquitetônico permitem a construção de maquetes virtuais tridimensionais do edifício (Figura 55), o que possibilita, a depender da ferramenta utilizada, visualizar as interfaces entre os sistemas construtivos; simular o comportamento dos materiais; criar um banco de dados dos elementos utilizados, das técnicas empregadas, do estado de conservação e do histórico de intervenções; e comunicar todas estas informações aos interessados (DEZEN-KEMPTER, 2014). 
Figura 55. Modelo 3D do antigo Templo de Bel, em Palmira, Síria

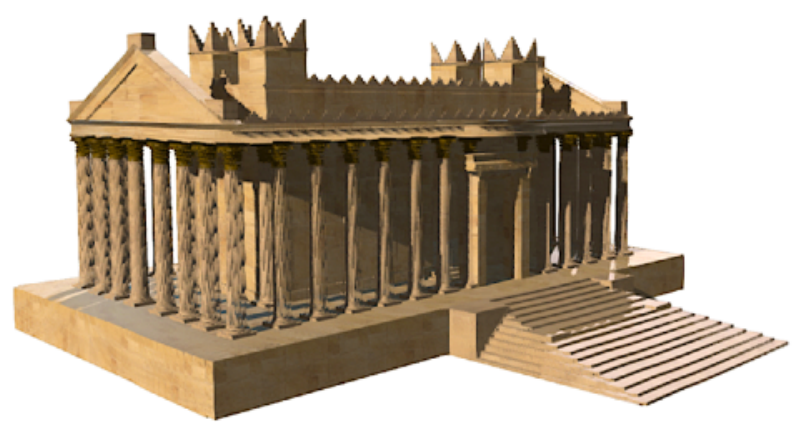

Fonte: PUBLIC AFFAIRS, 2016.

0 modelamento tridimensional de um edifício facilita a visualização dos sistemas passivos e ativos e permite uma melhor compreensão de estruturas complexas, a realização de cálculos mais precisos e a aferição do impacto de intervenções em estruturas antigas (Figura 56). Todas estas informações passam a constituir um banco de dados digital do patrimônio, que pode ser utilizado para os mais variados fins (STYLIADIS, 2007).

Figura 56. Análise estrutural a partir de modelo 3D
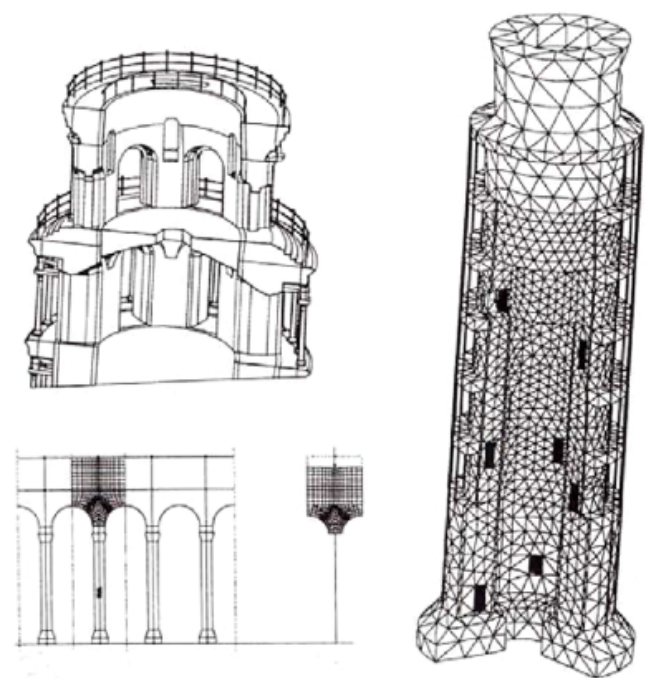

Fonte: ROCA et al., 1999.

A criação de aplicativos para internet específicos para a gestão do edifício (Figura 57) permite que informações 2D e 3D possam ser adicionadas, compartilhadas e consultadas por diferentes especialistas simultaneamente (GUARNIERI et al., 2010). 
Figura 57. Aplicativo para gestão documental do patrimônio

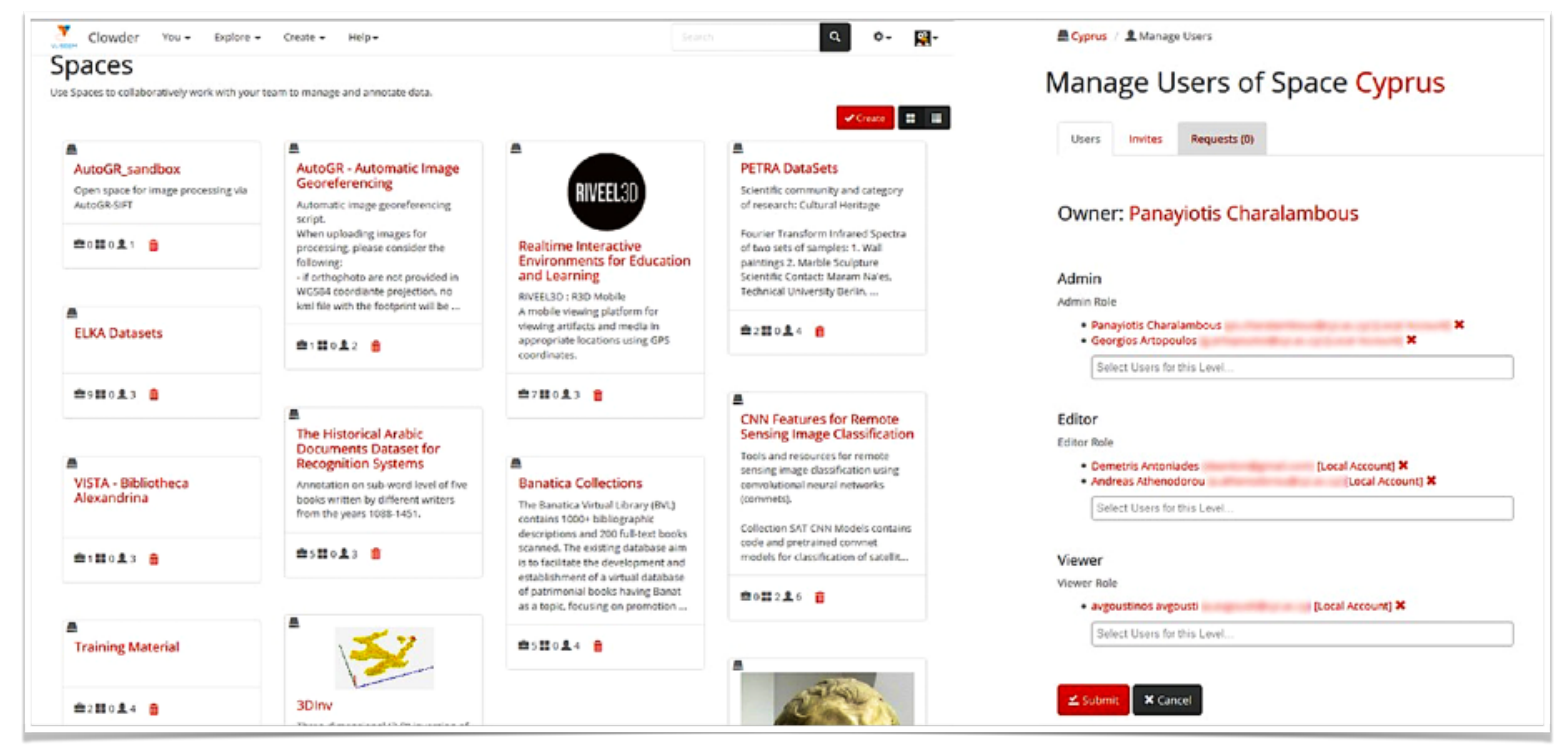

Fonte: VI SEEM, 2019.

Métodos computacionais de imageamento (fotogrametria, escaneamento a laser 3D) também podem ser úteis na arqueologia do patrimônio (Figura 58), pois permitem reconstruir estruturas e esclarecer hipóteses científicas sobre edifícios e conjuntos urbanísticos (PORTIER et al., 2000).

Figura 58. Escaneamento 3D e reconstrução digital de um edifício histórico

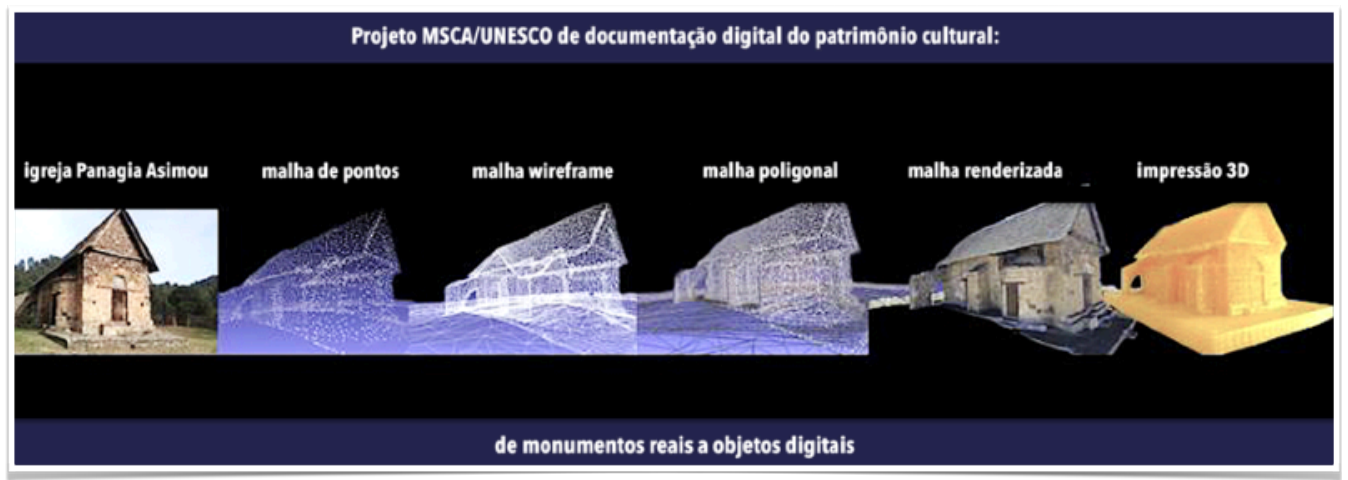

Fonte: traduzido de CARARE, 2020.

A associação dos sistemas de modelagem e de mapeamento por SIG permitem a gestão de dados (Figura 59) de modo semi-automático por diversos atores simultaneamente (LÓPEZ et al., 2018). 
Figura 59. Gestão de dados em um sistema SIG associado ao modelamento para reconstrução digital do patrimônio

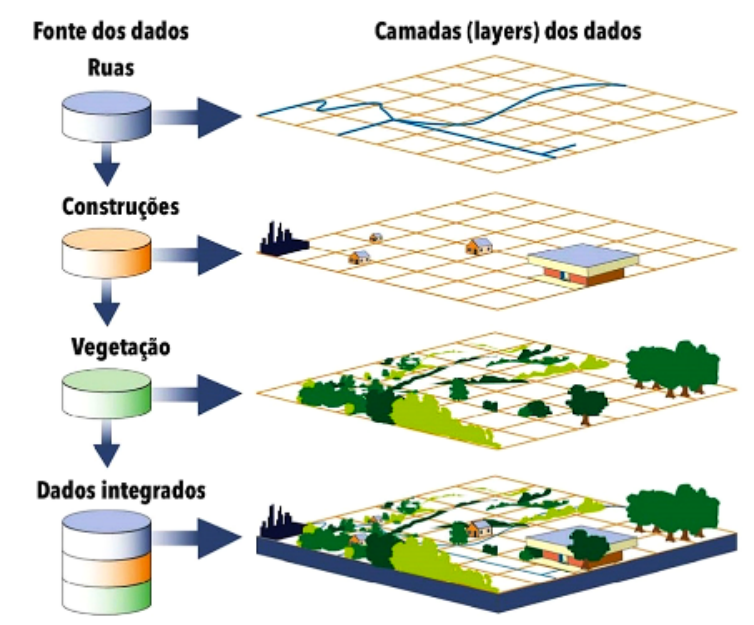

Fonte: traduzido de ZUERCHER, 2016.

0 sistema BIM (Building Information Modelling) é uma tecnologia que permite agregar uma grande quantidade de informaç̧ões de todos os processos relacionados a arquitetura, engenharia, construção e operação (AECO), podendo ser empregada ao longo de todo o ciclo de vida de um edifício, desde o seu projeto até a operação e a manutenção (AKANMU et al., 2015). A ISO 29481-1:2010 define BIM como "uma representação digital compartilhada das características funcionais e físicas de qualquer objeto construído (...) que constitui uma base de dados confiável para decisões". A AEC Initiative do governo britânico, em 2015, explicou BIM como:

(...) um modo de trabalho colaborativo, apoiado em tecnologias digitais, que fornece métodos mais eficientes de projetar, transmitir e manter elementos físicos construídos. 0 BIM congrega produtos-chave e os dados construtivos em um modelo 3D que pode ser usado para uma gestão efetiva da informação ao longo de todo o ciclo de vida da construção (AEC Initiative, 2015; tradução da pesquisadora).

Países como os Estados Unidos, Reino Unido e Finlândia já desenvolveram normas e regulamentos para implementação do BIM nos processos construtivos. Outros seguem pelo mesmo caminho pois é cada vez maior a percepção de que o BIM - e as tecnologias de modelamento e análise, imageamento, SIG e compartilhamento de dados associadas a ele - está adequado às demandas contemporâneas de globalização e virtualização dos processos construtivos e porque ele permite armazenar e acessar o histórico de dados da construção, facilitando o adequado gerenciamento do edifício (RODRIGUES et al., 2019). 
A tecnologia BIM não é um programa computacional, mas uma plataforma que integra processos, o que permite 0 trabalho colaborativo entre diversos especialistas e a visualização do modelo construtivo da edificação na forma de documentação técnica 2D (plantas, cortes, elevações, dentre outros), de modelos virtuais 3D, ou de animações 4D.

Na plataforma BIM cada elemento é um objeto paramétrico, ou seja, tem associado a ele parâmetros (conjunto de dados sobre dimensões, posição no espaço, materiais, dentre outros, que podem ser definidos caso a caso) que permitem sua 'construção' virtual. Cada objeto ou componente se combina a outros objetos para formar um sistema, cujos atributos podem ser analisados (TOLENTINO e FEITOSA, 2014). Os objetos paramétricos são criados no formato de dados IFC (Industry Foundation Classes), o que permite manter a associação entre o objeto e seus parâmetros, independentemente do programa computacional que se está utilizando (JACOSKI, 2002).

Mesmo que o uso da tecnologia BIM seja reconhecidamente eficiente como plataforma auxiliar ao longo de todo o ciclo de vida de uma edificação, programas específicos para a gestão do edifício em uso ainda estão em desenvolvimento (RE CECCONI et al., 2017). No caso dos edifícios históricos, temse ainda dificuldades específicas (RODRIGUES et al., 2019):

1. em muitos casos os documentos construtivos estão incompletos ou foram totalmente perdidos;

2. muitas bibliotecas de objetos paramétricos vêm sendo desenvolvidas para os elementos construtivos correntes mas não para itens que já não são mais fabricados. Além disso, nem sempre é possível criar bibliotecas padronizadas porque os elementos podem pertencem a uma época ou a uma cultura em que a fabricação era artesanal.

Com o intuito de minimizar estas dificuldades, desenvolvedores vêm trabalhando na construção da plataforma HBIM (Historical Building Information Modelling) que é um sistema que integra as tecnologias de imageamento por escaneamento a laser 3D e fotogrametria para acelerar o processo de construção do modelo virtual e de bibliotecas de objetos paramétricos (YILMAZ et al., 2007). 0 modelo, neste caso, não é utilizado como a etapa final do projeto para a execução de uma obra, mas sim como um instrumento para monitoramento e análise do comportamento físico e de possíveis processos de degradação do edifício (ORENI et al., 2012). Além disso, o uso do HBIM permite a associação de todas as informações relativas a um determinado objeto, sejam elas construtivas, arqueológicas, documentais, etc., que, de outro modo, dificilmente permaneceriam juntas (Figura 60) (PAUWELS et al., 2013). 
Figura 60. 0 sistema BIM adaptado ao patrimônio cultural

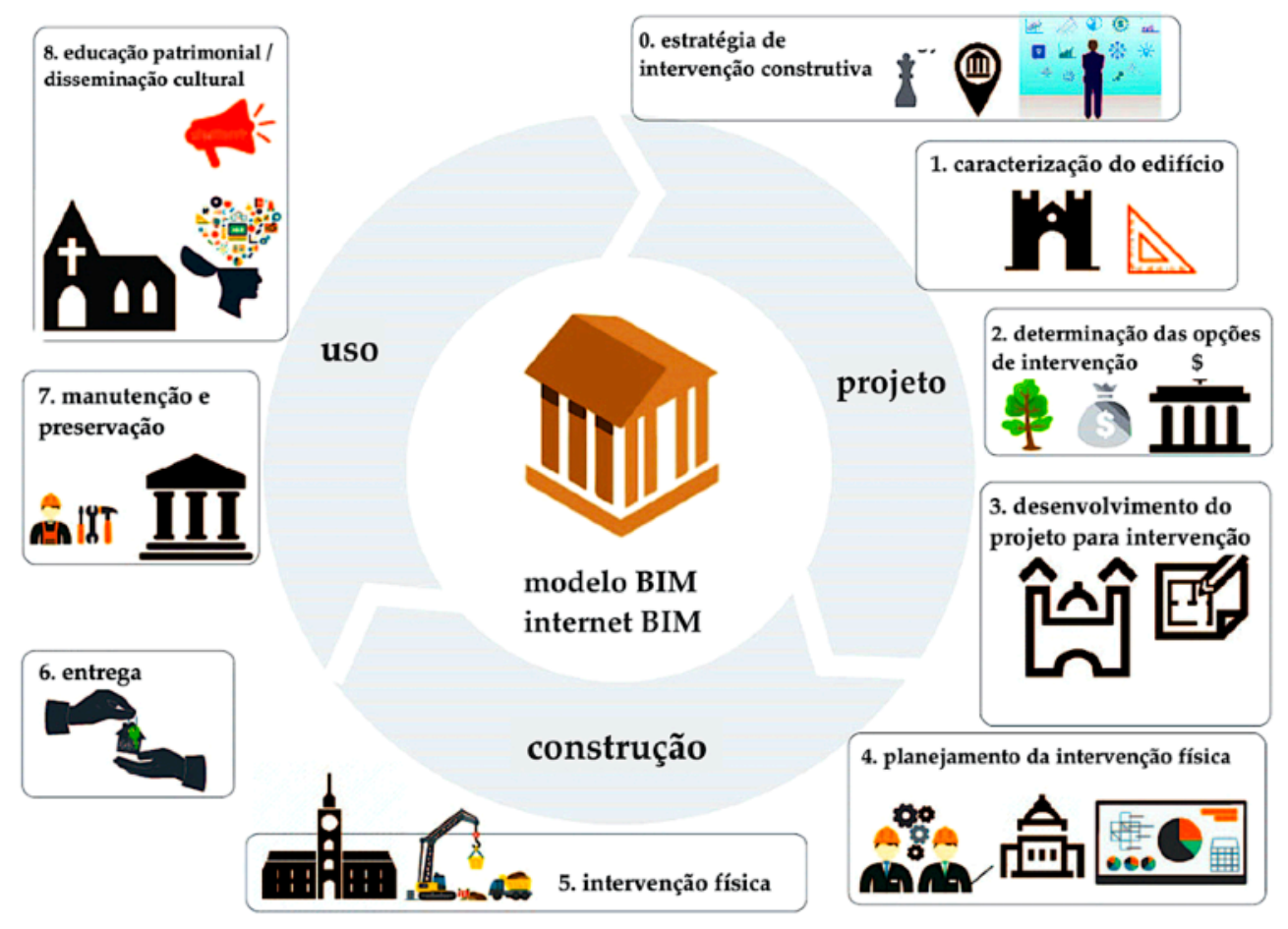

Fonte: traduzido e adaptado de JORDAN-PALOMAR et al., 2018.

0 método proposto pelo sistema HBIM contempla as seguintes etapas (RODRIGUES et al., 2019):

1. coleta e processamento de dados por escaneamento a laser 3D e fotogrametria;

2. identificação dos detalhes históricos a partir de literatura sobre o tema;

3. construção dos objetos paramétricos;

4. inserção dos objetos paramétricos no modelo;

5. produção da documentação final (conforme a demanda).

0 escaneamento a laser 3D é uma tecnologia não destrutiva e não invasiva que utiliza a luz laser para mapear a forma de um objeto. A câmera de escaneamento a laser 'lê' uma grande quantidade de pontos em uma superfície sólida e calcula a distância relativa entre eles. Esta nuvem de pontos georeferenciados (SIG) é interpretada por um software que, em um processo chamado de reconstrução, conecta os pontos, construindo um modelo 3D do objeto (Figura 61). Esta é uma tecnologia muito promissora porque permite uma construção relativamente rápida de modelos tridimensionais de bens culturais complexos, porém, ainda está em desenvolvimento. Por hora, é um trabalho exaustivo (quanto maior a quantidade de pontos, mais preciso o modelo, porém maior 0 arquivo digital), que exige muita experiência do operador da câmera para que todas as estações estejam devidamente alinhadas e do 
desenhista para que os pontos sejam corretamente interpretados, cujo resultado pode apresentar distorções pois o laser é muito sensível a trepidações e variações na iluminação (VACCA et al., 2012).

Figura 61. Criação e visualização do modelo 3D construído a partir de uma nuvem de pontos
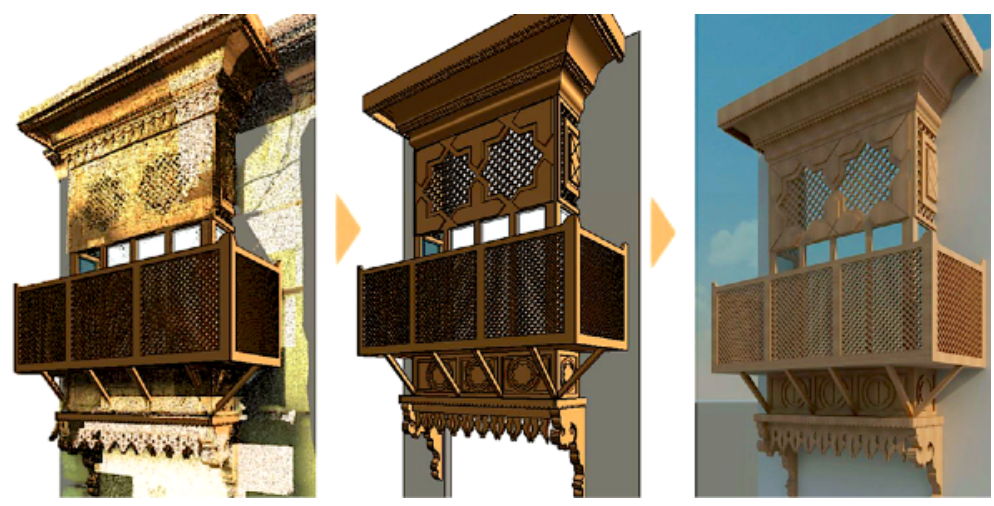

Fonte: TOBIÁšs, 2016.

A fotogrametria é uma técnica desenvolvida em meados do século XX que utiliza registros fotográficos de muito alta qualidade para obter medidas geométricas de uma superfície por meio de processos estereoscópios de vetorização de imagens georeferenciadas para um ambiente digital 3D, em um processo chamado de restituição (combinação ou rasterização da imagem). A estereoscopia é a técnica de construção de espaços tridimensionais a partir de imagens bidimensionais captadas com pequenas diferenças de posição entre elas. Ela foi desenvolvida a partir da compreensão do funcionamento do olho humano (TEMBA, 2000).

Quanto maior a quantidade de fotos, mais densa a nuvem de pontos e melhor a qualidade da imagem 3D (Figura 62). Como as fotos precisam ser captadas a partir de locais ligeiramente diferentes (a sobreposição deve ser de pelo menos $2 / 3$ entre as imagens), é fundamental o georeferenciamento (SIG) com o correto posicionamento relativo das estações de medição. Além disso, é preciso um cuidadoso trabalho de posicionamento das fotografias no programa de fusão das imagens (MVS Multi-Viewpoint Stereo) para que os algoritmos produzam uma nuvem densa e precisa de pontos. 
Figura 62. Fotogrametria da Basílica de Notre Dame em Montreal

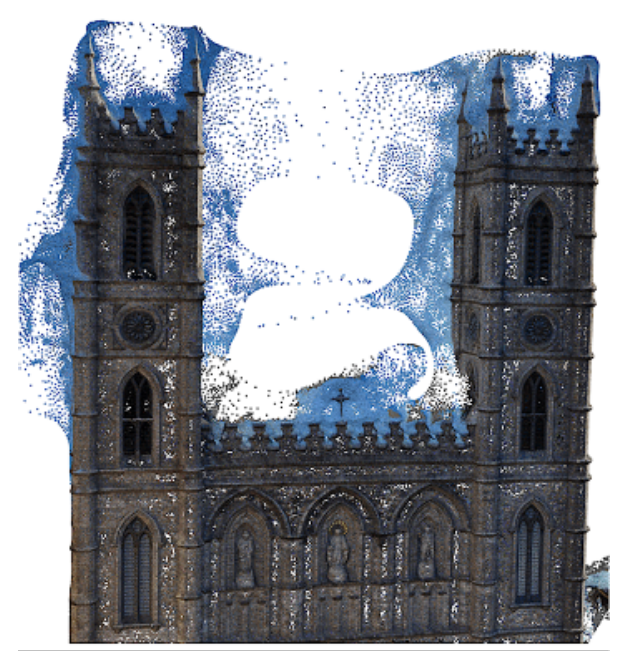

Fonte: BUILDIT SOFTWARE, 2016.

\subsubsection{Comissionamento e Gestão de Facilidades (FM)}

Além da gestão da documentação, é preciso fazer a gestão do edifício em uso. Nota-se que, em construções novas ou renovadas, sistemas ativos estão cada vez mais presentes, principalmente aqueles associados às novas tecnologias de automação. Estes sistemas são complexos e demandam grande capacidade de planejamento e de gestão dos dados de construção, instalação, operação e manutenção. Se, por um lado, a presença de equipamentos automatizados pode auxiliar na melhoria da eficiência de uso dos recursos, por outro lado, pode produzir falhas em cascata que levam à paralização de todo 0 edifício. Se as falhas são identificadas no início da operação do sistema, elas podem ser prontamente corrigidas, evitando danos maiores ao sistema e à edificação como um todo (SAES, 2006).

0 comissionamento é um conjunto de métodos que tem por objetivo: assegurar que os sistemas ativos cumpram os requisitos de projeto, em conformidade com normas e legislações pertinentes; documentar as fases iniciais de instalação e operação; e capacitar os profissionais de manutenção, com o objetivo de evitar falhas, diminuir desperdícios e retrabalhos e melhorar a qualidade, 0 desempenho e a sustentabilidade da edificação (Figura 63) (ISHIDA, 2015). 
Figura 63. 0 comissionamento ao longo do ciclo de vida do edifício

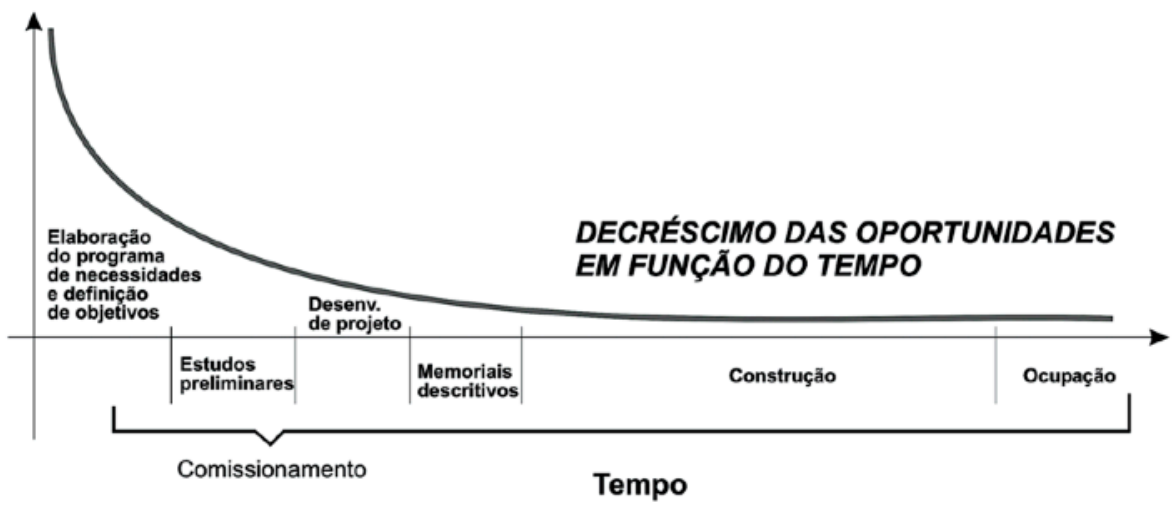

Fonte: FRANÇA, 2011.

Para que o comissionamento seja efetivo, os objetivos e resultados esperados devem estar bem definidos. Para isso, é necessário correlacionar as metas com os benchmarks, as boas-práticas e as normas existentes. 0 profissional responsável pelo comissionamento, recomissionamento (novos comissionamentos periódicos, na fase de operação e manutenção de edifícios, após o comissionamento) e retrocomissionamento (comissionamentos periódicos, na fase de operação e manutenção de edifícios, sem comissionamento) deve, dependendo da complexidade do projeto e/ou do edifício, trabalhar concomitantemente e em conjunto com o coordenador de projetos, o gerente de execução da obra e o gestor de facilidades (Figura 64) (CLETO et al., 2011).

Figura 64. Gestão das fases do edifício e as atividades de retrocomissionamento e recomissionamento

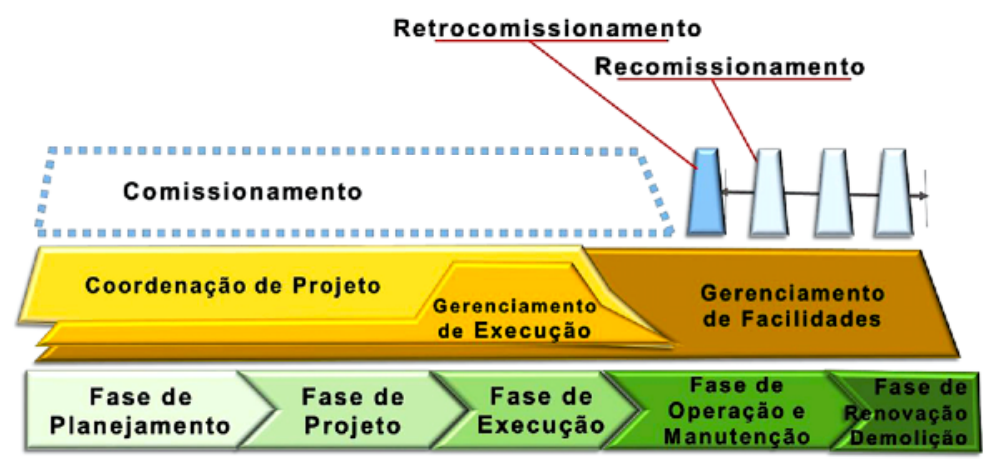

Fonte: ISHIDA, 2015.

Tradicionalmente, a gestão de facilidades (FM - Facility Management) é compreendida simplesmente como o gerenciamento de edifícios e seus sistemas (AMARATUNGA, 2001). Barrett, em 1995, definiu FM como "uma abordagem integrada para a manutenção, 0 aprimoramento e a adaptação de edifícios de uma organização de modo a criar um ambiente que apoie fortemente os objetivos primários desta 
organização". A ISO 41011:2017 - Facility management - Vocabulary (recentemente traduzida pela ABNT NBR ISO 41001:2020), define FM como "a função organizacional que integra pessoas, espaços e processos dentro do ambiente construído com o objetivo de melhorar a qualidade de vida de pessoas e a produtividade do núcleo de negócios".

Ou seja, a função do gestor de facilidades em uma instituição é garantir que os sistemas construtivos que fazem parte de um edifício estejam funcionando adequadamente e, para isso, ele deve conhecer: fatores de uso e ocupação, operação e manutenção; sustentabilidade; gestão de sistemas de informação e tecnologia; gestão de riscos; comunicação; desempenho e qualidade; liderança e planejamento estratégico; mercado imobiliário; gestão de projetos; finanças e negócios (IFMA, 2020). 0 gestor de facilidades deve ter capacidade de trabalhar em equipe para, em conjunto com outras áreas, compreender o contexto organizacional, identificar os pontos fracos da edificação e dos sistemas ativos, traçar as melhores estratégias e os instrumentos de avaliação, estabelecer prioridades de manutenção preventiva e corretiva associadas aos riscos, acompanhar a execução dos trabalhos, monitorar o desempenho dos objetivos traçados, aferir a eficácia dos resultados e, por fim, reiniciar o processo, a partir do conhecimento acumulado (Figura 65).

Figura 65. Metodologia de abordagem dos processos para FM

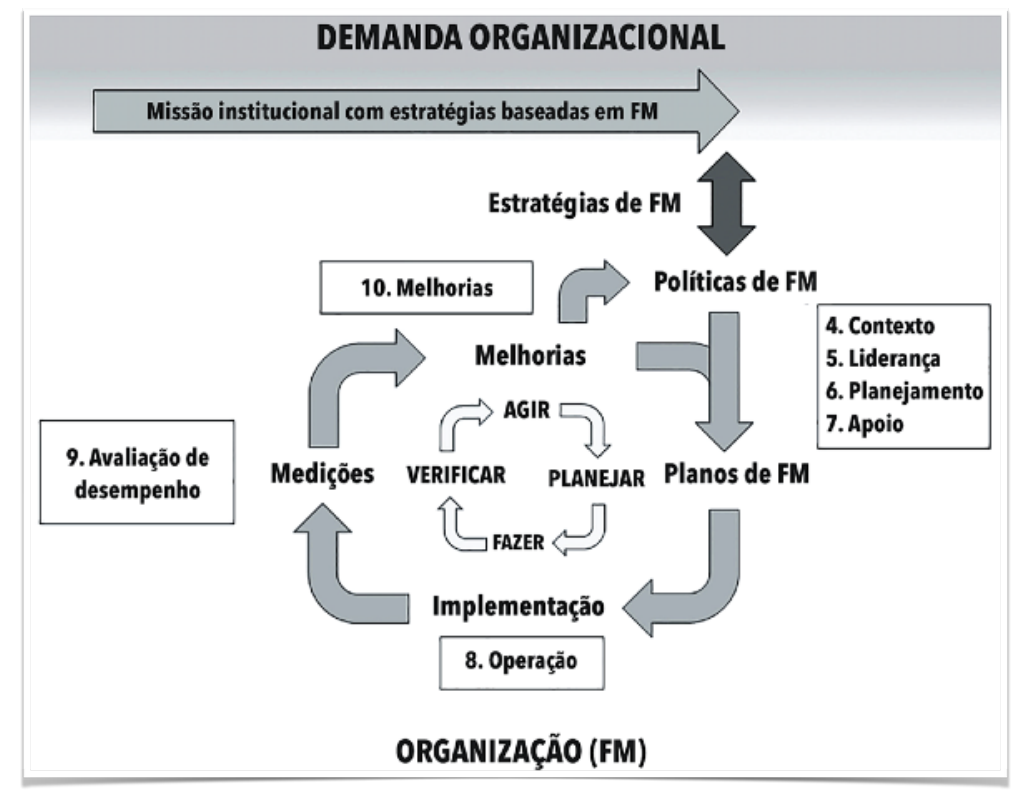

Fonte: traduzido e adaptado de ISO 41001:2017. 
A gestão integrada do edifício, das áreas de guarda e das áreas expositivas visando à conservação e à manutenção preventiva do patrimônio cultural móvel e imóvel não é tarefa fácil em nenhum lugar do mundo. A experiência do Museu do Louvre pode ajudar a esclarecer como transformar a teoria em ações práticas.

Em 2012, durante as 'Jornadas Profissionais da Conservação e da Restauração', a arquiteta Françoise Mardrus, responsável pela gestão de facilidades do palácio do Louvre e das Tuileries e a conservadora Anne de Wallens, responsável pela conservação preventiva e pela coordenação das gestões do museu do Louvre, em palestra gravada, intitulada 'A integração da conservação preventiva em grandes projetos: o caso do Museu do Louvre', relataram suas experiências com a criação da Seção de Conservação Preventiva e Coordenação de Gestão (DCPCR - Délégation de Conservation Préventive et Coordenation de Régie) do Museu do Louvreb2.

A arquiteta explicou que, até 1998, o Louvre possuía dois setores separados: um para gestão da arquitetura e das facilidades e outro para a conservação preventiva dos acervos. Os projetos eram executados pela equipe técnica do museu e não havia retorno das experiências internas. Percebia-se a necessidade de um corpo técnico que atuasse junto às reservas técnicas, que realizasse a manutenção preventiva dos sistemas prediais e que explicasse o funcionamento dos equipamentos novos à equipe de conservação ("a informação sempre chegava tarde demais"). A partir de 2000 foram implementadas medidas de avaliação da qualidade ambiental como subsídio para novos projetos e, pela primeira vez, foi criado um programa decenal para a restauração do palácio. Após 2004, o museu precisou lidar com grandes projetos, o que exigiu maior organização das equipes e a criação de uma Direção de Gestão de Projetos (DM0). Em 2007 foi criada a Seção de Conservação Preventiva e Coordenação de Gestão (DCPCR). Os fatores que levaram à criação desta seção foram: (a) práticas muito diversas das equipes de projeto e de conservação; (b) diálogo difícil com as direções administrativas e técnicas; (c) ausência de visão de conjunto orientada à conservação preventiva; (d) e ausência de coordenação e de coerência das políticas do museu (Figura 66). Além disso, havia o desejo de todas as equipes participassem de um treinamento duplo: em gestão ambiental e em conservação preventiva.

\footnotetext{
62 Disponível em: https://video-streaming.orange.fr/culture-art-creation/architecture-et-conservation-preventive-l-integration-de-la-conservationpreventive-dans-les-grands-projets-le-cas-du-musee-du-louvre-CNT000001avqra.html, acesso em fev. 2020.
} 
Figura 66. Organograma do Louvre, em 2012

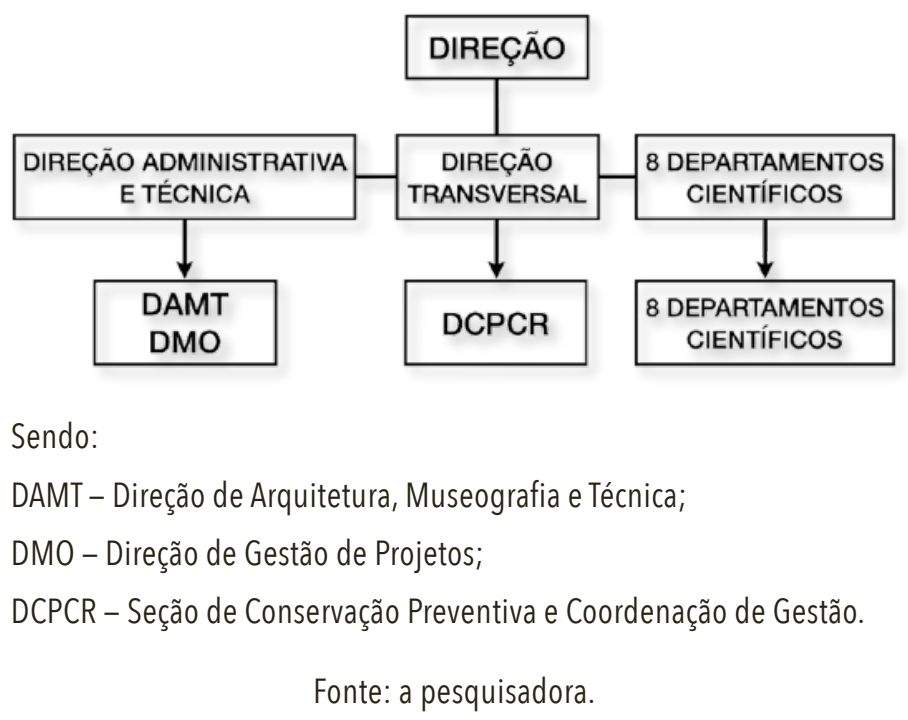

O DCPCR possui quatro missões transversais:

1. elaboração e aplicação de uma política de conservação preventiva: propositiva e com premissas, recomendações e definição de trabalhos de pesquisa entre todos os departamentos;

2. harmonização entre as práticas utilizadas;

3. elaboração e realização de cursos de formação em conservação preventiva e em gestão para todos os funcionários;

4. intervenção, tanto nas etapas iniciais dos grandes projetos, quanto nas etapas operacionais.

A arquiteta e a conservadora concluíram que uma integração possível depende de:

a. saber pedir e saber escutar;

b. capacidade de estabelecer um diálogo construtivo;

c. qualidade dos trabalhos ("frequentemente os profissionais são chamados para trabalhos sobre os quais eles não têm conhecimento...");

d. tempo acordado pois, muitas vezes, é preciso "perder para poder ganhar";

e. complexidade do local;

f. recursos humanos disponíveis. 


\section{OBJETIVOS}

Tendo-se como ponto de partida a constatação de que:

a. os conhecimentos científicos existentes aplicáveis à gestão da preservação de acervos culturais são, no Brasil (bem como em muitos outros lugares), estanques, pouco conectados, e não completamente adaptados às características construtivas, climáticas e de acervo de países em desenvolvimento localizados em regiões tropicais;

b. as metodologias propostas pelos organismos internacionais para o diagnóstico do estado de conservação de acervos e dos riscos ao patrimônio cultural não incentivam o trabalho conjunto dos profissionais responsáveis pela gestão e conservação dos acervos e aqueles responsáveis pela gestão de facilidades e manutenção do edifício e, raramente, incluem o ponto de vista dos usuários. Identificou-se a necessidade de uma metodologia que:

- estimulasse conexões entre especialistas em construção e em conservação, com o objetivo de auxiliar as instituições na identificação das vulnerabilidades e no planejamento das estratégias;

- respeitasse as características locais e as possibilidades de recursos existentes;

- favorecesse a tomada de decisão esclarecida frente a riscos e incertezas;

- incentivasse propostas e soluções criativas, bem como a colaboração com especialistas, outras instituições e a academia;

- facilitasse a documentação e o compartilhamento dos resultados em prol do avanço científico paulistano e brasileiro sobre o tema.

Portanto, o objetivo desta pesquisa foi o desenvolvimento de um modelo teórico-metodológico para diagnóstico do desempenho de ambientes para a guarda de acervos com suporte em papel localizados em edifícios históricos na cidade de São Paulo, que permitisse identificar as principais vulnerabilidades construtivas, suas causas físicas e operacionais, bem como os riscos, à construção e ao acervo, associados a elas, por meio de avaliações de especialistas combinadas à perspectiva dos usuários, e, assim, propor ações para a gestão integrada das áreas de guarda e dos acervos, que fizessem uso de métodos e técnicas para definição das prioridades, monitoramento das condições ambientais internas e do estado de conservação das obras, planejamento e execução de manutenção preventiva e corretiva do espaço construído e de suas facilidades e análise sistemática da efetividade das medidas adotadas. Pretende-se também que estas ações estejam voltadas à preservação sustentável do patrimônio cultural em sua integralidade. 


\section{HIPÓTESE}

A conservação preventiva do patrimônio cultural é uma disciplina científica bastante estabelecida internacionalmente, cuja principal característica é a proposição de uma análise global do acervo e do contexto que o cerca, pela percepção de que "uma gota de prevenção vale mais do que um oceano de recuperação" (AIC, 2018; tradução da pesquisadora). Portanto, políticas e ações orientadas pelo princípio da precaução pressupõem um entendimento criterioso das possíveis ameaças à integridade dos objetos culturais, sejam elas de ordem interna (processos naturais de envelhecimento) ou externa (perigos). Os riscos externos têm duas origens principais: as decisões administrativas e de gestão institucional e as características do ambiente circundante, ou seja, do local (posição geográfica) onde a instituição se situa, dos sistemas construtivos do edifício e das condições ambientais internas dos espaços de guarda e/ou exposição. Arquiteto e engenheiros podem contribuir diretamente com a qualidade do ambiente. Porém, é preciso considerar também que museus, bibliotecas e arquivos são tipologias construtivas complexas, que dependem de mão-de-obra especializada, capaz de identificar as correlações de causa e efeito entre o edifício, a gestão e os processos de envelhecimento e deterioração do patrimônio, e de trabalhar em equipe, com muitos outros especialistas, na busca por soluções adaptadas ao momento presente e a cada caso específico.

A hipótese desta pesquisa é que o sistema multimétodos de Avaliação Pós-Ocupação (APO) adaptado a áreas de guarda de acervos pode ser um grande aliado das instituições culturais frente às condições descritas porque:

a. inclui arquitetos e engenheiros como parceiros em todas as etapas da gestão preventiva de acervos (avaliação dos riscos, diagnóstico das vulnerabilidades e incertezas, criação de políticas, planos e protocolos, execução de atividades preventivas e corretivas, monitoramento dos parâmetros e verificação da efetividade dos resultados);

b. ao contrário de outras metodologias, a APO propõe uma visão holística, o que inclui a perspectiva dos especialistas e dos usuários;

c. é orientada à prevenção porque coloca as ameaças externas no centro da avaliação;

d. é flexível o suficiente para ser adaptada às mais variadas características e condições institucionais. 


\section{MÉTODO}

0 método científico pode ser definido como o conjunto de regras necessárias para a realização de uma experiência, utilizado com o objetivo de se chegar a resultados válidos. Existem diversos métodos lógicos aceitos pela comunidade científica e 0 que determina a escolha de um deles é o tipo de pesquisa que será desenvolvida (LAKATOS e MARCONI, 2000). Este estudo fez uso do método científico hipotético-dedutivo, proposto por Karl Popper. Neste método, inicia-se o estudo com a escolha de um problema, para o qual são coletados dados quantitativos e qualitativos, utilizando-se, para isso, múltiplos instrumentos provenientes de diversas áreas das ciências sociais e humanas, cuja metodologia esteja cientificamente descrita. Uma vez realizadas as observações, é possível formular hipóteses, as quais precisam ser testadas a partir do conhecimento teórico e prático do problema, na busca pelas causas e correlações entre eventos, podendo-se, assim, chegar a conclusões que permitam propor intervenções no objeto da análise (POPPER, 1975).

Assim, para esta pesquisa, decidiu-se que o problema a ser estudado era a contribuição de arquitetos e engenheiros na gestão do desempenho ambiental do objeto da análise, ou seja, das áreas de guarda de acervos com suporte em papel localizados em edifícios históricos na cidade de São Paulo. A coleta de dados qualitativos e quantitativos sobre o tema foi feita por meio de:

a. revisão sistemática da literatura;

b. participação em congressos, seminários, palestras, etc.;

c. treinamentos em conservação e pequenos reparos de papéis;

d. visitas a instituições culturais e científicas no Brasil (São Paulo, Rio de Janeiro e Brasília) e no exterior (Viena e Berlim);

e. conversas orientadas com especialistas (conservadores, bibliotecários, arquivistas, curadores, historiadores, arquitetos, engenheiros, gestores, físicos, químicos e biólogos), nacionais e internacionais (das Américas, da Europa, da Índia e da China);

f. visitas técnicas exploratórias e entrevistas estruturadas a quatro instituições paulistanas, casos de estudo desta pesquisa (Museu Paulista - Museu do Ipiranga, Biblioteca Brasiliana Guita e José Mindlin, Biblioteca Mário de Andrade e Arquivo Histórico Municipal).

A partir do conhecimento adquirido ao longo de mais de quatro anos de pesquisa foi possível compreender as principais ameaças às áreas de guarda de acervos em papel e as oportunidades de 
melhoria e, assim, formular a hipótese de que arquitetos e engenheiros, treinados em APO adaptada ao patrimônio cultural local, poderiam contribuir com a melhoria da qualidade dos ambientes construídos para a guarda de papéis, e com a ampliação do conhecimento técnico sobre como projetar, reformar, requalificar e manter edifícios culturais e suas facilidades. Esta pesquisa teve como resultado um modelo teórico-metodológico para diagnóstico das vulnerabilidades e planejamento de ações voltadas à preservação sustentável da instituição.

\subsection{OBJETO}

Esta pesquisa tem como objeto de estudo as áreas, em museus, bibliotecas e arquivos, utilizadas para a guarda de acervos com suporte em papel, em edifícios históricos na cidade de São Paulo.

A escolha deste objeto se justifica porque (SAFT e ORNSTEIN, 2020):

a. as áreas de guarda (e reservas técnicas) são ambientes cuja complexidade nem sempre está bem compreendida, principalmente por arquitetos e engenheiros. Elas não são simples 'depósitos' de objetos, mas sim estruturas muito complexas, compostas por diversos espaços, cada um com características específicas, de modo a favorecer a realização de diversos procedimentos específicos (tais como monitoramento ambiental e das coleções, documentação, catalogação, digitalização, conservação, etc.); garantir a segurança física, química e biológica de pessoas e de objetos frágeis, raros e valiosos; e assegurar, ao longo de toda a vida útil dos bens, o desempenho ambiental esperado, por meio de sistemas passivos e ativos robustos, estáveis e confiáveis. As instituições culturais estão, com frequência, adquirindo novos itens ou coleções e, portanto, há contínua demanda por mais área e mobiliários. É preciso considerar também que a maioria dos itens do acervo ficará a maior parte de suas vidas guardados nesses ambientes, e apenas algumas (poucas) vezes serão levados para áreas de consulta ou exposição. As sucessivas crises econômicas, a escassez de mão-de-obra qualificada, a pouca relevância dada ao setor cultural no Brasil e a carência de uma cultura de planejamento estratégico fazem com que estes espaços e suas coleções estejam, em grande medida, em dificuldades.

b. o papel é o suporte mais frequente em arquivos e bibliotecas e também em muitos museus. Não existe um único tipo de papel, mas sim uma variedade muito grande deles, produzidos em épocas diferentes, com técnicas variadas, para usos distintos. Além disso, ele é um material orgânico e higroscópico, que pode facilmente se degradar quando em condições ambientais incorretas, e também pode servir de alimento ou 
abrigo para microorganismos e animais. Assim, um ambiente adequado para a preservação de objetos com suporte em papel muito provavelmente também estará adequado para vários outros suportes.

c. a maioria dos edifícios históricos paulistanos tombados pelos órgão de preservação do patrimônio foram construídos entre meados do século XIX e início do século XX. Por diversas razões, dentre elas: legislação (edifícios tombados devem seguir regras que podem dificultar sua adaptação ao uso e ocupação); preservação (instituiç̧̃̃es culturais naturalmente estão orientadas à proteção do patrimônio e, provavelmente, se empenharão em manter os edifícios históricos nas suas características originais); custo (é custoso manter edifícios históricos e raramente o setor privado percebe as vantagens associadas à utilização desta tipologia); e características culturais (está disseminada no senso comum a ideia de que edifícios históricos devem ser utilizados como instituições culturais), uma boa parte dos museus, bibliotecas e arquivos brasileiros estão instalados em edifícios históricos. No entanto, estas construções, muitas vezes, não possuem as características necessárias para garantir um ambiente interno estável e seguro, nem a flexibilidade (construtiva e normativa) desejável para que possam ser executadas as adaptações necessárias ao cumprimento dos parâmetros recomendados pelos organismos internacionais de proteção de acervos em papel. Porém, em uma perspectiva contemporânea orientada à preservação sustentável do patrimônio cultural, o reuso deste recurso construtivo e a menor dependência de sistemas ativos elétricos fazem com que estes edifícios sejam ambiental e energeticamente mais eficientes. Assim, o desenvolvimento de estratégias inovadoras e criativas, que permitam utilizar estas construções para a guarda de acervos em condições físicas e ambientais seguras é altamente desejável. Estas soluções, se devidamente documentadas e publicadas, podem também ser incorporadas ao projeto de novos edifícios energeticamente eficientes. d. a cidade de São Paulo é a maior do Brasil, tanto em população, como em quantidade de instituições culturais e acervos (IBRAM, 2011). Sua localização geográfica, sob o Trópico de Capricórnio, 800 metros acima do nível do mar, resulta em um clima tropical de altitude (ou subtropical), com invernos frescos e pouco chuvosos e verões quentes e chuvosos (TARIFA e AZEVED0, 2001). Há significativa amplitude térmica diária e sazonal. Tanto a temperatura como a umidade podem variar consideravelmente ao longo de um dia, de uma estação e de um ano, o que favorece processos de degradação do papel (deformações, amarelecimentos, fungos e pragas). Somam-se também as ameaças, aos edifícios e à população, resultantes das mudanças climáticas locais e globais. A cidade tem registrado crescente incidência de temporais, 
granizos, vendavais e secas (RAMIRES e MELLO-THÉRY, 2018). Além disso, o excesso de veículos que circulam pelo espaço urbano resulta em um ar constantemente poluído, tanto por particulados como por gases nocivos às pessoas e ao patrimônio. As instituições e os edifícios que abrigam acervos precisam contemplar estratégias para identificação e mitigação das ameaças provenientes da localização geográfica e do clima externo e para a gestão das incertezas associadas à mudança climática.

\subsection{CRITÉRIO}

Diversos instrumentos foram empregados na coleta de dados sobre o objeto de estudo desta pesquisa. 0 critério utilizado foi a busca por fontes confiáveis que pudessem fornecer informações, tanto teóricas como práticas, sobre a gestão de instituições culturais, a conservação de acervos com suporte em papel e a função de arquitetos e engenheiros na gestão das facilidades, na manutenção do edifício e no projeto de reformas e novas construções. Atender a estes critérios não foi uma tarefa fácil porque a conservação preventiva ainda é, no Brasil, uma área do conhecimento pouco desenvolvida. No estado de São Paulo, por exemplo, não existe, até o presente momento, um curso em nível de graduação na área e as formações em nível de pós-graduação são insuficientes. Praticamente toda a produção de novos conhecimentos vêm de Estados Unidos, Canadá, Austrália e Europa ocidental, e nem sempre é fácil encontrá-la, dada a multiplicidade de fontes. Além disso os resultados das pesquisas, na maioria dos casos, não podem ser diretamente aplicados à realidade brasileira. Há muito pouca informação adaptada à preservação de acervos em papel em edifícios históricos nos trópicos, ainda que esta seja uma situação muito frequente e compartilhada por diversos países ao redor do globo.

Assim, tendo como critério as boas práticas e a confiabilidade da fonte, esta pesquisa utilizou dados:

a. teóricos, por meio de consulta à literatura nacional e internacional de referência (publicações científicas, normas e regulamentos, manuais, etc.), para coleta de informações sobre conceitos, recomendações, métodos e práticas relacionados aos temas abordados;

b. práticos, a partir das experiências coletadas junto às instituições de referência (benchmarks), mediante visitas de reconhecimento e consultas a funcionários especialistas em gestão, conservação ou manutenção;

c. práticos, na forma de treinamentos realizados na Escola Theobaldo de Nigris / SENAI, no Museu de Astronomia e Ciências Afins do Rio de Janeiro (MAST), no Museu de Arte Sacra de São Paulo (MAS) e na Biblioteca Brasiliana Guita e José Mindlin (BBM USP), para ações de conservação preventiva e curativa; 
d. técnico-empíricos, mediante conversas orientadas com muitos especialistas, de todas as áreas do conhecimento correlatas, e que trabalham diretamente com a conservação de acervos em papel;

e. práticos, sobre ambientes para a guarda de acervos em edifícios históricos na cidade de São Paulo (casos de estudo desta pesquisa), por meio de visitas exploratórias guiadas por um profissional-chave da instituição para observação das vulnerabilidades construtivas, seus impactos sobre os acervos, e as soluções empregadas visando a proteção dos objetos;

f. técnico-empíricos, através de entrevistas estruturadas com os profissionais que trabalham na gestão, conservação de acervos e manutenção dos edifícios que são casos de estudo desta pesquisa.

\subsection{ASPECTOS ÉTICOS}

A aplicação de entrevistas estruturadas exige que a pesquisa seja aprovada por um Comitê de Ética em Pesquisa (CEP). Este procedimento é necessário para assegurar aos participantes entrevistados que o pesquisador considerou, durante o planejamento da atividade, os princípios da ética em pesquisa. Portanto, foram elaborados o Projeto de Pesquisa Detalhado, bem como os modelos das cartas de Solicitação de Autorização, do Termo de Consentimento Livre e Esclarecido (TCLE) e dos Roteiros das Entrevista. Estes documentos foram encaminhados, via Plataforma Brasil, para conferência pelo CEP responsável, no caso desta pesquisa, a Escola de Artes, Ciências e Humanidades da Universidade de São Paulo (CEP - EACH USP). 0 Projeto Detalhado atendeu à Resolução 510 do Conselho Nacional de Saúde (2016) e descreveu 0 contexto do estudo, a hipótese, o objetivo, a metodologia proposta para a coleta e a análise dos dados, 0 desfecho pretendido e o cronograma de atividades. Esclareceu também qual o tamanho máximo da amostra de indivíduos entrevistados a ser considerada e os riscos e benefícios associados a cada atividade. Qualquer pesquisa tem algum tipo de risco, portanto, no caso desta pesquisa foi considerada a hipótese de o respondente sentir algum desconforto como consequência do tempo necessário para a realização da atividade e prever, para esta situação, que a entrevista seria imediatamente interrompida.

A carta de Solicitação de Autorização do responsável pela instituição participante continha as informações para contato com a pesquisadora e com o CEP responsável e a descrição das atividades pretendidas, dos riscos e dos benefícios e das regras para a publicação dos resultados, a saber, solicitação de autorização prévia e não identificação dos participantes. Este documento foi impresso em duas vias, sendo uma entregue ao responsável pela instituição e a outra lida e assinada pelo responsável e devolvida à pesquisadora (as cartas podem ser consultadas no Apêndice B). 
0 Termo de Consentimento Livre e Esclarecido (TCLE) continha uma breve descrição da pesquisa e da atividade a ser realizada, bem como seus riscos e benefícios, a garantia de que o respondente não seria identificado, a explicação de que a participação era voluntária, dos direitos do respondente e da relevância da sua participação para a pesquisa, e as informações para contato com a pesquisadora ou com o CEP responsável. 0 TCLE é um documento impresso em duas cópias, ficando uma de posse do respondente e a outra deve ser lida e assinada e devolvida à pesquisadora (o modelo de TCLE utilizado por esta pesquisa pode ser consultado no Apêndice C).

Foram elaborados três Roteiros de Entrevista distintos, um para cada um dos três profissionais-chave entrevistados em cada uma das quatro instituições caso de estudo desta pesquisa: o responsável pela conservação preventiva, o responsável pelos acervos em papel, e o responsável pela manutenção do edifício. 0 roteiro, enviado com antecedência via e-mail, continha uma identificação da pesquisa, os contatos da pesquisadora e do CEP responsável e perguntas abertas e fechadas relacionadas às atividades específicas de cada profissional (os modelos podem ser consultados no Apêndice D). A entrevista foi previamente agendada e realizada de forma presencial, entre os meses de fevereiro e abril de 2019. As respostas foram anotadas no Roteiro e conferidas pelo participante, e também gravadas, mediante autorização prévia.

0 projeto foi aprovado pelo CEP EACH USP em 09 de janeiro de 2019, sob número de protocolo CAAE 02912118.2.0000.5390 (ver Apêndice A).

Os fundamentos conceituais relativos à submissão, via Plataforma Brasil, de solicitação para aplicação de instrumentos que envolvem a participação de seres humanos estão descritos no capítulo 2, item 2.2.5, deste trabalho. A análise dos resultados está descrita no capítulo 5, item 5.7.

\subsection{PROCEDIMENTOS}

A motivação para esta pesquisa de doutorado foi uma demanda prática do Serviço de Conservação de Papel do Museu Paulista, em 2015. Com o fechamento do edifício-monumento ao público em 2013 para obras de restauro e readequação dos sistemas e da acessibilidade, a instituição decidiu pela transferência da maior parte dos acervos para outros edifícios, nas imediações da instituição. Conservadores do Setor de Papel solicitaram à direção do Museu à época o auxílio de arquitetos para identificação de potenciais vulnerabilidades construtivas no edifício para reserva técnica temporária de papel, e no planejamento de soluções adaptadas à realidade construtiva e orçamentária do Museu, com o objetivo de mitigar possíveis riscos de deterioração do acervo. 
A demanda, apesar de aparentemente simples, para que pudesse ser adequadamente respondida, demandava o conhecimento de conceitos relativos à conservação preventiva de acervos, os quais não são familiares a arquitetos não especialistas. Vislumbrou-se a possibilidade de uma pesquisa, em nível de pós-graduação, cujos resultados pudessem auxiliar, tanto na formação de arquitetos e engenheiros especialistas em preservação sustentável do patrimônio cultural, como no desenvolvimento de uma metodologia que facilitasse o trabalho conjunto de profissionais da construção e da conservação. Esta pesquisa foi aprovada no curso de doutorado do programa de pós-graduação em Arquitetura e Urbanismo da FAU USP em março de 2017.

Os trabalhos de pesquisa foram iniciados, ainda em 2016, com a coleta de informações teóricas que permitissem a construção de um arcabouço conceitual inicial sobre os temas correlatos a esta investigação. Para isso, utilizou-se como recurso a revisão sistemática da literatura, e também a participação em encontros, seminários, palestras e eventos similares que pudessem fornecer referências conceituais e normativas.

Em uma segunda etapa, verificou-se a necessidade de se complementar o conhecimento teórico com um treinamento prático, o que pôde ser alcançado com a participação em cursos livres de curta duração voltados para o treinamento profissional em análise de riscos, conservação e pequenos reparos de documentos com suporte em papel. Estes cursos tinham por finalidade treinar o aluno a realizar atividades, tais como, diagnósticos de conservação, registro e documentação de procedimentos, 'leitura' das características formativas e fisico-químicas do papel, planejamento e execução de procedimentos de conservação tais como higienização, pequenos reparos e acondicionamento, formulação de produtos químicos (águas, colas e solventes) para tratamentos pontuais específicos, identificação dos processos de deterioração e seus respectivos agentes, construção de um plano para gestão de riscos, com protocolos para prontidão a situações de emergência, e treinamentos para resgate de acervos após um evento adverso com água.

A partir desta experiência teórica e prática inicial, constatou-se que havia uma grande demanda dos profissionais do setor da conservação por soluções práticas, adaptadas a cada realidade institucional, e por metodologias de avaliação de riscos que incentivassem o trabalho colaborativo, de múltiplos especialistas, para produção de documentação diagnóstica simples e clara, que pudesse ser apresentada aos tomadores de decisão e os auxiliasse no planejamento de uma gestão mais eficiente dos recursos disponíveis. 
Diante das demandas percebidas, concluiu-se que o sistema multimétodos de APO, se adaptado ao patrimônio cultural, poderia ser uma resposta satisfatória, porque:

a. permite a combinação de múltiplos instrumentos. Tradicionalmente, são utilizados instrumentos provenientes da arquitetura e engenharia, do planejamento estratégico e da psicologia ambiental, mas outros, provenientes de diferentes áreas do conhecimento, desde que cientificamente validados e adequados para responder às perguntas formuladas na etapa de planejamento da APO, também podem ser incorporados, como, por exemplo, os instrumentos para avaliação de riscos ao acervo, técnicas para análise de processos de degradação dos materiais, dentre outros.

b. permite uma avaliação conjunta, feita por múltiplos especialistas. A APO normalmente é realizada por arquitetos treinados no uso de instrumentos para a coleta de dados quantitativos e qualitativos do desempenho do edifício em uso e da perspectiva dos usuários. Se corretamente adaptada, esta metodologia pode ser realizada em conjunto, por arquitetos e/ou engenheiros especialistas e conservadores treinados, visando a avaliação do desempenho do edifício na proteção dos objetos, a partir do entendimento de que, tanto os funcionários como o próprio acervo, são 'usuários' das áreas de guarda. c. permite uma apresentação clara e visual dos resultados. Os resultados de uma APO costumam ser sintetizados e apresentados na forma de Quadros e/ou Mapas de Diagnósticos e Recomendações. A experiência tem demonstrado que este formato é muito eficiente na comunicação das descobertas, dos riscos e das recomendações dos especialistas a terceiros, tais como diretores, gestores ou outros tomadores de decisão. Estes documentos também favorecem o registro das condições atuais de guarda e podem ser usados para comparação e acompanhamento ao longo do tempo (séries históricas) ou entre instituições similares, facilitando a gestão informada de riscos e incertezas.

0 passo seguinte da pesquisa foi o planejamento de atividades de reconhecimento para uma melhor compreensão das atividades cotidianas de gestão, preservação e manutenção, e das principais necessidades e dificuldades relacionadas às áreas de guarda. Para isso, foram planejadas visitas de reconhecimento a instituições que trabalham com acervos em papel e consultas a profissionais-chave. Assim, ao longo de 2018, foram visitados museus, bibliotecas e arquivos, localizados principalmente em edifícios históricos, administrados por entes universitários, públicos e privados, com acervos muito grandes ou pequenos, localizados nas cidades de São Paulo, Rio de Janeiro e Brasília. Apesar das inúmeras diferenças entre essas instituições, foram percebidas necessidades semelhantes, tais como: 
de um maior apoio da academia na busca de soluções adaptadas a cada caso singular; de mais oportunidades para formação profissional especializada; de recursos institucionais; e de valorização institucional do trabalho das equipes de conservação. As dificuldades também se assemelhavam e estavam relacionadas principalmente a: gestão dos recursos; qualidade ambiental interna; e comunicação interna e externa. Três instituições foram escolhidas como benchmarks para esta pesquisa: Museu Paulista, Fundação Casa de Rui Barbosa e Centro de Documentação e Informação da Câmara dos Deputados. Os principais aspectos identificados estão descritos no próximo item (5.5).

Em 2019 houve a oportunidade de realizar o mesmo procedimento descrito acima (visitas de reconhecimento e consultas a especialistas) em instituições internacionais. No primeiro semestre foram feitas visitas, como aluna convidada do Instituto de Conservação e Restauro da Faculdade de Artes Aplicadas da Universidade de Viena (Institut für Konservierung und Restaurierung Universität für Angewandte Kunst Wien), a museus, bibliotecas, arquivos, bem como reservas técnicas privadas localizados em Viena e seus arredores. No segundo semestre, com o apoio de uma bolsa de estudos da Fundação para o Patrimônio Cultural Prussiano (Stiftung Preußischer Kulturbesitz), foi possível realizar visitas e consultas a especialistas de universidades, laboratórios, museus, bibliotecas e arquivos localizados em Berlim e seus arredores. Uma descrição detalhada dos aspectos relevantes observados durante a realização destas atividades estão descritos no próximo item (5.5).

Em paralelo às visitas de reconhecimento, foram escolhidas quatro instituições, casos de estudo desta pesquisa, na qual foram realizados os mesmos procedimentos, porém, de modo mais estruturado. As instituições escolhidas representam os três principais tipos de instituição responsáveis pela guarda de acervos em papel: um museu (Museu Paulista - Museu do Ipiranga); uma biblioteca (Biblioteca Mário de Andrade); e um arquivo (Arquivo Histórico Municipal). Todas são instituições públicas, sediadas na cidade de São Paulo e em edifícios históricos, tombados por órgãos de proteção do patrimônio. Além destes três casos, decidiu-se incluir uma quarta instituição, a Biblioteca Brasiliana Guita e José Mindlin porque ela também se localiza em São Paulo, possui acervos majoritariamente em papel, porém, em contraste com as outras instituições, encontra-se em um edifício contemporâneo, construído há poucos anos e projetado especialmente para abrigar o acervo Mindlin. 0 objetivo pretendido foi identificar e comparar os impactos positivos e negativos do uso de técnicas tradicionais e contemporâneas de construção e de tratamento do ambiente interno para os objetos em papel, bem como o impacto das 
decisões projetuais, de adaptação de um edifício histórico e de construção de um edifício novo, para a conservação dos acervos. 0 procedimento utilizado foi o agendamento de visitas exploratórias em conjunto com um profissional responsável pelo acervo, e de entrevistas estruturadas com profissionais responsáveis pela gestão e conservação dos acervos e pela manutenção dos edifícios.

Por fim, a partir da análise dos dados coletados por meio dos múltiplos instrumentos utilizados, temse, como última etapa desta pesquisa, a proposição de um modelo teórico-metodológico para diagnóstico do desempenho ambiental de áreas de guarda de acervos em papel em edifícios históricos na cidade de São Paulo. Este modelo é o resultado da identificação dos pontos fortes e fracos das instituições visitadas, das oportunidades e ameaças à preservação dos acervos, e das demandas dos profissionais envolvidos, e consiste na combinação e adaptação de instrumentos e técnicas existentes (descritos no Capítulo 2 desta pesquisa) adaptados à necessidade de melhoria na qualidade do ambiente construído e à realidade local.

\subsection{ESTUDOS DE REFERÊNCIA (BENCHMARKS)}

Os estudos de referência (ou benchmarks) foram utilizados com 0 intuito de contribuir com 0 desenvolvimento desta pesquisa pelo ponto de vista da experiência prática das instituições culturais com a gestão das áreas de guarda para acervos com suporte em papel. Foram escolhidas três instituições brasileiras: o Setor de Papel do Museu do Ipiranga (em São Paulo), a Fundação Casa de Rui Barbosa (no Rio de Janeiro) e o Centro de Documentação e Informação da Câmara dos Deputados (em Brasília). Também foram utilizados como referência o conjunto dos museus, bibliotecas e arquivos nacionais e universitários da Áustria (localizados na capital, Viena) e da Alemanha (localizados na capital, Berlim). Em cada um dos estudos de referência foram realizadas visitas de reconhecimento e consultas a especialistas, com o propósito de se coletar informações sobre:

a. as características do estudo de referência;

b. os profissionais e a conservação dos acervos;

c. o papel de arquitetos e engenheiros.

Tem-se, a seguir, um relato dos aspectos identificados, para cada um dos estudos de referência. 
5.5.1 São Paulo: Museu Paulista - Museu do Ipiranga (múltiplas visitas, 2015 a 2019)

0 Museu Paulista (MP) é uma unidade da Universidade de São Paulo (USP). Ele está dividido em dois edifícios: o edifício-monumento do Museu do Ipiranga, localizado na cidade de São Paulo, e o Museu Republicano "Convenção de Itu", situado na cidade de Itu, interior do estado. Seu organograma é bastante complexo, com setores administrativos, de acervo e curadoria e de difusão cultural. Os serviços de conservação contemplam os setores de madeira, papel, pintura, têxteis e conservação preventiva. Dentre os mais de 450.000 itens nos mais variados suportes, há uma importante coleção de papéis (livros, revistas, jornais, documentos, panfletos, mapas, desenhos arquitetônicos, fotografias, dentre outros), distribuídos entre a reserva técnica de papéis e a biblioteca. Esta pesquisa acompanhou unicamente o setor responsável pelas coleções com suporte em papel.

a. Características do estudo de referência

0 edifício-monumento do Museu do Ipiranga é uma construção eclética do final do século XIX, feito com técnica tradicional de tijolo e cal, que utiliza estratégias ambientais passivas para a preservação de suas estruturas e maior bem-estar dos usuários, tais como porão ventilado, inércia térmica, galerias e amplos vãos para ventilação (Figura 67). 0 edifício foi projetado para ser um monumento e não um museu (função que adquiriu apenas após a conclusão das obras de construção, em 1890) e, por isso, não possui características construtivas desenhadas especificamente para a preservação de acervos. No entanto, as mesmas estratégias bioclimáticas para conforto humano podem ter sido positivas na manutenção de um ambiente interno relativamente estável para os objetos.

Figura 67. 0 edifício-monumento e seu jardim

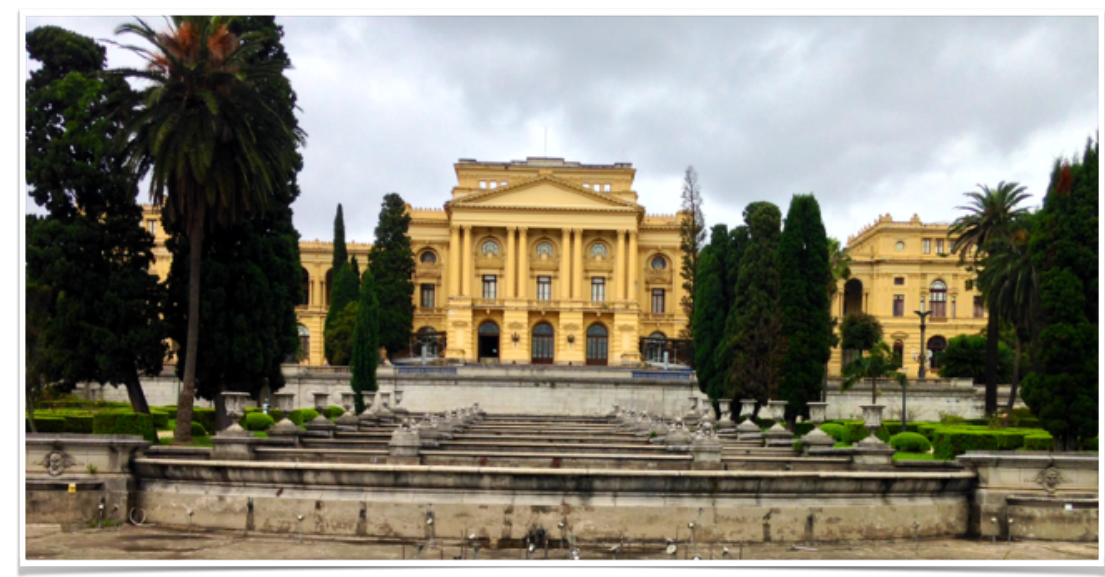

fonte: a pesquisadora 
0 desgaste natural de elementos estruturais, inadequações e falhas na ocupação e na manutenção dos espaços e intervenções incorretas fizeram com que o Museu, em 2013, precisasse ser fechado. Quando as inspeções técnicas comprovaram que, para garantir a segurança física dos usuários e a proteção do patrimônio, era preciso interromper as atividades para o público externo, foi preciso tomar decisões difíceis e explicá-las às instâncias superiores e à opinião pública. A preocupação com uma comunicação clara e correta, fundamentada em evidências científicas, se mostrou bastante acertada ao longo do tempo.

Para que o edifício-monumento pudesse ser reformado e restaurado, a maior parte dos acervos precisou ser temporariamente transferido para edifícios localizados no entorno do Museu, os quais passaram por adaptações para receber os objetos. Os itens com suporte em papel foram transferidos para dois edifícios distintos: um deles abrigou a reserva técnica e o outro a biblioteca. Em 2019 foram iniciadas as obras de reforma e ampliação do edifício-monumento.

A transferência dos acervos para outros locais precisava estar fundamentada no difícil equilíbrio entre o princípio da precaução (máximo cuidado possível com o patrimônio) e da otimização (melhor uso possível dos recursos disponíveis). Decidiu-se que as coleções seriam temporariamente realocadas para imóveis no entorno do Museu, o que facilitaria o transporte dos itens e o trabalho dos profissionais responsáveis pela conservação. Foi preciso um planejamento cuidadoso das adaptações necessárias para que os novos ambientes pudessem receber, com segurança, os acervos.

Os edifícios para guarda temporária dos acervos em papel são construções típicas da primeira metade do século XX. Possuem estrutura em concreto, vedações em alvenaria de tijolos, coberturas com telha cerâmica, janelas de ferro e vidro, portas de ferro ou de madeira e piso cerâmico ou em pedra. Ao contrário do Museu, são construções menores e mais simples, com poucos recursos passivos ou ativos que garantam qualidade ambiental (estabilidade e estanqueidade) ao longo do ano, seja para as pessoas ou para os objetos. Por serem imóveis de ocupação temporária, havia limites quanto ao grau de alteração possível para adequação dos espaços aos novos usos.

\section{b. Os profissionais e a conservação dos acervos}

0 Museu tem, em seu quadro, profissionais bastante especializados, e possui grande tradição no fomento de pesquisas, debates, cursos e publicações sobre temas relacionados à preservação da cultura brasileira. 
Os funcionários do Setor de Papel estavam muito conscientes da necessidade de abordar os desafios do fechamento do Museu e da transferência dos acervos pelo olhar da conservação preventiva. Por isso, se empenharam em criar uma rede de colaboradores, formada por historiadores, bibliotecários, arquivistas, arquitetos, engenheiros, físicos, químicos e biólogos que pudesse auxiliá-los na busca pelas melhores práticas possíveis para documentação, higienização, acondicionamento, transporte e guarda dos acervos nos novos ambientes. Era preciso também identificar e avaliar os possíveis riscos associados a eventuais vulnerabilidades na envolvente externa, nas facilidades e no desempenho ambiental interno das novas áreas de guarda e encontrar respostas, dentro das possibilidades normativas, administrativas e de recursos da universidade, para a mitigação ou eliminação das ameaças. Era necessário ponderar sobre as incertezas inerentes aos procedimentos de mudança para um novo endereço e de aclimatação de cada objeto a um novo padrão ambiental (com maior variação de T e UR e menor taxa de renovação do ar). E, por fim, era preciso buscar soluções alternativas, tendo em vista as características institucionais e construtivas, para minimizar processos de degradação de papéis (hidrólises e oxidações) causados por agentes de deterioração do acervo.

A abordagem do Setor de Papel do Museu é um benchmark para esta pesquisa de como aplicar a visão contemporânea de preservação sustentável do patrimônio a uma situação concreta, o que implica em utilizar as diretrizes e os parâmetros de conservação preventiva de acervos cotejados à luz das possibilidades institucionais (de um país tropical em desenvolvimento) e das incertezas inerentes à toda e qualquer escolha esclarecida e embasada cientificamente. Destaca-se, principalmente, 0 empenho dos funcionários em 'gastar tempo para ganhar tempo', pelo entendimento de que era preciso começar pelo princípio: revisão da literatura, consulta a especialistas, estudo das alternativas, reuniões com a equipe e as diretorias, desenho das ações, construção de protocolos, documentação de todo o processo, e, por fim, a realização das atividades planejadas, o registro de cada passo e, após a mudança para o novo endereço, o monitoramento dos resultados e o aprimoramento dos processos.

\section{c. 0 papel de arquitetos e engenheiros}

Pelas regras da USP, os serviços de manutenção (preventiva e corretiva de menor porte) dos edifícios devem ser feitos diretamente por cada unidade universitária. Já o projeto e a gestão de obras de reforma, requalificação ou ampliação de todas as unidades de todos os campi são atribuições da SEF Superintendência do Espaço Físico. Por causa desta regra, a maioria das unidades USP, incluindo 0 
Museu, não possuem em seu organograma um arquiteto ou engenheiro responsável pela gestão das facilidades e manutenção do edifício, que é realizada por técnicos em construção civil sob responsabilidade de um funcionário administrativo. Como consequência, a capacidade institucional de planejar manutenções preventivas tendo em vista a mitigação dos riscos aos acervos fica prejudicada. A SEF conta com uma equipe bastante competente e experiente de arquitetos e engenheiros. No entanto, eles são generalistas e não há uma política institucional voltada à especialização na tipologia construtiva de museus e bibliotecas da universidade. Como resultado, a possibilidade de colaboração entre os funcionários responsáveis pelo acervo e os arquitetos e engenheiros da SEF, sob a perspectiva do patrimônio edificado, é dificultada. Esforços vêm sendo feitos, tanto por parte da SEF, como das instituições culturais da USP, para que as eventuais lacunas de comunicação entre os setores sejam minimizadas. Esta relação mais harmoniosa já pode ser observada na parceria entre a SEF e o Museu para 0 acompanhamento e a fiscalização das obras no edifício-monumento.

5.5.2 Rio de Janeiro: Fundação Casa de Rui Barbosa (duas visitas, segundo semestre de 2016 e segundo semestre de 2017)

A Fundação Casa de Rui Barbosa é uma instituição subordinada ao Ministério da Educação. Foi fundada em 1924, quando o governo federal decidiu adquirir a propriedade, o mobiliário, a biblioteca e 0 arquivo, além da propriedade intelectual das obras de Rui Barbosa. Possui organograma complexo, que contempla a procuradoria federal, a administração geral, o centro de pesquisa, o centro de memória e informação e a auditoria. As coleções são vastas e variadas e incluem o arquivo institucional (200 metros lineares e conjuntos de documentos especiais); o arquivo Rui Barbosa (cerca de 60.000 documentos); arquivos históricos (mais de 4 metros lineares, além de diversos documentos); arquivos literários (vários conjuntos e coleções); biblioteca de Rui Barbosa (cerca de 23 mil títulos); e biblioteca São Clemente (vários documentos). 0 acervo é formado principalmente por livros, mas inclui também manuscritos, incunábulos, folhetos, cartas, fotografias, desenhos arquitetônicos, cartazes, fitas de vídeo-cassete, filmes $16 \mathrm{~mm}$, fitas de áudio em rolo, negativos, diapositivos, fotolitos, DVD, CD-Roms, dentre outros. Durante esta pesquisa foram realizadas visitas ao museu-casa e suas coleções.

\section{a. Características do estudo de referência}

O edifício-sede, casa de Rui Barbosa, é uma construção eclética (neoclássica) de meados do século XIX, que utiliza técnica tradicional de tijolo e cal e contempla estratégias passivas típicas para assegurar 
conforto e desempenho em um clima tropical, tais como o porão ventilado, amplas portas e janelas e inércia térmica. É uma casa parcialmente assobradada (na sua porção central anterior), inserida em um amplo terreno, com jardins e pomar (Figura 68).

Figura 68. 0 museu-casa e seu jardim frontal

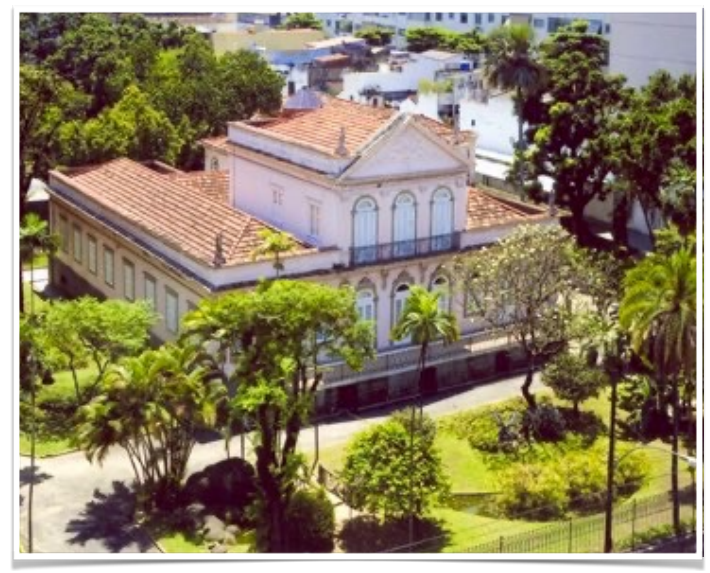

Fonte: FCRB, 2020.

0 bairro do Botafogo, onde a construção se localiza, costumava ser o local preferido da burguesia da época. Mas, com o passar dos anos, a região foi sendo adensada e as ruas passaram a conviver com tráfego intenso de veículos e pedestres. Apesar do tombamento pelo IPHAN delimitar o gabarito dos terrenos contíguos à casa a quatro andares, as ameaças do entorno, tais como poluentes e vibrações (pelos veículos) e aumento da temperatura e diminuição das correntes de vento e da permeabilidade do solo (pelo adensamento construtivo) são um risco permanente para o patrimônio imóvel e móvel. As coleções com suporte em papel pertencentes ao museu-casa ficam permanentemente expostos nos armários construídos especialmente para os ambientes, em madeira e vidro, dentro do gabinete (Sala Civilista), do corredor (Corredor Ruiano), da biblioteca (Sala Constituição), do quarto de vestir (Sala Casamento Civil), do aposento particular (Sala Código Civil) e do escritório do jurista (Sala de Haia), além do acervo guardado junto ao hall da escada de acesso ao sobrado.

\section{b. Os profissionais e a conservação dos acervos}

Por ser uma instituição educacional, a Fundação conta com profissionais de múltiplas áreas do conhecimento e oferece um amplo conjunto de serviços, tais como visitas guiadas ao museu, atividades para as crianças, cursos, palestras, etc., além de possuir um programa de pós-graduação em memória e acervos que é referência no país. 
A Fundação foi uma das primeiras instituições culturais brasileiras a implementar um plano de conservação preventiva, ainda no final dos anos 1990. Este plano explicitava a necessidade de um trabalho criterioso e continuado de identificação, nos sistemas construtivos da casa e no seu entorno imediato, dos potenciais agentes de deterioração do acervo, e de desenvolvimento de protocolos de documentação com o objetivo de sistematizar e programar ações de conservação e restauro.

Como parte do plano de conservação preventiva, foi criado um programa de gerenciamento de riscos do museu-casa para identificar as vulnerabilidades e mitigar os danos, tanto para o edifício como para as coleções nele abrigadas. A metodologia empregada estava baseada na norma de gestão de riscos australiana (AS/NZS 4360:2004). Foi constituída uma equipe multidisciplinar, com colaboração de consultoria externa, para diagnosticar as ameaças e estabelecer uma política de preservação, em acordo com a visão e os recursos institucionais.

Dentre as ações realizadas estavam:

a. mapeamento dos danos à fachada causados pelo uso indevido de argamassas e tintas sintéticas, experimentação de técnicas tradicionais para fabricação de argamassas e rebocos a base de cal, e investigação de tintas e pigmentos tradicionais. 0 resultado deste trabalho foi utilizado na restauração das fachadas do museu-casa;

b. plano para preservação sustentável do patrimônio mediante o desenvolvimento de protocolos para manutenção programada de sistemas construtivos:

- solo: reforma completa do sistema de drenagem do jardim, que estava degradado e já não era adequado aos volumes mais elevados de chuva, consequência das mudanças urbanas e climáticas, e instalação de tubulação de diâmetro maior e caixas de passagem;

- coberturas: inspeção de todas as peças, instalação de subcobertura (estanqueidade à água e isolamento térmico) e de rufos de cobre nas platibandas;

- forros: os estuques decorados apresentavam ataques por insetos, desagregação das argamassas, tricas e desprendimento de ornatos e precisaram ser consolidados e ter suas estruturas reforçadas;

- esquadrias: recuperação das 72 esquadrias externas visando melhorar a estanqueidade da edificação à umidade e à poluição;

- sistema hidráulico: reforma completa da rede de esgotamento sanitário, com instalação de tubulação nova e alteração do ponto de ligação com a rede pública; 
c. restauração completa da antiga cavalariça: além da degradação causada pela exposição aos agentes naturais, detectou-se infestação por cupim nos madeiramentos, fazendo-se necessário reformar toda a cobertura, renovar as instalações elétricas e de iluminação e recuperar as alvenarias, os pisos e as esquadrias;

0 plano de conservação preventiva também contemplou estratégias para gerenciamento ambiental e controle de pragas (insetos).

0 monitoramento da T e UR internas às áreas de guarda do museu-casa demonstraram que os parâmetros estavam sempre muito elevados, o que, somado à elevada taxa de poluentes, vinha provocando a degradação do patrimônio. 0 planejamento e a execução de ações de mitigação foi um projeto realizado em parceria entre a Fundação Casa de Rui Barbosa, o Getty Conservation Institute $(\mathrm{GCl})$ e a Fundação Vitae. A partir da avaliação e do diagnóstico do edifício, da coleção, e do clima interno foi proposto um sistema de condicionamento artificial alternativo (ventilação e desumidificação do ar interno), instalado no porão, com menor impacto possível nos sistemas construtivos e nas características originais da casa.

0 monitoramento das estruturas da casa detectou 0 ataque de cupins, tanto de solo como de madeira seca, em coberturas, forros e vedações verticais internas. Um projeto, em parceria com o Instituto de Pesquisas Tecnológicas do Estado de São Paulo (IPT), foi desenvolvido e, como resultado das inspeções e análises, foi proposta a aplicação de produtos químicos de baixa toxicidade em todas as peças de madeira e nas árvores do entorno e a instalação de iscas no solo para monitoramento.

\section{c. 0 papel de arquitetos e engenheiros}

A presença de profissionais próprios da instituição, provenientes de várias áreas do conhecimento, responsáveis pela gestão dos acervos e pela manutenção do conjunto edificado, combinado a um ambiente propício ao desenvolvimento de estudos e pesquisas, ao aprimoramento profissional voltado à preservação do patrimônio e ao desenvolvimento de parcerias com outras instituições científicas, são características que fizeram da Fundação um benchmark para esta pesquisa e demonstraram como profissionais especialistas em preservação sustentável do patrimônio cultural atuando colaborativamente podem resultar em um trabalho de excelência, criativo e adaptado à realidade financeira e climática local.

Este organograma funcional, cada vez mais raro no Brasil, e na própria Fundação, devido à política pública sistemática de redução dos cargos técnicos e de substituição dos funcionários próprios por 
terceirizados parece ir no sentido contrário do que se identificou como as melhores condições e práticas para a preservação do patrimônio cultural, bem como para o desenvolvimento de métodos e técnicas que permitam a criação de soluções adaptadas a condições específicas, que possam servir de referência para outras instituições similares.

\subsubsection{Brasília: CeDI - Centro de Documentação e Informação da Câmara dos Deputados (duas} visitas, primeiro semestre de 2017 e primeiro semestre de 2018)

A Diretoria Legislativa da Câmara dos Deputados é responsável pelas atividades de apoio técnico especializado aos deputados federais. Ela está dividida em gabinete, departamento de taquigrafia, revisão e redação, departamento de comissões, consultoria de orçamento e fiscalização financeira, consultoria legislativa e centro de documentação e informação. 0 Centro de Documentação e Informação (CeDI) é o órgão responsável pela gestão da informação e do conhecimento produzidos ou solicitados pela Câmara, e seus funcionários atuam na guarda, catalogação, documentação, conservação e pesquisa de materiais legislativos, bibliográficos e arquivísticos, tanto para o público interno como para o externo.

O CeDI está localizado no Anexo II do complexo arquitetônico projetado por Oscar Niemeyer para 0 Palácio do Congresso Nacional. Seu organograma é bastante complexo e contempla dois núcleos (de gestão estratégica e orçamentária; e de tecnologia, comunicação e relações institucionais) e seis coordenações (de arquivo; de biblioteca; de edições; de organização da informação legislativa; de preservação de conteúdos informacionais; e de relacionamento, pesquisa e informação).

0 acervo do Arquivo da Câmara dos Deputados possui mais de $20 \mathrm{~km}$ lineares de documentos históricos, intermediários e permanentes, além do acervo audiovisual (fotografias, mapas, desenhos, gravações de áudio e vídeo, microfilmes, dentre outros). Estes documentos registram parte significativa da história legislativa brasileira, desde a criação da Câmara dos Deputados em 1823 até 0 presente, e inclui 0 documento classificado como o mais valioso do país atualmente: o original da Constituição de 1988.

A Biblioteca Pedro Aleixo abriga em seu acervo cerca de 400 mil volumes, sendo mais de 2 mil livros e periódicos raros (Figura 69). 0 CeDI também é responsável pela guarda, conservação e restauração dos variados objetos de arte e mobiliários pertencentes à Câmara e ao seu Museu. 
Figura 69. Corredor das estantes - Biblioteca Pedro Aleixo

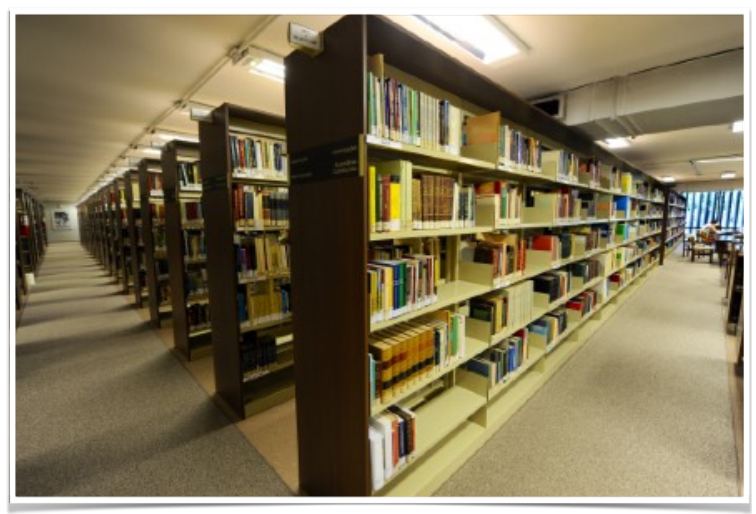

fonte: CÂMARA DOS DEPUTADOS, 2020.

\section{a. Características do estudo de referência}

0 Arquivo e a Biblioteca da Câmara dos Deputados tiveram muitos endereços ao longo dos seus quase cem anos de existência, inicialmente no Rio de Janeiro e, desde 1960, em Brasília. No projeto original de Oscar Niemeyer previu-se um espaço de quatro andares no Anexo I da Câmara para acomodar os acervos. No entanto, dada as condições precárias e insuficientes do espaço, a direção do CeDI pleiteou por acomodações mais adequadas. Como o Anexo II estava em fase final de projeto, Niemeyer fez alterações para incluir uma área de quase $9.000 \mathrm{~m}^{2}$ para a biblioteca. Os funcionários especialistas em conservação elaboraram um programa de necessidades que pudesse atender aos requisitos para a guarda e preservação adequada dos objetos. 0 projeto original foi então alterado pelo arquiteto Renato Sá para que pudesse contemplar estas demandas. 0 CeDI mudou pela última vez de endereço em 1965.

0 Anexo II da Câmara dos Deputados faz parte do conjunto edificado do Palácio do Congresso Nacional, um dos principais exemplares da arquitetura modernista brasileira. Ele está interligado ao Edifício Principal por meio de um túnel de acesso semi-enterrado. É um edifício de estrutura mista, com pilares e vigas de aço revestidas por concreto, lajes nervuradas, vedações em argamassa armada e caixilharia em aço.

As áreas de guarda de acervos e os laboratórios, possuem ambiente climatizado e iluminado artificialmente. A biblioteca também é climatizada mas faz uso combinado de iluminação natural e artificial. A reserva técnica do arquivo possui controle rígido de $T$ e UR, subdividido por salas com parâmetros específicos para cada tipo de suporte (Figura 70). 
Figura 70. Comunicação visual na entrada da Reserva Técnica indicando a temperatura para cada uma das salas

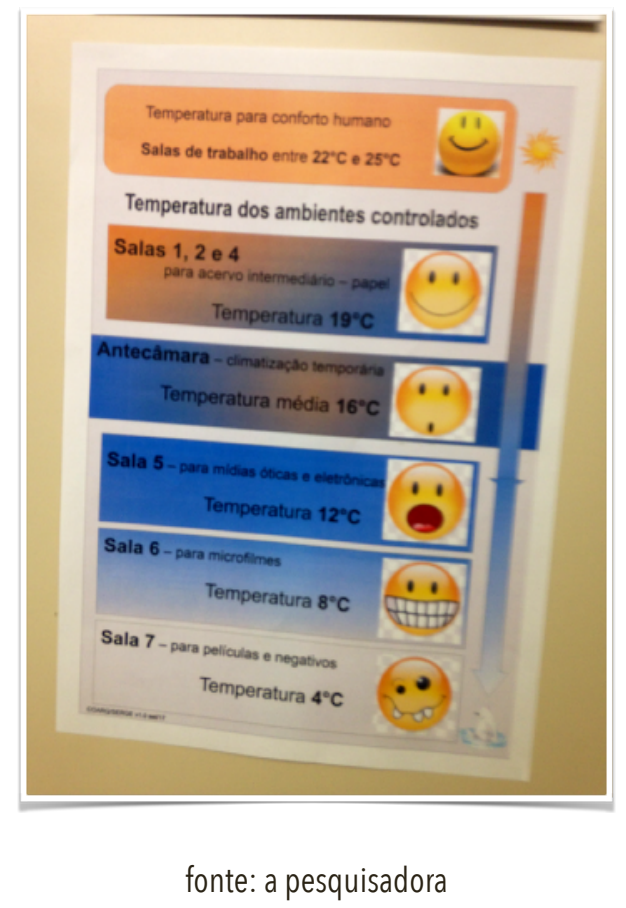

A Coordenação de Preservação de Conteúdos Informacionais é responsável pelos diversos laboratórios para: digitalização; conservação e restauro dos mais variados suportes (papel, madeira, metal, etc.); e por programas de treinamento técnico inclusivo para pessoas com deficiência (parceria com a Apae-DF).

0 CeDI foi escolhido como benchmark para esta pesquisa pela complexidade e eficiência da sua gestão institucional:

- ambientes, sistemas construtivos e equipamentos planejados especificamente para a salvaguarda, a conservação e o uso correto de acervos muito numerosos e valiosos;

- múltiplas equipes, próprias e terceirizadas, altamente especializadas nas mais variadas atividades relacionadas à gestão dos acervos, da informação ou da manutenção do conjunto edificado;

- cumprimento às normas, políticas, parâmetros e protocolos nacionais e internacionais de arquivística, biblioteconomia e conservação preventiva de acervos;

- publicação de documentação de referência para outras instituições culturais brasileiras.

Este benchmark demonstra a importância, para a adequada preservação do patrimônio, de haver à disposição da instituiç̧ão um conjunto de recursos: profissionais capacitados na quantidade e nas disciplinas necessárias; edifícios e sistemas adaptados aos usos; e recursos materiais e financeiros. 


\section{b. Os profissionais e a conservação dos acervos}

$0 \mathrm{CeDI}$ possui diversos especialistas arquivistas, bibliotecários e conservadores-restauradores, além de técnicos e auxiliares, responsáveis pela preservação de todos os acervos da instituição. Em 2012 foi instituída a política de preservação do patrimônio cultural da Câmara dos Deputados, que estabeleceu normas e critérios; previu a alocação de recursos para preservação; e definiu projetos para a conservação dos bens. Como parte desta política, ficou a cargo da Coordenação de Preservação de Conteúdos Informacionais o desenvolvimento de ações voltadas à conservação preventiva dos acervos. Assim, foram estabelecidas diretrizes e procedimentos para a identificação e mitigação dos riscos associados aos agentes de deterioração dos acervos. Todas as atividades são orientadas pelas normas nacionais e internacionais. Esta política, para maior efetividade, também incentiva a participação e a cooperação direta de todos os departamentos da Câmara.

Como parte das ações de conservação preventiva, destaca-se o empenho no treinamento dos funcionários e na produção, impressão e distribuição de material didático de conscientização, tanto para o público interno, como para o externo.

Entre 2012 e 2013 foi realizado um diagnóstico de conservação de todos acervos da Câmara, o que permitiu que fossem executadas adaptações nos ambientes, equipamentos e mobiliários visando a maior segurança dos itens.

A gestão do armazenamento e acondicionamento depende de planejamento, comunicação e coordenação das equipes para que as áreas de guarda estejam sempre organizadas, seguras e limpas. As reservas técnicas da Câmara contam com estantes, armários, arquivos e mapotecas, além de equipe treinada para a guarda correta de bens museológicos, arquivísticos e bibliográficos. Como parte do plano de conservação preventiva, foram definidas normas, procedimentos e rotinas para vistoria, manuseio, limpeza, higienização, consulta e visitação. Foi estabelecido também que todos os funcionários da instituição que lidam diretamente com acervos devem receber treinamento adequado, fornecido pela Coordenação de Preservação.

A manutenção predial é realizada em parceria entre as equipes da conservação e da manutenção e consiste em inspeções periódicas e no monitoramento diário das condições ambientais. Toda eventual reforma, em qualquer ambiente da Câmara, deve ser planejada em conjunto entre os dois departamentos para minimizar quaisquer riscos a itens dos acervos (que estão presentes por toda a instituição). 
0 tratamento ambiental dado às áreas de guarda pressupõe o cumprimento das recomendações internacionais para T, UR, luz visível e UV e poluentes. A Câmara possui reservas técnicas isoladas do meio externo e condicionadas por sistemas de climatização independentes, para minimizar a entrada de eventuais poluentes provenientes do meio externo ou de outros ambientes. 0 espaço foi divido em salas com T e UR específicas, conforme as necessidades de cada tipo de suporte. A luz artificial é acionada apenas quando necessária para o manuseio, a organização ou a pesquisa de objetos. Os materiais utilizados no ambiente construído, nos mobiliários e nas embalagens foram escolhidos de modo que gases prejudiciais não sejam liberados nem interajam com os itens. Os parâmetros são constantemente monitorados, não apenas nas áreas de guarda mas em todos os ambientes que possuem acervo. Os objetos são frequentemente vistoriados em um acompanhamento constante do estado de conservação de cada um deles.

A Coordenação de Preservação também é responsável pelo manejo integrado de pragas, que utiliza iscas e 0 monitoramento constante do acervo tendo em vista minimizar o uso de produtos químicos potencialmente nocivos à saúde humana. Novos itens são colocados em quarentena e vistoriados antes de serem introduzidos nas áreas de guarda. Todos os funcionários recebem treinamento sobre a correta gestão do lixo, e devem estar atentos para também educar visitantes e terceirizados quanto às boas práticas.

Existem também ações de treinamento e conscientização sobre as técnicas corretas para o manuseio e o transporte dos objetos, por tipo, e também sobre o controle de acesso aos itens. 0 objetivo é minimizar perdas, danos ou dissociações causados por desinformação, vandalismo ou roubo. Todos os ambientes são monitorados e controlados por câmeras, alarmes, sistemas biométricos e equipes de segurança. Deve-se ressaltar que o CeDI é responsável pela proteção de itens de grande valor histórico e de documentos sensíveis à segurança nacional. A polícia legislativa trabalha em parceria com os conservadores no treinamento e na contenção de ameaças, principalmente na eventualidade de situações de protestos e manifestações.

Os documentos raros, frágeis ou de grande interesse são reproduzidos digitalmente com a finalidade de: facilitar 0 acesso à informação; minimizar o risco de dano ou perda; e reduzir espaço com armazenamento. Dependendo das características de cada item, ele pode ser fotocopiado, microfilmado ou digitalizado.

A maior preocupação dos conservadores é com o risco de incêndio. 0 CeDI guarda grande quantidade de material altamente combustível. 0 plano de emergência, desenvolvido em parceria com 0 
Departamento Técnico prevê equipamentos para detecção e combate a incêndio, treinamento para proteção dos usuários e estratégias para a salvaguarda e a recuperação do patrimônio.

0 último eixo de ação é o de prevenção de acidentes. Dada a grande quantidade de pessoas (funcionários, terceirizados, imprensa, visitantes, e outros) que circulam diariamente pelas instalações da Câmara dos Deputados, acidentes a pessoas e objetos são um perigo constante. As equipes recebem treinamento específico de como supervisionar as pessoas e salvaguardar as coleções.

\section{c. 0 papel de arquitetos e engenheiros}

0 Palácio do Congresso Nacional é um complexo edificado composto por diversos edifícios, os quais estão dividido em duas instituições distintas: o Senado Federal e a Câmara dos Deputados. Cada instituição possui um conjunto completo de secretarias, diretorias, departamentos e coordenaç̧ões responsáveis pela correta execução de um amplo espectro de atividades importantes e sensíveis para 0 país. Sendo assim, a Câmara conta com um Departamento Técnico próprio para a gestão do edifício (manutenção, conservação e adequação de todos os sistemas construtivos), que está subdividido em seis coordenações (de planejamento e gestão; de administração de edifícios; de engenharia de equipamentos; de engenharia de obras; de engenharia de telecomunicações e audiovisual; e de projetos de arquitetura), com equipes de arquitetos e engenheiros especializados na conservação e adequação das facilidades e dos edifícios, tombados pelo IPHAN desde 2007.

Por ter equipes técnicas próprias especializadas, que possuem familiaridade com a instituição, os projetos de componentes e equipamentos adequados a cada função, a manutenção preventiva e corretiva dos sistemas e o cuidado com a preservação dos acervos e das obras de arte se dá de maneira bastante consciente, efetiva e integrada.

5.5.4 Viena (visitas a diversas instituições, ao longo do mês de maio de 2019)

0 Instituto para Conservação e Restauro da Universidade de Artes Aplicadas de Viena (Institut für Konservierung und Restaurierung, Universität für angewandt Kunst Wien) possui grande experiência no ensino, pesquisa e extensão em conservação preventiva, curativa e restauro do patrimônio cultural. Há mais de cinquenta anos trabalha com consultoria e parceria com instituições culturais asiáticas. 0 contato com o Instituto se deu em virtude da experiência deles em consultorias a museus na Índia, um país em desenvolvimento com clima tropical. Por sugestão da diretora, dra. Gabriela Krist, foi feito 
convite para conhecer, como aluna visitante, o trabalho dos conservadores e as características construtivas das principais reservas técnicas de Viena.

0 Instituto é um benchmark para esta pesquisa porque tem um curso de formação em nível superior em conservação e restauração que é referência mundial. A graduação, em período integral, tem duração de cinco anos, e contempla dois dias de aulas teóricas, dois dias de atividades práticas e um dia para apresentação e discussão, pelos alunos, das atividades realizadas na semana anterior (jour fixe1). A turma, de cerca de 15 alunos, é dividida entre os laboratórios (para esculturas, pinturas, vestuários, papéis e metais), onde realizam atividades práticas por um ano (Figura 71). A cada novo ano é feito um rodízio, para que todos os alunos aprendam a trabalhar com todos os suportes. Cada laboratório possui dois conservadores formados que assessoram os alunos. Os objetos utilizados nas atividades práticas de conservação ou restauração são fornecidos por instituições culturais ou por particulares, nacionais ou internacionais, que contratam o Instituto para a prestação do serviço. Os trabalhos se iniciam com o planejamento das atividades (e cálculo do valor do serviço), que é apresentado pelo aluno ao contratante; documentação do objeto; realização das atividades propostas; e documentação das ações. Os objetos mais desafiadores são tratados nos projetos de conclusão de curso. Na pós-graduação, além de objetos, os alunos podem escolher, como estudo de caso, a avaliação, o diagnóstico e a readequação de áreas de guarda. Os alunos, tanto da graduação como da pós-graduação, devem escolher seus objetos de estudo dentre as demandas disponíveis. 0 curso é gratuito mas o pagamento feito pelos contratantes auxilia na manutenção dos laboratórios de alto desempenho (Figura 71).

Figura 71. Vista da fachada principal do Instituto e de um dos andares com laboratórios (de papel e de metal)
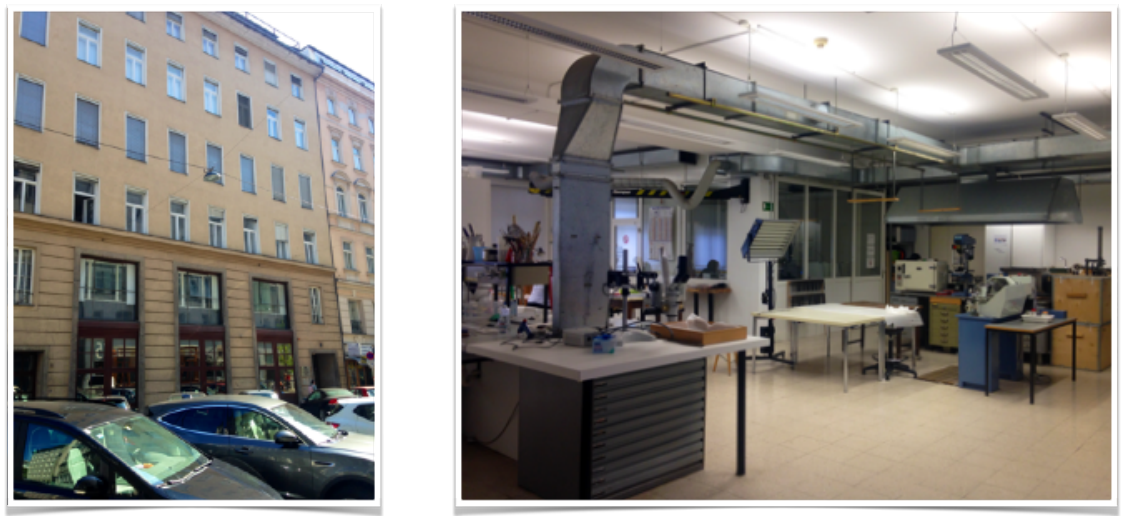

Fonte: a pesquisadora

\footnotetext{
1 Expressão de origem francesa utilizada principalmente no universo corporativo que significa reservar um dia para reuniões periódicas entre equipes para revisar estratégias e ações e discutir alternativas, com o propósito de desenvolver a cultura do encontro.
} 
Segundo os especialistas do Instituto, o curso de conservação e restauro tem por objetivo formar gestores, pessoas capacitadas na elaboração de projetos, coordenação de equipes multidisciplinares e planejamento de ações preventivas e/ou corretivas, seja para objetos individuais, seja para grandes áreas de reserva técnica. 0 Instituto oferece parceria na criação de cursos de mestrado em conservação preventiva, com duração de dois anos, para países em desenvolvimento, como o Brasil.

Durante a estadia em Viena, foi realizada uma visita exploratória à reserva técnica, biblioteca e área expositiva do mosteiro Neukloster, na cidade de Wiener Neustadt, trabalho de doutorado de Johanna Runkel (Figura 72). 0 trabalho se concentrou no diagnóstico das condições de guarda das áreas com acervo e posterior proposição: de mobiliários, embalagens e iluminação artificial mais adequados à preservação dos objetos; de proteção para as janelas com tela solar; e de monitoramento ambiental. Como a construção tinha elevada qualidade (isolamento e inércia térmica), o que mantinha T e UR relativamente estáveis ao longo do ano, recomendou-se que os ambientes fossem apenas moderadamente aquecidos no inverno para evitar que a UR ficasse muito baixa. A presença de equipes de artesãos pedreiros e marceneiros especializados, funcionários do mosteiro, foi essencial para a execução de trabalhos de readequação dos espaços com elevada qualidade técnica. Empresas especializadas em mobiliário para museus e em eletrotécnica para a preservação de acervos também foram importantes para garantir que os equipamentos eram os mais adaptados possível para cada ambiente. 0 maior desafio do trabalho, segundo a autora, foi mudar a cultura dos monges de como manusear e guardar os objetos de modo a preservar suas coleções. Os alunos de graduação participaram da pesquisa restaurando os itens danificados. 
Figura 72. Atividades de conservação propostas para o Neukloster em trabalho de doutorado

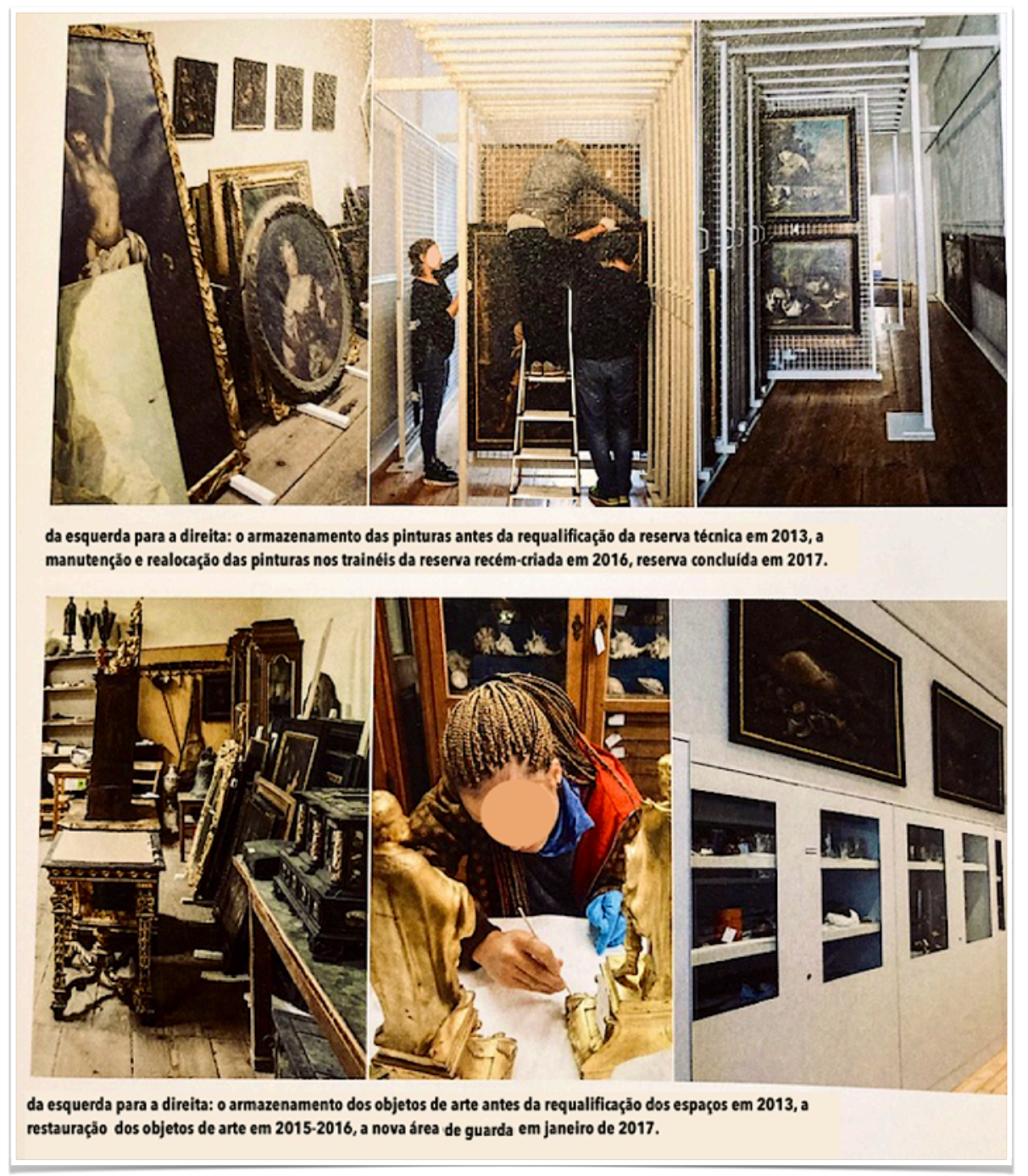

Fonte: traduzido de KRIST e RUNKEL, 2019.

Foi realizada também uma visita à Autoridade dos Monumentos Federais (Bundesdenkmalamt), responsável pelo tombamento do patrimônio austríaco e pela assessoria e fiscalização das obras de construção, reforma ou restauro em edifícios tombados. A Autoridade possui diversos laboratórios para análises fisico-química dos objetos que podem ser contratados por instituições culturais e por particulares para realização de laudos técnicos. Eles trabalham em parceria com o Instituto em atividades de conservação e restauro de bens culturais.

Foram feitas visitas a duas reservas técnicas particulares no entorno (rural) de Viena, acompanhadas por conservadores das instituições que ocupam estas reservas. São edificações com elevada qualidade construtiva e altamente especializadas, projetadas especificamente para a guarda de acervos. Foram planejadas por profissionais especialistas, e utilizam estratégias construtivas visando à segurança dos 
acervos contra os agentes de deterioração. Há uma tendência, entre as grandes instituições culturais de Viena, de alugar reservas técnicas particulares porque vêem nesta solução uma estratégia para ampliar suas áreas de guarda e/ou uma solução menos custosa do que escavar novos subsolos em edifícios históricos no centro da cidade. Estas construções contam com áreas de quarentena, câmara de anóxia ou de congelamento, laboratórios e salas para o trabalho dos conservadores, além de outras estruturas de apoio como copa e cozinha, vestiários e salas para descontração. 0 aspecto negativo é que tanto os bens culturais como os funcionários responsáveis por eles precisam se deslocar muitos quilômetros entre a sede e as reservas técnicas.

Por fim, visitou-se as áreas de guarda de acervos do MAK (Museum für angewandte Kunst), Albertina Museum, Österreichische Nationalbibliothek (Biblioteca Nacional Austríaca) e Österreichisches Staatsarchiv (Arquivo do Estado Austríaco). Estas visitas foram feitas acompanhadas por um conservador responsável pelos acervos. Em comum tem-se que todas as instituições estão localizadas em edifícios históricos (ecléticos ou modernistas) reformados e modernizados. Destes, o MAK, a Biblioteca e o Arquivo possuem reservas técnicas tradicionais, já o Albertina é uma referência neste quesito porque construiu, em 2006, uma reserva técnica completamente isolada - sem oxigênio, livre de luz, pó ou insetos - e manipulada exclusivamente por dois robôs (controlados por técnicos a partir de uma sala de comando). Segundo testemunho de um diretor, a solução foi avaliada como muito positiva, e uma nova reserva técnica, com a mesma tecnologia, será construída futuramente, para itens que ainda estão em reservas técnicas tradicionais (solução que vai na direção contrária à do aluguel de reservas técnica particulares). As principais características observadas durante as visitas foram:

- excelente qualidade construtiva (estanqueidade, robustez) e, mesmo quando em vários andares abaixo do nível do solo, muito poucas manifestações patológica;

- ambientes totalmente climatizados e iluminados artificialmente;

- grande diversidade de tipos de mobiliários e embalagens para o adequado acondicionamento dos objetos;

- reservas técnicas muito grandes mas sempre subdivididas em áreas menores, separadas por paredes estanques e portas corta-fogo;

- múltiplas portas de acesso com elementos para vedação de frestas, protegidas por alarme e sistemas biométricos, com autorização restrita; 
- sistemas para detecção e combate a incêndio, plano de emergência com identificação dos itens prioritários e treinamento em parceria com o corpo de bombeiros responsável pela área;

- uso de variadas estratégias (vedações, iscas, luz UV, fitas adesivas, etc.) para o manejo integrado de pragas (segundo os conservadores, esta é a maior ameaça aos acervos das suas instituições); não é permitido o uso de produtos químicos para dedetização;

- planejamento estratégico: as soluções são pensadas para serem definitivas, robustas e confiáveis;

- diretores especialistas nomeados para mandatos longos (cinco anos ou mais);

- gestão especializada dos recursos institucionais (parcerias público-privada);

- funcionários próprios especialistas para todos os setores, incluindo a conservação preventiva e a gestão das facilidades e da manutenção;

- terceirização das atividades não essenciais (como limpeza, manutenção), o que foi avaliado pelos conservadores como um ponto negativo, porém inevitável.

Diversos profissionais - dos museus, bibliotecas e arquivos visitados - quando perguntados sobre a excelente qualidade construtiva das áreas de guarda, explicaram que, após a Segunda Guerra Mundial, os acervos estavam em condições muito ruins e inúmeros documentos foram perdidos. 0 país decidiu, então, criar leis, normas e protocolos para elevar o desempenho destes ambientes. Instituiu-se uma cultura de planejamento estratégico de longo prazo, com metas bem definidas, tendo por objetivo se construir uma única vez, para durar o máximo de tempo possível. Em todas as instituições visitadas os funcionários tinham clareza de quais eram as metas de reforma ou ampliação previstas para a(s) próxima(s) década(s) e qual o calendário de atividades que cada um precisaria cumprir. Os funcionários pareciam estar bastante relaxados pois muitas das atividades institucionais estavam definidas com antecedência e, segundo relataram, não era comum terem de lidar com incertezas ou tarefas inesperadas. Além disso, o país investe muito na formação, em nível médio ou superior, dos técnicos da construção civil. Para que a pessoa possa ser considerada habilitada a realizar qualquer atividade, ela precisa passar por uma avaliação e receber um certificado de capacidade técnica. Por fim, as instituições culturais relataram que procuram equilibrar as vantagens da flexibilidade de serviços terceirizados, contratados por atividade ou projeto, com uma equipe técnica própria, diversificada e especializada, formada por servidores públicos que tendem a permanecer ao longo de toda a sua vida profissional na mesma instituição. 
5.5.5 Berlim (visitas a diversas instituições, ao longo dos meses de setembro a dezembro de 2019)

0 Laboratório de Pesquisa Rathgen (Rathgen-Forschungslabor) é o instituto responsável por realizar análises fisico-químicas e biológicas e por auxiliar os conservadores de todas as instituições sob comando da Fundação para o Patrimônio Cultural Prussiano (Stiftung Preußischer Kulturbesitz - SPK) no planejamento de ações para a conservação preventiva dos acervos dos museus, bibliotecas e arquivos estatais em Berlim. 0 Laboratório Rathgen disponibiliza duas bolsas de curta duração por semestre para pesquisadores estrangeiros que desenvolvam trabalhos relacionados à conservação preventiva de acervos (Figura 73). 0 interesse nesta bolsa de estudos, e no SPK como benchmark para esta pesquisa, se deve à sua estrutura organizacional, semelhante à observada na cidade de São Paulo, ou seja, uma única entidade que congrega múltiplos institutos e departamentos, cada um responsável por uma parte das funções institucionais, e que precisa salvaguardar inúmeros acervos muito valiosos.

Figura 73. Edifício onde se localiza o Laboratório Rathgen e sala de pesquisa para bolsistas no Laboratório
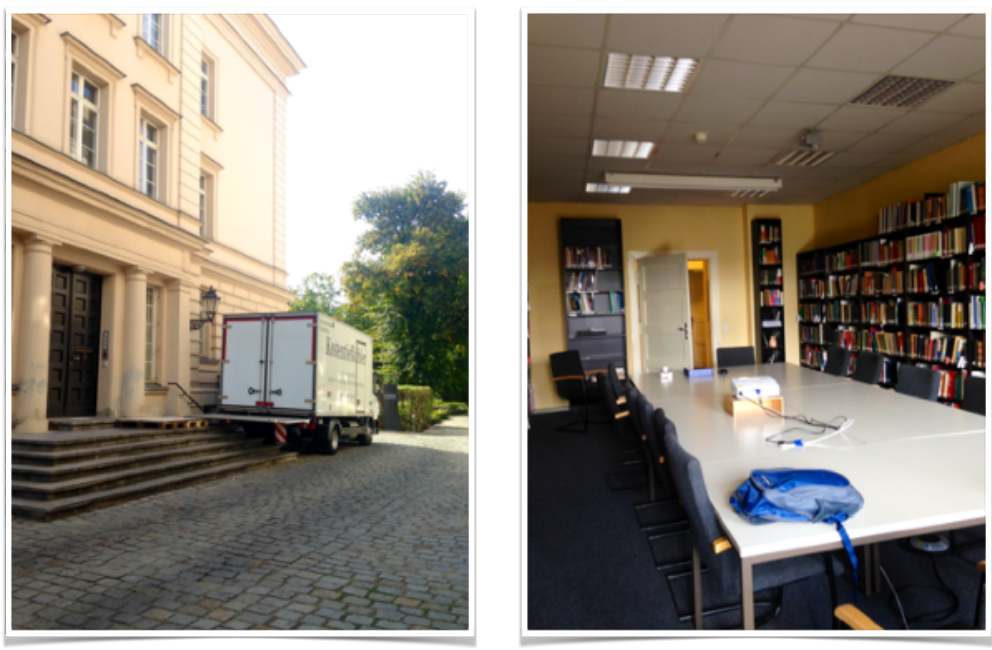

Fonte: a pesquisadora

A bolsa de pesquisa tinha por objetivo visitar as reservas técnicas de instituições culturais do SPK para inspeção visual do ambiente construído, e realização de consultas a conservadores, curadores, arquitetos, engenheiros e gestores sobre o desempenho das áreas de guarda e as estratégias utilizadas na mitigação dos riscos. Em contra-partida, os funcionários do Laboratório tinham interesse em receber informações sobre a abordagem da Avaliação Pós-Ocupação (APO), método ainda desconhecido por eles.

O SPK é uma Fundação que responde diretamente ao governo central alemão e recebe financiamento de todos os dezesseis estados da federação. Sua estrutura é muito grande, e inclui diversos museus, 
bibliotecas, arquivos e centros de pesquisa, organizados em cinco entidades: o Staatliche Museen zu Berlin (Museus Nacionais em Berlim), a Staatsbibliothek zu Berlin (Biblioteca Estatal em Berlim), o Geheimes Staatsarchiv (Arquivos Secretos do Estado da Prússia), o Ibero-Amerikanisches Institut (Instituto Ibero-Americano) e o Staatliches Institut für Musikforschung (Instituto Estatal para Pesquisa Musical). Seu organograma é bastante complexo e inclui mais de 2.000 funcionários próprios, além de inúmeros terceirizados. 0 planejamento estratégico da Fundação também é muito extenso, complexo e prevê metas para os próximos 50 anos. Há consciência institucional de que ainda existem muitos pontos a serem aprimorados mas os desafios estão principalmente relacionados ao fato de que parte dos institutos pertenciam à Alemanha Ocidental e a outra parte à Alemanha Oriental. Faz apenas 30 anos (desde a unificação em 1990), que se está construindo a integração e a uniformização entre elas. As instituições pertencentes ao SPK visitadas com o acompanhamento de um funcionário responsável foram: Bode-Museum, Neues Museum, Ethnologisches Museum, Archäologisches Zentrum, Kupferstichkabinett, Ibero-Amerikanisches Institut, Staatsbibliothek, Geheimes Staatsarchiv, e Bundesarchiv. Os principais aspectos observados durante as visitas e conversas foram:

- muita variedade construtiva: alguns edifícios já foram reformados e modernizados, outros ainda não. As áreas de guarda visitadas tinham em comum amplas dimensões (ainda com espaços para 0 crescimento dos acervos), subdivididas em ambientes menores, isolados por portas corta-fogo;

- muitas instituições possuem acervos divididos em mais de um endereço e é frequente a circulação de objetos e conservadores entre bairros da cidade. Por outro lado, o SPK possui imóveis suficientes para não precisar alugar reservas técnicas particulares;

- há um plano para restauro, reforma e/ou ampliação de todos os principais edifícios do SPK. Alguns projetos já foram executados (James-Simon-Galerie, Neues Museum, Humboldt Forum), alguns estão em andamento (Neue Nationalgalerie, Pergamonmuseum), outros estão sendo feitos por etapas (Staatsbibliothek) e outros estão na 'fila de espera' (Alte Nationalgalerie, Bode-Museum, Altes Museum, etc.). Os edifícios mais relevantes tiveram projeto de modernização escolhido por concurso de arquitetura, isso porque o objetivo do SPK era atrair arquitetos de renome e desenhos de impacto como mecanismo para atração turística. No entanto, os conservadores consultados relataram alguns aspectos negativos desta estratégia: o projeto já vem pronto, de cima para baixo; os arquitetos não são especialistas em acervos; gasta-se muito tempo e energia para se negociar adaptações ao projeto que 
garantam a segurança dos objetos e as condições necessárias à execução das atividades de conservação; os erros não são registrados e é frequente que uma solução pouco adequada (como o tipo de material ou tipo de mobiliário especificado, etc.) seja repetida;

- todos os projetos de reforma e manutenção são feitos por um órgão central, o Escritório Federal para Construção e Planejamento (Bundesamtes für Bauwesen und Raumordnung - BBR); toda a gestão das facilidades é feita por outro órgão, a Agência Federal para Tarefas Imobiliárias (Bundesanstalt für Immobilienaufgaben - BImA). Esta forma de organização foi motivo de algumas críticas por parte dos conservadores consultados porque: os profissionais (arquitetos e engenheiros) nem sempre estão completamente familiarizados com cada uma das instituições; há muita rotatividade de funcionários e a instituição nem sempre é atendida pelo mesmo profissional; o tempo de resposta pode ser longo já que é preciso entrar em uma fila de atendimento; o planejamento e a priorização das obras são decisões tomadas em instâncias superiores e os conservadores nem sempre são consultados; na maioria das vezes, as manutenções são corretivas, após a identificação de uma anomalia ou falha;

- o SPK possui muitos especialistas, em todas as áreas do conhecimento, no entanto, por ser uma estrutura muito grande e complexa, altamente hierarquizada, a comunicação foi apontada por alguns conservadores como um dos pontos a ser melhorado. Os profissionais da conservação, segundo eles, ainda não são totalmente reconhecidos como parte fundamental na tomada de decisões;

- segundo alguns funcionários, há uma política de redução dos funcionários próprios e substituição por terceirizados contratados por projeto, com consequente diminuição da quantidade de pessoas por setor e redução da capacidade de se realizar atividades preventivas em acervos muito numerosos. Os projetos (para higienização, conservação e/ou restauro de grandes quantidades de itens) foram considerados muito importantes já que uma parte significativa dos acervos ainda apresenta danos, consequência da Segunda Guerra Mundial e posterior período soviético;

- a maioria dos arquitetos e engenheiros que trabalham com áreas de guarda para acervos se especializaram na prática pois não existem cursos de formaç̧ão voltados para o tema (apenas congressos, encontros, etc.). Por outro lado, o cumprimento às leis e normas; 0 atendimento às boas práticas; a especificação de materiais, componentes e equipamentos robustos; o detalhamento cuidadoso do projeto; e a simulação energética são práticas correntes, adotadas por todo o setor da construção civil, cujo impacto é bastante positivo no patrimônio cultural. Existem também conservadores que fizeram 
dupla formação em arquitetura e prestam consultoria para as empresas de projeto. A contratação de consultores é prática corrente no setor público alemão (como é o caso do SPK);

- elevada qualidade construtiva (os atributos mais importantes, segundo os arquitetos e engenheiros consultados, são que os sistemas sejam robustos e confiáveis), no entanto, algumas manifestações patológicas foram observadas nos edifícios não reformados, principalmente rachaduras, trincas, destacamentos e infiltrações (ainda consequência do período soviético, quando as manutenções, segundo relatos, eram feitas com material e mão-de-obra de muito baixa qualidade), mas todas as manifestações estavam sendo monitoradas por engenheiros e os edifícios estavam na 'fila de espera' para a reforma e/ou o restauro;

- as áreas de guarda modernizadas utilizam condicionamento e iluminação artificial mas muitos edifícios históricos não reformados fazem uso apenas de aquecedores no inverno associados a umidificadores portáteis. Pode haver incidência de luz natural indireta em algumas salas. Percebe-se flutuações na T e UR destes ambientes, mas elas são minimizadas pela elevada inércia / isolamento térmico das paredes e pela boa qualidade / estanqueidade dos caixilhos;

- o manejo integrado de pragas é obrigatório e os profissionais responsáveis (do Laboratório Rathgen) devem aprovar quaisquer projeto de construção ou reforma no que tange à segurança do edifício contra microorganismos e insetos (traças e mariposas são as principais ameaças aos acervos berlinenses, principalmente papéis e tecidos); o controle é feito mediante emprego de variadas estratégias sem o uso de venenos (proibidos por lei);

- tanto os laboratórios centrais como as instituições de grande porte possuem câmeras de anóxia (tratamento mais demorado porém mais versátil) e/ou de congelamento (mais rápido mas apenas para alguns materiais) para controle de infestações por pragas;

- os mobiliários expositivos (vitrines, caixas, mesas, gavetas, etc.) são padronizados, pertencem ao SPK, e são distribuídos entre as instituições conforme a necessidade de cada exposição;

- muitas áreas de guarda possuem mobiliários históricos, projetados como parte da estrutura do edifício e, ainda que não tenham os melhores atributos, não podem ser substituídos;

- todas as reservas técnicas possuem detectores de fumaça, alarme e extintores, mas o SPK não considera seguro o uso de sprinklers nas áreas de guarda de acervos. A política institucional inclui manutenção cuidadosa de todos os sistemas elétricos, treinamento dos funcionários para o caso de 
uma evacuação e parceria com o corpo de bombeiros (incêndio) e a polícia local (ataque terrorista) para atendimento rápido em caso de emergência;

- na Alemanha não existe legislação específica que regulamente a profissão do conservador (assim como no Brasil) e é frequente que os profissionais tenham graduação em outras áreas do conhecimento. Por outro lado, existem ofertas de cursos de pós-graduação em conservação e restauro ou em conservação preventiva (menos procurado). Foi relatado que muitos profissionais ainda preferem trabalhar com atividades curativas ('de bancada') do que preventivas (de gestão).

A combinação de edifícios históricos muito bem construídos, leis, normas e regras de construção claras e amplamente utilizadas, e profissionais especializados se mostrou suficiente para que as áreas de guarda de acervos resistam às ameaças externas e mantenham um ambiente interno suficientemente seguro para o acervo, enquanto aguardam por modernizações. A visão estratégica do SPK, de muito longo prazo, bem como uma política continuada de reforma e readequação de todos os edifícios é uma oportunidade, tanto do ponto de vista econômico (gera empregos), quanto científico (estimula o desenvolvimento de técnicas e tecnologias).

Um grupo de estudo da Faculdade de Arquitetura da Universidade de Munique (Fakultät für Architektur, TUM), assim como o Instituto Fraunhofer, vêm utilizando potentes softwares de simulação energética para explorar alternativas que utilizam técnicas passivas (energia geotérmica, ar frio do subsolo, etc.) combinadas a sistemas ativos de alta eficiência para garantir o desempenho e a estabilidade de ambientes de guarda e/ou expositivos e tornar os edifícios culturais menos dependentes da rede elétrica. Alguns dos resultados encontrados estão, aos poucos, sendo incorporados aos novos projetos de SPK, dentro do programa "green museum".

\subsection{CASOS DE ESTUDO}

\subsubsection{Caracterização climática da cidade de São Paulo}

A cidade de São Paulo encontra-se na latitude $-23,548^{\circ}$, longitude $-46,636^{\circ}$ e à $749 \mathrm{~m}$ de altitude (com variação de \pm 65 metros). Do total de sua área urbana, 99\% é coberta por superfícies artificiais.

0 clima caracteriza-se por um verão morno, com precipitações e céu predominantemente encoberto, e um inverno fresco, com temperaturas amenas e céu parcialmente encoberto. A temperatura média, ao longo do 
ano, varia entre $13^{\circ} \mathrm{C}$ e $28^{\circ} \mathrm{C}$, raramente atingindo mínimas inferiores a $10^{\circ} \mathrm{C}$ ou máximas superiores a $32^{\circ} \mathrm{C}$. A amplitude média diária é de cerca de $8^{\circ} \mathrm{C}$ e a amplitude média anual é de $7^{\circ} \mathrm{C}$ (Figura 74 ).

As temperaturas máximas e mínimas médias, ainda que dentro da faixa recomendada pelo Heritage Collections Council $(\mathrm{HCC})$ para climas quentes e úmidos $\left(22^{\circ} \mathrm{C}\right.$ a $28^{\circ} \mathrm{C}$, ver maiores informações no Capítulo 2), são favoráveis ao incremento de reações químicas e ao desenvolvimento de pragas e microorganismos, o que eleva o risco de degradação de objetos. A elevada amplitude diária, se transferida para o acervo em papel, pode acelerar reações químicas bem como processos físicos de dilatações e retrações desiguais, com potencial estresse e fadiga de materiais. A suave amplitude térmica anual não é um risco significativo para a maioria dos objetos.

Figura 74. Temperatura média diária para o ano de 2020 (estação INMET Interlagos)

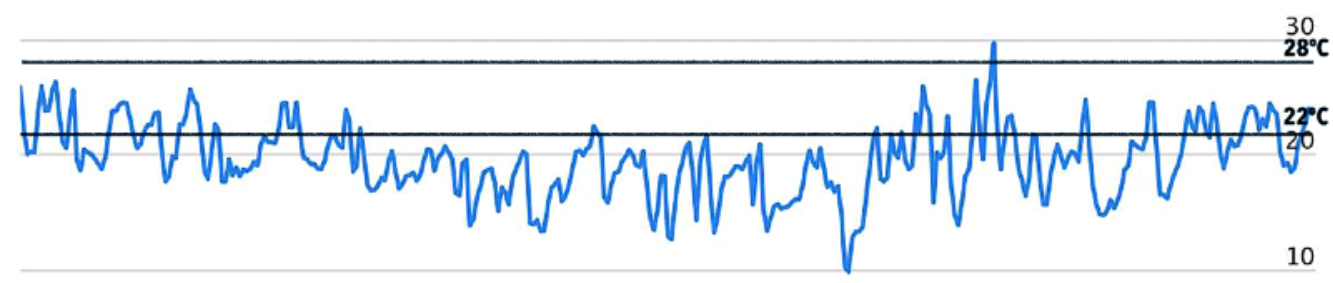

\begin{tabular}{|lll|l|l|l}
\hline Jan '20 Mar'20 Mai'20 Jul'20 & Set'20
\end{tabular}

Fonte: INMET, 2021.

Tanto os valores absolutos como a variação diária e anual da umidade relativa em São Paulo são elevados. 0 período mais úmido do ano dura 5,6 meses, de novembro a abril. 0 período mais seco é de 6,4 meses, de meados de abril ao final de outubro (Figura 75).

Valores acima do recomendado para maior parte do tempo (o HCC recomenda, para climas quentes e úmidos, valores entre 55\% e 70\% de UR), variações drásticas, e UR que pode cair para níveis muito baixos no inverno, são condições extremamente prejudiciais para acervos com suporte em papel, podendo acelerar processos de degradação tanto físicos (dilatações e retrações, amolecimentos e ressecamentos), quanto químicos (hidrólise) ou biológicos (infestações por pragas e microorganismos). 
Figura 75. Umidade Relativa média diária para 0 ano de 2020 (estação INMET Interlagos)
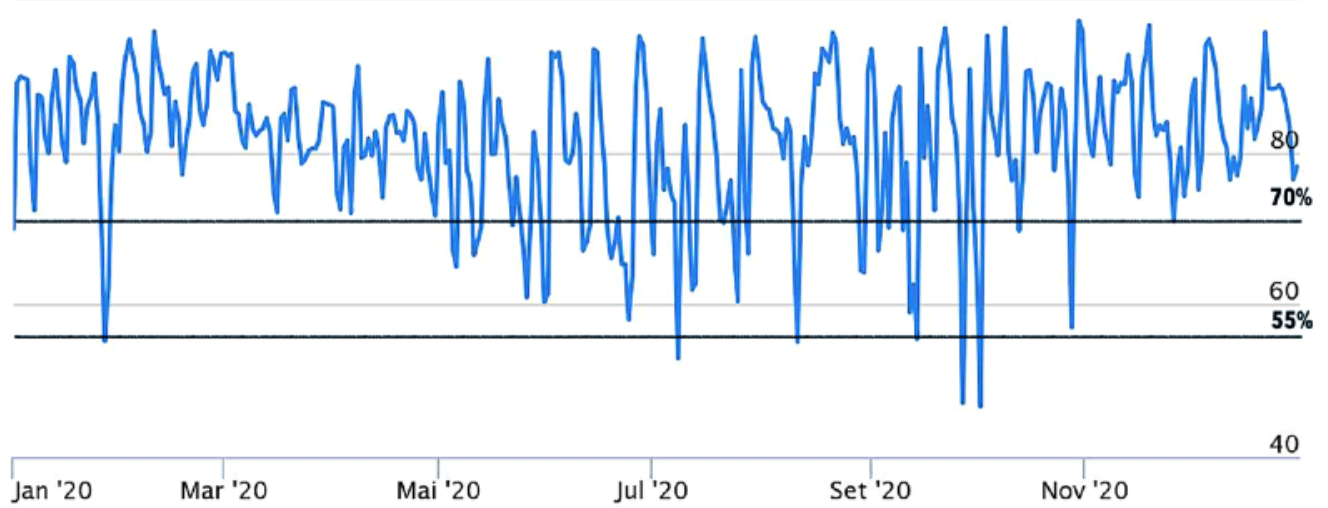

Fonte: INMET, 2021.

Quando a precipitação diária é igual ou superior a $1 \mathrm{~mm}$, considera-se que houve chuva naquele dia. Em São Paulo, a estação chuvosa dura 5,5 meses, de meados de outubro ao final de março, com probabilidade maior do que 42\% de haver precipitação. A estação seca tem 6,5 meses, de abril a outubro (Figura 76).

Figura 76. Probabilidade diária de precipitação (1980 -2016)

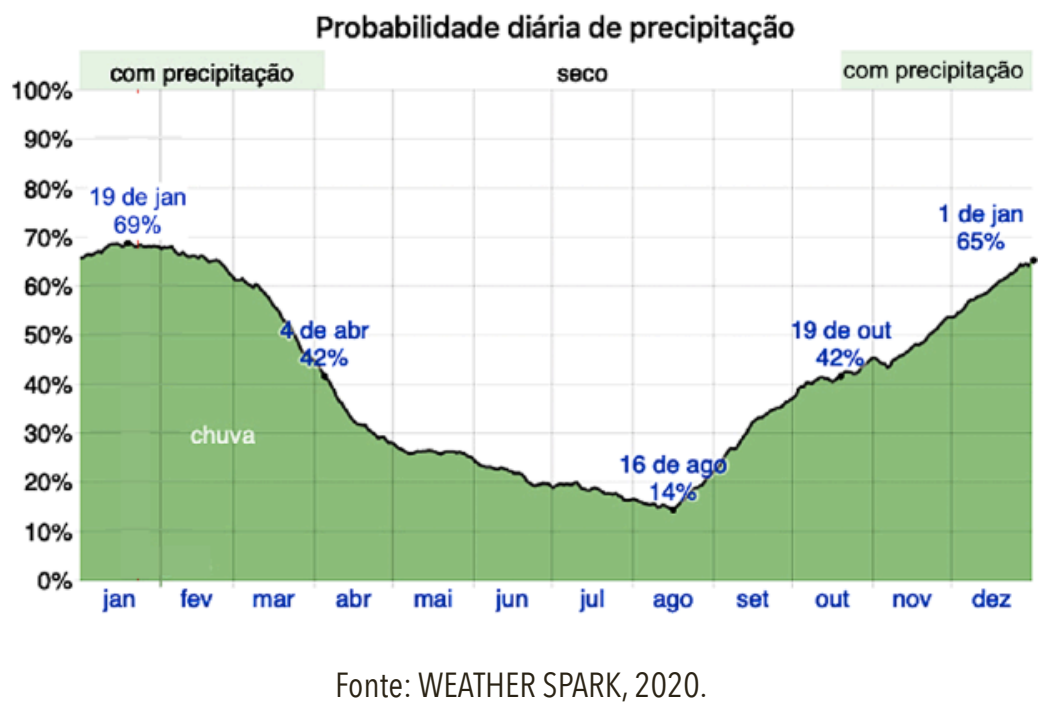

A precipitação acumulada ao longo do mês anterior, para cada dia do ano, tem variação sazonal extrema, com valores máximos ao redor do final de janeiro (acumulado médio mensal de $221 \mathrm{~mm}$ ), e mínimos por volta do início de agosto (acumulado médio mensal de $37 \mathrm{~mm}$ ).

A chuva, em São Paulo, está diretamente relacionada a T e UR elevadas, condição desfavorável para objetos em papel. Além disso, as chuvas de verão, com frequência, acontecem na forma de fortes pancadas ou temporais, o que eleva o risco de danos ao acervo por água, seja por causas naturais, como enchentes, ou humanas, como falhas na manutenção do sistema de drenagem. 
A cidade está localizada sob o Trópico de Capricórnio. Por isso, a quantidade de horas com luz solar é elevada e não varia muito ao longo do ano. Em 2020, o dia mais curto foi 20 de junho, com 10 horas e 41 minutos de luz solar e o dia mais longo foi 21 de dezembro, com 13 horas e 35 minutos (Figura 77).

Figura 77. Horas de luz solar

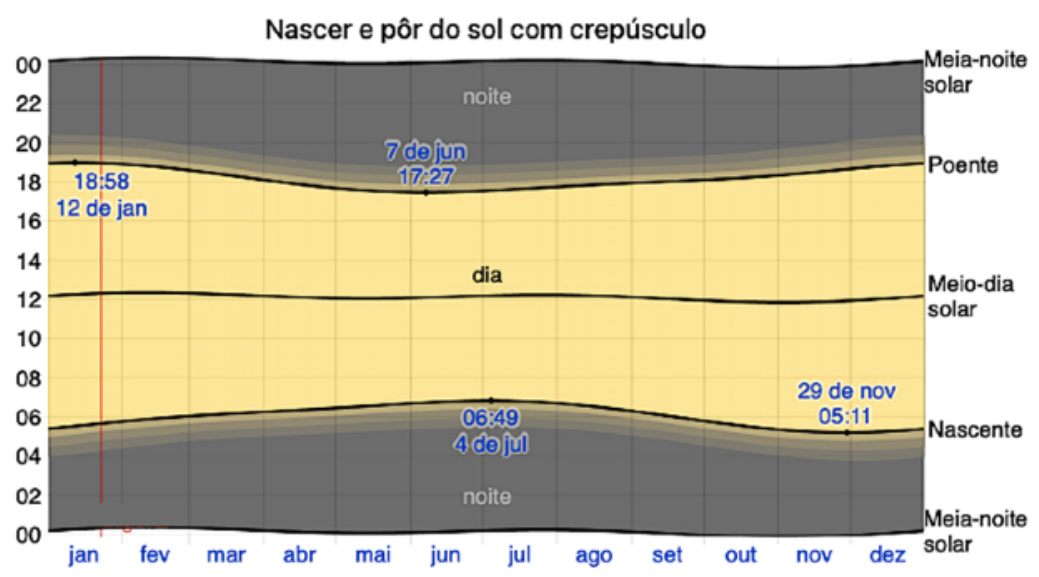

Fonte: WEATHER SPARK, 2020.

A porcentagem média de céu encoberto por nuvens sofre significativa variação sazonal ao longo do ano. A época com céu menos encoberto começa no final de março e vai até outubro, com cerca de 6,5 meses. 0 período do ano mais encoberto se inicia por volta do início de outubro e dura 5,5 meses, até março.

A energia solar incidente diária média passa por variações sazonais moderadas ao longo do ano. 0 período com mais radiação dura 2,8 meses, de meados de outubro ao início de janeiro, com média diária acima de 6,0 kWh/m² dia. 0 período mais escuro do ano tem 2,6 meses, do início de maio ao final de julho, com média diária inferior a 4,3 kWh/m² dia (Figura 78).

Da radiação solar total acima da atmosfera terrestre, 38,9\% está na faixa da luz visível, 52,8\% é radiação infravermelha e 8,3\% é radiação ultravioleta. Esta radiação é bastante atenuada por moléculas (oxigênio, ozônio, nitrogênio) e partículas (água, aerossóis, poeira) presentes na atmosfera. No entanto, pesquisas em seres humanos indicam que esta atenuação atmosférica, no sudeste brasileiro, não é suficiente para proteger a pele humana dos danos provocados pela radiação UV em nenhuma condição de céu (SILVA, 2010). Assim, ainda que não existam pesquisas específicas para acervos com suporte em papel na cidade de São Paulo, recomenda-se muita atenção à interação da luz natural com as coleções, mesmo em dias nublados. Recomenda-se também não utilizar iluminação natural (horizontal ou vertical) direta, ou pela cobertura (zenital) direta ou indireta. 
Figura 78. Radiação solar de ondas curtas, média diária (1980 -2016)

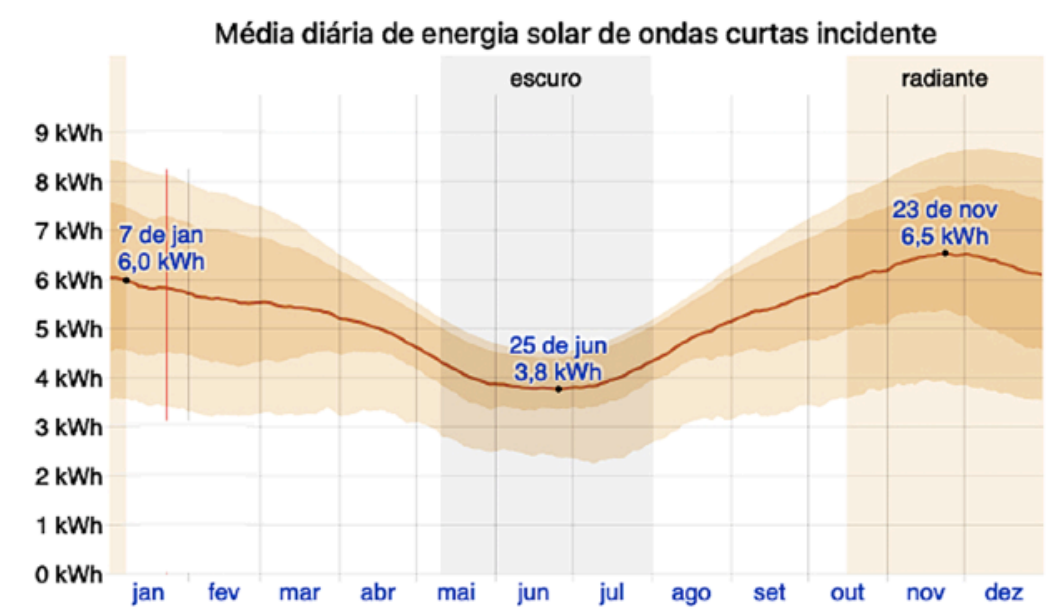

Fonte: WEATHER SPARK, 2020.

0 vetor médio horário de vento (velocidade e direção), medido a 10 metros acima do solo, é dependente da topografia local e de outros fatores. A velocidade horária média, para São Paulo, sofre pequenas variações sazonais. A época com mais ventos dura 4,3 meses, do final de agosto ao final de dezembro, com velocidades médias acima de $12,3 \mathrm{~km} / \mathrm{h}$. A época mais calma do ano tem 7,7 meses, do início de janeiro ao final de agosto. Os ventos são predominantemente de sudeste-leste para maior parte do ano (cerca de 10 meses).

São Paulo é uma cidade muito poluída, tanto por gases como por particulados. Os extensos períodos de calmaria fazem com que estes poluentes fiquem em suspensão sobre a malha urbana, contribuindo para a baixa qualidade do ar. Os compostos de nitrogênio, enxofre e carbono presentes no ar estão diretamente relacionados a danos por reações de acidificação e hidrólise ácida do papel.

\subsubsection{Considerações sobre as mudanças climáticas}

Não existem muitas mega cidades na mesma latitude de São Paulo. E a razão para isso é que, por causa do movimento de rotação da Terra, os trópicos são zonas de alta pressão, ou seja, de correntes de ar divergentes, o que resulta em menor umidade, menos chuva e maior propensão à formação de desertos. A excessão à regra, no hemisfério sul, são Brasil e Paraguai pelo efeito dos "rios aéreos" vindos da Amazônia. 0 desmatamento da floresta amazônica pode, potencialmente, levar à desertificação de boa parte do sudeste e centro-oeste brasileiro (NOBRE et al., 2011). 
A mudança climática global já é consenso entre os cientistas. A dúvida que ainda persiste é quanto à velocidade e à intensidade dos fenômenos climáticos que a humanidade enfrentará ao longo do século XXI (IPCC, 2020).

0 estudo interdisciplinar realizado por Nobre e outros (2011) para a Região Metropolitana de São Paulo (RMSP) procurou identificar os perigos e os impactos das mudanças climáticas para 2030 (Figura 79), e estimou que:

- a mancha urbana será aproximadamente 38\% maior, o que aumentará o risco de desastres naturais como enchentes, inundações e deslizamentos de encostas;

- se a expansão urbana acelerada permanecer desacompanhada da respectiva infraestrutura, a RMSP não estará preparada para os efeitos das mudanças climáticas;

- as temperaturas médias aumentarão gradualmente (até 2100 ) em 2 a $3^{\circ} \mathrm{C}$, com consequente aumento de:

- frequência e intensidade de chuvas intensas, com maior ocorrência de alagamentos;

- possibilidade de vendavais e granizos;

- intensidade e duração das ondas de calor;

- quantidade de dias muito secos;

- haverá elevação das taxas de poluentes na atmosfera, com severas consequências à saúde humana.

Figura 79. Sumário das projeções de mudanças climáticas para a RMSP

\begin{tabular}{|c|c|c|c|c|c|c|c|}
\hline & $\begin{array}{c}\text { Presente } \\
\text { Observado }\end{array}$ & $2030-40$ & Conf. & $2050-60$ & Conf. & 2080-90 & Conf. \\
\hline Temperatura & & & Alta & & Alta & & Alta \\
\hline Noites quentes & & & Alta & & Alta & & Alta \\
\hline Noites frias & & & Alta & & Alta & & Alta \\
\hline Dias quentes & & & Alta & & Alta & & Alta \\
\hline Dias fríos & & & Média & & Alta & & Alta \\
\hline Períodos quentes & & & Média & & Média & & Alta \\
\hline Ondas de calor & & & Média & & Média & & Alta \\
\hline Chuva total & & & Alta & & Alta & & Alta \\
\hline Chuva intensa & & & Média & & Média & & Alta \\
\hline $\begin{array}{l}\text { Precipitação > 95 } \\
\text { percentil }\end{array}$ & & & Média & & Média & & Alta \\
\hline $\begin{array}{l}\text { Dias com Precicpitação } \\
>10 \mathrm{~mm}\end{array}$ & & & Média & & Média & & Alta \\
\hline $\begin{array}{l}\text { Dias com } \\
\text { Precicinitacão }>20 \mathrm{~mm}\end{array}$ & & & Média & & Média & & Média \\
\hline Dias secos consecutivos & & & Média & & Méedia & & Alta \\
\hline
\end{tabular}

Quadro1: Sumário das projeções climáticas derivadas do modelo regional Eta-CPTEC $40 \mathrm{~km}$ para a RMSP, cenário A1B. A confiabilidade é definida qualitativamente, baseando-se na consistência entre as tendências das mudanças projetadas pelo modelo Eta CPTEC e pelos modelos globais do IPCC AR4 apresentados por Tebaldi et al (2006) e Vera et al (2006), para o cenário A1B e pelos cenários climáticos futuros produzidos por modelos regionais para o Sudeste do Brasil (Marengo et al. 2009 a, b). A análise para o presente é baseada nos estudos observacionais que cobrem períodos que variam entre $1960 \mathrm{e}$ 2005 (Dufek e Ambrizzi 2007, Haylock et al 2006, Marengo 2007, Obregón e Marengo 2007, Marengo et al (2009a, c). 
Todos os efeitos das mudanças climáticas na RMSP têm impacto direto sobre a segurança de edifícios históricos e seus acervos. Por hora, a maioria das equipes das instituições culturais paulistanas ainda não estão preparadas, nem para a mitigação dos risco, nem para agir em uma situação de emergência. 0 acompanhamento dos relatórios climáticos anuais fornecidos pelas agências de monitoramento do clima são fundamentais para entender as tendências e planejar ações preventivas.

\subsubsection{As interrelações entre edifícios históricos e áreas de guarda de acervos}

Edifícios com mais de cem anos (anteriores a 1920) muito provavelmente foram construídos com materiais naturais. Edifícios com mais de duzentos anos (pré 1820) certamente foram construídos com materiais naturais. Isto significa que suas estruturas e vedações são feitas de pedras, barros, cerâmicas e/ou madeiras, provavelmente unidos e/ou revestidos por uma massa a base de cal. Estas construções são conhecidas como edifícios de pedra e cal. A cal hidratada ( $\mathrm{CaOH})$ é um material de construção com características específicas: ele é macio e flexível quando aplicado e vai endurecendo $\left(\mathrm{CaOH} \rightarrow \mathrm{CaCO}_{3}\right)$ ao longo da sua vida útil pela contínua e permanente substituição de moléculas de água por moléculas de gás carbônico. Assim, edifícios construídos com esta técnica obrigatoriamente precisam ser mantidos 'ao natural': permeáveis ao vapor d'água e naturalmente ventilados, preferencialmente por ventilação cruzada.

As estruturas de pedra e cal possuem muitas qualidades quando comparadas às estruturas contemporâneas de concreto, como maior adaptação a esforços e menor propensão a trincas e quebras, maior durabilidade, maior sustentabilidade em todo o seu ciclo de vida, melhor qualidade ambiental para a saúde humana, dentre outros aspectos. Nikhil Joshi, professor da National University of Singapore e especialista em edifícios de pedra e cal, em palestra ao INTACH (Indian National Trust for Art and Cultural Heritage), em 21 de agosto de 2020, afirmou que, em se tratando da manutenção de edifícios históricos, "a longo prazo, a cal atribui qualidades à edificação e o cimento causa problemas porque as edificações de cal estão vivas, respiram, já as de concreto, são como um cadáver em decomposição". No entanto, estas características nem sempre são as mais favoráveis para as demandas ambientais de preservação de coleções.

Além disso, toda a metodologia para a conservação preventiva de acervos está fundamentada em uma percepção empírica muito antiga de que objetos guardados em locais completamente isolados, como cavernas ou subsolos de igrejas e castelos, ou enterrados, são aqueles que perduram por mais tempo. 
0 princípio associado a esta ideia é que estes ambientes mantêm UR e T estáveis aos longo dos anos, sem incidência de luz solar direta e com pouco contato com materiais contaminantes (em alguns casos, até mesmo uma camada de pó ou de líquen, apesar de causar algum dano superficial, protege 0 objeto de outros processos de degradação). Assim, as teorias modernas de conservação preventiva recomendam que os objetos sejam guardados em salas e/ou armários que, na medida do possível, reproduzam artificialmente estas condições 'ideais'.

Porém, é importante perceber que estas características nem sempre se harmonizam com as necessidades de preservação de um edifício de pedra e cal. 0 acervo precisa de temperaturas baixas e umidade relativa constante. 0 edifício precisa respirar e 'trabalhar' em harmonia com as flutuações do clima externo. Para se alcançar T e UR constantes, os ambientes de guarda precisam estar completamente isolados do meio externo, o que implica no uso combinado de barreiras ao vapor, isolantes térmicos e condicionamento artificial do ar. Os edifícios históricos, se submetidos à esta condição rapidamente se degradam ao ponto de se transformarem em ruína. 0 acervo precisa estar, o máximo possível, isolado de fontes de contaminação do ar. 0 edifício histórico demanda ventilação natural (cruzada e por efeito chaminé). 0 acervo deve estar o máximo possível protegido da luz solar. Edifícios históricos fazem uso da luz natural como estratégia germicida e como fonte para armazenamento de calor em sua massa. 0 acervo precisa estar em um ambiente com baixa quantidade de vapor d'água no ar para reduzir a velocidade de reações químicas que degradam os materiais. Edifícios de pedra e cal precisam permitir que os fluxos de vapor d'água percorram sua estrutura e evaporem naturalmente, pois a pressão do vapor retido no seu interior causa danos a materiais e componentes.

Assim, as instituições que precisam garantir uma boa qualidade ambiental interna para a guarda de acervos e, simultaneamente, precisam assegurar a preservação de edifícios históricos devem considerar que:

a. a preservação simultânea do edifício e do acervo é possível mas depende de minuciosa avaliação das características locais, dos riscos envolvidos e das alternativas projetuais para compatibilizar as necessidades próprias de cada patrimônio.

b. muitas vezes o acervo não está nas condições ambientais preconizadas pelos órgãos de proteção ao patrimônio, mas uma avaliação especializada do seu estado de conservação conclui que os processos de deterioração são muito leves. Ainda não existe consenso científico a esse respeito, mas alguns cientistas levantaram a hipótese de que acervos, principalmente aqueles com materiais orgânicos, têm 
a capacidade de se adaptarem, entrando em equilíbrio com o meio. Existem relatos empíricos de que uma brusca mudança (sem o devido processo de aclimatação) de um objeto de uma condição 'inadequada' (elevada T e UR e/ou elevada flutuação) para uma condição 'adequada' (baixa T e UR e/ou baixa flutuação) causou mais danos do que a permanência na situação inicial.

c. em uma mesma instituição, uma avaliação técnica cuidadosa dos ambientes pode demonstrar que algumas áreas, espaços e/ou mobiliários são mais adequados do que outros para a guarda de determinados itens do acervo, seja pelo menor contato com o clima externo, seja pela menor incidência de luz natural, seja por uma ventilação mais eficiente, etc.. É importante que a instituição faça uso de sistemas multimétodos de avaliação, como a APO, e possa, em conjunto com todas as equipes envolvidas, acolher modificações no uso e na ocupação dos espaços e no leiaute das salas, tendo-se como ponto de partida, sempre, o planejamento de ações embasadas nas prioridades institucionais e fundamentadas na segurança de pessoas, edifícios e acervos.

d. uma avaliação técnica cuidadosa do acervo pode identificar quais os itens muito frágeis, raros, de grande importância para uma comunidade, dentre outros valores, e determinar as condições mais adequadas para a guarda destes objetos. Assim, é possível planejar recursos para a construção de um espaço ou de um mobiliário específico, completamente isolado do meio externo e condicionado artificialmente, que assegure as melhores condições ambientais possíveis a este pequeno grupo de objetos. Uma avaliação especializada pode demonstrar que muitos itens de uma coleção são resistentes a condições ambientais menos estáveis e podem permanecer em espaços não isolados. Esta estratégia permite proteger de maneira sustentável o edifício, o acervo e também os itens com maior risco de degradação.

e. se a avaliação técnica especializada do edifício e dos acervos concluir que existe uma total incompatibilidade na coexistência de ambos, a instituição deve considerar estratégias mais complexas para a resolução deste perigo, tanto para o edifício como o acervo, como, por exemplo, a construção de um edifício anexo para reserva técnica, a transferência da guarda do acervo para uma empresa especializada, a mudança para outro edifício com condições mais adequadas às demandas institucionais, dentre outras opções. É importante destacar que esta decisão só pode ser tomada após ampla coleta de dados, análise rigorosa das informações e ponderação entre todos os especialistas quanto aos resultados, de modo que a solução não crie, ela mesma, novos perigos para o acervo. 
f. é situação bastante frequente que edifícios históricos, não adaptados para a guarda de acervos, adquiram esta função. Os espaços são ocupados conforme a necessidade, sem o devido planejamento. Com o passar dos anos, novas coleções vão sendo incorporadas e as condições de guarda se tornam cada vez mais precárias. Uma avaliação técnica criteriosa deve levar em conta o crescimento não estruturado dos acervos e as consequências do adensamento excessivo das áreas de guarda, para 0 edifício histórico, a qualidade ambiental interna e a conservação das coleções.

Não existe risco 'zero' nem degradação 'zero'. A preservação sustentável preconiza o difícil equilíbrio entre o princípio da precaução e da otimização dos recursos. Este ponto de equilíbrio só pode ser alcançado mediante auto-conhecimento institucional, que é consequência da sistemática e continuada compreensão dos múltiplos aspectos que impactam no desempenho do ambiente construído. Quando edifício e coleções precisam ser igualmente preservados, torna-se ainda mais relevante avaliar, diagnosticar, planejar, testar, implementar e, novamente, avaliar, em um ciclo contínuo de investigação das necessidades do momento presente, de usuários, construções e coleções.

Como parte desta pesquisa de doutorado, e na tentativa de melhor compreender como as instituiçõ̃es culturais paulistanas estão administrando este complexo desafio de preservar coleções e edifícios, foram escolhidos quatro casos de estudo. Para isso, levou-se em consideração que fossem instituições públicas e de grande porte, localizadas na cidade de São Paulo, em edifícios históricos adaptados, com acervos numerosos e relevantes, nas três principais tipologias para a guarda de acervos em papel: arquivo, biblioteca e museu. Assim, foram escolhidos: o Arquivo Histórico Municipal (AHM), a Biblioteca Mário de Andrade (BMA) e o Setor de Papel do Museu do Ipiranga - Museu Paulista (MP USP). Um quarto caso de estudo foi contemplado, a Biblioteca Brasiliana Guita e José Mindlin (BBM USP), a título de comparação, por ser ela a antítese dos anteriores, ou seja, um edifício contemporâneo, construído especialmente para a guarda de acervos em papel.

\subsubsection{Arquivo Histórico Municipal (AHM)}

\subsubsection{Breve histórico}

0 Arquivo Histórico Municipal é a mais antiga instituição arquivística encarregada do recolhimento e da guarda da produção documental do município de São Paulo, e sua origem, provavelmente, é de 1907, quando a Lei no 1.051 institui uma Seção responsável pelos serviços de instrução pública, 
estatística e arquivo municipal e determina que todo o patrimônio arquivístico das Câmaras e exIntendências fosse transferido para a prefeitura, o que incluía os documentos mais antigos da América Latina, as Atas da Câmara de Santo André da Borda do Campo, de 1555 a 1558, e as Atas da Câmara de São Paulo, do período entre 1560 e 1826. 0 Ato de 1936, art. 217, parágrafo único, define que "papel e documento histórico ou antigo é todo aquele existente no Arquivo Municipal há mais de 30 anos". De 1969 a 2010 foi denominado Arquivo Histórico Municipal Washington Luís (AHMWL). Em 2016, passou a se chamar apenas Arquivo Histórico Municipal (AHM).

0 AHM é o departamento da prefeitura responsável pela guarda permanente, identificação, ordenação, conservação e divulgação do conjunto documental produzido pela administração pública municipal. Seu acervo, de valor probatório e histórico-cultural, é fonte imprescindível para a recuperação de informações sobre a história da cidade.

A instituição ocupou diversos imóveis ao longo de sua existência. Em janeiro de 2000 foi transferida oficialmente para o Edifício Ramos de Azevedo, antigo Gabinete de Eletrotécnica. 0 edifício, projetado pelo escritório do arquiteto Ramos de Azevedo, foi inaugurado em 17 de abril de 1920 para receber os laboratórios da Escola Politécnica.

0 arquiteto Eudes Campos, em laudo para o Projeto de Restauro e Reforma do 'Edifício Ramos de Azevedo', em 1989, descreve o edifício:

Assim, no caso do Edifício Ramos de Azevedo, foi eleito o corpo do laboratório o compartimento dominante em torno do qual seriam agregadas as outras dependências do edifício. Concebido como um pátio coberto, já que seus fins eram eminentemente utilitários, deveria ser aquele espaço suficientemente amplo para receber 0 aparelhamento necessário a pesquisas, experiências em máquinas e equipamentos de grande porte, e atividades curriculares. Não só ocuparia a parte central da edificação, como também ultrapassaria em altura o resto da construção. Isolado das outras peças por intermédio de áreas de circulação, para ele se abririam janelas internas, as quais permitiriam aos estudantes estar em constante contato com o que ocorreria naquele local. (...)

Simétricos em relação ao eixo longitudinal, agenciaram-se as antigas salas de aula e demais compartimentos; ao fundo, posicionou-se o anfiteatro, cujo hemiciclo se projetava para fora do perímetro retangular da construção, exteriorizando desse modo outra atividade relevante a que a edificação se destinava, a função didática. (...) 
0 edifício, de acordo com a técnica construtiva usual na época, foi erguido sobre paredes autoportantes de alvenaria de tijolos revestidos de argamassa sobre embasamento de pedra. Os pavimentos assoalhados descansam sobre estrutura autônoma de madeira, ao passo que as partes molhadas e o laboratório central possuem piso de ladrilhos hidráulicos, ou pisos cimentados assentados sobre abobadilhas de tijolos.

A cobertura do edifício, por sua vez, é feita por meio de telhas "francesas" ou "mecânicas", de barro; exceto nas partes correspondentes ao laboratório e ao anfiteatro.

Na primeira dessas peças, o fechamento superior, sustentado por treliças metálicas aparentes, é parcialmente vedado por chapas de cobre nas semi-abobadas de barrete de clérigo.

A porção central daquele espaço, no entanto, é resguardada por telhado de duas águas, imediatamente sob o qual se acha instalado o sistema de ventilação permanente, constituído por venezianas laterais (desde o restauro substituídas por caixilhos de vidro). Nessas duas águas originalmente estavam dispostas placas de ardósia, ocorrendo a mesma solução na cobertura do anfiteatro. Hoje, esse material acha-se substituído por placas de cimento. (CAMPOS, 2008).

Na segunda metade da década de 1920 é construído, anexo ao edifício, o Gabinete de Máquinas. Em 1957 é inaugurada, no terreno vizinho, a Casa do Politécnico - CADOPO, edifício projetado pelo engenheiro-arquiteto Miguel Badra Jr. para uso do Grêmio e da residência universitária. Em 1987, a prefeitura autoriza a compra do Conjunto Ramos de Azevedo para fins culturais. Em 1990 finaliza-se 0 projeto para restauro e adaptação do edifício e as obras são iniciadas. Em 1993, a comissão mista de servidores municipais e representantes da USP, Unicamp e UNESP sugere a ocupação do edifício pelo Arquivo Histórico Municipal e a realização de estudos que viabilizem a aquisição da CADOPO. Em 2003, 0 AHM muda-se definitivamente para o edifício. Em 2005, após laudo do IPT, salas do segundo piso, na face leste, são interditadas por problemas na cobertura gerados por cupins e calhas deterioradas. Em 2006, são feitas obras emergenciais na cobertura e a substituição do piso do subsolo. Em 2007, iniciam-se as obras do segundo restauro da edificação através de parceria da PMSP com o Programa Monumenta e 0 BID. As obras contemplam a recuperação das fachadas, os elementos não finalizados na intervenção anterior, o restauro do antigo Gabinete de Máquinas e a recuperação dos vitrais. 0 edifício anexo é destinado aos documentos do período 1922-1935 que estavam custodiados pelo Arquivo Geral de Processos. Em 2008, a CADOPO é incorporada ao patrimônio municipal. Ela é uma construção de 8 andares, cuja área foi destinada à segunda fase da expansão do Arquivo. As obras de restauro da sede são finalizadas em 2009. As obras de reforma completa e readequação da CADOPO são finalizadas em 2015. A edificação passa a se chamar Torre da Memória e tem a função de abrigar a biblioteca e os documentos produzidos pela prefeitura até 1970. As reservas técnicas foram posicionadas entre o quarto e o oitavo 
andar. Nestes andares, as janelas foram removidas para se criar ambientes com umidade e temperatura controladas apenas por condicionamento artificial, o que deu ao prédio o aspecto de torre.

As imagens dos edifícios que compõem o AHM podem ser vistas nas Figuras 80 a 82.

Figura 80. Conjunto de edifícios do AHM, antes e depois das obras de reforma
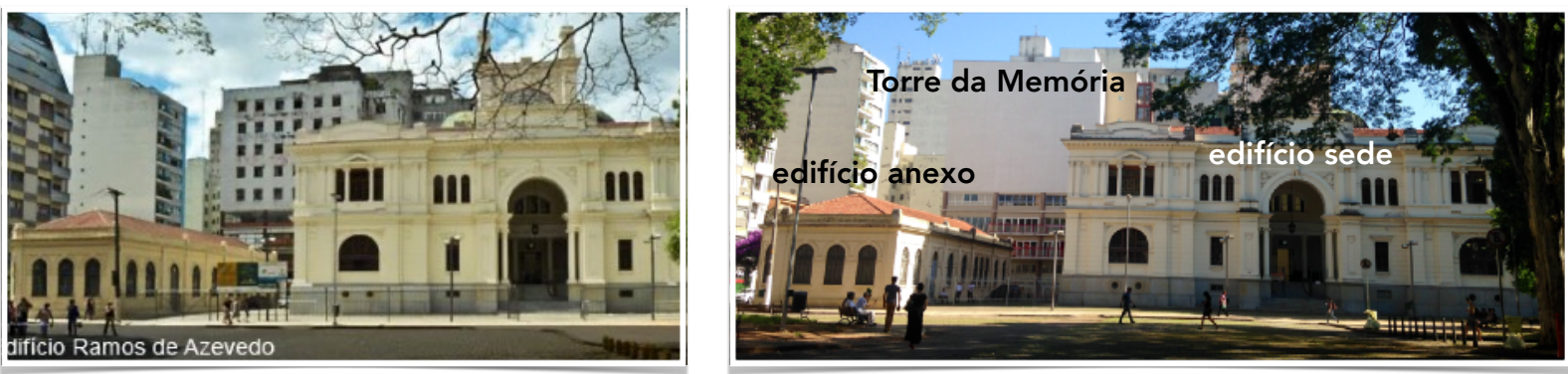

Fonte: AHM, 2020; a pesquisadora

Figura 81. Subsolo do edifício sede

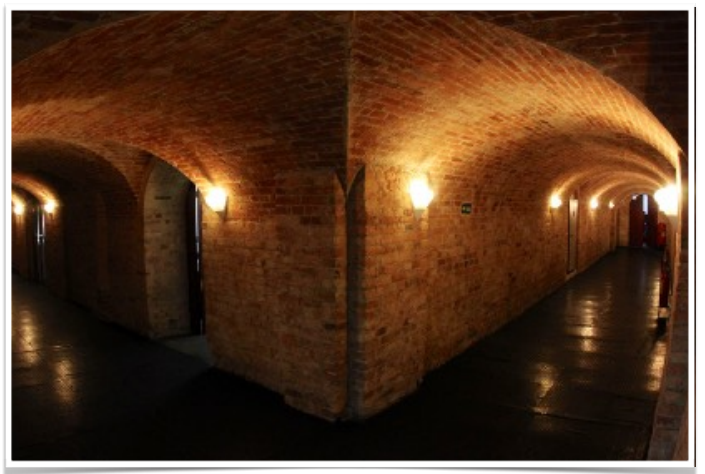

Fonte: AHM, 2020.

Figura 82. Biblioteca da Torre da Memória

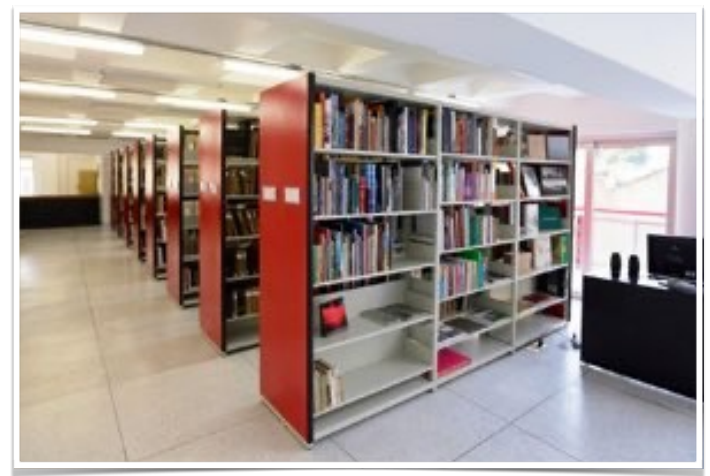

Fonte: AHM, 2020. 


\subsubsection{O acervo permanente}

0 acervo textual é composto por cerca de 2.000 metros lineares de documentos do executivo público da cidade de São Paulo e seus entes privados.

0 acervo cartográfico é composto por aproximadamente 15.000 plantas, mapas e desenhos técnicos provenientes de fundos públicos (CMSP e PMSP) e privados (Escritório Caio da Silva Prado, Jorge Macedo Vieira, João Brito da Silveira Leme) e de coleções (Severo e Villares, S.A.R.A Brasil e VASP - Cruzeiro). 0 acervo fotográfico é composto por cerca de 1.000 .000 de itens documentais (analógicos e digitais) proveniente de fundos públicos (CMSP e PMSP), privados (Armando Prado, Escritório Caio da Silva Prado) e coleções (Volcov, S.A.R.A Brasil, VASP - Cruzeiro e Aníbal Queirós Monteiro), para o período do final do século XIX até o século XXI. 0 acervo fotográfico é constituído por negativos PB (em acetato e vidro), negativos coloridos (em acetato), positivos, contatos e imagens produzidas em meio digital.

\subsubsection{Biblioteca Mário de Andrade (BMA)}

\subsubsection{Breve histórico}

A Biblioteca Mário de Andrade foi fundada em 1925, a partir da coleção de livros da Câmara Municipal de São Paulo, em cujo prédio ela funcionava. Ela é a maior biblioteca paulista e a segunda maior do Brasil, atrás apenas da Biblioteca Nacional, no Rio de Janeiro.

Em 1935 decidiu-se pela construção de um edifício projetado para ser a biblioteca. A prefeitura contratou 0 arquiteto francês Jacques Emile Paul Pilon, recém chegado ao país. Na década de 1930, a cidade de São Paulo passava por grande crescimento econômico e populacional e o centro estava em plena modernização. Muitos arquitetos estrangeiros foram chamados a participar e, com eles, chegaram ideias e estilos que estavam na vanguarda artística, como a arquitetura de tendência moderna. Isto é percebido no projeto da Biblioteca: um edifício modernista, bastante verticalizado (24 pavimentos), com formas geométricas puras, simetria e eixos de circulação interna e externa. A edificação também inova nas técnicas construtivas ao fazer uso do concreto armado e de prumadas para a distribuição das instalações elétricas e hidráulicas.

0 projeto da BMA tinha o intuito de representar uma 'nova São Paulo', uma cidade modernizada, industrializada, cosmopolita e culta, assim, continha espaços para leitura, guarda e conservação de acervo, salas para pesquisas e cursos e também um auditório. 
Durante as obras, o prefeito Prestes Maia, para reduzir custos, decidiu substituir os pilares laterais por colunas centrais, o que diminuiu em um terço o espaço para armazenamento das coleções. Ele também desistiu da construção de duas outras torres, o que inviabilizou a expansão do acervo.

A BMA é bastante conhecida por sua seção de obras raras e especiais, criada por Rubens Borba de Moraes, em 1945, a partir de acervos adquiridos em 1936 (biblioteca de Félix Pacheco), 1937 (biblioteca de Batista Pereira) e 1945 (biblioteca de Paulo Prado). Ao longo das décadas seguintes, muitos outros acervos valiosos foram incorporados.

Em 1944 foi inaugurada a Seção Circulante e, em 1945, a Seção de Artes, com livros, revistas e reproduções especializadas. A Biblioteca recebeu o nome de Mário de Andrade em 1960. Em 1975 ela passou a fazer parte do Departamento de Bibliotecas Públicas da Secretaria Municipal de Cultura. Em 2005 ela ganhou status de Departamento, passando a ter maior autonomia administrativa.

Como era previsível, já em 1965 não havia mais espaço para o armazenamento de novos itens e parte da coleção de periódicos precisou ser transferida para o prédio da Biblioteca de Santo Amaro. Em 1968, uma Comissão da BMA emitiu parecer favorável à construção da segunda torre da Biblioteca. Esta ideia também foi abandonada, em 1970, com a promessa de se construir um novo edifício, na rua Vergueiro. No entanto, mais uma vez, uma série de mudanças políticas terminou por extinguir o projeto e o espaço foi usado para a construção do Centro Cultural São Paulo, inaugurado em 1982.

0 edifício da Biblioteca passou por pequenas reformas em 1973 (segurança e infraestrutura) e 1991 (solução de problemas físicos, adequação espacial e recuperação estética).

Nos anos 2000, a Biblioteca estava novamente degradada e sem espaço para novos acervos. Em 2006, com o financiamento do BID para revitalização do centro de São Paulo, decidiu-se por uma reforma sistêmica, com intervenções no edifício, restauro dos mobiliários originais, desinfestação de parte do acervo de livros, higienização e reorganização física de todo o acervo. Contratou-se, para o projeto de arquitetura, o escritório Piratininga Arquitetos Associados, que propôs três níveis de intervenção:

a. circulação pública e paralela à rua da Consolação, com a construção de uma passarela envidraçada anexa ao edifício; 
b. instalação de uma plataforma elevatória integrada ao jardim da Praça Dom José Gaspar em conjunto com rampas de acesso normatizadas, para segurança e acessibilidade de pessoas com deficiência;

c. restauro e modernização geral: levantamento das manifestações patológicas e dos danos, recuperação das argamassas e dos revestimentos, modernização das infraestruturas (segurança, elétrica, hidráulica, telecomunicações, climatização e prevenção e combate a incêndios).

Além disso, foi projetado, no pavimento térreo, mobiliários para o armazenamento de até 60.000 itens da Seção Circulante. A reforma perdurou de dezembro de 2007 a outubro de 2010 e a reinauguração ocorreu em 25 de janeiro de 2011.

A existência de um edifício desocupado (antigo prédio do IPESP) ao lado da praça Dom Gaspar, pertencente ao estado de São Paulo possibilitou, após negociação com a prefeitura, a ampliação das áreas de acervo. 0 prédio de 16 andares passou por obras completas de reforma e readequação, com projeto do escritório Piratininga, iniciadas em dezembro de 2009 e finalizadas em dezembro de 2012. A reforma contemplou:

a. adaptação do edifício para receber 0 acervo de periódicos (hemeroteca) que se encontrava armazenado na Biblioteca Presidente Kennedy e na Biblioteca Adelpha Figueiredo;

b. instalação de salas de leitura e cabines individuais de pesquisa;

c. instalação de área para microfilmagem e digitalização;

d. instalação de área técnica e administrativa;

e. aquisição de estantes;

f. aquisição de parte do mobiliário para área de consulta e serviços técnicos e administrativos;

g. instalação de um novo elevador e substituição dos existentes;

h. instalação de sistema de condicionamento de ar;

i. instalação de escada de segurança (entre o térreo e $05^{\circ}$ pavimento).

0 edifício principal da BMA e do edifício anexo podem ser vistos nas Figuras 83 a 85. 
Figura 83. Edifício sede da BMA: embasamento com acesso público e torre para guarda do acervo

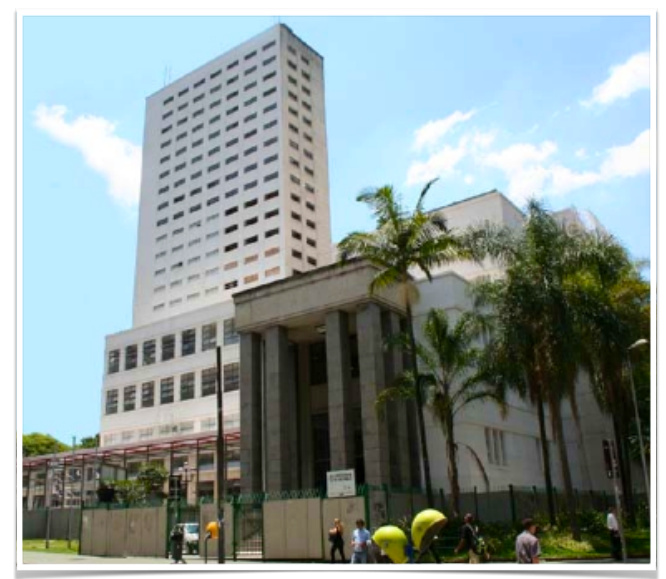

Fonte: BMA, 2020.

Figura 84. Imagem à esquerda, torre com as áreas de guarda do edifício sede vista a partir da cobertura do embasamento. Imagem à direita, edifício anexo (hemeroteca), vista a partir do edifício sede
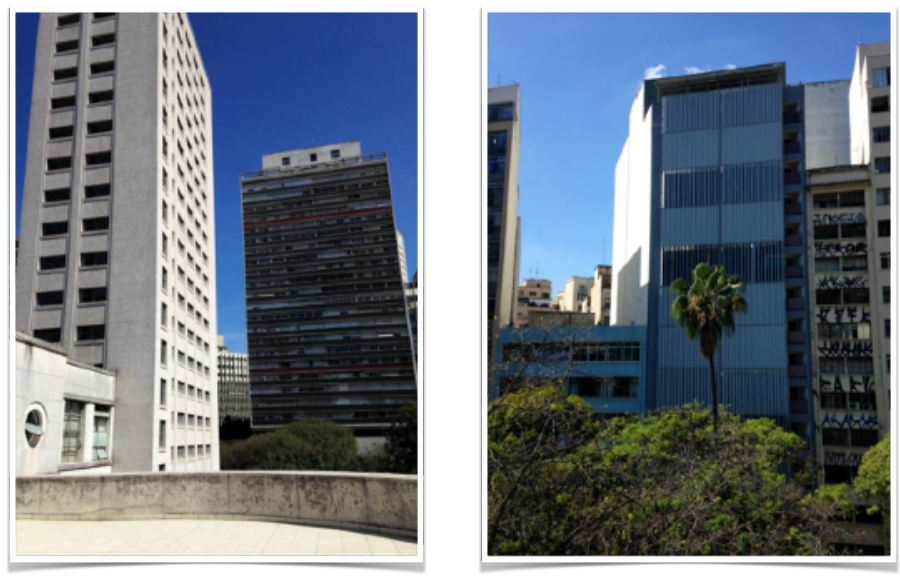

Fonte: a pesquisadora

Figura 85. Um dos andares de guarda de acervo no edifício anexo (hemeroteca)

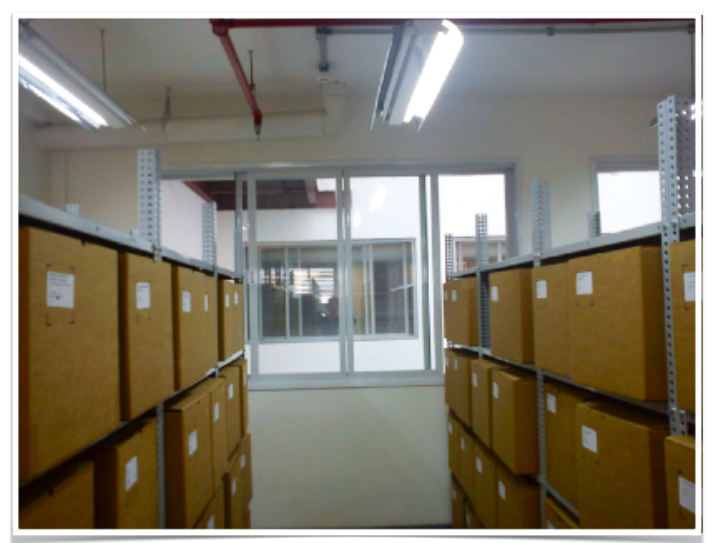

Fonte: a pesquisadora 
O Relatório de Gestão - 2009 a 2012, no Anexo II, explica quais as intervenções necessárias mas não contempladas no projeto de reforma da BMA:

0 projeto de ocupação do edifício principal da BMA sofreu adaptações e alterações, necessárias diante da demanda de espaços de trabalho não previstos no Plano Integrado de Modernização e Restauro. As áreas para acomodação de equipes internas e de equipes terceirizadas foram subdimensionadas, e a realidade impõe algumas intervenções que, até 0 momento, não puderam ser realizadas, tais como:

- instalações de paredes de drywall no subsolo, de forma a criar salas para funcionários;

- adaptações de salas no andar térreo - corredor de serviços - para acomodação adequada de almoxarifado e sala de quarentena para acervo;

- novo estudo para ocupação do $2^{\circ}$ andar do embasamento (correspondente ao $4^{\circ}$ andar da torre), com alterações no bloco de cabines para pesquisa, sala para consulta aos fichários (acervo ainda não disponível no catálogo eletrônico).

Talvez a intervenção mais necessária e urgente seja a instalação de sistema de ar-condicionado independente na Biblioteca Circulante. Motivo de constantes reclamações de usuários e de funcionários que lá trabalham, o calor nas salas da Circulante é intenso. 0 sistema de ventilação é insuficiente, agravado ainda pela construção do corredor externo em vidro.

A licitação para contratação de projeto executivo para instalação do ar condicionado está marcada para o final de dezembro/2012. A execução da obra está prevista em orçamento para 2013.

Duas outras pendências significativas na reforma da BMA são:

- construção de cobertura para proteção da plataforma externa para cadeirante. 0 equipamento nunca funcionou, pois não foi projetado para estar ao ar livre, sem proteção contra as intempéries;

- implantação do sistema de segurança patrimonial eletrônica, cujo projeto foi contratado pela BMA em 2008, mas não incorporado às obras em andamento;

- se a construção de escada de incêndio for, após estudo da legislação pelos técnicos da GTO, considerada necessária, deverá ser executada conforme projeto apresentado em 2010 pelo escritório Piratininga (BMA, 2012).

\subsubsection{Oacervo permanente}

A BMA possui o segundo maior acervo do país, com mais de 3,3 milhões de itens, dentre livros, periódicos, mapas e multimeios, além de importantes coleções de artes e obras raras.

As coleções estão divididas em: disponíveis para empréstimo ou apenas para consulta no local. As obras digitalizadas podem ser consultadas no endereço eletrônico da instituição.

Coleção disponível para empréstimo:

- Coleção Circulante: mais de 53 mil livros para consulta no local ou empréstimo. 
Coleções para consulta no local:

- Coleção de Obras Raras e Especiais: cerca de 52 mil livros, 8.774 volumes de periódicos, publicações oficiais e almanaques e cerca de 3.500 outros documentos, incluindo manuscritos, álbuns de fotografias originais, gravuras, desenhos, cartões-postais e moedas. Destacam-se 500 mapas raros; nove exemplares de incunábulos; obras únicas sobre o Brasil; edições originais dos principais viajantes estrangeiros; mais de 200 livros raros; 1.000 gravuras; e 4.500 fotografias antigas.

- Coleção de Arte: mais de 29 mil volumes de livros, 10 mil volumes de periódicos e cerca de três mil outros documentos (calendários, convites e catálogos de exposições, cartazes e reproduções de arte).

- Mapoteca: cerca de sete mil cartas geográficas e mapas políticos, históricos, físicos e geológicos e cerca de 4.300 volumes de atlas históricos e geográficos.

- Coleção São Paulo: acervo de materiais audiovisuais e bibliográficos sobre a cidade de São Paulo.

- Coleção Geral: aproximadamente 205 mil volumes de monografias de todas as áreas do conhecimento (por limitações de espaço físico, desde 2007, aceita apenas trabalhos sobre literatura e humanidades).

- Coleção de Referência: cerca de 3.900 volumes de dicionários, enciclopédias, guias, diretórios, dentre outras publicações.

- Coleção de Periódicos: cerca de 12 mil títulos de jornais, revistas e publicações oficiais.

\subsubsection{Museu Paulista - Setor de Papel do Museu do Ipiranga (MP USP)}

\subsubsection{Breve histórico}

0 Museu do Ipiranga, pertencente ao Museu Paulista da Universidade de São Paulo, destaca-se por estar entre os museus mais lembrados e visitados no Brasil.

Em 1825, após três anos de discussões, o Governo Imperial determina que um monumento em celebração da independência seja construído no "Sitio do Piranga". O local é determinado e a pedra fundamental é colocada. Este primeiro monumento (de autoria desconhecida) nunca foi executado por falta de verbas. Em 1882, por intervenção do Visconde do Rio Branco, convida-se Tommaso Gaudenzio Bezzi (engenheiro-arquiteto nascido em Turim) a elaborar um projeto, entregue em novembro de 1882. Em 1885, Luigi Pucci (mestre florentino) venceu o concurso para executar a obra do Monumento. Graças à eficiência e dedicação de Pucci, a obra foi concluída em quatro anos, em 1890, embora sem 
os acabamentos. É inaugurado em 1895. Em 1889 é proclamada a República e, em 1893, o Monumento é declarado propriedade do estado, que decide, então, transformá-lo em um museu.

Influenciado pelo caráter enciclopédico do final do século XIX e por seu primeiro diretor (1894-1916), o naturalista Hermann von Ihering (SCHAWRCZ, 1989; MENESES, 1994), passou a funcionar como um Museu de História Natural (MP USP, 1990), nos moldes dos museus e jardins botânicos criados ao redor do mundo para estudar e colecionar espécies animais, vegetais e minerais, não com o propósito moderno da educação ambiental, mas sim para satisfazer a curiosidade pública (MENDES, 2011).

A construção, em estilo eclético renascentista, possui 62 salões e ocupa uma área de $6.400 \mathrm{~m}^{2}$ (Figura 86). Está localizada dentro do Parque da Independência, que possui uma área de 16,1 hectares. 0 Parque abriga também o Monumento da Independência (inaugurado em 1922 para celebrar 0 Centenário da Independência), a Casa do Grito (edificação construída para marcar o local onde, supostamente, a comitiva de D. Pedro parou para descansar), os Jardins Franceses, a Capela Imperial (onde, desde 1972, repousam os restos mortais de D. Pedro I e das imperatrizes Maria Leopoldina e Amélia de Beauharnais), o Museu de Zoologia da USP e uma reserva de área verde.

Figura 86. 0 edifício-monumento logo após sua inauguração e em dezembro de 2019
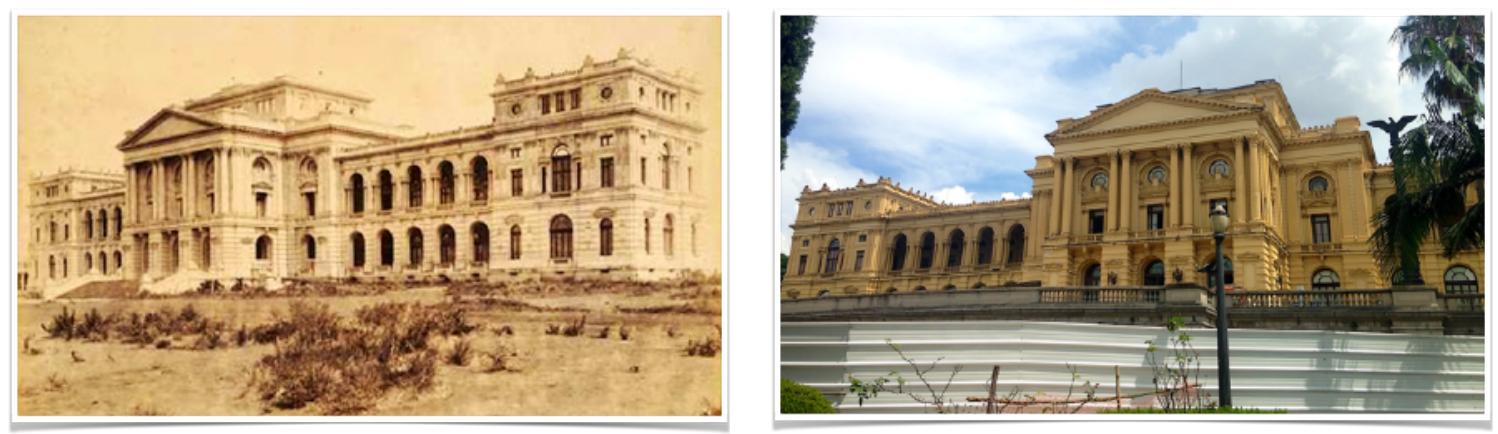

Fonte: MP USP, 2020 e a pesquisadora

0 Museu Paulista acompanhou a evolução da museologia. Na década de 1920, seu mais ilustre diretor, Affonso d'Escragnolle Taunay, reservou grande espaço no museu às coleções históricas, com o objetivo pedagógico de educar a população sobre a história nacional e, particularmente, paulista (SELLI, 2013). Em 1922, para as celebrações do Primeiro Centenário da Independência, foi executada a decoração interna do edifício, com pinturas e esculturas no Saguão, Escadaria e Salão Nobre, representando a História do Brasil. Como parte deste novo programa, em 1923, incorporou-se o Museu Republicano "Convenção de Itu", uma extensão do Museu no interior do estado, também concebido como um memorial nacional. 
O Museu não apenas coletava documentos iconográficos, como passou a produzi-los, encomendando-os a pintores e escultores. Taunay, durante os anos 1920, utilizou essa iconografia para criar, no imaginário da independência, a ideologia paulista do bandeirante, figura mítica associada à extensão do território, predecessor do tropeiro, do fazendeiro de café e do capitão de indústria (MENESES, 1994).

Quando da criação da Universidade de São Paulo, em 1934, o Museu Paulista foi declarado seu instituto complementar. Em 1963 ele foi definitivamente incorporado à Universidade.

Em 1989, os acervos antropológicos são transferidos para o Museu de Arqueologia e Etnografia da USP, e defini-se como a principal área de atuação do Museu o campo da História da Cultura Material, e três linhas de pesquisa: Cotidiano e Sociedade, Universo do Trabalho e História do Imaginário.

Na década de 1990, sob a direção de Ulpiano Bezerra de Menezes, foi proposta a criação de um museu verdadeiramente universitário, conjugando os museum studies da escola de Leicester com os material culture studies provenientes da arqueologia e da antropologia (ORNSTEIN e BARBUY, 2015).

Atualmente, o Museu Paulista possui um acervo de mais de 450.000 unidades, entre objetos, iconografia e documentação textual, representativos da sociedade brasileira, especialmente no que se refere à história paulista, o que também inclui uma biblioteca com mais de 70 mil itens.

A ala mais procurada pelos visitantes é o Salão Nobre, onde está o quadro "Independência ou Morte", de Pedro Américo. Além das mostras permanentes e temporárias, o Museu oferece também cursos, seminários e estágios em áreas educacionais. Ele também é um centro de excelência nas áreas de arqueologia, etnologia, geografia e história.

0 edifício-monumento enfrentava, há várias décadas, problemas construtivos e ambientais, os quais culminaram com o seu fechamento para o público externo em agosto de 2013. Havia necessidade iminente de restauro dos elementos estruturais, complementares e decorativos e de ampliação do seu conjunto edificado para lidar, não só com o crescente aumento de seus acervos - apenas o acervo textual cresceu de 146 coleções em 1994 para 801 coleções em 2003 (MAKINO et al., 2003) -, mas também com a proposta de ampliação do público visitante.

0 Boletim USP Destaques $n^{0} 72$, de 20132, explica que:

2 Disponível em: http://www.usp.br/imprensa/wp-content/ uploads/Destaques72.pdf, acesso em jan. 2020. 
0 Museu recebeu, na década de 1940, intervenção para transformar o subsolo em área expositiva e em salas para a administração. Originalmente, o subsolo deveria servir apenas para ventilação higiênica e saída de umidade ascendente. Esta intervenção implicou em cortes de partes de suas fundações para a abertura de corredores e de ambientes expositivos e para 0 trabalho administrativo na área. Por conta dessas obras, ocorreram fissuras na edificação.

Na década de 90, obras de contenção foram realizadas, com a colocação de perfis metálicos nas torres laterais, recuperação das coberturas em cobre, além da acomodação natural da edificação, que permitiram a plena estabilização do edifício até os dias de hoje.

Periodicamente, como medida complementar, a SEF realiza verificações quanto à quantidade de visitantes e eventuais sobrecargas de novos acervos e promove manutenção corretiva, preventiva e periódica para que não ocorram intervenções inadequadas quanto às suas fundações e estrutura. (...)

0 edifício foi construído com técnica mista de alvenaria estrutural sobre fundações em concreto ciclópico. Outros sistemas construtivos foram agregados, como uma estrutura de madeira para suporte da cobertura, além de elementos metálicos de travamento estrutural. Dada a complexidade construtiva, toda ação de restauro ou consolidação do imóvel deve considerar intervenções adequadas ao sistema original de forma a manter sua integridade.

Imagens do Edifício-Monumento após o encerramento das atividades de inspeção diagnóstica realizadas pela L. A. Falcão Bauer Centro Tecnológico de Controle de Qualidade Ltda, registradas em agosto de 2018, podem ser vistas na Figura 87.

Figura 87. Saguão com piso, colunas e estátua protegidos; piso do pavimento superior desmontado para verificação da estrutura de madeira; estrutura em abóboda de tijolos no subsolo
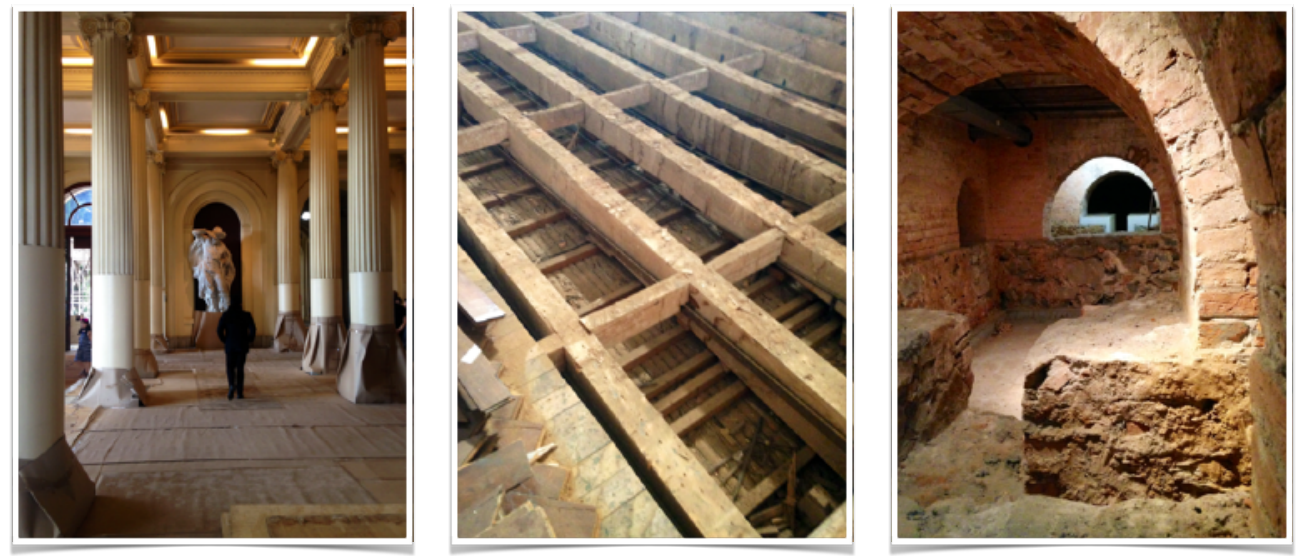

Fonte: a pesquisadora

As reservas e as áreas técnicas e administrativas precisaram ser transferidas para edifícios temporários, no entorno do Monumento. Há grande empenho das equipes de conservação para adaptar as coleções às novas áreas de guarda e os edifícios aos seus novos usos. 
Um dos edifícios temporários abriga, atualmente, as reservas de papel, as equipes responsáveis pela conservação (Setor de Papel) e pela documentação histórica e iconografia (SVIDHCO), bem como 0 laboratório de conservação de papéis (Figura 88 e 89).

Figura 88. Edifício temporário para reserva técnica do acervo em papel (frente e fundos)
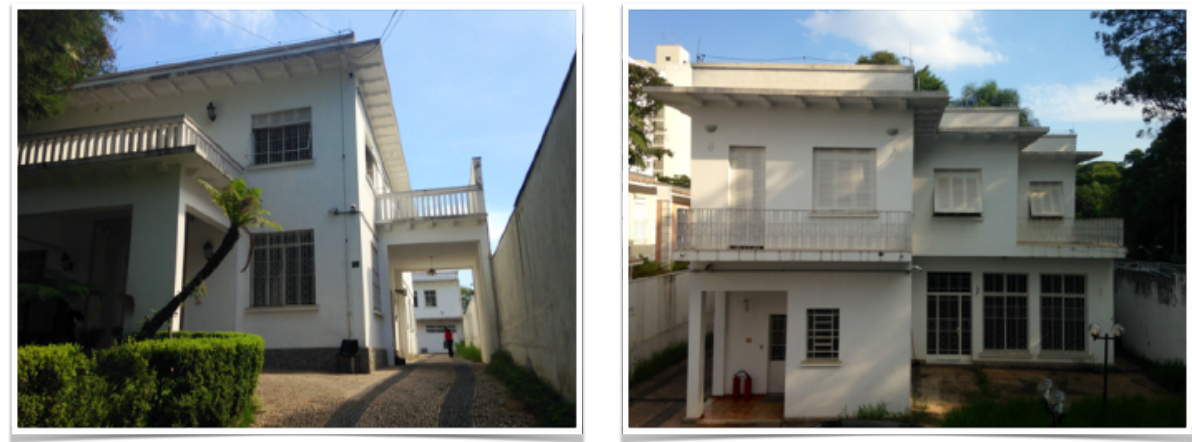

Fonte: a pesquisadora

Figura 89. Laboratório de conservação de papel no subsolo do edifício-monumento (à esquerda) e no novo endereço (à direita)
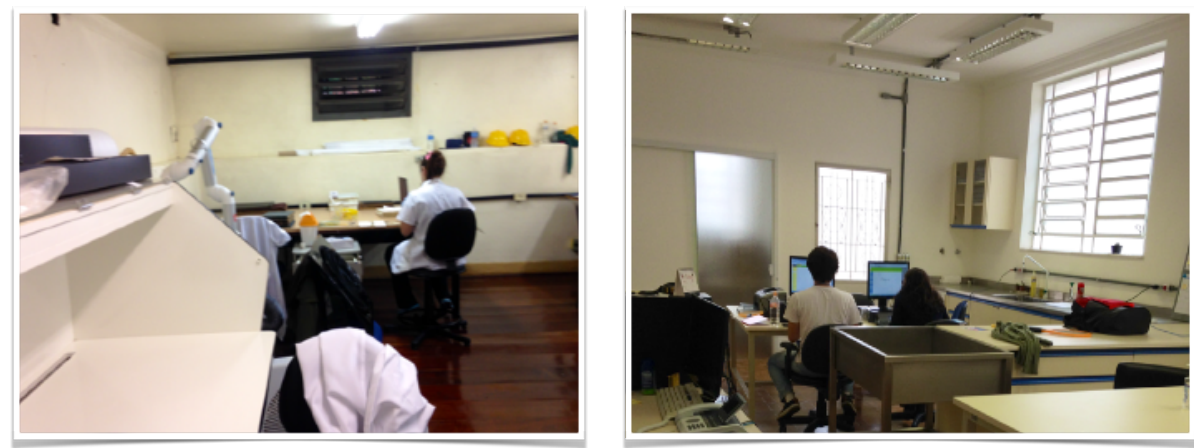

Fonte: a pesquisadora

A instituição considera que a melhor solução para as reservas técnicas seja a construção de um edifício central único para armazenamento de todas as coleções, que obedeça aos princípios das boas práticas da conservação preventiva, da eficiência energética e da sustentabilidade. Até o presente momento ainda não há definição quanto ao local, nem projeto para a construção desta nova reserva técnica.

Em setembro de 2017 foi lançado o "Concurso Nacional de Arquitetura para o Restauro e Modernização do Edifício-Monumento do Museu Paulista da Universidade de São Paulo". Após análise dos projetos, a comissão julgadora anunciou o escritório H+F Arquitetos como vencedor. Os princípios que nortearam o projeto foram: menor intervenção possível e reversibilidade dos acréscimos propostos. A proposta pretende recuperar a integridade física do monumento, acrescentar uma torre 
de serviços (escada protegida, elevadores, sanitários, shafts e áreas técnicas), criar uma nova área, no subsolo, climatizada, com espaço para recepção de visitantes, bilheterias, salas de uso múltiplo, área de exposição, auditório, cafeteria, loja de conveniências e acesso ao Saguão e aproveitar a área do desvão da cobertura para criar um espaço expositivo e um mirante (que já existia no projeto original, mas foi desativado pela dificuldade de acesso). As obras foram iniciadas em novembro de 2019, com previsão de entrega para a celebração do Bicentenário da Independência, em setembro de 2022. Imagens do projeto e da obra podem ser vistas nas Figuras 90 e 91.

Figura 90. Concepção final do projeto dos arquitetos Hereñú e Ferroni

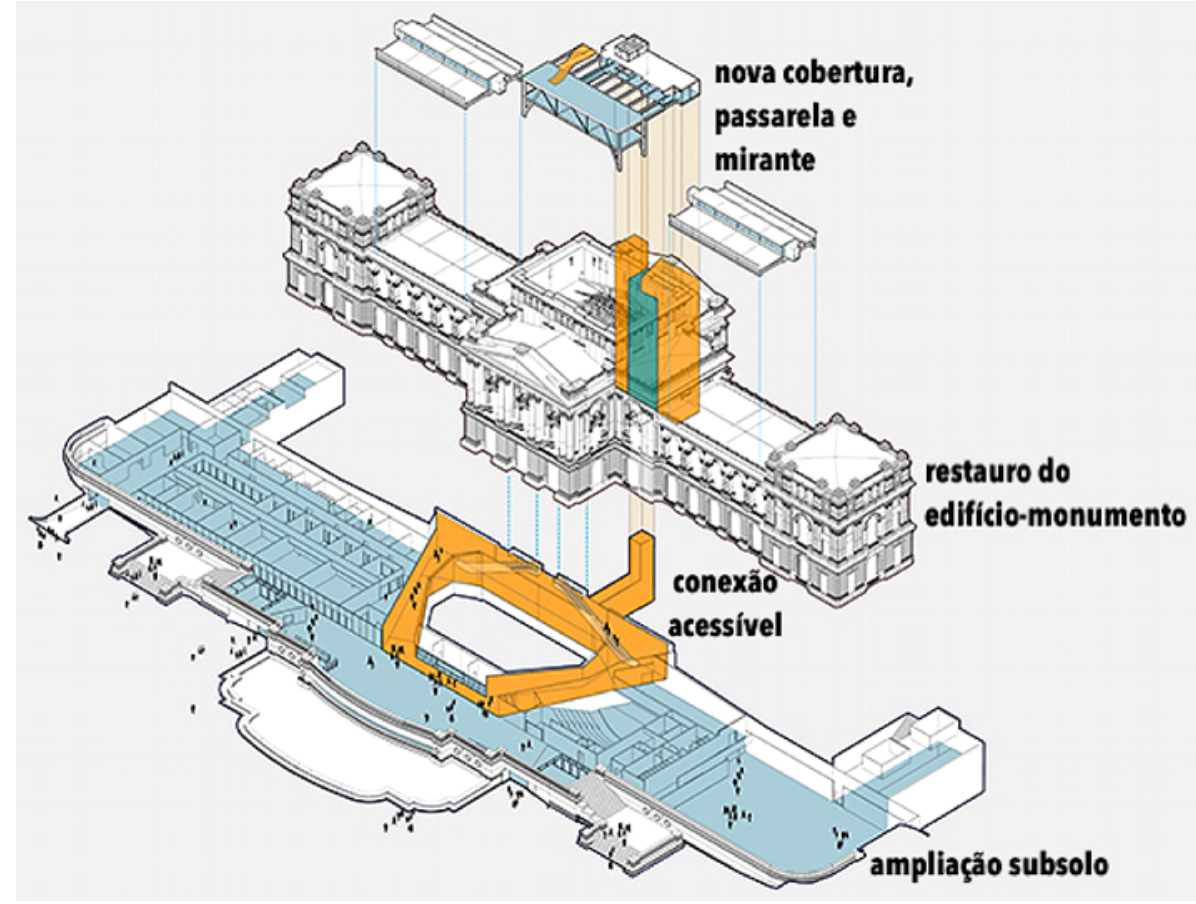

Fonte: adaptado de H+F ARQUITETOS, 2017.

Figura 91. Obras de escavação e contenção para ampliação no subsolo

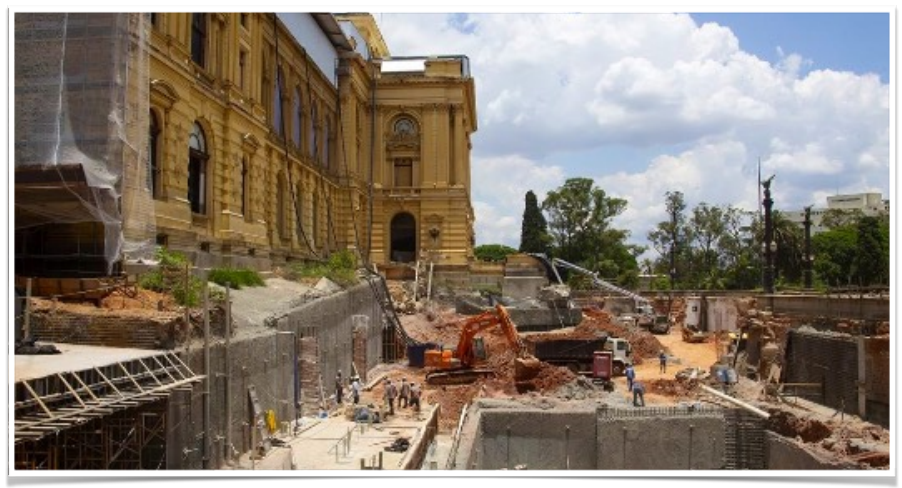

Fonte: JORNAL DA USP, 2020. 


\subsubsection{Acervo permanente}

0 Museu Paulista possui um acervo de mais de 450.000 itens, com objetos da vida cotidiana paulista (esculturas, quadros, joias, moedas, medalhas, móveis, documentos e utensílios), itens iconográficos, dentre eles as coleções de fotografia de Militão de Azevedo e de Haberkorn, e documentos arquivísticos, incluindo mapas históricos e manuscritos, do século XVI até meados do século XX.

0 acervo de iconografia possui cerca de 120.000 itens, que incluem pinturas, fotografias e cartazes. A reserva técnica de papel abriga cerca de 200 metros lineares de documentos.

A biblioteca possui acervo de cerca de 40.000 itens, sendo 1.000 livros raros, e 39.000 fascículos de periódicos.

\subsubsection{Biblioteca Brasiliana Guita e José Mindlin (BBM USP)}

\subsubsection{Breve histórico}

0 acervo Mindlin pode ser entendido a partir de quatro vertentes principais: assuntos brasileiros, literatura em geral, livros de arte, e livros como objeto de arte. Toda a biblioteca, que corresponde a aproximadamente 60 mil volumes, foi doada à USP em 2006. Ela reúne obras de literatura, história, relatos de viajantes, manuscritos históricos e literários, documentos, periódicos, mapas, livros científicos e didáticos, iconografia e livros de artistas sobre o Brasil ou que tenham sido escritos e/ou publicados por brasileiros. Ela é considerada a mais importante coleção do gênero formada por particulares. Sempre respeitando esta temática, a biblioteca continua a ampliar seus acervos.

Ainda em 2002, Mindlin e István Jancsó, diretor do Instituto de Estudos Brasileiros (IEB USP), idealizaram a construção de um moderno edifício que contemplasse todas as características necessárias para abrigar as duas mais importantes coleções brasilianas de São Paulo: a dos Mindlin e a do IEB (iniciada pelo historiador Sérgio Buarque de Holanda, em 1962).

0 projeto do conjunto BBM / IEB foi desenvolvido pelos escritórios de Eduardo de Almeida e Rodrigo Mindlin Loeb, com a assessoria da FAU USP. A Library of Congress, em Washington, foi consultada para definir as diretrizes para a conservação preventiva das obras.

Além dos recursos orçamentários da USP, a construção recebeu recursos de muitas outras fontes públicas e privadas. 0 gerenciamento da obra foi feito pela Fundação de Apoio à Universidade de São Paulo (FUSP), em parceria com a Superintendência do Espaço Físico (SEF), e foi inaugurado em 2013. 
0 resultado é um moderno conjunto edificado em concreto e vidro, com salas para acervo, consulta, administração e restauro das obras, salas de aula, auditório, livraria e cafeteria. 0 acesso único é feito por uma grande esplanada coberta que interliga os blocos: um para a BBM, um para o IEB, outro para a livraria da Edusp, com uma cafeteria no mezanino, e outro para o Auditório István Jancsó. Os acervos das duas bibliotecas permanecem separados mas interligados pela esplanada, que forma uma espécie de rua interna. 0 subsolo é compartilhado por todos os blocos e é onde se encontram as áreas técnicas, bem como algumas reservas, salas de estudo e os laboratórios para conservação e restauro. A cobertura metálica, com uma grande faixa central envidraçada, perpassa a esplanada e os edifícios da BBM e do IEB. No bloco da BBM, a esplanada termina em um grande átrio central a partir do qual se percebe três níveis de mezaninos, chamados de anéis (apesar de serem quadrados), onde estão os itens do acervo Mindlin. Eles possuem as seguintes características (ANTUNES, 2015):

- todas as portas de acesso são ativadas por controle biométrico (acesso restrito);

- todos os ambientes são climatizados;

- a umidade relativa foi fixada entre 50 e $60 \%$;

- a temperatura foi fixada entre 20 e $22^{\circ} \mathrm{C}$;

- todos os vidros possuem filtro de UV;

- a iluminação artificial nos anéis foi fixada em 50 lux;

- os envidraçados na cobertura do vão central possuem brises e filtro de UV;

- cada andar dos anéis possui quatro esterilizadores de ar.

0 projeto e a construção podem ser vistos nas Figuras 92 a 94 .

Figura 92. Projeto da BBM / IEB por Eduardo de Almeida + Mindlin Loeb + Dotto Arquitetos

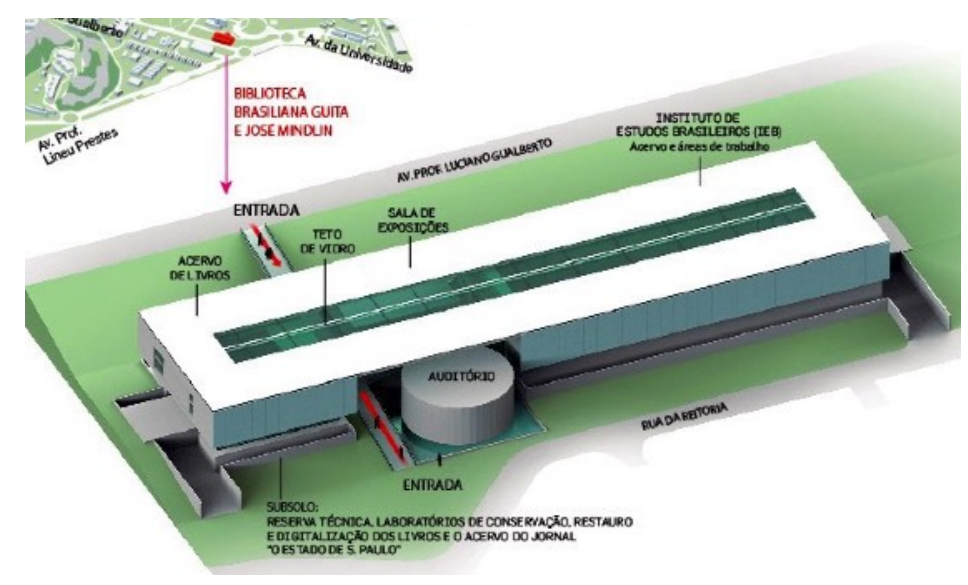

Fonte: BBM USP e 0 Estado de São Paulo, 2013. 
Figura 93. Vista do conjunto BBM / IEB USP

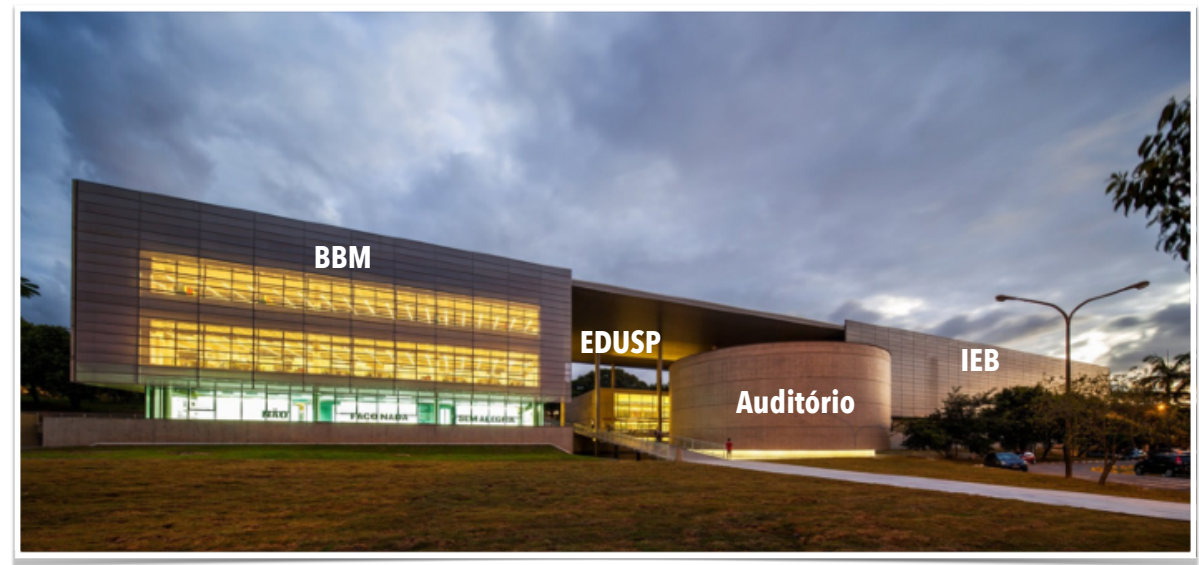

Fonte: adaptado de ARCHDAILY, 2013.

Figura 94. Vista interna dos anéis com o acervo Mindlin

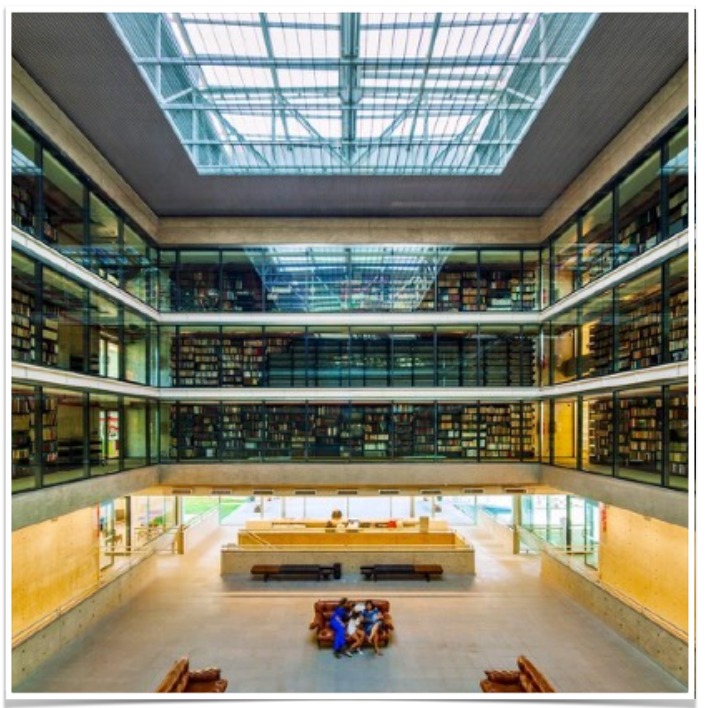

Fonte: Fonte: ARCHDAILY, 2013.

\subsubsection{Acervo permanente}

0 acervo da biblioteca contém cerca de 60 mil volumes (40.000 da coleção particular Mindlin e 20.00 da coleção do (EB), sendo 32,2 mil títulos de primeiras edições de originais, manuscritos, mapas, diários, álbuns de arte, periódicos etc., que abrangem uma grande variedade de temas relacionados ao Brasil. 0 exemplar mais antigo da Biblioteca é de 1508. A BBM possui quatro linhas de pesquisa: Estudos Brasileiros; História do Livro e da Leitura; Tecnologia do Conhecimento e Humanidades Digitais; e Preservação, Conservação e Restauração do Livro e do Papel. 


\subsubsection{Instrumentos}

Para o diagnóstico da qualidade ambiental de áreas de guarda de acervos em papel foram definidos dois instrumentos de APO: visitas técnicas acompanhadas por profissional especialista em conservação para inspeção técnica das áreas de guarda; e entrevistas estruturadas com pessoas-chave responsáveis pela conservação dos acervos e manutenção dos edifícios.

A definição dos instrumentos levou em conta a capacidade técnico-financeira (uma pesquisadora, com recursos próprios) e temporal (a duração do doutorado), bem como as características do objeto de análise. Áreas de guarda de acervos são, segundo o National Park Service (NPS) ${ }^{3}$ do governo dos Estados Unidos, um espaço físico e um processo em andamento:

- é um espaço dedicado ao armazenamento de objetos museológicos, espécimens de história natural, documentos bibliográfico e materiais arquivísticos. É uma área projetada ou adaptada para atender às normas e regulamentos de preservação, proteção e acessibilidade às coleções.

- é um processo em andamento de armazenamento, organização e cuidado com as coleções enquanto guardadas. Isto envolve avaliar e implementar estratégias e técnicas para melhorar a qualidade ambiental e a preservação de longo prazo dos acervos.

Assim, para que o espaço físico e o processo de guarda pudessem ser corretamente avaliados, os instrumentos da APO precisavam identificar:

1. as características construtivas e a sua correlação com os climas e microclimas internos identificados pelos conservadores;

2. as manifestações patológicas presentes no ambiente construído que poderiam ser uma ameaça às coleções, e a correlação entre elas e os agentes (causas) de deterioração do acervo;

3. o testemunho dos funcionários que cuidam dos acervos e dos edifícios.

A abordagem multimétodos da APO permitiu que se fizesse uso combinado de métodos qualiquantitativos (visita técnica exploratória) e qualitativos (entrevista estruturada) de análise para se obter uma compreensão mais precisa, com menos desvios e tendências. As autorizações concedidas pelos diretores do AHM, BMA, MP USP e BBM USP, bem como os roteiros das entrevistas elaborados para esta pesquisa podem ser consultados nos Apêndices deste trabalho.

3 Disponível em: https://www.nps.gov/museum/publications/mhi/chap7.pdf, acesso em fev. 2019; tradução da pesquisadora. 


\subsubsection{Visitas técnicas exploratórias}

A avaliação qualiquantitativa do ambiente físico pelo ponto de vista do especialista é muito importante, principalmente em países como o Brasil, onde deficiências na qualidade na construção podem estar presentes em todos os aspectos: atendimento às normais; qualidade de materiais, sistemas e equipamentos; e qualidade da mão-de-obra (0N0, 2018).

Assim, as visitas técnicas executadas por profissionais especializados têm por objetivo identificar as não conformidades na construção e seu entorno, buscar suas origens (projeto, execução, materiais el ou manutenção) e propor soluções. Durante uma visita técnica podem ser feitos levantamentos físicos, medições ambientais, inspeções, registros visuais (desenhos, fotos, filmes, gravações, etc.), e anotações das ocorrências.

Para todas as instituições que fizeram parte desta pesquisa, o estudo foi iniciado com uma visita exploratória a todas as áreas de guarda de acervos da instituição. As visitas foram acompanhadas pelos conservadores-chefe que, em conversas orientadas, explicaram o histórico de ocupação dos espaços, as características positivas e negativas do ambiente construído para a conservação do acervo, as condições ambientais nas áreas de guarda observadas pelos funcionários e as dificuldades enfrentadas para a preservação dos acervos. Todas as instituições foram visitadas mais de uma vez, sendo as visitas subsequentes guiadas por um roteiro prévio dos aspectos que se desejava investigar. Segue abaixo, quadro descritivo dos casos de estudo e dos principais riscos ao acervo e vulnerabilidades construtivas identificados (Quadro 32).

Quadro 32. Quadro-resumo dos aspectos identificados durante as visitas técnicas às instituições casos de estudo

\begin{tabular}{|c|c|c|c|c|}
\hline Informações: & 間 AнM & $\Leftrightarrow$ & MP USP & $\Leftrightarrow$ BBM USP \\
\hline data das visitas & $\begin{array}{l}\text { maio de } 2018 \text { e fevereiro de } \\
2019\end{array}$ & $\begin{array}{l}\text { novembro de 2015, } \\
\text { setembro de } 2017 \text { e } \\
\text { fevereiro de } 2019\end{array}$ & $\begin{array}{l}\text { regularmente, entre } \\
\text { segundo semestre de } \\
2015 \text { e primeiro } \\
\text { semestre de } 2019\end{array}$ & $\begin{array}{l}\text { dezembro de } 2017 \text { e } \\
\text { fevereiro de } 2019\end{array}$ \\
\hline $\begin{array}{l}\text { localização do } \\
\text { acervo }\end{array}$ & $\begin{array}{l}\text { subsolo do edifício sede; } \\
\text { anexo; alguns andares da } \\
\text { Torre da Memória }\end{array}$ & $\begin{array}{l}\text { múltiplos andares das } \\
\text { torres do edifício } \\
\text { principal e do edifício } \\
\text { anexo }\end{array}$ & $\begin{array}{l}\text { pavimento térreo de } \\
\text { dois edifícios para } \\
\text { guarda temporária do } \\
\text { acervo }\end{array}$ & anéis e subsolo \\
\hline
\end{tabular}


Quadro 32. Quadro-resumo dos aspectos identificados durante as visitas técnicas às instituições casos de estudo (continuação)

\begin{tabular}{|c|c|c|c|c|}
\hline Informações: & 間 & 2 & MP USP & BBM USP \\
\hline $\begin{array}{c}\text { características } \\
\text { das áreas de } \\
\text { guarda }\end{array}$ & $\begin{array}{l}\text { subsolo: paredes estruturais } \\
\text { de alvenaria de tijolos, laje } \\
\text { em abobadilhas de tijolos e } \\
\text { janelas altas e estreitas, } \\
\text { pouco acima do nível do piso } \\
\text { externo. Muitas janelas foram } \\
\text { vedadas e portas foram } \\
\text { instaladas para segurança das } \\
\text { salas com acervos, } \\
\text { interrompendo a ventilação } \\
\text { natural. Toda a área conta com } \\
\text { um sistema de climatização } \\
\text { artificial. } \\
\text { anexo: construção térrea, sem } \\
\text { divisões internas, de alvenaria } \\
\text { de tijolos, cobertura de telhas } \\
\text { cerâmicas e amplos caixilhos } \\
\text { de madeira. Parte do espaço } \\
\text { interno foi enclausurado em } \\
\text { com estrutura leve, de gesso } \\
\text { acartonado, para maior } \\
\text { segurança do acervo. } \\
\text { Torre da Memória: estrutura } \\
\text { em concreto armado, } \\
\text { fechamento em alvenaria e } \\
\text { caixilhos metálicos. Como não } \\
\text { há janelas nos andares } \\
\text { superiores, a construção é } \\
\text { totalmente dependente dos } \\
\text { sistemas ativos de ventilação } \\
\text { e condicionamento do ar. }\end{array}$ & $\begin{array}{l}\text { múltiplos andares da } \\
\text { sede e do anexo: em } \\
\text { ambos os casos, } \\
\text { estrutura de concreto } \\
\text { armado, vedações em } \\
\text { alvenarias e caixilhos } \\
\text { metálicos. As reservas } \\
\text { técnicas estão nos } \\
\text { pavimentos mais altos } \\
\text { dos dois edifícios, em } \\
\text { ambientes } \\
\text { especialmente } \\
\text { planejados apenas } \\
\text { para a guarda de } \\
\text { acervos, com } \\
\text { elementos externos e } \\
\text { internos de proteção } \\
\text { das janelas e ambiente } \\
\text { climatizado } \\
\text { artificialmente. }\end{array}$ & $\begin{array}{l}\text { dois edifícios } \\
\text { adaptados para a } \\
\text { guarda temporária dos } \\
\text { acervos em papel: } \\
\text { construção tradicional, } \\
\text { em estrutura de } \\
\text { concreto armado, } \\
\text { vedação em alvenaria e } \\
\text { amplos caixilhos } \\
\text { metálicos. } \\
\text { A maioria dos itens } \\
\text { estão guardados em } \\
\text { armários deslizantes e } \\
\text { mapotecas distribuídos } \\
\text { por salas no pavimento } \\
\text { térreo das edificações. } \\
\text { Os vãos foram } \\
\text { parcialmente } \\
\text { protegidos para } \\
\text { minimizar a incidência } \\
\text { de luz solar. Os } \\
\text { ambientes não fazem } \\
\text { uso de sistemas de } \\
\text { condicionamento } \\
\text { artificial do ar. }\end{array}$ & $\begin{array}{l}\text { anéis: ambientes com } \\
\text { fechamento em } \\
\text { concreto e vidro, com } \\
\text { luz natural zenital } \\
\text { através do vão central } \\
\text { do mezanino. } \\
\text { subsolo: envoltória em } \\
\text { concreto armado, sem } \\
\text { aberturas para } \\
\text { ventilação e iluminação } \\
\text { natural. } \\
\text { Todos os ambientes são } \\
\text { selados e dependentes } \\
\text { de condicionamento e } \\
\text { ventilação artificiais. }\end{array}$ \\
\hline $\begin{array}{l}\text { principais riscos } \\
\text { ao acervo / } \\
\text { agentes de } \\
\text { deterioração } \\
\text { observados ou } \\
\text { potenciais } \\
\text { Nota (1) } \\
\text { Nota (2) }\end{array}$ & $\begin{array}{l}\text { gestão incorreta; pragas } \\
\text { (insetos); microorganismos; } \\
\text { poluentes (partículas e } \\
\text { gases); luz visível e UV; T } \\
\text { incorreta; UR incorreta; água } \\
\text { (natural e não natural) }\end{array}$ & $\begin{array}{c}\text { gestão incorreta; } \\
\text { pragas (insetos); } \\
\text { microorganismos; } \\
\text { poluentes (partículas e } \\
\text { gases); luz visível e UV; } \\
\text { T incorreta; UR } \\
\text { incorreta; água (não } \\
\text { natural) }\end{array}$ & $\begin{array}{l}\text { gestão incorreta; } \\
\text { roubo, vandalismo e } \\
\text { deslocamento; pragas } \\
\text { (insetos e animais); } \\
\text { microorganismos; } \\
\text { poluentes (partículas e } \\
\text { gases); T incorreta; UR } \\
\text { incorreta; água (não } \\
\text { natural); fogo (indireto) }\end{array}$ & $\begin{array}{l}\text { gestão incorreta; } \\
\text { pragas (insetos); } \\
\text { microorganismos; luz } \\
\text { visível e UV; Tincorreta; } \\
\text { UR incorreta; água (não } \\
\text { natural) }\end{array}$ \\
\hline
\end{tabular}


Quadro 32. Quadro-resumo dos aspectos identificados durante as visitas técnicas às instituições casos de estudo (continuação)

\begin{tabular}{|c|c|c|c|c|}
\hline Informações: & 間 Анм & $\theta$ & MP USP & BBM USP \\
\hline $\begin{array}{c}\text { principais } \\
\text { vulnerabilidades } \\
\text { construtivas } \\
\text { identificadas } \\
\text { Nota (3) } \\
\text { Nota (4) }\end{array}$ & $\begin{array}{c}\text { vedações verticais; vãos e } \\
\text { esquadrias; instalações } \\
\text { hidrossanitárias; instalações } \\
\text { elétricas; instalações } \\
\text { mecânicas; instalações contra } \\
\text { incêndio }\end{array}$ & $\begin{array}{l}\text { vãos e esquadrias; } \\
\text { instalações } \\
\text { hidrossanitárias; } \\
\text { instalações elétricas; } \\
\text { instalações mecânicas; } \\
\text { instalações contra } \\
\text { incêndio }\end{array}$ & $\begin{array}{c}\text { cobertura; vãos e } \\
\text { esquadrias; instalações } \\
\text { hidrossanitárias; } \\
\text { instalações elétricas; } \\
\text { instalações contra } \\
\text { incêndio }\end{array}$ & $\begin{array}{l}\text { cobertura; instalações } \\
\text { hidrossanitárias; } \\
\text { instalações mecânicas; } \\
\text { instalações contra } \\
\text { incêndio }\end{array}$ \\
\hline
\end{tabular}

Fonte: a pesquisadora.

Nota (1): Os agentes de deterioração foram aqui classificados conforme proposta desta pesquisa, a saber: gestão incorreta; guarda e uso incorreto; roubo, vandalismo e deslocamento; pragas (insetos); pragas (animais); microorganismos; poluentes (partículas); poluentes (gases); luz visível e UV; T incorreta; UR incorreta; água (natural); água (não natural); fogo (direto); e fogo (indireto). Uma explicação detalhada de cada um dos agentes pode ser encontrada no capítulo 6 desta tese.

Nota (2): As ameaças observadas nas quatro instituições guardam mais semelhanças do que diferenças. DAs visitas à BBM indicaram uma menor quantidade de ameaças aos acervos, no entanto, muitas das vulnerabilidades identificadas nos edifícios históricos também estavam presentes na Biblioteca. Entende-se que a ausência de diagnósticos e de documentação orientadora para arquitetos projetistas dificulta um processo de melhoria continuada do ambiente construído para áreas de guarda. A seguir, tem-se uma breve descrição dos riscos observados durante as visitas exploratórias, para cada um dos agentes de deterioração:

- gestão incorreta: todas as instituições visitadas estavam orientadas às boas práticas de conservação preventiva e os conservadores possuíam grande conhecimento técnico e consciência da importância de se ter um enfoque preventivo, mais do que curativo. No entanto, as instituições relataram dificuldades pontuais relativas a inventário e documentação detalhada do acervo, bem como de políticas e protocolos para integração da conservação com a manutenção predial;

- guarda e uso incorreto: todas as instituições visitadas possuíam mobiliário adequado à guarda, transporte e manipulação dos acervos e os conservadores procuravam acondicionar os itens da melhor maneira possível. Ainda que as embalagens nem sempre seguissem os protocolos internacionais (papel neutro, 
reversibilidade, etc.), a maioria dos objetos não apresentava danos causados por acondicionamento e/ou armazenamento incorreto. A consulta aos itens não correntes (históricos, especiais, raros, etc.) por pesquisadores e visitantes é feita apenas na presença de um profissional da instituição, o que minimiza 0 risco de manuseio incorreto. As instituições vêm se esforçando para digitalizar os itens raros e frágeis, minimizando, assim, a necessidade de manipulação do objeto original. Para algumas situações específicas foi reportado que o microclima interno às embalagens poderia favorecer o desenvolvimento de fungos, no entanto, faltam pesquisas científicas que esclareçam melhor os mecanismos envolvidos;

- roubo, vandalismo e deslocamento: todas as instituições visitadas possuem mecanismos para minimizar riscos de que um item ou parte de um item seja subtraído ou danificado, tais como alarmes, câmeras, sensores, equipe de segurança e/ou procedimentos de consulta supervisionada. As instituições relataram já terem experienciado evento(s) de roubo ou vandalismo no passado, mas, com o aprimoramento dos protocolos nos últimos anos, os riscos foram minimizados. A BMA relatou que havia preocupação com vandalismo, dada a sua localização, no centro de São Paulo, local onde aconteciam muitos protestos. Este risco diminuiu nos últimos anos com a transferência das manifestações para outras regiões da cidade. No MP USP, como os acervos estão em imóveis temporários adaptados, existe, potencialmente, uma maior fragilidade construtiva, o que vem sendo monitorado pelos conservadores e equipes de segurança;

- pragas (insetos): insetos estão sempre presentes em climas tropicais e eles foram reportados para todas as áreas de guarda visitadas, apesar das instituições fazerem dedetizações anuais e utilizarem iscas para o monitoramento das pragas. Nota-se que falta um maior desenvolvimento de técnicas de manejo integrado de pragas adaptadas aos insetos bibliófagos regionais e que utilize estratégias e substâncias que não sejam perigosos nem à saúde humana nem ao meio ambiente. É frequente que itens e coleções adquiridos (doados ou comprados) tenham infestação por pragas ou por fungos. As instituições visitadas tinham áreas para a quarentena destes objetos mas não possuíam, em suas instalações, câmaras para desinfestação, seja por congelamento ou por anóxia;

- pragas (animais): a presença de animais foi relatada como preocupante pela maioria das instituições visitadas, principalmente a presença de pombos junto às envolventes externas e casos eventuais de ratos e/ou gatos em áreas de guarda. Todas as instituições relataram fazer uso de estratégias, tais como telas, espículas e/ou substâncias químicas para afugentar os animais dos edifícios; 
- microorganismos: 0 mofo foi o principal agente de deterioração reportado por todas as instituições visitadas e a maior causa de preocupação entre os conservadores. Como a presença de fungos está relacionada a alimento (papel); água (UR elevada); e ausência de luz solar (área de guarda), o seu controle é bastante desafiador. Sabe-se que taxas de ventilação elevadas podem reduzir a deposição de esporos sobre 0 acervo, sendo uma medida eficaz na mitigação da contaminação, mas a ventilação natural traz consigo outras ameaças potenciais (poluentes, insetos, variações bruscas de T e UR). A limpeza das áreas de guarda e dos acervos é importante mas deve ser executada com cautela, porque também pode ser fonte de riscos. Todas as instituições visitadas treinam as equipes terceirizadas de limpeza. Já a higienização dos acervos depende de projeto específico, com destinação de recursos. A principal estratégia adotada pelos conservadores é o uso de desumidificadores portáteis para redução da UR. No entanto, esta estratégia também têm riscos potenciais: a água precisa ser removida manualmente do compartimento do aparelho, o que pode causar um acidente; edifícios de pedra e cal precisam ser mantidos permeáveis à passagem do vapor d'água, sob pena de danos às estruturas e vedações, o que significa que a água removida do ambiente é reintroduzida pela pressão de vapor criada entre 0 ambiente externo (mais úmido) e o ambiente interno (menos úmido); 0 desumidificador pode aumentar as flutuações instantâneas na UR e estudos recentes parecem indicar que estas flutuações podem ser mais prejudiciais aos objetos do que os valores elevados porém constantes de UR. As instituições reportaram 0 uso eventual de tratamento com raios gama para a eliminação dos fungos, técnica considerada controversa pela literatura especializada, por dois motivos: 0 tratamento também danifica a fibra do papel, o que pode desencadear outros processos de degradação; e, se as condições ambientais não forem corrigidas, como os esporos fúngicos estão presentes no ar, o mofo irá se desenvolver novamente. 0 uso combinado de ar-condicionado e desumidificadores, em edifícios de concreto armado parece funcionar bem, mas, neste caso, tem-se outros desafios: as áreas de guarda visitadas, localizadas em edifícios modernistas ou contemporâneos, possuíam estrutura frágil (pouca inércia e isolamento térmico e elevada permeabilidade ao ar e ao vapor d'água), o que torna 0 uso de sistemas ativos de condicionamento do ar energética e ambientalmente pouco eficientes (não é possível manter níveis de T e UR constantes). Todas estas questões demandam novas pesquisas científicas e a proposiçãa de soluções alternativas, seja pela perspectiva do combate aos fungos (identificação das espécies, tratamentos eficazes, etc.), seja pela perspectiva da qualidade construtiva e da gestão das facilidades. 
- poluentes (partículas): todas as instituições visitadas relataram preocupação com a quantidade de particulados que se deposita sobre mobiliários e objetos dentro das áreas de guarda. Nos edifícios que fazem uso da ventilação natural, o ar externo não passa por nenhum sistema de filtragem, não havendo, portanto, nenhuma estratégia visando à eliminação deste poluente. Nos edifícios que fazem uso de sistemas ativos para condicionamento do ar, ainda que os conservadores tenham confirmado a existência manutenção programada dos filtros, foi relatada a presença de particulados nos ambientes de guarda. A causa pode estar relacionada à qualidade do serviço de manutenção ou à baixa capacidade de vedação dos caixilhos de portas e janelas;

- poluentes (gases): a situação é, provavelmente, similar à dos particulados, no entanto, como eles não são visíveis, e nenhuma das instituições consultadas faz medição da qualidade do ar interno, não foi possível aferir qual o impacto desta ameaça sobre os acervos. A redução ou eliminação dos gases nocivos presentes no ar externo depende de filtros especiais para absorção de gases e vapores, item que não é contemplado no plano de manutenção dos sistemas de condicionamento. Nenhuma instituição relatou a percepção de gases liberados internamente pelos materiais de construção;

- luz visível e UV: a deterioração de papéis, fotografias e pigmentos causada pela luz é uma das principais ameaças relatadas pelos conservadores nas instituições visitadas. Seja a radiação direta ou indireta, natural ou artificial, a exposição contínua à luz sempre resulta em algum grau de degradação de materiais orgânicos. No AHM, ainda que parte significativa do acervo esteja no subsolo do edifício principal, protegido da luz solar, itens guardados no anexo e na biblioteca da Torre da Memória são impactados pela luz natural. Na BMA, o edifício anexo foi adaptado para receber acervos e brises externos foram instalados na fachada principal, no entanto, uma parte da radiação consegue penetrar nos ambientes, ameaçando as frágeis coleções em papel jornal. Como a radiação também está associada à energia térmica, a incidência de luz direta sobre as paredes externas e os caixilhos metálicos dos edifícios resulta em elevações na temperatura por condução térmica, o que pode impactar no funcionamento adequado do sistema de condicionamento de ar e criar flutuações indesejadas em T e UR. A iluminação zenital, como observada na BMM, não é recomendada para a latitude de São Paulo, dada a elevada contribuição termo-energética da componente horizontal da radiação. 0 emprego de estratégias passivas tais como brises na cobertura, vidro com filtro de UV e telhas com isolamento térmico são suficientes para garantir o conforto humano, mas a radiação, ainda que baixa, porém constante, que incide diretamente sobre partes do acervo é um risco para os materiais 
mais frágeis. Além disso, esta radiação contribui para flutuações na Te UR interna e para um maior consumo energético, uma vez que o sistema de ar-condicionado precisa constantemente remover a energia excedente. Para todas as instituições visitadas, verificou-se posicionamento incorreto de luminárias e uso de luz fluorescente (em detrimento das lâmpadas LED, mais eficientes, porém mais custosas);

- Tincorreta: todas as instituições visitadas monitoram a temperatura interna e relataram dificuldades com a manutenção de valores constantes e dentro do intervalo recomendado pelas diretrizes internacionais. Por outro lado, faltam pesquisas que permitam ajustar os parâmetros recomendados à realidade local. 0 uso de sistemas de avaliação das áreas de guarda, que permitam identificar climas e microclimas internos, avaliar e documentar o estado de conservação dos itens e planejar a distribuição dos objetos de acordo com as características climáticas ou microclimáticas específicas poderia auxiliar na mitigação dos riscos. Todas as instituições visitadas que utilizam sistemas para o condicionamento do ar relataram alguma dificuldade. As empresas terceirizadas responsáveis pela gestão e manutenção dos equipamentos não conseguem garantir que os sistemas mantenham T e UR constantes, dentro dos parâmetros recomendados. São muito poucos os profissionais especialistas em ar-condicionado para o patrimônio cultural, por isso, o diálogo entre estas equipes e os conservadores encontra desafios. Além disso, percebeu-se que há uma tendência a se minimizar o impacto das características construtivas da edificação no desempenho ambiental em detrimento das características mecânicas dos equipamentos. As condições mais estáveis foram observadas na BBM. 0 AHM reportou bom desempenho ambiental no subsolo do edifício principal;

- UR incorreta: características similares às da temperatura podem ser observadas para a UR nas áreas de guarda visitadas. As instituiç̧ões monitoram os ambientes e sabem que os valores de UR interna estão quase sempre acima dos parâmetros máximos especificados pelas diretrizes internacionais. Nos ambientes condicionados e naqueles que fazem uso de desumidificadores verifica-se flutuações ao longo de 24 horas. Todas as áreas de guarda visitadas apresentavam algum sinal de degradação química da fibra de celulose (odor característico), indicativo de elevada T e UR. Assim como para a T, faltam pesquisas que possam orientar os conservadores quanto às alternativas, que minimizem os danos e estejam adaptadas à realidade brasileira. Algumas observações empíricas parecem indicar que o uso combinado de ar-condicionado e desumidificadores pode auxiliar na manutenção de condições mais estáveis, no entanto, não há pesquisas sobre 0 impacto desta solução nos materiais de construção de edifícios históricos. Também para este agente de deterioração, as melhores condições foram observadas na BBM e no subsolo do AHM; 
- água (natural): não foram identificadas vulnerabilidades significativas relacionadas a eventos adversos com água, tais como inundações. No entanto, todas as instituições visitadas reportaram eventos adversos cuja origem estava nos sistemas de cobertura e de drenagem da água pluvial. Tendo em vista as mudanças climáticas, ainda mais prevalentes em megacidades como São Paulo, com aumento na quantidade e intensidade de chuvas e granizo, existe o risco de sobrecarga de sistemas construtivos mais frágeis (coberturas, esquadrias, drenagem, etc.) em edifícios históricos. Além disso, temporais mais intensos têm potencial para provocar alagamentos em locais historicamente não suscetíveis, o que precisa ser monitorado por todas as instituições, principalmente aquelas com acervo no subsolo;

- água (não natural): as ameaças relacionadas a eventos adversos com água causados por inadequações ou falhas em sistemas construtivos estão entre as principais preocupações dos conservadores, uma vez que acidentes com água têm grande potencial de dano e perda de itens. Todas as instituiçõ̃es visitadas reportaram a ocorrência de algum evento adverso relacionado ao sistema hidráulico (água fria, esgoto ou drenagem) ou ao sistema de ar-condicionado (tubulação de água gelada ou drenos). Protocolos para limpezas e manutenções preventivas destes sistemas envolvem mudanças em regras e hábitos institucionais e têm se mostrado um grande desafio;

- fogo (direto): também não foram identificadas ameaças relevantes relacionadas ao fogo diretamente. A maior preocupação relatada pelos conservadores eram os balões, presença constante na cidade e causa de um incêndio importante na biblioteca do Centro Cultural São Paulo4. Até o momento em que foram realizadas as visitas, todas as instituições contavam com brigada e equipamentos de proteção contra incêndio mas ainda não tinham um plano completo de resposta a uma emergência nem realizavam simulados frequentes, que incluísse todos os funcionários;

- fogo (indireto): as instituições visitadas, coincidentemente, tinham em comum o fato de terem passado por reformas ou readequações nos últimos anos, o que significa que ao menos parte das instalações elétricas eram novas e os circuitos não estavam sobrecarregados. Foram observadas inadequações pontuais, de conhecimento da instituição e com baixo potencial de risco de incêndio. No entanto, por ser esta a principal causa de perda total de acervos, todos os conservadores relataram preocupações e, por precaução, nos edifícios históricos, os equipamentos (desumidificadores e/ou ventiladores) das reservas

\footnotetext{
${ }_{4}^{4}$ Maiores informações podem ser obtidas em: https://www.prefeitura.sp.gov.br/cidade/secretarias/comunicacao//noticias/?p=125819, acesso em jan. 2021.
} 
técnicas eram desligados quando não havia funcionários responsáveis pelas áreas de guarda (à noite, fins de semana, feriados e férias). Houve relatos de ocorrência de serviços de manutenção, realizados por empresas não especializadas, que trouxeram algum risco de incêndio à instituição. A modalidade de licitação pelo menor preço, que é a forma mais utilizada pelas instituições públicas, foi descrita como problemática por não considerar a complexidade e a fragilidade das áreas de guarda de acervos.

Nota (3): Tem-se semelhanças e diferenças construtivas entre os edifícios históricos visitados e 0 edifício da BBM USP. A principal semelhança está na maneira como se organiza a manutenção e a gestão das facilidades. Tanto as instituições administradas pela prefeitura de São Paulo (AHM e BMA) quanto aquelas administradas pela USP (reservas temporárias do MP e BBM) utilizam três mecanismos distintos e complementares para a manutenção preventiva e corretiva dos edifícios e seus sistemas: a. técnicos próprios da instituição para realização de pequenos reparos; b. serviço de manutenção corrente realizado por empresas terceirizadas (manutenção de sistemas mecânicos, elétricos, de segurança, etc.), contratadas pela própria instituição; c. projeto e contratação de obras de reforma, readequação, ampliação etc., sob responsabilidade de um setor externo (Departamento de Edificações - EDIF da prefeitura de São Paulo e Superintendência do Espaço Físico - SEF da USP). Apenas a BMA possui maior autonomia e equipe própria de arquitetos para a gestão das facilidades. Nas demais instituições esta tarefa está a cargo de um funcionário administrativo. Nenhuma instituição possuía, até 0 momento das visitas, plano para a gestão das facilidades com previsão de manutenção preventiva dos sistemas tendo em vista a mitigação de riscos ao acervo. Os arquitetos e engenheiros do setor externo à instituição não possuem especialização em patrimônio cultural ou conservação preventiva. Não havia, em nenhuma instituição visitada, política institucional orientada ao trabalho interdisciplinar entre os funcionários responsáveis pela manutenção do edifício e os responsáveis pela conservação dos acervos. As licitações, pelo menor preço (apenas a BMA possuía cadernos técnicos para licitações por técnica e preço), a diminuição gradativa de funcionários próprios em detrimento de terceirizados e a redução dos recursos financeiros foram fatores apontados por todas as instituições como os grandes desafios da atualidade e fonte de perigos para os acervos.

A principal diferença entre os casos de estudo está na técnica construtiva utilizada: os edifícios históricos possuem principalmente estrutura de concreto armado, com vedações verticais em alvenaria, esquadrias metálicas e cobertura com telha cerâmica ou laje de concreto, já o edifício da 
BBM possui estrutura e vedação em concreto armado, com grandes painéis envidraçados e cobertura metálica. Além disso, tem-se que a maioria dos edifícios históricos foram adaptados para que pudessem armazenar acervos (excessão à sede da BMA), já a a BBM foi projetada especificamente para ser uma biblioteca de livros e documentos especiais e raros. No entanto, também no que tange a estes aspectos, as diferenças se mostram menores do que as semelhanças. Todos os edifícios apresentam vulnerabilidades construtivas que estão associadas, principalmente, à combinação de baixa qualidade de materiais construtivos; falta de uma cultura, no setor público, que valorize o uso de materiais e equipamentos mais robustos, inicialmente mais custosos, porém com menor risco aos acervos ao longo da vida útil do edifício; e deficiências, durante a etapa de projeto, na avaliação da eficiência energética do edifício, e, na etapa de execução, de fiscalização das obras (comissionamento). Todas as edificações visitadas possuem vulnerabilidades relacionadas à baixa inércia térmica, à ausência de isolamento térmico (nas vedações e nos caixilhos e das pontes térmicas) e de barreiras ao ar e ao vapor e/ou a falhas nas estratégias para controlar ou bloquear a incidência de luz natural sobre o acervo. No caso da BBM, nota-se que estratégias bem planejadas para o conforto humano e a eficiência energética trazem, inadvertidamente, riscos potenciais aos acervos: a iluminação zenital, mesmo que protegida por brises e filtro de UV, permite a incidência de luz solar sobre parte dos itens guardados nos anéis; 0 uso de resfriamento evaporativo por meio de espelhos d'água pode causar um evento adverso, seja pela infiltração de água no subsolo, seja pela proliferação de microorganismos e insetos; a maior permeabilidade do solo com a criação de jardins nos dutos de iluminação do subsolo, mantem um ambiente sombreado e úmido, propício à proliferação de microorganismos e insetos; a automação e integração de sistemas prediais faz com que uma falha possa ter impactos potenciais sobre todos os sistemas ativos controlados por ele. Como o edifício da BBM é mais complexo que os demais, os mecanismos públicos padrão para manutenção predial, explicados acima, se mostram ainda mais insuficientes, e a presença de um gestor de facilidades especialista é altamente recomendada.

Nota (4): Tem-se, a seguir, uma breve descrição das principais vulnerabilidades encontradas. É importante destacar que, também neste caso, a classificação dos sistemas construtivos foi adaptada para esta pesquisa, e maiores explicações podem ser obtidas no capítulo 6 desta tese. Os sistemas construtivos que não foram descritos, não possuíam vulnerabilidades significativas ou não foram avaliados, uma vez que o escopo das visitas técnicas eram apenas as áreas de guarda e não o edifício como um todo. 
- cobertura: este sistema construtivo, seja nos edifícios históricos ou no contemporâneo, foi apontado pelos funcionários como um ponto vulnerável da edificação, que demanda inspeções constantes, manutenções de rotina e substituição preventiva de componentes para minimizar ameaças por roubo e vandalismo, poluentes, pragas (insetos e animais), T e UR incorretas, ou água. Todas as instituiç̧̃es visitadas relataram ter experienciado evento(s) adverso(s) por falhas ou manutenção insuficiente no sistema de cobertura;

- vedações verticais: foram observadas manifestações patológicas relacionadas a movimento ascendente de vapor d'água, infiltrações ou trincas, em paredes externas ou internas, de áreas com acervos em todas as instituições visitadas. A redução ou eliminação da ventilação natural nos edifícios históricos, inadequações ou falhas construtivas relacionadas à impermeabilização e drenagem da água e/ou ausência ou deficiência em manutenções e readequações ao longo dos anos são as prováveis causas destas manifestações. As ameaças aos acervos relacionadas a estas ocorrências são: pragas (insetos), microorganismos, Te UR incorretas, ou água;

- vãos e esquadrias: esquadrias, com alguma frequência, apresentam não conformidades e não permitem 0 adequado isolamento entre o meio externo e interno. Nos edifícios históricos, verificou-se que muitos caixilhos em ferro apresentavam pontos de oxidação e falhas no mecanismo de acionamento das folhas. Em alguns edifícios, observou-se inadequações na execução da instalação dos caixilhos e a presença de vãos e trincas no encontro deles com a parede. 0 uso de vidros simples e caixilhos sem isolamento térmico pode criar pontes térmicas e condensações, principalmente quando a temperatura externa está elevada e os ambientes são condicionados, o que eleva o risco de deterioração do próprio elemento construtivo e da envolvente, e traz ameaças aos acervos. Na maioria das vezes, verificou-se também que os vidros não tinham tratamento ou película para proteção UV. Em alguns casos, havia incidência de radiação solar direta nas áreas de guarda de acervos em alguns períodos do dia e do ano. As ameaças relacionadas a estas ocorrências são: poluentes, pragas (insetos), microorganismos, T e UR incorretas, luz visível e UV;

- instalações hidrossanitárias: foram identificados três tipos de manifestações patológicas relacionadas aos sistemas hidráulicos e de captação de águas pluviais: o tipo mais comum são as falhas nos sistemas de drenagem da água da chuva, seja pelo subdimensionamento dos dutos (inadequados ao regime pluviométrico atual), seja por limpeza insuficiente de calhas e condutores; também foram relatados vazamentos em tubulações que, incorretamente, passam por dentro das áreas de guarda; e, por fim, 
também foi relatada uma ocorrência de contaminação da água utilizada no tratamento do acervo por uso de material incorreto durante a execução do sistema de água fria/quente. Ocorrências nos sistemas hidráulicos estão entre os principais perigos a acervos em papel e a causa pode estar no projeto (tubulações que passam por dentro de áreas de guarda; subdimensionamento do sistema), na execução (vedação incorreta entre as partes; ângulo de queda incorreto), no material (material inadequado ao uso) ou na manutenção (ausência ou insuficiência; procedimentos em desacordo com as recomendações e normas técnicas). A inspeção e limpeza frequente dos sistemas hidrossanitários e uma mão-de-obra qualificada são essenciais para minimizar os riscos. Apenas parte das instituições visitadas tinham um plano de preparação para emergência com água, com materiais e equipamentos para proteção e resgate do acervo;

- instalações elétricas: as instituições visitadas apresentavam instalaç̧ões elétricas renovadas, em condições adequadas, no entanto, foi possível observar algumas ameaças pontuais relacionadas a uso e manutenção em desacordo com normas de segurança (fios expostos, extensões incorretas, tomadas sobrecarregadas). As principais ameaças ao acervo reportadas pelos conservadores estavam relacionadas às luminárias (tipo ou posicionamento incorreto) e/ou às lâmpadas (dificuldades para substituição de lâmpadas incandescentes ou fluorescentes e/ou na aquisição de lâmpadas LED adequadas para a preservação do acervo);

- instalações mecânicas: sistemas mecânicos tais como ar-condicionados, elevadores e bombas, foram descritos como vulnerabilidades dos edifícios e motivo de preocupação para os funcionários entrevistados. A principal razão são falhas na manutenção (insuficiente ou realizada por mão-de-obra pouco especializada). Foi relatado que sistemas mecânicos podem ficar desligados por longos períodos de tempo por falhas na gestão dos processos de licitação dos serviços de manutenção. Parte significativa das ocorrências identificadas estão no sistema de ar-condicionado. Dentre as principais vulnerabilidades relatadas, tem-se: o sistema não mantém os ambientes com T e UR estável e dentro dos parâmetros normativos; não é possível o controle individualizado dos ambientes e, portanto, acervos e funcionários devem compartilhar os mesmos parâmetros (muito frio para as pessoas ou muito quente para os acervos); 0 condicionamento não é uniforme por todo o ambiente e algumas zonas ficam mais quentes do que outras; a posição dos pontos de entrada e saída de ar causam perturbações aos usuários e/ou aos objetos; a tubulação de água gelada passa por dentro da reserva técnica. A maioria das ocorrências estão relacionadas a falhas no projeto ou na execução do serviço de instalação do sistema. Também foi reportada a hipótese de que uma limpeza incorreta em dutos e filtros possa estar associada a uma maior 
contaminação por fungos em objetos imediatamente abaixo das saídas de ar, no entanto, estudos e análises mais aprofundadas são necessárias para estabelecer correlações.

- instalações contra incêndio: as emergências com fogo são a principal causa de perda de acervos em papel. Apesar de todas as instituições visitadas possuírem equipamentos para combate a incêndio, nem todas tinham sistema de detecção e alarme. Além disso, foram relatadas falhas na manutenção de equipamentos. A maioria das instituições visitadas reportou que não havia inspeção de rotina nem manutenção preventiva de válvulas e tubulações, o que resultava em desconfiança quanto ao adequado funcionamento no caso de uma emergência. Também foram mencionados eventos relacionados a inoperância das bombas para transporte de água para os reservatórios e o desligamento de detectores de fumaça por mal funcionamento. Os conservadores observaram também que faltam planos de preparação para uma emergência com fogo, bem como treinamentos e simulados.

\subsubsection{Entrevistas estruturadas com pessoas-chave ${ }^{5}$}

A entrevista é um instrumento tradicional para obtenção de informações subjetivas dos usuários e é um importante mecanismo para se entender a interação pessoa-ambiente. Para que seja eficaz, a entrevista deve ser breve e simples e o entrevistador precisa despertar empatia, para que o entrevistado se sinta confortável para falar. É um instrumento qualitativo que permite 'humanizar' os dados técnicos e pode, muitas vezes, esclarecer alguns detalhes que não puderam ser captados durante as visitas técnicas (maiores informações podem ser obtidas no capítulo 2 desta tese).

Para esta pesquisa foram elaborados três roteiros, contendo questões fechadas nominais e ordinais combinadas com questões abertas para:

a. 0 responsável pela conservação dos acervos em papel: informações sobre diagnósticos dos espaços físicos e políticas de avaliação da qualidade ambiental das áreas de guarda;

b. o responsável pela gestão do acervo e monitoramento ambiental das áreas de guarda: informações sobre as condições dos acervos, os equipamentos utilizados nas áreas de guarda, o monitoramento ambiental e o tratamento dos dados; a presença de arquitetos/engenheiros na instituição; e a integração entre as equipes;

\footnotetext{
5 Conforme explicado no capítulo 5.3, acima, esta pesquisa foi aprovada pelo Comitê de Ética em Pesquisa - CEP EACH USP em 09 de janeiro de
} 2019, sob número de protocolo CAAE 02912118.2.0000.5390. Os modelos das entrevistas podem ser encontrados nos Apêndices. 
c. 0 responsável pela manutenção predial: informações sobre as condições dos espaços físicos; os procedimentos para manutenção dos equipamentos usados nas áreas de guarda; a relação com a conservação preventiva; e a presença de políticas de integração das equipes e de avaliação do ambiente construído.

As entrevistas foram realizadas após a assinatura da Solicitação de Autorização pelo responsável pela instituição, entre os meses de fevereiro e abril de 2019. Elas se iniciaram com a leitura e assinatura do TCLE6 ${ }^{6}$. As perguntas foram lidas e as respostas anotadas e gravadas. As informações receberam anuência do entrevistado. Por motivos éticos os entrevistados não serão identificados nominalmente nesta pesquisa. Apesar de não ser possível, a partir dos dados coletados, se fazer generalizações para todas as instituições culturais paulistanas (ou brasileiras), pretende-se, com as entrevistas, estabelecer semelhanças e diferenças entre os quatro casos de estudo (Quadros 33 a 35).

Quadro 33. Entrevista com profissional-chave da conservação preventiva

\section{Pergunta:}

\section{Síntese das respostas:}

Os entrevistados possuem graduações diversas (arte, arquitetura, história,

Função: biblioteconomia). Todos são responsáveis pela conservação de acervos. A conservação preventiva não é uma atribuição claramente definida em nenhuma das instituições caso de estudo.

Os acervos são muito numerosos e têm como principal suporte o papel, mas os itens são bastante variados e podem incluir microfilmes, fotografias, aquarelas, mapas, desenhos de arquitetura, couros, tecidos, acetatos, etc.

Para os entrevistados da BMA e da BBM, o estado de conservação é razoável, com algumas deformações e/ou focos de mofo; para os entrevistados do AHM e do MP, 0 acervo está em mau estado, com muitas sujidades, deformações, perdas e/ou mofo.

Para a BMA, a principal questão são os focos pontuais de mofo em muitas salas. Sem um estudo mais aprofundado é difícil entender porque estes focos aparecem em alguns locais e em outros não. $0 \mathrm{MP}$ fez vistorias e concluiu que a principal ameaça

Estado de conservação do acervo: são as sujidades, seguida da presença de fungos. A BBM mencionou que o estado de conservação variava conforme a coleção e o estado em que foram adquiridas (se foram incorporadas ao acervo com deformações ou danos por infestações por fungos e/ou insetos). 


\begin{tabular}{|c|c|}
\hline Pergunta: & Síntese das respostas: \\
\hline $\begin{array}{l}\text { Elementos presentes nas áreas } \\
\text { de guarda de acervos: } \\
\text { ar-condicionado: }\end{array}$ & $\begin{array}{l}\text { Apenas as reservas técnicas temporárias do MP não possuem nenhum equipamento de } \\
\text { condicionamento de ar. No entanto, nas demais instituições, os sistemas utilizados } \\
\text { apresentam algum problema (não conseguem manter a UR constante; foram } \\
\text { desenhados para o conforto humano e não do acervo; não é possível regular os } \\
\text { parâmetros por zona; quebram e ficam desligados com frequência; não se encontra } \\
\text { peças para a manutenção; e/ou as empresas terceirizadas de manutenção não } \\
\text { conseguem dar uma resposta satisfatória). }\end{array}$ \\
\hline ventiladores: & $\begin{array}{l}\text { Tanto o MP como a BMA (em algumas salas da sede) utilizam ventiladores pois, } \\
\text { segundo os entrevistados, existem estudos que parecem indicar que, se } \\
\text { corretamente posicionados dentro dos ambientes, eles podem minimizar a } \\
\text { formação de microclimas muito úmidos e dificultar o depósito de poeira e esporos } \\
\text { de fungos sobre o acervo. No MP constatou-se que, sem ventilação, a UR é mais alta } \\
\text { e mais estável e, com ventilação, a UR é mais baixa porém com mais flutuações. } \\
\text { Faltam estudos que indiquem qual opção traz maiores benefícios de longo prazo } \\
\text { para a preservação dos acervos. }\end{array}$ \\
\hline
\end{tabular}

A BMA utiliza desumidificares portáteis em todas as suas reservas. Isto significa uma quantidade considerável de trabalho para esvaziar os reservatórios dos aparelhos. A análise dos dados ambientais parece indicar que quando usados em conjunto com 0 ar-condicionado reduzem e estabilizam os níveis de UR interna. A BBM utiliza um desumidificador no subsolo, pela mesma razão da BMA, com a vantagem que 0 equipamento possui dreno, não precisando ser esvaziado manualmente. Nos anéis, faz uso apenas de esterilizadores de ar. 0 MP e o AHM não utilizam porque perceberam empiricamente que era preciso retirar grandes volumes de água dos reservatórios (risco para o acervo) e que o equipamento aumentava os níveis de flutuação diária da UR interna. Também foram informados que os edifícios históricos por não terem barreiras ao vapor não poderiam impedir o fluxo de vapor d'água entre o meio externo e 0 interno. Os entrevistados relataram a necessidade de mais pesquisas e recomendações sobre as melhores práticas para a desumidificação do ar.

Os envidraçados das áreas de guarda do edifício anexo do AHM e das áreas de guarda da BMA não possuem película de proteção com filtro de UV. Nas reservas temporárias do MP apenas parte das janelas receberam proteção e na BBM, tanto os vidros dos

filtro de UV: anéis como da cobertura possuem filtro de UV. No entanto, como qualquer quantidade de luz é potencialmente danosa, faltam estudos que demonstrem o grau de efetividade destas películas.

A BMA utiliza tela-mosquiteiro na maior parte das janelas das áreas de guarda e na BBM elas estão presentes apenas nas salas de estudo, uma vez que os envidraçados tela- mosquiteiro: das áreas de guarda são fixos. No MP e no AHM as janelas não têm proteção contra a entrada de insetos mas permanecem sempre fechadas. 
Quadro 33. Entrevista com profissional-chave da conservação preventiva (continuação)

\begin{tabular}{|c|c|}
\hline Pergunta: & Síntese das respostas: \\
\hline elementos de proteção: & $\begin{array}{l}\text { As janelas do anexo da BMA possuem brises externos, porém eles não são 100\% } \\
\text { eficientes contra a incidência de luz solar direta. A BBM utiliza telas solares e black-outs } \\
\text { nos laboratórios de conservação mas não nos anéis. } 0 \text { edifício sede da BMA, o AHM e } 0 \\
\text { MP não utilizam nenhum elemento para proteção dos envidraçados. }\end{array}$ \\
\hline Monitoramento ambiental: & $\begin{array}{l}\text { Todas as instituições fazem monitoramento da Te UR internas e dos insetos nas áreas de } \\
\text { guarda. O AHM também monitora a iluminância e a BBM e o MP monitoram a } \\
\text { quantidade de material particulado depositado sobre as superfícies. A BMA e a BBM } \\
\text { utilizam o sistema Climus para coleta e tratamento dos dados. O AHM e o MP utilizam } \\
\text { medidores portáteis como termômetros, termohigrômetros e dataloggers. } \\
\text { Os dados coletados são transformados em gráficos e organizados na forma de relatórios. } \\
\text { Os entrevistados relataram que os relatórios são usados principalmente como registro } \\
\text { documental das condições ambientais. Eles também costumam ser enviados a } \\
\text { supervisores e discutidos em reuniões. Não há, em nenhuma das instituições } \\
\text { consultadas, uma política de melhoria da qualidade ambiental baseada em diagnóstico. }\end{array}$ \\
\hline $\begin{array}{l}\text { Nível de preparo para lidar com a } \\
\text { manutenção do edifício e de } \\
\text { equipamentos: }\end{array}$ & $\begin{array}{l}\text { Os conservadores relataram se sentir pouco preparados ou preparados para lidar com os } \\
\text { profissionais responsáveis pela manutenção do edifício. Muito do preparo, segundo eles, } \\
\text { tem relação direta com a necessidade de se adquirir conhecimento na prática para poder } \\
\text { instruir as equipes terceirizadas quando seus serviços interferem diretamente com as } \\
\text { áreas de guarda. No entanto, estas informações nem sempre vêm de fontes confiáveis já } \\
\text { que não existe um curso de formação nesta área. Além disso, a linguagem técnica é } \\
\text { muito específica e alguns sistemas construtivos são muito complexos. Um dos } \\
\text { entrevistados relatou que se sentiria bem preparado se pudesse dialogar com arquitetos } \\
\quad \text { e engenheiros especialistas em áreas de guarda e conservação preventiva. }\end{array}$ \\
\hline $\begin{array}{l}\text { Presença de arquitetos ou } \\
\text { engenheiros na instituição, } \\
\text { responsáveis pela manutenção: }\end{array}$ & $\begin{array}{l}\text { Apenas a BMA possui equipe própria. } 0 \text { MP relatou que a SEF USP tem trabalhado } \\
\text { próxima ao museu neste período de transição, por causa da mudança dos acervos para } \\
\text { imóveis temporários (e a necessidade de adaptações construtivas) e do início das obras } \\
\text { no edifício-monumento. No entanto, em ambos os casos, a comunicação entre as equipes } \\
\text { de conservação e os arquitetos e engenheiros acontece de forma indireta, por meio das } \\
\text { chefias, de e-mails ou de ordens de serviço (OS), não havendo integração entre os setores. } \\
\text { Todos os entrevistados consideram que seria importante a presença de arquitetos ou } \\
\text { engenheiros especializados na própria instituição pois facilitaria uma execução mais ágil } \\
\text { dos trabalhos de manutenção preventiva e corretiva e poderia auxiliá-los na } \\
\text { compreensão de questões técnicas específicas, o que pode ser corroborado pela } \\
\text { experiência da BMA, que relatou como positiva a presençca de dois arquitetos no quadro } \\
\text { institucional, uma vez que a manutenção orientada à preservação de acervos é complexa. }\end{array}$ \\
\hline $\begin{array}{l}\text { Política de integração entre as } \\
\text { equipes de conservação e } \\
\text { manutenção: }\end{array}$ & $\begin{array}{l}\text { Em nenhuma das instituições consultadas existe uma política para integração entre } \\
\text { conservação preventiva e manutenção. A BBM relatou que existe política } \\
\text { institucional apenas para a preparação de exposições. Na BMA e no MP comentou-se } \\
\text { que havia uma integração informal, por ser esta uma necessidade compartilhada } \\
\text { entre todos os funcionários. }\end{array}$ \\
\hline
\end{tabular}

Fonte: a pesquisadora 
Quadro 34. Entrevista com profissional-chave de acervos em papel

\begin{tabular}{|c|c|}
\hline Pergunta: & Síntese das respostas: \\
\hline Função: & $\begin{array}{l}\text { Os entrevistados têm formação em humanidades (história e artes) e trabalham como } \\
\text { técnicos ou supervisores. }\end{array}$ \\
\hline $\begin{array}{l}\text { Diagnóstico da qualidade do } \\
\text { espaço físico: }\end{array}$ & $\begin{array}{l}\text { Todos os entrevistados consideram importante a realização de diagnóstico porque } \\
\text { percebem a necessidade de melhorias constantes, o que é dificultado pela ausência } \\
\text { de uma melhor compreensão dos problemas e das necessidades. Além disso, novas } \\
\text { demandas podem surgir com o passar do tempo. }\end{array}$ \\
\hline $\begin{array}{l}\text { Roteiros prontos para diagnóstico } \\
\text { de acervos: }\end{array}$ & $\begin{array}{c}\text { Os entrevistados do AHM e o MP sabem que existem roteiros para diagnóstico das } \\
\text { condições de guarda de acervos. Os entrevistados da BMA e da BBM não conhecem } \\
\text { estas metodologias. Apenas o MP já utilizou os roteiros do Re-Org e do National Park } \\
\text { Service (NPS). }\end{array}$ \\
\hline $\begin{array}{l}\text { Políticas institucionais para } \\
\text { avaliação e diagnóstico das áreas } \\
\text { de guarda: }\end{array}$ & $\begin{array}{c}\text { Segundo os entrevistados, nenhuma das instituições possui política de avaliação dos } \\
\text { ambientes voltada à conservação preventiva dos acervos; as iniciativas são pessoais e } \\
\text { individualizadas. }\end{array}$ \\
\hline Sugestões: & $\begin{array}{c}\text { Foram sugeridas principalmente avaliações diagnósticas dos sistemas de } \\
\text { condicionamento ambiental e desumidificação do ar com o objetivo de melhor } \\
\text { compreender as flutuações nos níveis de UR internos e sua relação com o } \\
\text { aparecimento de mofos e de pragas. Também foram sugeridas atividades como } \\
\text { treinamentos, oficinas e simulados, tanto para os funcionários próprios, como para os } \\
\text { terceirizados. }\end{array}$ \\
\hline
\end{tabular}

Fonte: a pesquisadora

Quadro 35. Entrevista com profissional-chave da manutenção do edifício

\begin{tabular}{l|l}
\hline \multicolumn{1}{c|}{ Pergunta: } & \multicolumn{1}{c}{ Síntese das respostas: } \\
\hline Função: & técnicos; na BMA, supervisor (arquiteto) \\
\hline Condições físicas do edifício: & $\begin{array}{l}\text { Os funcionários da BMA e da BBM afirmaram que o edifício está em bom estado, } \\
\text { tendo apenas ocorrências esporádicas. Os técnicos do AHM e do MP disseram que 0 } \\
\text { espaço construído está em estado razoável, com ocorrências frequentes. As principais } \\
\text { vulnerabilidades pontuadas se referem a problemas relacionados à água (vazamentos, } \\
\text { transbordamentos, movimento ascendente de vapor) e aos sistemas eletromecânicos } \\
\text { (lâmpadas, ar-condicionado). Foi observado por todos que as verbas são insuficientes } \\
\text { para a manutenção adequada de todos os sistemas. }\end{array}$ \\
\hline
\end{tabular}

(continua) 


\begin{tabular}{l|c}
$\begin{array}{l}\text { Elementos presentes nas áreas de } \\
\text { guarda de acervos: }\end{array}$ & $\begin{array}{c}\text { Apenas as reservas técnicas temporárias do MP não possuem nenhum sistema de } \\
\text { condicionamento do ar. Todos os entrevistados relataram que a manutenção é feita } \\
\text { por empresa terceirizada, mas, por falta de recursos ou de peças de reposição, } 0 \\
\text { sistema ou parte dele, com frequência funciona de maneira incorreta ou fica } \\
\text { desligado. }\end{array}$ \\
\hline
\end{tabular}

Apenas a BBM não faz uso de ventiladores em áreas de guarda (todos os andares são ventilados pelo sistema de condicionamento do ar). Na BMA foi explicado que os

ventilador: funcionários preferem não utilizar o sistema de ar-condicionado (compartilhado com as reservas técnicas) e utilizam ventiladores nas áreas de apoio técnico na maior parte do ano. No MP ele vem sendo utilizado como a principal estratégia na mitigação dos riscos aos acervos.

\section{desumidificador portátil:}

Todas as instituições possuem desumidificadores. Nas reservas temporárias do MP ele não está sendo utilizado. A BBM utiliza apenas na reserva técnica do subsolo, que é muito úmida, mesmo com o sistema de ar-condicionado. No AHM eles são utilizados

\section{cesumidificador portátil:} nas salas mais úmidas. Na BMA existem pelo menos dois desumidificadores por andar de reserva técnica, tanto na sede como no anexo. Novos equipamentos foram adquiridos recentemente, mas são portáteis e não estão conectados a um sistema de drenagem de água.

Todas as instituições possuem sistema de automação para a segu rança patrimonial (portas, alarmes, etc.). A BMA utiliza iluminação de fachada automatizada. A BBM automação predial: possui automação de todos os sistemas eletromecânicos, no entanto, a placa de controle do sistema só pode ser revisada pela empresa fornecedora, o que inviabilizaria o processo de licitação, por isso, está sendo estudada a viabilidade de substituição desta placa por um sistema alternativo.

Todos os entrevistados relataram que uma parte considerável do tempo destinado à manutenção dos edifícios é utilizada na inspeção e substituição de lâmpadas e

iluminação artificial: luminárias. Foi relatado que o uso de lâmpadas fluorescentes em detrimento das de LED ocorre porque os recursos nem sempre são suficientes e/ou a luminária / reator não são compatíveis com LED. Foi explicado também que a substituição de um modelo pelo outro vem acontecendo aos poucos.

segurança / alarme:

segurança / alarme:

Apenas a as edificações de ocupação temporária do MP não possuem bombas d'água. Em todas as demais instituições, as inspeções e manutenções de rotina são feitas por empresas terceirizadas. Ainda assim, foi relatado que parte das bombas, inclusive do sistema de proteção contra incêndio, podem ficar desligadas enquanto aguardam a resolução de entraves burocráticos para serem consertadas. 
Quadro 35. Entrevista com profissional-chave da manutenção do edifício (continuação)

Pergunta:

Síntese das respostas:

Apenas as edificações de ocupação temporária do MP não possuem elevadores em uso. Em todas as demais instituições os elevadores recebem manutenção periódica feita por empresa terceirizada. Foi relatado que a prestação de serviço é adequada e a elevadores: manutenção está em dia. Apenas no AHM a plataforma elevatória para acessibilidade não está contemplada na manutenção terceirizada e, no momento da entrevista, foi explicado que ela estava temporariamente desligada porque se aguardava a resolução de entraves burocráticos para ser consertada.

No AHM e no MP não há detectores nem sprinklers. Na BMA os sprinklers da sede são com gás e do anexo com água. Na BBM há sprinklers com água em todas as reservas.

0 AHM foi a única instituição que reportou falhas pontuais na manutenção de extintores e mangueiras.

Nível de preparo para lidar com a conservação preventiva de acervos (pouco preparado, preparado ou bem preparado):
Apenas o funcionário da BMA (arquiteto) se disse bem preparado para lidar com questões relacionadas aos acervos. Ele atribui seu preparo às reuniões semanais com os conservadores, quando são discutidos eventuais problemas detectados nas áreas de guarda e é decidido o melhor encaminhamento para cada ocorrência. Os técnicos das demais instituições afirmaram estar pouco preparados mas ponderaram que este é um trabalho exclusivo dos conservadores.

Todos afirmaram que a comunicação se dá principalmente por e-mail ou pessoalmente. Também foram mencionadas as ordens de serviço (OS) e as reuniões.

Nenhuma instituição possui uma política institucional para integração entre as equipes de conservação e manutenção. Apenas a BMA possui protocolo para realização de laudo técnico anual do estado de conservação dos edifícios e seus sistemas, atividade que é feita em conjunto pela equipe de projeto e as empresas terceirizadas. 0 relatório é encaminhado para a direção e serve de subsídio para a elaboração dos cadernos técnicos para licitação.
Políticas de integração entre equipes e de avaliação do espaço físico:

Sugestões:
Apenas o entrevistado da BMA quis fazer comentários. Ele pontuou que a perda de funcionários próprios, que não são substituídos após a aposentadoria do servidor, como, por exemplo, o cargo de zelador, tem impactado na qualidade dos serviços de manutenção predial porque é preciso maior fiscalização dos trabalhos terceirizados com uma equipe cada vez menor. 


\subsubsection{Análise do desempenho ambiental das áreas de guarda}

As reservas técnicas e outras áreas com acervos, frequentemente, utilizam equipamentos para medição de T e UR como o única estratégia para monitoramento das condições ambientais e intervenção junto ao ambiente ou ao acervo, quando se perceber uma oscilação crítica. Os dados permitem inferir correlações entre o aumento de um tipo de deterioração, detectado in loco (deformações, fungos, etc.), e os dados climáticos medidos. Apesar de serem uma fonte valiosa de informação, os conservadores das quatro instituições visitadas relataram ter dificuldades com a manipulação dos dados de modo a extrair deles as informações mais relevantes e sentem falta de treinamentos e protocolos que padronizem a coleta e a análise estatística dos bancos dos dados, permitindo comparações, ao longo dos anos ou com outras instituições similares.

A partir das visitas exploratórias e das entrevistas com pessoas-chave de cada uma das quatro instituições casos de estudo desta pesquisa, pode-se chegar a um diagnóstico do desempenho ambiental das áreas de guarda.

0 MP e o AHM utilizam dataloggers posicionados dentro das reservas técnicas. Estes equipamentos precisam ser calibrados e recalibrados periodicamente, conforme recomendação do fabricante. Em nenhuma das instituições os dados coletados eram ajustados levando-se em conta 0 erro de registro aferido pela calibração. Para análises globais, em que a precisão decimal não é determinante, 0 impacto dos erros de registro é pequeno, no entanto, na análise de microclimas, a soma do erro de leitura e da imprecisão do equipamento pode interferir na conclusão dos resultados, principalmente quando se quer comparar zonas diferentes dentro de uma mesma área de guarda (por exemplo, diferenças de T e UR dentro de dois armários distintos). Os dados coletados costumam ser transformados em gráficos mensais e/ou anuais e inseridos em relatórios periódicos das condições ambientais.

A BBM e a BMA utilizam o Sistema de Gerenciamento Ambiental Climus para medição e controle de T e UR, desenvolvido pelo engenheiro Saulo Güths, da UFSC7. Os dados coletados pelos sensores são automaticamente transferidos para um computador e o software do sistema gera gráficos de temperatura e umidade que podem ser usados pelos conservadores como parte de relatórios periódicos de acompanhamento da qualidade ambiental das áreas de guarda. Apesar do sistema coletar e tratar uma

\footnotetext{
7 Departamento de Engenharia Mecânica da Universidade Federal de Santa Catarina.
} 
grande quantidade de dados, também é preciso que um profissional treinado saiba processar estas informações para uma compreensão holística do desempenho ambiental das áreas de guarda.

Todas as instituições realizam reuniões periódicas para discussão dos relatórios. No entanto, as ações resultantes são sempre responsivas, visando à mitigação dos riscos imediatos; não existem políticas para a gestão da qualidade, com previsão de ações de curto, médio e longo prazo para a melhoria continuada do desempenho destes ambientes, mediante protocolos de inspeção, manutenção preventiva e readequação dos sistemas. Tem-se a seguir uma descrição das condições ambientais observadas, por instituição.

a. AHM: os dados climáticos coletados e analisados pela instituição demonstram que os sistemas ativos utilizados poderiam estar melhor adaptados às características construtivas de cada um dos edifícios. Algumas salas no subsolo poderiam utilizar sistemas alternativos (apenas ventilação e/ou desumidificação), já a Torre da Memória precisa de modernização do sistema para atender às demandas específicas de acervos em papel. Observa-se que as reservas técnicas do edifício sede apresentam condições de T e UR estáveis ao longo do ano, notando-se apenas diferenças nos valores absolutos de uma sala para outra, conforme a orientação solar de cada espaço. As reservas técnicas localizadas em uma posição central, sem contato com o ambiente externo, são as mais estáveis e com os itens em melhor estado de conservação. 0 edifício anexo é uma construção é mais frágil, com baixo isolamento e estanqueidade, e nota-se danos às envolventes verticais externas pela presença de umidade por vapor d'água ascendente. A menor inércia térmica do conjunto resulta em variações diárias maiores nos valores de Te UR. Na Torre da Memória, edifício reformado para armazenar acervos do arquivo e de sua biblioteca, os sistemas construtivos também têm baixa inércia térmica, não há janelas nas áreas de guarda e os ambientes são totalmente dependentes do sistema condicionamento artificial, que não foi projetado para as demandas específicas de cada um dos espaços com acervos. São as áreas com as mais elevadas taxas de variação na T e UR do conjunto edificado. A otimização de sistemas e a reorganização na ocupação dos ambientes, conforme as características climática e as demandas de cada objeto, poderiam ajudar na gestão global do patrimônio.

b. BMA: o conjunto edificado da biblioteca possui dois edifícios com características bastante diferentes: a sede é uma edificação com elevada massa térmica, projetada para ser uma biblioteca; a hemeroteca é uma edificação com duas faces envidraçadas (uma delas protegida por brises) e baixa 
inércia térmica, projetada para abrigar escritórios e adaptada para a reserva técnica de acervos. Na sede estão guardados, principalmente, os livros (menos frágeis) e, no anexo, ficam armazenados os jornais e revistas (mais frágeis). 0 sistema de condicionamento de ar da sede é muito antigo e, durante as visitas exploratórias, foi explicado que apenas o modo ventilação estava sendo utilizado enquanto a instituição avaliava como modernizar o sistema. Como o edifício foi muito bem projetado para a guarda de acervos, o uso combinado de ventilação com desumidificadores portáteis têm assegurado condições suficientemente adequadas para manter os acervos estáveis. Durante as entrevistas foi relatado a presença de excesso de material particulado nas reservas, provavelmente causada pela limpeza incorreta dos dutos ou por problemas na troca dos filtros. 0 ar-condicionado da hemeroteca é moderno mas foi projetado e instalado segundo diretrizes para o conforto humano e não para a conservação de papéis. Seu uso combinado com desumidificadores portáteis tem-se mostrado eficiente para manter uma condição climática interna estável. Os dois edifícios fazem uso de pelo menos dois desumidificadores portáteis por andar, os quais precisam ter a água retirada de seus reservatórios manualmente três vezes ao dia (logo pela manhã, ao meio dia e ao final do expediente) pois, quando o reservatório atinge sua capacidade máxima, 0 aparelho desliga-se automaticamente. Como os equipamentos não possuem drenos para a remoção da água, sempre existe o risco de um acidente com água dentro da reserva. Todas as áreas de guarda estão localizadas acima do nível do solo. Percebe-se claramente a influência da construção nos dados climáticos: os andares mais próximos ao solo possuem menor variação nos valores de T e UR ao longo de um dia do que aqueles mais próximos à cobertura. As janelas ficam permanentemente fechadas para bloquear a entrada de pragas, mas os conservadores relataram que é preciso sempre treinar os novos funcionários (há rotatividade nas equipes de estagiários, manutenção, limpeza e segurança) para que restos de alimentos não sejam deixados próximos às áreas de guarda, o que poderia atrair ratos e baratas. Os acervos da BMA há muitos anos convivem com colônias de fungos que, sob determinadas condições, se proliferam. Dada a quantidade de variáveis, foi explicado que não é fácil compreender o porquê das infestações, mas intui-se que características construtivas e dos sistemas ativos utilizados são fatores importantes. No período em que foram realizadas as visitas estas colônias estavam controladas, e não era possível perceber visualmente focos de mofo. Avaliações técnicas e análises específicas, realizadas por equipe 
interdisciplinar, poderiam auxiliar a instituição a melhor compreender as causas das infestações e encontrar soluções eficazes na mitigação dos riscos.

c. MP USP: a percepção da equipe de conservação é de que os objetos com suporte em papel estavam em equilíbrio com as condições ambientais do edifício-monumento (elevada massa térmica; pouca variação nos valores de T e UR internas ao longo de um dia) e a mudança para as novas áreas de guarda temporárias perturbou este equilíbrio. Foi observada a presença de fungos em alguns itens. Eles estavam sendo monitorados e pareciam estáveis, ou seja, a colônia, visualmente, não estava se desenvolvendo. A mudança para edificações com paredes mais finas, grandes áreas envidraçadas, e lajes expostas às intempéries, ou seja, com características construtivas que resultam em maior variação horária e diária de T e UR internas pode ser um fator importante, tanto no aparecimento de fungos, como em uma maior taxa de deformação (ondulações) em alguns papéis. As áreas de guarda (reservas técnicas e biblioteca) foram especialmente adaptadas no pavimento térreo dos edifícios para poderem receber as coleções do edifício-monumento. No entanto, como os ambientes são menores do que os do Museu (em área e volume), os acervos passaram de estantes fixas para deslizantes. Acredita-se que 0 maior adensamento de ocupação combinado com uma menor qualidade ambiental (temperaturas e umidades mais elevadas, maiores flutuações e menor taxa de renovação do ar) também podem estar contribuindo para uma taxa de deterioração mais elevada em alguns itens. Como o sistema elétrico não foi totalmente modernizado, e inspira preocupação, os ventiladores são desligados no período noturno, finais de semana e férias coletivas, o que pode favorecer oscilações na Te UR e o depósito de esporos de fungos e de material particulado sobre os objetos. Por fim, as aberturas possuem caixilhos antigos, com muitas frestas, o que, associado ao fato de existirem áreas ajardinadas e arborizadas próximas das reservas, também podem contribuir para variações climáticas. A equipe de conservação vem buscando alternativas para minimizar as ocorrências identificadas.

d. BBM USP: a percepção dos funcionários é de que a arquitetura foi concebida tendo como premissa a qualidade e a eficiência presumida dos sistemas construtivos: dos materiais impermeabilizantes como barreiras ao vapor; dos filtros de UV contra a radiação solar; do concreto como elemento para isolamento e amortecimento térmico; do sistema de condicionamento artificial automatizado para ambientes de guarda estáveis e seguros. Após a construção e a ocupação, foram observadas algumas inadequações: os ambientes estavam mais úmidos do que se esperava; a radiação solar incidente pela 
cobertura parece provocar desbotamento em alguns objetos; há variação de T e UR dentro das salas e entre as salas das reservas técnicas; e não há mão-de-obra capacitada e nem recursos suficientes para a adequada manutenção dos sistemas automatizados complexos. Os pavimentos para guarda dos acervos (anéis) foram especialmente construídos para este fim, estão acima do solo, em áreas isoladas e climatizadas artificialmente. No entanto, a incidência de luz solar pela cobertura pode estar contribuindo para que haja variações na T e UR ao longo do dia. Verifica-se também a ocorrência de variações no valor da UR dependendo da orientação solar do ambiente, o que pode estar associado à presença de fungos em alguns locais específicos. Percebeu-se também que os materiais com maior sujidade e mofo estão nas prateleiras superiores, o que pode indicar contaminação dos dutos do arcondicionado. No entanto, as correlações entre causas que possam estar associadas a sistemas construtivos e suas consequências para o acervo ainda precisam ser melhor compreendidas. Um gestor de facilidades especialista próprio da instituição é altamente recomendável.

\subsubsection{Considerações finais sobre os casos de estudo}

A partir das informações e impressões coletadas durante as visitas exploratórias guiadas e as entrevistas estruturadas com funcionários-chave das instituiç̧ões culturais estudadas, concluiu-se que:

1. na gestão de instituiç̧ões com acervos, a interdisciplinaridade é uma demanda premente, todos devem ser chamados a participar com suas especialidades. Funcionários em T (elevado conhecimento específico e amplo conhecimento do conjunto) devem ser valorizados;

2. é preciso dar voz a todos os envolvidos na guarda e conservação dos acervos, incluindo as equipes terceirizadas, afinal eles também são responsáveis por observar e zelar pelos valiosos objetos;

3. é preciso desenvolver a cultura do 'perder para ganhar', ou seja, de se separar um tempo para diagnosticar as vulnerabilidades e planejar as próximas ações, para que elas sejam efetivas;

4. é preciso ter consciência de que a preservação é um processo sistêmico, que deve ocorrer ao longo de toda a vida útil do edifício, por isso, edifícios complexos (como são as áreas de guarda) precisam que as instituições tenham em seu quadro organizacional um departamento de gestão de facilidades (FM);

4. é preciso sempre correlacionar custo com vida útil estimada e segurança, tanto para o edifício quanto para as coleções; 
5. é preciso reafirmar a relevância do conhecimento e do desenvolvimento científico como parte deste processo, ou seja, a necessidade de constante atualização: métodos, materiais e técnicas mais eficientes, em conformidade com os avanços tecnológicos e as necessidades do tempo presente;

6. é preciso valorizar o treinamento de todos os funcionários, para que eles possam aplicar técnicas e procedimentos de conservação e manutenção preventiva, em uma visão circular das atividades, orientada ao processo.

Jeff Joplin, diretor de FM do Denver Museum of Nature and Science, expressa com clareza a relação entre manutenção e conservação preventiva e a função de arquitetos e engenheiros como gestores de facilidades nas instituições culturais:

As demandas diárias da FM para a preservação de acervos exigem um trabalho coordenado entre a equipe da conservação preventiva (conservadores, arquivistas, gestores, curadores) e a equipe da manutenção do ambiente construído (gestores de facilidades, engenheiros e equipe de manutenção). Temas como normas e regulamentos, gestão de riscos, demandas das reservas técnicas, limitações de orçamento, prontidão para emergências e tarefas operacionais precisam estar claramente compreendidas, dentro de expectativas comuns. A partir do conhecimento das expectativas, funções e responsabilidades e das regras de participação é que se desenvolve uma instituição. Os sistemas do edifício incluem proteção a incêndio, AVAC [aquecimento, ventilação e ar-condicionado], a envolvente do edifício e os sistemas elétricos e hidráulicos, as práticas para manejo e controle de pragas, limpeza e segurança, e são os aspectos críticos das operações diárias. Os parâmetros, os indicadores e as boas práticas precisam ser determinados para uma adequada avaliação do desempenho e, consequentemente, a proposição de ações de melhoria. Os atrasos na manutenção e os desperdícios de recursos devem ser identificados para garantir que a manutenção do edifício e a qualidade ambiental para as coleções sejam mantidas independentemente do tipo e da idade do edifício. Cada um desses aspectos precisa estar equilibrado uns com os outros para assegurar o sucesso do sistema de FM (ELKIN e NORRIS, 2019; tradução da pesquisadora). 


\section{RESULTADOS}

As visitas técnicas orientadas por procedimentos de Avaliação Pós-Ocupação (APO) e realizadas ao conjunto de instituições que abrigam acervos culturais e científicos, tanto no Brasil como no exterior, benchmarks e casos de estudo desta pesquisa, possibilitaram a identificação de características que podem estar associadas às estratégias baseadas em excelência (eficiência, eficácia e efetividade) para a gestão institucional e das áreas de guarda de acervos. Estes atributos foram organizados em três grupos:

a. Atributos aplicáveis a toda e qualquer instituição, independentemente do país e das condições locais Dentre eles, tem-se:

- consciência de valor do patrimônio;

- capacidade de organização orientada à busca de soluções concretas e factíveis;

- capacidade de aprendizado e comunicação, com vistas à gestão de riscos e incertezas;

- colaboração, trabalho interdisciplinar e/ou transdisciplinar e em equipe.

Estes atributos podem ser classificados como estratégias de consciência institucional.

b. Atributos aplicáveis a toda e qualquer instituiçãa, desde que adaptados às condições locais Dentre eles, tem-se:

- gestão das facilidades, avaliação do desempenho do ambiente construído e manutenção preventiva;

- gestão dos acervos, avaliação dos agentes de deterioração e conservação preventiva;

- gestão dos riscos e preparação para emergências;

- gestão da informação;

- aplicação de princípios de sustentabilidade (uso racional dos recursos disponíveis).

Estes atributos podem ser classificados como estratégias de ação institucional.

c. Atributos condicionados às características locais e aos recursos disponíveis na instituição

Dentre eles, tem-se:

- análises técnicas e laboratoriais;

- tecnologias digitais;

- edifícios e sistemas 'inteligentes'.

Estes atributos podem ser classificados como estratégias de tecnologia institucional. 
Instituições culturais e acervos existem para servir às pessoas, proporcionando a elas a oportunidade de se conectarem, desfrutarem e aprenderem com os elementos legados por aqueles que experienciaram o mundo antes da geração atual. Portanto, antes mesmo de qualquer iniciativa de planejamento, as instituições culturais precisam ter clareza de quem são seus usuários (pesquisadores, visitantes, funcionários próprios e terceirizados, etc.) e quais necessidades específicas de cada grupo, uma vez que o patrimônio não pode ser entendido como um fim em si mesmo. Conhecidas as necessidades dos usuários, o planejamento estratégico das ações e da utilização dos recursos, sempre escassos, precisa ser o resultado de avaliações diagnósticas das características e condições de guarda dos acervos, orientadas a este propósito. Nesta pesquisa, constatou-se que muitas instituições tendem a supervalorizar a importância das estratégias de tecnologia institucional em detrimento das estratégias de consciência, o que pode resultar em estratégias de ação pouco efetivas, mesmo quando embasadas em um planejamento prévio.

\subsection{ANÁLISE SWOT1}

0 planejamento institucional estratégico, para que esteja voltado às necessidades bem como à sustentabilidade, precisa sempre ter em conta a realidade da instituição (seus públicos, seus acervos, seus edifícios, seus recursos, etc.) no momento presente. Alguns atributos podem ser alcançados mediante o incentivo ao aprendizado e ao comprometimento das equipes, já outros precisam de grandes aportes financeiros para serem implementados. Para uma maior clareza dos objetivos e eficiência nos resultados, o planejamento estratégico deve ter início pelo diagnóstico das condições existentes. Um instrumento muito usado nesta etapa é a análise SWOT (Strenghts, WeaknesS, Opportunities and Threats).

Tem-se abaixo uma matriz SWOT com a avaliação global das características observadas em instituições culturais com acervos em papel na cidade de São Paulo, produzida a partir das informações coletadas por meio das muitas consultas junto a profissionais que lidam direta ou indiretamente com acervos² (Quadro 36).

\footnotetext{
1 Em português, esta análise ficou conhecida como análise FOFA (acrônimo para Forças, Oportunidades, Fraquezas e Ameaças).

2 Ressalva-se que, para a construção desta matriz, não foi aplicada a metodologia de entrevistas estruturadas, em parte por não ser este 0 objetivo primário desta pesquisa, e, principalmente, porque não haveria tempo hábil para se realizar uma atividade tão extensa e complexa, a qual se recomenda que seja objeto de uma pesquisa mais aprofundada no futuro.
} 
Quadro 36. Análise SWOT para instituições com acervos em papel em São Paulo

\begin{tabular}{|c|c|c|c|c|}
\hline ASPECTO & FORÇA & FRAQUEZA & OPORTUNIDADE & AMEAÇA \\
\hline planejamento estratégico: & A-metodologia & B - metodologia & C-metodologia & D - metodologia \\
\hline gestão institucional: & $\begin{array}{l}\text { E- estrutura } \\
\text { organizacional }\end{array}$ & $\begin{array}{l}\text { F- estrutura } \\
\text { organizacional }\end{array}$ & $\begin{array}{l}\text { G- estrutura } \\
\text { organizacional }\end{array}$ & $\begin{array}{l}\text { H- estrutura } \\
\text { organizacional }\end{array}$ \\
\hline gestão do patrimônio: & $\begin{array}{l}\text { I- conservação } \\
\text { preventiva }\end{array}$ & $\begin{array}{l}\text { J- conservação } \\
\text { preventiva }\end{array}$ & $\begin{array}{l}\mathbf{K} \text { - conservação } \\
\text { preventiva }\end{array}$ & $\begin{array}{l}\text { L- conservação } \\
\text { preventiva }\end{array}$ \\
\hline gestão das facilidades: & $\begin{array}{l}\text { M - manutenção } \\
\text { preventiva }\end{array}$ & $\begin{array}{c}\mathbf{N} \text { - manutenção } \\
\text { preventiva }\end{array}$ & $\begin{array}{c}\mathbf{0} \text { - manutenção } \\
\text { preventiva }\end{array}$ & $\begin{array}{l}\text { P- manutenção } \\
\text { preventiva }\end{array}$ \\
\hline gestão dos riscos: & $\begin{array}{l}\mathbf{Q} \text { - agentes de } \\
\text { deterioração }\end{array}$ & $\begin{array}{l}\mathbf{R} \text { - agentes de } \\
\text { deterioração }\end{array}$ & $\begin{array}{l}\text { S - agentes de } \\
\text { deterioração }\end{array}$ & $\begin{array}{c}\mathbf{T} \text { - agentes de } \\
\text { deterioração }\end{array}$ \\
\hline
\end{tabular}

Fonte: a pesquisadora.

Tem-se, abaixo, os comentários explicativos para cada item do Quadro 36:

A (Força / planejamento estratégico): existe, no meio acadêmico e científico e nas entidades nacionais e internacionais de preservação do patrimônio, uma ampla opção de metodologias para a gestão de instituições culturais, a avaliação do desempenho dos ambientes construídos e das facilidades, e a análise do estado de conservação dos acervos.

B (Fraqueza / planejamento estratégico): exatamente porque são amplas e variadas, as metodologias precisam ser interpretadas e adaptadas à luz das condições locais. Muitas vezes, percebe-se um estado de paralisia institucional porque o planejamento é percebido como muito difícil e complexo, além das possibilidades institucionais e, por isso, ele é rejeitado antes mesmo de ser tentado. Quem estuda o tema da perspectiva da psicologia comportamental, afirma que se sai desta condição atribuindo-se mais valor à coragem de dar o primeiro passo do que ao medo de errar. 'Gastar' tempo com o planejamento, mesmo que simplificado e imperfeito, mas aberto a melhorias, é mais gratificante do que a continuidade de rotinas que estão claramente sendo percebidas pelo corpo de funcionários como ineficientes.

C (Oportunidade / planejamento estratégico): superado o estado inicial de paralisia, tem-se, para a maioria das instituições culturais, uma grande oportunidade de se iniciar um ciclo virtuoso. 0 planejamento estratégico, assim como as atividades de gestão, é mais difícil e trabalhoso nos seus estágios iniciais; uma vez estabelecidos planos e protocolos de trabalho adequados, sistematizados, que considerem revisões e melhorias, cria-se, então, como sustenta a literatura, uma rotina de trabalho 
mais simples e previsível, o que favorece 0 aprimoramento das metodologias e o envolvimento de outros atores.

D (Ameaça / planejamento estratégico): a instituição deve estudar benchmarks com cautela: modelos internacionais, de instituições muito maiores, com características climáticas e construtivas diversas, e com muito mais recursos costumam, frequentemente, ser usados como paradigmas de gestão. Além disso, é falsa a afirmação de que, a priori, as decisões tomadas por benchmarks são sempre acertadas. A abundância de recursos também pode resultar em uma gestão pouco sustentável, tanto quanto a falta deles. É frequente o hábito de se fazer comparações entre realidades muito diversas, resultando em uma depreciação de instituições já bastante frágeis. A melhor defesa contra essas ameaças é 0 desenvolvimento do planejamento estratégico possível, viável, negociado entre todos os funcionários, e que resulte em uma maior confiança institucional quanto às decisões adotadas.

E (Força / gestão institucional): as instituiç̧ões culturais paulistanas (e brasileiras) ainda são, em grande parte, públicas, sem fins lucrativos, e costumam ter em seus quadros profissionais especialistas altamente capacitados e comprometidos com a missão institucional. A despeito dos poucos recursos de que (sempre) dispõe a área da cultura, encontra-se, com muita frequência, profissionais que são chamados pela literatura especializada de 'vocacionais' (entendem seu trabalho como uma 'missão' de zelar pelo patrimônio). Nota-se também, muitas vezes, uma menor pressão por quantidade de resultados e um maior foco na qualidade.

F (Fraqueza / gestão institucional): por outro lado, este mesmo caráter público resulta, muitas vezes, em cargos de decisão comissionados, por indicação política, sem pré-requisito técnico. Estes gestores, com certa frequência, não têm uma relação prévia com a instituição, nem conhecimentos na área de preservação do patrimônio, e tendem a permanecer pouco tempo no cargo. A cada dois ou quatro anos é comum que os funcionários tenham o retrabalho de explicar, para uma nova chefia, as práticas correntes e os projetos em andamento, sem a garantia de que eles serão continuados. Além disso, as estruturas públicas de gestão costumam ser antiquadas, ainda dependentes de um modelo excessivamente piramidal (em oposição a uma estrutura em rede), com alta concentração de poder decisório na mão dos diretores. Tem-se também, como resultado desta estrutura, uma visão 
organizacional bastante hierarquizada, com pouca participação dos funcionários nas decisões institucionais, mesmo quando estes profissionais são especialistas com ampla formação nas áreas fins.

G (Oportunidade / gestão institucional): profissionais altamente especializados, dedicados e comprometidos são um recurso disponível muito valioso, e uma oportunidade para aprimoramentos. Cabe às instituições encontrar meios para incorporar estratégias organizacionais mais contemporâneas, flexíveis e colaborativas, que permitam fazer uso dos recursos subutilizados no cumprimento da missão institucional.

H (Ameaça / gestão institucional): o patrimônio cultural, mesmo quando negligenciado, sempre tem potencial de mobilizar afetos na população. E, por isso, está constantemente sob a ameaça de intervenções oportunistas. A união das instituições em redes colaborativas, de apoio mútuo, com a participação de todos os interessados, pode ajudar a fortalecê-las e torná-las mais resilientes a estas ameaças.

I (Força / gestão do patrimônio): as instituições culturais precisam cuidar de grandes quantidades de acervos, sempre crescentes, por isso, princípios da conservação preventiva, mesmo quando não completamente estruturados, já são uma realidade na maioria das instituições. Tem-se também um conjunto de experiências e práticas empíricas, desenvolvidas ao longo dos anos na busca por conservar da melhor forma possível os mais variados objetos, em climas tropicais e semi-tropicais, e em edifícios antigos e pouco adaptados. 0 próximo passo é a organização e documentação desse conjunto de conhecimento para que possa ser testado cientificamente e compartilhado entre as instituições.

J (Fraqueza / gestão do patrimônio): para que a conservação preventiva seja efetiva, ela depende de um ciclo completo de atividades que incluem avaliações, diagnósticos, propostas, testes, protocolos, ações e registro dos resultados, os quais precisam ser continuamente aplicados ao longo de todo 0 ciclo de vida do patrimônio. Muitas instituições não se sentem capazes de implementar a metodologia completa e tendem a ir direto para as ações. Soma-se a isto uma cultura, ainda muito prevalente, de conservação curativa e restauro de objetos já danificados pela ação do tempo ou por eventos adversos. Ainda é preciso ampliar a consciência de que a metodologia completa de conservação preventiva (adaptada à realidade local) é a melhor estratégia conhecida para que se possa preservar, nas melhores condições possíveis, por muitos anos, grandes quantidades de itens. 
K (Oportunidade / gestão do patrimônio): diante do exposto acima, tem-se aqui uma grande oportunidade, profissional e acadêmica, de aprimoramento de métodos, instrumentos e técnicas, que estejam adaptados aos materiais, climas, edificações e ambientes, podendo também vir a ser referência para outros estados e países, em desenvolvimento, localizados em regiões tropicais, que compartilham dos mesmos desafios.

L (Ameaça / gestão do patrimônio): a conservação preventiva depende de diagnósticos bem feitos e estes, por sua vez, dependem de uma adequada gestão da informação, ou seja, de documentação correta e organizada das coleções, do desempenho ambiental, e das decisões de conservação e manutenção tomadas ao longo dos anos. No entanto, este é um trabalho que demanda muitos recursos e que, com frequência, é postergado pelos tomadores de decisão. Porém, sem diagnósticos, tanto do edifício como dos acervos, não é possível tomar decisões efetivas e sustentáveis para a salvaguarda do patrimônio, recursos podem ser desperdiçados e ameaças podem permanecer ocultas para, subitamente, se transformarem em emergências, como se pode observar com alguma frequência.

M (Força / gestão das facilidades): o Brasil desenvolveu, nas últimas décadas, grande expertise na gestão de facilidades, o que inclui métodos para comissionamento, manutenção preventiva, preditiva e até mesmo prescritiva, voltada à gestão eficiente de tipologias complexas como hospitais, indústrias e aeroportos. Este know-how pode ser adaptado para edifícios que abrigam acervos, desde que compatibilizado com os preceitos de conservação preventiva do patrimônio. Ainda não se desenvolveu no país a consciência de que áreas de guarda de acervo são ambientes construídos complexos, que abrigam objetos frágeis e preciosos e, portanto, não podem ser vistos como meros 'depósitos', no sentido (equivocado) de 'os espaços que sobram em um edifício'.

N (Fraqueza / gestão das facilidades): as instituições de médio ou grande porte costumam ter em seus quadros equipes dedicadas à manutenção predial. No entanto, na maioria das vezes, estas equipes são chefiadas por funcionários administrativos, que não possuem conhecimento ou treinamento específico para gerenciar a operação e a manutenção dos sistemas. Não é raro se observar conflitos entre os setores da manutenção, que trabalham, na maioria das vezes, dentro de uma lógica exclusivamente responsiva, e aqueles que lidam com acervos, mais acostumados com os princípios preventivos. A fraqueza muitas vezes se encontra na ausência de comunicação clara entre as áreas, e de treinamentos 
e exercícios simulados que envolvam todas as equipes simultaneamente. Para as instituições de pequeno porte e aquelas que utilizam exclusivamente serviços terceirizados, os desafios são ainda maiores pela frequente rotatividade de funcionários e a desidentificação destes com o patrimônio.

0 (Oportunidade / gestão das facilidades): as frequentes emergências, com grandes perdas para 0 patrimônio, verificadas tanto no Brasil e como no mundo, muitas vezes estão relacionadas a problemas de ordem construtiva, o que evidencia a necessidade de uma maior participação de engenheiros e arquitetos especializados na manutenção da qualidade ambiental e na gestão de riscos ao patrimônio. Tem-se, portanto, uma grande oportunidade de trabalho, pesquisa e desenvolvimento tecnológico. É urgente que sejam criados novos cursos de treinamento, especialização e pós-graduação voltados à gestão de facilidades e manutenção preventiva do patrimônio edificado. Do ponto de vista financeiro e administrativo também não há dúvidas, como demonstra a literatura, das muitas vantagens de se prevenir ao invés de recuperar (após um dano) ou reconstruir (após uma perda).

P (Ameaça / gestão das facilidades): o aprofundamento das políticas de terceirização da mão-de-obra tem se mostrado cada vez mais como um risco para as instituições culturais: alta rotatividade, dificuldades para o treinamento, profissionais mal pagos e desmotivados, desidentificação institucional (eliminação do funcionário 'vocacional'), inviabilidade de políticas e projetos de longo prazo. A pandemia por COVID-19 evidenciou a distinção entre funcionários próprios, que, em muitos casos, puderam cumprir as recomendações de trabalho remoto, respeitando a quarentena e a separação por grupos de risco, e os funcionários terceirizados de manutenção, segurança e limpeza, que continuaram expostos a riscos, em obediência às regras da empresa para a qual trabalhavam. Portanto, é cada vez mais evidente a necessidade de se olhar para as políticas de terceirização, minimizar a rotatividade e a precarização do trabalho, treinar os funcionários responsáveis pela manutenção dos edifícios, seus sistemas e ambientes internos, e integrá-los na instituição.

$\mathbf{Q}$ (Força / gestão dos riscos): minimizar riscos frente às ameaças aos acervos (agentes de deterioração) não é tarefa fácil, nem mesmo para as instituições com muitos recursos localizadas em países desenvolvidos. É um desafio ainda maior para países e instituições com menos recursos e em um clima mais agressivo, como 0 tropical. No entanto, e, em parte porque os acervos se deterioram com maior facilidade, está amplamente disseminado entre os responsáveis pela preservação de acervos, o conceito de identificar e bloquear os 
agentes de deterioração. Percebe-se um grande esforço dos conservadores na compreensão de fenômenos que vão muito além de sua área de formação, como aqueles relacionados à construção civil, mecânica, física, química, biologia, etc., na tentativa de mitigar os impactos sobre os objetos.

$\mathbf{R}$ (Fraqueza / gestão dos riscos): se, por um lado, a angústia de presenciar cotidianamente a deterioração de objetos impulsiona as equipes de conservação a estudarem e buscarem soluções, por outro lado, outros setores institucionais não costumam estar integrados neste processo, e são poucas as instituiç̧ões que trabalham em uma perspectiva mais holística, de preservação sustentável do patrimônio cultural. É frequente o relato de que as equipes de conservação não conseguem sensibilizar outros setores para a importância de se investir recursos na ampliação e na melhoria da qualidade construtiva das áreas de guarda que precisam abrigar uma quantidade sempre crescente de acervos.

S (Oportunidade / gestão dos riscos): climas tropicais, edifícios históricos frágeis e guarda precária de acervos são uma realidade para instituições em uma vasta porção do globo, infelizmente, aquela com menos recursos e capacidade de pesquisa. A maioria das metodologias e recomendações para a gestão de riscos aos acervos foram criadas em países desenvolvidos, com climas temperados e edifícios (históricos adaptados ou novos) com maior qualidade construtiva (robustez). 0 desenvolvimento de técnicas, métodos e protocolos específicos para as regiões quentes e úmidas do planeta, que compatibilizem a gestão de riscos em edifícios históricos com o uso racional de recursos escassos é, talvez, a principal demanda do setor do patrimônio cultural no momento presente. Tem-se também a pressão global por maior sustentabilidade e eficiência energética. As soluções para a preservação de acervos em países desenvolvidos costumam ser muito eficientes, porém, nem sempre energeticamente sustentáveis. Nos países menos desenvolvidos, as soluções precisam, necessariamente, também ser sustentáveis.

T (Ameaça / gestão dos riscos): climas quentes e úmidos proporcionam as condições ideais para a acelerada deterioração da matéria, sendo por si só uma ameaça ao patrimônio. Por isso, países tropicais precisam ter um cuidado extra com as múltiplas ameaças relacionadas à deterioração por calor, umidade, luz solar, micro e macro-organismos. É um grande desafio sustentar, ao longo de toda vida útil do patrimônio, um ponto de equilíbrio entre a preservação possível, as melhores práticas e as condições e recursos disponíveis. 


\subsection{PROPOSTA}

A partir do conjunto de dados coletados junto aos benchmarks e casos de estudo, e do resultado da análise SWOT para instituições com acervo em papel na cidade de São Paulo, desenvolveu-se um modelo teórico-metodológico para:

- planejamento de avaliação integrada das condições de guarda dos acervos, pela perspectiva de especialistas (em edifícios e acervos) e usuários;

- diagnóstico das vulnerabilidades;

- e proposição de ações voltadas à mitigação ou eliminação dos riscos de danos e perdas do patrimônio cultural móvel e imóvel.

0 Modelo Integrado para Diagnóstico de Áreas de Guarda de Acervos proposto por esta pesquisa resulta da adaptação e combinação de estratégias e sistemas de avaliação já existentes, para acervos e para edificações, com o intuito de se fazer uma análise holística das ameaças ao patrimônio, esclarecer suas causas e propor ações adequadas para a mitigação ou eliminação dos riscos. A proposta aqui apresentada se baseia na experiência adquirida junto a instituições paulistanas com acervos em papel guardados em reservas técnicas de edifícios históricos. No entanto, por se tratar de um modelo de avaliação, entende-se que, com adaptações, ele também possa ser validado para outras tipologias e suportes.

0 modelo teórico-metodológico aqui proposto está embasado na ampla gama de conceitos descritos e discutidos no capítulo 2 desta tese (Revisão Sistemática da Literatura) e fundamentado na combinação de três sistemas metodológicos principais, a saber: o sistema multimétodos de Avaliação PósOcupação (APO), a metodologia de gestão de riscos ao patrimônio cultural desenvolvida pelo ICCROM / CCl e a estratégia SOBANE.

0 sistema multimétodos de APO possui características que fazem dela um excelente ponto de partida. Isto porque este sistema:

1. avalia o edifício já ocupado e em uso, o que permite uma compreensão bastante abrangente das múltiplas interrelações entre o edifício, os usuários e acervos, e os meios externo e interno, bem como a detecção de inadequações, anomalias ou falhas cuja origem pode estar no projeto, na construção, no uso e na ocupação e/ou nas rotinas de manutenção. 
2. é bastante flexível e permite a associação de múltiplos instrumentos, inclusive aqueles para análise do estado de conservação de acervos, e a escolha depende apenas da correta compreensão do que se deseja avaliar e dos recursos disponíveis.

3. é bastante inclusivo pois preconiza que a avaliação seja sempre conjunta, das características do entorno e técnico-construtivas do edifício, e das percepções dos usuários.

Como, nesta pesquisa, o foco de interesse eram as áreas para a guarda de acervos, procurou-se combinar a metodologia de APO com a metodologia de gestão de riscos ao patrimônio cultural desenvolvida pelo ICCROM / CCI. Esta metodologia foi escolhida por sua abrangência e ampla aceitação nacional e internacional. Ela propõe que seja feita a avaliação das seis camadas de proteção do acervo - acondicionamento, armazenamento, sala, edifício, entorno e região - e a identificação dos riscos associados aos dez agentes de deterioração dos objetos: forças físicas, dissociação, criminosos, pragas, poluentes, luz e UV, temperatura incorreta, UR incorreta, água e fogo. A partir desta avaliação, a metodologia propõe que seja elaborado um plano de ação para tratamento e monitoramento dos riscos, bem como um plano de preparação para emergências, para a caso de um risco se transformar em um evento adverso.

Por fim, levando-se em consideração a capacidade de recursos e a experiência da instituição com a aplicação de sistemas de avaliação, empregou-se a estratégia SOBANE (Screening, Observation, Analysis and Expertise), que é um sistema de planejamento desenvolvido pelo governo belga para a prevenção de riscos no ambiente de trabalho orientado ao planejamento de soluções adaptadas aos objetivos da instituição, aos recursos existentes e à inclusão de todos os sujeitos que devem fazer parte da análise. A estratégia propõe que se escolha um dentre quatro graus possíveis de avaliação: Seleção (S), OBservação (OB), ANálise (AN) ou Especialista (E), com crescente complexidade no nível de avaliação e de intervenção.

0 sistema de avaliação proposto por esta pesquisa será aqui apresentado em sua forma 'analógica', por meio de quadros e tabelas, mas, tendo em vista as facilidades tecnológicas contemporâneas, uma versão em formato 'digital', por meio de planilhas, softwares e/ou aplicativos para celular, tornaria 0 processo, principalmente nos graus menos complexos de avaliação (S e OB), mais ágil e amigável. 


\subsubsection{Etapa 1: Planejamento}

A seguir, na Figura 95, tem-se o fluxograma da etapa 1 de aplicação do modelo proposto.

Figura 95. Fluxograma do modelo teórico-metodológico proposto: Etapa 1 - Planejamento

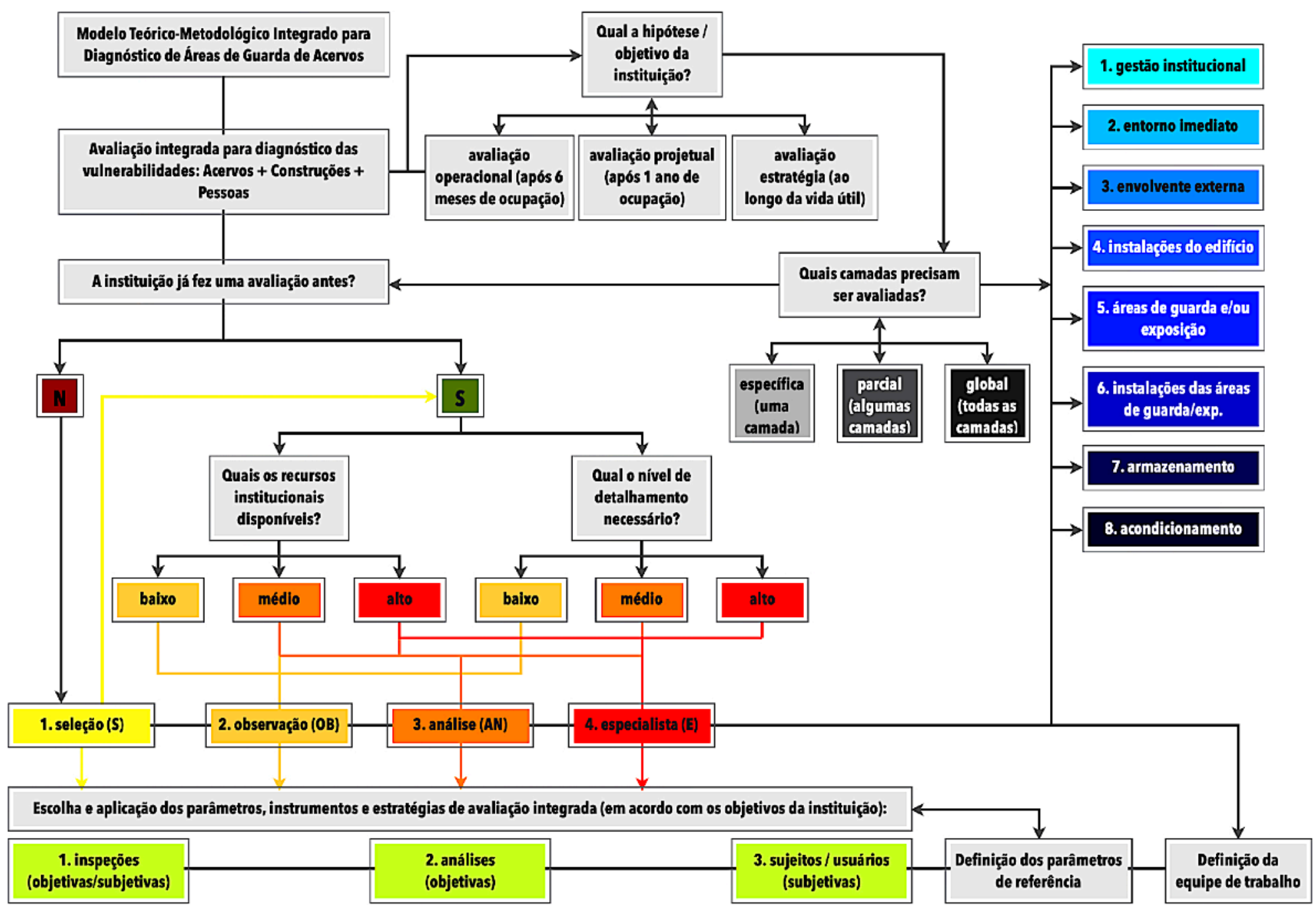

Fonte: a pesquisadora.

Um processo de melhoria tem início quando a instituição, ou parte de seus funcionários, percebe que existem questões para as quais não se conhece a resposta ou problemas para os quais não se tem certeza das causas, e cujos resultados podem ter impactos adversos. No caso das áreas de guarda de acervos em papel, frequentemente, as dúvidas estão relacionadas a como manter os mais variados objetos seguros e preservados pelo maior tempo possível dentro de um ambiente cujas características são singulares. Portanto, o primeiro passo na aplicação desta metodologia é que haja interesse institucional em compreender as vulnerabilidades e buscar soluções. Nem sempre a instituição, em sua integralidade, reconhece a importância do trabalho orientado por diagnósticos, planos e 
protocolos. Então, cabem aqui atividades de planejamento estratégico como pesquisas na literatura, dinâmicas de grupo e matrizes de priorização, que permitam demonstrar a todos os envolvidos a relevância, os benefícios e as oportunidades de se aplicar uma avaliação do desempenho (ver maiores detalhes no capítulo 2 desta tese).

Uma vez vencida quaisquer resistências iniciais, o passo seguinte é definir a equipe da etapa de planejamento. Normalmente ela é formada por membros da direção, de setores administrativos e de setores que trabalham diretamente com o patrimônio. A tarefa desta equipe é definir os objetivos pretendidos com a avaliação. Também é preciso levar em consideração se a avaliação será feita em um edifício ou ambiente recém-ocupado (recém-construído ou reformado), ocupado há um ano ou um pouco mais ou ocupado há vários anos. A diferença entre as três opções é que, no primeiro caso, o foco da avaliação deve ser na compreensão da efetividade das respostas - do projeto, da execução da obra, dos materiais e sistemas construtivos e dos mobiliários utilizados - às expectativas e necessidades, ou se é preciso fazer ajustes pontuais. Na segunda opção, o foco da avaliação é no desempenho do ambiente ou do edifício depois de um ciclo completo de ocupação e uso, com o intuito de identificar falhas em materiais e sistemas construtivos ou possíveis melhorias pontuais, no leiaute, por exemplo. Por fim, a terceira opção de avaliação deve ser escolhida quando o edifício já está ocupado e em uso há vários anos e o que se pretende identificar são ocorrências tais como desgastes de materiais, inadequações, demandas que se alteraram com o tempo, dentre outros aspectos.

Nesta etapa do planejamento também é preciso definir a abrangência da aplicação, se ela será específica para uma camada; parcial, para algumas camadas; ou global, para todas as camadas de avaliação. Esta decisão deve ser feita ponderando-se os objetivos pretendidos e os recursos institucionais disponíveis para a aplicação dos instrumentos e a análise dos resultados.

As camadas que envolvem o acervo foram adaptadas da metodologia do ICCROM / CCI para esta pesquisa. Propõe-se o uso de oito camadas de avaliação, uma vez que cada uma delas pode impactar 0 acervo de maneira distinta (Quadro 37 e Figura 96). 
Quadro 37. Quais camadas precisam ser avaliadas?

\begin{tabular}{c|l}
\hline Seleção: & \multicolumn{1}{c}{ Camada: } \\
\hline$\square$ & Camada 1 - gestão institucional \\
\hline$\square$ & Camada 2 - entorno imediato \\
\hline$\square$ & Camada 3 - envolvente externa (envelope) do edifício \\
\hline$\square$ & Camada 4 - instalações do edifício \\
$\square$ & Camada 5 - áreas de guarda \\
\hline$\square$ & Camada 6 - instalações da área de guarda \\
\hline$\square$ & Camada 7 - armazenamento dos itens \\
\hline$\square$ & Camada 8 - item e seu acondicionamento \\
\hline
\end{tabular}

Fonte: a pesquisadora

Figura 96. As oito camadas de avaliação propostas pela pesquisa

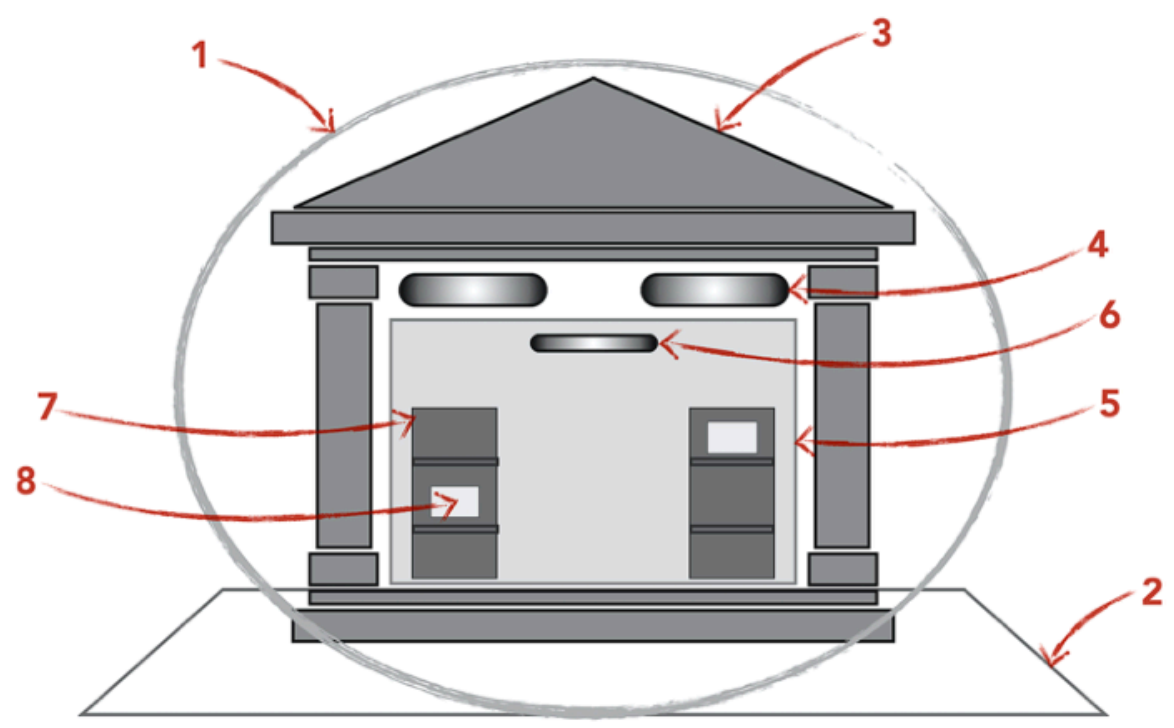

Fonte: a pesquisadora.

\section{Camada 1 - gestão institucional}

Para efeito desta pesquisa, considerou-se uma primeira camada cuja localização está em toda a parte e em parte alguma: é a gestão institucional, ou seja, quão eficiente é a administração dos recursos humanos, financeiros e energéticos, tanto pelo meio institucional interno como externo. A avaliação da gestão institucional deve considerar dois aspectos cujos impactos são igualmente importantes para a qualidade ambiental: a documentação e o organograma funcional. A documentação se refere a todas 
as regras, normas, procedimentos e protocolos que a instituição deve conhecer, possuir ou criar e cuja função é nortear o planejamento e a execução das atividades, segundo a missão, as competências e os objetivos específicos de cada instituição. 0 organograma trata da organização do trabalho institucional, seja quanto à quantidade ou qualidade das equipes, seja nas relações entre os funcionários próprios, entre próprios e terceirizados ou outros prestadores de serviço, bem como entre os funcionários e o público e a sociedade em geral.

\section{Camada 2 - entorno imediato}

A segunda camada é a primeira camada 'física' que influencia no desempenho ambiental interno. Ela é o entorno imediato do(s) edifício(s) onde estão guardados os acervos. Qual o tamanho do entorno a ser avaliado? A resposta deve ser dada pela própria instituição e pelos profissionais especialistas responsáveis pela avaliação, e depende da identificação do potencial que uma determinada característica do entorno tem de impactar negativamente (ameaçar) o patrimônio. Por exemplo, um córrego que, quando alaga, inunda áreas da instituição pertence ao entorno imediato, mas uma avenida cujas características (ruídos, poluentes, etc.) não têm impacto sobre o edifício e os acervos, já não faz parte deste entorno. 0 entorno imediato pode incluir áreas públicas, estruturas pertencentes a terceiros e também o terreno onde se localiza a instituição.

Além do entorno propriamente dito, faz-se necessário, nesta camada, avaliar o impacto do clima urbano (regional e/ou local) nas ameaças ao patrimônio. Esta pesquisa propõe que a variável clima urbano seja considerada com ênfase na avaliação, uma vez que é consenso na comunidade científica a necessidade de preparação para resposta a um cenário de emergência climática, o que implica na necessidade de uma gestão dos riscos ao patrimônio que inclua as incertezas associadas a eventos climáticos extremos, tais como tempestades, secas, vendavais, variações bruscas de temperatura, maior quantidade de raios, dentre outros.

\section{Camada 3 - envolvente externa (envelope) do edifício}

A terceira camada é a envolvente externa, também chamada de envelope do(s) edifício(s). A envolvente pode ser subdividida em sistemas construtivos: fundaçõ̃es, estruturas (externas), coberturas, vedações verticais (paredes externas), bem como vãos, revestimentos e pisos (externos). Nesta camada também é importante avaliar, além da membrana que dá forma ao edifício, o clima interno ao edifício. A análise 
de séries anuais de temperatura, umidade, radiação e poluentes permitem, por um lado, que se compreenda os mecanismos de funcionamento da envolvente externa (sua permeabilidade ou seu isolamento em relação ao meio externo) e, por outro lado, que se identifique as interrelações entre a envolvente, o clima interno, as atividades humanas e os impactos destes processos para os materiais de construção e os itens do acervo.

\section{Camada 4 - instalações (facilidades) do edifício}

A quarta camada se refere aos sistemas construtivos, também chamados de facilidades (facilities) do(s) edifício(s), compostos por elementos da construção cuja finalidade é 'facilitar' o uso e a ocupação do ambiente construído. Estes sistemas incluem os caixilhos de portas e janelas, as instalações elétricas, hidrossanitárias, mecânicas, contra incêndio, de segurança, de acessibilidade, bem como as sinalizações. Nesta camada são avaliadas todas as facilidades que impactam o edifício em sua totalidade, influenciando, assim, o desempenho ambiental interno global.

\section{Camada 5 - áreas de guarda}

A quinta camada é muito similar à terceira, porém em uma escala mais próxima. São as áreas e salas internas ao edifício onde há itens do(s) acervo(s). Nesta camada, são avaliados tanto os sistemas construtivos bem como o clima interno, para cada uma das áreas onde as coleções são guardadas (reservas técnicas), tratadas (laboratórios) ou disponibilizadas ao público (espaços expositivos ou para consulta), permitindo uma melhor compreensão dos riscos e dos processos de deterioração associados à qualidade construtiva e ambiental interna a estes espaços. Além disso, áreas do edifício que não são escopo deste trabalho, tais como salas administrativas, auditórios, refeitórios, dentre outros, também poderiam ser avaliadas nesta camada.

\section{Camada 6 - instalações (facilidades) da área de guarda}

A sexta camada é análoga à quarta, porém, a avaliação é específica para as facilidades (componentes e equipamentos) cuja influência está circunscrita ao desempenho ambiental interno das áreas de guarda, e não mais do edifício como um todo. 


\section{Camada 7 - armazenamento dos itens}

A sétima camada se atém a todos os tipos de mobiliário que podem estar sendo utilizados para guardar, transportar ou expor itens do acervo, o que inclui diversos tipos de armários, vitrines e suportes. Estes elementos devem ser avaliados quanto aos riscos diretos que podem trazer ao acervo bem como quanto aos impactos dos microclimas internos a eles.

\section{$\underline{\text { Camada } 8 \text { - item e seu acondicionamento }}$}

A oitava e última camada é aquela que avalia as embalagens que protegem um item ou um conjunto de itens do acervo, tais como caixas, pastas, envelopes, capas, molduras, etc., assim como o próprio objeto e suas características tridimensionais. Nesta camada devem ser analisadas as características físicas e químicas dos materiais, as interações próprias do sistema objeto-acondicionamento, os impactos do microclima interno a este sistema e os eventuais riscos associados.

Uma vez definidos os objetivos, o tipo de avaliação e as camadas que serão avaliadas, a equipe de planejamento deve ponderar se a instituição já aplicou uma metodologia de avaliação antes e, portanto, possui dados e experiência prévia que possam ser usados como ponto de partida para a avaliação, ou se é a primeira vez que uma metodologia diagnóstica será utilizada. Se for a primeira vez a escolha deve ser pelo grau 1 de avaliação do protocolo SOBANE, a Seleção (S). Caso a instituição já tenha realizado avaliações prévias, então é preciso ponderar, sempre tendo em vista os recursos disponíveis (humanos, temporais, financeiros, materiais, ferramentais, etc.), qual o grau de detalhamento pretendido: uma avaliação geral e global, feita pelos especialistas da própria instituição; uma avaliação mais completa, que faça uso de especialistas colaboradores externos; ou uma avaliação muito detalhada de algum aspecto particular, com a consultoria de experts e o emprego de equipamentos específicos. Quanto maior o grau de complexidade da avaliação, mais onerosa e demorada ela será e maior o volume de dados que serão gerados. Recomenda-se que a escolha do nível seja progressiva, por meio de um processo de triagem: para todo o acervo e edifício, o grau OBservação (OB); para partes do acervo e do edifício com maior vulnerabilidade, o grau ANálise (AN); e para elementos específicos do acervo e do edifício com muita vulnerabilidade, o grau Especialista (E). 


\subsubsection{Etapa 2: Execução}

A seguir, na Figura 97, tem-se o fluxograma da etapa 2 de aplicação do modelo proposto.

Figura 97. Fluxograma do modelo teórico-metodológico proposto: Etapa 2 - Execução

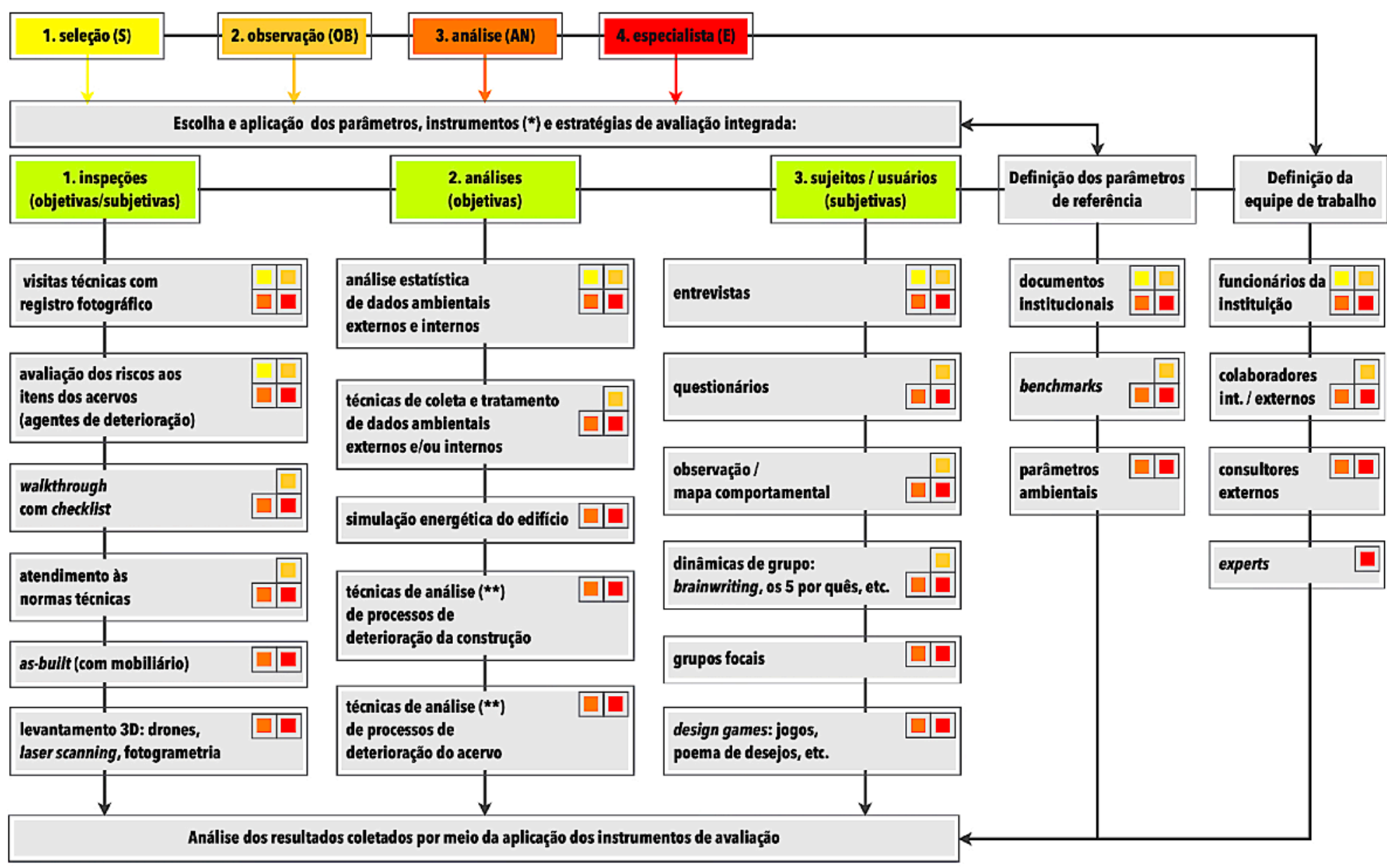

${ }^{*}$ ( ) abaixo, estão os principais instrumentos para a avaliação de edifícios e seus ambientes, acervos e perspectiva dos usuários. No entanto, outros instrumentos podem ser utilizados, desde que o método seja corretamente adaptado e empregado pelos especialistas responsáveis pela avaliação. $\left.{ }^{(\star *}\right)$ técnicas destrutivas e/ou não destrutivas; invasivas, minimamente invasivas e/ou não invasivas.

Fonte: a pesquisadora.

Uma vez finalizada a etapa de planejamento, ou seja, estabelecidos os objetivos, o tipo de avaliação, as camadas a serem avaliadas e o grau de avaliação, é preciso definir a equipe de especialistas que será responsável pela aplicação da metodologia nas áreas de guarda de acervos. É possível que alguns dos participantes da equipe de planejamento e de avaliação sejam coincidentes. Recomenda-se que as equipes de planejamento e de avaliação trabalhem em conjunto para coletar todos os documentos institucionais necessários à análise, tais como missão, planos e políticas institucionais, organograma, dados de monitoramento ambiental, documentação arquitetônica, dentre outros. 
A equipe de projeto deve iniciar os trabalhos por uma revisão sistemática da literatura pertinente: parâmetros, normas e leis aplicáveis ao estudo de caso, benchmarks, diretrizes e protocolos de entidades representativas, etc.. Quanto maior o grau de complexidade da avaliação no protocolo SOBANE, mais detalhada deve ser esta pesquisa inicial.

Em seguida, é preciso escolher os instrumentos de avaliação e planejar como cada um deles será utilizado. Isto depende dos recursos disponíveis, já determinados pela equipe de planejamento, das dimensões construtivas e do tamanho do acervo, e da capacidade técnica dos avaliadores (maiores informações sobre as habilidades necessárias à aplicação de cada instrumento podem ser consultadas no capítulo 2 desta tese).

0 grau S pode ser realizado por um ou mais funcionários da própria instituição e não há necessidade de se utilizar especialistas. 0 importante é que sejam feitas pelo menos visitas exploratórias, se possível em conjunto com um checklist, e registro visual (fotos, vídeos e/ou desenhos) das características e condições da(s) camada(s) de análise definida(s); conversas orientadas ou entrevistas não estruturadas com os usuários pertinentes à avaliação; e, se possível, uma análise comparativa entre o histórico de dados de Te UR do clima externo e interno. A aplicação destes instrumentos pode ser feita mediante emprego de modelos prontos, disponibilizados pela academia ou por entidades que trabalham com a preservação do patrimônio e adaptados à(s) camada(s) de análise, ou um passo-a-passo desenvolvido pela própria equipe de avaliação (uma discussão sob o assunto pode ser encontrada no capítulo 2). A escolha dos instrumentos e da forma de aplicação deve levar em conta o tamanho do acervo e a capacidade técnica dos avaliadores. Esta avaliação deve ser uma atividade rápida, realizada em poucos dias. 0 objetivo é anotar as ocorrências e os processos de deterioração relacionados ao edifício e ao acervo mediante inspeção visual. Não se pretende identificar todos os problemas, suas causas e consequências, mas sim documentar os riscos mais evidentes, para que a instituição tenha uma percepção mais clara e abrangente das suas principais vulnerabilidades e, a partir deste diagnóstico preliminar, possa planejar as próximas ações. As ocorrências identificadas devem ser anotadas em um relatório, com o objetivo de subsidiar o planejamento de uma avaliação futura no próximo grau, OBservação (OB) ou ANálise (AN).

0 grau $O B$ deve ser realizado por um ou mais funcionários do setor de conservação e um ou mais funcionários do setor de manutenção da instituição. De preferência, a avaliação deve ser conduzida por funcionários especialistas. Os principais instrumentos à disposição dos avaliadores são: (a) visitas técnicas e/ou walkthroughs com checklist, para inspeção técnica do ambiente construído e seu entorno 
e do acervo, e registro visual das vulnerabilidades, inadequações, anomalias e falhas (em sistemas e materiais construtivos); (b) entrevistas semi-estruturadas ou estruturadas, questionários parciais ou globais, mapas comportamentais e/ou dinâmicas de grupo, a depender do tipo de instituição e dos objetivos da avaliação, para coleta de dados pelo ponto de vista dos múltiplos usuários (diretores, funcionários que lidam direta ou indiretamente com as áreas de guarda e/ou o acervo, pesquisadores, visitantes, dentre outros); (c) coleta e tratamento de dados ambientais (T, UR, luz e poluentes) internos e externos. A aplicação dos instrumentos de avaliação pode ser dividida entre os responsáveis pelo edifício e pelo acervo, mas o planejamento prévio, a análise e a síntese dos resultados deve ser um trabalho interdisciplinar. Modelos prontos dos instrumentos escolhidos podem ser usados desde que adaptados para a avaliação específica. A elaboraçã̃o de um passo-a-passo desenvolvido pelos próprios avaliadores pode ser mais trabalhosa mas provavelmente estará mais adequada aos objetivos pretendidos. É importante, em ambos os casos, que os modelos sejam pré-testados para verificação da efetividade e as atividades com usuários devem ser registradas no Comitê de Ética em Pesquisa (ver maiores detalhes no capítulo 2). Colaboradores externos (arquitetos, engenheiros, conservadores, pesquisadores, etc.) também podem ser consultados, tanto na fase de preparação dos instrumentos, quanto na de análise dos dados. A partir dos resultados da avaliação, pode-se concluir que algumas ocorrências possuem causas complexas e, dado o impacto delas para o edifício, as pessoas e/ou 0 acervo, é recomendado que seja feita uma avaliação mais aprofundada destas vulnerabilidades.

0 grau AN deve ser realizado em conjunto pela equipe de funcionários (de preferência especialistas em acervo e edifício) e consultores externos especialistas em instrumentos e/ou técnicas para análise de aspectos específicos. Pode-se ter como ponto de partida os resultados de uma avaliação anterior no grau OB, ou, no caso de instituições muito grandes, complexas e com mais recursos, a equipe de planejamento pode considerar mais adequado sempre realizar avaliações no grau AN. Neste grau, podem ser associados outros instrumentos aos já mencionados anteriormente, no grau $0 \mathrm{~B}$, tais como: levantamento as-built, registro 3D e construção do modelo BIM do edifício; simulações do desempenho ambiental e da eficiência energética; técnicas e instrumentos para análises térmicas, de iluminação natural, de poluentes, mecânicas, físico-químicas de materiais (da construção e/ou de itens do acervo), biológicas, dentre outras; dinâmicas para grupos específicos de usuários, tais como grupos focais, design games, etc. (maiores informações sobre cada um dos instrumentos podem ser 
encontradas no capítulo 2). Uma avaliação tão complexa precisa ser iniciada por um planejamento muito criterioso, em que cada instrumento é desenhado para um propósito claro e específico. 0 resultado da avaliação será uma grande quantidade de dados, o que demandará uma análise interdisciplinar bastante especializada para que os diagnósticos sejam consistentes e permitam identificar as relações de causa e efeito, possibilitando, assim, a construção de um plano estratégico de longo prazo, com metas, protocolos e ações para a gestão das áreas de guarda e dos acervos e 0 atendimento dos objetivos institucionais frente a seus públicos. A avaliação no grau AN pode identificar algumas vulnerabilidades ainda mais específicas, que merecem um tratamento individualizado. Para estes elementos pode ser recomendada uma avaliação no grau E.

0 grau E, ao contrário dos anteriores, não deve ser aplicado a todo o conjunto de edifícios, acervos e usuários, mas apenas a questões pontuais, previamente identificadas nos graus OB ou AN. Esta avaliação deve ser feita por profissionais experts em instrumentos, técnicas e/ou equipamentos específicos, sob a supervisão e com a colaboraç̧ão da equipe interna de avaliação. Como este serviço pode ser bastante oneroso para a instituição, ele deve estar bem fundamentado. É preciso que haja clareza de quais os fenômenos que se deseja compreender e as respostas que se procura alcançar. Avaliações especializadas costumam ser utilizadas principalmente quando se está diante de elementos históricos que, dada a sua complexidade e relevância cultural, precisam de intervenções muito criteriosas para que eles não se percam nem percam sua identidade original. Neste grau podem ser empregados todos os instrumentos mencionados previamente, e ainda outros mais específicos, desde que devidamente adaptados ao objeto ou à situação particular. Ainda mais do que nos graus anteriores, no grau E os instrumentos devem estar muito bem calibrados, pré-testados e/ou validados para que haja elevada confiabilidade nos resultados.

A depender do grau da avaliação na estratégia SOBANE, dos recursos disponíveis e da finalidade pretendida com a investigação, a avaliação do acervo pode ser global, para todo o acervo, ou focada em coleções ou itens específicos. Em todos os casos, o que se pretende compreender são os processos que possam ameaçar sua integridade ou degradar materiais.

As ameaças aos acervos podem ser classificadas segundo o potencial agente de deterioração de um objeto. 0 conceito de agente de deterioração foi inicialmente proposto pelo $\mathrm{CCl}$ e amplamente defendido pelo seu principal autor, Stephan Michalski. 0 método, que é referência mundial para a 
análise de riscos ao patrimônio cultural, consiste em identificar e classificar as possíveis ameaças em uma dentre nove categorias: forças físicas, roubo e vandalismo, pragas, poluentes, luz e UV, T incorreta, UR incorreta, água e fogo. José Luiz Pedersoli Jr., no período em que foi pesquisador associado do CCl, propôs que, à lista dos nove agentes de deterioração, fosse acrescentado mais um, a dissociação, que é entendida como a perda dos elos de conexão (física ou digital) entre as partes de um mesmo bem. Posteriormente, o AIC 3 propôs uma revisão e acrescentou, ao tópico dissociaçãa, a guarda negligente, e, a roubo e vandalismo, o deslocamento, que é entendida como a retirada de um item do seu contexto original, dificultando sua compreensão integral.

É importante destacar a íntima correlação entre os agentes de deterioração e o desempenho da envolvente e das facilidades do edifício. Por isso, esta pesquisa ressalta a relevância de uma avaliação conjunta entre conservação e construção civil para que o diagnóstico das causas e consequências seja 0 mais preciso possível, permitindo que sejam propostas soluções efetivas na mitigação dos riscos.

Com o intuito de facilitar a avaliação dos riscos observados com maior frequência ao longo desta pesquisa, os agentes de deterioração do patrimônio cultural foram parcialmente modificados para melhor se adaptarem à realidade local (Quadro 38).

Quadro 38. Agentes de deterioração, comparação entre diferentes propostas

\begin{tabular}{|c|c|c|c|}
\hline \multicolumn{4}{|c|}{ AVALIAÇÃO DOS RISCOS AO PATRIMÔNIO - AGENTES DE DETERIORAÇÃO } \\
\hline $\begin{array}{c}\text { Proposta CCI } \\
\text { (Michalski, 1992) }\end{array}$ & $\begin{array}{l}\text { Proposta revisada CCI } \\
\text { (Pedersoli Jr. et al., 2016) }\end{array}$ & $\begin{array}{l}\text { Proposta AIC } \\
(2020)\end{array}$ & Proposta desta pesquisa \\
\hline & dissociação & $\begin{array}{l}\text { guarda negligente e } \\
\text { dissociação }\end{array}$ & 1. gestão incorreta \\
\hline forças físicas & forças físicas & forças físicas & 2. guarda e uso incorreto \\
\hline roubo e vandalismo & roubo e vandalismo & $\begin{array}{l}\text { roubo, vandalismo e } \\
\text { deslocamento }\end{array}$ & $\begin{array}{l}\text { 3. roubo, vandalismo e } \\
\text { deslocamento }\end{array}$ \\
\hline \multirow[t]{2}{*}{ pragas } & pragas & pragas & 4. pragas (insetos / animais) \\
\hline & & & 5. microorganismos \\
\hline poluentes & poluentes & poluentes & $\begin{array}{c}\text { 6. poluentes } \\
\text { (partículas / gases) }\end{array}$ \\
\hline
\end{tabular}

(continua)

3 Michalski, 1992; Pedersoli Jr. et al., 2016; AIC, 2020, disponível em: https://www.conservation-wiki.com/wiki/Ten_Agents_of_Deterioration 
Quadro 38. Agentes de deterioração, comparação entre diferentes propostas (continuação)

AVALIAÇÃO DOS RISCOS AO PATRIMÔNIO - AGENTES DE DETERIORAÇÃO

\begin{tabular}{c|c|c|c}
\hline $\begin{array}{c}\text { Proposta CCI } \\
\text { (Michalski, 1992) }\end{array}$ & $\begin{array}{c}\text { Proposta revisada CCI } \\
\text { (Pedersoli Jr. et al., 2016) }\end{array}$ & $\begin{array}{c}\text { Proposta AIC } \\
(2020)\end{array}$ & Proposta desta pesquisa \\
\hline luz e UV & luz e UV & luz e UV & 7. luz visível e UV \\
\hline Tincorreta & Tincorreta & Tincorreta & 8. Tincorreta \\
\hline UR incorreta & UR incorreta & UR incorreta & 9. UR incorreta \\
\hline água & água & água & $\begin{array}{c}\text { 10. água } \\
\text { (natural / não natural) }\end{array}$ \\
\hline fogo & fogo & fogo & 11. fogo (direto / indireto) \\
\hline
\end{tabular}

Fonte: a pesquisadora.

Assim, esta pesquisa propõe as seguintes alterações:

1. substituir dissociação e guarda negligente por gestão incorreta. Esta proposta resulta da constatação de que muitas das ameaças aos acervos têm sua origem em falhas na gestão, ainda que alheias à vontade institucional, seja pela ausência ou pela insuficiência de profissionais adequadamente capacitados, seja por lacunas relacionadas a: (a) políticas, planos, protocolos, documentação, catalogação, etc.; (b) atividades de pesquisa, formação, treinamento, simulados; (c) ações efetivas voltadas para a manutenção preventiva e corretiva; e a conservação preventiva, curativa e o restauro. Esta pesquisa considera importante que falhas na gestão da preservação do acervo (apenas subentendidas nas classificações do (CI e do AIC) estejam devidamente identificadas como uma ameaça aos objetos para que possam ser corretamente descritas e, assim, solucionadas pelos tomadores de decisão. Entende-se também que a guarda negligente é um dos aspectos de uma gestão incorreta dos acervos, a qual pode ter sua origem em ações imprudentes (precipitadas, sem a devida reflexão prévia), imperitas (realizadas por pessoas que não possuem o conhecimento ou a habilidade necessária) ou negligentes (inações ou ações incompletas ou incorretas). Além disso, para esta pesquisa, considerou-se que a dissociação, mais do que uma causa, é uma consequência de um agente de deterioração. As consequências de um processo de deterioração podem ser a dissociação e/ou uma perda e/ou um dano de um bem. Dissociação pode ser entendida também como um tipo específico de perda: a perda da informação que conecta as partes de um bem. 
2. substituir forças físicas por guarda e uso incorreto. A partir das consultas aos profissionais responsáveis pela preservação de acervos, constatou-se que o emprego do termo forças físicas tem-se mostrado vago e de difícil compreensão por parte dos avaliadores. Este agente se refere ao risco de danos resultantes do emprego de mobiliário e/ou embalagens inadequadas ou ainda do transporte e manuseio por meio de técnica incorreta. Assim, o uso do termo acondicionamento e uso incorreto se distancia da ação física potencial de dano (forças físicas) e se aproxima da decisão humana que impacta esta força, tornando mais evidente a causa primeira desta fonte de ameaça.

3. separar pragas de microorganismos. Os microorganismos, principalmente fungos em sua fase ativa (mofo), são o agente de deterioração mais comum nos acervos brasileiros. No entanto, não aparecem em destaque nas propostas internacionais, provavelmente por não terem o mesmo impacto nas áreas de guarda em climas frios e secos. Os conservadores consultados nesta pesquisa frequentemente relataram ter dúvidas se a ação de microorganismos deve ser classificada como um tipo de praga ou como uma consequência da umidade relativa (UR) incorreta. No entanto, nenhuma das hipóteses é totalmente adequada. 0 mofo não é um 'animal' que possa ser controlado pelos protocolos de manejo integrado de pragas (IPM - Pests Integrated Management). E ele também não pode ser automaticamente associado à UR incorreta: a umidade de uma determinada área pode estar acima dos parâmetros recomendados internacionalmente e, ainda assim, o acervo não apresentar mofo e, por outro lado, um ambiente pode ter valores de temperatura e umidade recomendados e, mesmo assim, se verificar o aparecimento de microorganismos por outras razões (sujidades, por exemplo). Assim, acredita-se ser importante destacar a presença de microorganismos como um agente de deterioração, e estimular o desenvolvimento de pesquisas e soluções seguras (para objetos, pessoas e o meio ambiente), orientadas à prevenção e ao controle desta ameaça.

4. subdividir pragas entre insetos e animais. Esta proposta é resultado da observação de que animais (principalmente aves e mamíferos) e insetos interagem com os acervos de modo muito diverso e demandam medidas de proteção e mitigação diferentes. Assim, esta separação inicial pode auxiliar os avaliadores na identificação destes dois tipos de ameaças, e na posterior recomendação das melhores práticas para cada caso. 
5. subdividir poluentes entre por partículas e por gases. Assim como no caso anterior, os poluentes sólidos e líquidos exigem ações de mitigação diferentes daquelas para gases. Deste modo, a clara anotação na ficha de avaliação do tipo de poluente facilita a recomendação das medidas mais adequadas para cada caso.

6. subdividir 0 agente água em natural e não natural. 0 emprego do termo água se mostrou, no decorrer deste trabalho, um pouco vago. Há uma grande diferença entre uma ameaça por enchente (causa natural) ou por um vazamento em uma tubulação (causa não natural). A distinção entre as causas durante a avaliação dos riscos pode facilitar a análise e a escolha das melhores ações de mitigação.

7. subdividir 0 agente fogo em direto e indireto. Neste caso também se mostra relevante haver uma distinção clara entre os riscos diretos, provocados por um incêndio (por balões, contágio, vandalismo etc.), e os riscos indiretos, principalmente como resultado de problemas elétricos (pane em equipamentos, curto-circuito na fiação, faíscas durante uma obra etc.). Aqui, mais uma vez, as ações necessárias para o controle e a mitigação dos riscos dependem da distinção entre as origens da ameaça.

A descrição de cada um dos agentes de deterioração recomendados por esta pesquisa pode ser observada nos Quadro 39, abaixo.

Quadro 39. Os agentes de deterioração (ameaças ao acervo) adaptados para esta pesquisa

AVALIAÇÃO DOS RISCOS AO PATRIMÔNIO - AGENTES DE DETERIORAÇÃo (PROPOSTA)
1. gestão incorreta: falhas nos meios necessários para o planejamento e/ou a execução de ações podem resultar
em danos, perdas ou dissociações de itens, de parte ou da totalidade de uma coleção ou de um acervo, e a causa
pode estar na ausência ou na insuficiência de documentos técnicos, profissionais especializados, conhecimento de
referência ou treinamento.
2. guarda e uso incorreto: caso o objeto seja guardado ou exposto dentro de um envoltório (envelope, pasta, caixa,
gaveta, armário, etc.) inadequado ou inseguro ou ainda transportado ou manuseado (por funcionários ou
visitantes) sem a técnica adequada e o devido cuidado, isto pode resultar em uma grande variedade de danos ao
item, bem como perdas e dissociações.
3. roubo, vandalismo e deslocamento: subtração, destruição ou mudança na posição de um ou mais objetos de um
acervo, feito intencionalmente, e cujo resultado pode ser o dano, a perda ou a dissociação de itens ou coleções.
4a. pragas (insetos): a ação de insetos pode danificar partes de um acervo (pela deposição de excrementos, por
exemplo) ou ainda provocar perda total e parcial de itens (quando se alimentam de materiais que compõem o item).
4b. pragas (animais): a ação de animais (aves e mamíferos) pode danificar partes de um acervo (pela deposição de
excrementos, por exemplo) ou ainda pode provocar dissociação (caso fiquem inadvertidamente presos dentro de
uma reserva, por exemplo) ou perda de itens (quando utilizam materiais na confecção de ninhos, por exemplo).

(continua) 
Quadro 39. Os agentes de deterioração (ameaças ao acervo) adaptados para esta pesquisa (continuação)

\begin{tabular}{|c|c|}
\hline & AVALIAÇÃO DOS RISCOS AO PATRIMÔNIO - AGENTES DE DETERIORAÇÃO (PROPOSTA) \\
\hline & $\begin{array}{l}\text { 5. microorganismos: os fungos, bem como a associação deles com algas e bactérias, estão entre as causas mais } \\
\text { comuns de danos e perdas do patrimônio em climas tropicais. Estes microorganismos precisam, para sua } \\
\text { sobrevivência, de oxigênio, umidade e alimento (materiais orgânicos ou inorgânicos que compõem o patrimônio). }\end{array}$ \\
\hline & $\begin{array}{l}\text { 6a. poluentes (partículas): sólidos e líquidos produzidos no ambiente externo ou interno, bem como particulados } \\
\text { transportados pelo ar, que, ao se depositar sobre o acervo ou reagir quimicamente com alguns materiais, pode } \\
\text { provocar danos ao patrimônio. Vírus e bactérias não são um risco direto ao acervo mas podem ser um risco aos } \\
\text { seres humanos e devem ser considerados nas estratégias contra poluentes. }\end{array}$ \\
\hline & $\begin{array}{l}\text { 6b. poluentes (gases): gases gerados no ambiente externo ou interno ou liberados por materiais de construção e } \\
\text { transportados pelo ar podem ser nocivos às pessoas e também reagir quimicamente com alguns materiais, } \\
\text { provocando danos aos acervos. }\end{array}$ \\
\hline & $\begin{array}{l}\text { 7. Luz visível e UV: a radiação eletromagnética interage com toda a matéria existente e é catalisadora de reações } \\
\text { químicas. Quanto maior a frequência da radiação, mais energética ela é e, portanto, maior o potencial de dano aos } \\
\text { objetos. Quanto maior a intensidade de luz incidente sobre um objeto, maior o risco, no entanto, qualquer } \\
\text { quantidade de radiaçãa luminosa pode causar danos, a depender da sensibilidade do material. }\end{array}$ \\
\hline & $\begin{array}{l}\text { 8. Tincorreta: temperaturas elevadas favorecem e aceleram reações químicas, e têm como consequência a } \\
\text { deterioração do patrimônio. Flutuações bruscas de temperatura podem causar danos mecânicos relacionados a } \\
\text { dilatações e contrações rápidas e desiguais dos materiais que compõem um determinado objeto. }\end{array}$ \\
\hline & $\begin{array}{l}\text { 9. UR incorreta: } 0 \text { vapor d'água presente no ar pode causar deteriorações ao patrimônio de muitas formas } \\
\text { diferentes. Se } 0 \text { ar estiver muito seco, materiais podem sofrer danos por ressecamento. Se } 0 \text { ar estiver muito } \\
\text { úmido, a água pode dissolver substâncias, catalizar reações químicas ou ainda favorecer o crescimento de } \\
\text { microorganismos, o que pode resultar na deterioração de materiais dos acervos. Mudanças bruscas na umidade } \\
\text { podem resultar em danos mecânicos ou ainda provocar condensações nos objetos ou no seu entorno imediato. }\end{array}$ \\
\hline & $\begin{array}{l}\text { 10a. água (natural): fenômenos climáticos naturais como tempestades, enchentes, tsunamis, etc. podem ser fonte } \\
\text { de grandes ameaças de danos e perdas de patrimônio. As mudanças climáticas têm acentuado os riscos } \\
\text { relacionados a eventos extremos associados à água. }\end{array}$ \\
\hline$(i 0)$ & $\begin{array}{l}\text { 10b. água (não natural): a construção civil e outras atividades humanas podem, por negligência, imperícia ou } \\
\text { imprudência, resultar em eventos adversos com água, com riscos de danos ou perdas de itens, coleções ou acervos. }\end{array}$ \\
\hline & $\begin{array}{l}\text { 11a. fogo (direto): o fogo, produzido naturalmente ou pela ação humana, pode atingir o patrimônio, e resultar em } \\
\text { perda total ou parcial de acervos. }\end{array}$ \\
\hline & $\begin{array}{l}\text { 11b. fogo (indireto): sistemas elétricos e equipamentos com defeito podem, indiretamente, provocar um incêndio } \\
\text { e resultar em perdas totais ou parciais do patrimônio. Eventos adversos por problemas elétricos estão entre as } \\
\text { causas mais frequentes de perda de acervos. }\end{array}$ \\
\hline
\end{tabular}

Fonte: a pesquisadora. 
As consequências de um processo de deterioração podem ser um dano, uma perda ou a dissociação, de um item, de uma coleção ou do acervo. Os danos podem ser classificados segundo sua natureza (mecânicos, térmicos, químicos, biológicos ou eletromagnéticos) e sua intensidade (muito leves, leves, moderados, severos ou muito severo). Os danos podem ter como consequência manchas (sujidades, amarelecimento, desbotamento), deformações (ondulações, rugas, vincos) ou estragos (rasgos, cortes, furos, quebras). As perdas podem ser classificadas como parcial ou total. A dissociação é um tipo de perda, não do item em si, mas da informaç̧ão que correlaciona suas partes.

As avaliações técnicas, além de verificar as condições de preservação do acervo, precisam também observar as características, e possíveis inadequações, anomalias ou falhas, em cada uma das partes que compõem o edifício e os ambientes para a guarda dos acervos. A identificação de não conformidades e seus impactos diretos ou indiretos sobre os itens do acervo, a guarda dos objetos e seu acesso pelos usuários pode ser feita por meio de múltiplos instrumentos, qualitativos e quantitativos.

Para facilitar a avaliação, o edifício costuma ser dividido em partes, chamadas sistemas construtivos. A classificação utilizada por esta pesquisa foi parcialmente adaptada da tese de livre docência de Simões (2004), a qual, por sua vez, foi baseada na norma internacional de desempenho ISO 6241:1984 Performance standards in buildings (substituída pela atual ISO 19208:2016 - Framework for specifying performance in buildings). Nestes documentos, os sistemas construtivos estão divididos em: terrapleno; fundações; estrutura; cobertura; vedos; vãos; paramentos/revestimentos; pavimentos; instalações eletromecânicas; e instalações hidrossanitárias. A norma ABNT NBR 15575:2013 - Edificações habitacionais - Desempenho também divide o edifício em sistemas construtivos, porém, de modo mais simplificado, em: sistemas estruturais; de pisos; de vedações verticais externas e internas; de coberturas; e hidrossanitários.

Decidiu-se, com base nas observações realizadas ao longo desta pesquisa, por uma maior subdivisão dos sistemas do edifício, conforme Quadro 40, a seguir, de modo a destacar cada um dos elementos que impactam na segurança dos acervos e, assim, facilitar o trabalho de avaliação e de correlação entre as vulnerabilidades da construção e seu entorno, os agentes de deterioração do acervo e os riscos ao patrimônio e aos usuários. 
AVALIAÇÃO DO EDIFÍCIO - SISTEMAS CONSTRUTIVOS (PROPOSTA)

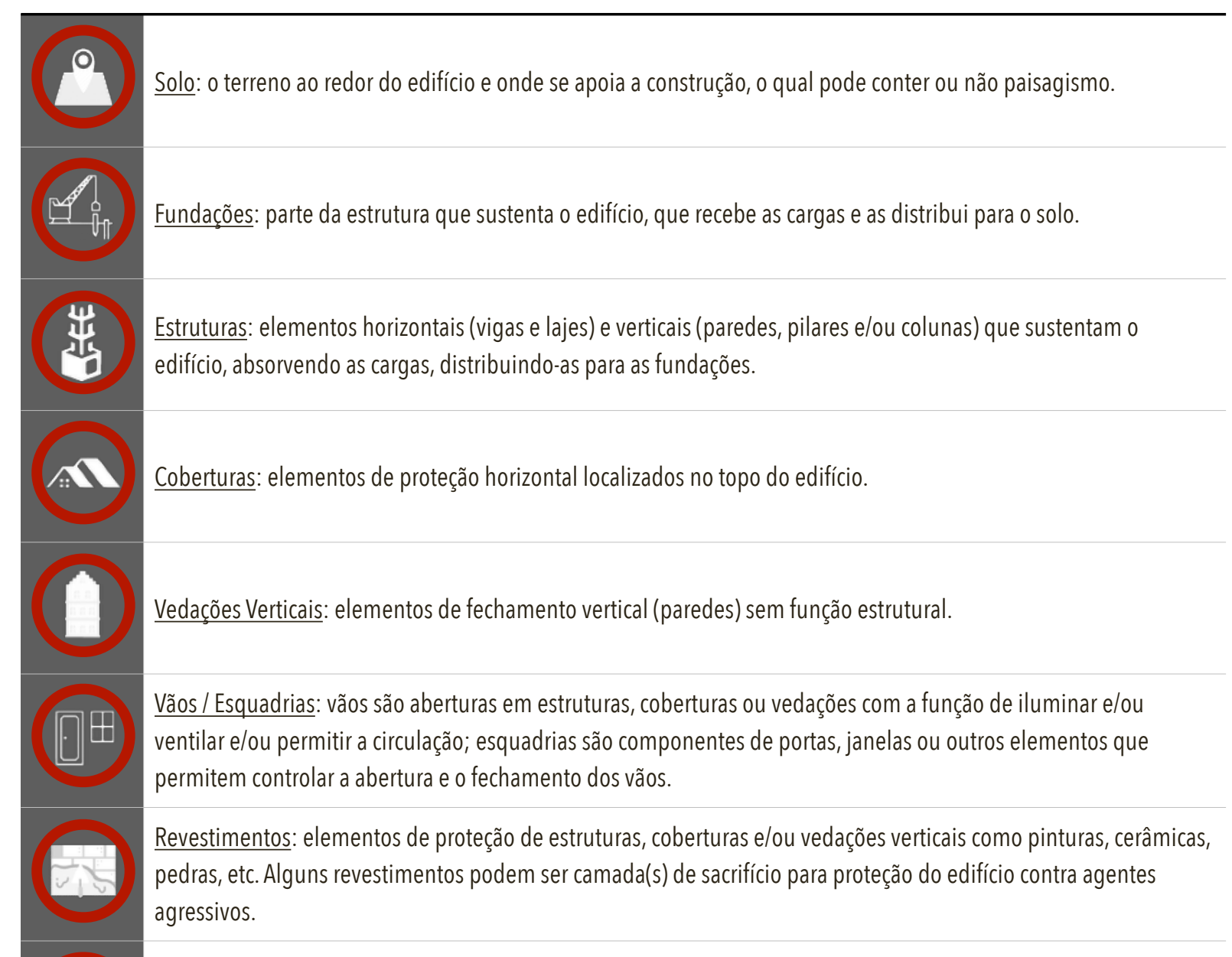

Pisos: elementos de revestimento de lajes e contrapisos, tanto no ambiente interno como externo.

Instalaçõoes Hidrossanitárias: conjunto de elementos e equipamentos usados para o transporte e armazenamento de água fria, água quente, esgoto e água pluvial.

Instalações Elétricas: conjunto de elementos e equipamentos utilizados no fornecimento de energia elétrica e na iluminação artificial no edifício.

Instalações Mecânicas: equipamentos com finalidades variadas, que não associadas aos demais sistemas, como, por exemplo, ar-condicionados, elevadores, monta-cargas, esteiras rolantes, etc..

Instalações contra Incêndio: conjunto de elementos e equipamentos que compõem o sistema de proteção predial contra incêndios, em acordo com as instruções técnicas do corpo de bombeiros. 
Quadro 40. Os sistemas construtivos, adaptados para esta pesquisa (continuação)

\section{AVALIAÇÃO DO EDIFÍCIO - SISTEMAS CONSTRUTIVOS (PROPOSTA)}

Instalações de Segurança Patrimonial: conjunto de elementos e equipamentos que compõem o sistema de
proteção contra roubos e vandalismos.
acessível a todos os usuários, em conformidade com a norma ABNT NBR 9050:2020 - Acessibilidade a edificações,
mobiliário, espaços e equipamentos urbanos.
conservação dos objetos que compõem os acervos, tais como estantes, armários, mapotecas, mesas, carrinhos, etc..
Mobiliário para exposição do acervo: conjunto de móveis e suportes utilizados para a exposição dos mais variados
itens do acervo, tais como vitrines, mesas, gavetas, quadros, etc..
Sinalização: conjunto de elementos e equipamentos que compõem o sistema de orientação horizontal e vertical
do edifício e seus espaços internos e externos.

Fonte: a pesquisadora.

\subsubsection{Etapa 3: Análise}

Uma vez finalizada a etapa de aplicação dos instrumentos e coleta dos dados, é preciso fazer a análise dos resultados. No grau $S$, a equipe deve compilar e correlacionar as descobertas para o ambiente construído, o acervo e os usuários e organizá-los na forma de um relatório. No grau OB, além do relatório de diagnósticos, devem ser feitos o tratamento e a análise dos dados ambientais coletados. Também é possível fazer uso de técnicas provenientes do planejamento estratégico, tais como diagramas e matrizes, para melhor sintetizar os dados coletados durante as atividades com os usuários. No grau AN, além das análises do grau OB aplicadas a todos os dados coletados por meio de técnicas e equipamentos específicos, deve ser empregada uma metodologia para o cálculo de riscos, tanto para o edifício como para o acervo, e os resultados podem ser apresentados na forma de mapas e matrizes de riscos e danos, para uma visualização gráfica dos resultados (ver maiores informações no capítulo 2 desta tese). Análises mecânicas, físico-químicas e/ou biológicas podem ter seus resultados compilados em relatórios específicos contendo imagens, gráficos, tabelas ou outros recursos de apresentação. Levantamentos métrico-arquitetônicos e construtivos podem ser inseridos em um modelo BIM do edifício, com os dados paramétricos dos elementos construtivos, e que pode estar 
associado a um plano de gestão das facilidades. No grau E, a análise dos resultados faz uso das mesmas metodologias do grau AN, porém, correlacionando o desempenho do edifício e do acervo como um todo aos dados coletados para os elementos específicos, objeto das análises dos experts.

A seguir, na Figura 98, tem-se o fluxograma da etapa 3 de aplicação do modelo proposto.

Figura 98. Fluxograma do modelo teórico-metodológico proposto: Etapa 3 - Análise

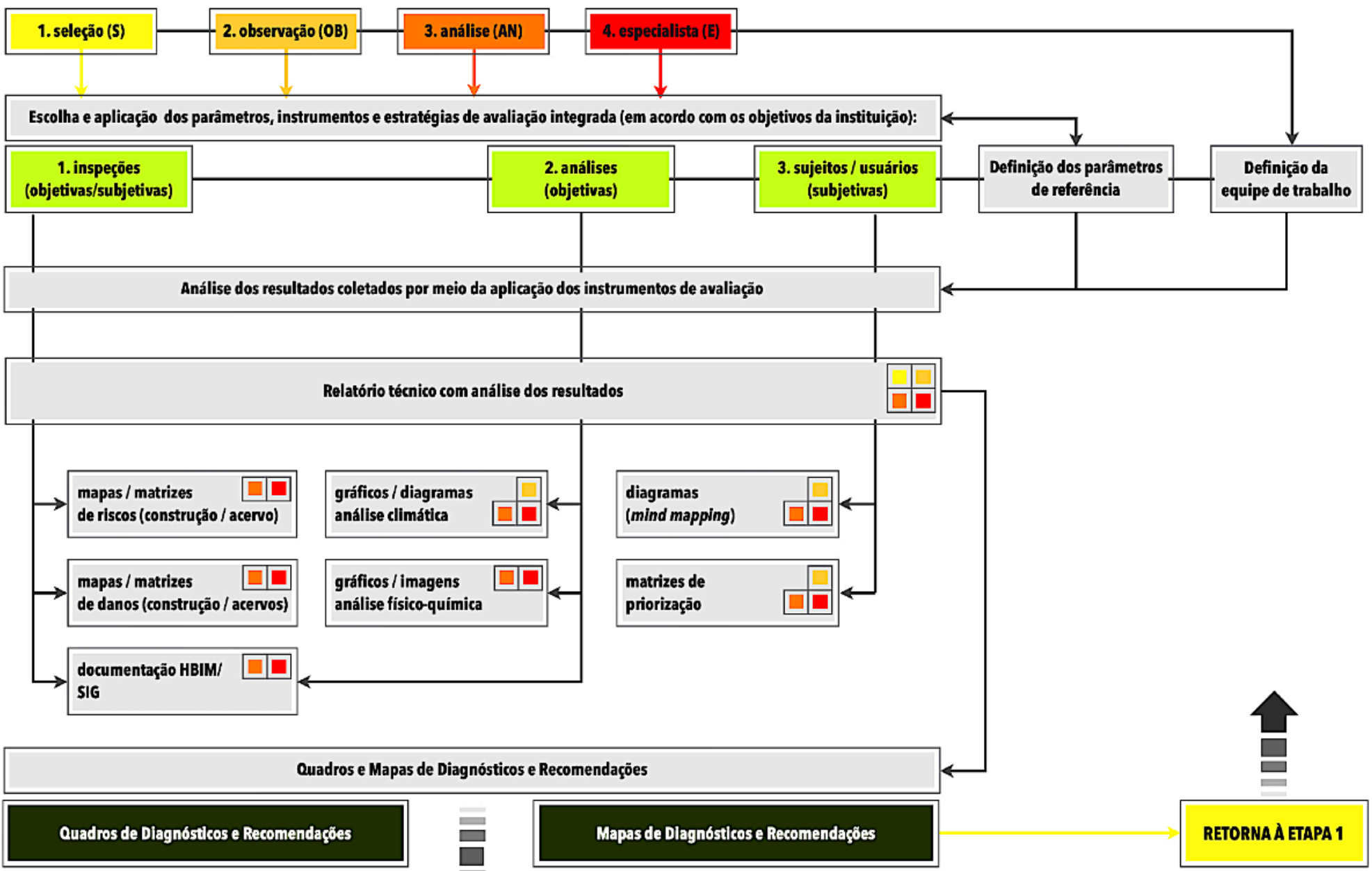

Fonte: a pesquisadora.

0 tratamento dos dados ambientais externos e internos, pode fazer uso de diferentes metodologias, provenientes de áreas do conhecimento como geografia, climatologia, urbanismo, estatística, dentre outras, se devidamente adaptadas para a avaliação do desempenho em áreas de guarda de acervos. Dentre os dados que podem ser coletados para a análise, tem-se:

- máximas, médias e mínimas diárias de temperatura do ar externo e interno, para períodos de um ano ou mais; 
- variações horárias, diárias, mensais e anuais entre temperaturas máximas e mínimas (regime de flutuações) externas e internas;

- tendências de mudança no padrão da temperatura externa;

- máximas, médias e mínimas diárias de umidade relativa externa e interna, para períodos de um ano ou mais;

- variações horárias, diárias, mensais e anuais entre umidades máximas e mínimas (regime de flutuações) externas e internas;

- tendências de mudança no padrão da umidade relativa externa;

- temperaturas de ponto de orvalho horárias para o clima interno e/ou microclimas específicos;

- radiação solar total e por faixa espectral: infra-vermelho, luz visível e ultra-violeta;

- radiação luminosa total e por faixa espectral (lâmpadas): infra-vermelho, luz visível e ultra-violeta;

- padrão hídrico e tendências;

- padrão de orientação e velocidade dos ventos;

- taxas de poluentes (particulados e gases), externos e internos;

- cobertura vegetal do entorno; dentre outros.

Os resultados das análises podem ser apresentados na forma de:

- gráficos comparativos (externo, interno e intervalo recomendado);

- dispersão dos dados anuais plotados sobre ábacos;

- tabelas, dentre outros.

Muitos dos parâmetros ambientais internos de áreas de guarda de acervo precisam ser coletados por longos períodos de tempo, de preferência ao longo de todo o ciclo de vida do patrimônio. Por isso, recomenda-se fortemente que as instituições culturais invistam na instalação de sensores para captação de dados de T, UR, luz e poluentes e na aquisição de sistemas (softwares) para 0 armazenamento e tratamento dos dados. É muito importante que os sensores sejam calibrados e instalados em acordo com as normas e recomendações específicas, de modo a assegurar a confiabilidade dos dados. Os equipamentos / sistemas existentes no mercado são muito variados, por isso, é importante observar a precisão dos aparelhos, a autonomia da bateria, o processo de transferência dos dados e a confiabilidade do sistema como um todo. Para que a análise seja efetiva é importante reduzir ao mínimo as interrupções na coleta dos dados. 
Os dados de T, UR, luz visível e UV e poluentes internos às áreas de guarda precisam ser cotejados com os valores recomendados pelas normas e diretrizes internacionais e ponderados com a observação (e a análise) do estado de conservação dos objetos. Modificações no ambiente construído e/ou nos parâmetros ambientais da área de guarda só devem ser recomendados caso uma ameaça ou um processo de degradação seja identificado.

Revisões metodológicas realizadas por instituições internacionais após vários anos de aplicação dos parâmetros ambientais recomendados, demonstraram que o mero atendimento às normas sem a contínua avaliação e monitoramento do ambiente e do acervo pode resultar em mais danos do que benefícios ou ser energeticamente insustentável (maiores informações sobre o tema no capítulo 2 desta tese).

Como parte da análise, recomenda-se que os dados anuais (um ano completo ou o ano climático típico) de T e UR (horários ou diários) sejam plotados sobre a carta bioclimática, que é um ábaco indicativo das estratégias passivas e ativas para o conforto humano, adaptado por Givoni (1992) para climas tropicais (Figura 99).

Figura 99. Carta psicrométrica com as estratégias bioclimáticas adaptadas por Givoni (1992)

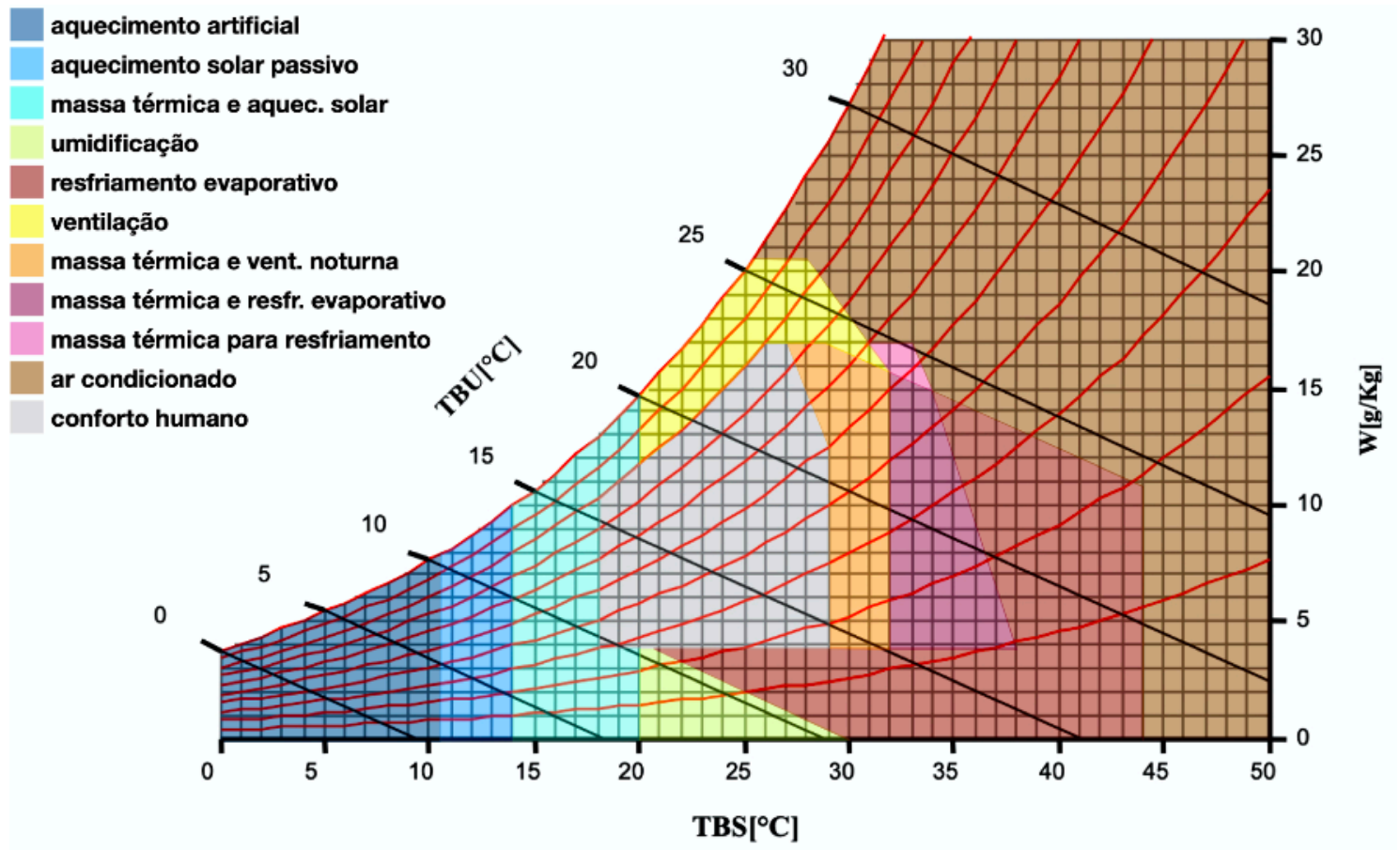

Fonte: adaptado de AUT284, 2013.

Os dados anuais de T e UR também podem ser plotados sobre o ábaco proposto por Krist e Runkel (2019) para a avaliação dos riscos ao acervo (Figura 100). 
Figura 100. Dispersão de T e UR internas, com indicação das zonas de dano provável ao acervo

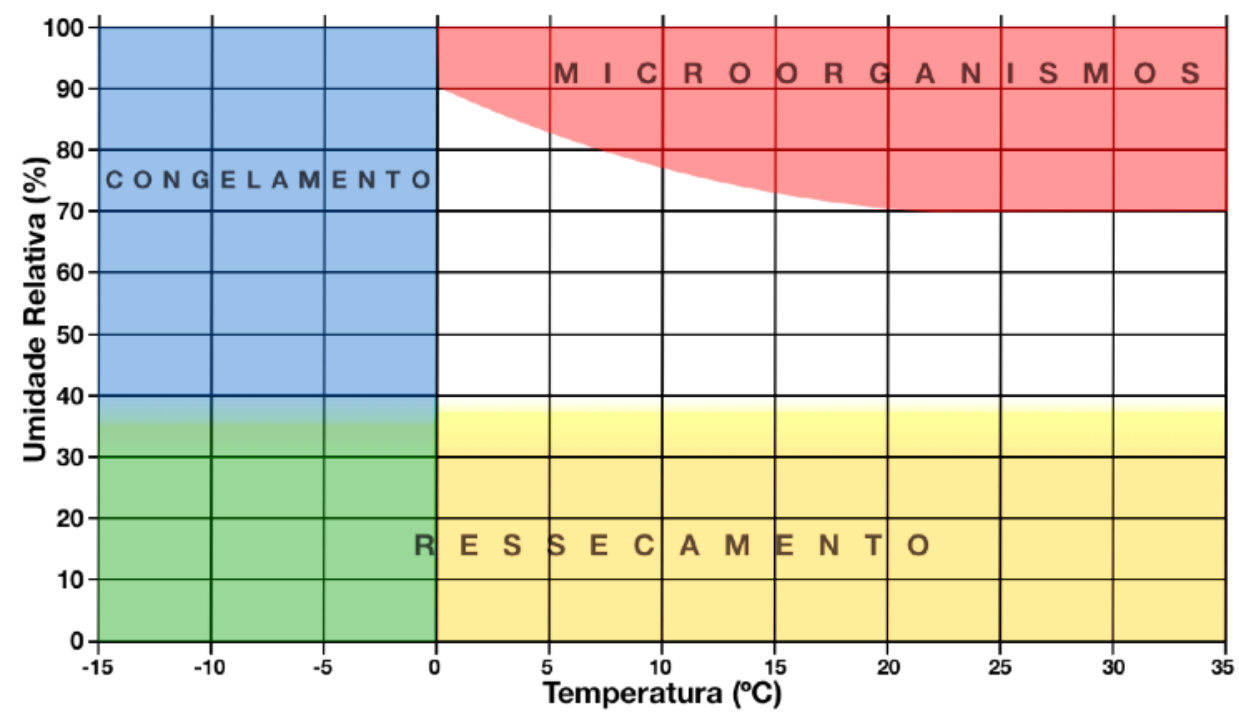

Legenda: zona vermelha: maior probabilidade de desenvolvimento de microorganismos; zona azul: possíveis danos por congelamento; zona branca: maior probabilidade de não haver danos aos objetos; zona amarela: risco de ressecamento de materiais e zona verde: possibilidade de danos por ressecamento e congelamento simultaneamente

Fonte: KRIST e RUNKEL, 2019.

A sobreposição dos dois gráficos, proposto por esta pesquisa, pode auxiliar na análise combinada dos dados, pela perspectiva do ser humano e do acervo (Figura 101).

Figura 101. Carta bioclimática com anotação das zonas de maior risco para acervos com suporte em papel

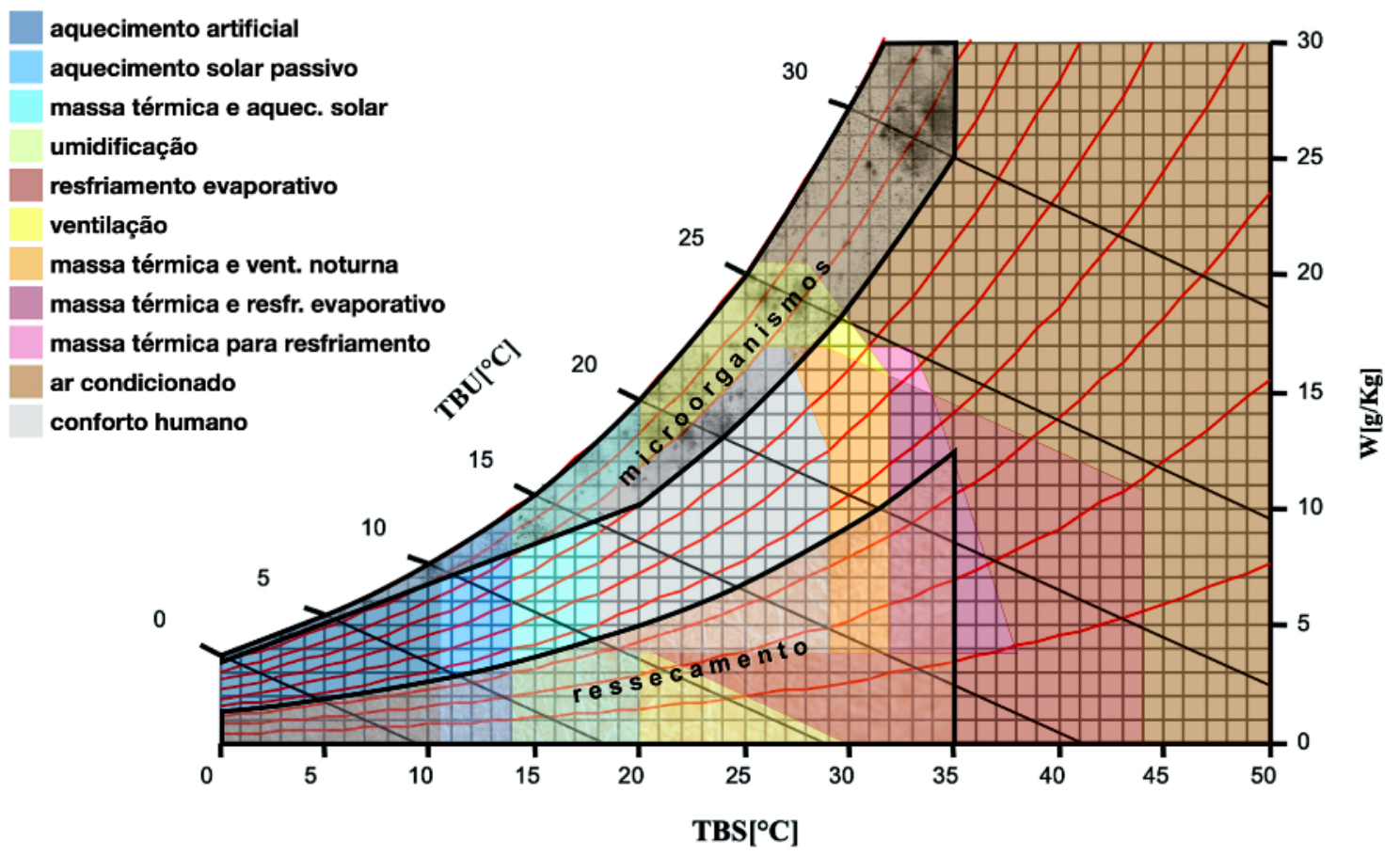

Fonte: a pesquisadora. 
Dados climáticos são sempre quantitativos e precisam ser analisados com cuidado:

- clima é diferente de previsão do tempo; um clima só pode ser caracterizado se houver informações confiáveis para longos períodos de tempo (muitos anos);

- valores médios podem 'esconder' eventos extremos, como flutuações bruscas de temperatura e umidade, rajadas de ventos, etc.. Valores e flutuações extremas são as situações de maior risco para 0 acervo e precisam ser identificadas;

- o clima é caracterizado a partir de séries históricas, que registram um comportamento passado; caso um fator se altere, é possível que todo o padrão climático se modifique (é a chamada mudança climática local e/ou global);

- as projeções estatísticas (modelos climáticos) tratam de possíveis cenários futuros (tendências), os quais podem não se realizar; eles são úteis no planejamento de estratégias para a adaptação e resiliência do edifício a eventos extremos mas devem sempre ser ponderados com a capacidade de recursos da instituição, o mais importante é que as decisões sejam escolhas informadas e conscientes.

\subsubsection{Etapa 4: Resultados}

A última etapa desta proposta é a do planejamento das ações para mitigação ou resolução das ocorrências identificadas e analisadas. A utilização de quadros e mapas síntese das atividades e dos diagnósticos pode auxiliar na comunicação entre a equipe de avaliação, os tomadores de decisão, os demais funcionários da instituição e o público em geral.

A seguir, na Figura 102, tem-se o fluxograma da etapa 4 de aplicação do modelo proposto. 
Figura 102. Fluxograma do modelo teórico-metodológico proposto: Etapa 4 - Resultados

Quadros e Mapas de Diagnósticos e Recomendaçöes
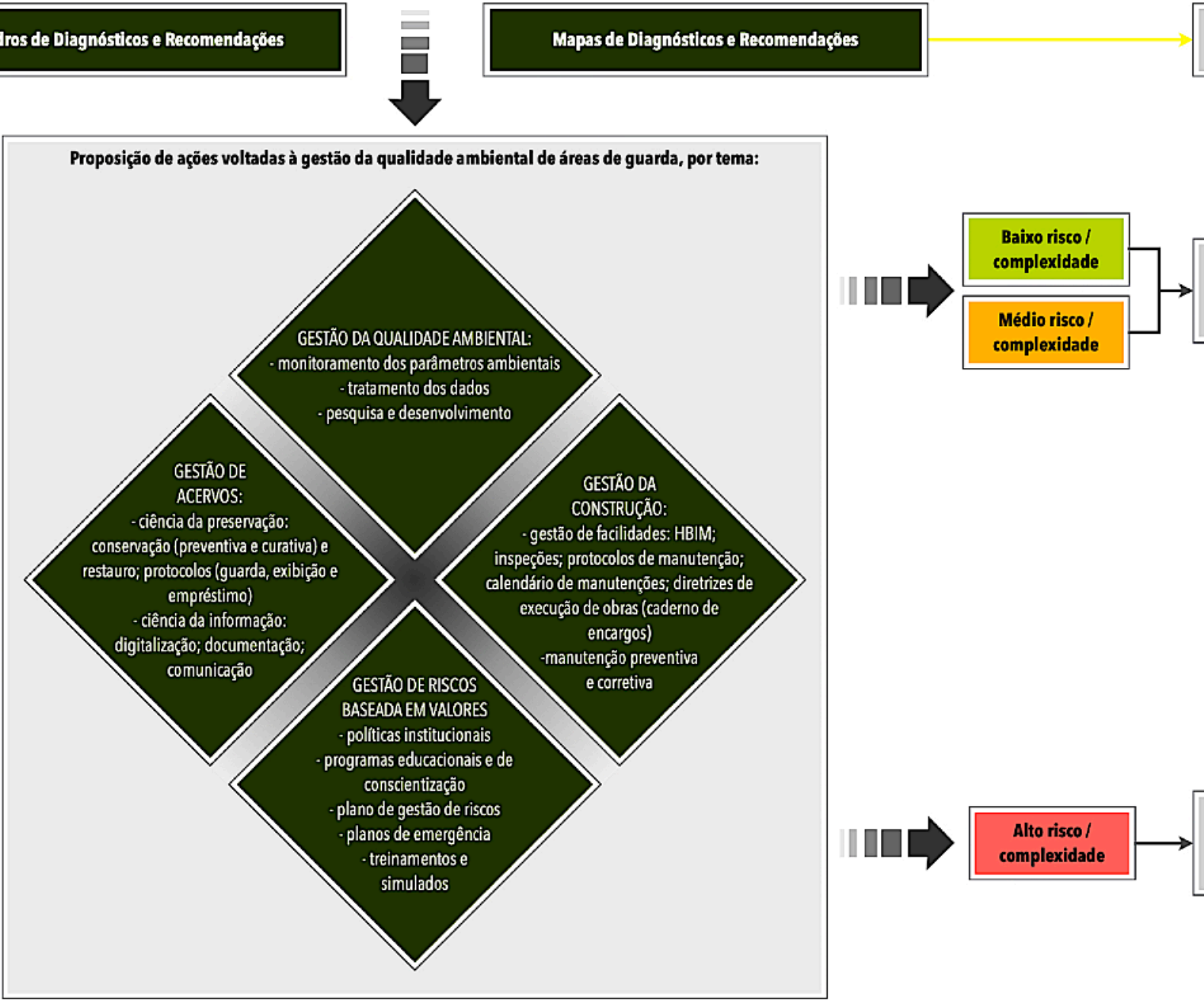

Nova avaliação em um nivel mais detalhado

Fonte: a pesquisadora.

A seguir, são apresentados os modelos de Quadros e Mapas de Diagnósticos e Recomendações, por grau de avaliação, desenvolvidos por esta pesquisa. Porém, é preciso salientar que estes modelos devem ser entendidos como uma referência inicial, e devem adaptados caso a caso. Como mencionado anteriormente, os modelos são apresentados, neste trabalho, em formato analógico, a título de explicação do método, mas o uso de tecnologias digitais para automação de checklists, levantamentos métricos e visuais, análises técnicas e apresentação dos resultados, os quais podem também estar associados à tecnologia SIG e/ou BIM, é desejável porque permite melhor gestão das informações, maior precisão e rapidez na coleta e análise dos dados e agilidade na comunicação dos resultados (uma discussão sobre o tema pode ser encontrada do capítulo 2). 
Propõe-se que o Quadro de Diagnósticos e Recomendações (QDR) para o grau S contenha, pelo menos, o número de identificação de cada ocorrência, uma imagem ilustrativa, a descrição da ocorrência, a camada de avaliação em que ela se encontra, o sistema ou os sistemas construtivos associados à ocorrência e o agente ou os agentes de deterioração associados a ela. Recomenda-se também vincular ao QDR os documentos institucionais utilizados e o relatório final da avaliação (Quadro 41).

A título de exemplo: se a ocorrência 01 for uma janela com com uma não conformidade, a camada de avaliação é a área de guarda, o sistema correspondente é vão / esquadria e os agentes de deterioração (ameaças) associados são gestão incorreta (falhas na inspeção ou na manutenção), roubo, vandalismo e deslocamento (pode facilitar a entrada de pessoas não autorizadas) e pragas / insetos (não é possível vedá-la).

As mesmas informações anotadas no QDR podem ser traduzidas para o formato de Mapas de Diagnósticos e Recomendações (MDR). 0 MDR utiliza a(s) planta(s) do edifício ou da área de análise e associa a ela(s) as ocorrências identificadas e uma caixa de informações para cada ocorrência (Figura 104). Nas caixas de informações, os resultados são parcialmente representados por símbolos, o que facilita a comunicação visual dos diagnósticos (Figura 103). 
Quadro 41. Quadro de Diagnósticos e Recomendações (QDR) sugerido para o grau S

\section{AVALIAÇÃO GRAU S (Screening / Seleção)}

\begin{tabular}{|c|c|c|c|c|c|}
\hline \multicolumn{6}{|c|}{ Documentos institucionais vinculados: } \\
\hline $\mathrm{N}^{0}$ & $\begin{array}{l}\text { registro } \\
\text { visual }\end{array}$ & descrição da ocorrência & $\begin{array}{l}\text { camada de avaliação } \\
\text { (caixa de seleção) }\end{array}$ & $\begin{array}{c}\text { sistema(s) construtivo(s) } \\
\text { associado(s) } \\
\text { (caixa de seleção / } \\
\text { descrição) }\end{array}$ & $\begin{array}{c}\text { agente(s) de } \\
\text { deterioração associado(s) } \\
\text { (caixa de seleção / } \\
\text { descrição) }\end{array}$ \\
\hline & $\begin{array}{l}\text { imagem } \\
\text { ou } \\
\text {-link para } \\
\text { registros } \\
\text { visuais }\end{array}$ & & $\begin{array}{l} \\
\square \text { gestão } \\
\square \text { entorno } \\
\square \text { envolv. externa } \\
\square \text { inst. edifício } \\
\square \text { áreas de guarda } \\
\square \text { inst. áreas guarda } \\
\square \text { armazenamento } \\
\square \text { acondicionamento }\end{array}$ & $\begin{array}{l}\square \text { solo } \\
\square \text { fundação } \\
\square \text { estrutura } \\
\square \text { cobertura } \\
\square \text { vedação vertical } \\
\square \text { vão / esquadria } \\
\square \text { revestimento } \\
\square \text { piso } \\
\square \text { inst. hidrossanitária } \\
\square \text { inst. elétrica } \\
\square \text { inst. mecânica } \\
\square \text { inst. incêndio } \\
\square \text { inst. segurança } \\
\square \text { inst. acessibilidade } \\
\square \text { mobiliário guarda } \\
\square \text { mobiliário exposição } \\
\square \text { sinalização }\end{array}$ & $\begin{array}{l}\square \text { gestão incorreta } \\
\square \text { guarda e } \\
\text { uso incorreto } \\
\square \text { roubo, vandalismo, } \\
\text { deslocamento } \\
\square \text { pragas (insetos) } \\
\square \text { pragas (animais) } \\
\square \text { poluentes (partículas) } \\
\square \text { poluentes (gases) } \\
\square \text { luz visível e UV } \\
\square \text { i incorreta } \\
\square \text { UR incorreta } \\
\square \text { água (natural) } \\
\square \text { água (não natural) } \\
\square \text { fogo (direto) } \\
\square \text { fogo (indireto) } \\
\text { Descrição do(s) risco(s): }\end{array}$ \\
\hline 0 & & & & & \\
\hline & & & & . & \\
\hline
\end{tabular}

Fonte: a pesquisadora. 
Figura 103. Legenda de símbolos propostos para os Mapas de Diagnósticos e Recomendações (parte 1)

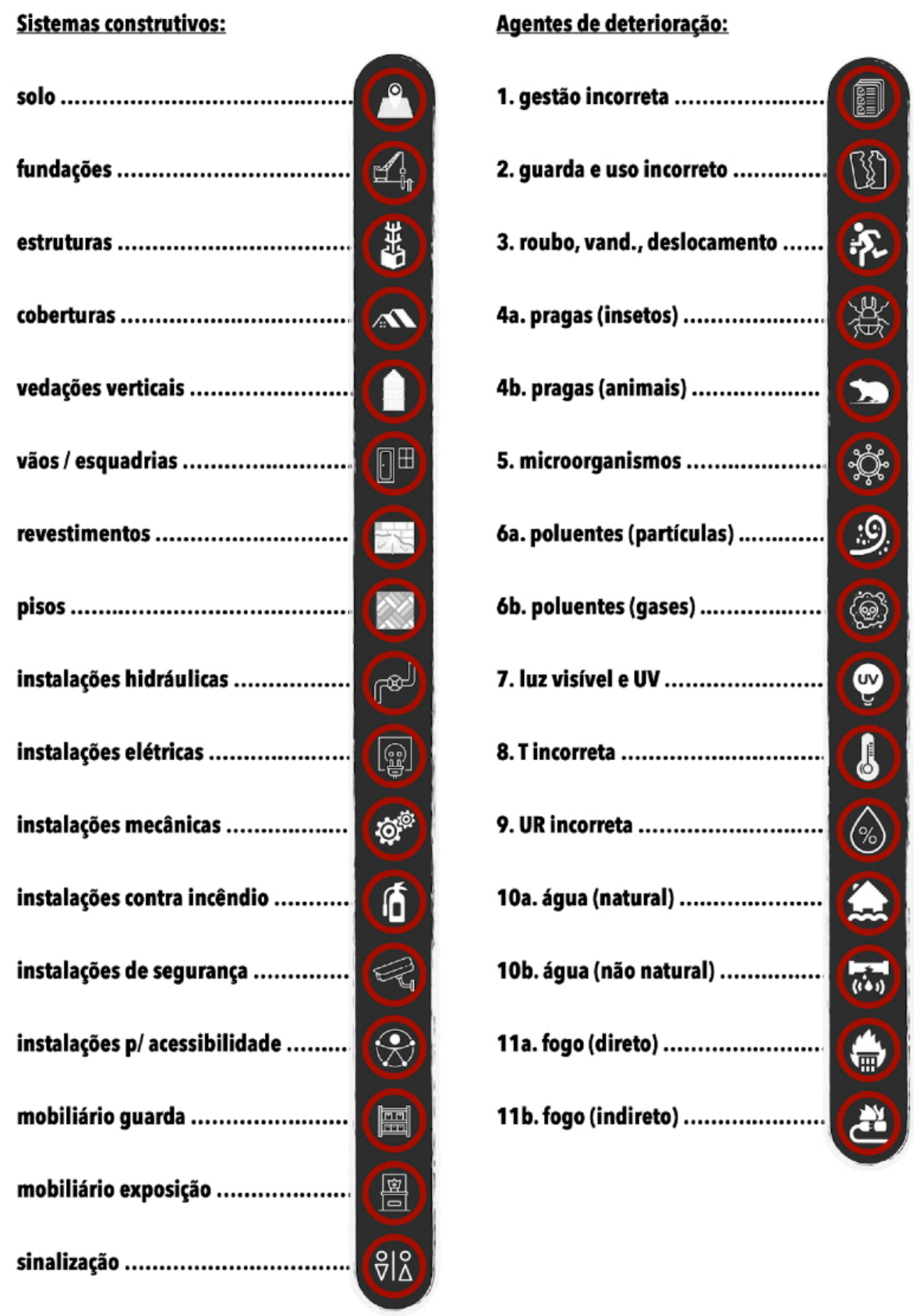

Fonte: a pesquisadora. 
Figura 103. Legenda de símbolos propostos para os Mapas de Diagnósticos e Recomendações (parte 2)

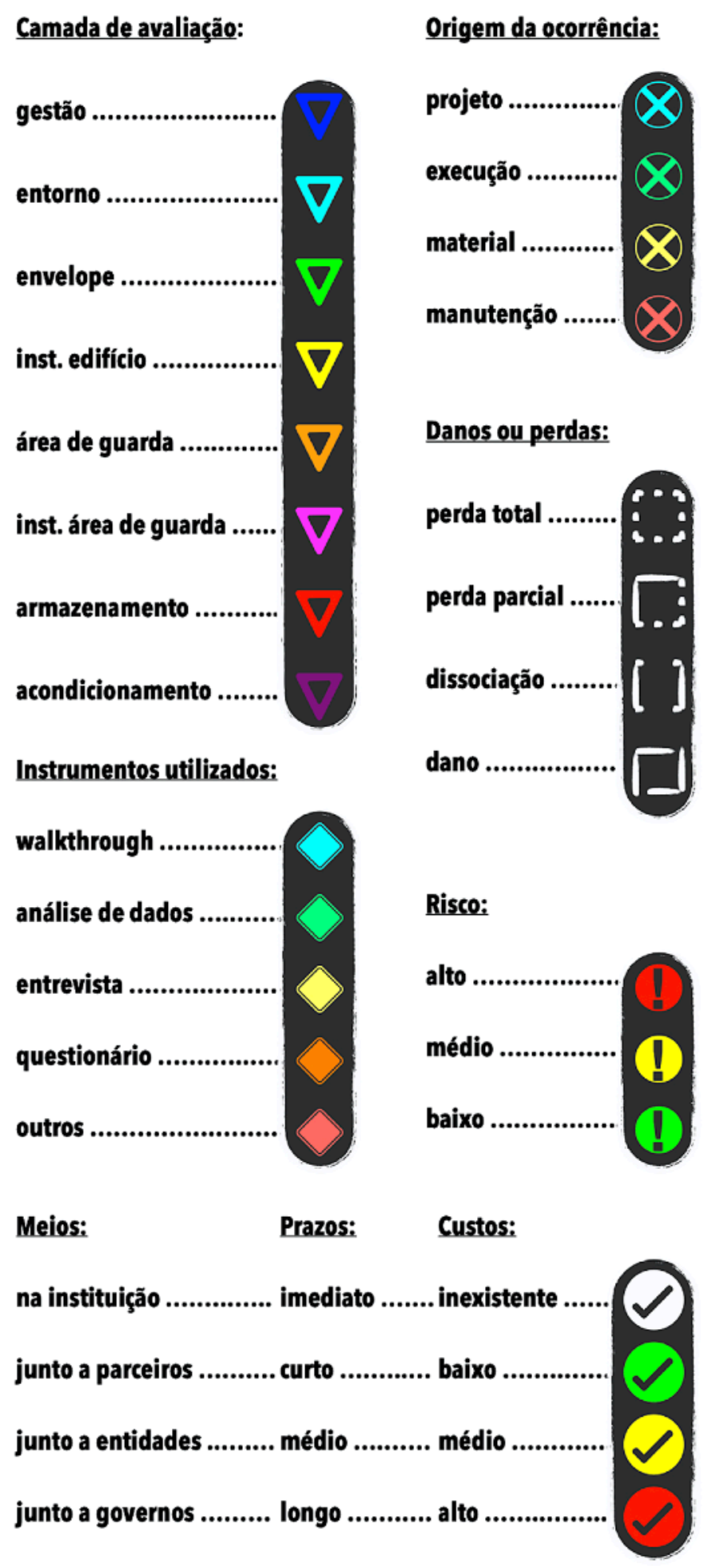

Fonte: a pesquisadora. 
Figura 104. Mapa de Diagnósticos e Recomendações (MDR) sugerido para o grau S

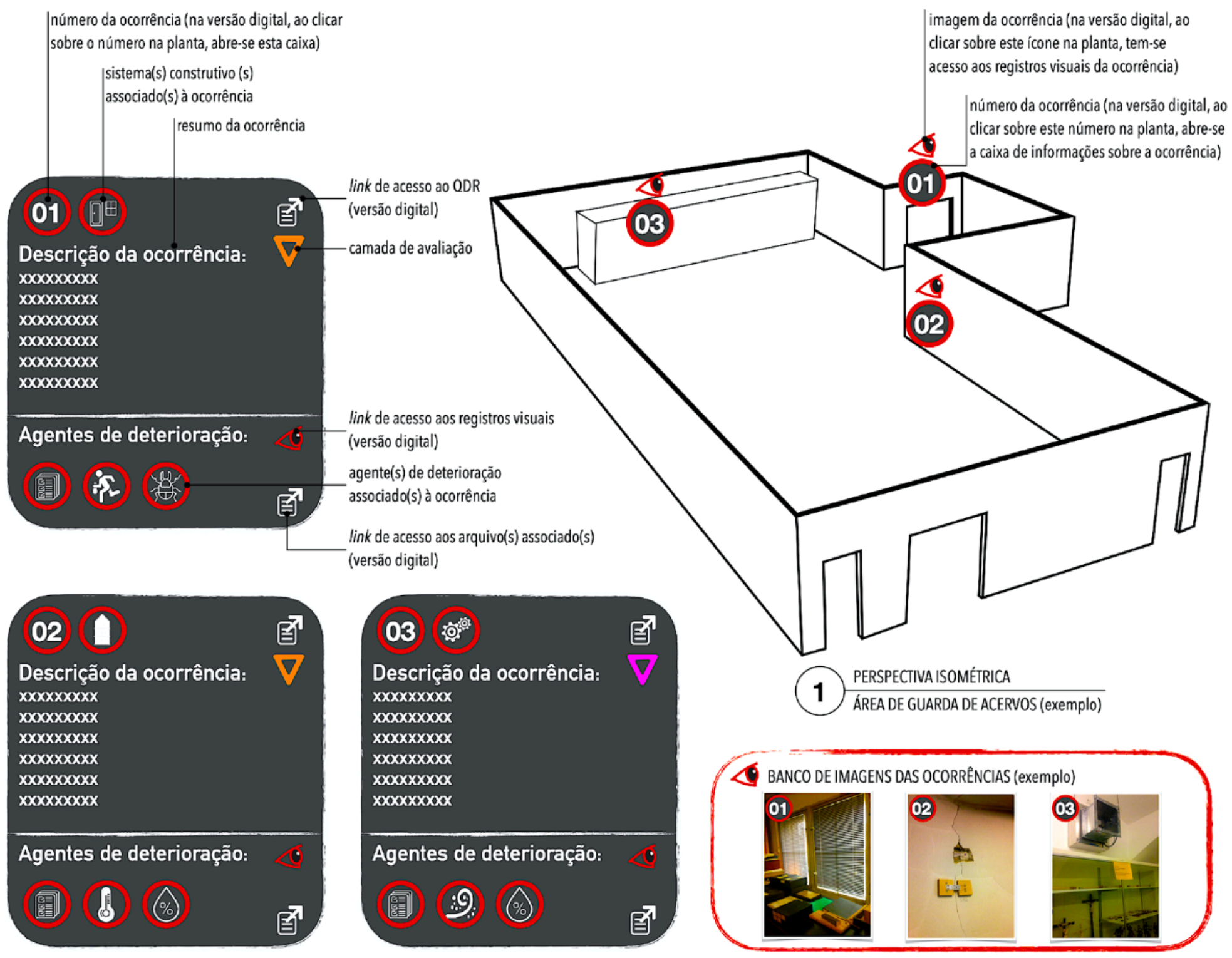

Fonte: a pesquisadora. 
0 Quadro de Diagnósticos e Recomendações (QDR) para o grau OB deve conter, além das informações já descritas para o grau S, a anotação dos instrumentos utilizados na identificação da ocorrência, as leis, normas e/ou recomendações pertinentes, as propostas da equipe de avaliação para mitigação ou resolução da ocorrência, os meios, prazos e custos relativos estimados pela equipe e a viabilidade de resolução da ocorrência (Quadro 42).

As recomendações propostas pela equipe de avaliação para cada uma das ocorrências devem contemplar ações em pelo menos uma dentre quatro áreas:

- gestão da qualidade ambiental: plano para monitoramento e análise dos parâmetros ambientais e para 0 desenvolvimento de ações voltadas à melhoria do desempenho do ambiente interno das áreas de guarda;

- gestão da construção: plano para a gestão das facilidades, que contemple ações voltadas ao monitoramento, à documentação, e à manutenção preventiva e corretiva dos sistemas construtivos e, se for 0 caso, plano (caderno de encargos) e projeto para obras de readequação, reforma, ampliação, dentre outras;

- gestão de acervos: plano para a conservação preventiva, curativa e/ou restauro de coleções ou itens; protocolos para a guarda, a exposição e o empréstimo adequados; plano para monitoramento, documentação e/ou digitalização do acervo; plano para comunicação com público interno e/ou externo;

- gestão de riscos: políticas e programas institucionais baseados em valores, para o público interno e externo; planejamento estratégico para resolução dos riscos identificados e para aplicação de novas avaliações; planos de preparação para as emergências potenciais identificadas; plano de treinamentos e simulados para todos os funcionários.

A atribuição de pesos a meios, prazos e custos, no grau OB, pode ser feita a partir da experiência dos avaliadores, e considera cada ocorrência apenas de maneira relativa, ou seja, o quanto a sua resolução é mais simples e rápida do que as outras ocorrências. 0 cálculo da viabilidade é feita por meio da soma dos pesos atribuídos pelos avaliadores aos meios, prazos e custos. 0 objetivo, com esta classificação, é que ela seja uma orientação preliminar para o planejamento estratégico das prioridades institucionais. Por isso, as equipes responsáveis pela execução dos planos podem concluir que as prioridades sugeridas pela equipe de avaliação precisam ser recombinadas para maior eficiência na execução das ações de manutenção e conservação.

A título de exemplo: se a ocorrência 01 for uma janela com uma não conformidade, ela foi identificada por meio de inspeção visual (visita técnica), a legislação pertinente é a ABNT NBR 15.575:2013, que 
estabelece parâmetros para o desempenho de esquadrias, a proposta da equipe de avaliação é que seja executada a manutenção corretiva com substituição das peças defeituosas, e a equipe estima que a viabilidade relativa de execução da proposta é alta pois pode ser feita pela própria instituição, no curto prazo e com custo médio.

As mesmas informações anotadas no QDR também estão representadas visualmente no Mapa de Diagnósticos e Recomendações (MDR) para o grau OB (Figura 105).

Quadro 42. Quadros de Diagnósticos e Recomendações (QDR) sugerido para o grau OB

\section{AVALIAÇÃO GRAU OB (OBservation / OBservação)}

\begin{tabular}{|c|c|c|c|c|c|c|}
\hline \multicolumn{7}{|c|}{ Documentos institucionais vinculados: } \\
\hline $\mathrm{N}^{0}$ & $\begin{array}{l}\text { todas as } \\
\text { colunas } \\
\text { pertencentes } \\
\text { ao grau S }\end{array}$ & $\begin{array}{c}\text { instrumentos } \\
\text { utilizados } \\
\text { (caixa de seleção / } \\
\text { descrição) }\end{array}$ & $\begin{array}{l}\text { legislaç̧ões } \\
\text { pertinentes } \\
\text { associadas à } \\
\text { ocorrência } \\
\text { (descrição) }\end{array}$ & $\begin{array}{c}\text { propostas para } \\
\text { mitigação ou } \\
\text { eliminaçãa do perigo } \\
\text { (caixa de seleção / } \\
\text { descrição) }\end{array}$ & $\begin{array}{l}\text { meios prováveis / } \\
\text { prazos relativos } \\
\text { estimados / } \\
\text { custos relativos } \\
\text { estimados }\end{array}$ & $\begin{array}{c}\text { viabilidade } \\
\text { relativa }\end{array}$ \\
\hline & $\begin{array}{c}\text { registro } \\
\text { visual } \\
\text { descrição da } \\
\text { ocorrência } \\
\text { camada de } \\
\text { avaliação } \\
\text { sistema(s) } \\
\text { construtivo(s) } \\
\text { associado(s) } \\
\text { agente(s) de } \\
\text { deterioração } \\
\text { associado(s) }\end{array}$ & $\begin{array}{l}\square \text { avaliação do edifício } \\
\text { quais? } \\
\square \text { avaliação do acervo } \\
\text { quais? } \\
\square \text { perspect. do usuário } \\
\text { quais? }\end{array}$ & & $\begin{array}{l}\square \text { gestão da qualidade } \\
\text { ambiental } \\
\text { quais? } \\
\square \text { gestão do edifício } \\
\text { quais? } \\
\square \text { gestão do acervo } \\
\text { quais? } \\
\square \text { gestão de riscos } \\
\text { quais? }\end{array}$ & $\begin{array}{l}\text { Meios / peso atribuído: } \\
\square \text { instituição ( } 1 \text { ponto) } \\
\square \text { parceiros ( } 2 \text { pontos) } \\
\square \text { entidades (3 pontos) } \\
\square \text { governos (4 pontos) } \\
\text { Prazo / peso atribuído: } \\
\square \text { imediato ( } 1 \text { ponto) } \\
\square \text { curto (2 pontos) } \\
\square \text { médio (3 pontos) } \\
\square \text { longo (4 pontos) } \\
\text { Custo / peso atribuído: } \\
\square \text { inexistente (1 ponto) } \\
\square \text { baixo (2 pontos) } \\
\square \text { médio (3 pontos) } \\
\square \text { alto (4 pontos) }\end{array}$ & $\begin{array}{c}\text { Soma dos } \\
\text { pesos } \\
\text { relativos } \\
\text { atribuídos } \\
\text { a: } \\
\text { meios + } \\
\text { prazo + } \\
\text { custo: } \\
\text { alta }= \\
3 \text { a } 6 \\
\text { média }= \\
7 \text { a } 11 \\
\text { baixa }= \\
12\end{array}$ \\
\hline 0 & & & & & & \\
\hline & $\begin{array}{l}\text { ) digital(is) } \\
\text { ivo anexo }\end{array}$ & $\begin{array}{l}\text { ssociado(s) à avalia } \\
\text { link de acesso) }\end{array}$ & 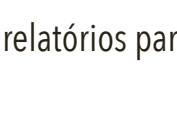 & S, relatorio tinal, $\mathrm{p}$ & os, projetos, prot & \\
\hline
\end{tabular}

Fonte: a pesquisadora. 
Figura 105. Mapa de Diagnósticos e Recomendações (MDR) sugerido para o grau OB

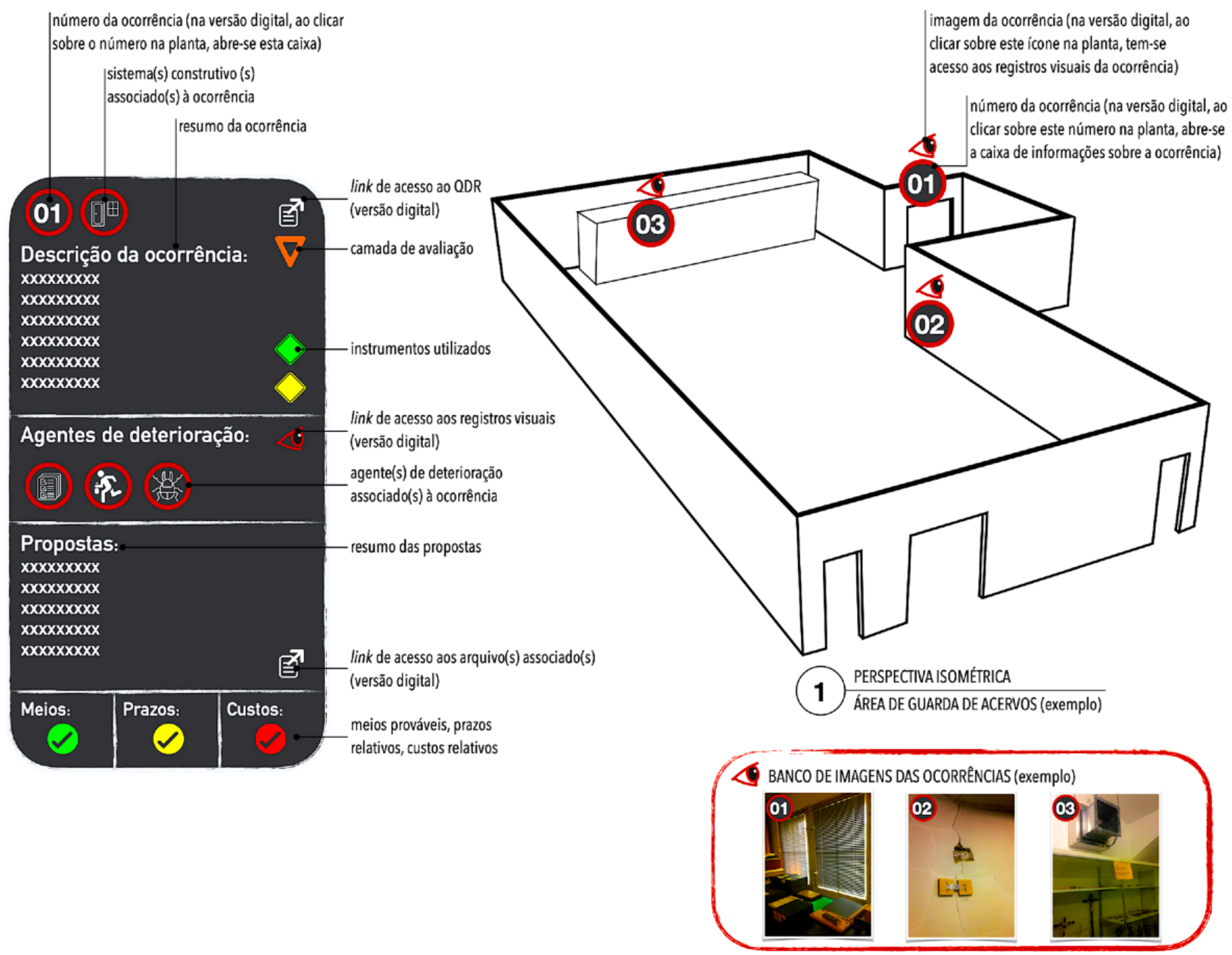

Fonte: a pesquisadora. 
0 Quadro de Diagnósticos e Recomendações (QDR) para o grau AN deve conter, além das informações já descritas para os graus $S$ e OB, também (Quadro 43):

- a identificação da origem da inadequação, anomalia ou falha associada à ocorrência, ou seja, se no projeto, na execução da obra, no material / sistema construtivo ou nos procedimentos de manutenção; - a identificação das consequências da ocorrência para os itens do acervo, ou seja, se um dano mecânico, químico ou biológico, uma perda parcial, total e/ou dissociação de partes ou da totalidade do objeto, e se este dano ou perda foi observado em itens do acervo durante a avaliação ou se é um resultado esperado, caso uma ameaça se transforme em um evento adverso;

- a classificação do risco associado a cada ocorrência, calculado pelo especialista em análise de riscos, para o edifício, 0 acervo e o patrimônio como um todo;

- a identificação (ou o link de acesso), para os casos em que se aplica, de documentos relativos a cada uma das análises técnicas específicas (relatórios, tabelas, gráficos, matrizes, etc.), para cada ocorrência. Neste grau de avaliação os meios, prazos e custos devem ser, na medida do possível, calculados pela equipe de avaliação a partir da experiência dos avaliadores e das tabelas de referência disponibilizadas por entidades do setor da construção civil.

Todas as informações anotadas no QDR também estão representadas visualmente no Mapa de Diagnósticos e Recomendações (MDR) para o grau AN (Figura 106). 
Quadro 43. Quadro de Diagnósticos e Recomendações (QDR) sugerido para o grau AN

\section{AVALIAÇÃO GRAU AN (ANalysis / ANálise)}

\begin{tabular}{|c|c|c|c|c|c|}
\hline \multicolumn{6}{|c|}{ Documentos institucionais vinculados: (arquivo anexo ou link de acesso) } \\
\hline $\mathrm{N}^{0}$ & $\begin{array}{c}\text { todas as colunas } \\
\text { pertencentes aos } \\
\text { graus } \mathrm{S} \text { e OB }\end{array}$ & $\begin{array}{l}\text { origem da ocorrência } \\
\text { (caixa de seleçãa) }\end{array}$ & $\begin{array}{c}\text { danos ou perdas } \\
\text { potenciais / observadas } \\
\text { (caixa de seleção / } \\
\text { descrição) }\end{array}$ & $\begin{array}{l}\text { risco calculado } \\
\text { (caixa de seleção) }\end{array}$ & $\begin{array}{l}\text { documento(s) } \\
\text { vinculado(s) ao } \\
\text { instrumento }\end{array}$ \\
\hline 01 & $\begin{array}{c}\text { registro visual } \\
\text { descrição da } \\
\text { ocorrência } \\
\text { camada de } \\
\text { avaliaçã̃o } \\
\text { sistema(s) } \\
\text { construtivo(s) } \\
\text { associado(s) } \\
\text { agente(s) de } \\
\text { deterioração } \\
\text { associado(s) } \\
\text { instrumentos } \\
\text { utilizados } \\
\text { legislações } \\
\text { pertinentes } \\
\text { propostas para } \\
\text { mitigaçãa ou } \\
\text { eliminação do } \\
\text { perigo } \\
\text { meios, prazos } \\
\text { estimados, custos } \\
\text { estimados } \\
\text { viabilidade }\end{array}$ & $\begin{array}{l}\square \text { projeto } \\
\square \text { execução } \\
\square \text { material de construção } \\
\square \text { manutenção }\end{array}$ & $\begin{array}{l}\square \text { dano mecânico } \\
\square \text { dano químico } \\
\square \text { dano biológico } \\
\square \text { perda parcial } \\
\square \text { perda total } \\
\square \text { dissociação } \\
\text { Descrição do(s) dano(s) } \\
\text { e/ou da(s) perda(s) - } \\
\text { anotar se potencial ou } \\
\text { observada: }\end{array}$ & $\begin{array}{l}\text { edifício: } \\
\square \text { alto } \\
\square \text { médio } \\
\square \text { baixo } \\
\text { acervo: } \\
\square \text { alto } \\
\square \text { médio } \\
\square \text { baixo } \\
\text { global: } \\
\square \text { alto } \\
\square \text { médio } \\
\square \text { baixo }\end{array}$ & $\begin{array}{l}\square \text { ambiente }{ }^{-(\text {link) }} \\
\text { identificação: } \\
\square \text { edifício \(link) } \\
\text { identificação: } \\
\square \text { acervo - (link) } \\
\text { identificação: } \\
\square \text { usuário — (link) } \\
\text { identificação: }\end{array}$ \\
\hline $\begin{array}{l}02 \\
\ldots\end{array}$ & & & & & \\
\hline & $\begin{array}{l}\text { (s) digital(is) as } \\
\text { quivo anexo ou }\end{array}$ & $\begin{array}{l}\text { iado(s) à avaliação (rela } \\
\text { de acesso) }\end{array}$ & rios parciais, relatório f & nal, planos, projet & , protocolos): \\
\hline
\end{tabular}

Fonte: a pesquisadora. 
Figura 106. Mapa de Diagnósticos e Recomendações (MDR) sugerido para o grau AN

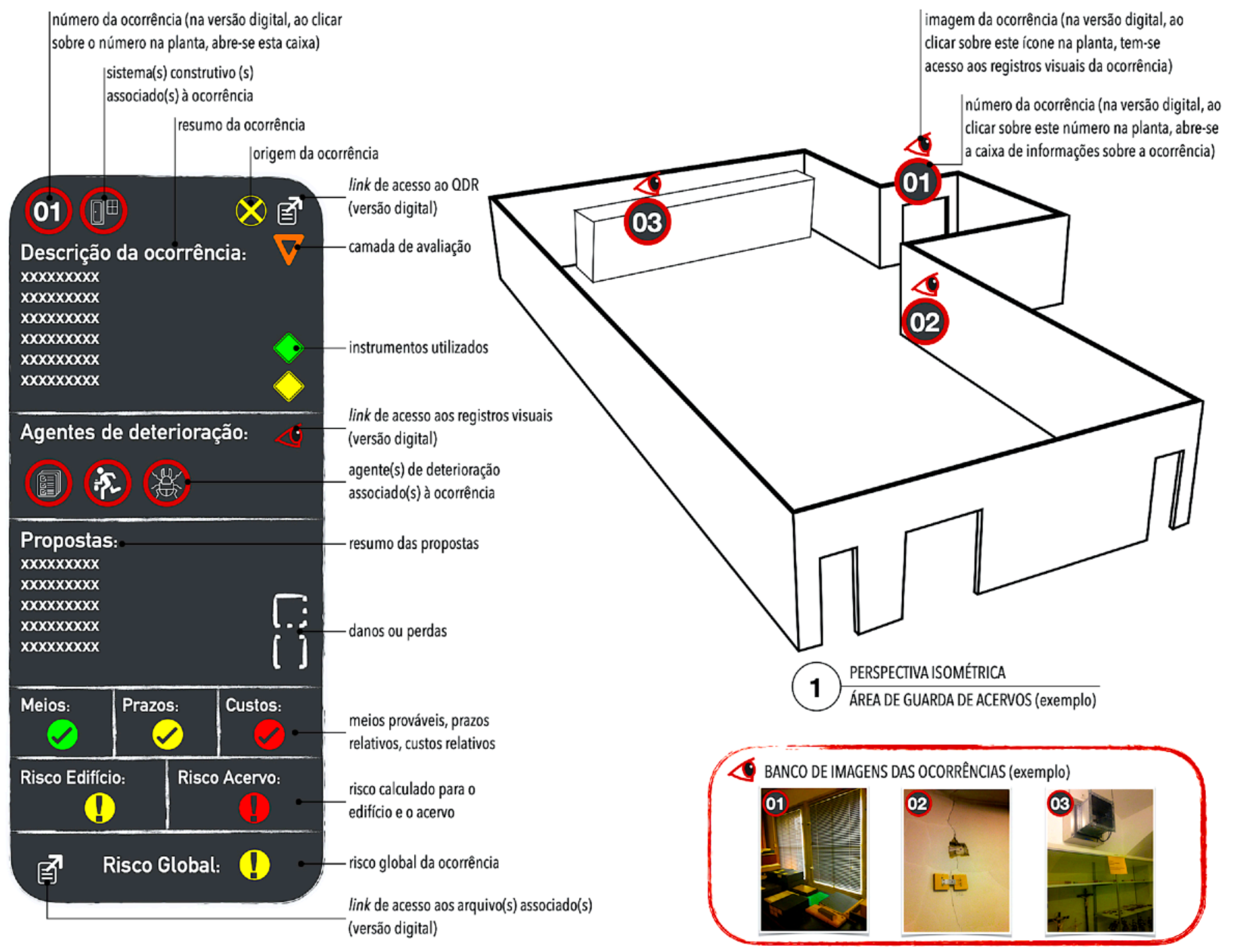

Fonte: a pesquisadora. 
No grau $E$, devem ser utilizados os mesmos modelos de QDR e MDR do grau AN, porém, com a adição das informações e dos arquivos relativos a cada análise específica.

0 Relatório Final da avaliação deve contemplar o registro de todas as etapas descritas por este modelo integrado para o diagnóstico de áreas de guarda de acervos, incluindo os instrumentos utilizados, a análise dos dados, os QDRs e os MDRs. Por fim, a equipe de avaliação deve fazer uso de gráficos, matrizes e/ou diagramas para síntese dos resultados apresentados nos QDR, tais como, por exemplo, o diagrama de radar, em que é possível representar a quantidade de ocorrências identificadas por quesito de avaliação, seja ele camadas, sistemas construtivos, agentes de deterioração, origem da ocorrência, etc., o que pode auxiliar a instituição na identificação das vulnerabilidades mais prevalentes (Figura 107).

Figura 107. Exemplos de diagramas de radar com indicação da quantidade de ocorrências, por quesito de avaliação (neste exemplo, agentes de deterioração e sistemas construtivos)

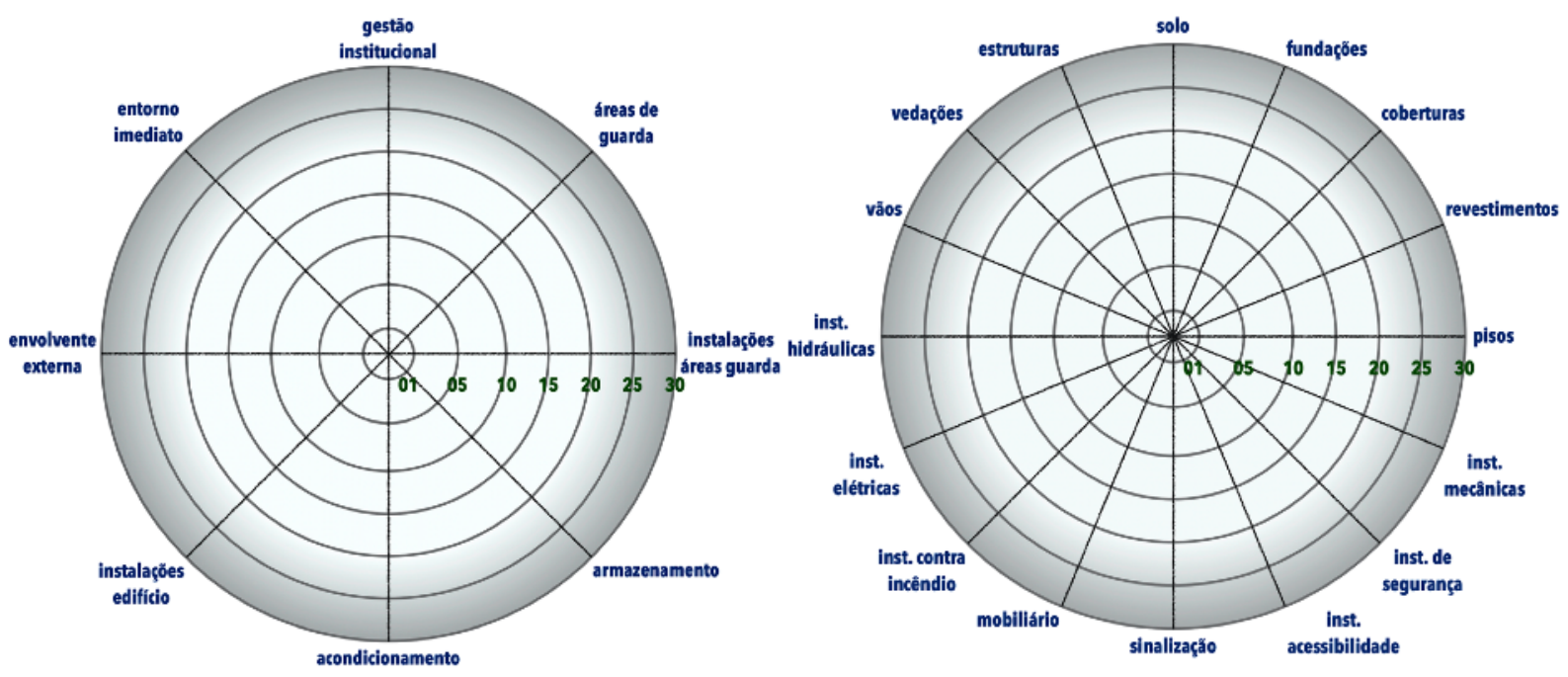

Fonte: a pesquisadora.

0 encaminhamento do Relatório Final de Diagnósticos e Recomendações elaborado pela equipe de avaliação aos tomadores de decisão encerra esta etapa. 0 passo seguinte é a instituição organizar as equipes que serão responsáveis pela elaboração dos planos, projetos, protocolos e calendário de ações que permitam responder aos perigos identificados e executar as recomendações propostas. 0 modelo proposto recomenda que, para as ocorrências identificadas como de baixo ou médio risco, impacto ou complexidade, sejam dados os encaminhamentos adequados (manutenções, reformas, mudanças em rotinas e comportamentos, dentre outros) e se faça o monitoramento continuado, tanto do ambientes como do acervo e das ações propostas, e, para as ocorrências identificadas como de alto risco, impacto ou 
complexidade, se possível, seja planejada a realização de uma avaliação no grau E, o que permitirá uma investigação mais aprofundada e uma resposta mais precisa. 0 conjunto dos documentos gerados pelas avaliações devem fazer parte do planejamento institucional estratégico para o próximo ciclo. Ao final de cada ciclo, o processo deve ser reiniciado, porém, tendo como ponto de partida a experiência adquirida previamente e os dados coletados por meio dos monitoramentos realizados ao longo do ciclo anterior.

Por fim, é importante salientar que a organização, a documentação e o acondicionamento dos objetos; 0 desempenho ambiental interno das áreas de guarda; e o estado de conservação dos acervos são sempre questões muito sensíveis para todas as instituiç̧ões culturais. Por um lado, uma publicização não cuidadosa e não criteriosa das condições de guarda pode causar interpretações equivocadas ou mal intencionadas e prejudicar ou mesmo interromper esforços institucionais orientados a melhorias. Por outro lado, é importante que, dentro do arcabouço científico, sejam estimuladas as ações de pesquisa, análise, discussão e proposição de soluções, e isto precisa ser feito em parceria com a comunidade externa interessada.

No planejamento de uma avaliação diagnóstica para áreas de guarda de acervos, o aspecto ético precisa estar sempre no cerne das atividades, uma vez que seu objeto de análise é a interação entre o ser humano, 0 ambiente construído e o patrimônio. Ainda na etapa de desenho da avaliação, o emprego de instrumentos de dinâmicas com pessoas-chave da instituição pode ajudar na definição do encaminhamento que será dado a cada um dos resultados descritos no Relatório Final: apenas para uso interno da instituição; para uso da instituição e dos colaboradores externos; para publicações especializadas; ou para comunicação voltada para o público externo. 


\section{$7 \quad$ CONCLUSÕES FINAIS}

A partir das múltiplas experiências obtidas no percurso desta pesquisa foi possível concluir, para as instituições culturais visitadas, os benchmarks e os casos de estudo, que:

a. em muitas das instituições brasileiras visitadas, estejam elas localizadas em edifícios históricos e patrimoniados ou novos, ainda que se reconheça a relevância de se fazer a transição de uma visão corretiva para uma visão preventiva, por diversas razões, muitas delas alheias à vontade do seu corpo técnico, não existem mecanismos que favoreçam a preservação sustentável e holística do patrimônio, 0 que pode estar relacionado a ausência ou deficiência de:

- atividades diagnósticas que permitam a correta compreensão dos riscos ao patrimônio associados ao desempenho ambiental das áreas de guarda, à qualidade da construção e/ou às atividades de manutenção do(s) edifício(s);

- pesquisas científicas sistemáticas que correlacionem a deterioração dos diversos materiais que compõem o patrimônio (móvel e imóvel) a climas e microclimas específicos;

- oportunidades de treinamentos e simulados para todos os funcionários de todos os setores da instituição para que, cada um em sua função, possa atuar a partir da correta percepção dos riscos às coleções associados a comportamentos e atividades;

- presença, na instituição, de gestores e/ou técnicos com treinamento em manutenção preventiva e corretiva de edifícios para a guarda e/ou exposição de acervos, e de suas facilidades;

- regras que favoreçam a escolha de gestores especialistas em gestão do patrimônio cultural e que incentivem a permanência da equipe por períodos de tempo longos o suficiente para que políticas e planos de melhoria de processos possam ser implementados;

- desenvolvimento de uma cultura de gestão institucional de longo prazo (planejamento estratégico), com metas claras e previsão de destinação de recursos para manutenção, reforma, adaptação, ampliação ou construção de edifícios, facilidades e/ou mobiliários para guarda e exposição adequada de acervos, que esteja orientada à qualidade do ambiente construído e à redução de riscos. 
b. em muitos dos museus, bibliotecas e arquivos visitados, seja no Brasil ou no exterior, foi possível identificar características classificadas pelos funcionários consultados como detentoras de qualidade institucional, entendida como confiabilidade no edifício e em seus sistemas construtivos, bom estado de conservação dos acervos e bem-estar dos funcionários na realização de suas tarefas. Para este contexto mais amplo, tem-se que:

- instituições culturais com maior autonomia administrativa, e que possuíam, em sua estrutura organizacional, uma equipe composta por técnicos, gestores de facilidades e arquitetos e/ou engenheiros dedicados à manutenção predial, que conheciam as características específicas do edifício e dos acervos e as necessidades dos conservadores funcionavam melhor. Por outro lado, as instituições que dependiam de um departamento centralizado externo de gestão das facilidades ou de empresas terceirizadas responsáveis por todos serviços de inspeção e manutenção relataram maiores dificuldades, relacionadas principalmente à compreensão da relevância, para a preservação dos bens, de se garantir que os serviços prestados observassem princípios de segurança, qualidade e prazo;

- instituições culturais que mantinham quadros estáveis de funcionários (próprios ou terceirizados) por vários anos, tanto para serviços de manutenção, limpeza, vigilância como de preservação, reportaram a percepção de uma melhor gestão dos riscos e uma resposta mais eficiente (rápida e orientada às características próprias do patrimônio) quando em situações de emergência;

- instituições culturais que possuíam em seus quadros de funcionários especialistas em todos os setores necessários ao seu correto funcionamento: gestão, manutenção, preservação, exposição, educação etc., relataram maior confiança nas decisões tomadas. Por outro lado, naquelas instituições onde havia um desequilíbrio entre os diversos setores e/ou ausência de especialistas, foi relatado uma maior quantidade de conflitos e, consequentemente, uma menor compreensão dos riscos potenciais;

- algumas instituições culturais que fizeram uso de concursos de arquitetura para a escolha de projetos de construção de novas áreas ou de reforma de espaços existentes expressaram ressalvas com a experiência, e descreveram a necessidade de, posteriormente, se consumir muito tempo e energia na adaptação da ideia vencedora às necessidades específicas de preservação das coleções. Pontuou-se também que os procedimentos para a realização de concursos (caderno de encargos, 
júri, critérios de seleção, grau de especialização dos participantes, etc.) precisam ser aprimorados para que não sejam um obstáculo à incorporação de soluções construtivas melhor adaptadas a reservas técnicas nem um incentivo à forma em detrimento das funções;

- instituições culturais que possuíam planejamento estratégico, decidido em conjunto por todos os setores institucionais, com distribuição equilibrada de recursos para guarda, conservação e exposição dos acervos, demonstraram uma percepção bastante positiva da relevância do trabalho executado em prol da preservação das coleções. Por outro lado, nas instituições com ausência ou insuficiência de políticas, planos, projetos e protocolos, funcionários reportaram que esta situação causava maiores preocupações do que a insuficiência de recursos financeiros isoladamente. Mesmo em instituições financeiramente mais favorecidas, funcionários reportaram que falhas no planejamento e incertezas quanto ao futuro de curto e médio prazos eram uma fonte de estresse. Assim, conclui-se que a implementação de uma política voltada ao diagnóstico da instituição, que seja o resultado de um processo de análise dos múltiplos fatores que impactam nas atividades-chave, é uma medida fundamental quando o objetivo pretendido é o cuidado e a preservação do patrimônio. É a partir da síntese das informaç̧ões coletadas por meio dos múltiplos instrumentos e métodos reconhecidos e disponíveis que se pode compreender, para cada caso individual, quais são as ameaças e suas origens e, assim, propor ações efetivas para mitigar ou eliminar os perigos.

Portanto, pode-se confirmar a hipótese formulada por esta pesquisa de que é a análise global do patrimônio cultural em sua integralidade (pessoas/usuários, edifícios, acervos e práticas/ procedimentos) que permite, por meio de um processo de auto-análise e auto-conhecimento institucional, se chegar a um diagnóstico confiável e ao tratamento mais recomendado.

Os benchmarks e casos de estudo analisados demonstraram que, seja no Brasil ou no exterior, as instituições mais 'saudáveis', na opinião de seus funcionários, eram aquelas que possuíam autonomia e recursos, principalmente técnicos e de gestão, para integrar seus diversos setores e planejar suas ações na direção da preservação sustentável do 'corpo' patrimonial.

0 modelo teórico-metodológico proposto cumpre o objetivo desta pesquisa e contribui para 0 desenvolvimento de uma metodologia para avaliação integrada do desempenho das áreas de guarda de acervos com suporte em papel pois propõe uma abordagem que responde aos aspectos identificados como mais relevantes, ou seja: 
a. estimula a conexão entre os especialistas das diversas áreas do conhecimento que podem contribuir com a identificação dos riscos;

b. está adaptada às características locais e aos recursos disponíveis na instituição;

c. permite que as decisões sejam tomadas de maneira esclarecida, a partir de um diagnóstico holístico do patrimônio e de uma apresentação clara e objetiva dos resultados;

d. estimula recomendações criativas e adaptadas às necessidades próprias de cada instituição pois 'dá voz' não apenas aos especialistas como a todos os usuários;

e. permite que todas as etapas sejam corretamente documentadas, o que incentiva uma cultura de melhoria continuada das condições de guarda e pode contribuir com o conhecimento científico para a incremento da qualidade das áreas de guarda de acervos em instituições similares.

Quanto menor a quantidade de recursos disponíveis na instituição, mais ela pode se beneficiar ao orientar seus esforços para o planejamento e o diagnóstico. A conscientização é a palavra-chave quando se pretende que todos os usuários percebam a relevância de fazerem parte da resolução dos problemas. Ações bem intencionadas mas fragmentadas, desconectadas, tendem a resultar em muito esforço com pouca efetividade. Não é raro observar que, nestas condições, as pessoas trabalham mais do que o necessário para alcançar resultados pouco satisfatórios. 0 pensamento criativo, inteligente e adaptado ao meio é um princípio fundamental em qualquer atividade preventiva.

Uma das principais perguntas que ocupa pensadores e estudiosos da conservação preventiva de acervos é: por quanto tempo será possível preservar um determinado bem? Esta pergunta, evidentemente, não tem uma resposta definitiva pois, por mais que a ciência avance no estudo de sistemas complexos e no processamento de bigdata (grandes bancos de dados), ainda que seja possível prever, nunca será possível conhecer o futuro (sempre haverá algum grau de incerteza). Assim, esta pesquisa propôs o caminho do auto-conhecimento institucional por meio de avaliações e diagnósticos porque reconhece que esta abordagem, ao pretender que se faça, a cada dia, o melhor possível, com ações fundamentadas nas condições e características identificadas para o presente, possibilita o cuidado consciente do patrimônio, o que posterga o momento do fim e possibilita que este momento esteja integrado às decisões institucionais. 


\subsection{DESAFIOS ENCONTRADOS}

0 desenvolvimento desta pesquisa se mostrou um desafio gratificante. Por um lado, a possibilidade de contribuir com o conhecimento científico para a salvaguarda do patrimônio cultural permitiu participar do grande esforço coletivo, realizado em todas as gerações, de garantir que as pessoas, hoje e no futuro, possam usufruir e aprender com o patrimônio legado pelos antepassados, assegurando que o maior número possível de indivíduos possa ter acesso à informação e ao conhecimento, fundamentais ao bemestar de comunidades e nações. Por outro lado, esta é uma área do conhecimento muito complexa, fragmentada e com poucos recursos, o que dificulta uma leitura holística acurada do conjunto de saberes que podem contribuir com o desenvolvimento da pesquisa orientada à preservação cultural do patrimônio. Esta pesquisa encontrou limites, que podem ser divididos em iniciais e finais.

As dificuldades iniciais estavam relacionadas ao acesso a informações técnicas e a pesquisas científicas relevantes ao tema desta tese - métodos para a gestão da qualidade ambiental de áreas de guarda de acervos em papel em edifícios históricos:

- não existe, por enquanto, em São Paulo, muitas oportunidades para que arquitetos possam de especializar em preservação do patrimônio cultural;

- são poucas as informações disponíveis sobre parâmetros para a gestão e manutenção de edifícios culturais e das áreas de guarda de acervos e, ainda menos, as que relacionem reservas técnicas a edifícios históricos localizados nos trópicos;

- as pesquisas científicas estão dispersas por múltiplas áreas do conhecimento e a pesquisa transdisciplinar ainda é escassa;

- existem poucos arquitetos e engenheiros no Brasil especialistas em gestão e manutenção do patrimônio cultural edificado;

- ainda que em publicações internacionais (acadêmicas e de entidades para a preservação do patrimônio) seja possível encontrar uma grande variedade de pesquisas aplicadas, os resultados são específicos para outras realidades e não podem ser diretamente transpostos para as condições e características próprias das instituições públicas paulistanas (ou brasileiras).

Estas dificuldades evidenciam a necessidade de maior oferta, na cidade de São Paulo (e no Brasil como um todo), de linhas de pesquisas, publicações e cursos de treinamento, especialização e/ou pósgraduação em: 
- arquitetura e engenharia voltados ao projeto e à gestão de edifícios complexos para a guarda de acervos;

- gestão para a preservação sustentável do patrimônio cultural;

- desenvolvimento de materiais, técnicas e tecnologias para mitigação dos riscos aos acervos e melhoria do desempenho ambiental das áreas de guarda localizadas em regiões tropicais e sub-tropicais.

As dificuldades finais podem ser vinculadas ao imponderável. Quando esta pesquisa foi planejada, pretendia-se o desenvolvimento de um modelo metodológico integrado simplificado a ser aplicado às reservas técnicas do Setor de Papel do Museu Paulista para validação do método de avaliação do ambiente construído, desempenho ambiental, acervos e percepção dos usuários, por meio de sua aplicação em um trabalho colaborativo entre conservador e arquiteto. No entanto, com o início da pandemia pelo novo coronavírus, em março de 2020, e o fechamento das instituições culturais, a programação inicial precisou ser alterada. Decidiu-se, então, pelo desenvolvimento de um modelo teórico-metodológico mais abrangente, com quatro graus de avaliação, cuja validação precisará ser feita em momento oportuno, após o fim da pandemia e a normalização das atividades nas instituições culturais.

\subsection{POSSIBILIDADES FUTURAS}

Esta pesquisa necessariamente precisará se estender para além desta tese de doutorado. 0 modelo teórico-metodológico precisa ser aplicado às instituições culturais casos de estudo e/ou a instituições similares, em cada um dos quatro graus de avaliação SOBANE, para que possa ser completamente validado. As propostas de classificação dos agentes de deterioração e dos sistemas construtivos precisam ser testadas na prática para aferição da sua efetividade na descrição das ameaças e vulnerabilidades. Os pesos atribuídos a meios, prazos e custos também precisam ser submetidos a meta-avaliações, para verificação de sua adequação a cada caso.

A aplicação do método a casos diversos daqueles previstos no desenho desta pesquisa permitirá que o modelo possa ser adaptado e validado para instituições culturais abrigadas em outras tipologias construtivas, com acervos que possuem materiais de suporte distintos do papel e/ou em outras cidades do país.

Além disso, conforme mencionado no capítulo 6 desta tese, a automação parcial ou total dos instrumentos de avaliação (levantamentos e registros), do tratamento e da análise dos dados e/ou da 
apresentação dos resultados (QDR e MDR) é um desdobramento desejável para esta pesquisa pois permitiria uma avaliação mais rápida e amigável, principalmente nos graus de avaliação de menor complexidade (S e OB), para os quais planilhas-modelo (templates) adaptáveis a cada caso poderiam ser mais facilmente produzidas. Esta automação poderia fazer uso integrado de aplicativos para celular para a coleta dos dados e de programas computacionais para a análise, síntese e apresentação dos diagnósticos. Para os graus AN e E, um sistema de automação similar, porém com maior capacidade de processamento de dados, integrado a sistemas SIG e BIM e/ou a sistemas para gestão da informação documental do patrimônio, seria de grande utilidade, não apenas na etapa de diagnóstico e planejamento estratégico, mas também nas etapas seguintes de execução, documentação e monitoramento das ações planejadas.

0 modelo teórico-metodológico proposto também pode acomodar a investigação de aspectos inesperados, não contemplados por esta pesquisa, tais como os impactos e vulnerabilidades relacionados a pandemias, desde que estas questões sejam incorporadas aos instrumentos escolhidos e adaptados pela equipe de avaliação.

A pandemia pelo novo coronavírus suscitou importantes discussões no campo cultural ao longo do ano de 2020, dentre elas destacam-se:

a. a importância de instituições como museus, bibliotecas e arquivos para as sociedades contemporâneas e a relevância de se preservar objetos originais em um mundo cada vez mais digitalizado;

b. os impactos psico-emocionais impostos pela quarentena e a importância da interação interpessoal entre os seres humanos e destes com a arte e a cultura para a mediação das sensações de bem-estar e da capacidade de aprendizado;

c. as perdas de recursos públicos destinados à cultura, de recursos próprios pelo impacto do fechamento das instituições, e de acervos pelo aumento de casos de roubo e de emergências por eventos adversos com fogo, água e outros agentes de deterioração;

d. a necessidade de medidas de segurança voltadas à saúde dos seres humanos dentro de ambientes fechados, dentre elas mecanismos para ventilação adequada de todos os espaços, uso de equipamentos específicos para a filtragem do ar e eliminação de microorganismos nocivos, manutenção criteriosa dos sistemas de condicionamento do ar, utilização de equipamentos para a medição da qualidade do ar interno e atenção rigorosa ao uso dos EPIs, quando necessário; 
e. a importância de se elaborar também um plano de preparação para emergência por pandemia.

Todas estas questões impactam diretamente a gestão da preservação do patrimônio cultural e precisarão passar a ser contempladas no planejamento estratégico das instituiç̧ões culturais. A avaliação diagnóstica pode auxiliar na compreensão de:

a. qual o ponto de equilíbrio entre a instituição real e sua contraparte virtual;

b. como reformular planos e procedimentos, na busca por uma nova abordagem orientada à sustentabilidade, que re-equilibre prevenção e otimização dos recursos possíveis;

c. o que pode ser aprimorado na instituição quanto a manutenção, treinamento e prontidão a emergências por patógenos nocivos à saúde humana.

Não é viável, para a maioria das instituições culturais, lidar isoladamente com um número tão significativo de variáveis complexas e distintas sem a participação de redes de colaboração e apoio mútuo, seja para o compartilhamento de estratégias voltadas à preservação dos acervos, seja para a discussão conjunta de soluções frente a eventos inesperados (como a pandemia pelo novo coronavírus), ou ainda para o auxílio mútuo em uma situação de emergência. Em momentos de crise, como se tem observado em 2020 e 2021, faz-se ainda mais necessário estimular a criação e 0 fortalecimento de redes de colaboração, para que o setor cultural, em sua integralidade, possa superar os desafios e se fortalecer na medida da ampliação da consciência de sua missão e propósito para com a sociedade presente e futura.

Um dos desdobramentos desta pesquisa foi a criação, em 2018, da Rede de Conservação Preventiva da USP. Em 2017, alguns profissionais que atuam direta ou indiretamente junto ao patrimônio científico e cultural da USP se reuniram com o propósito de buscar formas de ampliar os mecanismos de comunicação entre as unidades. Entre os dias 25 e 26 de outubro de 2018 foi realizado o "I Encontro de Conservação Preventiva de Acervos: Qualidade Ambiental de Áreas de Guarda de Acervos", com apoio institucional da BBM USP (SAFT et al., 2019).

Os propósitos da REDE são:

- contribuir para a preservação do patrimônio cultural e científico da USP com eficiência e qualidade, para assegurar sua transmissão às próximas gerações;

- incentivar a melhoria da comunicação e a troca profissional entre funcionários, pesquisadores, professores e alunos que trabalham diretamente com os acervos da USP; 
- fortalecer os laços entre os profissionais da área de conservação de acervos e demais áreas correlatas, promovendo a troca de conhecimentos e estimulando a ajuda mútua em caso de emergências;

- garantir que as pesquisas e práticas de conservação preventiva adotadas pelos institutos da USP ocorram de forma efetiva e sustentável, devendo, portanto, ser registradas, aferidas e disseminadas.

Os principais objetivos do grupo são:

- compartilhar e divulgar pesquisas e atividades desenvolvidas na área de preservação e conservação do patrimônio cultural e científico brasileiro.

- ressaltar a importância da preservação e conservação do patrimônio na construção do conhecimento coletivo e nas atividades de pesquisa científica e de extensão universitária;

- auxiliar as unidades da USP a identificar e preservar potenciais acervos, prestando assessoria às equipes locais;

- auxiliar na capacitação profissional.

Ainda que a pandemia pelo novo coronavírus tenha interrompido as atividades planejadas para 2020 e 2021, pretende-se, em um futuro próximo, dar continuidade ao trabalho que vinha sendo desenvolvido e fortalecer o grupo por meio de: reuniões para compartilhamento de problemas e soluções; inspeções em áreas de guarda e proposição coletiva de alternativas para mitigação dos riscos; compartilhamento de planos, estratégias, materiais e equipamentos para resposta a emergências; simulados de situações de emergência; encontros e seminários. Pretende-se também que a REDE possa se associar a outras redes similares, no Brasil e/ou no exterior, visando o fortalecimento das atividades de preservação sustentável do patrimônio, de conservação preventiva dos acervos, de gestão integrada das áreas de guarda e de pesquisa e desenvolvimento aplicados à preservação do patrimônio cultural brasileiro.

Há muita demanda por parcerias entre instituições culturais e a academia, nas suas mais variadas áreas do conhecimento. Ainda que o patrimônio suscite interesse e admiração, são poucos os trabalhos aplicados à preservação integral dos bens móveis e imóveis, com enfoque na prevenção dos riscos. Espera-se que esta pesquisa de doutorado seja uma contribuição para a avaliação e o diagnóstico do desempenho do ambiente construído e a gestão de áreas de guarda de acervos, e que possa inspirar outros pesquisadores a dar continuidade no desenvolvimento de soluções preventivas adaptadas à imensa variedade e riqueza de tipologias e acervos que compõem o patrimônio cultural brasileiro. 


\section{REFERÊNCIAS}

ABATE, T.P.; ONO, R.; KOWALTOWSKI, D.. Tools to include blind students in school building performance assessments. Journal of Acessibility and Design for All, v. 6, n. 1, p. 1-26, 2016.

ABIKO, A. K.; ORNSTEIN, S. W.. Inserção urbana e avaliação pós-ocupação (APO) da habitação de interesse social. Coletânea Habitare - FINEP. São Paulo: FAU USP, 2002.

ABNT - Associação Brasileira de Normas Técnicas. ABNT NBR 5671: Participação dos intervenientes em serviços e obras de engenharia e arquitetura. Rio de Janeiro: ABNT, 1991.

ABNT - Associação Brasileira de Normas Técnicas. ABNT NBR 5674: Manutenção de Edificações - Requisitos para o sistema de gestão de manutenção. Rio de Janeiro: ABNT, 2012.

ABNT - Associação Brasileira de Normas Técnicas. ABNT NBR / ISO /CIE 8995-1: Iluminação de ambientes de trabalho. Rio de Janeiro: ABNT, 2013.

ABNT - Associação Brasileira de Normas Técnicas. ABNT NBR / ISO 9000: Sistemas de gestão da qualidade - Fundamentos e vocabulário. Rio de Janeiro: ABNT, 2005.

ABNT - Associação Brasileira de Normas Técnicas. ABNT NBR 9050: Acessibilidade a edificações, mobiliário, espaços e equipamentos urbanos. Rio de Janeiro: ABNT, 2015.

ABNT - Associação Brasileira de Normas Técnicas. ABNT NBR 14037: Diretrizes para elaboração de manuais de uso, operação e manutenção das edificações. Rio de Janeiro: ABNT, 2014.

ABNT - Associação Brasileira de Normas Técnicas. ABNT NBR 15575: Edificações habitacionais - Desempenho. Rio de Janeiro: ABNT, 2013.

ABNT - Associação Brasileira de Normas Técnicas. ABNT NBR 16280: Reforma em edificações - Sistema de gestão de reformas. Rio de Janeiro: ABNT, 2015.

ABNT - Associação Brasileira de Normas Técnicas. ABNT NBR / ISO 31000: Gestão de Riscos - Diretrizes. Rio de Janeiro: ABNT, 2018.

AEC INITIATIVE. AEC BIM Technology Protocol. Practical Implementation of BIM for the UK Architectural, Engineering and Construction (AEC) Industry, Version 2.1.1. Jacarta: The AEC Initiative, 2015.

ADCOCK, E.. IFLA Principles for the care and handling of library material. Washington, 1998. Disponível em: www.ifla.org/files/assets/pac/ipi/ipi1-en.pdf. Acesso em 27 mai. 2016.

AHM. Arquivo Histórico. 2020. Disponível em: https://www.prefeitura.sp.gov.br/cidade/secretarias/cultura/ arquivo_historicol. Acesso em 12 jan. 2020.

AIC - American Institute for Conservation. AIC Wiki. Preventive care. AIC, 2018. Disponível em: https://www.conservationwiki.com/wiki/Preventive_Care\#cite_note-1.Acesso em: 15 dez. 2019. 
AKANMU, A. et al.. Auto-generated site layout: an integrated approach to real-time sensing of temporary facilities in infrastructure projects. Structure and Infrastructure Engineering, v. 12, n. 10, p. 1243-1255, 2015. Disponível em: https:// www.researchgate.net/publication/282148089_Auto-Generated_Site_Layout_An_Integrated_Approach_to_Realtime_sensing_of_Temporary_Facilities_in_Infrastructure_Projects. Acesso em 26 dez. 2018.

AMARATUNGA, R.D.G.. Theory Building in Facilities Management Performance Measurement: Application of Some Core Performance Measurement and Management Principles. Doctorate - Research Institute for Business and Informatics School of Construction and Property Management, The University of Salford, UK, 2001.

ANTUNES, C.. Biblioteca Brasiliana Guita e José Mindlin BBM - USP. In: VIEIRA, B.; ALVES, A.. Acervos especiais: memórias e diálogos. São Paulo: Cultura Acadêmica, 2015. Disponível em: https://www.fclar.unesp.br/Home/Instituicao/Administracao/ DivisaoTecnicaAcademica/ApoioaoEnsino/LaboratorioEditorial/colecao-memoria-da-fcl-n9.pdf. Acesso em 19 fev. 2019.

ARCHDAlLY. Biblioteca Brasiliana / Eduardo de Almeida + Mindlin Loeb + Dotto Arquitetos. Archdaily, 2013. Disponivel em: https://www.archdaily.com.br/br/01-107652/biblioteca-brasiliana-slash-rodrigo-mindlin-loeb-plus-eduardode-almeida. Acesso em 18 jan. 2020.

AREA, M.C.; CHERADAME, H.. Paper Aging and Degradation: recent findings and Research Methods. Bio-Resources, v. 6, n. 4, p. 5307-5337, 2011.

AREDES, D. R.. A evolução do papel e suas formas de conservação. Monografia - Universidade Federal de Santa Maria. São Lourenço do Sul, 2014. Disponível em: https://repositorio.ufsm.br/bitstream/handle/1/11709/ Aredes_Diego_Rodrigues.pdf?sequence=1.Acesso em 12 out. 2018.

ASHRAE - American Society of Heating, Refrigerating and Air Conditioning. Chapter 23 - Museums, galleries, archives, and libraries. In: ASHRAE Applications Handbook. Atlanta: 2015.

ASHRAE - American Society of Heating, Refrigerating and Air Conditioning. Chapter 23 - Museums, galleries, archives, and libraries. In: ASHRAE Applications Handbook. Atlanta, p. 23.1-23.23, 2011.

ASSIS, E. P.. Acessibilidade nos bens culturais imóveis: possibilidades e limites nos museus e centros culturais. Dissertação (Mestrado) - Faculdade de Arquitetura e Urbanismo da Universidade de São Paulo, São Paulo, 2012.

ASU - Arizona State University / Department of Physics and Astronomy. Sources of Light: The Sun and Lamps. Disponível em: https://www.asu.edu/courses/phs208/patternsbb/PiN/rdg/color/source.shtml. Acesso em 17 out. 2020.

ATKINSON, J.. Environmental conditions for the safeguarding of collections: A background to the current debate on the control of relative humidity and temperature. Studies in Conservation, v. 59, p. 205-212, 2014. Disponível em: https://doi.org/ 10.1179/2047058414Y.0000000141. Acesso em: 20 jun. 2020.

AULD, H. et al.. The changing climate and national building codes and standards. Toronto: Adaptation and Impacts Research Section, Environment Canada, s. 5.6, 2011.

AUT284. Arquitetura e Clima: Diagnóstico climático. São Paulo: FAU USP, 2013. Endereço: https://www.fau.usp.br/arquivos/ disciplinas/au/aut0264/Aut264_aula3_diagnosticoclimatico_2013.pdf.Acesso em 19 set. 2020. 
AUTODESK. Measure light accurately for an optimized building design. 2018b. Disponível em: https:// knowledge.autodesk.com/search-result/caas/simplecontent/content/building-architecture-handling-light-analysis-designphase.html. Acesso em: 13 jun. 2020.

AUTODESK. Sustainable Building Design. 2018a. Disponível em: https://knowledge.autodesk.com/search-result/caas/ simplecontent/content/measuring-light-levels.html. Acesso em: 13 jun. 2020.

AUSTRALIAN / NEW ZEALAND STANDARD. AS/NZS 4360:2004 - Risk management. Disponível em: bch.cbd.int/database/ attachment/?id=12285. Acesso em 29 mai. 2016.

AVEN, T.. On how to define, understand and describe risk. Reliability Engineering \& System Safety, v. 95, n. 6, p. 623-631, 2010.

AVRAMANI, E.; MASON, R.; DE LA TORRE, M.. Values and Heritage Conservation - Research Report. Los Angeles: GCl, 2000. Disponível em: https://www.getty.edu/conservation/publications_resources/pdf_publications/ values_heritage_research_report.html.Acesso em: 14 out. 2020.

AVRAMANI, E. et al. (eds.). Values in Heritage Management: Emerging Approaches and Research Directions. Los Angeles: GCl, 2019. Disponível em: https://heritagemanagement.netlify.app. Acesso em: 13 out. 2020.

AZEVEDO, A.; SOUSA, A.; CASTRO, T.. Espectroscopia óptica de baixo custo: uma estratégia para a introdução de conceitos de física quântica no ensino médio. Revista Brasileira de Ensino de Física, v. 41, n. 4, 2019. Disponível em: https://doi.org/ 10.1590/1806-9126-rbef-2018-0349. Acesso em: 25 out. 2020.

BANIASSADI, A.; SAILOR. D. J.. Synergies and trade-offs between energy efficiency and resiliency to extreme heat - A case study. Building and Environment, v. 132, p. 263-272, 2018.

BARBIER, F.. A Europa de Gutenberg: o livro e a invenção da modernidade ocidental (séculos XIII-XVI). São Paulo: EDUSP, 2018.

BARTHES, R.. 0 Rumor da Língua. Lisboa: Edições 70, 1984.

BECHTEL, R. B.; MARANS, R. W.; MICHELSON, E.. Methods in environmental and behavioral research. New York: Van Nostrand Reinhold, 1987.

BERNARDES, J. P. et al.. Património Cultural Edificado: reflexões em torno da gestão do Património Classificado. Lusophone Journal of Cultural Studies, v. 2, p. 34- 52, 2014.

BERVIAN, P. A.; CERVO, A. L.. Metodologia Científica. São Paulo: Makron Books, 1996.

BLADES, N.. Modelling of climate change effects on historic buildings. In: 7th European Conference "Sauveur" - Safeguarded Cultural Heritage - Understanding \& Viability for the Enlarged Europe, 2006. Proceedings. Prague: ITAM; ARCCHIP, v. 2, p. 913-915, 2007. Disponível em: www.arcchip.cz/ec-conference/download/B-968_end.pdf. Acesso em 26 mai. 2016.

BLOWER, H.; AZEVEDO, G.. Avaliação Pós-Ocupação em Creche Institucional do Município do Rio de Janeiro: uma experiência no lugar de educação infantil. Gestão \& Tecnologia de Projetos, São Paulo, v. 5, n. 2, p. 99-130, 2010. Disponível em: https://doi.org/10.4237/gtp.v5i2.164. Acesso em 20 fev. 2019. 
BMA. Biblioteca Mário de Andrade. 2020. Disponível em: https://www.prefeitura.sp.gov.br/cidade/secretarias/cultura/ bmal. Acesso em 12 jan. 2020.

BMA. Biblioteca Mário de Andrade: Relatório de Gestão 2009 a 2012. BMA, 2012. Disponível em: https:// www.prefeitura.sp.gov.br/cidade/upload/gesta02009-12_1364917782.pdf. Acesso em 15 jan. 2021.

BOJANOSKI, S. de F.. Terminologia em Conservação de bens culturais em papel: produção de um glossário para profissionais em formação. Tese (Doutorado) - Universidade Federal de Pelotas, Pelotas, 2018. Disponível em: https:// wp.ufpel.edu.br/ppgmp/files/2018/04/tese_Silvana_F_Bojanoski.pdf. Acesso em 20 fev. 2019.

BOYLAN, P. (ed.). Running a Museum: A Practical Handbook. UNESCO. Paris: ICOM, 2004. Disponível em: unesdoc.unesco.org/images/0014/001410/141067e.pdf. Acesso em 27 mai. 2016.

BORA, A.. Risk, risk society, risk behaviour, and social problems. In: Ritzer, G. (ed): The Blackwell Encyclopedia of Sociology, v. VIII, p. 3926-3932. Oxford: Blackwell, 2006. Disponível em: https://doi.org/ 10.1002/9781405165518.wbeosr069. Acesso em: 14 set. 2020.

BRADLEY, R.; DRECHSLER, M.. Types of Uncertainty. Erkenntnis, n. 79, p. 1225-1248, 2014. Disponível em: https://doi.org/ 10.1007/s10670-013-9518-4. Acesso em: 18 abr. 2020.

BRASIL. Lei n. 8.159, de 08 de janeiro de 1991. Dispõe sobre a política nacional de arquivos públicos e privados e dá outras providências. 1991. Disponível em: www.planalto.gov.br/ccivil_03/leis/L8159.htm. Acesso em: 26 mai. 2016.

BRASIL. Lei $\mathbf{n}^{\mathbf{0}} \mathbf{1 3 . 5 8 9}$, de 04 de janeiro de 2018. Dispõe sobre manutenção de instalações e equipamentos de sistemas de climatização de ambientes. 2018. Disponível em: http://www.planalto.gov.br/ccivil_03/_ato2015-2018/2018/lei/ I13589.htm. Acesso em: 26 jan. 2021.

BRASIL. MINISTÉRIO DO MEIO AMBIENTE. Resolução CONAMA n 491, de 19 de novembro de 2018. Dispõe sobre padrões de qualidade do ar. 2018. Disponível em: http://www2.mma.gov.br/port/conama/legiabre.cfm?codlegi=740. Acesso em: 26 jan. 2021.

BRASIL. MINISTÉRIO DA SAÚDE. Gabinete do Ministro. Portaria n $\mathbf{3}^{\mathbf{3 . 5 2 3}}$, de 28 de agosto de 1998. Dispõe sobre procedimentos de verificação visual (...) de todos os componentes dos sistemas de climatização (...). 1998. Disponível em: https://bvsms.saude.gov.br/bvs/saudelegis/gm/1998/prt3523_28_08_1998.html. Acesso em: 26 jan. 2021.

BRASIL. MINISTÉRIO DA SAÚDE. Agência Nacional de Vigilância Sanitária. Resolução-RE nº 09, de 16 de janeiro de 2003. Dispõe sobre Padrões Referenciais de Qualidade do Ar Interior, em ambientes climatizados artificialmente de uso público e coletivo, 2003. Disponível em: https://www.saude.mg.gov.br/images/documentos/RES_RE_09.pdf. Acesso em: 26 jan. 2021.

BRASILEIRO, L.B., COLODETE, J.L., PILÓ-VELOSO, D.. A utilização de perácidos na deslignificação e no branqueamento de polpas celulósicas. Química Nova, v.24, n.6, p. 819-829, 2001.

BRATASZ, Ł.. Allowable Microclimatic Variations in Museums and Historic Buildings: Reviewing the Guidelines. International Scientific Workshop, Heritage Science and Sustainable Development for the Preservation of Art and Cultural Assets - On the Way to the GREEN Museum, Rathgen-Forschungslabor, Berlin, 2013. Disponível em: https://pan-pl.academia.edu/ LukaszBratasz. Acesso em: 13 fev. 2020. 
BRAUNGART, M.; McDONOUGH, M.. Cradle-to-Cradle - Remaking the Way We Make Things. New York: North Point Press, 2008.

BROKERHOF, A. et al.. Interfacing research and risk management for a better safeguarding of cultural heritage. In: 7th European Conference "Sauveur" - Safeguarded Cultural Heritage - Understanding \& Viability for the Enlarged Europe, 2006. Proceedings. Prague: ITAM; ARCCHIP, v. 2, p. 913-915, 2007. Disponível em: www.arcchip.cz/ec-conference/download/ B-968_end.pdf. Acesso em 26 mai. 2016.

BROOKS, D. Museum and Critical Storage Environments. YEA Conference Specialty Environmental Design. Illinois: ASHRAE, 2014. Disponível em: illinoisashrae.org/images/meeting/032514/YEA_Conf_Presentations_2014/ museum_storage_design.pdf. Acesso em 29 mai. 2016.

BROWN, J. P.; ROSE, W. B.. Humidity and moisture in historic buildings: the origins of building and object conservation. APT Bulletin, n. 27, p. 12-24, 1996.

BROWN, T.. Design Thinking - Uma metodologia poderosa para decretar o fim das velhas ideias. Rio de Janeiro: Alta Books, 2017.

BRULON, B.. A invenção do Ecomuseu: 0 caso do Écomusée du Creusot Montceau-les-Mines e a prática da museologia experimental. Rio de Janeiro: Mana, vol. 21, 2015. Disponível em: www.scielo.br/pdf/mana/v21n2/0104-9313mana-21-02-00267.pdf. Acesso em 28 mai. 2016.

BUCKLEY, K.. Heritage Work: Understanding the Values, Applying the Values. In: AVRAMI, E. et al. (eds.). Values in Heritage Management: Emerging Approaches and Research Directions. Los Angeles: GCl, 2019. Disponível em: https:// heritagemanagement.netlify.app/part-two/4/. Acesso em: 14 out. 2020.

BUILDIT SOFTWARE. Photogrammetry of Cultural Heritage. 2016. Disponível em: http://www.builditsoftware.com/ 2016/01/photogrammetry-cultural-heritage-comparison-results-ipad-dslr-cameras/?lang=fr. Acesso em 16 jan. 2020.

BULLEN, P.; LOVE, P.. Adaptive reuse of heritage buildings. Structural Survey, v. 29, n. 5, p. 411-421, 2011. Disponível em: https://doi.org/10.1108/02630801111182439. Acesso em 05 out. 2020.

BYRNE, D.; BRAYSHAW, H.; IRELAND, T.. Social Significance: A Discussion Paper. Sydney: New South Wales National Parks and Wildlife Service, 2003. Disponível em: https://www.environment.nsw.gov.au/-/media/OEH/Corporate-Site/Documents/ Aboriginal-cultural-heritage/social-significance-a-discussion-paper-010001.pdf. Acesso em: 15 out. 2020.

CABRALES, C.. A História do Papel. 2019. Disponível em: https://papeloteca.wordpress.com/a-historia-do-papel/. Acesso em 23 jan. 2019.

Cadernos de Sociomuseologia, Vol. 15. Declaração de Lisboa - Resoluções da Comissão Internacional de Formação de Pessoal de Museus - ICTOP, 1994. Lisboa: Universidade Lusófona de Humanidades e Tecnologias, 1999. Disponível em: recil.grupolusofona.pt/bitstream/handle/10437/3771/declaração\%20de\%20lisboa.pdf?sequence=1. Acesso em 28 mai. 2016.

Cadernos de Sociomuseologia, Vol. 28. Definição evolutiva de Sociomuseologia - Proposta para reflexão por Mário C. Moutinho. Lisboa: Universidade Lusófona de Humanidades e Tecnologias, 2007. Disponível em: www.museologiaportugal.net/files/definicao_evolutiva_de_sociomuseologia.pdf. Acesso em 28 mai. 2016. 
Cadernos de Sociomuseologia, Vol. 38. Declaration of Quebec - Basic Principles of a New Museology, 1984. Lisboa: Universidade Lusófona de Humanidades e Tecnologias, 2010. Disponível em: revistas.ulusofona.pt/index.php/ cadernosociomuseologia/article/viewFile/1641/1306. Acesso em 28 mai. 2016.

CÂMARA DOS DEPUTADOS. Biblioteca 2020. Disponível em: https://www2.camara.leg.br/a-camara/documentos-e-pesquisa/ biblioteca/historico/apresentacao/conheca/modernizacao-da-biblioteca. Acesso em 22 jan. 2020.

CAMARGO, R. F.. Conheça os principais métodos de priorização de projetos e processos. Treasy, 2018. Disponível em: https://www.treasy.com.br/blog/metodos-de-priorizacao/. Acesso em 12 dez. 2020.

CAMPOS, Eudes. Edifício Ramos de Azevedo: arquitetura. Informativo Arquivo Histórico Municipal, 2008. Disponível em: http://www.arquiamigos.org.br/info/info21/i-edarq.htm. Acesso em 16 fev. 2019.

CARARE. EU study on quality in 3D digitisation kicks off. 2020. Disponível em: https://www.carare.eu/en/news/eustudy-quality-3d-digitisation-kicks/. Acesso em 16 set. 2020.

CARTER, H. A.. The Chemistry of Paper Preservation (Part I). Journal of Chemical Education, v. 73, n. 5, 1996.

CARTER, H. A.. The Chemistry of Paper Preservation (Part II). The Yellowing of Paper and Conservation Bleaching. Journal of Chemical Education, v. 73, n.11, 1996.

CARVALHO, C.. Conservação preventiva de edifícios e sítios históricos: pesquisa e prática. Revista CPC, São Paulo, n.18, p. 141-153, 2014. Disponível em: http://dx.doi.org/10.11606/issn.1980-4466.v0i18p141-153. Acesso em 15 set. 2019.

CARVALHO, C.. 0 espaço como elemento de preservação dos acervos com suporte em papel. Rio de Janeiro: Fundação Casa de Rui Barbosa, 2001. Disponível em: http://rubi.casaruibarbosa.gov.br/bitstream/20.500.11997/786/1/ FCRB_ClaudiaCarvalho_OEspaco_como_elemento_representacao_dosacervos_com_suporte_em_papel.pdf. Acesso em 08 set. 2015.

CARVALHO, C.. 0 gerenciamento de riscos para o patrimônio cultural da Fundação Casa de Rui Barbosa. Rio de Janeiro: Fundação Casa de Rui Barbosa, 2011. Disponível em: http:// www.casaruibarbosa.gov.br/conservacaopreventiva/ arquivos/file/Downloads/Gerenciamento\%20de\%20Riscos\%20para\%200\%20patrimonio\%20cultural\%20FCRB.pdf. Acesso em 08 set. 2015.

CARVALHO, C.. 0 projeto de conservação preventiva do Museu Casa de Rui Barbosa. Rio de Janeiro: Fundação Casa de Rui Barbosa. Disponível em: www.casaruibarbosa.gov.br/dados/DoC/artigos/a-j/ FCRB_ClaudiaCarvalho_Projeto_de_conservacao_preventiva_do_museu_Casa_de_Rui_Barbosa.pdf.Acesso em: 08 set. 2015.

CASAROTTO, C.. Aprenda o que é análise SWOT, ou análise FOFA, e saiba como fazer uma análise estratégica do seu negócio. Rock Content, 2019. Disponível em: https://rockcontent.com/blog/como-fazer-uma-analise-swot/. Acesso em 26 jan. 2020.

CASSAR, M.. Environmental Management - Guidelines for Museums and Galleries. UK: Museums \& Galleries Commission / Routledge, 1995. 
CASSARES, N.; TANAKA, A. P. H. (org.). Preservação de Acervos Bibliográficos: homenagem a Guida Mindlin. São Paulo: Arquivo Público, 2008.

CAVALAGLI, N.; KITA, A.; CASTALDO, V.; PISELLO, A.; UBERTINI, F.. Hierarchical environmental risk mapping of material degradation in historic masonry buildings: An integrated approach considering climate change and structural damage. Construction and Building Materials, n. 215, p. 998-1014, 2019. Disponível em: https://doi.org/10.1016/ j.conbuildmat.2019.04.204. Acesso em: 10 out. 2020.

CAVALCANTE, S.; ELALI, G. A. (org.). Psicologia Ambiental: conceitos para a leitura da relação pessoa- ambiente. Rio de Janeiro: Editora Vozes, 2018.

CBIC - Câmara Brasileira da Indústria da Construção. Desempenho de edificações habitacionais: guia orientativo para atendimento à norma ABNT NBR 15575/2013. Fortaleza: Gadioli Cipolla Comunicação, 2013.

CCI - Canadian Conservation Institute / ICCROM - International Centre for the Study of the Preservation and Restoration of Cultural Property. RE-ORG: Um Método para Reorganizar a Reserva Técnica de Museus. Tradução Programa IBERMUSEUS, 2018. Disponível em: https://www.iccrom.org/themes/preventive-conservation/re-org/resources. Acesso em: 16 mai. 2019.

CELULOSEONLINE. É possível modificar a molécula de celulose? 2016. Disponível em: https:// www.celuloseonline.com.br/e-possivel-modificar-molecula-de-celulosel. Acesso em 14 out. 2018.

CEB - Council of Europe Development Bank. Addressing environmental challenges and their social implications in Europe. Paris: CEB, 2015. Disponível em: www.coebank.org/en/news-and-publications/ceb-publications/addressingenvironmental- challenges/. Acesso em 28 mai. 2016.

CEN - European Committee for Standardization. BS EN 15757:2010 - Conservation of Cultural Property - Specifications for Temperature and Relative Humidity to Limit Climate-Induced Mechanical Damage in Organic Hygroscopic Materials. Bruxelas: CEN, 2010.

CEN - European Committee for Standardization. BS EN 16242:2012 - Conservation of Cultural Heritage - Procedures and Instruments for Measuring Humidity in the Air and Moisture Exchanges Between Air and Cultural Property. Bruxelas: CEN, 2012.

CERVO, A.; BERVIAN, P.. Metodologia Científica: para uso dos estudantes universitários. 3a edição. São Paulo: McGraw Hill do Brasil, 1983.

CHARTIER, R.. A aventura do livro: do leitor ao navegador. São Paulo: Fundação Editora da Unesp, 1998.

CHIAVENATO, I.. Introdução à teoria geral da administração: uma visão abrangente da moderna administração das organizações. Elsevier, 2003.

CHILD, M.. Considerações complementares sobre seleção para preservação - uma abordagem materialística. In: HAZEN, D. et al. Planejamento de preservação e gerenciamento de programas. Rio de Janeiro: Projeto CPBA; Arquivo Nacional, 2001.

CIMELLARO, G.; REINHORN, A.; BRUNEAU, M.. Framework for analytical quantification of disaster resilience. Engineering Structures, v. 32, n. 11, p. 3639-3649, 2010. Disponível em: https://doi.org/10.1016/j.engstruct.2010.08.008. Acesso em: 25 out. 2020. 
CLETO, F. R.; et al.. Códigos de práticas: uma proposta de documentos técnicos de referência de boas práticas para a construção de edifícios no Brasil. Ambiente Construído, Porto Alegre, v. 11, n. 2, p. 7-19, 2011.

COLE, G.A.. Management Theory and Practice. London: Lefts Educational, 1996.

COX, L.; BABAYEV, D.; HUBER, W.. Some limitations of qualitative risk rating systems. Risk Analysis, v. 25, n. 3, p. 651-662, 2005. Disponível em: https://doi.org/10.1111/j.1539-6924.2005.00615.x. Acesso em 20 out., 2020.

CRED - Centre for Research on the Epidemiology of Disasters / UNDRR - United Nations Office for Disaster Risk Reduction. Human Costs of Disasters: an overview of the last 20 years (2000 - 2019). CRED / UNDRR, 2019. Disponível em: https:// www.emdat.be/publications?field_publication_type_tid=All. Acesso em: 11 nov. 2020.

DA COSTA, A. C. A. et al.. Archaeometric investigations on naturally and thermally-aged iron-gall inks using different tannin sources. Central European Journal of Chemistry, 2013. Disponível em: https://doi.org/10.2478/s11532-013-0303-7. Acesso em 15 out. 2018.

DA COSTA, E. A.. Gestão estratégica: da empresa que temos para a empresa que queremos. São Paulo: ed. Saraiva, 2010.

D'AGOSTINO, V. et al.. The museum environment: A protocol for evaluation of microclimatic conditions. Energy and Buildings, n. 95, p. 124 - 129, 2015. Disponível em: https://www.researchgate.net/publication/ 268212129_The_Museum_Environment_A_Protocol_for_Evaluation_of_Microclimatic_Conditions. Acesso em 25.jan. 2019.

D’ALMEIDA, M. L. O.. Composição química dos materiais lignocelulósicos. In: D’ALMEIDA, M.L.O. (ed.). Celulose e papel: tecnologia de fabricação da pasta celulósica. São Paulo: IPT-Senai, v.1, p.45-106, 1988.

D'AYALA , D.; COPPING, A.; WANG, H.. A Conceptual Model for Multi-Hazard Assessment of the Vulnerability of Historic Buildings. New Delhi: Structural Analysis of Historical Constructions, 2006. Disponível em: http:// www.hms.civil.uminho.pt/sahc/2006/0121.pdf. Acesso em: 16 dez. 2020.

DARNTON, R.. A questão dos Livros. São Paulo: Companhia das Letras, 2010.

DCMS - Department for Culture, Media \& Sport. The Culture White Paper. Londres: DCMS, 2016. Disponível em: https:// assets.publishing.service.gov.uk/government/uploads/system/uploads/attachment_data/file/510798/ DCMS_The_Culture_White_Paper_3_.pdf.Acesso em 27 jan. 2019.

DE JONG, T. M. de; VAN DER VOORDT, D. J. M. (ed.). Ways to Study and Research. Urban, Architectural and Technical Design. Delft: Delft University Press, 2002.

DE MENESES, U. T. B.. Museu Paulista. Estudos avançados, São Paulo, v. 8, n. 22, 1994. Disponível em: http://www.scielo.br/ scielo.php?script=sci_arttext\&pid=S0103-40141994000300084\#not2. Acesso em 21 mai. 2017.

DESIGNSPARK. How is hardware driving the IloT revolution? 2018. Disponivel em: https://www.rs-online.com/ designspark/how-is-hardware-driving-the-iiot-revolution. Acesso em 25 jan. 2019. 
DEZEN-KEMPTER, E.. Digital Dialogues: integration of documentary data in model based information systems for the conservation. In: Proceedings of the XVII Conference of the Iberoamerican Society of Digital Graphics - SIGraDi: KnowledgeBased Design, v. 1, p. 293-296, 2014.

DIAPReM - Development of Integrated Automatic Procedures for Restoration of Monuments. DIAPReM e Leica no Brasil: estudos de caso (material de divulgação). Ferrara: TekneHub, DA UNIFE, 2017.

DIAS, S. R. (coord). Gestão de Marketing. São Paulo: Saraiva, 2003.

DISKO, S.; TUGENDHAT, H. (eds.).. World Heritage Sites and Indigenous Peoples' Rights. Copenhagen: International Work Group for Indigenous Affairs, 2014. Disponível em: https://www.iwgia.org/images/publications/ 0698_INTRODUCTION_orld_Heritage_SItes_FINAL-eb-2.pdf.Acesso em: 12 out. 2020.

DMLIGHTS. How to interpret a light distribution curve? 2015. Disponível em: https:/www.dmlights.com/blog/ interpret-light-distribution-curve/. Acesso em: 12 jun. 2020.

DMF. Show Your True Colors: Using lights with high CRI and R9 values ensures proper color rendering of objects. 2020. Disponível em: https://www.dmflighting.com/show-true-colors/. Acesso em: 12 jun. 2020.

DORGE, V.; JONES, S. L. (org.). Building an Emergency Plan: A Guide for Museums and Other Cultural Institutions. LoS Angeles: $\mathrm{GCl}, 1999$.

DOSMAN, J.. The Evolution of Conservation and Disaster Planning in the Face of Disaster: Responses to the Florence flood. SHIFT Queen's Journal of Visual and Material Culture, n. 1, p. 1-5, 2008. Disponível em: shiftjournal.org/wp-content/ uploads/2014/11/dosman.pdf. Acesso em 27 mai. 2016.

DOS SANTOS, A.. Application of Flow Principles in the Production Management of Construction Sites. Doctorate in Philosophy - School of Construction and Property Management, The University of Salford, UK, 1999. Disponível em: http:// usir.salford.ac.uk/2231/. Acesso em 12 jan. 2019.

DRUCKER, F. P.. Introdução à administração. São Paulo: Pioneira Thompson Learning, 2002.

DUARTE JUNIOR, R.. Programa Monumenta: uma experiência em preservação urbana no Brasil . Revista CPC, n. 10, p. 49-88, 2010. Disponível em: https://doi.org/10.11606/issn.1980-4466.v0i10p49-88. Acesso em 03 junho 2021.

ECO, U.. Como se faz uma pesquisa. São Paulo: Editora Perspectiva, 1977.

ECO, U. (org.). Idade Média - Bárbaros, cristãos e muçulmanos. Alfragide: Publicações Dom Quixote, 2010.

ELKIN, L.; NORRIS, C. (eds.). Preventive Conservation: Collection Storage. SPNHC, AIC, Smithsonian Institution, the George Washington University, 2019. Disponível em: https://spnhc. biowikifarm.net/wiki/Collection_Storage. Acesso em 09 fev. 2019.

Ellen MacArthur Foundation. Growth within: A Circular Economy Vision for a Competitive Europe. UK: Ellen MacArthur Foundation, 2015. Disponível em: https://www.ellenmacarthurfoundation.org/assets/downloads/publications/ EllenMacArthurFoundation_Growth-Within_July15.pdf. Acesso em 12 mai. 2018. 
EPE - Empresa de Pesquisa Energética. Análise da Eficiência Energética em Segmentos Industriais Selecionados Segmento Celulose e Papel. Brasil: 2018. Disponível em: http://www.epe.gov.br/sites-pt/publicacoes-dados-abertos/ publicacoes/PublicacoesArquivos/publicacao-314/topico-407/PRODUT0\%204_Vpublicacao.pdf. Acesso em 10 jan. 2019.

ERHARDT, D.; TUMOSA, C.; MECKLENBURG, M.. Applying science to the question of museum climate. In: PADFIELD, T.; BORCHERSEN, K. (ed.). Contributions to the Museum Microclimates Conference. Copenhagen: The National Museum of Denmark, p. 11-18, 2007.

ESTADO DE SÃO PAULO. SECRETARIA DE ESTADO DOS NEGÓCIOS DA SEGURANÇA PÚBLICA. Instrução Técnica n 01, de 2011. Procedimentos Administrativos. São Paulo, 2011. Disponível em: http://www.corpodebombeiros.sp.gov.br/ dsci_publicacoes2/_lib/file/doc/portaria_015_600_15_IT_01_alteracao_item_9.4.11.pdf. Acesso em 12 out. 2020.

ESTADO DE SÃO PAULO. SECRETARIA DE ESTADO DOS NEGÓCIOS DA SEGURANÇA PÚBLICA. Instrução Técnica nº 02, de 2018. Conceitos básicos de segurança contra incêndio. São Paulo, 2011. Disponível em: http:// www.corpodebombeiros.sp.gov.br/dsci_publicacoes2/_lib/file/doc/it_02_2018.pdf.Acesso em 12 out. 2020.

ESTADO DE SÃO PAULO. SECRETARIA DE ESTADO DOS NEGÓCIOS DA SEGURANÇA PÚBLICA. Instrução Técnica $\mathbf{n}^{0} \mathbf{4 0}$, de 2011. Edificações históricas, museus e instituições culturais com acervos museológicos. São Paulo, 2011. Disponível em: http://www.corpodebombeiros.sp.gov.br/dsci_publicacoes2/_lib/file/doc/it_40_2018.pdf. Acesso em 12 out. 2017.

FABRICIO, M.M.; ORNSTEIN, S.W. (org.). Qualidade no Projeto de Edifícios. São Carlos: RIMA, 2010.

FARINAS, C. S.. Documentos - 54. A parede celular vegetal e as enzimas envolvidas na sua degradação. Empresa Brasileira de Pesquisa Agropecuária; Embrapa Instrumentação; Ministério da Agricultura, Pecuária e Abastecimento. São Carlos, 2011. Disponível em: https://www.infoteca.cnptia.embrapa.br/bitstream/doc/ 919344/1/D0C542011.pdf.. Acesso em 05 out. 2018.

FCRB. Fundação Casa de Rui Barbosa. 2020. Disponível em: http://www.casaruibarbosa.gov.br/geral.php?ID_S=307. Acesso em 22 jan. 2020.

FEBVRE, L.; MARTIN, H-J.. 0 Aparecimento do Livro. São Paulo: EDUSP, 2017.

FENGEL, D.; WEGENER, G.. Wood Chemistry, Ultrastructure, Reactions. Berlim: Walter de Gruyter, 1989.

FFC - Federal Facilities Council. Learning from our buildings: a state-of-the-practice summary of post-occupancy evaluation. Washington: National Academy Press, 2001. Disponível em: https:// www.researchgate.net/publication/ 236144343_Learning_from_our_buildings_a_state-of-the-practice_summary_of_Post-Occupancy_Evaluation. Acesso em 27 mai. 2016.

FIELD, C. B. et al. (eds.). Managing the Risks of Extreme Events and Disasters to Advance Climate Change Adaptation. Special Report of the Intergovernmental Panel on Climate Change, 2011. Disponivel em: www.ipcc.ch/pdf/ special-reports/srex/SREX_Full_Report.pdf. Acesso em 27 mai. 2016.

FINCH, E. (ed.). Facilities change management. Londres: Wiley-Blackwell, 2012.

FORSTER, A.; KAYAN, B.. Maintenance for historic buildings: a current perspective. Journal of Quality in Maintenance Engineering, v. 27, n. 3, p. 210-229, 2009. 
FRANÇA, A. J. G. L.. Ambientes contemporâneos para o ensino-aprendizagem: Avaliação Pós- Ocupacional aplicada a três edifícios escolares públicos situados na Região Metropolitana de São Paulo. Dissertação (Mestrado) - Faculdade de Arquitetura e Urbanismo da Universidade de São Paulo, São Paulo, 2011.

FRANÇA, A. J. G. L.. Melhoria contínua aplicada à edificação de tipologia padronizada: a gestão do conhecimento no contexto do portfólio de ativos de uma organização. Tese (Doutorado) - Faculdade de Arquitetura e Urbanismo da Universidade de São Paulo, São Paulo, 2016. Disponível em: http://www.teses.usp.br/teses/disponiveis/16/16132/tde07102016-114149/. Acesso em 25 set. 2017.

GCl - The Getty Conservation Institute. Assessing the Values of Cultural Heritage. Research Report. Los Angeles: GCl, 2002. Disponível em: www.getty.edu/conservation/ publications_resources/pdf_publications/pdf/assessing.pdf. Acesso em 29 mai. 2016.

GCl - The Getty Conservation Institute. Collections in Hot \& Humid Environments (1997-2002). GCl, 2021. Disponível em: https://www.getty.edu/conservation/our_projects/science/hothumid/. Acesso em 29 mai. 2021.

$\mathrm{GCl}$ - The Getty Conservation Institute. The Conservation Assessment: A Proposed Model for Evaluating Museum Environmental Management Needs. Los Angeles: GCl, 1998. Disponível em: http://www.getty.edu/conservation/ publications_resources/pdf_publications/evaluating_museum_environmental_mngmnt.html. Acesso em 29 mai. 2016.

GCl - The Getty Conservation Institute. Values and Heritage Conservation. Research Report. Los Angeles: GCl, 2000. Disponível em: www.getty.edu/conservation/publications_resources/pdf_publications/pdf/valuesrpt.pdf.Acesso em 29 mai. 2016.

GIRARD, L. F.. The role of cultural urban landscape towards a new urban economics: New structural assets for increasing economic productivity through hybrid processes. Hous. Policies Urban Economics, v. 1, p. 3-27, 2014.

GIRARD, L. F. et al.. Towards an economic impact assessment framework for Historic Urban Landscape conservation and regeneration projects. BDC. Boll. Cent. Calza Bini, v. 15, p. 1-29, 2015.

GIVONI, B.. Comfort, climate analysis and building design guidelines. Energy and Building, v.18, 1992.

GLOGSTER. The Four Great Inventions of Ancient China. 2015. Disponivel em: https://edu.glogster.com/glog/the-fourgreat-inventions-of-ancient-china/207qguinbl0. Acesso em 15 fev. 2020.

GLOUBERMAN, S. e ZIMMERMAN, B.. Complicated and Complex Systems: What Would Successful Reform of Medicare Look Like? Commission on the Future of Healthcare in Canada, discussion paper n. 8, 2002. Disponível em: https://www.researchgate.net/ publication/265240426_Complicated_and_Complex_Systems_What_Would_Successful_Reform_of_Medicare_Look_Like. Acesso em: 09 abr. 2020.

GONÇALVES, W.; ARAÚJO, D; FERREIRA, C.. Critérios de Raridade de Acervos Raros e Especiais. Uso de Critérios de Raridade e Valoração de Acervo no Gerenciamento de Riscos em Acervos Bibliográficos Raros e Especiais. In: X ENAR - Encontro Nacional de Acervo Raro, UFMG, 2012. Disponível em: https://slideplayer.com.br/slide/14544/. Acesso em 07 dez. 2018.

GROAT, L.; WANG, D.. Architectural Research Methods. New York: John Wiley \& Sons, 2002. 
GROSS, M.. The unknown in process: dynamic connections of ignorance, non-knowledge and related concepts. Current Sociology, v. 55, n. 5, p. 742-759, 2007. Disponível em: https://www.researchgate.net/publication/ 249680084_The_Unknown_in_ProcessDynamic_Connections_of_Ignorance_Non-Knowledge_and_Related_Concepts. Acesso em: 14 set. 2020.

GUARNIERI, A.; PIROTII, F.; VETTORE, A.. Cultural heritage interactive 3D models on the web: an approach using open source and free software. Journal of Cultural Heritage, v. 11, n. 3, p. 350-353, 2010.

GUICHEN, G. de. La conservation préventive: un changement profond de mentalité. Study Series. Paris: ICOM, p. 4-6, 1995. Disponível em: http://archives.icom.museum/study_series_pdf/1_ICOM-CC.pdf. Acesso em 19 jun. 2018.

GOLDRAT, E. M.. Corrente Crítica. São Paulo, ed. Nobel, 1998.

GÜNTHER, H.; ELALI, G. A.; PINHEIRO, J. Q.. A abordagem multimétodos em Estudos Pessoa-Ambiente: características, definições e implicações. In: PINHEIRO, J. Q.; GUNTHER, H. (Orgs.). Métodos de pesquisa nos estudos pessoaambiente. São Paulo: Casa do Psicólogo, 2008.

H+F ARQUITETOS. Museu Paulista. Hereñú \& Ferroni Arquitetos, 2017. Disponível em: https://www.hf.arq.br/projeto/ museu-paulistal. Acesso em 19 jan. 2021.

HADJRI, K.; CROZIER, C.. Post-occupancy evaluation: purpose, benefits and barriers. Facilities - Emerald Group Publishing, v. 27, n. 1-2, p. 21-33, 2009. Disponível em: https://www.researchgate.net/publication/235263738_Postoccupancy_evaluation_Purpose_benefits_and_barriers. Acesso em 27 mai. 2018.

HARMELING, S.; ECKSTEIN, D.. Global Climate Risk Index 2013: Who Suffers Most from Extreme Weather Events? Extreme Weather Events in 2011 and 1992 to 2011. Berlim: Germanwatch, 2012. Disponivel em: germanwatch.org/en/download/ 7170.pdf. Acesso em 28 mai. 2016.

HARRISON, R.. Heritage: Critical Approaches. Abingdon: Routledge, 2013.

HASSAN, N. et al.. Introducing Cultural Heritage into the Sustainable Development Agenda. In: Proceedings of the Hangzhou International Congress. Hangzhou, p. 1-5, 2013.

HAWKS, C.; WALLER, R.. A Tale of Two Systems: Synergy in Managing Risks to People and to Collections. Journal for Museum and Archives Professionals, v. 9, n. 1, p. 115-124, 2013. Disponível em: http://protectheritage.com/ Lisbon2011/wp-content/uploads/2011/11/A-Tale-of-Two-Systems-Poster-Reduced-file-size.pdf. Acesso em 09 fev. 2020.

HEFCE - Higher Education Funding Council for England. Guide to Post Occupancy Evaluation. HEFCE, University of Westminster, 2006. Disponível em: http://www.smg.ac.uk/documents/POEBrochureFinal06.pdf. Acesso em: 11 nov. 2020.

HEINEMANN, S.. Chemical Pulp. In: HOLIK, H. (ed.). Raw Materials for Paper and Board Manufacture. Handbook of Paper and Board, 2006. Disponível em: https://onlinelibrary.wiley.com. Acesso em 12 out. 2018.

HENDERSON, J.. Managing Uncertainty for Preventive Conservation. Studies in Conservation, n. 63, v. 1, p. 108-112, 2018. Disponível em: https://doi.org/10.1080/00393630.2018.1479936. Acesso em: 10 ago. 2020. 
HENRY, M.. The heritage Building Envelope as a Passive and Active Climate Moderator: Opportunities and Issues in Reducing Dependency on Air-Conditioning. Contribution to the Experts' Roundtable on Sustainable Climate management Strategies. Tenerife: GCl, 2007.

HERITAGE COLLECTIONS COUNCIL. reCollections Caring for Collections Across Australia - Damage and Decay. Australia: Heritage Collections Council Secretariat, 1998.

HERSHBERGER, R. G. Architectural Programming and Predesign Manager. New York: McGraw Hill, 1999.

HEWIT, M.. Por que o reuso de edifícios existentes pode (e deve) ser o principal foco dos arquitetos. ArchDaily Brasil, n. 27, 2019. Tradução de Vinicius Libardoni. Disponível em: https://www.archdaily.com.br/br/910021/por-que-o-reuso-de-edificiosexistentes-pode-e-deve-ser-0-principal-foco-dos-arquitetos. Acesso em 30 ago. 2020.

HINTON, T.. Response to Professor David Throsby's presentation on 'The Value of Heritage'. Canberra: 2006. Disponível em: www.environment.gov.au/system/files/resources/da10a766-2ef7-4989-b202-edac0f5d6f3e/files/economicsresponse-throsby.pdf. Acesso em 29 mai. 2016.

HISTORIC ENGLAND. Annex 2: Glossary. National Planning Policy Framework. Londres: Department for Communities and Local Government of United Kingdom, 2012.

HISTORIC ENGLAND. BIM for Heritage: developing a Historic Building Information Model. National Planning Policy Framework. Swindon: Historic England, 2017.

HOLIK, H.. Paper and Board Today. Handbook of Paper and Board, 2006.

HOLLÓS, A. C.; PEDERSOLI JÚNIOR., J. L.. Gerenciamento de riscos: uma abordagem interdisciplinar. Revista Ponto de Acesso, Salvador, v. 3, n. 1, p. 72-81, 2009. Disponível em: https://portalseer.ufba.br/index.php/revistaici/article/view/ 3314/2424. Acesso em 23 ago. 2018.

HOOGDUIN, L.. Decision Making in a Complex and Uncertain World. University of Groningen lecturers, 2015. Disponível em: https://www.rug.nl/feb/education/complexity-uncertainty_mooc?lang=en. Acesso em: 17 abr. 2020.

HUBBE, M.. Fatores a considerar para melhorar e ampliar a reciclabilidade do papel. 0 PAPEL, v. 71, n. 4, p. 40-60, 2010. Disponível em: http://www.revistaopapel.org.br/noticia-anexos/1293626069_6296a7d7f51cb9d67a96253b02357b90_817105003.pdf. Acesso em: 16 dez. 2020.

IBRAM - Instituto Brasileiro de Museus (a). Cartilha 2017: Gestão de Riscos ao Patrimônio Musealizado Brasileiro. Brasília: Ibermuseus, Ibram e Ministério da Cultura, 2017. Disponível em: http://www.ibermuseus.org/wp-content/uploads/2017/09/ screen_CartilhaPortugues_singlepages_lowres72pdi.pdf. Acesso em 05 set. 2018.

IBRAM - Instituto Brasileiro de Museus (b). Cartilha 2017: Programa para a Gestão de Riscos ao Patrimônio Musealizado Brasileiro. Brasília: Ibermuseus, Ibram e Ministério da Cultura, 2017. Disponível em: https:// www.museus.gov.br/wp-content/ uploads/2017/09/Gestao_de_riscos_Portugues_2017.pdf. Acesso em 05 set. 2018.

IBRAM - Instituto Brasileiro de Museus. Museu e Turismo: estratégias de cooperação. Brasília: Instituto Brasileiro de Museus, 2014. Disponível em: http://www.museus.gov.br/wp-content/uploads/2013/12/Museus_e_Turismo.pdf. Acesso em 05 fev. 2019. 
IBRAM - Instituto Brasileiro de Museus. Museus em números. Brasília: Ibram, v. 1, 2011. Disponível em: http:// www.museus.gov.br/wp-content/uploads/2011/11/Museus_em_Numeros_Volume_1.pdf. Acesso em 27 out. 2019.

ICCROM - International Centre for the Study of the Preservation and Restoration of Cultural Property. Definition of cultural heritage - references to documents in history. ICCROM Working Group 'Heritage and Society', 2005. Disponível em: cif.icomos.org/pdf_docs/Documents\%20on\%20line/ Heritage\%20definitions.pdf. Acesso em 28 mai. 2016.

ICCROM - International Centre for the Study of the Preservation and Restoration of Cultural Property. RE-ORG. ICCROM, 2018. Disponível em: https://www.iccrom.org/section/preventive-conservation/re-org. Acesso em: 07 abr. 2020.

ICOM - International Council of Museums. Resolutions Adopted by ICOM'S 22nd General Assembly. Vienna, 2007. Disponível em: https://icom.museum/wp-content/uploads/2018/07//COMs-Resolutions_2007_Eng.pdf. Acesso em: 07 abr. 2020.

ICOM - International Council of Museums. Museums as Cultural Hubs: The Future of Tradition. Kioto, 2007. Disponível em: https://icomjapan.org/material/file/ICOM_Kyoto_2019_PB_en.pdf.Acesso em: 12 abr. 2020.

ICOM-CC - International Council of Museums - Committee for Conservation. 15th Triennial Conference. New Delhi, 2008. Disponível em: http://www.icom-cc.org/243/icom-cc-triennial-conferences/15th-triennial-conference,-new-delhi,-india,-2008/ \#.YMpLOS35RpQ. Acesso em: 25 mai. 2020.

ICOMOS - International Council on Monuments and Sites. Carta Patrimonial - Princípios para a análise, conservação e restauro estrutural do patrimônio arquitetônico. Adotada pela $14^{\mathrm{a}}$ Assembleia Geral do ICOMOS, Victoria Falls, Zimbabwe, outubro de 2003. Disponível em: https://5cidade.files.wordpress.com/2008/03/carta-do-icomos-2003_principios.pdf. Acesso em 18 jun. 2020.

ICOMOS - International Council on Monuments and Sites. Cultural Heritage, the UN Sustainable Development Goals, and the New Urban Agenda. ICOMOS, 2016. Disponível em: https://www.usicomos.org/mainsite/wp-content/uploads/ 2016/05/Final-Concept-Note.pdf. Acesso em 27 jan. 2019.

ICOMOS - International Council on Monuments and Sites. International charters for conservation and restoration. Paris, 2003. Disponível em: www.icomos.org/charters/charters. pdf. Acesso em 28 mai. 2016.

ICOMOS - International Council on Monuments and Sites. The Paris Declaration - On heritage as a driver of development. In: XVIléme Assemblée Générale. Paris: ICOMOS, 2011. Disponível em: https://www.icomos.org/Paris2011/ GA2011_Declaration_de_Paris_EN_20120109.pdf. Acesso em 27 jan. 2019.

IEDI - Instituto de Estudos para o Desenvolvimento Industrial. Indústria 4.0: A Política Industrial da Alemanha para o Futuro. Carta IEDI, edição 807, 2017. Disponível em: https://iedi.org.br/cartas/carta_iedi_n_807.html. Acesso em 13 dez. 2018.

IFLA - International Federation of Library Associations and Institutions. IFLA Principles of Engagement in library-related activities of disaster risk reduction and in times of conflict, crisis or natural disaster. Den Haag, 2012. Disponivel em: www.ifla.org/files/assets/hq/gb/strategic-plan/cultural_heritage_principles_of_engagement_en.pdf.Acesso em 27 mai. 2016.

INMET. Tempo. 2021. Disponível em: https://tempo.inmet.gov.br. acesso em 15 jan. 2021. 
IPCC. Intergovernmental Panel on Climate Change. 2020. Disponível em: https://www.ipcc.ch. Acesso em: 20 ago 2020.

IPHAN - Instituto do Patrimônio Histórico e Artístico Nacional. Declaração do México. Brasília, 2015. Disponível em: portal.iphan.gov.br/uploads/ckfinder/arquivos/Declaraca0\%20do\%20Mexico\%201985.pdf. Acesso em 28 mai. 2016.

IPHAN - Instituto do Patrimônio Histórico e Artístico Nacional. Recomendação de Nairóbi. Brasília, 2015. Disponível em: portal.iphan.gov.br/uploads/ckfinder/arquivos/Recomendaca0\%20de\%20Nairobi\%201976.pdf. Acesso em 28 mai. 2016.

IPI - Image Permanence Institute. IPI's Guide to Sustainable Preservation Practices for Managing Storage Environments. IPI, 2012. Disponível em: https://s3.cad.rit.edu/ipi-assets/publications/sustainable_preservation_practices.pdf. Acesso em: 03 mai. 2020.

IPI - Image Permanence Institute. Responding to Issues. Palestra apresentada em 09 julho de 2020. Disponível em: https://imagepermanenceinstitute.org/education/webinars.html. Acesso em 09 jul. 2020.

IRM - Institute of Risk Management. The Risk Culture: Under the Microscope guidance for Boards. IRM, 2012. Disponível em: www.theirm.org/media/885907/Risk_Culture_A5_WEB15_0ct_2012.pdf. Acesso em 28 mai. 2016.

ISHIDA, C. F.. Modelo Conceitual para Comissionamento de Sistemas Prediais. Dissertação (Mestrado) - Escola Politécnica da Universidade de São Paulo, São Paulo, 2015.

ISO - International Organization for Standardization. ISO 15686-7:2017 - Buildings and constructed assets - Service life planning - Part 7: Performance evaluation for feedback of service life data from practice. Genebra: ISO, 2017.

ISO - International Organization for Standardization. ISO 19208:2016 - Framework for specifying performance in buildings. Genebra: ISO, 2016.

ISO - International Organization for Standardization. ISO 29481-1:2010 - Building Information Modelling - Information Delivery Manual-Part 1, Methodology and Format. Genebra: ISO, 2010.

ISO - International Organization for Standardization. ISO 31000:2009 - Risk management - Principles and guidelines. Genebra: ISO, 2009.

ISO - International Organization for Standardization. ISO 41001:2018 Facility management - Management systems Requirements with guidance for use. Genebra: ISO, 2018.

ISO - International Organization for Standardization. ISO 41011:2017 - Facility management -- Vocabulary. Genebra: ISO, 2017.

JACOSKI, C. A.; LAMBERTS, R.. A Utilização de Arquivos IFC para a Integração de Dados Junto à Indústria da Construção. In: Seminário de Tecnologia da Informação e Comunicação na Construção Civil, Curitiba, v.1, 2002. Disponivel em:https:/www.researchgate.net/ publication/260480722_A_utilizacao_de_arquivos_IFC_para_a_integracao_de_dados_junto_a_Industria_da_Construcao. Acesso em: 20 dez. 2018.

JIN, X.. Breaking Down Cellulose. Stanford University, 2010. Disponível em: http://large.stanford.edu/courses/2010/ ph240/jin2/. Acesso em 15 out. 2018. 
JOKILEHTO, J.. A history of architectural conservation. Oxford: Butterworth-Heinemann, 1999 Apud: CARVALHO, C.. Conservação preventiva de edifícios e sítios históricos: pesquisa e prática. Revista CPC, São Paulo, n.18, p. 141-153, dez. 2014/abr. 2015.

JORDAN-PALOMAR, I. et al.. Protocol to Manage Heritage - Building Interventions Using Heritage Building Information Modelling (HBIM). Sustainability, v. 10, n. 908, p. 1-19, 2018. Disponível em: https://www.researchgate.net/ publication/ 323941469_Protocol_to_Manage_Heritage-Building_Interventions_Using_Heritage_Building_Information_Modelling_HBIM. Acesso em: 20 jan. 2019.

JORNAL DA USP. Restauração do Museu do Ipiranga tem $\mathbf{4 0 \%}$ da obra concluída. Jornal da USP, 2020. Disponível em: https://jornal.usp.br/institucional/restauracao-do-museu-do-ipiranga-tem-40-das-obras-concluidas/. Acesso em 11 jan. 2021.

KAHNEMAN, D.. Thinking, Fast and Slow. London: Farrar, Straus and Giroux, 2013.

KATZ, D.; KHAN, R. L.. Psicologia social das organizações. São Paulo: Atlas, 1987.

KERSCHNER, R.. Providing Safe and Practical Environments for Cultural Property in Historic Buildings - and beyond. Experts' Roundtable on Sustainable Climate Management. Tenerife: GCl, 2007. Disponível em: https:// www.getty.edu/conservation/our_projects/science/climate/paper_kerschner.pdf. Acesso em: 19 mai. 2020.

KINCAID, S.. An investigation into the fire safety management of historic buildings. Built Environment Research Transactions, Sheffield Hallam University, v. 4, n. 1, p. 24-37, 2012. Disponível em: http://orcid.org/0000-0002-1162-3989. Acesso em 25 out. 2020.

KLEIN, G.. Sources of Power: How People Make Decisions. Boston: The MIT Press, 2017.

KLEMM, D. et al.. Comprehensive Cellulose Chemistry. Volume 2: Functionalization of cellulose. Weinheim: Wiley-VCH, 1998.

KLOCK, U.; ANDRADE, A. S. de; HERNANDEZ, J. A.. Polpa e Papel. Curitiba: Universidade Federal do Paraná. Setor de Ciências Agrárias. Departamento de Engenharia e Tecnologia Florestal, 2013. Disponível em: http://www.madeira.ufpr.br/ disciplinasklock/polpaepapel/manualpolpa2013.pdf. Acesso em 10 jan. 2019.

KLÜPPEL, G. P.. A Casa e o Clima: (Trans)Formações da Arquitetura Habitacional no Brasil (Século XVII - Século XIX). Tese (Doutorado) - Universidade Federal da Bahia, Salvador, 2009. Disponível em: https://repositorio.ufba.br/ri/handle/ri/24902. Acesso em 23 jan. 2020.

KLÜPPEL, G. P.; SANTANA, M. C. de. Manual de conservação preventiva para edificações. Brasilia: MinC/IPHAN/ Programa Monumenta, 2000.

KNIGHT, D. B. et al.. Increasing frequencies of warm and humid air masses over the conterminous United States from 1948 to 2005. Geophysical Research Letters, v. 35, 2008.

KOMPATSCHER, K. et al.. Intermittent conditioning of library archives: Microclimate analysis and energy impact. Building and Environment, n. 147, p. 50-66, 2018. Disponível em: https://doi.org/10.1016/j.buildenv.2018.10.013. Acesso em 17 jun. 2020. 
KOWALTOWSKI, D. C. C. K. et al.. Métodos e instrumentos de avaliação de projetos destinados à habitação social. In: VILLA, S. B.; ORNSTEIN, S. W. (org.). Qualidade ambiental na habitação: Avaliação pós-ocupação. São Paulo: Editora Oficina de Textos, p. 149-184, 2013.

KRAMER, R. et al.. Energy conservation in museums using different setpoint strategies: a case study for a state-of-the-art museum using building simulations. Applied Energy, n. 158, p. 446-458, 2015. Disponível em: http://dx.doi.org/10.1016/ j.apenergy. 2015.08.044. Acesso em 25 jan. 2019.

KRAMER, R. P.; SCHELLEN, H. L.; VAN SCHIJNDEL, A. W. M.. Impact of ASHRAE's museum climate classes on energy consumption and indoor climate fluctuations: Full-scale measurements in museum Hermitage Amsterdam. Energy and Buildings, n. 130, p. 286-294, 2016.

KRUS, M.; KILIAN, R.: SEDLBAUER, K.. Mould growth prediction by computational simulation on historic buildings. Museum Microclimates, National Museum of Denmark, p. 185-189 , 2007. Disponível em: https://www.researchgate.net/ figure/Isopleth-systems-for-3-categories-of-substrates-showing-the-influence-of-the-substrate_fig1_279341417/download. Acesso em: 19 out. 2020.

KÜHL, B. M. Notas sobre a Carta de Veneza. Anais do Museu Paulista, São Paulo, v. 18, n. 2, p. 287-320, dez. 2010. Disponível em: https://www.revistas.usp.br/anaismp/article/view/5539/7069. Acesso em 12 jun. 2020.

LAFONTAINE, R.. Environmental Norms for Canadian Museums, Art Galleries and Archive. Technical Bulletin $n^{0} 5$. Ottawa: CCl, 1979.

LA GENNUSA, M. et al.. Conflicting needs of the thermal indoor environment of museums: In search of a practical compromise. Journal of Cultural Heritage, n. 9, p. 125-134, 2008. Disponível em: https://www.researchgate.net/ publication/248546107_Conflicting_needs_of_the_thermal_indoor_environment_of_museums_In_search_of_a_practic al_compromise. Acesso em 26 jan. 2019.

LAKATOS, E.; MARCONI, M.. Fundamentos de metodologia científica. São Paulo: Atlas, 2001.

LAKATOS, E.; MARCONI, M.. Metodologia científica. São Paulo: Atlas, 2004.

LANDER, S.. What Are the Three Types of Uncertainty in Management? 2018. Disponivel em: https:// yourbusiness.azcentral.com/implications-environmental-analysis-strategic-plan-16738.html. Acesso em: 15 abr. 2020.

LANE, D.; MAXFIELD, R.. Ontological uncertainty and innovation. Journal of Evolutionary Economics, n. 15, v. 1, p. 3-50, 2005. Disponível em: https://doi.org/10.1007/s00191-004-0227-7. Acesso em: 18 abr. 2020.

LAWSON, B.. Como arquitetos e designers pensam. São Paulo: Editora Oficina de Textos, 2011.

LÉVY, P.. A Inteligência Colectiva - Para uma antropologia do Ciberespaço. Lisboa: Instituto Piaget, Epistemologia e Sociedade, 1994.

LEWI, H.; SMITH, W.; MURRAY, A.; COOKE, S.. Visitor, Contributor and Conversationalist: Multiple Digital Identities of the Heritage Citizen. Historic Environment, v. 28, n. 2, p. 12-25, 2016. Disponível em: https:/www.researchgate.net/ publication/317711402_Visitor_contributor_and_conversationalist_multiple_digital_identities_of_the_heritage_citizen. Acesso em: 14 out. 2020. 
LIBRARY OF CONGRESS. The Deterioration and Preservation of Paper: Some Essentials Facts. Library of Congress, Collections Care - Resources, 2016.

LONGSDON, L. et al.. A importância da APO para a gestão de facilidades de instituições públicas. In: Simpósio Brasileiro de Qualidade do Projeto no Ambiente Construído - 2017 - João Pessoa-PB; Anais... PortoAlegre: ANTAC, 2017.

LÓPEZ, F. et al.. A review of heritage building information modeling (H-BIM). Multimodal Technologies and Interaction, v. 2, n. 2, p. 21, 2018. Disponível em:https://www.researchgate.net/publication/ 324987991_A_Review_of_Heritage_Building_Information_Modeling_H-BIM. Acesso em 27 jan. 2019.

LYNN, J. et al. (ed.). Intergovernmental Panel on Climate Change (IPCC) Expert Meeting Communication: Meeting Report, 0slo, 2016. Disponível em: www.ipcc.ch/pdf/supporting-material/EMR_COM_full_report.pdf. Acesso em 27 mai. 2016.

MACLEOD, S. (org.). Reshaping Museum Space: Architecture, Design, Exhibitions. New York: Routledge, 2005.

MAIRESSE, F.. Le musée, temple spectaculaire: une histoire du projet muséal. Paris: Presses Universitaires de Lyon, 2002.

MAEKAWA, S. et al.. Climate Controls in a Historic House Museum in the Tropics: A Case Study of Collection Care and Human Comfort. Québec: PLEA, 2009. Disponível em: www.getty.edu/conservation/our_projects/science/climate/ barbosa_plea.pdf. Acesso em 08 set. 2015.

MAKINO, M. et al.. 0 Serviço de Documentação Textual e Iconografia do Museu Paulista. Anais do Museu Paulista, São Paulo, n. 11, p. 259-304, 2003. Disponível em: www.redalyc.org/articulo.oa?id=27301114. Acesso em 26 mai. 2016.

MALCHAIRE, J. B.. Participative management strategy for occupational healthy, safety and well-being risks. Giornale italiano di medicina del lavoro ed ergonomia, n. 28, v.4, p. 478-486, 2006. Disponível em: https://www.researchgate.net/ publication/6426338_Participative_management_strategy_for_occupational_health_safety_and_well-being_risks. Acesso em 28 jan. 2019.

MALLARACH, J-M.; VERSCHUUREN, B.. Changing Concepts and Values in Natural Heritage Conservation: A View through IUCN and UNESCO Policies. In: AVRAMI, E. et al. (eds.). Values in Heritage Management: Emerging Approaches and Research Directions. Los Angeles: GCl, 2019. Disponível em: https://heritagemanagement.netlify.app/part-two/10/. Acesso em: 10 out. 2020.

MANYENA, S.. The concept of resilience revisited. Disasters, v. 30, n. 4, p. 434-450, 2006. Disponível em: https://doi.org/ 10.1111/j.0361-3666.2006.00331.x. Acesso em: 06 abr. 2019.

MANZINI, E. J.. Entrevista semi-estruturada: análise de objetivos e de roteiros. In: Seminário Internacional sobre Pesquisa e Estudos Qualitativos. A pesquisa qualitativa em debate. Anais... Bauru: USC, 2004.

MARKHAM, A. et al.. World Heritage and Tourism in a Changing Climate. United Nations Environment Programme, Nairobi, Kenya. Paris: UNESCO, 2016. Disponível em: https://whc.unesco.org/en/tourism-climate-change/. Acesso em 28 jan. 2019.

MARTENS, M.. Climate Risk Assessment in Museums. Tese (Doutorado) - Technische Universiteit Eindhoven, 2012. Disponível em: https://pure.tue.nl/ws/files/3542048/729797.pdf. Acesso em: 07 jul. 2020. 
MARTINEZ-MOLINA, A. et al.. Assessing visitors' thermal comfort in historic museum buildings: Results from a Post-Occupancy Evaluation on a case study. Building and Environment, v. 132, p. 291-302, 2018. Disponível em: https:// www.sciencedirect.com/science/article/pii/ S0360132318300696. Acesso em 21 jan. 2019.

MAXIMIANO, A. C. A.. Introdução à administração. São Paulo: ed. Atlas, 2007.

MCANDREW, F. T.. Environmental psychology. Pacific Grove: Brooks/Cole, 1993.

McCORMICK-G00DHART, M.. The Allowable Temperature and Relative Humidity Range for the Safe Use and Storage of Photographic Materials. Journal of the Society of Archivists, v. 17, n. 1, p. 7-21, 1996. Disponível em: https:// www.aardenburg-imaging.com/wp-content/uploads/2015/11/Aal_2007_1206_TA-01.pdf. Acesso em: 08 set. 2020.

MENDES, M.. 0 uso de energias renováveis em edifícios de museus. Tese (Doutorado) - Universidade Lusófona de Humanidades e Tecnologias, Lisboa, 2011. Disponível em: www.museologia-portugal.net/files/upload/doutoramentos/ manuel_furtado.pdf. Acesso em 26 mai. 2016.

MICHALSKI, S.. A Systematic Approach to the Conservation (Care) of Museum Collections. Ottawa: CCI, 1992. Disponivel

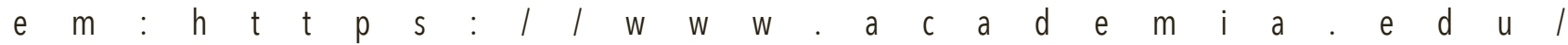
741954/1992_A_systematic_approach_to_the_conservation_care_of_museums_collections_with_technical_appendices_by_Ma ureen_MacDonald_Stefan_Michalski_Thomas_.Acesso em 29 mai. 2016.

MICHALSKI, S.. Care and Preservation of Collections. In: BOYLAN, P. J. (Ed.). Running a Museum: a practical handbook. Paris: International Council of Museums, p. 51-90, 2004. Disponível em: unesdoc.unesco.org/images/ 0014/001410/141067e.pdf. Acesso em 26 mai. 2016.

MICHALSKI, S.. Los niveles ABC para la evaluación de riesgos en las colecciones museísticas e información para interpretar los riegos derivados de una incorrecta Humedad Relativa y Temperatura. Madrid: Instituto Canadiense de Conservación, 2009. Disponível em: ge-iic.com/files/grupoconservacionpre/Michalski_Madrid.pdf. Acesso em 29 mai. 2016.

MICHALSKI, S.. Relative humidity: a discussion of correct / incorrect values. ICOM Committee of Conservation, v. II, p. 624-629, 1993. Disponível em: https://www.academia.edu/741937/1993_Relative_humidity_a_discussion_of_correct_incorrect_values. Acesso em: 15 abr. 2020.

MICHALSKI, S.. The Ideal Climate, Risk Management, the ASHRAE Chapter, Proofed Fluctuations, and Toward a Full Risk Analysis Model. Contribution to the Experts' Roundtable on Sustainable Climate Management Strategies. Tenerife: GCl, 2007. Disponível em: www.getty.edu/conservation/our_projects/science/climate/paper_michalski.pdf. Acesso em 29 mai. 2016.

Millennium Ecosystem Assessment. Millennium Assessment Report. 2005. Disponível em: https:// www.millenniumassessment.org/en/Index-2.html. Acesso em: 27 out. 2020.

MINTZBERG, H.. Structure in Fives: Designing Effective Organisations. Prentice Hill, 1983.

MOTA, F. C. P.. Teoria Geral da Administração. São Paulo: ed. Thomson Learning, 2006. 
MP USP. História do Museu Paulista. 2020. Disponível em: http://www.mp.usp.br/o-museu/historia-do-museu-paulista. Acesso em 18 jan. 2020.

MULLINS, L.J.. Management and Organisational Behaviour. London: Pitman, 1996.

MUÑOZ-VIÑAS, S.. The Transactional Nature of Heritage Conservation. Reinwardt Memorial Lecture, Amsterdam University of the Arts, 2017. Disponivel em: https://www.reinwardt.ahk.nl/media/rwa/docs/Publicaties/ Rwa_memorial_lecture_2017_munoz_web.pdf. Acesso em 28 jun. 2020.

Museums Galleries Scotland. Advice Sheet - Conservation and Lighting. Edinburgh, 2009. Disponível em: https:// 326gtd123dbk1xdkdm489u1q-wpengine.netdna-ssl.com/wp-content/uploads/2016/11/Conservation-and-LightingMuseums-Galleries-Scotland.pdf. Acesso em: 03 mai. 2020.

NA PRÁTICA. Saiba como a Matriz de Einsenhower pode ajudar a priorizar melhor suas tarefas diárias. 2021. Disponível em: https://www.napratica.org.br/matriz-de-eisenhower-produtividade/. Acesso em: 12 dez. 2020.

NIJKAMP, P.; BITHAS, K. Sustainable Development and Monument Conservation Planning: a case study on Olympia. Paris: ICOMOS, 1993. Disponível em: www.icomos.org/publications/93sy_eco12.pdf. Acesso em 28 mai. 2016.

NISHIMURA, D.. Understanding Preservation Metrics. Image Permanence Institute e Rochester Institute of Technology, 2011. Disponível em: https://s3.cad.rit.edu/ipi-assets/publications/understanding_preservation_metrics.pdf. Acesso em 10 ago. 2020.

NMDC - National Museum Directors's Conference. Guiding Principles for Reducing Museums' Carbon Footprint. UK: NMDC, 2009. Disponível em: http://www.nationalmuseums.org.uk/media/documents/what_we_do_documents/ guiding_principles_reducing_carbon_footprint.pdf.Acessado em: 05 out. 2020.

NOBRE, C. et al.. Vulnerabilidades das Megacidades Brasileiras às Mudanças Climáticas: Região Metropolitana de São Paulo. Rio Claro: INPE; UNICAMP; USP; IPT; UNESP, 2011. Disponível em: https://www.researchgate.net/publication/ 264383509_Vulnerabilidades_das_megacidades_basileiras_as_mudancas_climaticas_Regiao_Metropolitana_de_Sao_Pa ulo_-_Relatorio_Final. Acesso em 12 mar. 2020.

NOCCA, F.. The Role of Cultural Heritage in Sustainable Development: Multidimensional Indicators as Decision-Making Tool. Sustainability, v. 9, n. 1882, p. 1-28, 2017. Disponivel em: https://www.mdpi.com/2071-1050/9/10/1882. Acesso em 21 jan. 2019.

ODLYHA, M. et al.. Microclimate indoor monitoring for cultural heritage. In: 7th European Conference "Sauveur" - Safeguarded Cultural Heritage - Understanding \& Viability for the Enlarged Europe, 2006. Proceedings. Prague: ITAM; ARCCHIP, v. 2, p. 899-901, 2007. Disponível em: www.arcchip.cz/ec-conference/download/B-968_end.pdf. Acesso em 26 mai. 2016.

OKSMAN, S.; COLLONELLI, E.. Projeto de restauro e ampliação do Museu Paulista da Universidade de São Paulo. Disponível em: arquimuseus.arq.br/seminario2014/transferencias/eix001-arquitetura_e_patrimonio/e01eduardo_argenton_collonlli-silvio_oksman.pdf. Acesso em 28 mai. 2016.

OLIVEIRA, C. H. de S.. Museu Paulista da USP: percursos e desafios. Estudos avançados, São Paulo, v. 25, n. 73, 2011. Disponível em: http://www.scielo.br/scielo.php?script=sci_arttext\&pid=S0103-40142011000300025. Acesso em 20 mai. 2017. 
OLOGIA. 0 Processo de Design Thinking. 2010. Disponível em: https://pt.slideshare.net/ologia/design-thinking-process. Acesso em 09 set. 2018.

ONO, R.; MOREIRA, K. B.. Segurança em Museus. Cadernos Museológicos - Volume 1. Brasília: MinC e IBRAM, 2011. Disponível em: http://www.museus.gov.br/wp-content/uploads/2012/08/Seguranca-em-Museus.pdf. Acesso em 5 set. 2018.

ONO, R., ORNSTEIN, S. W.. Avaliação Pós-Ocupação em Museus: Uma Análise dos Instrumentos para Avaliar a Satisfação dos Usuários. In: SBQP TIC 2013 - III Simpósio Brasileiro de Qualidade do Projeto no Ambiente Construído e IV Encontro de Tecnologia de Informação e Comunicação na Construção, 2013, Campinas. Anais... Porto Alegre: ANTAC, v. 1, p.1458 - 1469, 2013.

ONO, R. et al.. Avaliação Pós-Ocupação: Pré-Teste de Instrumentos para Verificação do Desempenho de Empreendimentos Habitacionais em Sistemas Construtivos Inovadores. Gestão e Tecnologia de Projetos, São Paulo, v. 10, n. 1, 2015. Disponível em: http://dx.doi.org.br/10.11606/gtp.v10i1.88979. Acesso em 15 jan. 2019.

ONO, R. et al. (org.). Avaliação pós-ocupação: na arquitetura, no urbanismo e no design: da teoria à prática. São Paulo: Editora Oficina de Textos, 2018.

ORENI, D.; BRUMANA, R.; CUCA, B.. Towards a methodology for 3d content models: the reconstruction of ancient vaults for maintenance and structural behaviour in the logic of BIM management. In: Proceedings of 2012 18th International Conference on Virtual Systems and Multimedia, Milan, p. 475-482, 2012. Disponível em: https://www.semanticscholar.org/ paper/Towards-a-methodology-for-3D-content-models\%3 A-The-of-0reni-Brumanal 4356bedac25b92e237213cd42af1de5742b9ae49. Acesso em 18 jan. 2019.

ORNSTEIN, S.. Avaliação Pós-Ocupação no Brasil, 30 anos: o que há de novo? Revista Projetar - Projeto e Percepção do Ambiente, v.2, n.2. Ago. 2017. Disponível em: http://www.revistaprojetar.ct.ufrn.br/index.php/revprojetar/article/view/ 209/11. Acesso em 26 mai. 2018.

ORNSTEIN, S.. Com os usuários em mente: um desafio para a boa prática arquitetônica? PARC Pesquisa em Arquitetura e Construção, Campinas, v. 7, n. 3, p. 189-197, 2016.

ORNSTEIN, S.. Desempenho do ambiente construído, interdisciplinaridade, e arquitetura. São Paulo: FAU USP, 1996.

ORNSTEIN, S.. Divergências metodológicas e de resultados nos estudos voltados às relações ambiente comportamento (RAC) realizados nas escolas brasileiras de arquitetura. Psicologia e ambiente, São Paulo, Editora da PUC-SP, 2004.

ORNSTEIN, S.; BARBUY, H.. Museu Paulista: Contribuições Acadêmicas e Políticas Públicas. USP 80 Anos. São Paulo, Universidade de São Paulo, 2015.

ORNSTEIN, S.; BRUNA, G.; ROMÉRO, M.. Ambiente Construído e comportamento. São Paulo: Nobel, FAUUSP, FUPAM, 1995.

ORNSTEIN, S.; ONO, R.. Post-Occupancy Evaluation and Design Quality in Brazil: concepts, approaches and an example of application. Architectural Engineering and Design Management, v. 6, p. 48-67, 2010. Disponível em: www.earthscan.co.uk/journals/aedm. Acesso em 01 out. 2017.

ORNSTEIN, S. W. et al.. Post-Occupancy Evaluation in Brazil: its impact on professional practice. In: PREISER, W. F. E.; VISCHER, J. C. (ed.). Enhancing Building Performance. New York: Wiley-Blackwell, v. 1, p. 247-258, 2012. 
ORTIZ, P. et al.. Approach to environmental risk analysis for the main monuments in a historical city. Journal of Cultural Heritage, v. 15, n. 4, p. 432-440, 2014. Disponível em: https://www.researchgate.net/publication/ 259157294_Approach_to_environmental_risk_analysis_for_the_main_monuments_in_a_historical_city. Acesso em: 25 out. 2020.

OSWALD, A.; MÜLLER, W. (ed.). Management 4.0 - Handbook for Agile Practices. Alemanha: Books on Demand, 2017.

PADFIELD, T.. The Preservation Index and the Time Weighted Preservation Index. 2004. Disponível em: https:// www.conservationphysics.org/twpi/twpi_01.html. Acesso em 10 ago. 2020.

PADFIELD, T.; LARSEN, P.. How to Design Museums with a Naturally Stable Climate. Annual General Meeting of the International Institute for Conservation, 2004. Disponível em: https://www.conservationphysics.org/musdes/musdes.pdf. Acesso em: mai. 2020.

PAGLIONE, C. Z.. Glossário visual de conservação: um guia de danos comuns em papéis e livros. São Paulo: Biblioteca Brasiliana Guita e José Mindlin, 2017. Disponível em: https://www.bbm.usp.br/sites/default/files/publicacoes/ release_glossario.pdf. Acesso em 05 fev. 2019.

PANAGIOTOU, G.. Bringing SWOT into Focus. Business Strategy Review, v. 14, n. 2, p. 8-10, 2003. Disponível em: https:// onlinelibrary.wiley.com/doi/abs/10.1111/1467-8616.00253. Acesso em 15 dez. 2018.

PARK, K. H. (coord.). Introdução ao estudo da administração. São Paulo: Pioneira, 1997.

PAUPÉRIO, E. et. al. Inspecção e diagnóstico de estruturas. Contributo para a sua preservação. Seminário "Cuidar das casas. A manutenção do património corrente", p. 1-23, 2011. Disponível em: https://sigarra.up.pt/faup/pt/ pub_geral.pub_view?pi_pub_base_id=138653.Acesso em 11 out. 2020.

PAUWELS, P. et al.. Integrating building information modeling and semantic web technologies for the management of built heritage information. In: IEEE 2013 Digital Heritage International Congress (DigitalHeritage), p. 481-488. Marselha, 2013. Disponível em: https://ieeexplore.iee.org/document/6743787. Acesso em 20 jan. 2019.

PEDERSOLI JR. J. L.; ANTOMARCHI, C.; MICHALSKI, S.. A Guide to Risk Management of Cultural Heritage. ICCROM; CCI, 2016. Disponível em: https://www.iccrom.org/wp-content/uploads/Guide-to-Risk-Managment_English.pdf.Acesso em 28 jan. 2019.

PENG, M. W.; VLAS, C. O.. Diffusion of a Twentieth-Century Innovation. Electronic Business Journal, v. 16, n. 1, 2017. Disponível em: https://www.researchgate.net/publication/318506670_Diffusion_of_a_twentieth-century_innovation. Acesso em 30 ago. 2018.

PÉRIER-D'IETEREN, C.. What's at stake now in Conservation-Restoration. Study Series, Paris, ICOM, p. 2-4, 1995. Disponível em: http://archives.icom.museum/study_series_pdf/1_ICOM-CC.pdf. Acesso em 19 jun. 2018.

PETERSON, M.. The precautionary principle should not be used as a basis for decision-making. EMBO Reports, v. 8, n. 4, p. 305-308,2007. Disponível em: https://www.researchgate.net/publication/ 51383098_The_precautionary_principle_should_not_be_used_as_a_basis_for_decisionmaking_Talking_Point_on_the_precautionary_principle.Acesso em: 14 set. 2020. 
PINHEIRO, J. de Q.; ELALI, G. A. (org.). Inter-Ações Pessoa - Ambiente. Nove Estudos Potiguares. Natal: Editora da Universidade do Rio Grande do Norte, 2010.

PINHEIRO, J. de Q.; GÜNTHER, H. (org.). Métodos de pesquisa nos estudos pessoa-ambiente. São Paulo: Casa do Psicólogo, 2008.

POPPER, K. S. A lógica da pesquisa científica. São Paulo: Cultrix, 1975.

PORTIER, S.; MALTRET, J.; ZOLLER, J.. Computer graphics: assistance for archaeological hypotheses. Automation in Construction, v. 9, n. 1, p. 117-128, 2000.

PREISER, W.; DAVIS, A.; SALAMA, A.; HARDY, A. (ed.). Architecture Beyond Criticism: expert judgement and performance evaluation. New York: Routledge, 2015. Disponível em: https://www.researchgate.net/publication/ 303079622_Architecture_Beyond_Criticism_Expert_Judgement_and_Performance_Evaluation. Acesso em 26 mai. 2018.

PREISER, W.; MALLORY-HILL, S.; WATSON, C. (ed.). Enhancing Building Performance. UK: Wiley- Blackwell, 2012.

PREISER, W; OSTROFF, E. (Ed.). Universal Design Handbook. New York: McGraw Hill, 2001.

PREISER, W.; RABINOWITZ, H.; WHITE, E.. Post Occupancy Evaluation. New York: Van Nostrand Reinhold, 1988.

PREISER, W. F. E.; SCHARAMM, U.. A conceptual framework for building performance evaluation. In: PREISER, W. F. E.; VISCHER, J. C. (ed.). Assessing building performance. Oxford: Elsevier, p. 15-26, 2005.

PREISER, W. F. E.; VISCHER, J.C. (ed.). Assessing Building Performance. Oxford: Elsevier, 2005.

PRIM0, J.. Pensar contemporaneamente a museologia. Cadernos de Sociomuseologia, n. 16. p. 5-38. Lisboa: Universidade Lusófona de Humanidades e Tecnologias, 1999. Disponível em: recil.ulusofona.pt/bitstream/handle/ 10437/3780/Pensar\%20contemporaneamente.pdf?sequence=1. Acesso em 28 mai. 2016.

PRINCE CLAUS FUND. Culture is a Basic Need. PCF, 2006. Disponível em: www.princeclausfund.org/files/ docs/ PCFJournal14.pdf. Acesso em 27 mai. 2016.

PROGRAMA MONUMENTA. Sítios Históricos e Conjuntos Urbanos de Monumentos Nacionais. Brasília: MinC/IPHAN/ Programa Monumenta, 2005.

PROJECT SMART. The Standish Group Report - Chaos Report. UK, 2014. Disponível em: https:// www.projectsmart.co.uk/ white-papers/chaos-report.pdf. Acesso em 21 jan. 2019.

PUBLIC AFFAIRS. Marriage of technology and cultural heritage is fraught. Berkeley News, 2016. Disponível em: https://news.berkeley.edu/2016/05/06/the-marriage-of-technology-and-cultural-heritage-is-fraught/. Acesso em 16 jan. 2019.

RAMIRES, J. Z.; MELLO-THÉRY, N. A.. Uso e ocupação do solo em São Paulo, alterações climáticas e os riscos ambientais contemporâneos. Revista Franco-brasileira de Geografia, Confins, n. 34, 2018. Disponível em: https:// journals.openedition.org/confins/12779. Acesso em: 20 dez. 2019. 
RAUSAND, M.; HAUGEN, S.. Risk assessment: theory, methods, and applications. New York: John Wiley \& Sons, 2020.

RE CECCONI, F.; MALTESE, S.; DEJACO, M. C.. Leveraging BIM for digital built environment asset management. Innovative Infrastructure Solutions, v. 2, n. 1, p. 14, 2017. Disponível em: https:// link.springer.com/article/10.1007/ s41062-017-0061-z. Acesso em 21 jan. 2019.

REED, R.. Ancient Skins Parchments \& Leathers. Leeds: Seminar Press, 1972.

RHEINGANTZ, P. et al.. Notas de Aula da Disciplina Avaliação de desempenho do ambiente construído. Rio de Janeiro: PROARQ / FAU / UFRJ, 2007.

RHEINGANTZ, P. A. et al.. Observando a Qualidade do Lugar: Procedimentos para a Avaliação Pós-Ocupação. Rio de Janeiro: Proarq/FAU/UFRJ, 2009. Disponível em: http://www.fau.ufrj.br/prolugar/assets/obs_a_qua_lugar.pdf.Acesso em 28 mai. 2016.

RHEINGANTZ, P. A.; PEDRO, R. M. L. R.; SZAPIRO, A. M. (org.). Qualidade do Lugar e Cultura Contemporânea. Modos de ser e habitar as cidades. Porto Alegre: Sulina, 2016.

RIT / Image Permanence Institute. Sustainable Preservation Practices for managing storage environments. RIT, 2020. Disponível em: https://ipisustainability.org. Acesso em 10 nov. 2020.

RIZZI, A. et al.. 3D recording for 2D delivering - The employment of 3D models for studies and analyses. In: ISPRS Trento 2011 Workshop: International Archives of the Photogrammetry, Remote Sensing and Spatial Information Sciences, v. XXXVIII-5/w16, p. 301-309, 2011. Disponível em: https://www.researchgate.net/publication/288280423_3D_recording_for_2D_delivering__The_employment_of_3D_models_for_studies_and_analyses. Acesso em 21 jan. 2019.

ROCA, P.; CERVERA, M.; GARIUP, G.; PELÀ, L.. Structural Analysis of Masonry Historical Constructions. Classical and Advanced Approaches. Conference Paper, 1999. Disponível em: https://www.researchgate.net/profile/Miguel_Cervera/ publication/270162082_Studies_on_the_structure_of_Gothic_Cathedrals/links/5c31cdb7458515a4c71116e5/Studies-onthe-structure-of-Gothic-Cathedrals.pdf. Acesso em 16 jan. 2021.

RODRIGUES, F. et al.. Development of a Web Application for Historical Building Management through BIM Technology. Hindawi - Advances in Civil Engineering, v. 2019, p. 1-15, 2019. Disponível em: https://doi.org/ 10.1155/2019/9872736. Acesso em 30 jan. 2019.

ROGERS, G.. The ideal of the ideal environment. In: Journal of the International Institute for Conservation of Historic and Artistic Work. Canadian Group 2, n. 1, p. 34 - 39, 1976.

ROMÃO, X.; PAUPÉRIO, E.; PEREIRA, N.. A framework for the simplified risk analysis of cultural heritage assets. Journal of Cultural Heritage, n. 20, p. 696-708, 2016. Disponível em: http://dx.doi.org/10.1016/j.culher.2016.05.007. Acesso em 19 out. 2020.

ROMÉRO, M. de A.; ORNSTEIN, S. W. (coord.). Avaliação pós-ocupação: Métodos e Técnicas aplicados à habitação social. Coleção Habitare. Porto Alegre: ANTAC, 2003.

ROSSI, P. H.; FREEMAN, H. E.. Evaluation: a systematic approach. Newbury Park: Sage Publications, 1989. 
ROUCHON, V. et al.. Room-Temperature Study of Iron Gall Ink Impregnated Paper Degradation under Various Oxygen and Humidity Conditions: Time-Dependent Monitoring by Viscosity and X-ray Absorption Near-Edge Spectrometry Measurements. Analytical Chemistry, v. 83, p. 2589-2597, 2011. Disponível em: https://pubs.acs.org/doi/pdf/10.1021/ac1029242. Acesso em 12 out. 2018.

ROWE, P. G.. Design Thinking. Cambridge: The MIT Press, 1992.

SAES, F.. Comissionamento em Edificações. Revista Infra, São Paulo, ed. 77, 2006.

SAFT, J.; ORNSTEIN, S.. Avaliação Pós-Ocupação (APO) Aplicada a Áreas de Guarda de Acervos na Cidade de São Paulo, Brasil. ENCORE2020: $4^{\circ}$ Encontro de Conservação e Reabilitação de Edifícios. Livro de Atas, v. 01, p. 1011-1022, 2020. Disponível em: http://encore2020.Inec.pt. Acesso em: 07 dez. 2020.

SAFT, J. et al.. A criação de uma Rede de Conservação Preventiva da USP: proposta e objetivos. APOYOnline 30th Anniversary Conference Postprints, Rio de Janeiro, 2019. Disponivel em: http://apoyonline.org/en_US/apoyo-programs/30thanniversary/rio-de-janeiro-2019/post-conference-report/. Acesso em 28 jan. 2021.

SAFT, J. et al.. Quadros Sinópticos e Mapas de Diagnósticos e de Recomendações como subsídios para a gestão de edifícios complexos: 0 caso de um museu de grande porte na cidade de São Paulo. In: Encontro Nacional de Tecnologia do Ambiente Construído, 2018. Anais... Foz do Iguaçu: ANTAC, 2018.

SANDEL, M.. Justiça: 0 que é fazer a coisa certa. Rio de Janeiro: Civilização Brasileira, 2015.

SANOFF, H.. Design Games. Los Altos: William Kaufmann Inc., 1984.

SANOFF, H.. School Building Assessment Methods. Washington: National Clearinghouse for Educational Facilities, 2001. Disponível em: www.edfacilities.org. Acesso em 01 out. 2017.

SCHAEFFER, T. T.. Effects of light on materials in collections: data on photoflash and related sources. Library of Congress Cataloging, 2001.

SCHWARCZ, L. M.. Nascimento dos Museus Brasileiros: 1870 - 1910. História das Ciências Sociais no Brasil. São Paulo: Vértice, 1989.

SCHWEIDLER, M.. The Restoration of Engravings, Drawings, Books and Other Works on Paper. Los Angeles: GCl, 2006. Disponivel em: https://www.getty.edu/conservation/publications_resources/books/restoration_works_on_paper.html. Acesso em: 22 out. 2020.

SEERY, M. K.. Harnessing Technology in Chemistry Education. NDIR, Ireland, v. 9, p. 76-86, 2013. Disponível em: https:// www.researchgate.net/publication/328336803_Harnessing_technology_in_chemistry_education. Acesso em 10 out. 2020.

SELLI, P.. 0 Museu Paulista e as concepções de museu em São Paulo. Revista CPC, São Paulo, n. 15, p. 67-84, 2013. Disponível em: http://www.revistas.usp.br/cpc/article/view/68629. Acesso em 28 mai. 2016. 
SHAHEED, F.. Report of the Independent Expert in the Field of Cultural Rights. Human Rights Council, Seventeenth Session, UN General Assembly. A/HRC/17/38. New York: HRC, 2011. Disponível em: www.unesco.org/new/fileadmin/ MULTIMEDIA/HQ/CLT/images/Report\%20of\%20Farida \%20Shaheed.pdf. Acesso em 27 mai. 2016.

SIDOTI, A.. The National Library of Florence: difficult decisions following the 1966 Flood. In: VAROLI- PIAZZA, R. (ed.). Sharing Decisions: Lessons Leant from an ICCROM Course. Rome: ICCROM, 2007. Disponível em: www.iccrom.org/ifrcdn/pdf/ ICCROM_15_SharingConservDecisions-It_en.pdf.Acesso em 27 mai. 2016.

SILVA, A.. Taxa de dose eritematosa sob céu encoberto por alto-estrato: estudo de caso. Revista Brasileira de Geofísica, v. 28, n. 3, 2010. Disponível em: https://www.scielo.br/scielo.php?script=sci_arttext\&pid=S0102-261X2010000300003. Acesso em 12 mar. 2020.

SILVA, V.P.; VARGAS, M. R.; ONO, R.. Prevenção contra Incêndio no Projeto de Arquitetura. Rio de Janeiro: IABr/CBCA, 2010.

SIMÕES, J. R. L.. Patologias - origens e reflexos no desempenho técnico-construtivo de edifícios: análise das patologias e de seus reflexos no desempenho técnico-construtivo de edifícios universitários da CUASO - USP/SP utilizando-se elementos da ISP6241 e procedimentos da APU - avaliação pós-uso. Tese (Livre-Docência) - Faculdade de Arquitetura e Urbanismo da Universidade de São Paulo, São Paulo, 2004.

SMITH, K.. Environmental hazards: assessing risk and reducing disaster. UK: Routledge, 2013.

SOMMER, R.. Personal Space: The Behavioral Basis of Design. New Jersey: Prentice-Hall Inc., 1969.

SOUTO-MAIOR, J.. Planeação Estratégica e Comunicativa. João Pessoa: Editora Universitária da UFPB, 2012.

SPALDING, M.. História da leitura. Digestivo Cultural, 2011. Disponível em: https://www.digestivocultural.com/colunistas/ coluna.asp?codigo=3275\&titulo=Historia_da_leitura_(I):_as_tabuas_da_lei_e_0_rolo. Acesso em 08 dez. 2018.

SPINELLI, J.; PEDERSOLI JÚNIOR., J. L.. Biblioteca Nacional - Plano de gerenciamento de riscos: salvaguarda \& emergência. Rio de Janeiro: Fundação Biblioteca Nacional, 2010. Disponível em: http:// objdigital.bn.br/acervo_digital/div_obrasgerais/ drg_plano_risco_por/drg_plano_risco_por.pdf. Acesso em 28 jan. 2019.

STANIFORTH, S.. Conservation Heating to Slow Conservation: A Tale of the Appropriate Rather Than the Ideal. Contribution to the Experts' Roundtable on Sustainable Climate management Strategies. Tenerife: GCl, 2007. Disponível em: https://www.getty.edu/conservation/our_projects/science/climate/paper_kerschner.pdf.Acesso em: 18 mai. 2020.

STANIFORTH, S.. Relative Humidity as an Agent of Deterioration. In: LITHGOW, K.; LLOYD, H.; PARRY, J.; STANIFORTH, S.; SEELEY, N. (ed.). The National Trust Manual of Housekeeping. Amsterdam: The National Trust, p. 113, 2006.

STANIFORTH, S. (ed.). Historical perspectives on preventive conservation. Readings in conservation. Los Angeles: GCl, 2013.

STANIFORTH, S.; HAYES, B.; BULLOCK, L.. Appropriate technologies for relative humidity control for museum collections housed in historic buildings. In: ROY, A.; SMITH, P. (ed.). Preventive Conservation Practice, Theory and Research. London: International Institute of Conservation, p.123-128, 1994. 
STOVEL, H.. Risk Preparedness: A Management Manual for World Heritage. Roma: ICCROM, 1998. Disponível em: www.iccrom.org/ifrcdn/pdf/ICCROM_17_RiskPreparedness_en.pdf. Acesso em 27 mai. 2016.

STYLIADIS, A. D.. Digital documentation of historical buildings with 3D modeling functionality. Automation in Construction, v. 16, n. 4, p. 498-510, 2007. Disponível em: https://www.researchgate.net/publication/ 222212549_Digital_documentation_of_historical_buildings_with_3D_modeling_functionality. Acesso em 28 jan. 2019.

SUPERBRIGHTLEDS. Light-color Temperature on Flowers. 2020. Disponível em: https://www.superbrightleds.com/blog/lightbulb-color-temperature-light-room/5946/light-color-temp-on-flowers/. Acesso em 10 jun. 2020.

SWEENEY, A., CLARKE, N., HIGGS, M.. Shared Leadership in Commercial Organizations: A Systematic Review of Definitions, Theoretical Frameworks and Organizational Outcomes. International Journal of Management Reviews, 2018. Disponível em: https://doi.org/10.1111/ijmr.12181. Acesso em 25 jan. 2019.

TAIZ, L.; ZEIGER, E... Plant physiology. Sunderland: Sinauer Associates, 2002.

TANDON, A.. ICCROM Programme on disaster and risk management. ICCROM, 2013. Disponível em: www.iccrom.org/ wp-content/uploads/RDRM-Background-paper_AT_REV_30-April-2.pdf. Acesso em 26 mai. 2016.

TANNERT, C.; ELVERS, H-D.; JANDRIG, B.. The ethics of uncertainty. In the light of possible dangers, research becomes a moral duty. EMBO Reports, v. 8, n. 10, p. 892-896, 2007. Disponível em: https://www.ncbi.nlm.nih.gov/pmc/articles/ PMC2002561/. Acesso em: 14 set. 2020.

TARIFA, J. R.; AZEVEDO, T. R. (orgs.). Os climas na cidade de São Paulo: teoria e prática. GEOUSP, ? São Paulo, Coleção Novos Caminhos, v. 4, 2001.

TASSARA, E. T. de 0. (ed.). Psicologia e Ambiente. Revista Psicologia USP, Instituto de Psicologia, v. 16, n. 1/2, 2005.

TEMBA, P.. Fundamentos da Fotogrametria. Belo Horizonte: Departamento de Cartografia da UFMG, 2000. Disponível em: http://csr.ufmg.br/geoprocessamento/publicacoes/fotogrametria.pdf. Acesso em 29 jan. 2019.

THOMSON, G.. The museum environment. London: Butterworths, 1986.

THROSBY, D.. The value of heritage. Heritage Economics Workshop. ANU, 2007. Disponível em: www.environment.gov.au/ system/files/resources/da10a766-2ef7-4989-b202-edac0f5d6f3e/files/ economics-value.pdf. Acesso em 29 mai. 2016.

TOBIÁŠ, P.. BIM, GIS and semantic models of cultural heritage buildings. Geoinformatics FCE CTU, v. 15, n. 2, p. 27-41, 2016. Disponível em: https://ojs.cvut.cz/ojs/index.php/gi/article/view/gi.15.2.3. Acesso em 21 jan. 2019.

TOLEDO, F.. Prevenção Através do Controle Ambiental. Seminário Internacional de Riscos ao Patrimônio Cultural: Avaliação, Prevenção e Salvaguarda. Rio de Janeiro: Museu Histórico Nacional, 2010. Disponível em: http:// ww w. casaruibarbosa.gov.br/conservaca o preventiva/arquivos/file/Downloads/ PREVENCAO\%20ATRAVES\%20D0\%20CONTROLE\%20AMBIENTAL.pdf. Acesso em 29 mai. 2016. 

João Pessoa: ArqDoc, 2014. Disponível em: https://www.researchgate.net/publication/ 268520822_A_UTILIZACAO_DE_TECNOLOGIAS_DIGITAIS_NA_DOCUMENTACAO_DO_PATRIMONIO_ARQUITETONICO. Acesso em 21 jan. 2019.

THOMAZONI, A.. L.. A definição do partido arquitetônico pautado nos estudos dos fluxos frente à modernização de hospitais complexos. Tese (Doutorado) - Faculdade de Arquitetura e Urbanismo da Universidade de São Paulo, São Paulo, 2016.

THOMAZONI, A.. Avaliação pós-ocupação (APO) funcional. 0 caso de dois centros de diagnósticos por imagem em Campinas, SP. Dissertação (Mestrado) - Faculdade de Arquitetura e Urbanismo da Universidade de São Paulo, São Paulo, 2009.

TROI, A.. Energy issues and cultural heritage - to study the interrelation is a key subject at EURAC research. In: 7th European Conference "Sauveur" - Safeguarded Cultural Heritage - Understanding \& Viability for the Enlarged Europe, 2006. Proceedings. Prague: ITAM; ARCCHIP, v. 2, p. 909-911, 2007. Disponível em: www.arcchip.cz/ec-conference/download/ B-968_end.pdf. Acesso em 26 mai. 2016.

UFPR - Universidade Federal do Paraná. Madeira. UFPR, 2018. Disponível em: http://www.madeira.ufpr.br/disciplinassilvana/ indicepapel.pdf. Acesso em 12 dez. 2018.

ULAS, E. et al.. A Practical Guide for Sustainable Climate Control and Lightning in Museums and Galleries. Sidney: International Conservation Services and Steensen Varming, 2014. Disponível em: http://www.magsq.com.au/ _dbase_upl/APracticalGuideforSustainableClimateControlandLightinginMuseumsandGalleries.pdf. Acesso em: 18 ago. 2020.

UNDRR - United Nations Office for Disaster Risk Reduction. Sendai framework for disaster risk reduction 2015-2030. Genebra: UNDRR, 2015. Disponível em: https://www.undrr.org/publication/sendai-framework-disaster-riskreduction-2015-2030. Acesso em: 06 abr. 2019.

UNDRR - United Nations Office for Disaster Risk Reduction. Synthesis report on consultations on a post-2015 framework on disaster risk reduction (HFA2). Genebra: UNDRR, 2013. Disponível em: https://www.undrr.org/ publication/synthesis-report-consultations-post-2015-framework-disaster-risk-reduction-hfa2. Acesso em: 06 abr. 2019.

UNESCO - United Nations Educational, Scientific and Cultural Organization. Basic texts of the $\mathbf{1 9 7 2}$ World Heritage Convention. Paris: UNESCO, 2005. Disponível em: whc.unesco.org/documents/publi_basictexts_en.pdf.Acesso em 28 mai. 2016.

UNESCO - United Nations Educational, Scientific and Cultural Organization. Convenção para a Proteção dos Bens Culturais em caso de Conflito Armado (Convenção de Haia). Haia: UNESCO, 1954. Disponível em: https://en.unesco.org/sites/default/files/ brazil_decreto_44851_11_11_1958_por_orof.pdf.Acesso em 12 mai.2020.

UNESCO - United Nations Educational, Scientific and Cultural Organization. Convention concerning the protection of the world cultural and natural heritage. Paris: UNESCO, 1972. Disponível em: whc.unesco.org/archive/conventionen.pdf. Acesso em 28 mai. 2016.

UNESCO - United Nations Educational, Scientific and Cultural Organization. Convention on Wetlands of International Importance especially as Waterfowl Habitat. Paris: UNESCO, 1994. Disponível em: www.ramsar.org/sites/default/files/ documents/library/current_convention_text_e.pdf.Acesso em 28 mai. 2016. 
UNESCO - United Nations Educational, Scientific and Cultural Organization. Draft Outcome Document of the United Nations Conference on Housing and Sustainable Urban Development (Habitat III). New York: UNESCO, 2016. Disponível em: http://nua.unhabitat.org/uploads/DraftOutcomeDocumentofHabitatllI_en.pdf. Acesso em 28 mai. 2016.

UNESCO - United Nations Educational, Scientific and Cultural Organization. Expert meeting on Post-Conflict approaches in the Middle East, its conventions and other international (policy) initiatives in North Africa and the Middle East. Leiden: The Netherlands National Commission for UNESCO, 2012. Disponível em: www.unesco.nl/event/expertmeeting-post- conflict- approaches-middle-east. Acesso em 27 mai. 2016.

UNESCO - United Nations Educational, Scientific and Cultural Organization. Florence Declaration - Culture, Creativity and Sustainable Development. Research, Innovation, Opportunities. Third UNESCO World Forum on Culture and Cultural Industries. Florença: UNESCO, 2014. Disponível em: www.unesco.org/new/fileadmin/MULTIMEDIA/HQ/CLT/pdf/ FINAL_FlorenceDeclaration_1December_EN.pdf. Acesso em 29 mai. 2016.

UNESCO - United Nations Educational, Scientific and Cultural Organization. Recommendation on the Historic Urban Landscape. Paris: UNESCO World Heritage Centre, 2011. Disponível em:https://whc.unesco.org/uploads/activities/ documents/activity-638-98.pdf. Acesso em 12 mai. 2018.

UNESCO - United Nations Educational, Scientific and Cultural Organization. Segundo Protocolo à Convenção para a Proteção dos Bens Culturais em caso de Conflito Armado (Convenção de Haia). Haia: UNESCO, 1999. Disponível em: https:// unesdoc.unesco.org/ark:/48223/pf0000130696_fre. Acesso em 12 mai. 2020.

UNESCO - United Nations Educational, Scientific and Cultural Organization. Sustainable Development, our common task. Paris: UNESCO, 2005. Disponível em: unesdoc.unesco.org/images/0013/001393/139369e.pdf. Acesso em 28 mai. 2016.

UNESCO - United Nations Educational, Scientific and Cultural Organization. The future we want: Final document of the Rio+20 Conference. In: Proceedings of the Rio20. Rio de Janeiro: UNESCO Conference for Sustainable Development, 2012. Disponível em: https://sustainabledevelopment.un.org/content/documents/733FutureWeWant.pdf. Acesso em 28 mai. 2016.

UNESCO - United Nations Educational, Scientific and Cultural Organization. The Hangzhou Declaration - Placing Culture at the Heart of Sustainable Development Policies. Culture: key to sustainable development. Hangzhou International Congress. Hangzhou: UNESCO, 2013. Disponível em: www.unesco.org/new/fileadmin/MULTIMEDIA/HO/CLT/pdf/ 3_Hangzhou_Declaration_EN.pdf. Acesso em 29 mai. 2016.

UNESCO - United Nations Educational, Scientific and Cultural Organization. Transforming our World: The 2030 Agenda for Sustainable Development. New York: United Nations, 2015. Disponível em: https://sustainabledevelopment.un.org/ post2015/transformingourworld. Acesso em 29 mai. 2016.

UNI - Ente Italiano di Unificazione. UNI 10829:2001 - Works of Art of Historical Importance. Ambient Conditions for the Conservation. Measurement and Analysis. Milano, 2001.

UNISDR - United Nations Office for Disaster Risk Reduction. Building cities resilience to disasters: protecting cultural heritage and adapting to climate change. Veneza, 2012. Disponível em: www.unisdr.org/files/ 25027_finalvenicereport1920march.pdf. A Acesso em 27 mai. 2016.

UNISDR - United Nations Office for Disaster Risk Reduction. Economic losses from disasters set new record in 2012 : Media Release. 2013. Disponível em: www.unisdr.org/archive/31685. Acesso em 27 mai. 2016. 
UNISDR - United Nations International Strategy for Disaster Reduction. Hyogo Framework for Action 2005-2015: building the resilience of Nations and Communities to Disasters. Extract from the final report of the World Conference on Disaster Reduction. International strategy for disaster reduction. Kobe: UNISDR, 2005. Disponível em: https://www.unisdr.org/ 2005/wcdr/intergover/official-doc/L-docs/Hyogo-framework-for-action-english.pdf. Acesso em: 15 abr. 2019.

UNISDR - United Nations International Strategy for Disaster Reduction. Terminology on Disaster Risk Reduction. International strategy for disaster reduction. Genebra: UNISDR, 2009. Disponivel em: http://www.unisdr.org/we/inform/ terminology. Acesso em 15 abr. 2019.

UNOSD - United Nations Office for Sustainable Development. United Nations Conference on Environment \& Development - AGENDA 21. Rio de Janeiro: 1992. Disponível em: sustainabledevelopment.un.org/content/documents/ Agenda21.pdf. Acesso em 28 mai. 2016.

VACCA, G. et al.. Laser scanner survey to cultural heritage conservation and restoration. In: XXII ISPRS Congress International Archives of the Photogrammetry, Remote Sensing and Spatial Information Sciences, Melbourne, v. XXXIX-B5, p. 589-594,2012. Disponível em: https://www.researchgate.net/publication/ 274675078_LASER_SCANNER_SURVEY_TO_CULTURAL_HERITAGE_CONSERVATION_AND_RESTORATION.Acesso em 01 fev. 2019.

VAN DER MOST, P.; DEFIZE, P.; HAVERMANS, J.. Archives Damage Atlas - a tool for assessing damage. Metamorfoze, 2010.

VAN DER REYDEN, D.. Recent Scientific Research in Paper Conservation. Journal of the American Institute for Conservation, v. 31, n.1, a. 14, p. 117-138, 1992.

VAN DER VOORDT, D. J. M.; VAN WEGEN, H. B. R.. Arquitetura sob o olhar do usuário: programa de necessidades, projeto e avaliação de edificações. São Paulo: Editora Oficina de Textos, 2013.

VAROLI-PIAZZA, R.. Sharing Conservation Decisions. Roma: ICCROM Courses, 2007. Disponível em: https:// www.iccrom.org/sites/default/files/2018-01/iccrom_15_sharingconservdecisions-It_en.pdf. Acesso em 27 mai. 2016.

VI SEEM. Digital Cultural Heritage Software and tools. 2019. Disponível em: https://training.vi-seem.eu/index.php/ domain-specific-software-and-tools/digital-cultural-heritage-software-and-tools. Acesso em 16 jan. 2019.

VIDUKA, A.. Conservation and Finds Handling. UNESCO, 2012. Disponível em: www.unesco.org/ new/ fileadmin/ MULTIMEDIA/HQ/CLT/images/630X300/UNIT11.pdf. Acesso em 27 mai. 2016.

VILLA, S. B.. Avaliando a habitação: relações entre qualidade, projeto e avaliação pós-ocupação em apartamentos. Revista Ambiente Construído, Porto Alegre, ANTAC, v. 9, n. 2, p. 119-138, 2009.

VILLA, S. B.; ORNSTEIN, S. W. (org.). Qualidade ambiental na habitação: Avaliação Pós-Ocupação. São Paulo: Editora Oficina de Textos, 2013.

VILLA, S. B.; SARAMAGO, R. de C. P.; GARCIA, L. C.. Desenvolvimento de Metodologia de Avaliação Pós-Ocupação do Programa Minha Casa Minha Vida: aspectos funcionais, comportamentais e ambientais. Texto para discussão 2234. Rio de Janeiro: Ipea, 2016. 
WALKER, A.. Preservation Advisory Centre - Basic preservation. Londres, 2013. Disponível em: www.bl.uk/aboutus/ stratpolprog/collectioncare/publications/booklets/basic_preservation.pdf. Acesso em: 27 mai. 2016.

WATS JR., J.; KAPLAN, M.. Fire Risk Index for historic buildings. Fire Technology, v. 37, n. 2, p. 167-180, 2001. Disponível em: https://www.researchgate.net/publication/262852223_Fire_Risk_Index_for_Historic_Buildings. Acesso em: 25 out. 2020.

WEATHER SPARK. Condições meteorológicas médias de São Paulo. 2020. Disponível em: https://pt.weatherspark.com/ y/30268/Clima-caracter\%C3\%ADstico-em-São-Paulo-Brasil-durante-0-ano,. Acesso em 27 mar. 2020.

WHOLEY, J. S.; HATRY, H. P.; NEWCOMER, K. E.. Handbook of Practical Program Evaluation. San Francisco: Jossey Bass Publishers, 1994.

WORLD ECONOMIC FORUM. Building Resilience to Natural Disasters: A framework for Private Sector Engagement. WEF, 2008. Disponível em: www.unisdr.org/files/1392_DisastersRepFINCopyright.pdf. Acesso em 27 mai. 2016.

WORLD ECONOMIC FORUM. Global Risks 2014: Ninth Edition. WEF, 2014. Disponível em: https://reports.weforum.org/ global-risks-2014/. Acesso em 27 out. 2020.

WORLD ECONOMIC FORUM. How much do natural disasters cost the world? WEF, 2015. Disponível em: https:// www.weforum.org/agenda/2015/12/how-much-do-natural-disasters-cost-the-world/. Acesso em 20 jun. 2020.

WREN, D.A.. The Evolution of Management Thought. New York: Wiley, 1994.

WRIGHT, T.. The Strategic Management Process. Cascade, 2019. Disponível em: https://www.executestrategy.net/blog/ strategic-management-process/. Acesso em 25 jan. 2019.

WWF - World Wildlife Fund. Living Planet Report 2020 - Bending the curve of biodiversity loss. Gland: WWF, 2020. Disponível em: https://livingplanet.panda.org/en-us/. Acesso em: 23 out. 2020.

YILMAZ, H. M. et al.. Importance of digital close-range photogrammetry in documentation of cultural heritage. Journal of Cultural Heritage, v. 8, n. 4, p. 428- 433, 2007. Disponível em: https://www.researchgate.net/publication/ 240435687_Importance_of_digital_close-range_photogrammetry_in_documentation_of_cultural_heritage. Acesso em 20 jan. 2019.

YIN, R. K.. Estudo de Caso. Planejamento e Métodos. Porto Alegre: Bookman, 2005.

ZANELLI, J. C.; BORGES-ANDRADE, J. E.; BASTOS, A. V. B. (org.). Psicologia, organizações e trabalho no Brasil. Porto Alegre: Artmed Editora, 2014.

ZEISEL, J.. Inquiry by design: environment / behavior / neuroscience in architecture, interiors, landscape, and planning. New York: W. W. Norton, 2006.

ZUERCHER, M. Archaeological Evaluation of Pentland Historical Cemetery, Queensland, Australia. Charters Towers Regional Council \& Pentland Progress Association Inc. 2016. Disponível em: https://www.researchgate.net/publication/ 316959729_Archaeological_Evaluation_of_Pentland_Historical_Cemetery_Queensland_Australia/figures?lo=1. Acesso em: 16 jan. 2019. 


\section{GLOSSÁRIO}

Abrasão: desgaste de superfície decorrente de ação mecânica causadora de atrito. A abrasão fragiliza o material, ajudando os processos de rasgos e perdas (PAGLIONE, 2017).

Ação corrosiva: fragilização e quebra das fibras de celulose do papel, causada pelo efeito corrosivo de elementos ácidos presentes em tintas. A tinta ferrogálica é a causa mais comum de ação corrosiva em documentos e livros (PAGLIONE, 2017).

Ação educativa: procedimentos que promovem a educação no museu, tendo o acervo como centro de suas atividades, permitindo ao homem apreender, em um sentido amplo, o bem cultural, tendo em vista o desenvolvimento de uma consciência crítica e abrangente da realidade que o cerca (IBRAM, 2014).

Acervo: bens culturais, de caráter material ou imaterial, móvel ou imóvel, que compõem o campo documental de determinado museu, podendo estar ou não cadastrados na instituição. É o conjunto de objetos/ documentos que corresponde ao interesse e objetivo de preservação, pesquisa e comunicação de um museu (IBRAM, 2014).

Acervo conjunto: objetos ou itens de titularidade de um museu (ou seja, inventariados) composto por várias coleções de objetos com tipologias semelhantes (coleção de máscaras, coleção de manuscritos etc.) ou que tenham uma característica específica que os una, por exemplo, terem pertencido a um único colecionador, estarem ligados a um evento histórico específico, etc. (CCI / ICCROM, 2018).

Acessibilidade: possibilidade e condição de alcance, percepção e entendimento para utilização com segurança e autonomia de edificações, espaço, mobiliário, equipamento urbano e elementos, conforme a ABNT NBR 9.050:2015 (THOMAZONI, 2016).

Acidificação: quando o papel se torna ácido devido a fatores internos (incluindo seus elementos constituintes) e/ou externos (incluindo 0 ambiente) (DER MOST et al., 2010).

Adesão mecânica: quando partes soltas ou rasgadas de um objeto são unidas por cola (DER MOST et al., 2010).

Adesivos: produtos com capacidade de unir dois materiais, mediante a adesão química ou mecânica entre as suas superfícies (BOJANOSKI, 2018).

Aditivos: substâncias químicas adicionadas ao papel para conferir a ele determinadas características especiais (UFJF, 2020).

Agentes de deterioração: constituem em ameaças aos bens culturais, que na abordagem integrada de Conservação são definidos em 10 agentes, que representam os principais riscos: forças físicas, roubo e vandalismo, fogo, água, pragas, poluentes, luz, temperatura incorreta, umidade relativa incorreta, dissociação (BOJANOSKI, 2018).

Ameaça: indicação de perigo iminente (DORGE e JONES, 1999).

Amido (de milho ou de mandioca): pó branco, de granulação uniforme utilizado na fabricação de adesivo que é adicionado à massa de papel, durante a etapa de colagem, na proporção de 2 a 3\%, sendo sua principal função aumentar a retenção de carga mineral e dar ao papel melhores características de toque e de brilho (UFJF, 2020).

AKD (Dímero Alquil Ceteno): mistura de ácidos palmítico e esteárico, é utilizada como agente de colagem na fabricação de papéis alcalinos pois permite que os grupos hidrófobos fiquem na superfície das fibras de celulose tornando-as resistentes à penetração de líquidos polares, como água e álcool (UFJF, 2020). 
Alúmen (sulfato de alumínio): sal anidro obtido da dissolução da bauxita (óxido de alumínio hidratado) com ácido sulfúrico, solúvel em água e levemente solúvel em etanol, é usado na indústria papeleira para precipitar a cola de breu sobre as fibras do papel, normalmente adicionado no final da preparação da massa (UFJF, 2020).

Análise de riscos: processo de compreender a natureza e determinar o nível (magnitude, severidade) de um risco ou combinação de riscos, mediante a combinação das consequências e de suas probabilidades (ABNT, 2018).

Anóxia: tratamento de desinfestação e desinfecção de obras em papel contaminadas por insetos e microrganismos, realizado em câmaras ou bolsas hermeticamente fechadas e com total ausência de oxigênio (BOJANOSKI, 2018).

Área do texto: parte de uma página ou manuscrito que foi impressa ou escrita (DER MOST et al., 2010). Armazenamento: procedimento de Conservação relacionado com a organização e guarda do acervo em local e mobiliário adequados (BOJANOSKI, 2018).

Área total de armazenamento $\left(\mathrm{m}^{2}\right)$ : área bruta total para armazenamento, ou seja, as dimensões (comprimento x largura) da sala de reserva técnica (CCI / ICCROM, 2018).

Área útil de armazenamento ( $\left.\mathrm{m}^{2}\right)$ : área líquida disponível, que pode ser ocupada por unidades de armazenamento. É igual à área total menos qualquer espaço não utilizável (reservado para outras funções) (CCI / ICCROM, 2018).

Área útil da unidade de armazenamento $\left(\mathrm{m}^{2}\right)$ : área de piso ocupada por cada unidade de armazenamento, ou seja, comprimento X profundidade da unidade (CCI / ICCROM, 2018).

Arquivo: é a soma de todos os documentos arquivísticos, recebidos ou produzidos por uma pessoa, um grupo de pessoas ou uma organização (DER MOST et al., 2010).

Ataque de insetos: dano físico caracterizado por área com perda do suporte devido a ataques de insetos. Os insetos mais comuns que atacam materiais constituintes dos livros (papel, couro, cola, tecidos) são: baratas, brocas, cupins e traças (PAGLIONE, 2017).

Autenticidade: significa a soma de características substanciais, historicamente verificadas, desde o original até 0 estado atual, como resultado de um conjunto de transformações que ocorreram ao longo do tempo (The Charter of Krakow, 2000).

Avaliação de riscos: processo de comparar os resultados da análise de riscos com os critérios de risco da organização, para determinar se um risco e/ou sua magnitude é aceitável ou tolerável (ABNT, 2018).

Avaliação Pós-Ocupação (AP0): é o processo de avaliar edifícios de modo sistemático e rigoroso após sua construção e ocupação por algum tempo. Os últimos passos na evolução da APO vão na direção da Avaliação do Desempenho do Edifício (Building Performance Evaluation - BPE) e da Avaliação Universal do Projeto (Universal Design Evaluation - UDE), enfatizando uma abordagem holística e orientada ao processo (process-oriented approach), em oposição à abordagem antiga orientada ao resultado (FFC, 2001).

Bem cultural: em seu sentido amplo, entende-se por bem cultural todo testemunho do homem e seu meio apreciado em si mesmo, sem estabelecer limitações derivadas de sua propriedade, uso, antiguidade ou valor econômico. Os bens culturais podem ser divididos em três grandes categorias: naturais, materiais (tangíveis) e imateriais (IBRAM, 2014).

Benchmarks: casos de referência para as melhores práticas, na busca por aprimoramento de processos. 
Borda quebradiça: fragilidade nas regiões dos cortes do papel, geralmente acompanhada de rasgos e perdas. Dano físico causado geralmente por quebra das cadeias de celulose do papel e/ou por guarda inadequada (PAGLIONE, 2017).

Brainstorming: técnica na qual são realizados exercícios mentais com a finalidade de resolver problemas específicos, desenvolver um projeto ou melhorar uma situação existente.

Brainwriting: técnica eficaz e simples para coletar ideias inovadoras, onde um grupo de pessoas registram por escrito possíveis formas de como resolver problemas específicos, desenvolver um projeto ou melhorar uma situação existente.

Breu: produto natural, sólido e resinoso, extraído de árvores da família das pináceas, é uma importante matéria-prima para a fabricação de agente de colagem para papéis (UFJF, 2020).

Cabeceado: peça de material flexível que é costurada ou colada na parte superior e inferior da lombada antes da encadernação (DER MOST et al., 2010).

Caderno: conjunto de páginas dobradas e agrupadas para formar uma única dobra. Vários cadernos podem ser unidos para formar o miolo de um livro (DER MOST et al., 2010).

Capa solta: dissociação da capa com o miolo, geralmente causado por fatores mecânicos decorrentes de uso ou de construção da encadernação (PAGLIONE, 2017).

Carboximetilcelulose - CMC: adesivo sintético resultante de um processo de modificação da celulose (eterificação), que tem inúmeros usos na Conservação e Restauração de obras em papel, como por exemplo, adesivo, agente de reencolagem, veículo para aplicação de solventes, na remoção de intervenções anteriores, dentre outros (BOJANOSKI, 2018).

Carga: produto mineral ou orgânico, geralmente inerte, empregado para assegurar o tipo desejado de apresentação e/ou consistência. As cargas adicionadas ao papel proporcionam aumento da opacidade, da 'brancura' e da resistência mecânica deste. São substâncias inorgânicas de composição diversa, dentre as quais, atualmente, podemos citar como os mais importantes: caulim, carbonato de cálcio, sulfato de bário (UFJF, 2020).

Catálogo: também chamado de 'índice principal', 'fichário', 'índice progressivo' ou 'catálogo de fichas'. Os objetos devem ser classificados em ordem crescente de número de inventário, na mesma ordem adotada no livro de registro, e contêm o código de localização de cada objeto. Não são acessíveis ao público. Estes códigos são parte integrante de um banco de dados do acervo (CCI / ICCROM, 2018).

Celulose: polímero de carboidratos encontrada nas paredes celulares de todos os vegetais. As fibras de celulose são os principais componentes do papel (BOJANOSKI, 2018).

Classificação: sequência de operações realizadas em um museu que visam distribuir os objetos/documentos em diferentes categorias, agrupando-os de acordo com suas analogias e características comuns (IBRAM, 2014).

Código (sistema) de localização: código identificador único que conecta cada objeto a um local específico dentro de uma unidade de armazenamento (CCI / ICCROM, 2018).

Colagem: ato de adicionar cola à massa do papel, durante o processo de fabricação, o que o torna menos absorvente à água e outros líquidos. A colagem interna consiste em acrescentar à massa, antes da formação da folha, elementos de colagem (como AKD) com o objetivo de aumentar a resistência à penetração de líquidos. A colagem superficial consiste em revestir a 
folha acabada, de um ou ambos os lados, com finas camadas de cola para aumentar sua resistência à água, à abrasão, ao vinco e a resistência ao arrancamento, promover lisura, reduzir a porosidade e melhorar a printabilidade (UFJF, 2020).

Coleção: trata-se de um conjunto de objetos naturais e artificiais, reunidos por pessoas ou instituições, que perderam seu valor de uso, mantidos fora do circuito econômico, sujeitos a proteção especial em local reservado para esse fim (IBRAM, 2014).

Comissionamento: processo que assegura que os sistemas e componentes de uma edificação estejam projetados, instalados, testados, operados e mantidos de acordo com as necessidades e os requisitos operacionais.

Consequência: resultado de um evento que afeta positiva ou negativamente os objetivos da organização (Portal TCU).

Conservação: é o conjunto de medidas destinadas a conter as deteriorações de um objeto ou resguardá-lo de danos. Identificase com os trabalhos de intervenções técnicas e científicas, periódicas ou permanentes, repetidas e continuadas, aplicadas diretamente sobre uma obra ou seu entorno com o objetivo de prolongar sua vida útil e sua integridade (IBRAM, 2014).

Controle ambiental (climático): procedimentos de conservação preventiva para controlar as condições ambientais das áreas de guarda e de exposição de bens culturais, incluindo o monitoramento e a adequação da temperatura, umidade relativa, luz e exclusão de poluentes (BOJANOSKI, 2018).

Corante: toda substância natural ou sintética que se fixa uniformemente às fibras do substrato e alteram sua cor.

Corrosão: dano ocasionado no papel pela degradação das tintas ferrogálicas ou metaloácidas, identificado numa etapa inicial pela formação de halos em volta da escrita, que posteriormente tornam-se marrons e, em um estágio mais avançado, ocasionam a perda de suporte (BOJANOSKI, 2018).

Corte: dano físico causado por incisão com objeto afiado que separa as fibras do papel, deixando bordas retas. Cortes propiciam a separação e perda de área (PAGLIONE, 2017).

Costura solta ou rompida: dano físico à estrutura da encadernação na qual a linha da costura se encontra rompida ou frouxa, causado por desgaste, corte, ou características de resiliência do material da linha. Pode ocasionar perdas e deformações nas folhas (PAGLIONE, 2017).

Curadoria: designação genérica do processo de concepção, organização e montagem da exposição. Inclui todos os passos necessários à exposição de um acervo, quais sejam: conceituação, documentação e seleção do acervo, produção de textos, publicações e planejamento da disposição física dos objetos. Refere-se também ao cargo ou função exercida por aquele que é responsável por zelar pelo acervo de um museu (IBRAM, 2014).

Danos (a bens culturais): alterações e deformaç̧ões resultantes dos processos de deterioração ou de degradação dos bens culturais, podendo ter origem química, física ou biológica (BOJANOSKI, 2018).

Datalogger: equipamento eletrônico de monitoramento do ambiente, que coleta e registra dados de temperatura e umidade relativa do ar em intervalos programados de tempo (BOJANOSKI, 2018).

Delaminação: separação em camadas (lâminas) do cartão das capas (pastas) ou de papéis compostos. A delaminação é um dano físico causado por manuseio, guarda inadequada e contato com água (PAGLIONE, 2017).

Desacidificação: tratamento químico realizado com a aplicação de produtos que neutralizam a acidez do papel e inserem uma carga alcalina entre as fibras (BOJANOSKI, 2018). 
Desastre: um evento que resulta em perda, dano ou destruição significativa.Uma emergência pode se tornar um desastre se ações imediatas não forem tomadas para proteger funcionários, visitantes e as coleções (DORGE e JONES, 1999).

Descoloração de elemento sustentado: ocorre quando o pigmento do elemento sustentado (tinta, lápis, impressão etc.) sofre alguma decomposição físico-química causando esmaecimento ou alteração visual (PAGLIONE, 2017).

Descoloração do suporte: alteração de tom ou coloração do suporte, devido a mudanças nas propriedades físico-químicas do material e/ou do pigmento empregado no tingimento. Geralmente essa descoloração decorre da exposição prolongada à luz (PAGLIONE, 2017).

Desempenho: capacidade de responder às metas ou aos requisitos previamente estabelecidos (ABNT NBR ISO 9004:2010)

Design thinking: conjunto de ideias e insights para abordar problemas, relacionados a aquisições de informações, análise de conhecimento e propostas de soluções.

Dextrina: pasta translúcida, obtida a partir do amido por ação de calor, usada como substituto na colagem (UFJF, 2020).

Diagrama: esquema simplificado, cuja função é sintetizar um assunto ou processo.

Diagnóstico: observação, análise e registro para identificar o estado de conservação de um acervo como um todo (conservação preventiva) ou de um objeto específico (conservação e restauração) (BOJANOSKI, 2018).

Dobra: parte do material que se sobrepõe à outra parte de si; a dobra é um dano físico que acarreta o enfraquecimento das fibras do papel na região (PAGLIONE, 2017).

Documento: material escrito, desenhado ou impresso (DER MOST et al., 2010).

Documentação: conjunto de informações registradas sobre um bem cultural ou acervo, indicando o estado de conservação, os resultados das investigações históricas, de análises científicas e testes, os tratamentos propostos e realizados, os produtos e técnicas utilizadas, etc. (BOJANOSKI, 2018).

Emergência: um evento ou uma série de eventos não antecipados que exigem ação imediata (DORGE e JONES, 1999).

Encolagem com breu e alúmen: em 1806 os fabricantes de papel descobriram que se alúmen fosse adicionado à polpa de celulose, o papel poderia ser encolado com breu. Este processo é um dos fatores responsáveis pela acidificação do papel (DER MOST et al., 2010).

Entrevista: instrumento para avaliação da percepção do usuário através de uma conversa na qual o entrevistador faz perguntas sobre um tema previamente definido ao entrevistado. A entrevista pode ser estruturada, quando segue um roteiro rígido, semi-estruturada, quando o roteiro é o ponto de partida para uma conversa menos dirigida ou não-estruturada, quando se tem apenas os tópicos, os quais podem ser abordados livremente pelo entrevistado.

Equipamento urbano: todos os bens públicos e privados de utilidade pública, destinados à prestação de serviços necessários ao funcionamento da cidade, implantados mediante autorização do poder público, em espaços públicos e privados, conforme a ABNT NBR 9.050:2015 (THOMAZONI, 2016).

Estrutura da costura: os fios com os quais os cadernos são unidos para formar o miolo de um livro (DER MOST et al., 2010). 
Estrutura de gestão de riscos: conjunto de componentes que fornecem os fundamentos e os arranjos organizacionais para a concepção, implementação, monitoramento, análise crítica e melhoria contínua da gestão de riscos através de toda a organização (ABNT, 2018).

Escurecimento: dano caracterizado pela alteração da cor do papel, em geral resultado do acúmulo de sujidades ou pelo processo avançado de acidez (BOJANOSKI, 2018).

Esmaecimento: dano ocasionado pela alteração nos pigmentos das tintas, que resulta na perda de cor e diminuição da legibilidade da escrita nos documentos (BOJANOSKI, 2018).

Evento: um incidente ou uma ocorrência de fontes internas ou externas à organização, que podem impactar a implementação da estratégia e a realização de objetivos de modo negativo, positivo ou ambos. Eventos com impacto negativo representam riscos. Eventos com impacto positivo representam oportunidades; ocorrência ou mudança em um conjunto específico de circunstâncias, podendo consistir em alguma coisa não acontecer. A expressão 'eventos potenciais' é muitas vezes utilizada para caracterizar riscos (ABNT, 2018).

Exames visuais: métodos de exames que utilizam uma variedade de fontes e técnicas de iluminação para realizar a observação direta ou ampliada do papel em um nível superficial ou dos estratos internos e dos meios de registro da informação. Permitem identificar características de manufatura, danos e alterações existentes no documento (BOJANOSKI, 2018).

Exposição: exibição pública de acervo organizado e disposto com o objetivo de comunicar um conceito ou uma interpretação da realidade. Pode ser de caráter permanente ou temporário; fixa ou itinerante; presencial ou virtual (IBRAM, 2014).

Festo: dobra entre as páginas de um livro que permite que ele seja aberto (DER MOST et al., 2010).

Ferrugem: produto de corrosão de materiais metálicos que contenham ferro em sua composição. Geralmente causada pela presença de grampos e clips metálicos, a ferrugem corrói o papel e fragiliza a área em que se deposita (PAGLIONE, 2017).

Ficha de diagnóstico: ficha que faz parte da documentação de conservação e restauração, com a finalidade de registrar e documentar para usos futuros as características físicas, condições de conservação, resultados de testes e exames, assim como todos os procedimentos propostos e realizados em cada bem cultural (BOJANOSKI, 2018).

Fita adesiva: tiras de plástico com cola, usadas comumente para remendos de rasgos e cortes. A cola da fita adesiva provoca manchas e danifica o suporte, deixando frágil a região na qual fora aplicada (PAGLIONE, 2017).

Fluorescência: propriedade de determinados corpos de, quando expostos à luz, irradias luz eles mesmos. Mofos ativos no papel, por exemplo, podem irradiar luz em uma grande variedade de cores quando expostos a radiação UV (DER MOST et al., 2010).

Folha separada: desmembramento de um caderno ou folha do resto do miolo, causado geralmente por fragilidade do papel ou da costura que o segurava ao conjunto da encadernação (PAGLIONE, 2017).

Fonte de risco: elemento que, individualmente ou combinado, tem o potencial intrínseco para dar origem ao risco (ABNT, 2018).

Foxing: manchas arredondadas causadas no papel pela presença de pequenos depósitos metálicos, geralmente na fase de produção do papel. Podem estar em associação com fungos (PAGLIONE, 2017). 
Funções de apoio à reserva técnica: todas as funções relacionadas ao armazenamento, por exemplo, pesquisa, quarentena, documentação, preparação de acervos, etc. (CCI / ICCROM, 2018).

Fungos: observáveis através de manchas de diversas cores e formatos, os fungos causam danos a materiais orgânicos ao decompô-los, fragilizando, assim, a estrutura do objeto. Fungos ativos podem contaminar materiais vizinhos e 0 ambiente em que se encontram (PAGLIONE, 2017).

Gerenciamento de riscos: aplicação de uma arquitetura (princípios, estrutura e processo) para identificar riscos, analisar e avaliar se devem ser modificados por algum tratamento a fim de atender critérios de risco. Ao longo desse processo, comunica-se e consulta-se as partes interessadas, monitora-se e analisa-se criticamente os riscos e os controles que os modificam, a fim de assegurar que nenhum tratamento de risco adicional é requerido (ABNT, 2018).

Gestão: estruturas responsáveis pelo planejamento, execução, controle, ação, enfim, pelo manejo dos recursos e poderes colocados à disposição de órgãos e entidades para a consecução de seus objetivos, com vistas ao atendimento das necessidades e expectativas dos cidadãos e demais partes interessadas (Portal TCU).

Gestão de riscos: atividades coordenadas para dirigir e controlar uma organização no que se refere ao risco (ABNT, 2018).

Gestão estratégica: técnicas de gestão, avaliações e conjunto de ferramentas (como softwares) concebidas para ajudar organizações na tomada de decisões estratégicas de alto nível.

Gestão de facilidades (FM - Facility Management): função organizacional que integra pessoas, espaços e processos dentro de um ambiente construído com o objetivo de melhorar a qualidade de vida das pessoas e a produtividade do negócio principal (ABNT, 2020).

Gestor: pessoa que ocupa função de gestão (administração) em qualquer nível hierárquico da organização.

Governança: conjunto de políticas e processos que moldam a maneira como uma organização é dirigida, administrada, controlada e presta contas do cumprimento das suas obrigações de accountability. No setor público, a governança compreende essencialmente os mecanismos de liderança, estratégia e controle postos em prática para avaliar, direcionar e monitorar a atuação da gestão, com vistas à condução de políticas públicas e à prestação de serviços de interesse da sociedade (BRASIL, 2014).

Gramatura: é a massa, em gramas, de fibras secas presentes em um metro quadrado de papel; a massa, em g/ m², de uma folha de papel (UFJF, 2020).

Hemicelulose: substância componente das paredes dos vegetais, muito similar à celulose, porém suas estruturas moleculares são menores por possuírem menor grau de polimerização (BOJANOSKI, 2018).

Hidrólise ácida: reação química na qual ocorre a quebra das ligações das moléculas em presença de água, catalisada em meio ácido e que resulta em um processo de degradação do papel (BOJANOSKI, 2018).

Higienização: procedimento de limpeza realizado em obras, acervos ou nos ambientes de guarda de acervos para a retirada de componentes que comprometem a conservação dos bens culturais (BOJANOSKI, 2018).

Identidade: é entendida como a referência comum tanto de valores presentes gerados na esfera de uma comunidade como valores passados identificados por sua autenticidade (The Charter of Krakow, 2000). 
Identificação de riscos: processo de busca, reconhecimento e descrição de riscos; envolve a identificação das fontes de risco, os eventos, suas causas e suas consequências potenciais (ABNT, 2018), pode envolver análise de dados históricos, análises teóricas, opiniões de pessoas informadas e de especialistas, e as necessidades das partes interessadas.

Incerteza: métodos científicos são imperfeitos, portanto, os resultados esperados devem estar referenciados à probabilidade do evento ocorrer dentro de certos parâmetros, levando-se em conta acasos, imprevisibilidades e desconhecimentos, e deficiências inerentes ao método escolhido.

Indicadores-chave de desempenho: número, percentagem ou razão que mede um aspecto do desempenho na realização de objetivos estratégicos e operacionais relevantes para o negócio, relacionados aos objetivos-chave da organização, com o objetivo de comparar esta medida com metas preestabelecidas (Portal TCU).

Interdisciplinar: conjunto de disciplinas trabalhadas cooperativamente.

Intervenção anterior: marca ou vestígio de aplicação de suporte estranho ao original, geralmente de procedência ordinária, que ao envelhecer causa danos físicos e químicos, sendo necessária, muitas vezes, a sua remoção (PAGLIONE, 2017).

Instalações: elementos permanentemente fixados ao edifício ou que fazem parte da sua estrutura principal (por exemplo, sistemas hidráulicos; sistemas elétricos; iluminação; aquecimento, ventilação e ar-condicionado (AVAC); proteção contra incêndios; sistemas de segurança; etc. (CCI / ICCROM, 2018).

Instrumento de avaliação: cada uma das metodologias disponíveis para avaliação do edifício em uso ou para a coleta de dados pela perspectiva dos usuários.

Instrumento de pesquisa: obra de referência, publicada ou não, que identifica, localiza, resume, descreve ou transcreve, em diferentes graus e amplitudes, coleções, categorias e peças existentes num museu, com a finalidade de controle e de acesso ao acervo (IBRAM, 2014).

Inventário: metodologia de pesquisa que constitui o primeiro passo na atividade de conhecimento, salva-guarda e valorização dos bens culturais de um acervo, consistindo na descrição individual, padronizada e completa, para cada item e sua localização física na reserva técnica (IBRAM, 2014; CCI / ICCROM, 2018).

Irradiação por raios gama: técnica de desinfestação ou desinfecção de acervos que emprega radiações ionizantes de natureza eletromagnética de alta frequência (BOJANOSKI, 2018).

Item não pertencente ao acervo: qualquer item, objeto ou material que não foi (e nunca será) inventariado como acervo do museu. Pode incluir publicações, painéis de exposição, mobiliário de escritório, vitrines, materiais de embalagem e acondicionamento, pertences pessoais de funcionários e entulho (CCI / ICCROM, 2018).

Lignina: substância componente das paredes dos vegetais que confere rigidez às plantas. É encontrada em abundância nas madeiras, principal fonte de celulose para a fabricação do papel moderno (BOJANOSKI, 2018).

Livro: conjunto de páginas encadernadas. 
Livro de Registro: livro de capa dura com páginas progressivamente numeradas e carimbadas, que contém a descrição, 0 número de inventário e a data de entrada de todos os objetos que compõem o acervo do museu. Após sua inclusão no livro de registro, os objetos passam a oficialmente fazer parte do acervo. Essa função também pode ser exercida pelo banco de dados do acervo (CCI / ICCROM, 2018).

Livro / registro de movimentação: documento que registra quando um objeto é retirado da exposição permanente ou da reserva técnica, seja para empréstimo, estudo, digitalização, conservação, restauração ou outra atividade. Esta informação é parte integrante de um banco de dados do acervo (CCI / ICCROM, 2018).

Lombada: suporte do livro por onde as folhas estão unidas (DER MOST et al., 2010).

Madeira dura: derivada de árvores folhosas (angiospermas), principalmente do gênero eucaliptus, com a qual se obtém a polpa de fibras curtas, utilizada na fabricação de papéis para impressão e escrita (UFJF, 2020).

Madeira mole: derivada de árvores coníferas (gimnospermas), principalmente do gênero pinus, com a qual se obtém a polpa de fibras longas, utilizada na fabricação de papéis para usos especiais (UFJF, 2020).

Mancha: área do suporte de coloração ou tonalidade diferente, causada por substância que suja ou que desloca a sujeira interna do papel. Manchas podem causar danos ao papel ao inserirem substâncias de característica ácida ou catalisadoras de reações que deterioram a celulose (PAGLIONE, 2017).

Manejo integrado de pragas (IPM - Integrated Pests Management): conjunto de ações e procedimentos de conservação preventiva que utiliza primeiramente os meios não-químicos para controlar 0 ataque de pragas em acervos, como 0 controle do ambiente, das fontes de alimentação e dos pontos de entrada das pragas no prédio e o monitoramento de vestígios de pragas e das infestações ou contaminações (BOJANOSKI, 2018).

Manuscrito: um item que foi escrito à mão (DER MOST et al., 2010).

Mapa mental (mind mapping): um tipo de diagrama, voltado para a gestão de informaç̧ões, de conhecimento e de capital intelectual, para a compreensão e solução de problemas, como ferramenta de brainstorming e no auxílio da gestão estratégica de uma empresa ou negócio.

Matriz: tabela formada por linhas e colunas, cuja função é relacionar dados.

Matriz de avaliação de riscos: papel de trabalho que estrutura e sistematiza a identificação de riscos, a análise de riscos e a avaliação de riscos, incluindo a avaliação de controles internos e outras respostas a riscos, podendo incluir as decisões sobre o tratamento de riscos (Portal TCU).

Matriz de risco: matriz gráfica que exprime o conjunto de combinações de probabilidade e impacto de riscos e serve para classificar os níveis de risco (Portal TCU).

Medidas de contingência: ações previamente planejadas que devem ser executadas caso um ou mais riscos se concretizem (Portal TCU).

Metilcelulose: produto sintético resultante de um processo de modificação da celulose (eterificação), que tem inúmeros usos como, por exemplo, adesivo, agente de reencolagem e veículo para aplicação de solventes, na remoção de intervenções anteriores, dentre outros (BOJANOSKI, 2018). 
Migração ácida: observável através de manchas amareladas e de alteração de cores, ocorre quando um material ácido entra em contato direto com o papel. A acidez por sua vez despolimeriza a celulose, enfraquecendo o papel (PAGLIONE, 2017).

Miolo do livro: unidade composta por cadernos, incluindo elementos inseridos ou adicionados, que são ou serão unidos para formar um livro (DER MOST et al., 2010).

Mobiliário (armazenamento): elementos móveis utilizados para guardar acervos, tais como estantes, armários, gaveteiros, trainéis, etc. (CCI / ICCROM, 2018).

Mofo: colônia de fungos filamentosos, capazes de decompor a matéria orgânica, com aparência algodonosa ou aveludada.

Monitoramento: verificação, supervisão, observação crítica ou identificação da situação, executadas de forma contínua, a fim de identificar mudanças em relação ao nível de desempenho requerido ou esperado. Monitoramento pode ser aplicado a riscos, a controles, à estrutura de gestão de riscos e ao processo de gestão de riscos (Portal TCU).

Monumento: é uma entidade identificada como de valor e formadora de uma base para a memória. Nele a memória reconhece aspectos que são pertinentes a ações e pensamentos humanos, associados com a linha do tempo histórica. Ele pode ainda estar ao nosso alcance, mesmo que não tenha sido interpretado (The Charter of Krakow, 2000).

Morfologia: estudo da forma e da estrutura de organismos. Morfologia das fibras é o estudo se sua estrutura química (DER MOST et al., 2010).

Multidisciplinar: conjunto de disciplinas trabalhadas simultaneamente.

Musealização: uma das formas de preservação do patrimônio cultural, realizada pelo museu. Constitui a ação, orientada por determinados critérios e valores, de recolhimento, conservação e difusão de objetos como testemunhos do homem e do seu meio. Processo que pressupõe a atribuição de significado aos artefatos, capaz de conferir-lhes um valor documental ou representacional (IBRAM, 2014).

Museografia [Museologia aplicada]: campo do conhecimento responsável pela execução dos projetos museológicos por meio de diferentes recursos - planejamento da disposição de objetos, vitrines, suportes expositivos, legendas e sistemas de iluminação, segurança, conservação e circulação (IBRAM, 2014).

Museologia: disciplina que tem por objeto o estudo de uma relação específica do homem com a realidade, ou seja, do homem/sujeito que conhece com os objetos/testemunhos da realidade, no espaço/cenário museu, que pode ser institucionalizado ou não (IBRAM, 2014).

Museu: consideram-se museus as instituições sem fim lucrativo que conservam, investigam, interpretam, comunicam e expõem para fins de conservação, estudo, pesquisa, educação, contemplação e turismo, conjuntos e coleções de valor histórico, artístico, científico, técnico ou de qualquer outra natureza cultural, abertas ao público, a serviço da sociedade e seu desenvolvimento (IBRAM, 2014).

Nervuras: faixas elevadas sobre a encadernação da lombada que atravessam a lombada de um livro (DER MOST et al., 2010).

Nível de risco: magnitude de um risco ou combinação de riscos, expressa em termos da combinação das consequências [impacto] e de suas probabilidades (ABNT, 2018). 
Número de inventário: identificação única e exclusiva atribuída a um objeto do acervo. É o elemento que vincula o objeto físico a toda documentação relativa a ele (CCI / ICCROM, 2018).

Objeto: cada elemento que integra formalmente o acervo de um museu, biblioteca ou arquivo, e que forma uma coleção (DER MOST et al., 2010; CCI / ICCROM, 2018).

Objeto museológico: objeto retirado do contexto para o qual foi originalmente concebido e que, incorporando novas funções, transformando-se em signo pelo processo de musealização, tem seu potencial de representação ampliado (IBRAM, 2014).

Objetos unidos: contém um conjunto de documentos ou seções individuais que originalmente estavam separados mas foram unidos ou costurados no formato de um livro (DER MOST et al., 2010).

Ondulação: deformação causada pela interferência da umidade nas fibras do papel que secou de modo não uniforme. São mais pronunciadas quando um suporte é aderido a outro com sentido de fibra diferente (PAGLIONE, 2017).

Oxidação: reação de um elemento com oxigênio (DER MOST et al., 2010).

Papel: folha formada, seca e acabada, de uma suspensão de fibras vegetais, as quais foram desintegradas, refinadas e depuradas e tiveram ou não a adição de outros ingredientes, para dar ao produto final, características de utilização.

Papel de trapo: papel fabricado artesanalmente no mundo Ocidental até meados do século XIX, cuja fonte de celulose eram os tecidos de algodão, cânhamo e linho (BOJANOSKI, 2018).

Papel japonês: papel de fabricação japonesa, tradicionalmente feito a partir das fibras de arbustos (kozo, mitsumata e gampi), muito usado na conservação e restauração de obras em papel por suas características e qualidades, como a transparência e resistência (BOJANOSKI, 2018).

Papel mata-borrão: papel com pouca encolagem e com alta capacidade de absorção de líquidos (BOJANOSKI, 2018).

Papel moderno: papel fabricado por processos industriais a partir de meados do século XIX, cuja fonte de celulose é a madeira (BOJANOSKI, 2018).

- ácido: papel fabricado em meio ácido ( $\mathrm{pH}$ de 4,0 a 5,0), com adição de cola à base de breu, sulfato de alumínio e, geralmente, caulim como carga mineral.

- alcalino: papel fabricado em meio alcalino (pH superior a 7), com resinas sintéticas como ASA (anidrido de alquil succinico), AKD (dímero de alquil ceteno) e carbonato de cálcio como carga, apresentando elevada permanência, opacidade e brancura (UFJF, 2020).

Papel off-set: papel para impressão, com ou sem revestimento, fabricado com pasta química branqueada, contendo carga mineral entre $10 \%$ e $15 \%$, boa colagem interna e superficial, produzido nas gramaturas de $60 \mathrm{~g} / \mathrm{m}^{2}$ a $150 \mathrm{~g} / \mathrm{m}^{2} \mathrm{com}$ requisitos específicos para o processo de impressão off-set (UFJF, 2020).

Papel vegetal: papel que se tornou translúcido por calandragem ou impregnação e é frequentemente usado para desenhos (DER MOST et al., 2010). 
Papiro: suporte para a escrita desenvolvido no Egito por volta de 2.500 a.E.C.. Era confeccionado a partir dos talos da Cyperus papyrus. Eles eram descascados até que restasse apenas o miolo esbranquiçado e poroso, o qual era, então, cortado em finas lâminas, mergulhadas em água (especulasse sobre a adição de lama do Nilo ou de vinagre) por 3 a 6 dias, para se remover parte do açúcar e criar uma consistência colante. Para confeccionar uma folha, as lâminas eram entrelaçadas na horizontal e na vertical, sobrepostas umas às outras. A seguir, este trançado era disposto entre dois pedaços de couro, prensado e colocado sob um peso de pedra, onde era mantido por alguns dias, até secar. Ao final, tinha-se uma folha com fibras uniformemente distribuídas, de coloração amarelada. Para um melhor acabamento, a folha ainda podia ser alisada com uma pedra pome. 0 papiro não é um material absorvente, a tinta fica depositada nas irregularidades da superfície, onde se seca. Ao final, a folha era enrolada em uma vareta de madeira ou marfim para criar um rolo com o registro pictórico ou escrito. As características positivas do papiro são: rápido e fácil de ser feito, a escrita pode ser apagada e versatilidade para transporte. Porém, seus aspectos negativos são: permite a escrita em apenas uma das faces, é suscetível a pragas, não suporta umidade elevada e não resiste à pressão, podendo facilmente se quebrar.

Partido arquitetônico: na arquitetura, é o nome que se dá à consequência formal de uma série de determinantes tais como o programa do edifício, a conformação topográfica do terreno, a orientação, o sistema estrutural adotado, as condições locais, as condições das posturas que regulamentam as construções e, sobretudo, a intenção plástica do arquiteto e nas soluções formais as mais diferenciadas; percebe-se que antes de tudo, há a predominância da intenção plástica, quase sempre eminentemente personalista. Diz- se partido horizontal aquele no qual predominam as circulações horizontais, ao contrário do partido vertical, que recorre aos sistemas mecânicos de circulação vertical, como nos casos dos monoblocos, edifícios onde foi preferida a superposição das funções (CORONA e LEMOS, 1989; apud: THOMAZONI, 2016).

Pastas: objetos planos mais ou menos rígidos (usualmente feitos de madeira) que são aplicados na parte da frente e de trás do miolo do texto para protegê-lo e que são presos à lombada (DER MOST et al., 2010).

Pasta destacada: dano físico que ocorre quando uma das pastas da capa se desprende da lombada que permanece atrelada à encadernação. Geralmente é causada por um desgaste físico do suporte (PAGLIONE, 2017).

Patrimônio: é este complexo trabalho humano no qual uma comunidade reconhece seus valores particulares e específicos e com os quais se identifica. Identificação e especificação do patrimônio é, portanto, um processo relacionado à escolha de valores (The Charter of Krakow, 2000).

Patrimônio cultural: entende-se por patrimônio cultural toda produção humana, de ordem emocional, intelectual, material e imaterial, independente de sua origem, época, natureza ou aspecto formal, que propicie o conhecimento e a consciência do homem sobre si mesmo e sobre o mundo que o rodeia (IBRAM, 2014).

Pequenos reparos: procedimentos de conservação, com o objetivo de resolver danos iniciais e manter 0 acervo em uso, como, por exemplo, colar um rasgo ou costurar um caderno solto de um livro (BOJANOSKI, 2018).

Perfil do dano: tipo ou grau de dano a um documento (DER MOST et al., 2010). 
Pergaminho: suporte de escrita produzido a partir da pele de animais, que passa por um processo alcalino de limpeza, estiramento e secagem. Foi o principal suporte de escrita na antiguidade ocidental, especialmente na Idade Média, convivendo em um período com o papiro e sendo posteriormente substituído pelo papel. Também é encontrado nos acervos como revestimento das encadernações (BOJANOSKI, 2018).

Perigo: fenômeno natural ou humano que pode ocorrer na ou próximo a uma instituição e pode ameaçar a vida humana e seu bem-estar ou causar danos físicos e perdas econômicas (DORGE e JONES, 1999).

Pigmento: substância que altera a cor de um material por refletir e absorver seletivamente certos comprimentos de onda.

Plano de gestão de riscos: esquema dentro da estrutura de gestão de riscos que especifica a abordagem, os componentes de gestão e os recursos a serem aplicados para gerenciar riscos, incluindo, tipicamente, procedimentos, práticas, atribuição de responsabilidades, sequência e cronologia das atividades (ABNT, 2018). Um manual ou complemento à política de gestão de riscos que pode ser aplicado a um determinado produto, processo e projeto, em parte ou em toda a organização (ABNT, 2018).

Plano de preparação de emergência e resposta (ou Plano de Emergência, ou '0 Plano'): identifica as vulnerabilidades da instituição; indica como prevenir ou mitigar potenciais efeitos; descreve as respostas da equipe; e fornece um projeto para a recuperação. 0 plano pode, se necessário, ser resumido em um manual para planejamento de emergência (DORGE e JONES, 1999).

Plano de recuperação: parte de um plano de emergência, ele destaca os passos que devem ser tomados para se retornar às operações normais (DORGE e JONES, 1999).

Plano de resposta: parte de um plano de emergência, inclui procedimentos que devem ser tomados como resposta a uma emergência (DORGE e JONES, 1999).

Polímero: espécie química com grande massa molar, formada pela união (polimerização) de unidades estruturais menores, os monômeros (UFJF, 2020).

Política de aquisição de acervo: diretrizes definidas pelo museu, visando da constituição à dinamização de acervos, através do recolhimento e da incorporação sistemática de objetos, que é balizada pelo perfil identitário daquele museu (IBRAM, 2014).

Política de gestão de riscos: documento que contém a declaração das intenções e diretrizes gerais relacionadas à gestão de riscos e estabelece claramente os objetivos e o comprometimento da organização em relação à gestão de riscos. Não se trata de uma declaração de propósitos genérica, mas de um documento que, além de declarar os princípios, explica porque a gestão de riscos é adotada, o que se pretende com ela, onde, como e quando ela é aplicada, quem são os responsáveis em todos os níveis, dentre outros aspectos (ABNT, 2018).

Poluentes: agente de deterioração relacionado às substâncias presentes nos ambientes e que apresentam efeitos adversos aos bens culturais. Podem ser de origem natural ou de atividades humana e apresentarem-se como gases, aerossóis, líquidos ou sólidos. Os poluentes podem ser transportados pelo ar, transferido entre os materiais que estejam em contato, existir como parte do material que compõe o objeto, ou ainda podem se formar durante reações químicas intrínsecas (BOJANOSKI, 2018). 
Pragas: agente de deterioração relacionado aos organismos vivos capazes de deformar, danificar e destruir os bens culturais. Os maiores riscos, em geral, estão associados a algumas espécies de microrganismos, de insetos e roedores. No entanto, em algumas situações específicas, outras espécies, como morcegos, aves, dentre outros, também podem ocasionar problemas aos acervos (BOJANOSKI, 2018).

Preparação: atividades que preparam e equipam os funcionários para lidar com emergências como procedimentos de evacuação, informações dos contatos atualizados e estoque de suprimentos (DORGE e JONES, 1999).

Preservação: são as medidas necessárias para se proteger um bem cultural do risco de perda. 0 termo preservação está vinculado à ideia de "ver antecipadamente" o perigo de destruição (IBRAM, 2014).

Prevenção: atividades, como a eliminação de perigos, cujo objetivo é prevenir que uma emergência ocorra e reduzir danos a pessoas, coleções e propriedades no caso de emergências inevitáveis (DORGE e JONES, 1999).

Procedimentos de emergência: descrição concisa e passo-a-passo de qual deve ser a primeira resposta de cada membro da equipe no caso de ocorrer uma emergência - normalmente publicado na forma de um folheto (DORGE e JONES, 1999).

Processo: conjunto de atividades inter-relacionadas ou interativas que transformam insumos (entradas) em produtos/ serviços (saídas) com valor agregado. Processos são geralmente planejados e realizados de maneira contínua para agregar valor na geração de produtos e serviços. Processos podem ser agrupados em macroprocessos e subdivididos em subprocessos (BRASIL, 2011).

Processo de avaliação de riscos: processo global representado pelo conjunto de métodos e técnicas que possibilitam a identificação de riscos, a análise de riscos e a avaliação de riscos que possam impactar os objetivos de organizações, programas, projetos e atividades. Envolve a identificação das fontes de risco, dos eventos e de sua probabilidade de ocorrência, de suas causas e suas consequências potenciais, das áreas de impacto, das circunstâncias envolvidas, inclusive aquelas relativas a cenários alternativos (ABNT, 2018).

Processos de degradação: processos que ocasionam alterações e destruição dos bens culturais, afetando a natureza dos seus materiais constituintes, relacionados a fatores químicos, biológicos, térmicos etc., a partir de uma ou múltiplas causas (BOJANOSKI, 2018).

Processo de gestão de riscos: aplicação sistemática de políticas, procedimentos e práticas de gestão em atividades de comunicação, consulta, estabelecimento do contexto, e na identificação, análise, avaliação, tratamento, monitoramento e análise crítica de riscos (ABNT, 2018). Sinônimo de gerenciamento de riscos.

Processos de governança: os processos que integram os mecanismos de liderança, estratégia e controle e que permitem aos responsáveis pela governança a avaliar, direcionar e monitorar a atuação da gestão (BRASIL, 2014).

Processo sulfato (kraft): método de obtenção de polpa de celulose por digestão de cavacos de madeira num licor alcalino composto de soda cáustica e sulfato de sódio (UFJ, 2020).

Processo sulfito: método de obtenção de polpa de celulose por digestão de cavacos de madeira num licor ácido composto de ácido sulfuroso e um sal, geralmente bissulfito de cálcio (UFJF, 2020). 
Programa de preparação e resposta a emergências: um programa sistemático e multidepartamental que guia a equipe no processo de preparação para emergências e leva ao desenvolvimento e à manutenção de um plano de emergência efetivo (DORGE e JONES, 1999).

Projeto arquitetônico: atividade técnica de concepção de uma obra arquitetônica. Está subdividida em:

a. Pré-projeto: programa de necessidades e estudo de viabilidade;

b. Estudos preliminares: definição das ideias projetuais;

c. Anteprojeto: concepção e representação das informações necessárias para a compreensão do projeto;

d. Projeto: concepção e representação das informaç̧̃̃es necessárias para a execução do projeto; projeto legal; projeto executivo; coordenação e compatibilização de projetos;

e. As-built: representação das alterações durante e após a obra.

Projeto de restauração: resulta de escolhas da política de conservação e é o processo pelo qual a conservação do patrimônio edificado e da paisagem é alcançada (The Charter of Krakow, 2000).

Qualidade: medida de atendimento a expectativas, dada por um conjunto de características intrínsecas (ABNT NBR ISO 9001:2015).

Queimadura: dano físico produzido por fogo ou calor excessivo. Muitas vezes acompanhada por danos ocasionados por água, como manchas e fungos (PAGLIONE, 2017).

Rasgo: dano físico onde as fibras do papel são rompidas for uma força física aplicada, deixando bordas irregulares (PAGLIONE, 2017).

Recuperação: ações tomadas após uma emergência para que as operações voltem ao normal. Dependendo do tipo e da extensão da emergência, este pode ser um processo de longa duração (DORGE e JONES, 1999).

Red rot: Deterioração ácida do couro curtido em tanino, que se desfaz em um pó de coloração que varia entre o laranja claro e o castanho (PAGLIONE, 2017).

Reserva técnica: espaço físico destinado ao armazenamento dos itens do acervo de um museu quando estas não estão em exposição. A guarda de um acervo demanda uma reserva técnica com condições físicas adequadas, condições climáticas estáveis e condições de segurança apropriadas à conservação das obras (IBRAM, 2014; CCI / ICCROM, 2018).

Responsabilização (accountability): responsabilidade de uma organização ou indivíduo sobre suas decisões e atividades e prestação de contas a seus órgãos de governança, autoridades legais e, de modo mais amplo, às demais partes interessadas no que se refere a essas decisões e atividades (ABNT, 2010).

Resposta: atividades que fornecem cuidado temporário e alívio às vítimas de emergências e previne situações evitáveis e danos ao patrimônio (DORGE e JONES, 1999).

Restauração: é uma operação direcionada ao patrimônio tangível, com o objetivo de conservar sua autenticidade e sua apropriação pela comunidade (The Charter of Krakow, 2000).

Reversão de alvura ou reversão de cor: perda de alvura ou amarelecimento do papel com o tempo por processos naturais ou de degradação das fibras (UFF, 2020). 
Risco: possibilidade de um evento ocorrer e afetar adversamente a realização de objetivos; possibilidade de algo acontecer e ter impacto nos objetivos, sendo medido em termos de consequências e probabilidades (BRASIL, 2010); efeito da incerteza nos objetivos (ABNT, 2018). Possibilidade de ferimentos ou perda de vida ou de danos ao patrimônio por perigo(s) identificado(s) (DORGE e JONES, 1999).

Rolo: folhas de papiro ou pergaminho unidas umas as outras e enroladas em torno de uma vareta de madeira ou marfim.

Ruga: caracterizado pelo franzido no papel, é um dano físico causado por forças mecânicas como manuseio, acondicionamento ou choque (PAGLIONE, 2017).

Sangramento de tinta: mancha decorrente do contato entre a tinta e um solvente causando uma aparência turva nas bordas das linhas (PAGLIONE, 2017).

Sistema de documentação: o sistema de documentação de um objeto é composto por cinco partes essenciais: número de inventário; livro de registro; código de localização; catálogo; registro de movimentação. Todos esses elementos estão interligados e têm funções específicas. Algumas dessas funções podem fazer parte de um banco de dados do acervo (CCI / ICCROM, 2018).

Sujidade: depósitos superficiais ou penetrantes de sujeiras (poeira, restos de comida, borracha, excrementos de insetos etc.). Sujidades atraem insetos, fungos e podem acidificar a região em que se depositam (PAGLIONE, 2017).

Superfície de armazenamento disponível $\left(\mathrm{m}^{2}\right)$ : espaço disponível em estantes, trainéis, gavetas, etc. que pode ser efetivamente utilizado para armazenar acervos (CCI / ICCROM, 2018).

Suporte: é o material físico no qual a confecção da obra irá se desenvolver, e onde a informação é registrada, como, por exemplo, o papel, a argila, a tela e a madeira. No caso das pinturas de cavalete, o suporte é a tela, tecido que pode ser de linho ou algodão, onde a camada pictórica ou a pintura é fixada (IBRAM, 2014).

Suporte da costura: elemento colocado ao longo da lombada e incorporado à estrutura da costura, formando uma conexão entre o miolo e a encadernação (DER MOST et al., 2010).

Taxa de ocupação da altura útil (\%): proporção da altura útil da sala ocupada por unidades de armazenamento. Indica quanto do espaço vertical disponível está sendo utilizado, ou seja, é a altura das unidades de armazenamento dividida pela altura útil da sala (CCI / ICCROM, 2018).

Taxa de ocupação do piso por unidades de armazenamento (\%): proporção da área total de piso da reserva técnica ocupada pelas unidades de armazenamento (CCI / ICCROM, 2018).

Taxa de ocupação da reserva técnica (\%): proporção do volume total disponível para armazenamento em uso pelo acervo. É calculada multiplicando-se: ocupação média por unidade de armazenamento $\mathrm{X}$ altura útil de armazenamento $\mathrm{X}$ área útil de armazenamento (CCI / ICCROM, 2018).

Taxa de ocupação da unidade de armazenamento (\%): proporção do espaço total disponível em uso pelo acervo, para cada unidade de armazenamento (CCI / ICCROM, 2018). 
Taxa de ocupação máxima do piso por tipo de unidade de armazenamento (\%): fração da área de piso que pode ser utilizada com segurança para instalar unidades de armazenamento, levando em consideração o espaço necessário para acessar e movimentar 0 acervo (CCI / ICCROM, 2018).

Tinta ferrogálica: tinta de escrita composta basicamente por sulfato de ferro (vitríolo), taninos, goma arábica e água. Conhecida desde a Antiguidade, a tinta ferrogálica foi muito usada na Idade Média em substituição às tintas à base de carbono. É encontrada até meados do século XX, sendo muito comum em textos manuscritos, mas também foi popular entre artista que a utilizavam em desenhos. 0 processo de degradação da tinta ferrogálica, definido como corrosão, é uma das principais causas de danos aos documentos em arquivos. Este processo caracteriza-se inicialmente pela formação de halos em torno da escrita e depois, na migração da tinta para o verso da página e páginas vizinhas. Em estado mais avançado, resulta no enfraquecimento e perda total do suporte nas áreas da escrita. Apesar dos termos tinta ferrogálica e tinta metaloácida serem usadas como sinônimos entre os profissionais, existem diferenças entre eles. A tinta ferrogálica tem na sua composição 0 sulfato de ferro. Contudo, vários outros metais foram usados nas receitas deste tipo de tinta. Portanto, 0 termo tinta metaloácida é um termo mais genérico que inclui todas as tintas com as características indicadas na definição. A identificação dos metais que compõem a tinta pode ser realizada com testes químicos (BOJANOSKI, 2018).

Transdisciplinar: conjunto de disciplinas trabalhadas complementarmente.

Unidade de armazenamento: cada peça individual do mobiliário para armazenamento, por exemplo, uma estante, um armário, um gaveteiro, um trainel vertical de dois lados, um trainel fixo, etc. (CCI / ICCROM, 2018).

Velino: pele de bezerro, ovelha ou cabra natimorto. É extremamente liso e macio e, por isso, utilizado nos manuscritos de mais alta qualidade.

Vinco: deformação decorrente da dobra e que fragiliza o papel. São áreas mais propensas a rasgos e perdas de material (PAGLIONE, 2017).

Visita técnica: instrumento utilizado por especialista para avaliação de aspectos construtivos, ambientais, de uso e ocupação, dentro outros, mediante a ida programada a um edifício tendo em vista um objetivo previamente definido.

Volume: conjunto de folhas ou cadernos unidos no formato de um livro (DER MOST et al., 2010). Vulnerabilidade: a extensão da área (região geográfica, comunidade, serviços, coleções e estruturas) que pode ser danificada ou atingida pelo impacto de um perigo (DORGE e JONES, 1999).

Walkthrough: instrumento de avaliação do espaço físico de uma edificação por um especialista no qual se percorre um trajeto previamente definido, com um objetivo estabelecido e, frequentemente, acompanhado por uma pessoa-chave da instituição.

Zona perdida: dano físico que resulta de um corte ou rasgo, cuja zona separada não exista mais ou não possa ser localizada (PAGLIONE, 2017).

Zona separada: dano físico que ocorre quando um material (por exemplo, uma folha de papel) é cortado ou rasgado, todavia podendo ter suas partes localizadas e discriminadas (PAGLIONE, 2017). 


\section{APÊNDICES}

A - Aprovação da pesquisa junto ao CEP

\section{USP - ESCOLA DE ARTES, CIÊNCIAS E HUMANIDADES DA UNIVERSIDADE DE SÃO}

\section{PARECER CONSUBSTANCIADO DO CEP}

\section{DADOS DO PROJETO DE PESQUISA}

Título da Pesquisa: Princípios ambientais para a gestão de reservas de papel em edifícios históricos na região dos trópicos

Pesquisador: JULIANA BECHARA SAFT

Área Temática:

Versão: 2

CAAE: 02912118.2 .0000 .5390

Instituição Proponente: UNIVERSIDADE DE SAO PAULO

Patrocinador Principal: Financiamento Próprio

\section{DADOS DO PARECER}

Número do Parecer: 3.109.743

\section{Apresentação do Projeto:}

A qualidade dos ambientes de guarda de acervos culturais, como as reservas técnicas, é, por um lado, fundamental para a preservação, pelo maior tempo possível, dos objetos sob a guarda de museus, centros culturais, bibliotecas e arquivos e, por outro lado, passível de fragilidades, por falhas no conhecimento técnico e nos recursos disponíveis. Soma-se a isto o fato de que a maioria das instituições culturais brasileiras estão sediadas em edifícios históricos, muitas vezes eles mesmos bens imóveis do acervo, porém pouco adaptados ao um novo uso como equipamento cultural. O sistema multimétodos de Avaliação Pós-Ocupação (APO), através de instrumentos como visitas técnicas, análise de dados ambientais e entrevistas com pessoas-chave, permite que se alcance uma melhor compreensão do desempenho dos ambientes avaliados tanto para os usuários quanto para o acervo, possibilitando a identificação dos riscos e a proposição de recomendações para uma gestão mais eficiente destes espaços, tanto do ponto de vista da manutenção preventiva do ambiente físico, quanto das políticas de proteção e de conservação preventiva do acervo móvel.

\section{Objetivo da Pesquisa:}

Objetivo Primário:

O objetivo primário desta pesquisa é identificar as principais inadequações de ambientes de guarda de objetos culturais com suporte em papel localizados em edifícios históricos na cidade de

Endereço: Av. Arlindo Béttio, $n^{\circ} 1000$

Bairro: Ermelino Matarazzo

UF: SP Município: SAO PAULO

CEP: $03.828-000$

Telefone: (11)3091-1046

E-mail: cep-each@usp.br 


\section{USP - ESCOLA DE ARTES, CIÊNCIAS E HUMANIDADES DA UNIVERSIDADE DE SÃO}

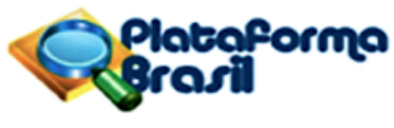

Continuaçāo do Parecer: 3.109.743

São Paulo, suas causas físicas e operacionais, as consequências e os riscos associados para a conservação preventiva dos acervos e, por fim, propor ações de gestão das reservas técnicas que correlacionem métodos eficientes para monitoramento das condições ambientais e do estado de conservação das obras, manutenção preventiva do espaço edificado e seus equipamentos, análises sistemáticas da eficiência das medidas adotadas e treinamentos simulados para eventuais situações de emergência.

\section{Avaliação dos Riscos e Benefícios:}

Riscos:

O risco é mínimo e as questões são de caráter acadêmico e técnico. Se existir qualquer tipo de desconforto ao entrevistado em relação ao tempo previsto para a realização de cada entrevista, esta será interrompida.

Benefícios:

Esta pesquisa tem como principais benefícios potenciais:

1. ampliação do conhecimento das características físicas e funcionais de reservas técnicas para bens culturais com suporte em papel localizadas em edifícios históricos na cidade de São Paulo, suas necessidades, seus pontos fortes e fracos;

2. proposição de um método que possa ser implantado por instituições culturais brasileiras para a gestão da qualidade ambiental de reservas técnicas, com a diminuição de riscos ao patrimônio imóvel e móvel e a mitigação de possíveis danos a estes patrimônios;

3. aprimoramento do sistema multi-métodos de Avaliação Pós-Ocupação aplicado a instituições culturais brasileiras; e

4. contribuição à área do conhecimento que estuda a conservação preventiva de bens culturais móveis e a manutenção preventiva do patrimônio edificado.

\section{Comentários e Considerações sobre a Pesquisa:}

Pesquisa de interesse para a preservação de materiais históricos, bem como da gestão ambiental patrimonial.

Considerações sobre os Termos de apresentação obrigatória:

Todos os termos foram apresentados.

Recomendações:

Não há recomendações.

Conclusões ou Pendências e Lista de Inadequações:

Sem pendências. Protocolo aprovado.

Endereço: Av. Arlindo Béttio, $n^{\circ} 1000$

Bairro: Ermelino Matarazzo

UF: SP Município: SAO PAULO

CEP: $03.828-000$

Telefone: (11)3091-1046

E-mail: cep-each@usp.br 


\section{USP - ESCOLA DE ARTES, CIÊNCIAS E HUMANIDADES DA UNIVERSIDADE DE SÃO}

Continuação do Parecer: 3.109 .743

\section{Considerações Finais a critério do CEP:}

Este parecer foi elaborado baseado nos documentos abaixo relacionados:

\begin{tabular}{|c|c|c|c|c|}
\hline Tipo Documento & Arquivo & Postagem & Autor & Situação \\
\hline $\begin{array}{l}\text { Informações Básicas } \\
\text { do Projeto }\end{array}$ & $\begin{array}{l}\text { PB_INFORMAÇŌES_BÁSICAS_DO_P } \\
\text { ROJETO_1211254.pdf }\end{array}$ & $\begin{array}{l}03 / 01 / 2019 \\
11: 24: 22\end{array}$ & & Aceito \\
\hline Outros & JSAFT_AUTORIZACAO_02.pdf & $\begin{array}{l}03 / 01 / 2019 \\
11: 23: 45\end{array}$ & $\begin{array}{l}\text { JULIANA BECHARA } \\
\text { SAFT }\end{array}$ & Aceito \\
\hline $\begin{array}{l}\text { Projeto Detalhado / } \\
\text { Brochura } \\
\text { Investigador }\end{array}$ & $\begin{array}{l}\text { JSAFT_PROJETO_DETALHADO_02.pd } \\
\mathbf{f}\end{array}$ & $\begin{array}{l}03 / 01 / 2019 \\
11: 22: 23\end{array}$ & $\begin{array}{l}\text { JULIANA BECHARA } \\
\text { SAFT }\end{array}$ & Aceito \\
\hline $\begin{array}{l}\text { TCLE / Termos de } \\
\text { Assentimento / } \\
\text { Justificativa de } \\
\text { Ausência }\end{array}$ & JSAFT_TCLE_02.pdf & $\begin{array}{l}03 / 01 / 2019 \\
11: 20: 11\end{array}$ & $\begin{array}{l}\text { JULIANA BECHARA } \\
\text { SAFT }\end{array}$ & Aceito \\
\hline Outros & JSAFT_AUTORIZACAO.pdf & $\begin{array}{c}11 / 11 / 2018 \\
07: 42: 23\end{array}$ & $\begin{array}{l}\text { JULIANA BECHARA } \\
\text { SAFT }\end{array}$ & Aceito \\
\hline Outros & JSAFT_CARTA.pdf & $\begin{array}{l}02 / 11 / 2018 \\
10: 08: 31\end{array}$ & $\begin{array}{l}\text { JULIANA BECHARA } \\
\text { SAFT }\end{array}$ & Aceito \\
\hline Outros & JSAFT_ROTEIRO_03.pdf & $\begin{array}{l}11 / 10 / 2018 \\
07: 13: 46\end{array}$ & $\begin{array}{l}\text { JULIANA BECHARA } \\
\text { SAFT }\end{array}$ & Aceito \\
\hline Outros & JSAFT_ROTEIRO_02.pdf & $\begin{array}{c}11 / 10 / 2018 \\
07: 13: 03\end{array}$ & $\begin{array}{l}\text { JULIANA BECHARA } \\
\text { SAFT }\end{array}$ & Aceito \\
\hline Outros & JSAFT_ROTEIRO_01.pdf & $\begin{array}{l}11 / 10 / 2018 \\
07: 12: 39\end{array}$ & $\begin{array}{l}\text { JULIANA BECHARA } \\
\text { SAFT }\end{array}$ & Aceito \\
\hline $\begin{array}{l}\text { TCLE / Termos de } \\
\text { Assentimento / } \\
\text { Justificativa de } \\
\text { Ausência }\end{array}$ & JSAFT_TCLE.pdf & $\begin{array}{l}\text { 11/10/2018 } \\
07: 09: 59\end{array}$ & $\begin{array}{l}\text { JULIANA BECHARA } \\
\text { SAFT }\end{array}$ & Aceito \\
\hline $\begin{array}{l}\text { Projeto Detalhado / } \\
\text { Brochura } \\
\text { Investigador }\end{array}$ & JSAFT_PROJETO_DETALHADO.pdf & $\begin{array}{c}\text { 11/10/2018 } \\
07: 09: 39\end{array}$ & $\begin{array}{l}\text { JULIANA BECHARA } \\
\text { SAFT }\end{array}$ & Aceito \\
\hline Folha de Rosto & JSAFT_FolhaDeRosto.pdf & $\begin{array}{c}11 / 10 / 2018 \\
07: 08: 44\end{array}$ & $\begin{array}{l}\text { JULIANA BECHARA } \\
\text { SAFT }\end{array}$ & Aceito \\
\hline
\end{tabular}

\section{Situação do Parecer:}

Aprovado

Necessita Apreciação da CONEP:

Não

SAO PAULO, 09 de Janeiro de 2019

Assinado por:

Rosa Yuka Sato Chubaci

(Coordenador(a))

Endereço: Av. Arlindo Béttio, $\mathrm{n}^{\circ} 1000$

Bairro: Ermelino Matarazzo

CEP: $03.828-000$

UF: SP

Município: SAO PAULO

Telefone: (11)3091-1046

E-mail: cep-each@usp.br 


\section{SOLICITAÇÃO DE AUTORIZAÇÃO}

Ao Arquivo Histórico Municipal

Prezad

Eu, Juliana Bechara Saft, arquiteta e urbanista, doutoranda no Programa de Pós-Graduação em Arquitetura e Urbanismo, na área de concentração de Tecnologia da Arquitetura, em curso na Faculdade de Arquitetura e Urbanismo da Universidade de São Paulo (FAU USP), venho por meio desta solicitar autorização para realizar atividades de pesquisa no Arquivo Histórico Municipal como parte do trabalho que tem como tema "Princípios ambientais para a gestão de reservas de papel em edifícios históricos na região dos trópicos".

Gostaria de solicitar autorização para realizar as seguintes atividades: entrevistas com pessoas chave dos setores de conservação e manutenção, visitas técnicas às áreas de reserva técnica, $\mathrm{e}$ análise e tratamento de dados ambientais das áreas de guarda de acervos. As respostas das entrevistas são anônimas. Os dados coletados durante esta pesquisa têm caráter exclusivamente acadêmico e no âmbito da área de arquitetura e urbanismo. Os resultados farão parte da tese de doutorado e poderão ser publicados em artigos científicos, mas sem identificar as pessoas que participaram do estudo.

Os riscos desta pesquisa são mínimos mas, se existir qualquer desconforto às pessoas entrevistadas, a atividade poderá ser interrompida a qualquer momento. Os benefícios resultantes de sua realização estão relacionados à obtenção de dados para a análise da qualidade ambiental de reservas técnicas resultando em diretrizes que possam ser aplicadas na adequação de ambientes de guarda de objetos com suporte em papel às
necessidades dos itens de acervo e dos usuários.

As entrevistas serão transcritas e encaminhadas aos participantes antes do término desta pesquisa, para ciência e outras considerações que se julgar pertinentes. Nenhuma
imagem de funcionário fará parte desta pesquisa.

Quando esta pesquisa for finalizada, um exemplar da tese de doutorado será encaminhado à instituição participante e também ficará disponível na biblioteca da Faculdade de Arquitetura e Urbanismo da Universidade de São Paulo, para consulta pública.

A participação do Arquivo Histórico Municipal é muito importante para esta pesquisa.
Autorização dada por:

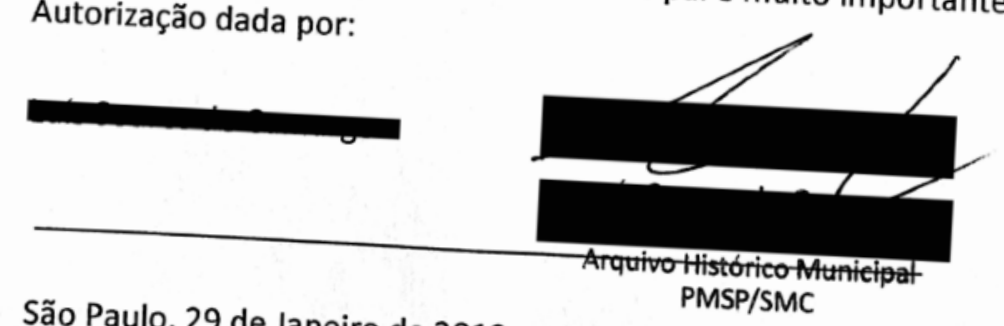

São Paulo, 29 de Janeiro de 2019. 
SOLICITAÇÃO DE AUTORIZAÇÃO

Săo Paulo, 10 de janeiro de 2019

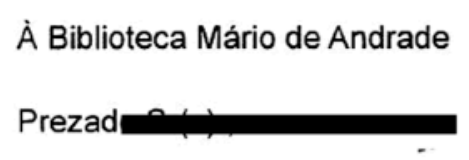

Eu, Juliana Bechara Saft, arquiteta e urbanista, doutoranda no Programa de Pós-Graduação em Arquitetura e Urbanismo, na área de concentração de Tecnologia da Arquitetura, em curso na Faculdade de Arquitetura e Urbanismo da Universidade de São Paulo (FAU USP), venho por meio desta solicitar autorização para realizar atividades de pesquisa na Biblioteca Mário de Andrade como parte do trabalho que tem como tema "Principios ambientais para a gestão de reservas de papel em edificios históricos na região dos trópicos".

Gostaria de solicitar autorização para realizar as seguintes atividades: entrevistas com pessoaschave do(s) setor(es) de conservação e manutenção, visitas técnicas às áreas de reserva técnica, e análise e tratamento de dados ambientais das áreas de guarda de acervos. As respostas das entrevistas são anônimas. Os dados coletados durante esta pesquisa têm caráter exclusivamente acadêmico e no âmbito da área de arquitetura e urbanismo. Os resultados farão parte da tese de doutorado e poderão ser publicados em artigos cientificos, mas sem identificar as pessoas que participaram do estudo.

Os riscos desta pesquisa são minimos mas, se existir qualquer desconforto às pessoas entrevistadas, a atividade poderá ser interrompida a qualquer momento. Os beneficios resultantes de sua realização estão relacionados à obtenção de dados para a análise da qualidade ambiental de reservas técnicas resultando em diretrizes que possam ser aplicadas na adequação de ambientes de guarda de objetos com suporte em papel às necessidades dos itens de acervo e dos usuários. 
As entrevistas serão transcritas e encaminhadas aos participantes antes do término desta pesquisa, para ciência e outras considerações que se julgar pertinentes. Nenhuma imagem de funcionário fará parte desta pesquisa.

Quando esta pesquisa for finalizada, um exemplar da tese de doutorado será encaminhado à instituição participante e também ficará disponivel na biblioteca da Faculdade de Arquitetura e Urbanismo da Universidade de São Paulo, para consulta pública.

A participação da Biblioteca Mário de Andrade é muito importante para esta pesquisa.

Para maiores informações, consultar:

- o CEP: Escola de Artes, Ciências e Humanidades da Universidade de São Paulo (EACH USP)

Endereço: Av. Arlindo Béttio, $n^{\circ}$ 1.000. Ermelino Matarazzo, São Paulo, SP. CEP: 03.828-000

Telefone: 1130911046

e-mail: cep-each@usp.br

ou

- a pesquisadora Juliana Bechara Saft, pelo telefone 11989634140 ou pelo e-mail jsaft@usp.br.

Autorização dada por:

Nome:

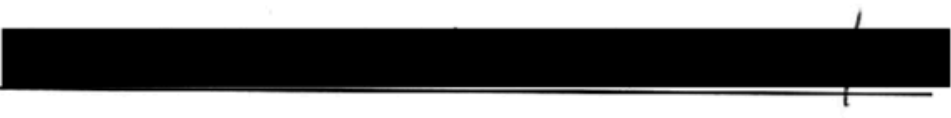

Assinatura:

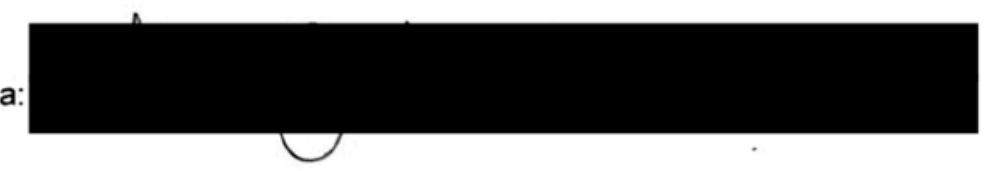

São Paulo

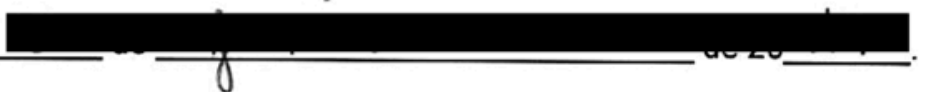


SOLICITAÇÃO DE AUTORIZAÇÃO

São Paulo, 10 de janeiro de 2019

Ao Museu Paulista da USP

Prezad

Eu, Juliana Bechara Saft, arquiteta e urbanista, doutoranda no Programa de Pós-Graduação em Arquitetura e Urbanismo, na área de concentração de Tecnologia da Arquitetura, em curso na Faculdade de Arquitetura e Urbanismo da Universidade de São Paulo (FAU USP), venho por meio desta solicitar autorização para realizar atividades de pesquisa no Museu Paulista da USP como parte do trabalho que tem como tema "Princípios ambientais para a gestão de reservas de papel em edifícios históricos na região dos trópicos".

Gostaria de solicitar autorização para realizar as seguintes atividades: entrevistas com pessoaschave do(s) setor(es) de conservação e manutenção, visitas técnicas às áreas de reserva técnica, e análise e tratamento de dados ambientais das áreas de guarda de acervos. As respostas das entrevistas são anônimas. Os dados coletados durante esta pesquisa têm caráter exclusivamente acadêmico e no âmbito da área de arquitetura e urbanismo. Os resultados farão parte da tese de doutorado e poderão ser publicados em artigos científicos, mas sem identificar as pessoas que participaram do estudo.

Os riscos desta pesquisa são mínimos mas, se existir qualquer desconforto às pessoas entrevistadas, a atividade poderá ser interrompida a qualquer momento. Os benefícios resultantes de sua realização estão relacionados à obtenção de dados para a análise da qualidade ambiental de reservas técnicas resultando em diretrizes que possam ser aplicadas na adequação de ambientes de guarda de objetos com suporte em papel às necessidades dos itens de acervo e dos usuários. 
As entrevistas serão transcritas e encaminhadas aos participantes antes do término desta pesquisa, para ciência e outras considerações que se julgar pertinentes. Nenhuma imagem de funcionário fará parte desta pesquisa.

Quando esta pesquisa for finalizada, um exemplar da tese de doutorado será encaminhado à instituição participante e também ficará disponível na biblioteca da Faculdade de Arquitetura e Urbanismo da Universidade de São Paulo, para consulta pública.

A participação do Museu Paulista da USP é muito importante para esta pesquisa.

Para maiores informações, consultar:

- o CEP: Escola de Artes, Ciências e Humanidades da Universidade de São Paulo (EACH USP)

Endereço: Av. Arlindo Béttio, n 1.000. Ermelino Matarazzo, São Paulo, SP. CEP: 03.828-000

Telefone: 1130911046

e-mail: cep-each@usp.br

ou

- a pesquisadora Juliana Bechara Saft, pelo telefone 11989634140 ou pelo e-mail jsaft@usp.br.

Autorização dada por:

Nome:

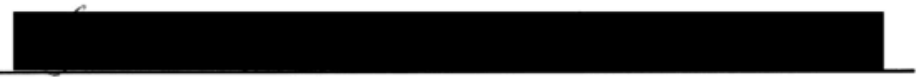

Assinatura:

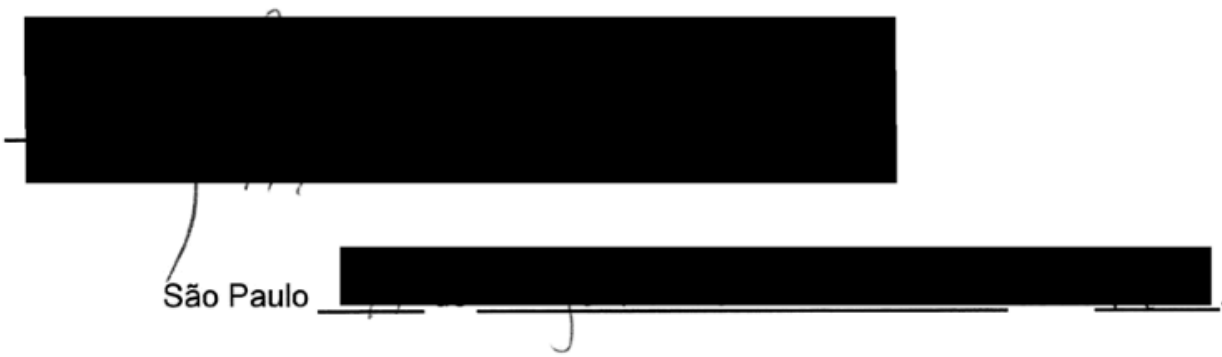




\section{SOLICITAÇÃO DE AUTORIZAÇÃO}

São Paulo, 10 de janeiro de 2019

À Biblioteca Brasiliana Guita e José Mindlin da USP

Prezad

Eu, Juliana Bechara Saft, arquiteta e urbanista, doutoranda no Programa de Pós-Graduação em Arquitetura e Urbanismo, na área de concentração de Tecnologia da Arquitetura, em curso na Faculdade de Arquitetura e Urbanismo da Universidade de São Paulo (FAU USP), venho por meio desta solicitar autorização para realizar atividades de pesquisa na BBM USP como parte do trabalho que tem como tema "Princípios ambientais para a gestão de reservas de papel em edifícios históricos na região dos trópicos".

Gostaria de solicitar autorização para realizar as seguintes atividades: entrevistas com pessoaschave do(s) setor(es) de conservação e manutenção, visitas técnicas às áreas de reserva técnica, e análise e tratamento de dados ambientais das áreas de guarda de acervos. As respostas das entrevistas são anônimas. Os dados coletados durante esta pesquisa têm caráter exclusivamente acadêmico e no âmbito da área de arquitetura e urbanismo. Os resultados farão parte da tese de doutorado e poderão ser publicados em artigos científicos, mas sem identificar as pessoas que participaram do estudo.

Os riscos desta pesquisa são mínimos mas, se existir qualquer desconforto às pessoas entrevistadas, a atividade poderá ser interrompida a qualquer momento. Os benefícios resultantes de sua realização estão relacionados à obtenção de dados para a análise da qualidade ambiental de reservas técnicas resultando em diretrizes que possam ser aplicadas na adequação de ambientes de guarda de objetos com suporte em papel às necessidades dos itens de acervo e dos usuários. 
As entrevistas serão transcritas e encaminhadas aos participantes antes do término desta pesquisa, para ciência e outras considerações que se julgar pertinentes. Nenhuma imagem de funcionário fará parte desta pesquisa.

Quando esta pesquisa for finalizada, um exemplar da tese de doutorado será encaminhado à instituição participante e também ficará disponível na biblioteca da Faculdade de Arquitetura e Urbanismo da Universidade de São Paulo, para consulta pública.

A participação da BBM USP é muito importante para esta pesquisa.

Para maiores informações, consultar:

- o CEP: Escola de Artes, Ciências e Humanidades da Universidade de São Paulo (EACH USP)

Endereço: Av. Arlindo Béttio, $n^{\circ}$ 1.000. Ermelino Matarazzo, São Paulo, SP. CEP: 03.828-000

Telefone: 1130911046

e-mail: cep-each@usp.br

ou

- a pesquisadora Juliana Bechara Saft, pelo telefone 11989634140 ou pelo e-mail jsaft@usp.br.

Autorização dada por:

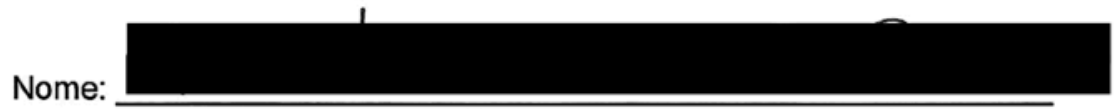

Assinatu

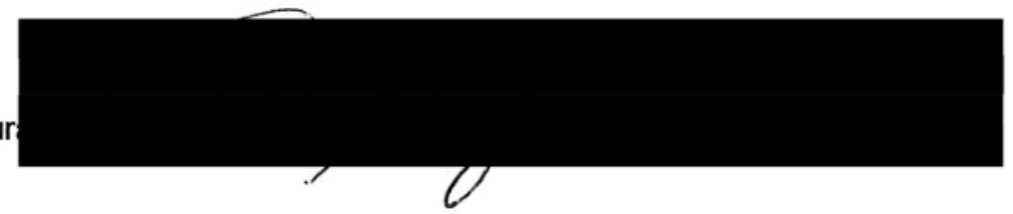

São Paulo

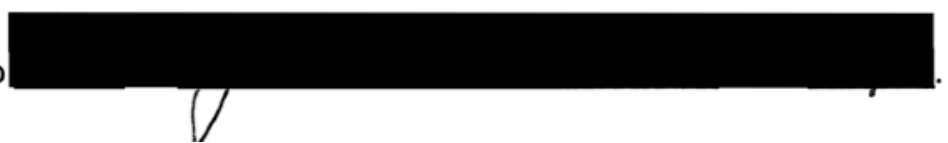




\section{TERMO DE CONSENTIMENTO LIVRE E ESCLARECIDO}

(entrevistas individuais ou em grupo com especialistas pessoas-chave)

Pesquisadora responsável: Juliana Bechara Saft

Orientadora: Profa. Dra. Sheila Walbe Ornstein

Esta é uma pesquisa de doutorado do Programa de Pós-Graduação em Arquitetura e Urbanismo, na área de concentração de Tecnologia da Arquitetura, em curso na Faculdade de Arquitetura e Urbanismo da Universidade de São Paulo (FAU USP) que tem como tema "Princípios ambientais para a gestão de reservas de papel em edifícios históricos na região dos trópicos".

Você está sendo convidado(a) a contribuir com opiniões sobre os ambientes para reservas técnicas e ambientes afins no [MUSEU / INSTITUIÇÃO] por meio de uma entrevista individual ou em grupo. Esta atividade está inicialmente planejada para ter aproximadamente trinta minutos de duração.

A sua participação é muito importante. As respostas são anônimas. Esta pesquisa tem caráter exclusivamente acadêmico e no âmbito da área de arquitetura e urbanismo. Os resultados farão parte da tese de doutorado e poderão ser publicados em artigos científicos, mas sem identificar as pessoas que participaram do estudo.

Os riscos desta pesquisa são mínimos mas, se existir qualquer desconforto, a entrevista poderá ser interrompida a qualquer momento. Os benefícios resultantes de sua realização estão relacionados à obtenção de dados para a análise da qualidade ambiental de reservas técnicas resultando em diretrizes que possam ser aplicadas na adequação de ambientes de guarda de objetos com suporte em papel às necessidades dos itens de acervo e dos usuários.

A entrevista transcrita será encaminhada a você antes do término desta pesquisa, para ciência e outras considerações que julgar pertinentes.

Nenhum dado visual ou pessoal seu fará parte desta pesquisa. Sua participação é voluntária e não é passível de nenhum tipo de recompensa. 
Após ler e receber explicações sobre a pesquisa, você terá direito de:

1. receber resposta e esclarecimento a qualquer pergunta sobre procedimentos e aspectos relacionados à pesquisa;

2. retirar seu consentimento e deixar de participar deste estudo a qualquer momento;

3. não ser identificado, mantendo-se o caráter confidencial das informações relacionadas à privacidade;

4. receber a segunda via deste Termo.

Quando esta pesquisa for finalizada, um exemplar da tese de doutorado será encaminhado

à instituição participante e também ficará disponível na biblioteca da Faculdade de Arquitetura e Urbanismo da Universidade de São Paulo, para consulta pública.

Para maiores informações sobre esta pesquisa, consultar:

CEP: Escola de Artes, Ciências e Humanidades da Universidade de São Paulo (EACH USP)

Endereço: Av. Arlindo Béttio, n 1.000. Ermelino Matarazzo, São Paulo, SP. CEP: 03.828-000 telefone: 113091 1046, e-mail: cep-each@usp.br ou a pesquisadora Juliana Bechara Saft, pelo telefone 11989634140 ou pelo e-mail jsaft@usp.br.

Declaro estar ciente do exposto acima e concordo com minha participação nesta pesquisa.

São Paulo de de 20

Nome:

Assinatura:

Eu, Juliana Bechara Saft, declaro que forneci todas as informações referentes ao projeto ao participante da pesquisa e/ou responsável bem como uma segunda via deste Termo.

Data: 1

Muito obrigada por sua colaboração! 


\section{ROTEIRO PARA ENTREVISTAS (INDIVIDUAIS OU EM GRUPO) COM ESPECIALISTAS PESSOAS-CHAVE}

Pesquisadora responsável: Juliana Bechara Saft

Orientadora: Profa. Dra. Sheila Walbe Ornstein

Esta é uma pesquisa de doutorado do Programa de Pós-Graduação em Arquitetura e Urbanismo (área de concentração: Tecnologia da Arquitetura) em curso na Faculdade de Arquitetura e Urbanismo da Universidade de São Paulo (FAU USP).

Para maiores informações sobre esta pesquisa, consultar:

CEP: Escola de Artes, Ciências e Humanidades da Universidade de São Paulo (EACH USP) Endereço: Av. Arlindo Béttio, n 1.000. Ermelino Matarazzo, São Paulo, SP. CEP: 03.828-000 telefone: 113091 1046, e-mail: cep-each@usp.br ou a pesquisadora Juliana Bechara Saft, pelo telefone 11989634140 ou pelo e-mail jsaft@usp.br.

\section{Entrevista com especialistas em conservação preventiva}

Data:

Instituição:

Nome participante(s):

Função(ões):

Tempo que trabalha na instituição:

Tamanho (aproximado) do acervo:

Tipos de suportes mais frequentes: 
1. Como você descreve as condições físicas do acervo:

○em ótimo estado

em bom estado, mas com pequenas deformações

em estado razoável, com deformações e/ou mofo

○em mau estado, com muitas deformações, perdas e/ou mofo

em estado crítico

a. Por favor, faça uma breve descrição de como você percebe o estado de conservação do acervo:

2. Assinale, da lista abaixo, quais os elementos que estão presentes nos ambientes de guarda da instituição. Para cada item assinalado, descreva a contribuição (positiva e/ou negativa) da presença dele no ambiente de guarda para a preservação do acervo.

ar-condicionado

ventiladores 
película com filtro UV nos envidraçados

$\bigcirc$ tela- mosquiteiro nas janelas

cortina / tela solar / black-out / persiana. Especificar qual(is):

3. Os ambientes de guarda têm suas condições ambientais monitoradas? (*)
$\bigcirc \operatorname{sim}$
กño

a. Se sim, quais variáveis?
temperatura
OU.R.
Oluz
outro

b. Qual(is) equipamento(s) é(são) utilizado(s) no monitoramento? 
c. Qual o tratamento dado às informações coletadas?

d. Se os dados são processados, qual a destinação que a instituição dá aos resultados obtidos?

4. O quão preparado(a) você se sente para lidar com questões relacionadas à manutenção do ambiente físico das reservas técnicas e seus equipamentos?
pouco preparado
Opreparado
bem preparado
กão sei

a. Por que?

5. A instituição possui arquitetos e/ou engenheiros cuidando da manutenção do edifício e de seus equipamentos?
$\bigcirc \operatorname{sim}$
กño 
a. Se sim, como se dá a comunicação entre a equipe de conservação dos acervos e a de manutenção do edifício?

b. Você considera importante a presença de um arquiteto ou engenheiro na equipe da instituição?
$\bigcirc \operatorname{sim}$
กão

c. Por que?

d. A instituição possui alguma política de integração entre equipes de manutenção, conservação e/ou exposição visando à conservação preventiva do acervo?

Muito obrigada por sua colaboração! 
ROTEIRO PARA ENTREVISTAS (INDIVIDUAIS OU EM GRUPO) COM ESPECIALISTAS PESSOAS-CHAVE

Pesquisadora responsável: Juliana Bechara Saft

Orientadora: Profa. Dra. Sheila Walbe Ornstein

Esta é uma pesquisa de doutorado do Programa de Pós-Graduação em Arquitetura e Urbanismo (área de concentração: Tecnologia da Arquitetura) em curso na Faculdade de Arquitetura e Urbanismo da Universidade de São Paulo (FAU USP).

Para maiores informações sobre esta pesquisa, consultar:

CEP: Escola de Artes, Ciências e Humanidades da Universidade de São Paulo (EACH USP) Endereço: Av. Arlindo Béttio, n 1.000. Ermelino Matarazzo, São Paulo, SP. CEP: 03.828-000 telefone: 113091 1046, e-mail: cep-each@usp.br ou a pesquisadora Juliana Bechara Saft, pelo telefone 11989634140 ou pelo e-mail jsaft@usp.br.

\section{Entrevista com especialistas em acervos em papel}

Data:

Instituição:

Nome participante(s):

Função(ões):

Tempo que trabalha na instituição:

Tamanho (aproximado) do acervo:

Tipos de suportes mais frequentes: 
1. Você considera importante que a instituição faça diagnósticos da qualidade do espaço físico?
$\bigcirc \operatorname{sim}$
não

a. Por que?

2. Você sabe que instituições como, por exemplo, o Getty Institute possuem roteiros prontos para diagnóstico da qualidade ambiental do ambiente físico?
$\bigcirc \operatorname{sim}$
กño

a. Se sim, você já utilizou algum roteiro pré-existente? Qual?

$\bigcirc \operatorname{sim}$

กão

b. Se você conhece mas nunca utilizou, por quê?

3. A instituição possui alguma política para avaliação / diagnóstico dos ambientes físicos visando à conservação preventiva?
$\bigcirc \operatorname{sim}$
กño 
a. Se sim, qual o procedimento adotado?

b. Quais os resultados práticos obtidos?

4. Por favor, aponte algumas sugestões para a melhoria na gestão da qualidade ambiental dos espaços de guarda visando à conservação preventiva dos acervos da sua instituição:

Muito obrigada por sua colaboração! 
F - Roteiro de entrevista 03

\section{ROTEIRO PARA ENTREVISTAS (INDIVIDUAIS OU EM GRUPO) COM ESPECIALISTAS PESSOAS-CHAVE}

Pesquisadora responsável: Juliana Bechara Saft

Orientadora: Profa. Dra. Sheila Walbe Ornstein

Esta é uma pesquisa de doutorado do Programa de Pós-Graduação em Arquitetura e Urbanismo (área de concentração: Tecnologia da Arquitetura) em curso na Faculdade de Arquitetura e Urbanismo da Universidade de São Paulo (FAU USP).

Para maiores informações sobre esta pesquisa, consultar:

CEP: Escola de Artes, Ciências e Humanidades da Universidade de São Paulo (EACH USP) Endereço: Av. Arlindo Béttio, $n^{\circ}$ 1.000. Ermelino Matarazzo, São Paulo, SP. CEP: 03.828-000 telefone: 113091 1046, e-mail: cep-each@usp.br ou a pesquisadora Juliana Bechara Saft, pelo telefone 11989634140 ou pelo e-mail jsaft@usp.br.

\section{Entrevista com especialistas na manutenção do edifício}

Data:

Instituição:

Nome participante(s):

Função(ões):

Tempo que trabalha na instituição:

Tamanho (aproximado) do acervo:

Tipos de suportes mais frequentes: 
1. Como você descreve as condições físicas do edifício:

em ótimo estado

em bom estado, mas com pequenas ocorrências esporádicas

em estado razoável, com ocorrências frequentes

em mau estado, com muitas ocorrências frequentes

em estado crítico

a. Por favor, faça uma breve descrição de como você percebe o estado de conservação do edifício:

2. Assinale, da lista abaixo, quais os elementos que estão presentes na instituição. Para cada item assinalado, descreva os procedimentos para a sua manutenção.

ar-condicionado

ventiladores 
$\bigcirc$ desumidificadores

automação

iluminação artificial

alarme

bombas

Oelevadores

sistema de proteção contra incêndio Especificar qual(is): 
3. O quão preparado(a) você se sente para lidar com questões relacionadas à conservação preventiva dos acervos?
pouco preparado
Preparado
bem preparado
não sei

a. Por que?

4. Como se dá a comunicação entre a equipe de conservação dos acervos e a de manutenção do edifício?

a. Você considera importante um trabalho integrado entre as equipes de conservação do acervo, curadoria e manutenção do edifício?
sim
กão

b. Por que? 
c. A instituição possui alguma política para a integração entre equipes de manutenção, conservação e/ou exposição visando à conservação preventiva do acervo?

5. A instituição possui alguma política para avaliação / diagnóstico dos ambientes físicos visando à manutenção preventiva?
$\bigcirc \operatorname{sim}$
$\bigcirc$ não

a. Se sim, qual o procedimento adotado?

b. Quais os resultados práticos obtidos? 
6. Por favor, aponte algumas sugestões para a melhoria na gestão da manutenção preventiva do edifício visando à conservação preventiva dos acervos da sua instituição:

Muito obrigada por sua colaboração! 
En 